Ex Libris औै

PROFESSOR J. S. WILL 
$\left(2 x^{2}+3=2\right.$

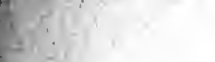

.
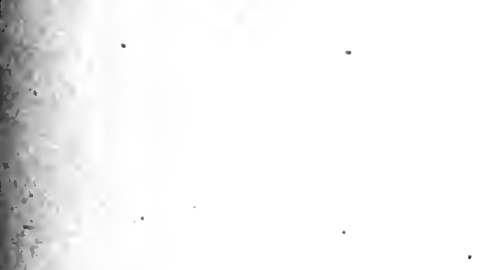

1

- 


\section{ANTHOLOGY OF}

\section{FRENCH PROSE AND POETRY}

BY

WILLIAMSON UPDIKE VREELAND

DOCTEUR ÈS LETTRES

PROFESSOR OF ROMANCE LANGUAGES, PRINCETON UNIVERSITY

AND

RÉGIS MICHAUD

LICENCIÉ ÈS LETTRES

PRECEPTOR OF MODERN LANGUAGES, PRINCETON UNIVERSITY

GINN AND COMPANY

BOSTON : NEW YORK - CHICAGO - LONDON 
COPYRIGHT, 1910, BY

WILLIAMSON UPDIKE VREELAND AND RÉGIS MICHAUD ALL RIGHTS RESERVED

9ro.8<smiles>CCC1CCCCC1</smiles><smiles>C1CCCCC1</smiles><smiles>CCCCCCC</smiles>

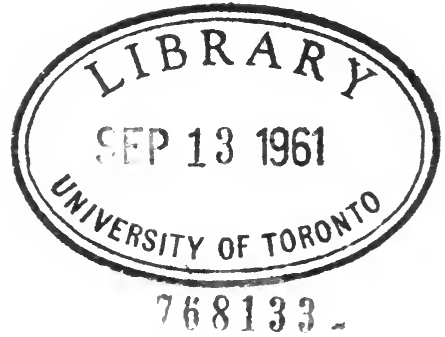




\section{PREFACE}

The use of anthologies as an introduction to the general study of literature, and also as a preparation for an appreciative reading of complete texts, is rapidly growing in favor. They have for a long time been used on the continent, and were recently recommended by an international congress which met at Paris. They introduce the student to works with which he may, later on, be inclined to cultivate a more intimate acquaintance. By enabling the student to pass, in a brief interval, from the tragedy of Corneille, for example, to that of Racine, from Molière's comedy to the comedy of Marivaux and Beaumarchais, from the prose of Rousseau to that of Bernardin de Saint-Pierre and Chateaubriand, they give him, if not a complete, at least a first-hand idea of the succession of schools of writers and of the development of the methods of composition in poetry and prose. They also encourage him to appreciate the beauty and perfection of individual pages and even paragraphs, independent of the development of the plot. And the experience in our own classes has convinced us that, for American students, to whom it is desired to give, at the same time, proficiency in reading different styles of varied degrees of difficulty and some real acquaintance with the foreign authors themselves, with their style and their thought, the use of anthologies is of the greatest importance.

The present volume has been made with these practical ends in view. In the French anthologies, published in France, 
we have found that in some cases the selections are too scrappy for American students and for American methods of instruction; in other cases some of the best and most familiar passages are omitted for the good reason that they are generally known by all French youths; and in still other cases the volumes are so burdened with selections from writers of minor importance, or else so critical that they seem to form a disconnected history of the literature rather than to be the representative passages of important writers. For these reasons the compilers have, in the present volume, attempted to prepare a book particularly suited to the needs of American college or advanced high-school classes.

The compilers desire to express to MM. Calmann-Lévy their appreciation of the permission to reprint selections from Anatole France and Pierre Loti; and also to M. A. Massein, who granted permission to reprint the pages from Paul Verlaine. 


\section{CONTENTS}

FrançoIs de MalHerbe (1555-1628)

PAGE

Biographical note . . . . . . . . . . . . . . . . . . . . 3

Consolation de Monsieur Périer sur la mort de sa fille . . . . . . 3

JeAn-Louis Guez DE Balzac (1597-1654)

Note . . . . . . . . . . . . . . . . . 7

A la campagne . . . . . . . . . . . . . . . . . . . . 7

René Descartes (1596-1650)

Biographical note . . . . . . . . . . . . . . 10

Descartes revise ses connaissances . . . . . . . . . . 10

Pierre Corneille (I606-i 684)

Biographical note . . . . . . . . . . . . . . . I5

Le Cid. . . . . . . . . . . . . . . . . . 15

Cinna . . . . . . . . . . . . . . . 21

Polyeucte . . . . . . . . . . . . . . . . . . 25

Nicomède . . . . . . . . . . . . . . . . 30

Cardinal de Retz (1613-1679)

Biographical note . . . . . . . . . . . . . . 35

Une scène de la Fronde . . . . . . . . . . . . . . . . 35

Blaise Pascal (1623-1662)

Biographical note . . . . . . . . . . . . . 38

De l'autorité des anciens . . . . . . . . . . . . . . $3^{8}$

Place de l'homme dans l'univers . . . . . . . . . . 40

L'imagination . . . . . . . . . . . . . . . 43

La Rochefoucauld (1613-1680)

Biographical note . . . . . . . . . . . . . . . . . . 46

Portrait du duc de la Rochefoucauld fait par lui-même . . . . . 46

Maximes . . . . . . . . . . . . . . . . 48 
MOLIÈRE (I622-I673)

Biographical note . . . . . . . . . . . . . . $5^{\mathbf{I}}$

Le misanthrope . . . . . . . . . . . . . . . 52

Le souper de l'avare . . . . . . . . . . . . . 57

La leçon de prononciation . . . . . . . . . . . . 6r

Les femmes savantes . . . . . . . . . . . 64

La Fontaine (1621-1695)

Biographical note . . . . . . . . . . . . . 68

Le corbeau et le renard . . . . . . . . . . . . 68

Le chêne et le roseau . . . . . . . . . . . . . 69

Le meunier, son fils et l'âne . . . . . . . . . . . 70

Les animaux malades de la peste . . . . . . . . . . 72

La laitière et le pot au lait . . . . . . . . . . . . 74

Le savetier et le financier . . . . . . . . . . . 75

Le paysan du Danube . . . . . . . . . . . . . 76

Epître à monseigneur l'évêque de Soissons . . . . . . . . . 79

Nicolas Bolleau-Despréaux (1636-I7II)

Biographical note . . . . . . . . . . . . . . 82

Le repas ridicule . . . . . . . . . . . . . . 82

Les plaisirs des champs . . . . . . . . . . . 87

Rien n'est beau que le vrai ........... . . 90

MAdAMe de SÉvigné (1626-1696)

Biographical note . . . . . . . . . . . . . . . . 93

Un courtisan . . . . . . . . . . . . . . . . . . 93

Après une séparation . . . . . . . . . . . . . 94

Mort de Turenne . . . . . . . . . . . . . . 96

Un printemps . . . . . . . . . . . . . . . . 98

Madame de La FayetTe (1634-1693)

Biographical note . . . . . . . . . . . . . 100

Mort de Henri II . . . . . . . . . . . . . . . I00

JeAN RACINe (1639-I699)

Biographical note . . . . . . . . . . . . . . I03

Andromaque . . . . . . . . . . . . . . . . 104

Britannicus ................ . . 109

Phèdre . . . . . . . . . . . . . . . . II3

Athalie ................. . . II9 
JACQUES-BÉNigne Bossuet (1627-1704)

Biographical note . . . . . . . . . . . . . . I 22

Sur l'ambition . . . . . . . . . . . . . . . . I 22

Conclusion du discours sur l'histoire universelle . . . . . . I26

Mort de Madame . . . . . . . . . . . . . . 127

Bataille de Rocroi . . . . . . . . . . . . . . . 130

Louis Bourdaloue (1632-1704)

Biographical note . . . . . . . . . . . . . . . I I34

L'abus des richesses . . . . . . . . . . . . . . . . 134

La manie du jeu . . . . . . . . . . . . . . . 136

JEAN DE LA BRUYÉRE (1645-1696)

Biographical note . . . . . . . . . . . . . . . 140

Pensées diverses . . . . . . . . . . . . . . . . 140

Roman d'Emire . . . . . . . . . . . . . . . I4 I

Le diseur de nouvelles . . . . . . . . . . . . . . 143

Le riche . . . . . . . . . . . . . . . . . I44

Le pauvre . . . . . . . . . . . . . . . . . . 144

La cour . . . . . . . . . . . . . . . . . . . I45

L'égoïste . . . . . . . . . . . . . . . 146

Corneille et Racine . . . . . . . . . . . . . . . I47

Les paysans . . . . . . . . . . . . . . . . . . . . . . 148

FÉnelon (1651-1715)

Biographical note . . . . . . . . . . . . . 149

La Bétique . . . . . . . . . . . . . . . . . . . . 149

Tableau des funérailles de Phocion . . . . . . . . . . 153

L'éloquence . . . . . . . . . . . . 156

Fontenelle (1657-1757)

Biographical note . . . . . . . . . . . . . . . . I59

La science pour tous . . . . . . . . . . . . . . . 159

Le système de Copernic . . . . . . . . . . . . . . . . I6I

Socrate et Montaigne . . . . . . . . . . . . . 163

Louis de Saint-Simon (1675-1755)

Biographical note . . . . . . . . . . . . . . . 166

Mort de Monseigneur . . . . . . . . . . . . . 166

Jugement de Saint-Simon sur ses Mémoires . . . . . . 170

Alain-René Le Sage (i668-i747)

Biographical note . . . . . . . . . . . . . . . 172

Monsieur Turcaret . . . . . . . . . . . . . . 172

Gil Blas chez l'archevêque de Grenade . . . . . . . . . 174 
Montesquieu (I689-1755)

Biographical note . . . . . . . . . . . . . . . . . . I79

La curiosité parisienne . . . . . . . . . . . . . 179

Le désir de la gloire . . . . . . . . . . . . . . 180

L'Angleterre . . . . . . . . . . . . . . . . . . . . 182

Portrait de Montesquieu par lui-même . . . . . . . . 185

Marivaux (1688-1763)

Biographical note . . . . . . . . . . . . . . . 188

Le jeu de l'amour et du hasard . . . . . . . . . . . I88

Les embarras de Paris . . . . . . . . . . . . . I9I

\section{Vauvenargues (17 1 5-1747)}

Biographical note . . . . . . . . . . . . . . 195

Réflexions et maximes . . . . . . . . . . . . 195

Voltaire (I694-I778)

Biographical note . . . . . . . . . . . . . . . . . 199

Charles XII à Bender . . . . . . . . . . . . . . . 200

L'homme de la nature . . . . . . . . . . . . 203

Le carnaval de Venise . . . . . . . . . . . . 204

La vanité . . . . . . . . . . . . . . . 207

La tolérance . . . . . . . . . . . . . 209

JeAn-Jacques Rousseau (1712-1778)

Biographical note . . . . . . . . . . . . . . . . . . 2II

Origines de la société humaine . . . . . . . . . . 212

Les montagnes du Valais . . . . . . . . . . . . . 215

Les vendanges à Clarens . . . . . . . . . . . . . . . . . 217

Si j'étais riche . . . . . . . . . . . . . . 221

Denis Diderot (I7I3-1784)

Biographical note . . . . . . . . . . . . . . . . 223

Conditions de la grande poésie . . . . . . . . . . . 223

Le rossignol et le coucou . . . . . . . . . . . . . 226

Délire musical . . . . . . . . . . . . . . . 228

BUFFON (1707-1788)

Biographical note . . . . . . . . . . . . . $23 \mathrm{r}$

Les premiers hommes . . . . . . . . . . . . 23I

Sur le style . . . . . . . . . . . . . . 234 
Beaumarchais (1732-I799)

Biographical note . . . . . . . . . . . . . . . 237

Une Querelle ....... . . . . . . . . 238

Monologue de Figaro . . . . . . . . . . . . 241

Bernardin de Saint-Pierre (1737-I8I4)

Biographical note . . . . . . . . . . . . 244

Les nuages . . . . . . . . . . . . . . . . 244

Le naufrage du Saint-Géran . . . . . . . . . . . 247

ANDRÉ CHÉNIER (1762-I794)

Biographical note . . . . . . . . . . . . . . . 251

Le jeune malade . . . . . . . . . . . . . . . . . . . 251

Les derniers vers d'André Chénier . . . . . . . . . 255

Madame de STä̈L (1766-1817)

Biographical note . . . . . . . . . . . . . . . 258

Les ruines de Pompéi . . . . . . . . . . . . . . . . 259

De l'esprit de conversation . . . . . . . . . . . . 262

Chateaubriand (i $768-1848$ )

Biographical note . . . . . . . . . . . . . 266

Le Méschacebé . . . . . . . . . . . . . . . . . 267

Bataille des Francs et des Romains . . . . . . . . . . . . . 269

Souvenirs de jeunesse . . . . . . . . . . . . . . . . . . 272

LAMARTINE (1790-I869)

Biographical note . . . . . . . . . . . . . . 276

L'isolement . . . . . . . . . . . . . . 276

Le lac . . . . . . . . . . . . . . . . . 278

Le crucifix . . . . . . . . . . . . . . 280

Un village dans les Alpes . . . . . . . . . . . . . . . 283

Invocation d'Harold mourant . . . . . . . . . . . . 286

AlFRed de Vigny (1797-1863)

Biographical note . . . . . . . . . . . . . . . 288

Le cor . . . . . . . . . . . . . . . . . 288

La mort du loup . . . . . . . . . . . . . . 291

Victor Hugo (I802-I885)

Biographical note . . . . . . . . . . . . . . . 294

Tristesse d'Olympio . . . . . . . . . . . . . . . 295

L'expiation . . . . . . . . . . . . . . . 298 
VICTOR Hugo - continued

La fille du poète . . . . . . . . . . . . . , 304

Saison des semailles . . . . . . . . . . . . . 305

Quasimodo ................ . 306

Sainte-Beuve (1804-i 869)

Biographical note . . . . . . . . . . . . . 309

Racine . . . . . . . . . . . . . . . . . . 309

Qu'est-ce qu'un classique? . . . . . . . . . . . $3^{12}$

Alfred De Musset (1810-1857)

Biographical note . . . . . . . . . . . . . 317

La nuit de décembre . . . . . . . . . . . . . 317

Chanson ................... . 321

Tristesse . . . . . . . . . . . . . . . . . 322

Souvenir . . . . . . . . . . . . . . 322

Fantasio . . . . . . . . . . . . . . . . 324

LamenNais ( $1782-1854$ )

Biographical note . . . . . . . . . . . . . . 328

La Providence . . . . . . . . . . . . . . . . . 328

La musique dans la nature et dans le temple chrétien . . . . 330

George Sand (1804-1876)

Biographical note . . . . . . . . . . . . . . 332

Scène rustique . . . . . . . . . . . . . . . . 332

Le cornemuseux inspiré . . . . . . . . . . . 336

Le Puy en Velay . . . . . . . . . . . . . . . 339

JULES MiChelet (I $798-1874$ )

Biographical note . . . . . . . . . . . . . . 342

Supplice de Jeanne d'Arc. . . . . . . . . . . . . . . 342

La Bretagne . . . . . . . . . . . . . . . . . 346

Les volontaires de 1792 - La Marseillaise . . . . . . . 348

Prosper Mérimée (1803-1870)

Biographical note . . . . . . . . . . . . . $35^{2}$

L'enlèvement de la redoute . . . . . . . . . . $35^{2}$

HoNoré de BalzaC (I799-I850)

Biographical note . . . . . . . . . . . . . 358

La maison du chat qui pelote . . . . . . . . . . 358

Monsieur Grandet . . . . . . . . . . . 362

La mort du père Goriot . . . . . . . . . . . 365 
Théophile Gautier (1811-1872)

Biographical note . . . . . . . . . . . . 37 I

L'art . . . . . . . . . . . . . . . . . 371

Ce que disent les hirondelles . . . . . . . . . . . . 373

Grenade . . . . . . . . . . . . . . . 375

Emile Augier (1820-I889)

Biographical note . . . . . . . . . . . . . 378

Les ambitions de Monsieur Poirier . . . . . . . . 378

LECONTE DE LISLE (I8I8-I894)

Biographical note . . . . . . . . . . . . . . 383

Héraklès au taureau . . . . . . . . . . . . . 383

Kléarista . . . . . . . . . . . . . . 384

Les éléphants . . . . . . . . . . . . . 385

La chute des étoiles . . . . . . . . . . . . . . . 387

Les elfes . . . . . . . . . . . . . . . 388

Gustave Flaubert (1821-1880)

Biographical note . . . . . . . . . . . . . . 390

La noce de campagne . . . . . . . . . . . . . . . 390

Salammbô . . . . . . . . . . . . . . . 393

TAINE (1828-1893)

Biographical note . . . . . . . . . . . . . . . . 397

La Champagne et La Fontaine. . . . . . . . . . . . 397

Valeur des littératures . . . . . . . . . . . . 400

Shakespeare . . . . . . . . . . . . . . . 402

ReNan (1823-1892)

Biographical note . . . . . . . . . . . . . 404

Le Sinaï . . . . . . . . . . . . . . . . 404

Philosophie de l'histoire . . . . . . . . . . . 405

EMILE Zola (1840-1902)

Biographical note . . . . . . . . . . . . . 409

La grève de Germinal . . . . . . . . . . . . . . 409

Paris vu des hauteurs de Passy. . . . . . . . . . . . $4 \mathrm{I} 3$

Sully-Prudhomme (1839-1907)

Biographical note . . . . . . . . . . . . $4_{4}^{16}$

Les yeux . . . . . . . . . . . . . . . 416

Le vase brisé . . . . . . . . . . . . . . . 417

Le missel . . . . . . . . . . . . . . . . . 417

Les Danaïdes . . . . . . . . . . . . . . . . . . 419

Un songe . . . . . . . . . . . . . . . . 419 
Pierre Loti (I850-

PAGE

Biographical note . . . . . . . . . . . . . . 420

Pêcheurs d'Islande . . . . . . . . . . . . . . 420

Au Japon . . . . . . . . . . . . . . . . . . . . . . 424

Paul Verlaine (1844-1896)

Biographical note . . . . . . . . . . . . . . . 426

Mon rêve familier . . . . . . . . . . . . . . 426

Chanson d'automne . . . . . . . . . . . . . . . . . . 427

Il pleure dans mon cœur . . . . . . . . . . . . . . . . . 427

Ecoutez la chanson bien douce . . . . . . . . . . 428

Art poétique . . . . . . . . . . . . . . . . . . . . . 429

Anatole France (1844- )

Biographical note . . . . . . . . . . . . . . . $4 \jmath^{\mathbf{I}}$

La fée et le savant . . . . . . . . . . . . . . 43I

Index of Authors . . . . . . . . . . . . . 435 


\section{ANTHOLOGY OF FRENCH PROSE AND POETRY}


th 


\title{
FRANÇOIS DE MALHERBE
}

\author{
Caen, 1 555-1628, Paris
}

After receiving an unusually excellent education, first in Caen, his native town, then in Paris, Basel, and Heidelberg, Malherbe went to Provence (1 576), and spent a large part of the next twenty years there. In 1605 he went to Paris, where he became the first "écuyer du roi," and, later, "gentilhomme ordinaire de la chambre." Most of the remainder of his life was spent at the French court.

$\mathrm{He}$ is best known as a lyric poet, though his verses hardly fill one small volume. And of the poems in this volume his reputation rests on a small number in which the ideas are simply and perfectly expressed. He left also an interesting correspondence.

His importance lies in the fact that he was the first to set forth the principles which in a sense reacted against, and in a sense organized, the chaotic individualism of the Renaissance. He aimed at simplicity, perfect clearness, and precision, and wanted to describe things in their most general features. $\mathrm{He}$ wrote slowly, with the utmost care and the most scrupulous attention to form. He had few ideas and was lacking in sentiment and imagination, but had great common sense, good taste; and an excellent choice of words. Balzac, Voiture, Vaugelas, the Academy, and the Hôtel de Rambouillet continued in the same direction, purifying and fixing the language, and making it the perfect means of expression which it became with Racine and Bossuet.

CONSOLATION DE MONSIEUR PÉRIER SUR LA MORT

$$
\text { DE SA FILLE }
$$

Ta douleur, du Périer, sera donc éternelle, Et les tristes discours

Que te met en l'esprit l'amitié paternelle

L'augmenteront toujours?

Le malheur de ta fille au tombeau descendue,

Par un commun trépas,

Est-ce quelque dédale, où ta raison perdue

Ne se retrouve pas?

Je sais de quels appas son enfance était pleine,

Et n'ai pas entrepris, 
Injurieux ami, de soulager ta peine Avecque son mépris.

Mais elle était du monde, où les plus belle choses

Ont le pire destin;

Et rose elle a vécu ce que vivent les roses, L'espace d'un matin.

Puis quand ainsi serait, que selon ta prière Elle aurait obtenu

D'avoir en cheveux blancs terminé sa carrière, Qu'en fût-il advenu?

Penses-tu que plus vieille en la maison céleste Elle eût eu plus d'accueil ?

Ou qu'elle eût moins senti la poussière funeste, Et les vers du cercueil ?

Non, non, mon du Périer, aussitôt que la Parque

Ote l'âme du corps,

L'âge s'évanouit au deçà de la barque, Et ne suit point les morts.

Tithon ${ }^{1}$ n'a plus les ans qui le firent cigale; Et Pluton aujourd'hui,

Sans égard du passé, les mérites égale

D'Archémore ${ }^{2}$ et de lui.

Ne te lasse donc plus d'inutiles complaintes;

Mais sage à l'avenir,

Aime une ombre comme ombre, et des cendres éteintes Eteins le souvenir.

C'est bien, je le confesse, une juste coutume, Que le cœur affligé,

Par le canal des yeux vidant son amertume, Cherche d'être allégé.

Même quand il advient que la tombe sépare Ce que nature a joint,

1 Tithonus received from the gods the gift of immortality, but not that of eternal youth. In his old age he withered away and was metamorphosed into a grasshopper.

2 Archemorus, or Opheltes, was killed in his infancy by a serpent. 
Celui qui ne s'émeut a l'âme d'un barbare,

Ou n'en a du tout point.

Mais d'être inconsolable, et dedans sa mémoire

Enfermer un ennui,

N'est-ce pas se haïr pour acquérir la gloire

De bien aimer autrui?

Priam qui vit ses fils abattus par Achille,

Dénué de support,

Et hors de tout espoir du salut de sa ville,

Reçut du réconfort.

François, quand la Castille, inégale à ses armes,

Lui vola son Dauphin, ${ }^{1}$

Sembla d'un si grand coup devoir jeter des larmes,

Qui n'eussent point de fin.

Il les sécha pourtant, et comme un autre Alcide ${ }^{2}$

Contre fortune instruit,

Fit qu'à ses ennemis d'un acte si perfide

La honte fut le fruit.

Leur camp qui la Durance ${ }^{3}$ avait presque tarie

De bataillons épais,

Entendant sa constance eut peur de sa furie,

Et demanda la paix.

De moi, déjà deux fois ${ }^{4}$ d'une pareille foudre

Je me suis vu perclus,

Et deux fois la raison m'a si bien fait résoudre,

Qu'il ne m'en souvient plus.

Non qu'il ne me soit grief que la terre possède

Ce qui me fut si cher;

Mais en un accident qui n'a point de remède, Il n'en faut point chercher.

${ }^{1}$ Francis, oldest son of Francis I, was born in 1517 . He died suddenly in 1526 , and it was falsely believed that he had been poisoned at the instigation of Charles $V$ of Spain.

2 Alcides, a patronymic of Hercules.

3 Durance, a river in Provence. Charles V invaded Provence in 1536 . He was shortly forced to retreat and conclude an armistice.

4 Malherbe had lost two children. 
La mort a des rigueurs à nulle autre pareilles ;

On a beau la prier,

La cruelle qu'elle est se bouche les oreilles,

Et nous laisse crier.

Le pauvre en sa cabane, où le chaume le couvre, Est sujet à ses lois ;

Et la garde qui veille aux barrières du Louvre N'en défend point nos Rois.

De murmurer contre elle, et perdre patience, Il est mal à propos;

Vouloir ce que Dieu veut, est la seule science Qui nous met en repos. 


\section{JEAN-LOUIS GUEZ DE BALZAC}

Balzac(near Angoulême), I 597-i 654, Balzac

Balzac's letters, published in I624, met with unusual success. Many of them were affected, bombastic, not at all natural, but they were carefully written in a clear, sonorous, and oratorical style, and played an important part in forming the prose of the first part of the century.

\section{A LA CAMPAGNE}

\section{A MONSIEUR DE LA MOTTE-AIGRON}

Il fit hier un de ces beaux jours sans soleil, que vous dites qui ressemblent à cette belle aveugle, ${ }^{1}$ dont Philippe second était amoureux. En vérité je n'eus jamais tant de plaisir à m'entretenir moimême, et quoique je me promenasse en une campagne toute nue, et qui ne saurait servir à l'usage des hommes que pour être le 5 champ d'une bataille, néanmoins l'ombre que le ciel faisait de tous côtés m'empêchait de désirer celle des grottes et des forêts. La paix était générale depuis la plus haute région de l'air jusque sur la face de la terre; l'eau de la rivière paraissait aussi plate que celle d'un lac, et si en pleine mer un tel calme surprenait pour toujours les ro vaisseaux, ils ne pourraient jamais ni se sauver ni se perdre. Je vous dis ceci afin que vous regrettiez un jour si heureux que vous avez perdu à la ville, et que vous descendiez quelquefois de votre Angoulême, où vous allez du pair avec ${ }^{2}$ nos tours et nos clochers, pour venir recevoir les plaisirs des anciens rois, qui se désaltéraient 15 dans les fontaines et se nourrissaient de ce qui tombe des arbres. Nous sommes ici en un petit rond tout couronné de montagnes, où il reste encore quelques grains de cet or dont les premiers siècles ont été faits. Certainement quand le feu s'allume aux quatre coins de la France, et qu'à cent pas d'ici la terre est toute couverte de troupes, ${ }^{8} 20$

1 The Princess of Eboli, mistress of Philip II of Spain.

2 "where you are on a level with."

8 In the war against the Protestants. 
les armées ennemies d'un commun consentement pardonnent toujours à notre village; et le printemps, qui commence les sièges, et les autres entreprises de la guerre, et qui depuis douze ans a été moins attendu pour le changement des saisons que pour celui des 5 affaires, ne nous fait rien voir de nouveau que des violettes et des roses. Notre peuple ne se conserve dans son innocence, ni par la crainte des lois, ni par l'étude de la sagesse; pour bien faire, il suit simplement la bonté de sa nature et tire plus d'avantage de l'ignorance du vice que nous n'en n'avons de la connaissance de la vertu.

Io De sorte que dans ce royaume de demie lieue on ne sait que c'est ${ }^{1}$ de tromper, que les oiseaux et les bêtes, et le style du Palais ${ }^{2}$ est une langue aussi inconnue que celle de l'Amérique, ou de quelque autre nouveau monde, qui s'est sauvé de l'avarice de Ferdinand et de l'ambition d'Isabelle. Les choses qui nuisent à la santé des I 5 hommes ou qui offensent leurs yeux en sont généralement bannies. Il ne s'y vit jamais de lézards ni de couleuvres, et de toutes les sortes de reptiles nous ne connaissons que les melons et les fraises. Je ne veux pas vous faire le portrait d'une maison, dont le dessein n'a pas été conduit selon les règles de l'architecture, et la matière 20 n'est pas si précieuse que le marbre et le porphyre. Je vous dirai seulement qu'à la porte il y a un bois, où, en plein midi, il n'entre de jour que ce qu'il en faut pour n'être pas nuit et pour empêcher que toutes les couleurs ne soient noires. Tellement que de l'obscurité et de la lumière il se fait un troisième temps, qui peut être 25 supporté des yeux des malades, et cacher les défauts des femmes qui sont fardées. Les arbres y sont verts jusqu'à la racine, tant de leurs propres feuilles que du lierre qui les embrasse, et pour le fruit qui leur manque leurs branches sont chargées de tourtres et de faisans en toutes les saisons de l'année. De là j'entre en une prairie $3^{\circ}$ où je marche sur les tulipes et les anémones que j'ai fait mêler avec les autres fleurs, pour me confirmer en l'opinion que j'ai apportée de mes voyages que les Françaises ne sont pas si belles que les étrangères. Je descends aussi quelquefois dans cette vallée, qui est la plus secrète partie de mon désert et qui jusques ici n'avait été 35 connue de personne. C'est un pays à souhaiter et à peindre, que j'ai choisi pour vaquer à mes plus chères occupations et passer les plus douces heures de ma vie. L'eau et les arbres ne le laissent jamais manquer de frais et de vert. Les cygnes, qui couvraient

\footnotetext{
1 For ce que c'est que.
} 2 The Palais de Justice. 
autrefois toute la rivière, se sont retirés en ce lieu de sûreté et vivent dans un canal, qui fait rêver les plus grands parleurs aussitôt qu'ils s'en approchent, et au bord duquel je suis toujours heureux, soit que je sois joyeux, soit que je sois triste. Pour peu que je m'y arrête, il me semble que je retourne en ma première innocence. Mes désirs, 5 mes craintes et mes espérances cessent tout d'un coup; tous les mouvements de mon âme se relâchent, et je n'ai point de passions, ou si j'en ai, je les gouverne comme des bêtes apprivoisées. Le soleil envoie bien de la clarté jusque-là, mais il n'y fait jamais aller de chaleur; le lieu est si bas, qu'il ne saurait recevoir que les der- 10 nières pointes de ses rayons, qui sont d'autant plus beaux qu'ils ont moins de force, et que leur lumière est toute pure. Mais comme c'est moi qui ai découvert cette nouvelle terre, aussi je la possède sans compagnon, et je n'en voudrais pas faire part à mon propre frère. . . . $\mathrm{Au}$ demeurant par quelque porte que je sorte du logis, et de quelque ${ }_{15}$ part que je tourne les yeux en cette agréable solitude, je rencontre toujours la Charente, dans laquelle les animaux qui vont boire, voient le ciel aussi clairement que nous faisons, et jouissent de l'avantage qu'ailleurs les hommes leur veulent ôter. Mais cette belle eau aime tellement cette belle terre, qu'elle se divise en mille branches, 20 et fait une infinité d'îles et de détours, afin de s'y amuser davantage; et quand elle se déborde, ce n'est que pour rendre l'année plus riche, et pour nous faire prendre à la campagne ses truites et ses brochets, qui valent bien les crocodiles du Nil et le faux or de toutes les rivières des poètes. . . .

Le IV septembre MidxxiI 


\section{RENÉ DESCARTES \\ La Haye (Touraine), I 596-I650, Stockholm}

René Descartes was born at La Haye in Touraine. When eight years of age he was sent to the Jesuit college of La Flèche, where he studied for eight years. The next four years were spent mostly in Paris. At the age of twentyone he enlisted as a volunteer, and served first in Holland, then in Bavaria. It was at this time, in the winter of $1619-1620$, at Neuburg on the Danube, that he more or less definitely formulated the principles which had been evolving in his mind since he left La Flèche. These principles were to take definite form in the "Discours de la méthode," and it was through them he thought he might arrive at certain knowledge. So he determined to spend the rest of his life in the application of the "Method," and in the search for truth. Most of the next nine years were given to travel, "rambling about here and there in the world, endeavoring to be a spectator rather than an actor in all its comedies." Then, in 1629 , he retired to Holland, where he spent the next twenty years, devoting himself to philosophical meditation and writing. In I6 49 he somewhat reluctantly accepted an invitation from Queen Christina of Sweden to visit Stockholm; but the rigorous northern winter proved too severe for Descartes's feeble constitution, and he died of inflammation of the lungs, February II, I650.

The fundamental principles of Descartes's philosophy are contained in the "Discours de la méthode." Having come to the conclusion that many of the current ideas and beliefs were either false or uncertain, he determined to find a sound foundation on which to build. He found this in doubt. The very act of doubting presupposes thinking, and thinking presupposes one's existence as a thinking being: "Cogito, ergo sum," he said: "I think, therefore I am." With this as a starting-point he built up his method of philosophy, which, whether he so intended it or not, led away from revelation, tradition, and authority toward pure rationalism, and, for a time at least, walked hand in hand with French Classicism.

His principal works are the "Discours de la méthode" (I637); the "Méditations philosophiques" (I64I and I647); and the "Traité des passions" (I649).

\section{DESCARTES REVISE SES CONNAISSANCES}

J'ai été nourri ${ }^{1}$ aux lettres dès mon enfance; et pour ce qu'on me persuadait que par leur moyen on pouvait acquérir une connaissance claire et assurée de tout ce qui est utile à la vie, j'avais un extrême

1 In modern French, élezié. 
désir de les apprendre. Mais sitôt que j'eus achevé tout ce cours d'études, au bout duquel on a coutume d'être reçu au rang des doctes, je changeai entièrement d'opinion; car je me trouvais embarrassé de tant de doutes et d'erreurs qu'il me semblait n'avoir fait autre profit, en tâchant de m’instruire, sinon que j'avais découvert de plus en plus mon ignorance; et néanmoins j'étais en l'une des plus célèbres écoles de l'Europe, ${ }^{1}$ où je pensais qu'il devait y avoir de savants hommes, s'il y en avait en aucun endroit de la terre. J'y avais appris tout ce que les autres y apprenaient, et même, ne m'étant pas contenté des sciences qu'on nous enseignait, j'avais ro parcouru tous les livres traitant de celles qu'on estime les plus curieuses et les plus rares, qui avaient pu tomber entre mes mains. Avec cela je savais les jugements que les autres faisaient de moi, et je ne voyais point qu'on m'estimât inférieur à mes condisciples, bien qu'il y en eût déjà entre eux quelques-uns qu'on destinait à remplir 15 les places de nos maîtres; et enfin notre siècle me semblait aussi florissant et aussi fertile en bons esprits qu'ait été aucun des précédents; ce qui me faisait prendre la liberté de juger par moi de tous les autres, et de penser qu'il n'y avait aucune doctrine dans le monde qui fût telle qu'on m'avait auparavant fait espérer.

Je ne laissais pas toutefois d'estimer les exercices auxquels on s'occupe dans les écoles. Je savais que les langues qu'on y apprend sont nécessaires pour l'intelligence des livres anciens; que la gentillesse des fables réveille l'esprit; que les actions mémorables des histoires le relèvent, et qu'étant lues avec discrétion elles aident à 25 former le jugement; que la lecture de tous les bons livres est comme une conversation avec les plus honnêtes gens des siècles passés qui en ont été les auteurs, et même une conversation étudiée en laquelle ils ne nous découvrent que les meilleures de leurs pensées; que l'éloquence a des forces et des beautés incomparables ; 30 que la poésie a des délicatesses et des douceurs très ravissantes; que les mathématiques ont des inventions très subtiles, et qui peuvent beaucoup servir tant à contenter les curieux qu'à faciliter tous les arts et diminuer le travail des hommes; que les écrits qui traitent des mœurs contiennent plusieurs enseignements et plusieurs exhor- 35 tations à la vertu qui sont fort utiles; que la théologie enseigne à gagner le ciel; que la philosophie donne moyen de parler vraisemblablement de toutes choses et se faire admirer des moins savants;

1 The college of the Jesuits at La Flèche. 
que la jurisprudence, la médecine et les autres sciences apportent des honneurs et des richesses à ceux qui les cultivent; et enfin qu'il est bon de les avoir toutes examinées, même les plus superstitieuses et les plus fausses, afin de connaitre leur juste valeur et se garder d'en 5 être trompé.

Mais je croyais avoir déjà donné assez de temps aux langues, et même aussi à la lecture des livres anciens, et à leurs histoires, et à leurs fables; car c'est quasi le même de converser avec ceux des autres siècles que de voyager. Il est bon de savoir quelque chose ro des mœurs de divers peuples, afin de juger des nôtres plus sainement, et que nous ne pensions pas que tout ce qui est contre nos modes soit ridicule et contre raison, ainsi qu'ont coutume de faire ceux qui n'ont rien vu. ${ }^{1}$ Mais lorsqu'on emploie trop de temps à voyager, on devient enfin étranger en son pays; et lorsqu'on est trop curieux des I 5 choses qui se pratiquaient aux siècles passés, on demeure ordinairement fort ignorant de celles qui se pratiquent en celui-ci. . . .

J'estimais fort l'éloquence et j'étais amoureux de la poésie; mais je pensais que l'une et l'autre étaient des dons de l'esprit plutôt que des fruits de l'étude. Ceux qui ont le raisonnement le plus fort, et 20 qui digèrent le mieux leurs pensées afin de les rendre claires et intelligibles, peuvent toujours le mieux persuader ce qu'ils proposent, encore qu'ils ne parlassent que bas-breton et qu'ils n'eussent jamais appris de rhétorique; et ceux qui ont les inventions les plus agréables et qui les savent exprimer avec le plus d'ornement et de douceur ne 25 laisseraient pas d'être les meilleurs poètes, encore que l'art poétique leur fût inconnu.

Je me plaisais surtout aux mathématiques, à cause de la certitude et de l'évidence de leurs raisons ; mais je ne remarquais point encore leur vrai usage, et, pensant qu'elles ne servaient qu'aux arts méca3o niques, je m'étonnais de ce que leurs fondements étant si fermes et si solides, on n'avait rien bâti dessus de plus relevé: comme au contraire je comparais les écrits des anciens païens qui traitent des mœurs à des palais fort superbes et fort magnifiques qui n'étaient bâtis que sur du sable et sur de la boue. Ils élèvent fort haut les 35 vertus, et les font paraître estimables par-dessus toutes les choses qui sont au monde, mais ils n'enseignent pas assez à les connaître, et souvent ce qu'ils appellent d'un si beau nom n'est qu'une insensibilité, ou un orgueil, ou un désespoir, ou un parricide.

1 Unlike his contemporaries, Descartes spent much time in travel. 
Je révérais notre théologie et prétendais autant qu'aucun autre à gagner le ciel, mais ayant appris, comme chose très assurée, que le chemin n'en est pas moins ouvert aux plus ignorants qu'aux plus doctes, et que les vérités révélées qui y conduisent sont au-dessus de notre intelligence, je n'eusse osé les soumettre à la faiblesse de mes raisonnements; et je pensais que pour entreprendre de les examiner et y réussir, il était besoin d'avoir quelque extraordinaire assistance du ciel et d'être plus qu'homme.

Je ne dirai rien de la philosophie, sinon que, voyant qu'elle a été cultivée par les plus excellents esprits qui aient vécu depuis plu- 10 sieurs siècles, et que néanmoins il ne s'y trouve encore aucune chose dont on ne dispute, et par conséquent qui ne soit douteuse, je n'avais point assez de présomption pour espérer d'y rencontrer ${ }^{1}$ mieux que les autres; et que, considérant combien il peut y avoir de diverses opinions touchant une même matière qui soient soutenues par des 15 gens doctes, sans qu'il y en puisse avoir jamais plus d'une seule qui soit vraie, je réputais presque pour faux tout ce qui n'était que vraisemblable.

Puis, pour les autres sciences, d'autant qu'elles empruntent leurs principes de la philosophie, je jugeais qu'on ne pouvait avoir rien 20 bâti qui fût solide sur des fondements si peu fermes, et ni l'honneur ni le gain qu'elles promettent n'étaient suffisants pour me convier à les apprendre; car je ne me sentais point, grâces à Dieu, de condition qui m'obligeât à faire un métier de la science pour le soulagement de ma fortune; et, quoique je ne fisse pas profession de 25 mépriser la gloire en cynique, je faisais néanmoins fort peu d'état de celle que je n'espérais point pouvoir acquérir qu'à faux titres. Et enfin, pour les mauvaises doctrines, je pensais déjà connaître assez ce qu'elles valaient pour n'être plus sujet à être trompé ni par les promesses d'un alchimiste, ni par les prédictions d'un astrologue, 30 ni par les impostures d'un magicien, ni par les artifices ou la vanterie d'aucun de ceux qui font profession de savoir plus qu'ils ne savent.

C'est pourquoi, sitôt que l'âge me permit de sortir de la sujétion de mes précepteurs, je quittai entièrement l'étude des lettres; et me résolvant de ne chercher plus d'autre science que celle qui se pourrait 35 trouver en moi-méme ou bien dans le grand livre du monde, j'employai le reste de ma jeunesse à voyager, à voir des cours et des armées, à fréquenter des gens de diverses humeurs et conditions, à recueillir 
diverses expériences, à m'éprouver moi-même dans les rencontres que la fortune me proposait, et partout à faire telle réflexion sur les choses qui se présentaient que j'en pusse tirer quelque profit. Car il me semblait que je pourrais rencontrer beaucoup plus de vérité dans 5 les raisonnements que chacun fait touchant les affaires qui lui importent, et dont l'événement le doit punir bientôt après s'il a mal jugé, que dans ceux que fait un homme de lettres dans son cabinet touchant des spéculations qui ne produisent aucun effet, et qui ne lui sont d'autre conséquence sinon que peut-être il en tirera d'autant plus ıo de vanité qu'elles seront plus éloignées du sens commun, à cause qu'il aura dû employer d'autant plus d'esprit et d'artifice à tâcher de les rendre vraisemblables. Et j'avais toujours un extrême désir d'apprendre à distinguer le vrai d'avec le faux, pour voir clair en mes actions et marcher avec assurance en cette vie.

I 5 Il est vrai que pendant que je ne faisais que considérer les mœurs des autres hommes, je n'y trouvais guère de quoi m'assurer, et que j'y remarquais quasi autant de diversité que j'avais fait auparavant entre les opinions des philosophes. En sorte que le plus grand profit que j'en retirais était que, voyant plusieurs choses qui, bien qu'elles 20 nous semblent fort extravagantes et ridicules, ne laissent pas d'être communément reçues et approuvées par d'autres grands peuples, j'apprenais à ne rien croire trop fermement de ce qui ne m'avait été persuadé que par l'exemple et par la coutume; et ainsi je me délivrais peu à peu de beaucoup d'erreurs qui peuvent offusquer notre 25 lumière naturelle et nous rendre moins capables d'entendre raison. Mais après que j'eus employé quelques années à étudier ainsi dans le livre du monde et à tâcher d'acquérir quelque expérience, je pris un jour la résolution d'étudier aussi en moi-même et d'employer toutes les forces de mon esprit à choisir les chemins que je devais 3o suivre; ce qui me réussit beaucoup mieux, ce me semble, que si je ne me fusse jamais éloigné ni de mon pays ni de mes livres.

— «Discours de la méthode », Part first 


\title{
PIERRE CORNEILLE
}

\author{
Rouen, $1606-1684$, Paris
}

Born at Rouen in 1606 , Pierre Corneille received his education at the hands of the Jesuits. IIe was an excellent student, particularly in writing Latin verse, and was the recipient of several prizes. II studies finished, he took up law and was admitted to the bar in 1624 . Inclination and chance, however, turned him to the stage, and in 1629 he began his literary career with a very successful comedy entitled "Mélite." By this play, by "Clitandre," an unsuccessful comedy acted in $1_{632}$, and by "La veuve" ( $\left.16_{33}\right)$, a comedy, Corneille attracted the attention of Richelieu, who made him one of the "five poets," chosen to elaborate plots furnished them by the Cardinal himself. But this collaboration was not of long duration, and in 1636 Corneille brought out "Le Cid," one of the most successful plays ever produced on the French stage. Even the jealousy of some of his fellow-writers, and the more or less unjust criticism of the Academy, could not dampen popular enthusiasm, though they did seem to discourage Corneille for a time. But with "Horace," played in I640, and "Cinna," played the same year, began the series of masterpieces which followed each other in quick succession for the next ten years - "Polyeucte" (1643); "Pompée" (1643-1644); "Le menteur" (probably I643), a comedy ; "La suite du menteur" (I643-1644); "Rodogune" (I644-I645); "Héraclius" (1647); "Don Sanche" (1650); "Nicomède" (I651). He was elected to the Academy in 1647 , in the midst of these successes. In 1652 "Pertharite" failed at its first presentation; and, owing to this, and to the success with which a versified translation of the first twenty chapters of the "Imitation of Christ" had met in I65I, Corneille gave up the stage for seven years, and brought out, in 1656 , the complete translation of the "Imitation." But in 1659 he was induced to return to the stage, and from then until 1674 his activity did not cease. Despite beautiful verses, and even scenes, the plays of this period add nothing to the permanent reputation of the poet, and so his death, in 1684 , was but little noticed. The masterpieces of his best period, however, give him one of the first places in all French literature.

\section{LE CID}

I

Don Diegue, Don Rodrigue

DON DIEGGE

Rodrigue, as-tu du cœur?

DON RODRIGUE

Tout autre que mon père 
L'éprouverait sur l'heure.

\title{
DON DIÈGUE
}

Agréable colère !

Digne ressentiment à ma douleur bien doux!

Je reconnais mon sang à ce noble courroux;

Ma jeunesse revit en cette ardeur si prompte.

Viens, mon fils, viens, mon sang, viens réparer ma honte;

Viens me venger.

\author{
DON RODRIGUE \\ De quoi? \\ DON DIÈGUE \\ D'un affront si cruel,
}

Qu'à l'honneur de tous deux il porte un coup mortel :

D'un soufflet. L'insolent en eût perdu la vie;

Mais mon âge a trompé ma généreuse envie:

Io

Et ce fer que mon bras ne peut plus soutenir,

Je le remets au tien pour venger et punir.

Va contre un arrogant éprouver ton courage:

Ce n'est que dans le sang qu'on lave un tel outrage ;

Meurs ou tue. Au surplus, pour ne te point flatter,

I 5 Je te donne à combattre un homme à redouter ;

Je l'ai vu, tout couvert de sang et de poussière,

Porter partout l'effroi dans une armée entière.

J'ai vu par sa valeur cent escadrons rompus ;

Et pour t'en dire encor quelque chose de plus,

20

Plus que brave soldat, plus que grand capitaine,

C'est . . .

DON RODRIGUE

De grâce, achevez.

DON DIÈGLE

Le père de Chimène.

Le . . .

\author{
DON RODRIGUE
}

DON DIÈGUE

Ne réplique point, je connais ton amour;

Mais qui peut vivre infâme est indigne du jour.

Plus l'offenseur est cher, et plus grande est l'offense.

Enfin tu sais l'affront, et tu tiens la vengeance: 
Je ne te dis plus rien. Venge-moi, venge-toi;

Montre-toi digne fils d'un père tel que moi.

Accablé des malheurs où le destin me range,

Je vais les déplorer: va, cours, vole, et nous venge.

- Act I, scene 5

II

\section{Don Rodrigue}

Percé jusques au fond du cœur

D'une atteinte imprévue aussi bien que mortelle,

Misérable vengeur d'une juste querelle,

Et malheureux objet d'une injuste rigueur,

Je demeure immobile, et mon âme abattue

Cède au coup qui me tue.

10

Si près de voir mon feu récompensé,

O Dieu, l'étrange peine!

En cet affront mon père est l'offensé,

Et l'offenseur le père de Chimène!

Que je sens de rudes combats!

Contre mon propre honneur mon amour s'intéresse :

Il faut venger un père, et perdre une maîtresse:

L'un m'anime le cœur, l'autre retient mon bras.

Réduit au triste choix ou de trahir ma flamme,

Ou de vivre en infâme,

Des deux côtés mon mal est infini.

O Dieu, l'étrange peine!

Faut-il laisser un affront impuni?

Faut-il punir le père de Chimène?

Père, maîtresse, honneur, amour, Noble et dure contrainte, aimable tyrannie,

Tous mes plaisirs sont morts, ou ma gloire ternie.

L'un me rend malheureux, l'autre indigne du jour.

Cher et cruel espoir d'une âme généreuse,

Mais ensemble amoureuse,

Digne ennemi de mon plus grand bonheur,

Fer qui causes ma peine,

M'es-tu donné pour venger mon honneur?

M'es-tu donné pour perdre ma Chimène?

Il vaut mieux courir au trépas.

Je dois à ma maîtresse aussi bien qu'à mon père : 
J'attire en me vengeant sa haine et sa colère;

J'attire ses mépris en ne me vengeant pas.

A mon plus doux espoir l'un me rend infidèle,

Et l'autre indigne d'elle.

Mon mal augmente à le vouloir guérir ;

Tout redouble ma peine.

Allons, mon âme ; et puisqu'il faut mourir, Mourons du moins sans offenser Chimène.

Mourir sans tirer ma raison!

Io Rechercher un trépas si mortel à ma gloire !

Endurer que l'Espagne impute à ma mémoire

D'avoir mal soutenu l'honneur de ma maison!

Respecter un amour dont mon âme égarée

Voit la perte assurée!

I5 N'écoutons plus ce penser suborneur,

Qui ne sert qu'à ma peine.

Allons, mon bras, sauvons du moins l'honneur,

Puisqu' après tout il faut perdre Chimène.

Oui, mon esprit s'était déçu.

Je dois tout à mon père avant qu'à ma maîtresse :

Que je meure au combat, ou meure de tristesse,

Je rendrai mon sang pur comme je l'ai reçu.

Je m'accuse déjà de trop de négligence :

Courons à la vengeance;

Et tout honteux d'avoir tant balancé,

Ne soyons plus en peine,

Puisqu' aujourd'hui mon père est l'offensé,

Si l'offenseur est père de Chimène.

- Act I, scene 6

III

Le Comte, Don Rodrigue

DON RODRIGUE

A moi, Comte, deux mots.

LE COMTE

Parle.

DON RODRIGUE

Ote-moi d'un doute. 
LE COMTE

Oui.

DON RODRIGUE

Parlons bas; écoute.

Sais-tu que ce vieillard fut la même vertu, La vaillance et l'honneur de son temps? le sais-tu?

\section{LE COMTE}

Peut-être.

\section{DON RODRIGUE}

Cette ardeur que dans les yeux je porte, Sais-tu que c'est son sang? le sais-tu?

LE COMTE

DON RODRIGUE

A quatre pas d'ici je te le fais savoir.

\section{LE COMTE}

Jeune présomptueux!

\section{DON RODRIGUE}

Parle sans t'émouvoir.

Je suis jeune, il est vrai ; mais aux âmes bien nées La valeur n'attend point le nombre des années.

\section{LE COMTE}

Te mesurer à moi! Qui t'a rendu si vain, Toi qu'on n'a jamais vu les armes à la main?

\section{DON RODRIGUE}

Mes pareils à deux fois ne se font point connaître, Et pour leurs coups d'essai veulent des coups de maitre.

$$
\text { LE COMTE }
$$

Sais-tu bien qui je suis?

\section{DON RODRIGUE}

Oui ; tout autre que moi

$\mathrm{Au}$ seul bruit de ton nom pourrait trembler d'effroi. Les palmes dont je vois ta tête si couverte Semblent porter écrit le destin de ma perte. 
J'attaque en téméraire un bras toujours vainqueur;

Mais j'aurai trop de force, ayant assez de cœur.

A qui venge son père il n'est rien impossible.

Ton bras est invaincu, mais non pas invincible.

\section{LE COMTE}

Ce grand cœur qui paraît aux discours que tu tiens, Par tes yeux, chaque jour, se découvrait aux miens;

Et croyant voir en toi l'honneur de la Castille, Mon âme avec plaisir te destinait ma fille.

Je sais ta passion, et suis ravi de voir

Que tous ses mouvements cèdent à ton devoir ;

Qu'ils n'ont point affaibli cette ardeur magnanime;

Que ta haute vertu répond à mon estime;

Et que voulant pour gendre un cavalier parfait,

Je ne me trompais point au choix que j'avais fait .

I 5 Mais je sens que pour toi ma pitié s'intéresse;

J'admire ton courage, et je plains ta jeunesse.

$\mathrm{Ne}$ cherche point à faire un coup d'essai fatal ;

Dispense ma valeur d'un combat inégal ;

Trop peu d'honneur pour moi suivrait cette victoire :

A vaincre sans péril, on triomphe sans gloire.

On te croirait toujours abattu sans effort;

Et j'aurais seulement le regret de ta mort.

DON RODRIGUE

L'une indigne pitié ton audace est suivie:

Qui m'ose ôter l'honneur craint de m'ôter la vie?

LE COMTE

$25 \quad$ Retire-toi d'ici.

DON RODRIGUE

Marchons sans discourir.

LE COMTE

Es-tu si las de vivre?

\section{DON RODRIGUE}

As-tu peur de mourir?

LE COMTE

Viens, tu fais ton devoir, et le fils dégénère Qui survit un moment à l'honneur de son père. 


\section{CINNA \\ Auguste, Cinna ${ }^{1}$}

AUGUSTE

Prends un siège, Ginna, prends, et sur toute chose

Observe exactement la loi que je t'impose:

Prête, sans me troubler, l'oreille à mes discours ;

D'aucun mot, d'aucun cri, n'en interromps le cours ;

Tiens ta langue captive; et si ce grand silence

A ton émotion fait quelque violence,

'Tu pourras me répondre après tout à loisir :

Sur ce point seulement contente mon désir.

CINNA

Je vous obéirai, Seigneur.

\section{AUGUSTE}

Qu'il te souvienne

De garder ta parole, et je tiendrai la mienne.

Tu vois le jour, Cinna; mais ceux dont tu le tiens

Furent les ennemis de mon père, et les miens :

$\mathrm{Au}$ milieu de leur camp tu reçus la naissance;

Et lorsqu'après leur mort tu vins en ma puissance,

Leur haine enracinée au milieu de ton sein

T'avait mis contre moi les armes à la main;

Tu fus mon ennemi même avant que de naître,

Et tu le fus encor quand tu me pus connaître,

Et l'inclination jamais n'a démenti

Ce sang qui t'avait fait du contraire parti :

Autant que tu l'as pu, les effets l'ont suivie.

Je ne m'en suis vengé qu'en te donnant la vie;

Je te fis prisonnier pour te combler de biens :

Ma cour fut ta prison, mes faveurs tes liens;

Je te restituai d'abord ton patrimoine;

Je t'enrichis après des dépouilles d'Antoine,

Et tu sais que depuis, à chaque occasion,

Je suis tombé pour toi dans la profusion.

Toutes les dignités que tu m'as demandées,

Je te les ai sur l'heure et sans peine accordées ;

1 At the instigation of Émilie, whom he loves, Cinna has formed a conspiracy to kill the emperor Auguste, his benefactor. The conspiracy has been discovered, and Auguste has summoned Cinna to him. 
Je t'ai préféré même à ceux dont les parents Ont jadis dans mon camp tenu les premiers rangs, A ceux qui de leur sang m'ont acheté l'empire, Et qui m'ont conservé le jour que je respire. De la façon enfin qu'avec toi j'ai vécu,

Les vainqueurs sont jaloux du bonheur du vaincu. Quand le ciel me voulut, en rappelant Mécène, Après tant de faveur montrer un peu de haine, Je te donnai sa place en ce triste accident, Et te fis, après lui, mon plus cher confident. Aujourd'hui même encor, mon âme irrésolue Me pressant de quitter ma puissance absolue, De Maxime et de toi j'ai pris les seuls avis, Et ce sont, malgré lui, les tiens que j'ai suivis. Bien plus, ce même jour je te donne Émilie, Le digne objet des vœux de toute l'Italie, Et qu'ont mise si haut mon amour et mes soins, Qu'en te couronnant roi je t'aurais donné moins. Tu t'en souviens, Cinna: tant d'heur et tant de gloire Ne peuvent pas sitôt sortir de ta mémoire ; Mais ce qu'on ne pourrait jamais s'imaginer, Cinna, tu t'en souviens, et veux m'assassiner.

\section{CINNA}

Moi, seigneur ! moi, que j'eusse une âme si traîtresse ; Qu'un si lâche dessein ...

\section{AUGUSTE}

Tu tiens mal ta promesse:

Sieds-toi, je n'ai pas dit encor ce que je veux;

Tu te justifieras après, si tu le peux.

Écoute cependant, et tiens mieux ta parole.

Tu veux m'assassiner demain, au Capitole, Pendant le sacrifice, et ta main pour signal

30 Me doit, au lieu d'encens, donner le coup fatal;

La moitié de tes gens doit occuper la porte, L'autre moitié te suivre et te prêter main-forte.

Ai-je de bons avis, ou de mauvais soupçons?

De tous ces meurtriers te dirai-je les noms?

Procule, Glabrion, Virginian, Rutile, Marcel, Plaute, Lénas, Pompone, Albin, Icile, Maxime, qu'après toi j'avais le plus aimé; 
Le reste ne vaut pas l'honneur d'être nommé :

Un tas d'hommes perdus de dettes et de crimes, Que pressent de mes lois les ordres légitimes, Et qui désespérant de les plus éviter,

Si tout n'est renversé, ne sauraient subsister.

Tu te tais maintenant, et gardes le silence, Plus par confusion que par obéissance.

Quel était ton dessein, et que prétendais-tu

Après m'avoir au temple à tes pieds abattu ?

Affranchir ton pays d'un pouvoir monarchique!

Si j'ai bien entendu tantôt ta politique,

Son salut désormais dépend d'un souverain

Qui pour tout conserver tienne tout en sa main;

Et si sa liberté te faisait entreprendre,

Tu ne m'eusses jamais empêché de la rendre;

'Tu l'aurais acceptée au nom de tout l'État,

Sans vouloir l'acquérir par un assassinat.

Quel était donc ton but? D'y régner en ma place?

D'un étrange malheur son destin le menace,

Si pour monter au trône et lui donner la loi

Tu ne trouves dans Rome autre obstacle que moi,

Si jusques à ce point son sort est déplorable,

Que tu sois après moi le plus considérable,

Et que ce grand fardeau de l'empire romain

Ne puisse après ma mort tomber mieux qu'en ta main.

Apprends à te connaître, et descends en toi-même :

On t'honore dans Rome, on te courtise, on t'aime,

Chacun tremble sous toi, chacun t'offre des vœux,

Ta fortune est bien haut, tu peux ce que tu veux;

Mais tu ferais pitié même à ceux qu'elle irrite,

Si je t'abandonnais à ton peu de mérite.

Ose me démentir, dis-moi ce que tu vaux,

Conte-moi tes vertus, tes glorieux travaux,

Les rares qualités par où tu m'as dû plaire,

Et tout ce qui t'élève au-dessus du vulgaire.

$\mathrm{Ma}$ faveur fait ta gloire, et ton pouvoir en vient :

Elle seule t'élève, et seule te soutient;

C'est elle qu'on adore, et non pas ta personne

Tu n'as crédit ni rang qu'autant qu'elle t'en donne,

Et pour te faire choir je n'aurais aujourd'hui

Qu'à retirer la main qui seule est ton appui. 
J'aime mieux toutefois céder à ton envie:

Règne, si tu le peux, aux dépens de ma vie;

Mais oses-tu penser que les Serviliens,

Les Cosses, les Métels, les Pauls, les Fabiens,

Et tant d'autres enfin de qui les grands courages

Des héros de leur sang sont les vives images, Quittent le noble orgueil d'un sang si généreux Jusqu'à pouvoir souffrir que tu règnes sur eux? Parle, parle, il est temps.

\section{CINNA}

Je demeure stupide;

Non que votre colère ou la mort m'intimide : Je vois qu'on m'a trahi, vous m'y voyez rêver, Et j'en cherche l'auteur sans le pouvoir trouver. Mais c'est trop y tenir toute l'âme occupée: Seigneur, je suis Romain, et du sang de Pompée ; Le père et les deux fils, lâchement égorgés, Par la mort de César étaient trop peu vengés. C'est là d'un beau dessein l'illustre et seule cause ;

Et puisqu'à vos rigueurs la trahison m'expose, N'attendez point de moi d'infâmes repentirs, D'inutiles regrets, ni de honteux soupirs.

Le sort vous est propice autant qu'il m'est contraire ; Je sais ce que j'ai fait, et ce qu'il vous faut faire: Vous devez un exemple à la postérité, Et mon trépas importe à votre sûreté.

\section{AUguste}

Tu me braves, Cinna, tu fais le magnanime, Et loin de t'excuser, tu couronnes ton crime. Voyons si ta constance ira jusques au bout. Tu sais ce qui t'est dû, tu vois que je sais tout : Fais ton arrêt toi-même, et choisis tes supplices. 
POLYEUCTE

Polyeucte, Pauline

POLYEUCTE

Madame, quel dessein vous fait me demander?

Est-ce pour me combattre ou pour me seconder?

Cet effort généreux de votre amour parfaite

Vient-il à mon secours, vient-il à ma défaite?

Apportez-vous ici la haine, ou l'amitié,

Comme mon ennemie, ou ma chère moitié ?

\section{PAULINE}

Vous n'avez point ici d'ennemi que vous-même :

Seul vous vous haïssez, lorsque chacun vous aime;

Seul vous exécutez tout ce que j'ai rêvé :

$\mathrm{Ne}$ veuillez pas vous perdre, et vous êtes sauvé.

A quelque extrémité que votre crime passe,

Vous êtes innocent si vous vous faites grâce.

Daignez considérer le sang dont vous sortez,

Vos grandes actions, vos rares qualités :

Chéri de tout le peuple, estimé chez le prince,

Gendre du gouverneur de toute la province;

Je ne vous compte à rien le nom de mon époux :

C'est un bonheur pour moi qui n'est pas grand pour vous ;

Mais après vos exploits, après votre naissance,

Après votre pouvoir, voyez notre espérance,

Et n'abandonnez pas à la main d'un bourreau

Ce qu'à nos justes vœux promet un sort si beau.

\section{POLYEUCTE}

Je considère plus; je sais mes avantages,

Et l'espoir que sur eux forment les grands courages :

Ils n'aspirent enfin qu'à des biens passagers,

Que troublent les soucis, que suivent les dangers;

La mort nous les ravit, la fortune s'en joue;

Aujourd'hui dans le trône, et demain dans la boue;

Et leur plus haut éclat fait tant de mécontents, Que peu de vos Césars en ont joui longtemps.

J'ai de l'ambition, mais plus noble et plus belle:

Cette grandeur périt, j'en veux une immortelle,

1 In his zeal for Christianity, to which he has just been converted, Polyeucte, husband of Pauline, still unconverted, went to the temple and broke the pagan idols. He was thrown into prison by his father-in-law, Félix, and it is there that Pauline visits him. 
Un bonheur assuré, sans mesure et sans fin, Au-dessus de l'envie, au-dessus du destin. Est-ce trop l'acheter que d'une triste vie Qui tantôt, qui soudain me peut être ravie, 5 Qui ne me fait jouir que d'un instant qui fuit, Et ne peut m'assurer de celui qui le suit?

\section{PAULINE}

Voilà de vos chrétiens les ridicules songes;

Voilà jusqu'à quel point vous charment leurs mensonges :

Tout votre sang est peu pour un bonheur si doux!

Mais pour en disposer, ce sang est-il à vous?

Vous n'avez pas la vie ainsi qu'un héritage ;

Le jour qui vous la donne en même temps l'engage:

Vous la devez au prince, au public, à l’État.

\section{POLYEUCTE}

Je la voudrais pour eux perdre dans un combat;

I 5 Je sais quel en est l'heur, et quelle en est la gloire.

Des aieux de Décie ${ }^{1}$ on vante la mémoire;

Et ce nom, précieux encore à vos Romains,

$\mathrm{Au}$ bout de six cents ans lui met l'empire aux mains.

Je dois ma vie au peuple, au prince, à sa couronne ;

2o Mais je la dois bien plus au Dieu qui me la donne:

Si mourir pour son prince est un illustre sort,

Quand on meurt pour son. Dieu, quelle sera la mort!

Quel Dieu !

PAULINE

\section{POLYEUCTE}

Tout beau, Pauline: il entend vos paroles, Et ce n'est pas un Dieu comme vos Dieux frivoles,

25 Insensibles et sourds, impuissants, mutilés, De bois, de marbre, ou d'or, comme vous les voulez:

C'est le Dieu des chrétiens, c'est le mier, c'est le vôtre ;

Et la terre et le ciel n'en connaissent point d'autre.

PAULINE

Adorez-le dans l'âme, et n'en témoignez rien.

\section{POLYEUCTE}

1 Roman emperor, 249-251, persecutor of the Christians. Polyeucte suffered under him. Publius Decius gave his life for his army $34^{\circ}$ B.C.; so did his son, 295 B.C. 
PAULINE

Ne feignez qu'un moment, laissez partir Sévère, Et donnez lieu d'agir aux bontés de mon père.

\section{POLYEUC'TE}

Les bontés de mon Dieu sont bien plus à chérir, Il m'ôte des périls que j'aurais pu courir. Et sans me laisser lieu de tourner en arrière, Sa faveur me couronne entrant dans la carrière;

Du premier coup de vent il me conduit au port, Et sortant du baptême, il m'envoie à la mort.

Si vous pouviez comprendre et le peu qu'est la vie,

Et de quelles douceurs cette mort est suivie!

Mais que sert de parler de ces trésors cachés

A des esprits que Dieu n'a pas encor touchés?

\section{PAULINE}

Cruel, car il est temps que ma douleur éclate, Et qu'un juste reproche accable une âme ingrate, Est-ce là ce beau feu? sont-ce là tes serments ? Témoignes-tu pour moi les moindres sentiments?

Je ne te parlais point de l'état déplorable

Où ta mort va laisser ta femme inconsolable;

Je croyais que l'amour t'en parlerait assez,

Et je ne voulais pas de sentiments forcés;

Mais cette amour si ferme et si bien méritée

Que tu m'avais promise, et que je t'ai portée,

Quand tu me veux quitter, quand tu me fais mourir,

Te peut-elle arracher une larme, un soupir?

$\mathrm{Tu}$ me quittes, ingrat, et le fais avec joie;

Tu ne la caches pas, tu veux que je la voie;

Et ton cœur, insensible à ces tristes appas,

Se figure un bonheur où je ne serai pas!

C'est donc là le dégoût qu'apporte l'hyménée?

Je te suis odieuse après m'être donnée!

Hélas !

\section{POLYEUCTE}

\section{PAULINE}

Que cet hélas a de peine à sortir ! Encor s'il commençait un heureux repentir, Que tout forcé qu'il est, j'y trouverais de charmes! Mais courage, il s'émeut, je vois couler des larmes. 
POLYEUCTE

J'en verse, et plût à Dieu qu'à force d'en verser

Ce cœur trop endurci se pût enfin percer!

Le déplorable état où je vous abandonne

Est bien digne des pleurs que mon amour vous donne;

Et si l'on peut au ciel sentir quelques douleurs,

J'y pleurerai pour vous l'excès de vos malheurs ;

Mais si, dans ce séjour de gloire et de lumière,

Ce Dieu tout juste et bon peut souffrir ma prière,

S'il y daigne écouter un conjugal amour,

10

Sur votre aveuglement il répandra le jour.

Seigneur, de vos bontés il faut que je l'obtienne; Elle a trop de vertus pour n'être pas chrétienne: Avec trop de mérite il vous plut la former, Pour ne vous pas connaître et ne vous pas aimer,

I 5 Pour vivre des enfers esclave infortunée,

Et sous leur triste joug mourir comme elle est née.

\section{PAULINE}

Que dis-tu, malheureux ? qu'oses-tu souhaiter?

\section{POLYEUCTE}

Ce que de tout mon sang je voudrais acheter.

$$
\text { PAULINE }
$$

Que plutôt ...

\section{POLYEUCTE}

C'est en vain qu'on se met en défense :

20 Ce Dieu touche les cœurs lorsque moins on y pense.

Ce bienheureux moment n'est pas encor venu;

Il viendra, mais le temps ne m'en est pas connu.

\section{PAULINE}

Quittez cette chimère, et m'aimez.

\section{POLYEUCTE}

Je vous aime,

Beaucoup moins que mon Dieu, mais bien plus que moi-même.

\section{PAULINE}

25 Au nom de cet amour ne m'abandonnez pas. 
POLYEUC'TE

Au nom de cet amour, daignez suivre mes pas.

PAULINE

C'est peu de me quitter, tu veux donc me séduire?

POLYEUCTE

C'est peu d'aller au ciel, je vous y veux conduire.

Imaginations !

PAULINE

POLYEUCTE

Célestes vérités!

PAULINE

Etrange aveuglement!

POLYEUCTE

Eternelles clartés !

PAULINE

Tu préfères la mort à l'amour de Pauline!

POLYEUC'TE

Vous préférez le monde à la bonté divine!

PAULINE

$\mathrm{Va}$, cruel, va mourir : tu ne m'aimas jamais.

POLYEUCTE

Vivez heureuse au monde, et me laissez en paix.

PAULINE

Oui, je t'y vais laisser; ne t'en mets plus en peine; Je vais ...

- Act IV, scene 3 


\author{
NICOMÈDE \\ Nicomède, Prusias, Flaminius ${ }^{1}$
}

FLAMINIUS

Sur le point de partir, Rome, Seigneur, me mande Que je vous fasse encor pour elle une demande.

Elle a nourri ${ }^{2}$ vingt ans un prince votre fils; Et vous pouvez juger les soins qu'elle en a pris

Par les hautes vertus et les illustres marques

Qui font briller en lui le sang de vos monarques.

Surtout il est instruit en l'art de bien régner:

C'est à vous de le croire, et de le témoigner.

$\mathrm{Si}$ vous faites état de cette nourriture, ${ }^{3}$

Donnez ordre qu'il règne: elle vous en conjure;

Et vous offenseriez l'estime qu'elle en fait

Si vous le laissiez vivre et mourir en sujet.

Faites donc aujourd'hui que je lui puisse dire

Où vous lui destinez un souverain empire.

PRUSIAS

Les soins qu'ont pris de lui le peuple et le sénat Ne trouveront en moi jamais un père ingrat:

Je crois que pour régner il en a les mérites,

Et n'en veux point douter après ce que vous dites;

Mais vous voyez, Seigneur, le Prince son aîné,

Dont le bras généreux trois fois m'a couronné;

Il ne fait que sortir encor d'une victoire ;

Et pour tant de hauts faits je lui dois quelque gloire:

Souffrez qu'il ait l'honneur de répondre pour moi.

\title{
NICOMÈDE
}

Seigneur, c'est a vous seul de faire Attale roi.

\section{PRUSIAS}

C'est votre intérêt seul que sa demande touche. NICOMÈDE

La vôtre toutefois m'ouvrira seul la bouche.

De quoi se mêle Rome, et d'où prend le sénat,

1 Rome has sent to the court of Prusias, king of Bithynia, her ambassador Flaminius, to support the interests of the prince Attale, a friend of Rome, in preference to those of his elder brother, Nicomède, who is hostile to Roman influence.

2 élevé, in modern French. 
Vous vivant, vous régnant, ce droit sur votre Etat?

Vivez, régnez, Seigneur, jusqu'à la sépulture,

Et laissez faire après, ou Rome, ou la nature.

\section{PRUSIAS}

Pour de pareils amis il faut se faire effort.

\section{NICOMÈDE}

Qui partage vos biens aspire à votre mort ;

Et de pareils amis, en bonne politique ...

PRUSIAS

Ah! ne me brouillez point avec la République:

Portez plus de respect à de tels alliés.

\section{NICOMÈDE}

Je ne puis voir sous eux les rois humiliés ;

Et quel que soit ce fils que Rome vous renvoie,

Seigneur, je lui rendrais son présent avec joie.

S'il est si bien instruit en l'art de commander,

C'est un rare trésor qu'elle devrait garder,

Et conserver chez soi sa chère nourriture, ${ }^{1}$

Ou pour le consulat, ou pour la dictature.

\section{FLAMINIUS}

Seigneur, dans ce discours qui nous traite si mal, Vous voyez un effet des leçons d'Annibal;

Ce perfide ennemi de la grandeur romaine

N'en a mis en son cœur que mépris et que haine.

NICOMÈDE

Non, mais il m'a surtout laissé ferme en ce point, D'estimer beaucoup Rome, et ne la craindre point.

On me croit son disciple, et je le tiens à gloire;

Et quand Flaminius attaque sa mémoire,

Il doit savoir qu'un jour il me fera raison

D'avoir réduit mon maître au secours du poison,

Et n'oublier jamais qu'autrefois ce grand homme

Commença par son père ${ }^{2}$ à triompher de Rome.

\section{FLAMINIUS}

Ah! c'est trop m'outrager!

1 élève.

${ }^{2}$ Corneille incorrectly supposes that Flaminius is the son of the Flaminius conquered by Hannibal at Lake Trasimeno. 


\section{NICOMÈDE}

N'outragez plus les morts.

\section{PRUSIAS}

Et vous, ne cherchez point à former de discords : Parlez, et nettement, sur ce qu'il me propose.

\section{NICOMÈDE}

Eh bien! s'il est besoin de répondre autre chose, Attale doit régner, Rome l'a résolu; Et puisqu'elle a partout un pouvoir absolu, C'est aux rois d'obéir alors qu'elle commande.

Attale a le cœur grand, l'esprit grand, l'âme grande, Et toutes les grandeurs dont se fait un grand roi ; Mais c'est trop que d'en croire un Romain sur sa foi. Par quelque grand effet voyons s'il en est digne, S'il a cette vertu, cette valeur insigne:

Donnez-lui votre armée, et voyons ces grands coups; Qu'il en fasse pour lui ce que j'ai fait pour vous ; Qu'il règne avec éclat sur sa propre conquête, Et que de sa victoire il couronne sa tête. Je lui prête mon bras, et veux dès maintenant, S'il daigne s'en servir, être son lieutenant. L'exemple des Romains m'autorise à le faire: Le fameux Scipion le fut bien de son frère; Et lorsqu'Antiochus fut par eux détrôné, Sous les lois du plus jeune on vit marcher l'aîné. Les bords de l'Hellespont, ceux de la mer Egée, Les restes de l'Asie à nos côtés rangée, Offrent une matière à son ambition . . .

\section{FLAMINIUS}

Rome prend tout ce reste en sa protection; Et vous n'y pouvez plus étendre vos conquêtes, Sans attirer sur vous d'effroyables tempêtes.

\section{NICOMÈDE}

J'ignore sur ce point les volontés du Roi ; Mais peut-être qu'un jour je dépendrai de moi, Et nous verrons alors l'effet de ces menaces.

Vous pouvez cependant faire munir ces places, Préparer un obstacle à mes nouveaux desseins, 
Disposer de bonne heure un secours de Romains ; Et si Flaminius en est le capitaine,

Nous pourrons lui trouver un lac de Trasimène.

PRUSIAS

Prince, vous abusez trop tôt de ma bonté:

Le rang d'ambassadeur doit être respecté,

Et l'honneur souverain qu'ici je vous défère . . .

NICOMÈdE

Ou laissez-moi parler, Sire, ou faites-moi taire.

Je ne sais pas répondre autrement pour un roi

A qui dessus son trône on veut faire la loi.

PRUSIAS

Vous m'offensez moi-même en parlant de la sorte,

Et vous devez dompter l'ardeur qui vous emporte.

\section{NICOMÈDE}

Quoi ? je verrai, Seigneur, qu'on borne vos Etats, Qu'au milieu de ma course on m'arrête le bras,

Que de vous menacer on a même l'audace,

Et je ne rendrai point menace pour menace!

Et je remercierai qui me dit hautement

Qu'il ne m'est plus permis de vaincre impunément !

\section{PRUSIAS, d Flaminius}

Seigneur, vous pardonnez aux chaleurs de son âge ;

Le temps et la raison pourront le rendre sage.

\section{NICOMÈDE}

La raison et le temps m'ouvrent assez les yeux,

Et l'âge ne fera que me les ouvrir mieux.

Si j'avais jusqu'ici vécu comme ce frère, Avec une vertu qui fût imaginaire

(Car je l'appelle ainsi quand elle est sans effets;

Et l'admiration de tant d'hommes parfaits

Dont il a vu dans Rome éclater le mérite,

N'est pas grande vertu si l'on ne les imite);

Si j'avais donc vécu dans ce même repos

Qu'il a vécu dans Rome auprès de ses héros,

Elle me laisserait la Bithynie entière,

Telle que de tout temps l'aîné la tient d'un père, 
Et s'empresserait moins à le faire régner, $\mathrm{Si}$ vos armes sous moi n'avaient su rien gagner. Mais parce qu'elle voit avec la Bithynie Par trois sceptres conquis trop de puissance unie, Il faut la diviser; et dans ce beau projet, Ce prince est trop bien né pour vivre mon sujet! Puisqu'il peut la servir à me faire descendre, Il a plus de vertu que n'en eut Alexandre; Et je lui dois quitter, pour le mettre en mon rang, Le bien de mes aieux, ou le prix de mon sang. Grâces aux immortels, l'effort de mon courage Et ma grandeur future ont mis Rome en ombrage :

Vous pouvez l'en guérir, Seigneur, et promptement; Mais n'exigez d'un fils aucun consentement : Le maître qui prit soin d'instruire ma jeunesse Ne m'a jamais appris à faire une bassesse. 


\title{
JEAN-FRANÇOIS-PAUL DE GONDI, CARDINAL DE RETZ
}

\author{
Montmirail, I613-1679, Paris
}

De Retz was destined by his family for the church, despite the fact that, during his youth, he did not show any clerical leanings. After the death of Louis XIII he was made coadjutor (1643), and, in 1651 , cardinal under the name of Retz. He took an active part in the Fronde against the court, and thus fell into disfavor. In 1662 he retired to Commercy and there wrote his "Mémoires," in which he relates much of the history of the Fronde in a peculiarly vivid fashion.

\section{UNE SCÈNE DE LA FRONDE ${ }^{1}$}

Le Cardinal, ${ }^{2}$ après une douzaine de galimatias qui se contredisaient les uns les autres, conclut à se donner encore du temps jusques au lendemain, et de faire connaître, en attendant, au peuple que la Reine ${ }^{8}$ lui accordait la liberté de Broussel, ${ }^{4}$ pourvu qu'il se séparât et qu'il ne continuât pas à la demander en foule. Le Cardinal ajouta que personne ne pouvait plus agréablement ni plus efficacement que moi porter cette parole. Je vis le piège ; mais je ne m'en pus défendre, et d'autant moins que le maréchal de la Meilleraie, ${ }^{5}$ qui n'avait point de vue, y donna même avec impétuosité, et m'y entraîna, pour ainsi parler, avec lui. Il dit à la Reine qu'il sortirait avec moi dans les ro rues, et que nous y ferions des merveilles. «Je n'en doute point, lui répondis-je, pourvu qu'il plaise à la Reine de nous faire expédier en bonne forme la promesse de la liberté des prisonniers; car je n'ai pas assez de crédit parmi le peuple pour m'en faire croire sans cela.» L'on me loua de ma modestie. Le maréchal ne douta de rien: «La parole i 5

1 Revolt of the princes and of the Parliament of Paris against Mazarin, 1648-1653.

2 Cardinal de Mazarin.

3 Anne of Austria, queen of France.

4 Pierre Broussel, member of Parliament. His arrest, with that of two of his colleagues, precipitated the Fronde.

5 The duc de La Meilleraie (1602-1664), a distinguished general and marshal of France. 
de la Reine valait mieux que tous les écrits!» En un mot, l'on se moqua de moi, et je me trouvai tout d'un coup dans la cruelle nécessité de jouer le plus méchant personnage où peut-être jamais particulier se soit rencontré. Je voulus répliquer; mais la Reine entra brusquement 5 dans sa chambre grise; Monsieur ${ }^{1}$ me poussa, mais tendrement, avec ses deux mains, en me disant: “Rendez le repos à l'État »; le maréchal m'entraîna, et tous les gardes du corps me portaient amoureusement sur leurs bras, en me criant: “ Il n'y a que vous qui puissiez remédier au mal.» Je sortis ainsi avec mon rochet et mon camail, en ıo donnant des bénédictions à droite et à gauche, et vous croyez bien que cette occupation ne m'empêchait pas de faire toutes les réflexions convenables à l'embarras dans lequel je me trouvais. Je pris toutefois, sans balancer, le parti d'aller purement à mon devoir, de prêcher l'obéissance et de faire mes efforts pour apaiser le tumulte. La seule I 5 mesure que je me résolus de garder fut celle de ne rien promettre en mon nom au peuple, et de lui dire simplement que la Reine m'avait assuré qu'elle rendrait Broussel, pourvu que l'on fît cesser l'émotion.

L'impétuosité du maréchal de la Meilleraie ne me laissa pas lieu de mesurer mes expressions; car au lieu de venir avec moi comme il 20 m'avait dit, il se mit à la tête des chevau-légers de la garde, et il s'avança, l'épée à la main, en criant de toute sa force: «Vive.le Roi! Liberté à Broussel! » Comme il était vu de beaucoup plus de gens qu'il n'y en avait qui l'entendissent, il échauffa beaucoup plus de monde par son épée qu'il n'en apaisa par sa voix. L'on cria aux 25 armes. Un crocheteur mit un sabre à la main vis-à-vis des QuinzeVingts: le maréchal le tua d'un coup de pistolet. Les cris redoublèrent; l'on courut de tous côtés aux armes; une foule de peuple, qui m'avait suivi depuis le Palais-Royal, me porta plutôt qu'elle ne me poussa jusques à la Croix-du-Tiroir, ${ }^{2}$ et j'y trouvai le maréchal de la

30 Meilleraie aux mains avec une grosse troupe de bourgeois, qui avaient pris les armes dans la rue de l'Arbre-Sec. Je me jetai dans la foule pour essayer de les séparer, et je crus que les uns et les autres porteraient au moins quelque respect à mon habit et à ma dignité. Je ne me trompai pas absolument; car le maréchal, qui était fort embar35 rassé, prit avec joie ce prétexte pour commander aux chevau-légers de ne plus tirer; et les bourgeois s'arrêtèrent, et se contentèrent de faire ferme dans le carrefour; mais il y en eut vingt ou trente qui

1 Gaston d'Orléans, brother of Louis XIII (1608-1660).

2 At the corner of the streets Saint-Honoré and l'Arbre-Sec. 
sortirent avec des hallebardes et des mousquetons de la rue des Prouvelles, qui ne furent pas si modérés, et qui ne me voyant pas ou ne me voulant pas voir, firent une charge fort brusque aux chevau-légers, cassèrent d'un coup de pistolet le bras à Fontrailles, ${ }^{1}$ qui était auprès du maréchal l'épée à la main, blessèrent un de mes pages, qui portait le derrière de ma soutane, et me donnèrent à moi-même un coup de pierre au-dessous de l'oreille, qui me porta par terre. Je ne fus pas plus tôt relevé, qu'un garçon d'apothicaire m'appuya le mousqueton dans la tête. Quoique je ne le connusse point du tout, je crus qu'il était bon de ne le lui pas témoigner dans ce moment, et je lui dis au ro contraire: «Ah! malheureux! si ton père te voyait....) Il s'imagina que j'étais le meilleur ami de son père, que je n'avais pourtant jamais vu. Je crois que cette pensée lui donna celle de me regarder plus attentivement. Mon habit lui frappa les yeux : il me demanda si j'étais Monsieur le Coadjuteur; et aussitôt que je le lui eus dit, il 15 cria: “Vive le Coadjuteur!» Tout le monde fit le même cri; l'on courut à moi; et le maréchal de la Meilleraie se retira avec plus de liberté au Palais-Royal, parce que j'affectai, pour lui en donner le temps, de marcher du côté des halles.

Tout le monde me suivit, et j'en eus besoin, car je trouvai cette 20 fourmilière de fripiers toute en armes. Je les flattai, je les caressai, je les injuriai, je les menaçai: enfin je les persuadai. Ils quittèrent les armes, ce qui fut le salut de Paris, parce que, s'ils les eussent eues encore à la main à l'entrée de la nuit, qui s'approchait, la ville eût été infailliblement pillée.

Je n'ai guère eu en ma vie de satisfaction plus sensible que celle-là.

— From « Mémoires »,Part second

1 The marquis de Fontrailles was an active participant in the Fronde, also author of "Mémoires." 


\section{BLAISE PASCAL}

\section{Clermont, $1623-1662$, Paris}

Unusually precocious by nature, Pascal, in addition, received a careful education under the direction of his father. He was particularly interested in mathematics, and, at the age of sixteen, won considerable general reputation, and also attracted the attention of Descartes, by the publication of his "Traité des sections coniques." In consequence of this he decided to devote his life to a study of the physical sciences. However, in 1646 he became interested in Jansenism; and, though he afterwards relaxed somewhat for a time from the strict principles of the sect, and gave himself up to the distraction of social life, he finally, in I654, renounced worldly pursuits, and, in 1655 , joined the Jansenist Society of Port-Royal, just in time to take part in the famous quarrel which the Jesuits were forcing upon the Jansenists. It was in this quarrel, in defense of Dr. Arnauld, leader of the Jansenists of Port-Royal, that Pascal wrote those masterpieces, perfect examples of keen and cutting irony, the "Lettres provinciales" (1656-1657).

After he had finished the "Lettres provinciales," his thoughts were almost constantly on the problems of life and immortality and the comparative unimportance of all things else; and it was during this period, from 1657 until his death, that he wrote the "Pensées" which he intended ultimately to unite in a Defense of the Christian Religion. In this work he was planning to give the facts of religion a force and certitude which none could fail to appreciate. But, delicate from birth, a sufferer for many years, he was not destined to finish his great work, and he died in 1662 at the age of thirty-nine. The first edition of the "Pensées" to conform to the manuscript of Pascal was published in 1844 . There had been a garbled edition brought out by the Jansenists in 1670 .

\section{DE L'AUTORITÉ DES ANCIENS}

Partageons avec plus de justice notre crédulité et notre défiance, et bornons ce respect que nous avons pour les anciens. Comme la raison le fait naître, elle doit aussi le mesurer; et considérons que, s'ils fussent demeurés dans cette retenue de n'oser rien ajouter aux con5 naissances qu'ils avaient reçues, ou que ceux de leur temps eussent fait la même difficulté de recevoir les nouveautés qu'ils leur offraient, ils se seraient privés eux-mêmes et leur postérité du fruit de leurs inventions. . . .

Les secrets de la nature sont cachés ; quoiqu'elle agisse toujours, on Io ne découvre pas toujours ses effets: le temps les révèle d'âge en âge, 
et, quoique toujours égale en elle-même, elle n'est pas toujours également connue. Les expériences qui nous en donnent l'intelligence multiplient continuellement; et, comme elles sont les seuls principes de la physique, les conséquences multiplient à proportion. C'est de cette façon que l'on peut aujourd'hui prendre d'autres sentiments et de nouvelles opinions sans mépris et sans ingratitude, puisque les premières connaissances qu'ils nous ont données ont servi de degrés aux nôtres, et que dans ces avantages nous leur sommes redevables de l'ascendant que nous avons sur eux; parce que, s'étant élevés jusqu'à un certain degré où ils nous ont portés, le moindre effort nous io fait monter plus haut, et avec moins de peine et moins de gloire nous nous trouvons au-dessus d'eux. C'est de là que nous pouvons découvrir des choses qu'il leur était impossible d'apercevoir. Notre vue a plús d'étendue, et, quoiqu'ils connussent aussi bien que nous tout ce qu'ils pouvaient remarquer de la nature, ils n'en connaissaient pas is tant néanmoins, et nous voyons plus qu'eux.

Cependant il est étrange de quelle sorte on révère leurs sentiments. On fait un crime de les contredire et un attentat d'y ajouter, comme s'ils n'avaient plus laissé de vérités à connaître. N'est-ce pas là traiter indignement la raison de l'homme, et la mettre en parallèle avec 20 l'instinct des animaux, puisqu'on en ôte la principale différence, qui consiste en ce que les effets du raisonnement augmentent sans cesse, au lieu que l'instinct demeure toujours dans un état égal? Les ruches des abeilles étaient aussi bien mesurées il y a mille ans qu'aujourd'hui, et chacune d'elles forme cet hexagone aussi exactement la pre- 25 mière fois que la dernière. Il en est de même de tout ce que les animaux produisent par ce mouvement occulte. La nature les instruit à mesure que la nécessité les presse; mais cette science fragile se perd avec les besoins qu'ils en ont: comme ils la reçoivent sans étude, ils n'ont pas le bonheur de la conserver; et toutes les fois qu'elle leur 30 est donnée, elle leur est nouvelle, puisque, la nature n'ayant pour objet que de maintenir les animaux dans un ordre de perfection bornée, elle leur inspire cette science nécessaire, toujours égale, de peur qu'ils ne tombent dans le dépérissement, et ne permet pas qu'ils y ajoutent, de peur qu'ils ne passent les limites qu'elle leur a prescrites. 35 Il n'en est pas de même de l'homme, qui n'est produit que pour l'infinité. Il est dans l'ignorance au premier âge de sa vie; mais il s'instruit sans cesse dans son progrès : car il tire avantage non seulement de sa propre expérience, mais encore de celle de ses prédécesseurs, 
parce qu'il garde toujours dans sa mémoire les connaissances qu'il s'est une fois acquises, et que celles des anciens lui sont toujours présentes dans les livres qu'ils en ont laissés. Et comme il conserve ces connaissances, il peut aussi les augmenter facilement; de sorte 5 que les hommes sont aujourd'hui en quelque sorte dans le même état où se trouveraient ces anciens philosophes, s'ils pouvaient avoir vieilli jusques à présent, en ajoutant aux connaissances qu'ils avaient celles que leurs études auraient pu leur acquérir à la faveur de tant de siècles. De là vient que, par une prérogative particulière, non seuleIo ment chacun des hommes s'avance de jour en jour dans les sciences, mais que tous les hommes ensemble y font un continuel progrès à mesure que l'univers vieillit, parce que la même chose arrive dans la succession des hommes que dans les âges différents d'un particulier. De sorte que toute la suite des hommes, pendant le cours de tant de I5 siècles, doit être considérée comme un même homme qui subsiste toujours et qui apprend continuellement: d'où l'on voit avec combien d'injustice nous respectons l'antiquité dans ses philosophes; car, comme la vieillesse est l'âge le plus distant de l'enfance, qui ne voit que la vieillesse dans cet homme universel ne doit pas être cherchée 20 dans les temps proches de sa naissance, mais dans ceux qui en sont les plus éloignés? Ceux que nous appelons anciens étaient véritablement nouveaux en toutes choses, et formaient l'enfance des hommes proprement ; et comme nous avons joint à leurs connaissances l'expérience des siècles qui les ont suivis, c'est en nous que l'on peut trou25 ver cette antiquité que nous révérons dans les autres.

Ils doivent être admirés dans les conséquences qu'ils ont bien tirées du peu de principes qu'ils avaient, et ils doivent être excusés dans celles où ils ont plutôt manqué du bonheur de l'expérience que de la force du raisonnement.

- Fragment of a "Traité du vide "

\section{PLACE DE L'HOMME DANS L'UNIVERS}

30 Que l'homme contemple donc la nature entière dans sa haute et pleine majesté, qu'il éloigne sa vue des objets bas qui l'environnent. Qu'il regarde cette éclatante lumière, mise comme une lampe éternelle pour éclairer l'univers, que la terre lui paraisse comme un point au prix du vaste tour que cet astre décrit et qu'il s'étonne de ce que ce 35 vaste tour lui-même n'est qu'une pointe très délicate à l'égard de celui 
que les astres qui roulent dans le firmament embrassent. Mais si notre vue s'arrête là, que l'imagination passe outre; elle se lassera plutôt de concevoir, que la nature de fournir. Tout ce monde visible n'est qu'un trait imperceptible dans l'ample sein de la nature. Nulle idée n'en approche. Nous avons beau enfler nos conceptions, au delà des espaces imaginables, nous n'enfantons que des atomes, au prix de la réalité des choses. C'est une sphère infinie dont le centre est partout, la circonférence nulle part. Enfin c'est le plus grand caractère sensible de la toute-puissance de Dieu, que notre imagination se perde dans cette pensée.

Que l'homme, étant revenu à soi, considère ce qu'il est au prix de ce qui est; qu'il se regarde comme égaré dans ce canton détourné de la nature; et que de ce petit cachot où il se trouve logé, j'entends l'univers, il apprenne à estimer la terre, les royaumes, les villes et soi-même son juste prix. Qu'est-ce qu'un homme dans l'infini?

Mais pour lui présenter un autre prodige aussi étonnant, qu'il recherche dans, ce qu'il connaît les choses les plus délicates. Qu'un ciron ${ }^{1}$ lui offre dans la petitesse de son corps des parties incomparablement plus petites, des jambes avec des jointures, des veines dans ces jambes, du sang dans ces veines, des humeurs dans ce sang, des 20 gouttes dans ces humeurs, des vapeurs dans ces gouttes; que, divisant encore ces dernières choses, il épuise ses forces en ces conceptions, et que le dernier objet où il peut arriver soit maintenant celui de notre discours ; il pensera peut-être que c'est là l'extrême petitesse de la nature. Je veux lui faire voir là dedans un abîme nouveau. Je 25 lui veux peindre non seulement l'univers visible, mais l'immensité qu'on peut concevoir de la nature, dans l'enceinte de ce raccourci d'atome. Qu'il y voie une infinité d'univers, dont chacun a son firmament, ses planètes, sa terre, en la même proportion que le monde visible; dans cette terre, des animaux, et enfin des cirons, dans les- 30 quels il retrouvera ce que les premiers ont donné ; et trouvant encore dans les autres la même chose sans fin et sans repos, qu'il se perde dans ces merveilles, aussi étonnantes dans leur petitesse que les autres par leur étendue; car qui n'admirera que notre corps, qui tantôt n'était pas perceptible dans l'univers, imperceptible lui-même dans le 35 sein du tout, soit à présent un colosse, un monde, ou plutôt un tout, à l'égard du néant où l'on ne peut arriver ?

1 In the seventeenth century the ciron was considered the smallest of the insects visible to the naked eye. 
Qui se considèrera de la sorte s'effrayera de soi-même, et, se considérant soutenu dans la masse que la nature lui a donnée, entre ces deux abîmes de l'infini et du néant, il tremblera dans la vue de ces merveilles; et je crois que sa curiosité se changeant en admiration, il 5 sera plus disposé à les contempler en silence qu'à les rechercher avec présomption.

Car, enfin, qu'est-ce que l'homme dans la nature? Un néant à l'égard de l'infini, un tout à l'égard du néant, un milieu entre rien et tout. Infiniment éloigné de comprendre les extrêmes, la fin des choses to et leur principe sont pour lui invinciblement cachés dans un secret impénétrable, également incapable de voir le néant d'où il est tiré, et l'infini où il est englouti.

Que fera-t-il donc, sinon d'apercevoir [quelque] apparence du milieu des choses, dans un désespoir éternel de connaître ni leur principe ni I 5 leur fin? Toutes choses sont sorties du néant et portées jusqu'à l'infini. Qui suivra ces étonnantes démarches? L'auteur de ces merveilles les comprend. Tout autre ne le peut faire. . . .

Connaissons donc notre portée; nous sommes quelque chose, et ne sommes pas tout; ce que nous avons d'être nous dérobe la conso naissance des premiers principes, qui naissent du néant; et le peu que nous avons d'être nous cache la vue de l'infini.

Notre intelligence tient dans l'ordre des choses intelligibles le même rang que notre corps dans l'étendue de la nature.

Bornés en tout genre, cet état qui tient le milieu entre deux ex25 trêmes se trouve en toutes nos impuissances. Nos sens n'aperçoivent rien d'extrême, trop de bruit nous assourdit, trop de lumière éblouit, trop de distance et trop de proximité empêche la vue, trop de longueur et trop de brièveté de discours l'obscurcit, trop de vérité nous étonne: j'en sais qui ne peuvent comprendre que qui de zéro ôte 3o 4 reste zéro; les premiers principes ont trop d'évidence pour nous, trop de plaisir incommode, trop de consonances déplaisent dans la musique; et trop de bienfaits irritent, nous voulons avoir de quoi surpayer la dette. . . . Nous ne sentons ni l'extrême chaud ni l'extrême froid. Les qualités excessives nous sont ennemies, et non pas

35 sensibles: nous ne les sentons plus, nous les souffrons. Trop de jeunesse et trop de vieillesse empêchent l'esprit, trop et trop peu d'instruction; enfin les choses extrêmes sont pour nous comme si elles n'étaient point, et nous ne sommes point à leur égard: elles nous échappent, ou nous à elles. 
Voilà notre état véritable; c'est ce qui nous rend incapables de savoir certainement et d'ignorer absolument. Nous voguons sur un milieu vaste, toujours incertains et flottants, poussés d'un bout vers l'autre. Quelque terme où nous pensions nous attacher et nous affermir, il branle et nous quitte; et si nous le suivons, il échappe à nos prises, nous glisse et fuit d'une fuite éternelle. Rien ne s'arrête pour nous. C'est l'état qui nous est naturel, et toutefois le plus contraire à notre inclination; nous brûlons de désir de trouver une assiette ferme, et une dernière base constante pour y édifier une tour qui s'élève à l'infini, mais tout notre fondement craque, et la terre s'ouvre ro jusqu'aux abîmes.

Ne cherchons donc point d'assurance et de fermeté. Notre raison est toujours déçue par l'inconstance des apparences, rien ne peut fixer le fini entre les deux infinis, qui l'enferment et le fuient.

— "Pensées, " 72

\section{L'IMAGINATION}

Cette superbe puissance, ennemie de la raison, qui se plaît à la i 5 contrôler et à la dominer, pour montrer combien elle peut en toutes choses, a établi dans l'homme une seconde nature. Elle a ses heureux, ses malheureux, ses sains, ses malades, ses riches, ses pauvres; elle fait croire, douter, nier la raison; elle suspend les sens, elle les fait sentir; elle a ses fous et ses sages; et rien ne nous dépite davantage 20 que de voir qu'elle remplit ses hôtes d'une satisfaction bien autrement pleine et entière que la raison. Les habiles par imagination se plaisent tout autrement à eux-mêmes que les prudents ne se peuvent raisonnablement plaire. Ils regardent les gens avec empire; ils disputent avec hardiesse et confiance; les autres, avec crainte et défiance; et 25 cette gaité de visage leur donne souvent l'avantage dans l'opinion des écoutants, tant les sages imaginaires ont de faveur auprès des juges de même nature. Elle ne peut rendre sages les fous; mais elle les rend heureux, à l'envi de la raison qui ne peut rendre ses amis que misérables, l'une les couvrant de gloire, l'autre de honte.

Qui dispense la réputation? qui donne le respect et la vénération aux personnes, aux ouvrages, aux lois, aux grands, sinon cette faculté imaginante? Toutes les richesses de la terre insuffisantes sans son consentement!

$\mathrm{Ne}$ diriez-vous pas que ce magistrat, dont la vieillesse vénérable 35 impose le respect à tout un peuple, se gouverne par une raison pure 
et sublime, et qu'il juge des choses dans leur nature sans s'arrêter à de vaines circonstances qui ne blessent que l'imagination des faibles? Voyez-le entrer dans un sermon où il apporte un zèle tout dévot, renforçant la solidité de sa raison par l'ardeur de sa charité; le voilà prêt 5 à l'oür avec un respect exemplaire. Que le prédicateur vienne à paraître, que la nature lui ait donné une voix enrouée et un tour de visage bizarre, que son barbier l'ait mal rasé, si le hasard l'a encore barbouillé de surcroît, quelque grandes vérités qu'il annonce, je parie la perte de la gravité de notre sénateur.

Io Le plus grand philosophe du monde, sur une planche plus large qu'il ne faut, s'il y a au-dessous un précipice, quoique sa raison le convainque de sa sûreté, son imagination prévaudra. Plusieurs n'en sauraient soutenir la pensée sans pâlir et suer.

Je ne veux pas rapporter tous ses effets. . . .

I5 Je rapporterais presque toutes les actions des hommes qui ne branlent presque que par ses secousses. Car la raison a été obligée de céder, et la plus sage prend pour ses principes ceux que l'imagination des hommes a témérairement introduits en chaque lieu. . . .

Nos magistrats ont bien connu ce mystère. Leurs robes rouges, 20 leurs hermines, dont ils s'emmaillotent en chats fourrés, ${ }^{1}$ les palais où ils jugent, les fleurs de lis, tout cet appareil auguste était fort nécessaire; et si les médecins n'avaient des soutanes et des mules, ${ }^{2}$ et que les docteurs ${ }^{3}$ n'eussent des bonnets carrés et des robes trop amples de quatre parties, ${ }^{4}$ jamais ils n'auraient dupé le monde qui ne peut 25 résister à cette montre si authentique. S'ils avaient la véritable justice et si les médecins avaient le vrai art de guérir, ils n'auraient que faire de bonnets carrés; la majesté de ces sciences serait assez vénérable d'elle-même. Mais n'ayant que des sciences imaginaires, il faut qu'ils prennent ces vains instruments qui frappent l'imagination à laquelle 30 ils ont affaire; et par là, en effet, ils s'attirent le respect. Les seuls gens de guerre ne se sont pas déguisés de la sorte, ${ }^{5}$ parce qu'en effet leur part est plus essentielle, ils s'établissent par la force, les autres par grimace.

C'est ainsi que nos rois n'ont pas recherché ces déguisements. Ils 35 ne se sont pas masqués d'habits extraordinaires pour paraître tels; mais ils se sont accompagnés de gardes, de hallebardes. Ces trognes

1 "like cats in their furs"; an allusion to Rabelais's "Pantagruel," V, II.

2 "slippers." $\quad 3$ Particularly theological. 4 "four times too large."

. 5 Until 1670 the use of uniforms was not obligatory in the French army. 
armées qui n'ont de mains et de force que pour eux, les trompettes et les tambours qui marchent au-devant, et ces légions qui les environnent, font trembler les plus fermes; ils n'ont pas l'habit seulement, ils ont la force. Il faudrait avoir une raison bien épurée pour regarder comme un autre homme le Grand Seigneur ${ }^{1}$ environné, dans 5 son superbe sérail, de quarante mille janissaires. . . .

L'imagination dispose de tout; elle fait la beauté, la justice, et le bonheur, qui est le tout du monde.

— "Pensées, » 82

1 The Sultan. 


\section{FRANÇOIS MARSILLAC, DUC DE LA ROCHEFOUCAULD}

Paris, I6 $13-1680$, Paris

La Rochefoucauld, France's great maxim-writer, was born at Paris in $\mathbf{1 6} \mathbf{6} 3$. Though belonging to an ancient family, he received a very limited education, and at the age of sixteen entered the army. His career from then until 1652 was full of adventure and intrigue, first in connection with Richelieu, then in the Fronde. But having been severely wounded in $165^{2}$ at the battle of the Porte Saint-Antoine, he retired from active life, his health impaired, his fortune reduced, disappointed in his ambitions, and embittered at heart.

It was in this retirement, enjoying meanwhile the society of the salon of Mme. de Sablé and the intimate friendship of Mme. de La Fayette, that he wrote, in his "Mémoires," an account of the active period of his life. A surreptitious publication of these "Mémoires" in 1662 by the Elzevirs brought down upon La Rochefoucauld, from friends of whom he had spoken slightingly, a storm of vituperation for which the remarkable volume of " Maximes," published in 1665 , could scarcely compensate. In addition to the "Mémoires" and "Maximes," he left a few short treatises and about a hundred letters, showing in all, but particularly in the "Maximes," a remarkable precision of style.

\section{PORTRAIT DU DUC DE LA ROCHEFOUCAULD FAIT PAR LUI-MÊME}

Je suis d'une taille médiocre, libre, et bien proportionnée. J'ai le teint brun, mais assez uni ${ }^{1}$; le front élevé et d'une raisonnable grandeur; les yeux noirs, petits, et enfoncés, et les sourcils noirs et épais, mais bien tournés. Je serais fort empêché à dire de quelle sorte 5 j'ai le nez fait, car il n'est ni camus, ni aquilin, ni gros, ni pointu, au moins à ce que je crois: tout ce que je sais, c'est qu'il est plutôt grand que petit, et qu'il descend un peu trop en bas. J'ai la bouche grande, et les lèvres assez rouges d'ordinaire, et ni bien ni mal taillées; j'ai les dents blanches, et passablement bien rangées. On m'a dit Io autrefois que j'avais un peu trop de menton: je viens de me tâter et de me regarder dans le miroir, pour savoir ce qui en est, et je ne sais

$$
\text { "uniform." }
$$


pas trop bien qu'en juger. Pour le tour du visage, je l'ai ou carré, ou en ovale; lequel des deux, il me serait fort difficile de le dire. J'ai les cheveux noirs, naturellement frisés, et avec cela assez épais et assez longs pour pouvoir prétendre en belle tête. ${ }^{1}$ J'ai quelque chose de chagrin et de fier dans la mine: cela fait croire à la plupart des gens que je suis méprisant, quoique je ne le sois point du tout. J'ai l'action fort aisée, et même un peu trop, et jusques à faire beaucoup de gestes en parlant. Voilà naïvement comme je pense que je suis fait dehors ; et l'on trouvera, je crois, que ce que je pense de moi là-dessus n'est pas fort éloigné de ce qui en est. ...

J'ai les sentiments vertueux, les inclinations belles, et une si forte envie d'être tout à fait honnête homme, ${ }^{2}$ que mes amis ne me sauraient faire un plus grand plaisir que de m'avertir sincèrement de mes défauts. Ceux qui me connaissent un peu particulièrement, et qui ont eu la bonté de me donner quelquefois des avis là-dessus, savent que je les 15 ai toujours reçus avec toute la joie imaginable, et toute la soumission d'esprit que l'on saurait désirer. J'ai toutes les passions assez douces et assez réglées: on ne m'a presque jamais vu en colère, et je n'ai jamais eu de haine pour personne. Je ne suis pas pourtant incapable de me venger, si l'on m'avait offensé, et qu'il y allât de mon honneur 20 à me ressentir de l'injure qu'on m'aurait faite. Au contraire, je suis assuré que le devoir ferait si bien en moi l'office de la haine, que je poursuivrais ma vengeance avec encore plus de vigueur qu'un autre. L'ambition ne me travaille point. Je ne crains guère de choses, et ne crains aucunement la mort. Je suis peu sensible à la pitié, et je vou- 25 drais ne l'y être point du tout. Cependant il n'est rien que je ne fisse pour le soulagement d'une personne affligée ; et je crois effectivement que l'on doit tout faire, jusques à lui témoigner même beaucoup de compassion de son mal; car les misérables sont si sots, que cela leur fait le plus grand bien du monde. Mais je tiens aussi qu'il faut se 30 contenter d'en témoigner, et se garder soigneusement d'en avoir. C'est une passion qui n'est bonne à rien au dedans d'une âme bien faite, qui ne sert qu'à affaiblir le cœur, et qu'on doit laisser au peuple, qui n'exécutant jamais rien par raison, a besoin de passions pour le porter à faire les choses. J'aime mes amis, et je les aime d'une façon 35 que je ne balancerais pas un moment à sacrifier mes intérêts aux leurs. J'ai de la condescendance pour eux; je souffre patiemment leurs 
mauvaises humeurs et j'en excuse facilement toutes choses; seulement je ne leur fais pas beaucoup de caresses, et je n'ai pas non plus de grandes inquiétudes en leur absence. J'ai naturellement fort peu de curiosité pour la plus grande partie de tout ce qui en donne aux 5 autres gens. Je suis fort secret, et j'ai moins de difficulté que personne à taire ce qu'on m'a dit en confidence. Je suis extrêmement régulier à ma parole: je n'y manque jamais, de quelque conséquence que puisse être ce que j'ai promis, et je m'en suis fait toute ma vic une obligation indispensable. J'ai une civilité fort exacte parmi les ro femmes, et je ne crois pas avoir jamais rien dit devant elles qui leur ait pu faire de la peine. Quand elles ont l'esprit bien fait, j'aime mieux leur conversation que celle des hommes: on y trouve une certaine douceur qui ne se rencontre point parmi nous; et il me semble outre cela qu'elles s'expliquent avec plus de netteté, et qu'elles donI 5 nent un tour plus agréable aux choses qu'elles disent.

\section{MAXIMES}

XIX

Nous avons tous assez de force pour supporter les maux d'autrui. XXVI

Le soleil ni la mort ne se peuvent regarder fixement.

XXXI

Si nous n'avions point de défauts, nous ne prendrions pas tant de plaisir à en remarquer dans les autres.

LXVII

20 La bonne grâce est au corps ce que le bon sens est à l'esprit.

\section{LXXVI}

Il est du véritable amour comme de l'apparition des esprits : tout le monde en parle, mais peu de gens en ont vu.

\section{LXXXIX}

Tout le monde se plaint de sa mémoire, et personne ne se plaint de son jugement.

\section{CII}

25 L'esprit est toujours la dupe du cœur.

CXXXVIII

On aime mieux dire du mal de soi-même que de n'en point parler. 
CXXXIX

Une des choses qui fait que l'on trouve si peu de gens qui paraissent raisonnables et agréables dans la conversation, c'est qu'il n'y a presque personne qui ne pense plutôt à ce qu'il veut dire qu'à répondre précisément à ce qu'on lui dit. Les plus habiles et les plus complaisants se contentent de montrer seulement une mine attentive, 5 au même temps que l'on voit, dans leurs yeux et dans leur esprit, un égarement pour ce qu'on leur dit, et une précipitation pour retourner à ce qu'ils veulent dire, au lieu de considérer que c'est un mauvais moyen de plaire aux autres, ou de les persuader, que de chercher si fort à se plaire à soi-même, et que bien écouter et bien répondre est 10 une des plus grandes perfections qu'on puisse avoir dans la conversation.

\section{CXLII}

Comme c'est le caractère des grands esprits de faire entendre en peu de paroles beaucoup de choses, les petits esprits, au contraire, ont le don de beaucoup parler, et de ne rien dire.

\section{CLVII}

La gloire des grands hommes se doit toujours mesurer aux moyens 15 dont ils se sont servis pour l'acquérir.

\section{CLX}

Quelque éclatante que soit.une action, elle ne doit pas passer pour grande, lorsqu'elle n'est pas l'effet d'un grand dessein.

\section{CLXI}

Il doit y avoir une certaine proportion entre les actions et les desseins, si on en veut tirer tous les effets qu'elles peuvent produire.

CLXII

L'art de savoir bien mettre en œuvre de médiocres qualités dérobe l'estime, et donne souvent plus de réputation que le véritable mérite.

\section{CLXVI}

Le monde récompense plus souvent les apparences du mérite que le mérite même.

\section{CLXVIII}

L'espérance, toute trompeuse qu'elle est, sert au moins à nous 25 mener à la fin de la vie par un chemin agréable. 


\section{CLXXI}

Les vertus se perdent dans l'intérêt, comme les fleuves se perdent dans la mer.

\section{CCLVIII}

Le bon goût vient plus du jugement que de l'esprit.

\section{CCCXI}

S'il y a des hommes dont le ridicule n'ait jamais paru, c'est qu'on 5 ne l'a pas bien cherché.

\section{CCCXIII}

Pourquoi faut-il que nous ayons assez de mémoire pour retenir jusqu'aux moindres particularités de ce qui nous est arrivé, et que nous n'en ayons pas assez pour nous souvenir combien de fois nous les avons contées à une même personne?

CDXXXV

Io La fortune et l'humeur gouvernent le monde.

CDLIII

Dans les grandes affaires, on doit moins s'appliquer à faire naître des occasions, qu'à profiter de celles qui se présentent.

CDLXXIII

Quelque rare que soit le véritable amour, il l'est encore moins que la véritable amitié.

\section{CDXCVI}

I5 Les querelles ne dureraient pas longtemps si le tort n'était que d'un côté. 


\title{
MOLIÈRE
}

\author{
Paris, $1622-1673$, Paris
}

Jean-Baptiste Poquelin, son of an upholsterer to the king, received a good education at the hands of the Jesuits in the college of Clermont. He first turned to law, and was received at the bar; but even as a boy he was deeply interested in the stage, and he had hardly become of age when, in I 643 , he joined a troupe of well-born amateur players who styled themselves the "Illustre Théâtre." Two brothers by the name of Béjart and their sister Madeleine, whose daughter Molière married in 166z, formed part of the company. The young Poquelin, who now assumed the name of Molière, became director of this new undertaking, and, when financial troubles came, he was imprisoned for debt (1645). He was soon released, however, and then, in 1646 , started touring the provinces, playing the part of author, actor, and director of the troupe. With the experience and success of twelve years of touring to rely upon, he returned to Paris in $165^{8}$, and began his career there by playing Corneille's "Nicomède" and a short play of his own entitled "Le docteur amoureux." His company was called the "troupe de Monsieur" until in 1665 it became the "troupe du Roi." The year after his arrival at the capital he produced the first of his great masterpieces, "Les précieuses ridicules" ( 1659 ), a severe attack on préciosité.

The next fourteen years were years of untiring activity and growing success, in spite of jealous opposition. During this period twenty-nine pieces came from his pen. IIe himself usually took the most important rôle in his plays, a fact which probably kept him from being received into the Academy. Neither the unhappiness of his married life nor the progress of the disease which was finally to kill him could exhaust the wonderful fund of his imagination and power, or seriously affect the fertility of his invention, which continued creating the remarkably true and distinct types for which Molière is so conspicuous. His favor with the king made him bold, and one phase after another of human and social foibles received the brunt of his ridicule. But his health was failing, and, in the midst of his successful career, at the fourth representation of "Le malade imaginaire" (I673), he was seized with a fit of coughing on the stage, and had to retire. He died less than an hour later.

His best plays are "Les précieuses ridicules" (1659) ; "L'école des maris" (I66I); "L'école des femmes" (I662); "Tartuffe" (played privately in I664, publicly not until I669); "Don Juan" (I665); "Le misanthrope" (I666); "Le médecin malgré lui" (I666); "L'avare" (I668); "Le bourgeois gentilhomme" (I670); "Les femmes savantes" (I672); "Le malade imaginaire" (1673). 


\section{LE MISANTHROPE}

Philinte, Alceste

PHILINTE

Qu'est-ce donc? qu'avez-vous?

ALCESTE

Laissez-moi, je vous prie.

PHILINTE

Mais encore dites-moi quelle bizarrerie . . .

ALCESTE

Laissez-moi là, vous dis-je, et courez vous cacher.

PHILINTE

Mais on entend les gens, au moins, sans se fâcher.

ALCESTE

Moi, je veux me fâcher, et ne veux point entendre.

PHILINTE

Dans vos brusques chagrins je ne puis vous comprendre, Et quoique amis enfin, je suis tout des premiers ...

\section{ALCESTE}

Moi, votre ami? Rayez cela de vos papiers. J'ai fait jusques ici profession de l'être;

Io Mais après ce qu'en vous je viens de voir paraître, Je vous déclare net que je ne le suis plus, Et ne veux nulle place en des cœurs corrompus.

\section{PHILINTE}

Je suis donc bien coupable, Alceste, à votre compte?

ALCESTE

Allez, vous devriez mourir de pure honte;

I5 Une telle action ne saurait s'excuser,

Et tout homme d'honneur s'en doit scandaliser.

Je vous vois accabler un homme de caresses,

Et témoigner pour lui les dernières tendresses;

De protestations, d'offres et de serments,

Vous chargez la fureur de vos embrassements; Et quand je vous demande après quel est cet homme, A peine pouvez-vous dire comme il se nomme; Votre chaleur pour lui tombe en vous séparant, 
Et vous me le traitez, à moi, d'indifférent.

Morbleu ! c'est une chose indigne, lâche, infâme,

De s'abaisser ainsi jusqu'à trahir son âme ;

Et si, par un malheur, j'en avais fait autant,

Je m'irais, de regret, pendre tout à l'instant.

PHILINTE

Je ne vois pas, pour moi, que le cas soit pendable,

Et je vous supplierai d'avoir pour agréable

Que je me fasse un peu grâce sur votre arrêt,

Et ne me pende pas pour cela, s'il vous plaît.

ALCESTE

Que la plaisanterie est de mauvaise grâce!

PHILINTE

Mais, sérieusement, que voulez-vous qu'on fasse?

ALCESTE

Je veux qu'on soit sincère, et qu'en homme d'honneur, On ne lâche aucun mot qui ne parte du cœur.

PHILINTE

Lorsqu'un homme vous vient embrasser avec joie,

Il faut bien le payer de la même monnaie,

Répondre, comme on peut, à ses empressements,

Et rendre offre pour offre, et serments pour serments.

\section{ALCESTE}

Non, je ne puis souffrir cette lâche méthode

Qu'affectent la plupart de yos gens à la mode;

Et je ne hais rien tant que les contorsions

De tous ces grands faiseurs de protestations,

Ces affables donneurs d'embrassades frivoles,

Ces obligeants diseurs d'inutiles paroles,

Qui de civilités avec tous font combat,

Et traitent du même air l'honnête homme et le fat.

Quel avantage a-t-on qu'un homme vous caresse,

Vous jure amitié, foi, zèle, estime, tendresse,

Et vous fasse de vous un éloge éclatant,

Lorsque au premier faquin il court en faire autant?

Non, non, il n'est point d'âme un peu bien située

Qui veuille d'une estime ainsi prostituée;

Et la plus glorieuse a des régals peu chers,

Dès qu'on voit qu'on nous mêle avec tout l'univers : 
Sur quelque préférence une estime se fonde, Et c'est n'estimer rien qu'estimer tout le monde. Puisque vous y donnez, dans ces vices du temps, Morbleu! vous n'êtes pas pour être de mes gens; Je refuse d'un cœur la vaste complaisance

Qui ne fait de mérite aucune différence;

Je veux qu'on me distingue; et pour le trancher net,

L'ami du genre humain n'est point du tout mon fait.

\section{PHILINTE}

Mais, quand on est du monde, il faut bien que l'on rende Quelques dehors civils que l'usage demande.

\section{ALCESTE}

Non, vous dis-je, on devrait châtier, sans pitié, Ce commerce honteux de semblants d'amitié. Je veux que l'on soit homme, et qu'en toute rencontre Le fond de notre cœur dans nos discours se montre,

I5 Que ce soit lui qui parle, et que nos sentiments $\mathrm{Ne}$ se masquent jamais sous de vains compliments.

\section{PHILINTE}

Il est bien des endroits où la pleine franchise Deviendrait ridicule et serait peu permise; Et parfois, n'en déplaise à votre austère honneur, Il est bon de cacher ce qu'on a dans le cœur.

Serait-il à propos et de la bienséance

De dire à mille gens tout ce que d'eux on pense ?

Et quand on a quelqu'un qu'on hait ou qui déplaît, Lui doit-on déclarer la chose comme elle est?

$25 \quad$ Oui.

\section{ALCESTE}

\section{PHILINTE}

Quoi ? vous iriez dire à la vieille Émilie Qu'à son âge il sied mal de faire la jolie, Et que le blanc qu'elle a scandalise chacun?

Sans doute.

\section{ALCESTE}

\section{PHILINTE}

A Dorilas, qu'il est trop importun, Et qu'il n'est, à la cour, oreille qu'il ne lasse A conter sa bravoure et l'éclat de sa race? 
AI.CESTE

Fort bien.

PHILINTE

Vous vous moquez.

ALCESTE

Je ne me moque point,

Et je vais n'épargner personne sur ce point.

Mes yeux sont trop blessés, et la cour et la ville

Ne m'offrent rien qu'objets à m'échauffer la bile;

J'entre en une humeur noire, en un chagrin profond,

Quand je vois vivre entre eux les hommes comme ils font;

Je ne trouve partout que lâche flatterie,

Qu'injustice, intérêt, trahison, fourberie ;

Je n'y puis plus tenir, j'enrage, et mon dessein

Est de rompre en visière à tout le genre humain.

PHILINTE

Ce chagrin philosophe est un peu trop sauvage, Je ris des noirs accès où je vous envisage,

Et crois voir en nous deux, sous mêmes soins nourris, Ces deux frères que peint l'École des maris,

Dont . . .

\section{ALCESTE}

Mon Dieu! laissons là vos comparaisons fades.

PHILINTE

Non: tout de bon, quittez toutes ces incartades.

Le monde par vos soins ne se changera pas;

Et puisque la franchise a pour vous tant d'appas,

Je vous dirai tout franc que cette maladie,

Partout où vous allez, donne la comédie,

Et qu'un si grand courroux contre les mœurs du temps

Vous tourne en ridicule auprès de bien des gens.

\section{ALCESTE}

Tant mieux, morbleu! tant 'mieux, c'est ce que je demande;

Ce m'est un fort bon signe, et ma joie en est grande:

Tous les hommes me sont à tel point odieux,

Que je serais fâché d'être sage à leurs yeux.

\section{PHILINTE}

Vous voulez un grand mal à la nature humaine! 


\section{ALCESTE}

Oui, j'ai conçu pour elle une effroyable haine.

PHILINTE

Tous les pauvres mortels, sans nulle exception, Seront enveloppés dans cette aversion?

Encore en est-il bien, dans le siècle où nous sommes . . .

\section{ALCESTE}

Non : elle est générale, et je hais tous les hommes :

Les uns, parce qu'ils sont méchants et malfaisants, Et les autres, pour être aux méchants complaisants, Et n'avoir pas pour eux ces haines vigoureuses Que doit donner le vice aux âmes vertueuses. De cette complaisance on voit l'injuste excès Pour le franc scélérat avec qui j'ai procès : Au travers de son masque on voit à plein le traitre; Partout il est connu pour tout ce qu'il peut être; Et ses roulements d'yeux et son ton radouci N'imposent qu'à des gens qui ne sont point d'ici. On sait que ce pied plat, digne qu'on le confonde, Par de sales emplois s'est poussé dans le monde, Et que par eux son sort de splendeur revêtu Fait gronder le mérite et rougir la vertu. Quelques titres honteux qu'en tous lieux on lui donne, Son misérable honneur ne voit pour lui personne;

Nommez-le fourbe, infâme et scélérat maudit, Tout le monde en convient, et nul n'y contredit. Cependant sa grimace est partout bienvenue :

25 On l'accueille, on lui rit, partout il s'insinue ; Et s'il est, par la brigue, un rang à disputer, Sur le plus honnête homme on le voit l'emporter. Têtebleu! ce me sont de mortelles blessures, De voir qu'avec le vice on garde des mesures; Et parfois il me prend des mouvements soudains De fuir dans un désert l'approche des humains. 
LE SOUPER DE L'AVARE

\section{Harpagon, Valère, Maitre Jacques}

Harpagon. Valère, aide-moi à ceci. Ho çà, maître Jacques, approchez-vous, je vous ai gardé pour le dernier.

Maitre Jacques. Est-ce à votre cocher, Monsieur, ou bien à votre cuisinier, que vous voulez parler? car je suis l'un et l'autre.

Harpagon. C'est à tous les deux.

Maître Jacques. Mais à qui des deux le premier?

Harpagon. Au cuisinier.

Maître Jacques. Attendez donc, s'il vous plaît. (Il ôte sa casaque de cocher, et paraît vêtu en cuisinier.)

Harpagon. Quelle diantre de cérémonie est-ce là ?

Maître Jacques. Vous n'avez qu'à parler.

Harpagon. Je me suis engagé, maitre Jacques, à donner ce soír à souper.

Maître Jacques. Grande merveille!

Harpagon. Dis-moi un peu, nous feras-tu bonne chère?

Maître Jacques. Oui, si vous me donnez bien de l'argent.

Harpagon. Que diable, toujours de l'argent! Il semble qu'ils n'aient autre chose à dire: «De l'argent, de l'argent, de l'argent.» Ah! ils n'ont que ce mot à la bouche: «De l'argent.» Toujours parler d'argent. Voilà leur épée de chevet, de l'argent.

Valère. Je n'ai jamais vu de réponse plus impertinente que celle-là. Voilà une belle merveille que de faire bonne chère avec bien de l'argent: c'est une chose la plus aisée du monde, et il n'y a si pauvre esprit qui n'en fit bien autant; mais pour agir en habile homme, il faut parler de faire bonne chère avec peu d'argent.

Maître Jacques. Bonne chère avec peu d'argent!

Valère. Oui.

Maître Jacques. Par ma foi, Monsieur l'intendant, vous nous obligerez de nous faire voir ce secret, et de prendre mon office de cuisinier : aussi bien vous mêlez-vous céans d'être le factoton.

Harpagon. Taisez-vous. Qu'est-ce qu'il nous faudra?

Matitre Jacques. Voilà Monsieur votre intendant, qui vous fera bonne chère pour peu d'argent.

Harpagon. Haye! je veux que tu me répondes.

Maître Jacques. Combien serez-vous de gens à table? 
Harpagon. Nous serons huit ou dix; mais il ne faut prendre que huit: quand il y a à manger pour huit, il y en a bien pour dix.

Valère. Cela s'entend.

Maître Jacques. Hé bien! il faudra quatre grands potages, et cinq 5 assiettes. Potages ${ }^{1} \ldots$ Entrées ...

Harpagon. Que diable! voilà pour traiter toute une ville entière.

Maître Jacques. Rôt . . .

Harpagon (en lui mettant la main sur la bouche). Ah! traître, tu manges tout mon bien.

iо Maître Jacques. Entremets...

Harpagon. Encore?

Valère. Est-ce que vous avez envie de faire crever tout le monde? et Monsieur a-t-il invité des gens pour les assassiner à force de mangeaille? Allez-vous-en lire un peu les préceptes de la santé, et I 5 demander aux médecins s'il y a rien de plus préjudiciable à l'homme que de manger avec excès.

Harpagon. Il a raison.

Valère. Apprenez, maître Jacques, vous et vos pareils, que c'est un coupe-gorge qu'une table remplie de trop de viandes ${ }^{2}$; que pour se 20 bien montrer ami de ceux que l'on invite, il faut que la frugalité règne dans les repas qu'on donne; et que, suivant le dire d'un ancien, il faut manger pour vivre, et non pas vivre pour manger.

Harpagon. Ah! que cela est bien dit! Approche, que je t'embrasse pour ce mot. Voilà la plus belle sentence que j'aie entendue de ma 25 vie. II faut vivre pour manger, et non pas manger pour vi . . . Non, ce n'est pas cela. Comment est-ce que tu dis?

Valère. Qu'il faut manger pour vizre, et non pas vive pour manger.

Harpagon. Oui. Entends-tu? Qui est le grand homme qui a dit cela?

Valère. Je ne me souviens pas maintenant de son nom.

Harpagon. Souviens-toi de m'écrire ces mots: je les veux faire graver en lettres d'or sur la cheminée de ma salle.

Valère. Je n'y manquerai pas. Et pour votre soupé, vous n'avez qu'à me laisser faire: je réglerai tout cela comme il faut.

35 Harpagon. Fais donc.

Maître Jacques. Tant mieux : j'en aurai moins de peine.

1 The potages were more substantial than the soups of to-day, often containing meat and vegetables. The assiettes were entrees.

2 "food." 
Harpagon. Il faudra de ces choses dont on ne mange guère, et qui rassasient d'abord: quelque bon haricot ${ }^{1}$ bien gras, avec quelque pâté en $\operatorname{pot}^{2}$ garni de marrons.

Valère. Reposez-vous sur moi.

Harpagon. Maintenant, maitre Jacques, il faut nettoyer mon car- 5 rosse.

Maitre Jacques. Attendez. Ceci s'adresse au cocher. (Il remet sa casaque.) Vous dites...

Harpagon. Qu'il faut nettoyer mon carrosse, et tenir mes chevaux tous prêts pour conduire à la foire. . . .

Maître Jacques. Vos chevaux, Monsieur? Ma foi, ils ne sont point du tout en état de marcher. Je ne vous dirai point qu'ils sont sur la litière, les pauvres bêtes n'en ont point, et ce serait fort mal parler; mais vous leur faites observer des jeûnes si austères, que ce ne sont plus rien que des idées ou des fantômes, des façons de chevaux.

Harpagon. Les voilà bien malades: ils ne font rien.

Maître Jacques. Et pour ne faire rien, Monsieur, est-ce qu'il ne faut rien manger? Il leur vaudrait bien mieux, les pauvres animaux, de travailler beaucoup, de manger de même. Cela me fend le cœur, de les voir ainsi exténués; car enfin j'ai une tendresse pour mes chevaux, 20 qu'il me semble que c'est moi-même quand je les vois pâtir; je m'ôte tous les jours pour eux les choses de la bouche; et c'est être, Monsieur, d'un naturel trop dur, que de n'avoir nulle pitié de son prochain.

Harpagon. Le travail ne sera pas grand, d'aller jusqu'à la foire.

Maître Jacques. Non, Monsieur, je n'ai pas le courage de les mener, 25 et je ferais conscience de leur donner des coups de fouet, en l'état où ils sont. Comment voudriez-vous qu'ils traînassent un carrosse, qu'ils ne peuvent pas se traîner eux-mêmes?

Valère. Monsieur, j'obligerai le voisin le Picard à se charger de les conduire: aussi bien nous fera-t-il ici besoin pour apprêter le soupé.

Maître Jacques. Soit: j'aime mieux encore qu'ils meurent sous la main d'un autre que sous la mienne.

Valère. Maître Jacques fait bien le raisonnable.

Maître Jacques. Monsieur l'intendant fait bien le nécessaire.

Harpagon. Paix!

Maître Jacques. Monsieur, je ne saurais souffrir les flatteurs; et je vois que ce qu'il en fait, que ses contrôles perpétuels sur le pain et le vin, le bois, le sel, et la chandelle, ne sont rien que pour vous gratter 
et vous faire sa cour. J'enrage de cela, et je suis fâché tous les jours d'entendre ce qu'on dit de vous; car enfin je me sens pour vous de la tendresse, en dépit que j'en aie; et après mes chevaux, vous êtes la personne que j'aime le plus.

5 Harpagon. Pourrais-je savoir de vous, maître Jacques, ce que l'on dit de moi?

Maître Jacques. Oui, Monsieur, si j'étais assuré que cela ne vous fâchât point.

Harpagon. Non, en aucune façon.

ı Maître Jacques. Pardonnez-moi : je sais fort bien que je vous mettrais en colère.

Harpagon. Point du tout: au contraire, c'est me faire plaisir, et je suis bien aise d'apprendre comme on parle de moi.

Maître Jacques. Monsieur, puisque vous le voulez, je vous dirai fran-

I 5 chement qu'on se moque partout de vous; qu'on nous jette de tous côtés cent brocards à votre sujet; et que l'on n'est point plus ravi que de vous tenir au cul et aux chausses, ${ }^{1}$ et de faire sans cesse des contes de votre lésine. L'un dit que vous faites imprimer des almanachs particuliers, où vous faites doubler les quatre-temps et les vigiles, afin de pro-

20 fiter des jeûnes où vous obligez votre monde. L'autre, que vous avez toujours une querelle toute prête à faire à vos valets dans le temps des étrennes, ou de leur sortie d'avec vous, pour vous trouver une raison de ne leur donner rien. Celui-là conte qu'une fois vous fîtes assigner le chat d'un de vos voisins, pour vous avoir mangé un reste d'un

25 gigot de mouton. Celui-ci, que l'on vous surprit une nuit, en venant dérober vous-même l'avoine de vos chevaux; et que votre cocher, qui était celui d'avant moi, vous donna dans l'obscurité je ne sais combien de coups de bâton, dont vous ne voulûtes rien dire. Enfin voulezvous que je vous dise? On ne saurait aller nulle part où l'on ne vous 30 entende accommoder de toutes pièces; vous êtes la fable et la risée de tout le monde; et jamais on ne parle de vous, que sous les noms d'avare, de ladre, de vilain et de fesse-mathieu.

Harpagon (en le battant). Vous êtes un sot, un maraud, un coquin et un impudent.

35 Maître Jacques. Hé bien! ne l'avais-je pas deviné? Vous ne m'avez pas voulu croire: je vous l'avais bien dit que je vous fâcherais de vous dire la vérité.

Harpagon. Apprenez à parler. 


\section{LA LEÇON DE PRONONCIATION}

\section{Le Maître de Philosophie, Monsieur Jourdain}

Le Maitre de Philosophie. Voulez-vous apprendre la morale?

M. Jourdain. La morale?

Le Maître de Philosophie. Oui.

$M$. Jourdain. Qu'est-ce qu'elle dit cette morale?

Le Maître de Philosophie. Elle traite de la félicité, enseigne aux 5 hommes à modérer leurs passions, et . . .

M. Jourdain. Non, laissons cela. Je suis bilieux comme tous les diables; et il n'y a morale qui tienne, je me veux mettre en colère tout mon soûl, quand il m'en prend envie.

Le Maitre de Philosophie. Est-ce la physique que vous voulez ro apprendre?

$M$. Jourdain. Qu'est-ce qu'elle chante cette physique?

Le Maitre de Philosophie. La physique est celle qui explique les principes des choses naturelles, et les propriétés du corps ; qui discourt de la nature des éléments, des métaux, des minéraux, des pierres, des 15 plantes et des animaux, et nous enseigne les causes de tous les météores, l'arc-en-ciel, les feux volants, ${ }^{1}$ les comètes, les éclairs, le tonnerre, la foudre, la pluie, la neige, la grêle, les vents et les tourbillons.

$M$. Jourdain. Il y a trop de tintamarre là-dedans, trop de brouillamini.

Le Maître de Philosophie. Que voulez-vous donc que je vous ap- 20 prenne?

M. Jourdain. Apprenez-moi l'orthographe.

Le Maître de Philosophie. Très volontiers.

M. Jourdain. Après vous m'apprendrez l'almanach, pour savoir quand il y a de la lune et quand il n'y en a point.

Le Maître de Philosophie. Soit. Pour bien suivre votre pensée et traiter cette matière en philosophe, il faut commencer selon l'ordre des choses, par une exacte connaissance de la nature des lettres, et de la différente manière de les prononcer toutes. Et là-dessus j'ai à vous dire que les lettres sont divisées en voyelles, ainsi dites voyelles parce 30 qu'elles expriment les voix; et en consonnes, ainsi appelées consonnes parce qu'elles sonnent avec les voyelles, et ne font que marquer les diverses articulations des voix. Il y a cinq voyelles ou voix : $a, e, i, o, u$.

$M$. Jourdain. J'entends tout cela. 
Le Maitre de Philosophie. La voix a se forme en ouvrant fort la bouche : $a$.

M. Jourdain. A, a. Oui.

Le Maître de Philosophie. La voix e se forme en rapprochant la 5 mâchoire d'en bas de celle d'en haut: $a, e$.

M. Jourdain. $A, e, a, e$. Ma foi! oui. Ah! que cela est beau!

Le Maitre de Philosophie. Et la voix $i$ en rapprochant encore davantage les mâchoires l'une de l'autre, et écartant les deux coins de la bouche vers les oreilles : $a, e, i$.

Io $M$. Jourdain. $A, e, i, i, i, i$. Cela est vrai. Vive la science!

Le Mấtre de Philosophie. La voix $o$ se forme en rouvrant les mâchoires, et rapprochant les lèvres par les deux coins, le haut et le bas : $o$.

M. Jourdain. $O, o$. Il n'y a rien de plus juste. $A, e, i, o, i, o$. Cela ${ }_{5} 5$ est admirable! $I, o, i, o$.

Le Maitre de Philosophie. L'ouverture de la bouche fait justement comme un petit rond qui représente un $o$.

M. Jourdain. $O, o, o$. Vous avez raison, o. Ah! la belle chose, que de savoir quelque chose!

2o Le Maître de Philosophie. La voix $u$ se forme en rapprochant les dents sans les joindre entièrement, et allongeant les deux lèvres en dehors, les approchant aussi l'une de l'autre sans les joindre tout à fait: $u$.

$M$. Jourdain. $U, u$. Il n'y a rien de plus véritable: $u$.

25 Le Maître de Philosophie. Vos deux lèvres s'allongent comme si vous faisiez la moue: d'où vient que si vous la voulez faire à quelqu'un, et vous moquer de lui, vous ne sauriez lui dire que : $u$.

M. Jourdain. $U, u$. Cela est vrai. Ah! que n'ai-je étudié plus tôt: pour savoir tout cela?

3o Le Maitre de Philosophie. Demain, nous verrons les autres lettres, qui sont les consonnes.

M. Jourdain. Est-ce qu'il y a des choses aussi curieuses qu'à celles-ci ?

Le Maître de Philosophie. Sans doute. La consonne d, par exemple, 35 se prononce en donnant du bout de la langue au-dessus des dents d'en haut: $d a$.

M. Jourdain. Da, da. Oui. Ah! les belles choses! les belles choses!

Le Maitre de Philosophie. L'f en appuyant les dents d'en haut sur la lèvre de dessous: $f a$. 
M. Jourdain. Fa, fa. C'est la vérité. Ah! mon père et ma mère, que je vous veux de mal!

Le Maître de Philosophie. Et l'r, en portant le bout de la langue jusqu'au haut du palais, de sorte qu'étant frolée par l'air qui sort avec force, elle lui cède, et revient toujours au même endroit, faisant une manière de tremblement: $r r a$.

M. Jourdain. $R, r, r a ; r, r, r, r, r, r a$. Cela est vrai. Ah! l'habile homme que vous êtes! et que j'ai perdu de temps! $R, r, r, r a$.

Le Maitre de Philosophie. Je vous expliquerai à fond toutes ces curiosités.

M. Jourdain. Je vous en prie. Au reste, il faut que je vous fasse une confidence. Je suis amoureux d'une personne de grande qualité, et je souhaiterais que vous m'aidassiez à lui écrire quelque chose dans un petit billet que je veux laisser tomber à ses pieds.

Le Maitre de Philosophie. Fort bien.

$M$. Jourdain. Cela sera galant, oui.

Le Maître de Philosophie. Sans doute. Sont-ce des vers que vous lui voulez écrire?

$M$. Jourdain. Non, non, point de vers.

Le Maître de Philosophie. Vous ne voulez que de la prose?

$M$. Jourdain. Non, je ne veux ni prose ni vers.

Le Maître de Philosophie. Il faut bien que ce soit l'un, ou l'autre. M. Jourdain. Pourquoi?

Le Maître de Philosophie. Par la raison, Monsieur, qu'il n'y a pour s'exprimer que la prose, ou les vers.

$M$. Jourdain. Il n'y a que la prose ou les vers?

Le Maitre de Philosophie. Non, Monsieur: tout ce qui n'est point prose est vers; et tout ce qui n'est point vers est prose.

$M$. Jourdain. Et comme l'on parle qu'est-ce que c'est donc que cela?

Le Maître de Philosophie. De la prose.

$M$. Jourdain. Quoi ? quand je dis : «Nicole, apportez-moi mes pantoufles, et me donnez mon bonnet de nuit », c'est de la prose?

Le Maître de Philosophie. Oui, Monsieur.

$M$. Jourdain. Par ma foi! il y a plus de quarante ans que je dis de la prose sans que j'en susse rien, et je vous suis le plus obligé du monde 35 de m'avoir appris cela. 


\section{LES FEMMES SAVANTES}

\section{Philaminte, Chrysale, Bélise}

\section{CHRYSALE}

Vous êtes satisfaite, et la voilà partie;

Mais je n'approuve point une telle sortie $:^{1}$

C'est une fille propre aux choses qu'elle fait,

Et vous me la chassez pour un maigre sujet.

\section{PHILAMINTE}

Vous voulez que toujours je l'aie à mon service

Pour mettre incessamment mon oreille au supplice?

Pour rompre toute loi d'usage et de raison,

Par un barbare amas de vices d'oraison, ${ }^{2}$

De mots estropiés, cousus par intervalles,

De proverbes traînés dans les ruisseaux des Halles?

\section{BÉLISE}

Il est vrai que l'on sue à souffrir ses discours : Elle y met Vaugelas ${ }^{3}$ en pièces tous les jours ; Et les moindres défauts de ce grossier génie Sont ou le pléonasme, ou la cacophonie.

\section{CHRYSALE}

Qu'importe qu'elle manque aux lois de Vaugelas, Pourvu qu'à la cuisine elle ne manque pas?

J'aime bien mieux, pour moi, qu'en épluchant ses herbes, Elle accommode mal les noms avec les verbes, Et redise cent fois un bas ou méchant mot, Que de brûler ma viande, ou saler trop mon pot. Je vis de bonne soupe, et non de beau langage. Vaugelas n'apprend point à bien faire un potage ; Et Malherbe et Balzac, si savants en beaux mots, En cuisine peut-être auraient été des sots.

\section{PHILAMINTE}

1 Philaminte, a femme savante, wife of Chrysale, has dismissed her servant, Martine, because of the inelegance of her language.

2 "speech."

8 Vaugelas $(1585-1650$ ), a French grammarian, one of the first members of the French Academy, author of "Remarques sur la langue française" (1647). 
Au lieu de se hausser vers les spirituels !

Le corps, cette guenille, est-il d'une importance,

D'un prix à mériter seulement qu'on y pense,

Et ne devons-nous pas laisser cela bien loin?

CHRYSALE

Oui, mon corps est moi-même, et j'en veux prendre soin :

Guenille, si l'on veut, ma guenille m'est chère.

BÉLISE

Le corps avec l'esprit fait figure, ${ }^{1}$ mon frère ; .

Mais si vous en croyez tout le monde savant,

L'esprit doit sur le corps prendre le pas devant;

Et notre plus grand soin, notre première instance,

Doit être à le nourrir du suc de la science.

\section{CHRYSALE}

Ma foi! si vous songez à nourrir votre esprit, C'est de viande bien creuse, ${ }^{2}$ à ce que chacun dit, Et vous n'avez nul soin, nulle sollicitude

Pour...

\section{PHILAMINTE}

Ah! sollicitude à mon oreille est rude :

Il put ${ }^{3}$ étrangement son ancienneté.

$$
\text { BÉLISE }
$$

Il est vrai que le mot est bien collet monté. ${ }^{4}$

\section{CHRYSALE}

Voulez-vous que je dise? il faut qu'enfin j'éclate,

Que je lève le masque, et décharge ma rate.

De folles on vous traite, et j'ai fort sur le cœur . . .

Comment donc?

$$
\text { PHILAMINTE }
$$

\section{CHRYSALE}

C'est à vous que je parle, ma sœur.

Le moindre solécisme en parlant vous irrite;

Mais vous en faites, vous, d'étranges en conduite.

Vos livres éternels ne me contentent pas,

Et hors un gros Plutarque à mettre mes rabats,

1 "Joined to the mind the body is of some importance."

2 "very unsubstantial nourishment."

8 From the form puir; the modern form is puer.

4 "antiquated"; the collets montés had at that time passed out of fashion. 
Vous devriez brîler tout ce meuble inutile, Et laisser la science aux docteurs de la ville; M'ôter, pour faire bien, du grenier de céans Cette longue lunette à faire peur aux gens,

Et cent brimborions dont l'aspect importune;

Ne point aller chercher ce qu'on fait dans la lune,

Et vous mêler un peu de ce qu'on fait chez vous,

Où nous voyons aller tout sens dessus dessous.

Il n'est pas bien honnête, et pour beaucoup de causes,

Qu'une femme étudie et sache tant de choses.

Former aux bonnes mœurs l'esprit de ses enfants,

Faire aller son ménage, avoir l'œil sur ses gens,

Et régler la dépense avec économie,

Doit être son étude et sa philosophie.

Nos pères sur ce point étaient gens bien sensés, Qui disaient qu'une femme en sait toujours assez Quand la capacité de son esprit se hausse A connaître un pourpoint d'avec un haut-de-chausse.

Les leurs ne lisaient point, mais elles vivaient bien;

Leurs ménages étaient tout leur docte entretien,

Et leurs livres un dé, du fil et des aiguilles,

Dont elles travaillaient au trousseau de leurs filles.

Les femmes d'à présent sont bien loin de ces mœurs :

Elles veulent écrire, et devenir auteurs.

Nulle science n'est pour elles trop profonde,

Et céans beaucoup plus qu'en aucun lieu du monde:

Les secrets les plus hauts s'y laissent concevoir,

Et l'on sait tout chez moi, hors ce qu'il faut savoir ;

On y sait comme vont lune, étoile polaire,

Vénus, Saturne et Mars, dont je n'ai point affaire ;

$\mathrm{Et}$, dans ce vain savoir, qu'on va chercher si loin,

On ne sait comme va mon pot, dont j'ai besoin.

Mes gens à la science aspirent pour vous plaire,

Et tous ne font rien moins que ce qu'ils ont.à faire ;

Raisonner est l'emploi de toute ma maison,

Et le raisonnement en bannit la raison:

L'un me brûle mon rôt en lisant quelque histoire ;

L'autre rêve à des vers quand je demande à boire ;

Enfin je vois par eux votre exemple suivi,

Et j'ai des serviteurs, et ne suis point servi.

Une pauvre servante au moins m'était restée,

Qui de ce mauvais air n'était point infectée,

Et voilà qu'on la chasse avec un grand fracas, 
A cause qu'elle manque à parler Vaugelas.

Je vous le dis, ma sœur, tout ce train-là me blesse

(Car c'est, comme j'ai dit, à vous que je m'adresse).

Je n'aime point céans tous vos gens à latin,

Et principalement ce Monsieur 'Trissotin:

C'est lui qui dans des vers vous a tympanisées;

'Tous les propos qu'il tient sont des billevesées;

On cherche ce qu'il dit après qu'il a parlé,

Et je lui crois, pour moi, le timbre un peu fêlé.

PHILAMINTE

Quelle bassesse, ô Ciel, et d'âme, et de langage!

\section{BÉLISE}

Est-il de petits corps un plus lourd assemblage!

Un esprit composé d'atomes plus bourgeois!

Et de ce même sang se peut-il que je sois!

Je me veux mal de mort d'être de votre race, Et de confusion j'abandonne la place.

1 Petits corps is used here in the sense of atomes. 


\title{
JEAN DE LA FONTAINE
}

\author{
Château-Thierry, I 62 I - I695, Paris
}

After an indolent childhood in which there was little that pointed to future greatness, La Fontaine, at the age of nineteen, took up the study of theology. But, apparently incapable of serious application in any line, he decided before the expiration of two years that theology was not his vocation. Law, which he next turned to, seemed no more congenial. In I 664 he returned to ChâteauThierry, succeeded his father as "maître des eaux et forêts," and married a girl twelve years his junior, but continued, nevertheless, his aimless, irresponsible manner of life.

Meanwhile he was becoming interested in literature. His first volume appeared in 1654 , an adaptation of Terence's "Eunuchus." He was introduced to Fouquet in 1657 , and wrote, under his patronage, a number of poems of varied form and value, the best being the "Elégie aux nymphes de Vaux" (I66I), occasioned by Fouquet's disgrace. But his fame does not rest on the occasional poems which appeared from time to time, nor on his various plays and romances; it rests on the "Contes et nouvelles" (1665, I666, I67 I, I674), and, particularly, on the twelve books of "Fables," the first six books of which appeared in 1668 , five more books in 1678 , the last book in 1694 . The vivid, picturesque, graceful, and at the same time personal touch of these little poems places La Fontaine in the first rank, not only as a writer of fables, in which he is unsurpassed, but also as a poet.

Having wasted his patrimony, La Fontaine spent the last half of his life drifting about enjoying the hospitality of his friends, as unconcernedly as a child. $\mathrm{He}$ was received into the Academy in $\mathbf{1 6 8 4}$.

\section{LE CORBEAU ET LE RENARD}

Maître Corbeau, sur un arbre perché, Tenait en son bec un fromage.

Maître Renard, par l'odeur alléché,

Lui tint à peu près ce langage :

" Hé! bonjour, Monsieur du Corbeau.

Que vous êtes joli! que vous me semblez beau!

Sans mentir, si votre ramage

Se rapporte à votre plumage,

Vous êtes le phénix des hôtes de ces bois. ")

A ces mots le Corbeau ne se sent pas de joie;

Et pour montrer sa belle voix,

Il ouvre un large bec, laisse tomber sa proie. 
Le Renard s'en saisit, et dit: "Mon bon Monsieur,

Apprenez que tout flatteur

Vit aux dépens de celui qui l'écoute:

Cette leçon vaut bien un fromage, sans doute.»

Le Corbeau, honteux et confus,

Jura, mais un peu tard, qu'on ne l'y prendrait plus.

\section{LE CHÊNE ET LE ROSEAU}

Le Chêne un jour dit au Roseau :

"Vous avez bien sujet d'accuser la nature;

Un roitelet pour vous est un pesant fardeau;

Le moindre vent qui d'aventure

Fait rider la face de l'eau,

Vous oblige à baisser la tête,

Cependant que mon front, au Caucase pareil,

Non content d'arrêter les rayons du soleil,

Brave l'effort de la tempête.

Tout vous est aquilon, tout me semble zéphyr.

Encor si vous naissiez à l'abri du feuillage

Dont je couvre le voisinage,

Vous n'auriez pas tant à souffrir :

Je vous défendrais de l'orage;

Mais vous naissez le plus souvent

Sur les humides bords des royaumes du vent.

La nature envers vous me semble bien injuste.

- Votre compassion, lui répondit l'arbuste,

Part d'un bon naturel; mais quittez ce souci :

Les vents me sont moins qu'à vous redoutables;

Je plie, et ne romps pas. Vous avez jusqu'ici

Contre leurs coups épouvantables

Résisté sans courber le dos;

Mais attendons la fin. " Comme il disait ces mots,

Du bout de l'horizon accourt avec furie

Le plus terrible des enfants

Que le Nord eût portés jusque-là dans ses flancs.

L'arbre tient bon; le Roseau plie.

Le vent redouble ses efforts,

Et fait si bien qu'il déracine

Celui de qui la tête au ciel était voisine,

Et dont les pieds touchaient à l'empire des morts. 


\section{LE MEUNIER, SON FILS ET L'ANE}

L'invention des arts étant un droit d'aînesse,

Nous devons l'apologue à l'ancienne Grèce ;

Mais ce champ ne se peut tellement moissonner

Que les derniers venus n'y trouvent à glaner.

La feinte ${ }^{1}$ est un pays plein de terres désertes ;

Tous les jours nos auteurs y font des découvertes.

Je t'en veux dire un trait assez bien inventé :

Autrefois à Racan ${ }^{2}$ Malherbe l'a conté.

Ces deux rivaux d'Horace, héritiers de sa lyre,

Disciples d'Apollon, nos maîtres, pour mieux dire,

Se rencontrant un jour tout seuls et sans témoins

(Comme ils se confiaient leurs pensers et leurs soins),

Racan commence ainsi : "Dites-moi, je vous prie,

Vous qui devez savoir les choses de la vie,

Qui par tous ses degrés avez déjà passé,

Et que rien ne doit fuir en cet âge avancé,

A quoi me résoudrai-je? Il est temps que j'y pense.

Vous connaissez mon bien, mon talent, ma naissance :

Dois-je dans la province établir mon séjour,

Prendre emploi dans l'armée, ou bien charge à la cour ?

Tout au monde est mêlé d'amertume et de charmes :

La guerre a ses douceurs, l'hymen a ses alarmes.

Si je suivais mon goût, je saurais où buter ${ }^{3}$;

Mais j'ai les miens, la cour, le peuple à contenter.»

Malherbe là-dessus : "Contenter tout le monde!

Écoutez ce récit avant que je réponde.

" J'ai lu dans quelque endroit qu'un Meunier et son Fils,

L'un vieillard, l'autre enfant, non pas des plus petits,

Mais garçon de quinze ans, si j'ai bonne mémoire,

Allaient vendre leur Ane, un certain jour de foire.

Afin qu'il fût plus frais et de meilleur débit,

On lui lia les pieds, on vous le suspendit;

Puis cet homme et son Fils le portent comme un lustre.

Pauvres gens, idiots, couple ignorant et rustre!

Le premier qui les vit de rire s'éclata:

"Quelle farce, dit-il, vont jouer ces gens-là ?

Le plus âne des trois n'est pas celui qu'on pense. »

1 "fiction."

2 Racan (1589-1670), disciple of Malherbe, author of "Les bergeries," a long pastoral poem. 8 "to aim." 
Le Meunier, à ces mots, connaît son ignorance ;

Il met sur pieds sa bête, et la fait détaler.

L'Ane, qui goûtait fort l'autre façon d'aller,

Se plaint en son patois. Le Meunier n'en a cure ;

Il fait monter son Fils, il suit, et d'aventure

Passent trois bons marchands. Cet objet leur déplut.

Le plus vieux au garçon s'écria tant qu'il put:

" Oh la oh, descendez, que l'on ne vous le dise,

Jeune homme, qui menez laquais à barbe grise!

C'était à vous de suivre, au vieillard de monter.

-Messieurs, dit le Meunier, il vous faut contenter.»

L'enfant met pied à terre, et puis le vieillard monte,

Quand trois filles passant, l'une dit: "C'est grand'honte

Qu'il faille voir ainsi clocher ce jeune fils,

Tandis que ce nigaud, comme un évêque assis,

Fait le veau ${ }^{1}$ sur son Ane, et pense être bien sage.

- Il n'est, dit le Meunier, plus de veaux à mon âge :

Passez votre chemin, la fille, et m'en croyez. »

Après maints quolibets coup sur coup renvoyés,

L'homme crut avoir tort, et mit son Fils en croupe.

Au bout de trente pas, une troisième troupe

Trouve encore à gloser. L'un dit: "Ces gens sont fous !

Le Baudet n'en peut plus; il mourra sous leurs coups.

Hé quoi ? charger ainsi cette pauvre bourrique!

N'ont-ils point de pitié de leur vieux domestique?

Sans doute qu'à la foire ils vont vendre sa peau.

- Parbieu! dit le Meunier, est bien fou du cerveau

Qui prétend contenter tout le monde et son père.

Essayons toutefois si par quelque manière

Nous en viendrons à bout. ") Ils descendent tous deux.

L'Ane se prélassant marche seul devant eux.

Un quidam les rencontre, et dit: "Est-ce la mode

Que Baudet aille à l'aise, et Meunier s'incommode?

Qui de l'âne ou du maître est fait pour se lasser?

Je conseille à ces gens de le faire enchâsser.

Ils usent leurs souliers, et conservent leur Ane.

Nicolas, au rebours; car, quand il va voir Jeanne,

Il monte sur sa bête; et la chanson le dit. ${ }^{2}$

1 "takes his ease."

2 An allusion to a contemporary popular song :

Adieu, cruelle Jeanne;

$\mathrm{Si}$ vous ne m'aimez pas,

Je monte sur mon âne

Pour galoper au trépas. 
Beau trio de baudets!" Le Meunier repartit: " Je suis âne, il est vrai, j'en conviens, je l'avoue ; Mais que dorénavant on me blâme, on me loue, Qu'on dise quelque chose ou qu'on ne dise rien, J'en veux faire à ma tête. » Il le fit, et fit bien.

Quant à vous, suivez Mars, ou l'Amour, ou le Prince ; Allez, venez, courez; demeurez en province;

Prenez femme, abbaye, emploi, gouvernement:

Les gens en parleront, n'en doutez nullement. » — " Fables », Book III, I

\section{LES ANIMAUX MALADES DE LA PESTE}

Un mal qui répand la terreur,

Mal que le Ciel en sa fureur

Inventa pour punir les crimes de la terre,

La peste (puisqu'il faut l'appeler par son nom),

Capable d'enrichir en un jour l'Achéron,

5 Faisait aux animaux la guerre.

Ils ne mouraient pas tous, mais tous étaient frappés :

On n'en voyait point d'occupés

A chercher le soutien d'une mourante vie;

Nul mets n'excitait leur envie;

$\mathrm{Ni}$ loups ni renards n'épiaient

La douce et l'innocente proie;

Les tourterelles se fuyaient:

Plus d'amour, partant plus de joie.

Le Lion tint conseil, et dit: “Mes chers amis,

Je crois que le Ciel a permis

Pour nos péchés cette infortune.

Que le plus coupable de nous

Se sacrifie aux traits du céleste courroux;

Peut-être il obtiendra la guérison commune.

L'histoire nous apprend qu'en de tels accidents

On fait de pareils dévouements. ${ }^{1}$

Ne nous flattons donc point; voyons sans indulgence

1 At the Athenian feast of the Thargelia human sacrifices were offered in time of pestilence; in the most ancient times persons used to volunteer as victims. Compare the familiar story of Mettius Curtius at Rome, and similar self-sacrifices to secure the favor of the gods in war, as those of the Roman Decü (note on p. 26) and the Athenian Codrus. 
L'état de notre conscience.

Pour moi, satisfaisant mes appétits gloutons,

J'ai dévoré force moutons.

Que m'avaient-ils fait? Nulle offense;

Même il m'est arrivé quelquefois de manger

$$
\text { Le berger. }
$$

Je me dévouerai donc, s'il le faut: mais je pense

Qu'il est bon que chacun s'accuse ainsi que moi :

Car on doit souhaiter, selon toute justice,

Que le plus coupable périsse.

- Sire, dit le Renard, vous êtes trop bon roi ;

Vos scrupules font voir trop de délicatesse.

Eh bien! manger moutons, canaille, sotte espèce,

Est-ce un péché? Non, non. Vous leur fîtes, Seigneur,

En les croquant, beaucoup d'honneur;

Et quant au berger, l'on peut dire

Qu'il était digne de tous maux,

Etant de ces gens-là qui sur les animaux

Se font un chimérique empire.»

Ainsi dit le Renard; et flatteurs d'applaudir.

On n'osa trop approfondir

Du 'Tigre, ni de l'Ours, ni des autres puissances,

Les moins pardonnables offenses.

Tous les gens querelleurs, jusqu'aux simples mâtins,

$\mathrm{Au}$ dire de chacun, étaient de petits saints.

L'Ane vint à son tour, et dit: " J'ai souvenance

Qu'en un pré de moines passant,

La faim, l'occasion, l'herbe tendre, et, je pense,

Quelque diable aussi me poussant,

Je tondis de ce pré la largeur de ma langue.

Je n'en avais nul droit, puisqu'il faut parler net. »

A ces mots on cria haro sur le Baudet.

Un Loup, quelque peu clerc, prouva par sa harangue

Qu'il fallait dévouer ce maudit animal,

Ce pelé, ce galeux, d'où venait tout leur mal.

Sa peccadille fut jugée un cas pendable.

Manger l'herbe d'autrui! quel crime abominable !

Rien que la mort n'était capable

D'expier son forfait : on le lui fit bien voir.

Selon que vous serez puissant ou misérable,

Les jugements de cour vous rendront blanc ou noir. 


\section{LA LAITIÈRE ET LE POT AU LAIT}

Perrette, sur sa tête ayant un pot au lait

Bien posé sur un coussinet,

Prétendait arriver sans encombre à la ville.

Légère et court vêtue, elle allait à grands pas,

Ayant mis ce jour-là, pour être plus agile,

Cotillon simple et souliers plats.

Notre laitière ainsi troussée

Comptait déjà dans sa pensée

Tout le prix de son lait, en employait l'argent;

Io

Achetait un cent d'œufs, faisait triple couvée :

La chose allait à bien par son soin diligent.

( Il m'est, disait-elle, facile

D'élever des poulets autour de ma maison;

Le renard sera bien habile

S'il ne m'en laisse assez pour avoir un cochon.

Le porc à s'engraisser coûtera peu de son ;

Il était, quand je l'eus, de grosseur raisonnable :

J'aurai, le revendant, de l'argent bel et bon.

Et qui m'empêchera de mettre en notre étable,

$\mathrm{Vu}$ le prix dont il est, une vache et son veau,

Que je verrai sauter au milieu du troupeau?"

Perrette là-dessus saute aussi, transportée:

Le lait tombe; adieu veau, vache, cochon, couvée.

La dame de ces biens, quittant d'un œil marri

Sa fortune ainsi répandue,

Va s'excuser à son mari,

En grand danger d'être battue.

Le récit en farce en fut fait;

On l'appela le Pot au lait.

Quel esprit ne bat la campagne?

Qui ne fait châteaux en Espagne?

Picrochole, Pyrrhus, ${ }^{1}$ la Laitière, enfin tous,

Autant les sages que les fous.

Chacun songe en veillant; il n'est rien de plus doux :

Une flatteuse erreur emporte alors nos âmes ;

Tout le bien du monde est à nous,

1 In Rabelais's "Gargantua" (I, 33), Picrochole, after the wildest dreams of conquest, is brought back to earth by Échéphron, who says: "J'ay grand peur que toute ceste entreprinse sera semblable à la farce du pot au lait." Pyrrhus, king of Epirus, dreamed of conquering the world. See life of Pyrrhus in Plutarch's "Lives"; also Boileau, "Epîtres," 1, lines 61-90. 
Tous les honneurs, toutes les femmes.

Quand je suis seul, je fais au plus brave un défi;

Je m'écarte, je vais détrôner le Sophi ; ${ }^{1}$

On m'élit roi, mon peuple m'aime;

Les diadèmes vont sur ma tête pleuvant:

Quelque accident fait-il que je rentre en moi-même,

Je suis gros Jean ${ }^{2}$ comme devant.

— «Fables», Book VII, io

\section{LE SAVETIER ET LE FINANCIER}

Un Savetier chantait du matin jusqu'au soir ;

C'était merveilles de le voir,

Merveilles de l'ouïr ; il faisait des passages, ${ }^{\mathbf{3}}$

Plus content qu'aucun des sept sages.

Son voisin, au contraire, étant tout cousu d'or,

Chantait peu, dormait moins encor;

C'était un homme de finance.

Si, sur le point du jour, parfois il sommeillait,

Le Savetier alors en chantant l'éveillait ;

Et le Financier se plaignait

Que les soins de la Providence

N'eussent pas au marché fait vendre le dormir,

Comme le manger et le boire.

En son hôtel il fait venir

Iо

Le chanteur, et lui dit : "Or çà, sire Grégoire,

Que gagnez-vous par an? - Par an? Ma foi, Monsieur,

Dit, avec un ton de rieur,

Le gaillard Savetier, ce n'est point ma manière

De compter de la sorte; et je n'entasse guère

Un jour sur l'autre: il suffit qu'à la fin

J'attrape le bout de l'année;

Chaque jour amène son pain.

-Eh bien, que gagnez-vous, dites-moi, par journée?

-Tantôt plus, tantôt moins : le mal est que toujours

(Et sans cela nos gains seraient assez honnêtes),

Le mal est que dans l'an s'entremêlent des jours

Qu'il faut chômer; on nous ruine en fêtes;

L'une fait tort à l'autre; et Monsieur le curé

De quelque nouveau saint charge toujours son prône. "

1 Title given formerly to the sovereign of Persia.

2 "plain John." 
Le Financier, riant de sa naïveté,

Lui dit : " Je vous veux mettre aujourd'hui sur le trône.

Prenez ces cent écus; gardez-les avec soin,

Pour vous en servir au besoin.»)

Le Savetier crut voir tout l'argent que la terre

Avait, depuis plus de cent ans,

Produit pour l'usage des gens.

Il retourne chez lui; dans sa cave il enserre

L'argent, et sa joie à la fois.

Plus de chant: il perdit la voix,

Du moment qu'il gagna ce qui cause nos peines.

Le sommeil quitta son logis ;

Il eut pour hôtes les soucis,

Les soupçons, les alarmes vaines;

Tout le jour, il avait l'œil au guet; et la nuit,

Si quelque chat faisait du bruit,

Le chat prenait l'argent. A la fin le pauvre homme

S'en courut chez celui qu'il ne réveillait plus :

" Rendez-moi, lui dit-il, mes chansons et mon somme,

Et reprenez vos cent écus. »

— "Fables», Book VIII, 2

\section{LE PAYSAN DU DANUBE}

Il ne faut point juger des gens sur l'apparence.

Le conseil en est bon, mais il n'est pas nouveau.

Jadis l'erreur du Souriceau ${ }^{1}$

Me servit à prouver le discours que j'avance:

J'ai, pour le fonder à présent,

Le bon Socrate, Esope, et certain paysan

Des rives du Danube, homme dont Marc-Aurèle ${ }^{2}$

Nous fait un portrait fort fidèle.

On connaît les premiers : quant à l'autre, voici

Le personnage en raccourci.

Son menton nourrissait une barbe touffue;

Toute sa personne velue

Représentait un ours, mais un ours mal léché :

Sous un sourcil épais il avait l'œil caché,

Le regard de travers, nez tortu, grosse lèvre,

1 The fable of "Le Cochet, le Chat et le Souriceau," Book VI, 5.

2 This story is not found in Marcus Aurelius. La Fontaine got it from a translation of "Marco Aurelio con el reloj de principes," by Guevara. 
Portait sayon de poil de chèvre,

Et ceinture de joncs marins.

Cet homme ainsi bâti fut député des villes

Que lave le Danube. Il n'était point d'asiles

Où l'avarice des Romains

Ne pénétrât alors, et ne portât les mains.

Le député vint donc, et fit cette harangue :

" Romains, et vous Sénat assis pour m'écouter,

Je supplie avant tout les Dieux de m'assister :

Veuillent les Immortels, conducteurs de ma langue,

Que je ne dise rien qui doive être repris !

Sans leur aide, il ne peut entrer dans les esprits

Que tout mal et toute injustice:

Faute d'y recourir, on viole leurs lois.

Témoin nous que punit la romaine avarice: .

Rome est, par nos forfaits, plus que par ses exploits,

L'instrument de notre supplice.

Craignez, Romains, craignez que le Ciel quelque jour

$\mathrm{Ne}$ transporte chez vous les pleurs et la misère;

Et mettant en nos mains, par un juste retour,

Les armes dont se sert sa vengeance sévère,

Il ne vous fasse, en sa colère,

Nos esclaves à votre tour.

Et pourquoi sommes-nous les vôtres ? Qu'on me die ${ }^{1}$

En quoi vous valez mieux que cent peuples divers.

Quel droit vous a rendus maîtres de l'univers?

Pourquoi venir troubler une innocente vie?

Nous cultivions en paix d'heureux champs ; et nos mains

Etaient propres aux arts, ainsi qu'au labourage.

Qu'avez-vous appris aux Germains?

Ils ont l'adresse et le courage :

S'ils avaient eu l'avidité,

Comme vous, et la violence,

Peut-être en votre place ils auraient la puissance,

Et sauraient en user sans inhumanité.

Celle que vos préteurs ont sur nous exercée

N'entre qu'à peine en la pensée.

La majesté de vos autels

Elle-même en est offensée ;

Car sachez que les Immortels

Ont les regards sur nous. Grâces à vos exemples, 
Ils n'ont devant les yeux que des objets d'horreur,

De mépris d'eux et de leurs temples,

D'avarice qui va jusques à la fureur.

Rien ne suffit aux gens qui nous viennent de Rome:

La terre et le travail de l'homme

Font pour les assouvir des efforts superflus.

Retirez-les : on ne veut plus

Cultiver pour eux les campagnes.

Nous quittons les cités, nous fuyons aux montagnes;

Io Nous laissons nos chères compagnes;

Nous ne conversons ${ }^{1}$ plus qu'avec des ours affreux,

Découragés de mettre au jour des malheureux,

Et de peupler pour Rome un pays qu'elle opprime.

Quant à nos enfants déjà nés,

i5 Nous souhaitons de voir leurs jours bientôt bornés :

Vos préteurs au malheur nous font joindre le crime.

Retirez-les: ils ne nous apprendront

Que la mollesse et que le vice;

Les Germains comme eux deviendront

Gens de rapine et d'avarice.

C'est tout ce que j'ai vu dans Rome à mon abord.

N'a-t-on point de présent à faire,

Point de pourpre à donner : c'est en vain qu'on espère

Quelque refuge aux lois; encor leur ministère

A-t-il mille longueurs. Ce discours, un peu fort,

Doit commencer à vous déplaire.

Je finis. Punissez de mort

Une plainte un peu trop sincère. »)

A ces mots, il se couche; et chacun étonné

Admire le grand cœur, le bon sens, l'éloquence

Du sauvage ainsi prosterné.

On le créa patrice; et ce fut la vengeance

Qu'on crut qu'un tel discours méritait. On choisit

D'autres préteurs ; et par écrit

Le Sénat demanda ce qu'avait dit cet homme,

Pour servir de modèle aux parleurs à venir.

On ne sut pas longtemps à Rome

Cette éloquence entretenir.

— "Fables », Book XI, 7

1 Concerser here means "to live with." 
ÉPITTRE A MONSEIGNEUR L'ÉVÊQUE DE SOISSONS ${ }^{1}$

\section{EN LUI DONNANT UN QUINTILIEN DE LA TRADUCTION}

D'IIORATIO TOSCANELLA

Je vous fais un présent ${ }^{2}$ capable de me nuire.

Chez vous Quintilien s'en va tous nous détruire;

Car enfin qui le suit? qui de nous aujourd'hui

S'égale aux anciens tant estimés chez lui ?

Tel est mon sentiment, tel doit être le vôtre.

Mais si votre suffrage en entraîne quelque autre,

Il ne fait pas la foule; et je vois des auteurs

Qui, plus savants que moi, sont moins admirateurs.

Si vous les en croyez, on ne peut sans faiblesse

Rendre hommage aux esprits de Rome et de la Grèce.

"Craindre ces écrivains! on écrit tant chez nous!

La France excelle aux arts, ils y fleurissent tous;

Notre prince avec art nous conduit aux alarmes,

Et sans art nous louerions le succès de ses armes!

Dieu n'aimerait-il plus à former des talents?

Les Romains et les Grecs sont-ils seuls excellents?")

Ces discours sont fort beaux, mais fort souvent frivoles :

Je ne vois point l'effet répondre à ces paroles ;

Et, faute d'admirer les Grecs et les Romains,

On s'égare en voulant tenir d'autres chemins.

Quelques imitateurs, sot bétail, je l'avoue,

Suivent en vrais moutons le pasteur de Mantoue ${ }^{3}$ :

J'en use d'autre sorte; et, me laissant guider,

Souvent à marcher seul j'ose me hasarder.

On me verra toujours pratiquer cet usage ;

Mon imitation n'est pas un esclavage:

Je ne prends que l'idée, et les tours, et les lois,

Que nos maitres suivaient eux-mêmes autrefois.

Si d'ailleurs quelque endroit plein chez eux d'excellence

Peut entrer dans mes vers sans nulle violence,

Je l'y transporte, et veux qu'il n'ait rien d'affecté,

Tâchant de rendre mien cet air d'antiquité.

Je vois avec douleur ces routes méprisées :

Art et guides, tout est dans les Champs Elysées.

1 Pierre-Daniel Huet (1630-1721) was bishop of Soissons, then of Avranches. This Epitre is an answer to the literary doctrines of Charles Perrault brought out in the poem entitled "Le siècle de Louis le Grand," read before the Academy in I687.

2 The present was Toscanella's translation of Quintilian's "Institutio Oratoria."

3 Vergil. 
J'ai beau les évoquer, j'ai beau vanter leurs traits, On me laisse tout seul admirer leurs attraits.

Térence est dans mes mains; je m’instruis dans Horace;

Homère et son rival sont mes dieux du Parnasse.

Je le dis aux rochers; on veut d'autres discours :

$\mathrm{Ne}$ pas louer son siècle est parler à des sourds.

Je le loue, et je sais qu'il n'est pas sans mérite;

Mais près de ces grands noms notre gloire est petite:

Tel de nous, dépourvu de leur solidité,

N'a qu'un peu d'agrément, sans nul fonds de beauté;

Je ne nomme personne: on peut tous nous connaître.

Je pris certain auteur ${ }^{1}$ autrefois pour mon maître;

Il pensa me gâter. A la fin, grâce aux dieux,

Horace, par bonheur, me dessilla les yeux.

I5 L'auteur avait du bon, du meilleur; et la France

Estimait dans ses vers le tour et la cadence.

Qui ne les eût prisés? J'en demeurai ravi;

Mais ses traits ont perdu quiconque l'a suivi.

Son trop d'esprit s'épand en trop de belles choses :

Tous métaux y sont or, toutes fleurs y sont roses.

On me dit là-dessus : " De quoi vous plaignez-vous ? "

De quoi ? Voilà mes gens aussitôt en courroux;

Ils se moquent de moi, qui, plein de ma lecture,

Vais partout prêchant l'art de la simple nature.

25 Ennemi de ma gloire et de mon propre bien,

Malheureux, je m'attache à ce goût ancien.

" Qu'a-t-il sur nous, dit-on, soit en vers, soit en prose?

L'antiquité des noms ne fait rien à la chose,

L'autorité non plus, ni tout Quintilien. »

Confus à ces propos, j'écoute, et ne dis rien.

J'avouerai cependant qu'entre ceux qui les tiennent

J'en vois dont les écrits sont beaux et se soutiennent:

Je les prise, et prétends qu'ils me laissent aussi

Révérer les héros du livre que voici.

Recevez leur tribut des mains de Toscanelle;

$\mathrm{Ne}$ vous étonnez pas qu'il donne pour modèle

A des ultramontains un auteur sans brillants :

Tout peuple peut avoir du goût et du bon sens,

Ils sont de tout pays, du fond de l'Amérique;

Qu'on y mène un rhéteur habile et bon critique,

Il fera des savants. Hélas! qui sait encor

1 Vincent Voiture (1598-1648), a habitué of the Hôtel de Rambouillet, author of witty letters and elegant society verses. 
Si la science à l'homme est un si grand trésor?

Je chéris l'Arioste et j'estime le 'Tasse ;

Plein de Machiavel, entêté de Boccace,

J'en parle si souvent qu'on en est étourdi ;

J'en lis qui sont du Nord, et qui sont du Midi.

Non qu'il ne faille un choix dans leurs plus beaux ouvrages :

Quand notre siècle aurait ses savants et ses sages,

En trouverai-je un seul approchant de Platon?

La Grèce en fourmillait dans son moindre canton.

La France a la satire et le double théâtre ${ }^{1}$;

Des bergères d'Urfé ${ }^{2}$ chacun est idolâtre ;

On nous promet l'histoire, ${ }^{8}$ et c'est un beau projet.

J'attends beaucoup de l'art, beaucoup plus du sujet :

Il est riche, il est vaste, il est plein de noblesse;

Il me ferait trembler pour Rome et pour la Grèce.

Quant aux autres talents, l'ode, qui baisse un peu,

Veut de la patience; et nos gens ont du feu.

Malherbe avec Racan, parmi les chœurs des anges,

Là-haut de l'Éternel célébrant les louanges,

Ont emporté leur lyre ; et j'espère qu'un jour

J'entendrai leur concert au céleste séjour.

Digne et savant prélat, vos soins et vos lumières

Me feront renoncer à mes erreurs premières : ${ }^{4}$

Comme vous je dirai l'auteur de l'univers ;

Cependant agréez mon rhéteur et mes vers.

1 I.e. tragedy and comedy.

2 Honoré d'Urfé (1567-1625), author of the pastoral novel "Astrée."

3 The history of the reign of Louis XIV, begun by Pellisson, and, in 1677 , intrusted to Racine and Boileau.

$4 \mathrm{La}$ Fontaine here anticipates his conversion, which took place in 1692, five years after he wrote these lines. 


\section{NICOLAS BOILEAU-DESPRÉAUX}

Paris, I636-I 7 I I, Paris

Boileau first studied theology, then law, but gave up each in turn, and, after the death of his father (1657), from whom he inherited a competency, he turned. to literature. Three years later he began writing the "Satires," his first attack on affectation and false principles in literature and society. The first authorized edition of the first seven of these "Satires "appeared in I666; the eighth and ninth followed two years later. He turned next to writing his "Epitres," the first and second of which came out in 1672 , four more following in 1674 and 1675 . Meanwhile he had finished the "Art poétique" (I674), and the first four cantos of "Le lutrin" (1674), a burlesque poem. Cantos V and VI of "Le lutrin" were published in I $_{3}$, four more "Epitres" in the same year, and three more and one "Satire" in 1694. Later he added two more "Satires" to the ten already mentioned. His dialogue "Les héros de roman." though composed in $\mathrm{I} 66_{5}$, was not published or even committed to writing until much later. In I 677 Boileau, with Racine, was appointed historiographer to the king. He was elected to the Academy in 1684 , and died in 17 I I.

Boileau's importance is perhaps not so much in the poetic value of his verse, which, however, with its simple directness, its picturesque realism, its playful and sometimes sharp pleasantries, must not be underestimated, as in the sane influence he exerted on the men of his generation. He was a man of entire independence, outspoken, kind, a true friend, as well as a defender of high literary ideals, making literary perfection a matter of conscience. The rules he formulated and the standards he set up, representing the doctrines of classicism, were generally respected until the Romantic School, in the nineteenth century, introduced new ideals.

\section{LE REPAS RIDICULE}

— Ah! de grâce, un moment; ... souffrez que je respire ! ... Je sors de chez un fat, qui, pour m'empoisonner,

Je pense, exprès, chez lui, m'a forcé de dîner.

Je l'avais bien prévu! Depuis près d'une année

J'éludais tous les jours sa poursuite obstinée.

Mais hier, il m'aborde, et me serrant la main:

« Ah! Monsieur, m'a-t-il dit, je vous attends demain.

N'y manquez pas, au moins! J'ai quatorze bouteilles

D'un vin vieux ... . Boucingo ${ }^{1}$ n'en a point de pareilles,

1 Illustre marchand de vin (Boileau). 
Et je gagerais bien que, chez le Commandeur, ${ }^{1}$

Villandri ${ }^{2}$ priserait sa sève et sa verdeur.

Molière avec Tartuffe ${ }^{8}$ y doit jouer son rôle, Et Lambert, ${ }^{4}$ qui plus est, m'a donné sa parole ;

C'est tout dire en un mot, et vous le connaissez.

- Quoi! Lambert? — Oui, Lambert. - A demain. C'est assez. »

Ce matin donc, séduit par sa vaine promesse,

J'y cours, midi sonnant, au sortir de la messe.

A peine étais-je entré, que, ravi de me voir,

Mon homme, en m'embrassant, m'est venu recevoir,

$\mathrm{Et}$, montrant à mes yeux une allégresse entière :

" Nous n'avons, m'a-t-il dit, ni Lambert ni Molière ;

Mais, puisque je vous vois, je me tiens trop content.

Vous êtes un brave homme. . . E Entrez. On vous attend. . . .

A ces mots, mais trop tard, reconnaissant ma faute,

Je le suis en tremblant dans une chambre haute,

Où, malgré les volets, le soleil irrité

Formait un poêle ardent au milieu de l'été.

Le couvert était mis dans ce lieu de plaisance,

Où j'ai trouvé d'abord, pour toute connaissance,

Deux nobles campagnards, grands lecteurs de romans,

Qui m'ont dit tout Cyrus ${ }^{5}$ dans leurs longs compliments.

J'enrageais. Cependant, on apporte un potage :

Un coq y paraissait en pompeux équipage,

Qui, changeant sur ce plat et d'état et de nom,

Par tous les conviés s'est appelé chapon.

Deux assiettes suivaient, dont l'une était ornée

D'une langue en ragoût, de persil couronnée;

L'autre, d'un godiveau tout brûlé par dehors,

Dont un beurre gluant inondait tous les bords.

On s'assied: mais d'abord notre troupe serrée

Tenait à peine autour d'une table carrée,

Où chacun malgré soi l'un sur l'autre porté,

Faisait un tour à gauche, ${ }^{6}$ et mangeait de côté.

1 Jacques de Souvré, commandeur de Saint-Jean-de-Latran, was noted for the excellence of his table.

2 Homme de qualité qui allait fréquemment chez le commandeur de Souvré (Boileau).

8 At this date (1665) "Tartuffe" was prohibited; consequently there was great curiosity to hear Molière read it.

4 Lambert (1610-1696) was a distinguished composer and musician, qui promettait d tout le monde de venir, mais qui ne venait jamais (Boileau).

5 "Artamène ou le Grand Cyrus," a ten-volume novel by Mlle. de Scudéri.

6 " turned to the left." 
Jugez en cet état si je pouvais me plaire! Moi! qui ne compte rien ni le vin ni la chère, Si l'on n'est plus au large assis en un festin Qu'aux sermons ${ }^{1}$ de Cassagne, ${ }^{2}$ ou de l'abbé Cotin. ${ }^{8}$

Notre hôte, cependant, s'adressant à la troupe : "Que vous semble, a-t-il dit, du goût de cette soupe? Sentez-vous le citron, dont on a mis le jus Avec des jaunes d'œufs mêlés dans du verjus? Ma foi, vive Mignot ${ }^{4}$ et tout ce qu'il apprête! ” Les cheveux cependant me dressaient à la tête : Car Mignot, c'est tout dire, et dans le monde entier Jamais empoisonneur ne sut mieux son métier. J'approuvais tout pourtant de la mine et du geste, Pensant qu'au moins le vin dût réparer le reste. Pour m'en éclaircir donc, j'en demande ; et d'abord Un laquais effronté m'apporte un rouge-bord D'un Auvernat ${ }^{5}$ fumeux, qui, mêlé de Lignage, Se vendait chez Crenet $^{6}$ pour vin de l'Ermitage, Et qui, rouge et vermeil, mais fade et doucereux, N'avait rien qu'un goût plat et qu'un déboire affreux.

A peine ai-je senti cette liqueur traîtresse, Que de ces vins mêlés j'ai reconnu l'adresse. ${ }^{7}$ Toutefois, avec l'eau que j'y mets à foison, J'espérais adoucir la force du poison.

Mais, qui l'aurait pensé ? pour comble de disgrâce, Par le chaud qu'il faisait, nous n'avions point de glace! Point de glace, bon Dieu! dans le fort de l'été! $\mathrm{Au}$ mois de juin! Pour moi, j'étais si transporté, Que, donnant de fureur tout le festin au diable, Je me suis vu vingt fois prêt à quitter la table, Et, dût-on m'appeler et fantasque et bourru, J'allais sortir enfin, quand le rôt a paru.

Sur un lièvre, flanqué de six poulets étiques, S'élevaient trois lapins, animaux domestiques, Qui, dès leur tendre enfance élevés dans Paris, Sentaient encor le chou dont ils furent nourris :

1 The implication is that no one attended the sermons.

2 Jacques Cassagne (1636-1679), litterateur and preacher of secondary importance.

3 Charles Cotin (1604-1682), poet and preacher.

4 Jacques Mignot (1641-1731), a well-known caterer.

5 The Auvernat, Lignage, and Ermitage were three highly esteemed wines.

${ }^{6}$ Crenet kept the café called the Pomme de Pin, frequented by Boileau.

7 "artifice." 
Autour de cet amas de viandes entassées, Régnait un long cordon d'alouettes pressées ; Et, sur les bords du plat, six pigeons étalés Présentaient pour renfort leurs squelettes brûlés.

A côté de ce plat, paraissaient deux salades,

L'une, de pourpier jaune, et l'autre, d'herbes fades,

Dont l'huile de fort loin saisissait l'odorat,

Et nageait dans des flots de vinaigre rosat.

Tous mes sots, à l'instant, changeant de contenance,

Ont loué du festin la superbe ordonnance;

Tandis que mon faquin, qui se voyait priser,

Avec un ris moqueur les priait d'excuser.

Surtout certain hâbleur, à la gueule affamée,

Qui vint à ce festin conduit par la fumée,

Et qui s'est dit profès dans l'ordre des Coteaux, ${ }^{1}$

A fait, en bien mangeant, l'éloge des morceaux.

Je riais de le voir, avec sa mine étique,

Son rabat jadis blanc, et sa perruque antique,

En lapin de garenne ériger nos clapiers,

Et nos pigeons cauchois ${ }^{2}$ en superbes ramiers,

Et, pour flatter notre hôte, observant son visage,

Composer sur ses yeux son geste et son langage,

Quand notre hôte charmé, m'avisant sur ce point:

"Qu'avez-vous donc, dit-il, que vous ne mangez point?

Je vous trouve aujourd'hui l'âme tout inquiète,

Et les morceaux entiers restent sur votre assiette. . . .

Aimez-vous la muscade? On en a mis partout.

Ah! monsieur, ces poulets sont d'un merveilleux goût.

Ces pigeons sont dodus ; mangez, sur ma parole.

J'aime à voir aux lapins cette chair blanche et molle.

$\mathrm{Ma}$ foi! tout est passable, il faut le confesser,

Et Mignot aujourd'hui s'est voulu surpasser.

Quand on parle de sauce, il faut qu'on y raffine $;^{3}$

Pour moi, j'aime surtout que le poivre y domine:

J'en suis fourni, Dieu sait ! et j'ai tout Pelletier ${ }^{4}$

Roulé dans mon office en cornets de papier. »

A tous ces beaux discours, j'étais comme une pierre, Ou comme la statue est au Festin de Pierre $;^{5}$

1 The ordre des Coteaux was applied, in the seventeenth century, to those connoisseurs who, from the taste of the wine, claimed they could determine from what coteau, or vineyard, it came.

2 "of Caux" (Normandy).

3 "be exacting."

4 Pò̀te du dernier ordre, qui faisait tous les jours un sonnet (Boileau).

5 Molière's "Festin de Pierre" was first performed February 15, 1665. 
Et, sans dire un seul mot, j'avalais au hasard Quelque aile de poulet dont j'arrachais le lard. Cependant, mon hâbleur, avec une voix haute, Porte à mes campagnards la santé de notre hôte, Qui tous deux pleins de joie, en jetant un grand cri, Avec un rouge-bord acceptent son défi.

Un si galant exploit réveillant tout le monde,

On a porté partout des verres à la ronde, Où les doigts des laquais, dans la crasse tracés, T'émoignaient par écrit qu'on les avait rincés. Quand un des conviés, d'un ton mélancolique, Lamentant tristement une chanson bachique, Tous mes sots à la fois, ravis de l'écouter, Détonnant de concert, se mettent à chanter.

La musique sans doute était rare et charmante! L'un traîne en longs fredons ${ }^{1}$ une voix glapissante, Et l'autre, l'appuyant de son aigre fausset, Semble un violon faux qui jure sous l'archet.

Sur ce point, un jambon d'assez maigre apparence Arrive sous le nom de jambon de Mayence: ${ }^{2}$ Un valet le portait, marchant à pas comptés, Comme un recteur suivi des quatre facultés. ${ }^{3}$ Deux marmitons crasseux, revêtus de serviettes, Lui servaient de massiers, et portaient deux assiettes,

L'une, de champignons avec des ris de veau, Et l'autre, de pois verts, qui se noyaient dans l'eau. Un spectacle si beau surprenant l'assemblée, Chez tous les conviés la joie est redoublée, Et la troupe, à l'instant, cessant de fredonner, D'un ton gravement fou s'est mise à raisonner. Le vin au plus muet fournissant des paroles, Chacun a débité ses maximes frivoles, Réglé les intérêts de chaque potentat, Corrigé la police, et réformé l'État;

35 Puis, de là, s'embarquant dans la nouvelle guerre, A vaincu la Hollande ou battu l'Angleterre. ${ }^{4}$ Enfin, laissant en paix tous ces peuples divers, De propos en propos on a parlé de vers. 1 "trills."

2 The Mayence or Westphalian hams were held in high esteem.

3 The faculties of arts, medicine, law, and theology.

4 War between England and Holland broke out in 1665 . 


\section{LES PLAISIRS DES CHAMPS}

Oui, Lamoignon, ${ }^{1}$ je fuis les chagrins de la ville, Et contre eux la campagne est mon unique asile. Du lieu qui m'y retient veux-tu voir le tableau? C'est un petit village, ${ }^{2}$ ou plutôt un hameau, Bâti sur le penchant d'un long rang de collines, D'où l'œil s'égare au loin dans les plaines voisines.

La Seine, au pied des monts que son flot vient laver, Voit du sein de ses eaux. vingt îles s'élever, Qui, partageant son cours en diverses manières,

D'une rivière seule y forment vingt rivières.

Tous ses bords sont couverts de saules non plantés

Et de noyers, souvent du passant insultés.

Le village, au-dessus, forme un amphithéâtre:

L'habitant ne connaît ni la chaux ni le plâtre,

Et dans le roc, qui cède et se coupe aisément,

Chacun sait de sa main creuser son logement.

La maison du seigneur, seule, un peu plus ornée,

Se présente au dehors, de murs environnée;

Le soleil en naissant la regarde d'abord,

Et le mont la défend des outrages du Nord.

C'est là, cher Lamoignon, que mon esprit tranquille

Met à profit les jours que la Parque me file:

Ici, dans un vallon bornant tous mes désirs,

J'achète à peu de frais de solides plaisirs.

Tantôt, un livre en main, errant dans les prairies,

J'occupe ma raison d'utiles rêveries.

Tantôt, cherchant la fin d'un vers que je construi,

Je trouve au coin d'un bois le mot qui m'avait fui.

Quelquefois, aux appâts d'un hameçon perfide,

J'amorce en badinant le poisson trop avide ;

Ou, d'un plomb qui suit l'œil, et part avec l'éclair,

Je vais faire la guerre aux habitants de l'air.

Une table, au retour, propre et non magnifique,

Nous présente un repas agréable et rustique:

Là, sans s'assujettir aux dogmes du Broussain, ${ }^{3}$

Tout ce qu'on boit est bon, tout ce qu'on mange est sain;

La maison le fournit, la fermière l'ordonne ;

1 Chrestien-François de Lamoignon (1644-1709) was a member of Parliament and later président d mortier.

2 Hautile, near Roche-Guyon.

8 Broussain was well known for his culinary science. 
Et, mieux que Bergerat, ${ }^{1}$ l'appétit l'assaisonne. $O$ fortuné séjour! ô champs aimés des cieux! Que pour jamais, foulant vos prés délicieux, Ne puis-je ici fixer ma course vagabonde, Et, connu de vous seuls, oublier tout le monde!

Qu' heureux est le mortel, qui, du monde ignoré, Vit content de soi-même en un coin retiré; Que l'amour de ce rien qu'on nomme renommée N'a jamais enivré d'une vaine fumée; Qui de sa liberté forme tout son plaisir Et ne rend qu'à lui seul compte de son loisir! Il n'a point à souffrir d'affronts ni d'injustices, Et du peuple inconstant il brave les caprices. Mais, nous autres, faiseurs de livres et d'écrits, Sur les bords du Permesse ${ }^{2}$ aux louanges nourris, Nous ne saurions briser nos fers et nos entraves. Du lecteur dédaigneux honorables esclaves, Du rang où notre esprit une fois s'est fait voir, Sans un fâcheux éclat, nous ne saurions déchoir. Le public, enrichi du tribut de nos veilles, Croit qu'on doit ajouter merveilles sur merveilles; $\mathrm{Au}$ comble parvenus il veut que nous croissions; Il veut, en vieillissant, que nous rajeunissions ! Cependant tout décroît, et moi-même, à qui l'âge D'aucune ride encor n'a flétri le visage, Déjà moins plein de feu, pour animer ma voix, J'ai besoin du silence et de l'ombre des bois ; Ma muse, qui se plaît dans leurs routes perdues, Ne saurait plus marcher sur le pavé des rues; Ce n'est que dans ces bois, propres à m'exciter, Qu'Apollon quelquefois daigne encor m'écouter.

Ne demande donc plus par quelle humeur sauvage Tout l'été, loin de toi, demeurant au village, J'y passe obstinément les ardeurs du Lion, ${ }^{3}$

Et montre pour Paris si peu de passion.

C'est à toi, Lamoignon, que le rang, la naissance,

Le mérite éclatant, et la haute éloquence,

1 Fameux traiteur (Boileau).

2 Permessus, a river in Bœotia, consecrated to Apollo and the muses, was supposed to inspire poets.

3 The sun enters Leo in July. 
Appellent dans Paris aux sublimes emplois,

Qu'il sied bien d'y veiller pour le maintien des lois :

Tu dois là tous tes soins au bien de ta patrie;

'I'u ne t'en peux bannir que l'orphelin ne crie,

Que l'oppresseur ne montre un front audacieux;

Et 'Thémis ${ }^{1}$ pour voir clair a besoin de tes yeux.

Mais, pour moi, de Paris citoyen inhabile, Qui ne lui puis fournir qu'un rêveur inutile,

Il me faut du repos, des prés et des forêts.

Laisse-moi donc ici, sous leurs ombrages frais,

Attendre que septembre ait ramené l'automne,

Et que Cérès ${ }^{2}$ contente ait fait place à Pomone.

Quand Bacchus comblera de ses nouveaux bienfaits

Le vendangeur ravi de ployer sous le faix,

Aussitôt ton ami, redoutant moins la ville,

T'ira joindre à Paris, pour s'enfuir à Bâville.

Là, dans le seul loisir que 'Thémis t'a laissé,

Tu me verras souvent à te suivre empressé,

Pour monter à cheval rappelant mon audace,

Apprenti cavalier galoper sur ta trace.

Tantôt, sur l'herbe assis, au pied de ces coteaux

Où Polycrène ${ }^{4}$ épand ses libérales eaux,

Lamoignon, nous irons, libres d'inquiétude,

Discourir des vertus dont tu fais ton étude;

Chercher quels sont les biens véritables ou faux;

Si l'honnête homme en soi doit souffrir des défauts ;

Quel chemin le plus droit à la gloire nous guide,

Ou la vaste science, ou la vertu solide.

C'est ainsi que chez toi tu sauras m'attacher.

Heureux, si les fâcheux, prompts à nous y chercher,

N'y viennent point semer l'ennuyeuse tristesse!

Car, dans ce grand concours d'hommes de toute espèce,

Que sans cesse à Bâville attire le devoir,

$\mathrm{Au}$ lieu de quatre amis qu'on attendait le soir,

Quelquefois, de fâcheux arrivent trois volées

Qui du parc à l'instant assiègent les allées.

Alors, sauve qui peut! et quatre fois heureux Qui sait pour s'échapper quelque antre ignoré d'eux!

1 Goddess of justice.

— "Epître » VI

2 Ceres was goddess of the harvests, Pomona of the fruit trees.

3 The country residence of Lamoignon.

4 A spring near Bâville, thus named by Lamoignon. 


\section{RIEN N'EST BEAU QUE LE VRAI}

Sais-tu pourquoi mes vers sont lus dans les provinces, Sont recherchés du peuple et reçus chez les princes?

Ce n'est pas que leurs sons, agréables, nombreux,

Soient toujours à l'oreille également heureux,

Qu'en plus d'un lieu le sens n'y gêne la mesure,

Et qu'un mot quelquefois n'y brave la césure:

Mais c'est qu'en eux le vrai, du mensonge vainqueur,

Partout se montre aux yeux, et va saisir le cœur;

Que le bien et le mal y sont prisés au juste;

Que jamais un faquin n'y tint un rang auguste;

Et que mon cœur, toujours conduisant mon esprit,

$\mathrm{Ne}$ dit rien aux lecteurs qu'à soi-même il n'ait dit.

Ma pensée au grand jour partout s'offre et s'expose ;

Et mon vers, bien ou mal, dit toujours quelque chose.

I 5 C'est par là quelquefois que ma rime surprend ;

C'est là ce que n'ont point Jonas ${ }^{1}$ ni Childebrand,

$\mathrm{Ni}$ tous ces vains amas de frivoles sornettes,

Montre, Miroir d'amour, Amitiés, Amourettes,

Dont le titre souvent est l'unique soutien,

Et qui, parlant beaucoup, ne disent jamais rien.

Mais peut-être, enivré des vapeurs de ma muse,

Moi-même en ma faveur, Seignelay, ${ }^{2}$ je m'abuse;

Cessons de nous flatter : il n'est esprit si droit

Qui ne soit imposteur et faux par quelque endroit.

Sans cesse on prend le masque, et quittant la nature,

On craint de se montrer sous sa propre figure.

Par là le plus sincère assez souvent déplaît.

Rarement un esprit ose être ce qu'il est.

Vois-tu cet importun que tout le monde évite,

Cet homme à toujours fuir, qui jamais ne vous quitte?

Il n'est pas sans esprit; mais, né triste et pesant,

Il veut être folâtre, évaporé, plaisant ;

Il s'est fait de sa joie une loi nécessaire ;

Et ne déplaît enfin que pour vouloir trop plaire.

La simplicité plaît sans étude et sans art.

1 Productions of some of the authors whom Boileau helped to bring into disrepute. "Jonas" was by Coras; "Childebrand" by Carel de Sainte-Garde; "Montre" by Bonnecorse ; "Miroir d'amour" by Perrault ; "Amitiés" and "Amourettes" by Le Pays.

2 Jean-Baptiste Colbert, marquis de Seignelay $\left(165^{1-1690}\right)$, son of the great Colbert, was minister of marine and secretary of state. This Epître was addressed to him. 
Tout charme en un enfant, dont la langue sans fard.

A peine du filet encor débarrassée,

Sait d'un air innocent bégayer sa pensée.

Le faux est toujours fade, ennuyeux, languissant.

Mais la nature est vraie, et d'abord on la sent;

C'est elle seule en tout qu'on admire et qu'on aime.

Un esprit né chagrin plaît par son chagrin même.

Chacun, pris dans son air, est agréable en soi :

Ce n'est que l'air d'autrui qui peut déplaire en moi.

Ce marquis était né doux, commode, agréable ;

On vantait en tous lieux son ignorance aimable:

Mais, depuis quelques mois, devenu grand docteur,

Il a pris un faux air, une sotte hauteur;

Il ne veut plus parler que de rime et de prose;

Des auteurs décriés il prend en main la cause;

Il rit du mauvais goût de tant d'hommes divers,

Et va voir l'opéra seulement pour les vers.

Voulant se redresser, soi-même on s'estropie,

Et d'un original on fait une copie.

L'ignorance vaut mieux qu'un savoir affecté.

Rien n'est beau, je reviens, que par la vérité :

C'est par elle qu'on plait et qu'on peut longtemps plaire.

L'esprit lasse aisément si le cœur n'est sincère.

En vain, par sa grimace, un bouffon odieux

A table nous fait rire et divertit nos yeux;

Ses bons mots ont besoin de farine et de plâtre.

Prenez-le tête à tête, ôtez-lui son théâtre,

Ce n'est plus qu'un cœur bas, un coquin ténébreux;

Son visage essuyé n'a plus rien que d'affreux.

J'aime un esprit aisé qui se montre, qui s'ouvre,

Et qui plaît d'autant plus que plus il se découvre.

Mais la seule vertu peut souffrir la clarté :

Le vice, tơjours sombre, aime l'obscurité ;

Pour paraitre au grand jour il faut qu'il se déguise;

C'est lui qui de nos mœurs a banni la franchise.

Jadis l'homme vivait au travail occupé,

Et, ne trompant jamais, n'était jamais trompé :

On ne connaissait point la ruse et l'imposture;

Le Normand même ${ }^{1}$ alors ignorait le parjure;

1 The Normans were looked upon as cunning and deceitful. 
Aucun rhéteur encore, arrangeant le discours, N'avait d'un art menteur enseigné les détours. Mais sitôt qu'aux humains, faciles à séduire, L'abondance eut donné le loisir de se nuire,

La mollesse amena la fausse vanité ;

Chacun chercha pour plaire un visage emprunté.

Pour éblouir les yeux, la fortune arrogante

Affecta d'étaler une pompe insolente;

L'or éclata partout sur les riches habits;

On polit l'émeraude, on tailla le rubis :

Et la laine et la soie, en cent façons nouvelles, Apprirent à quitter leurs couleurs naturelles. La trop courte beauté monta sur des patins; La coquette tendit ses lacs tous les matins;

Et, mettant la céruse et le plâtre en usage, Composa de sa main les fleurs de son visage.

L'ardeur de ș'enrichir chassa la bonne foi ; Le courtisan n'eut plus de sentiments à soi.

Tout ne fut plus que fard, qu'erreur, que tromperie;

On vit partout régner la basse flatterie.

Le Parnasse surtout, fécond en imposteurs,

Diffama le papier par ses propos menteurs.

De là vient cet amas d'ouvrages mercenaires, Stances, odes, sonnets, épîtres liminaires,

25 Où toujours le héros passe pour sans pareil, Et, fût-il louche et borgne, est réputé soleil.

Ne crois pas toutefois, sur ce discours bizarre, Que d'un frivole encens malignement avare, J'en veuille sans raison frustrer tout l'univers.

La louange agréable est l'âme des beaux vers;

Mais je tiens, comme toi, qu'il faut qu'elle soit vraie, Et que son tour adroit n'ait rien qui nous effraie. 


\title{
MARIE DE RABUTIN-CHANTAL, MARQUISE DE SÉVIGNÉ
}

\author{
Paris, I 626-i 696, Grignan
}

Marie de Rabutin-Chantal lost her mother and her father, who was a baron, when she was very young. Her education, however, was most carefully looked after by an uncle, who likewise managed her patrimony with scrupulous integrity and intelligence. In 1644 she married the marquis de Sévigné, of an old Breton family, but not a good husband. He was killed in a duel in 1651 , leaving to his wife the care of an infant son and daughter. Henceforth her whole life's interest was in her children, particularly in her daughter, who in 1669 married the count de Grignan. Two years later (I67I) Madame de Grignan followed her husband to Provence, where he was lieutenant general, and it was then that Madame de Sévigné began to write to her daughter those letters which, with the letters written to other relatives and friends, give her such a high position in literature. She died of smallpox in 1696 at her daughter's home.

\section{UN COURTISAN}

\section{A MONSIEUR DE POMPONE 1}

\section{Lundi i ${ }^{\text {er }}$ décembre ( 1664 )}

Il faut que je vous conte une petite historiette, qui est très vraie, et qui vous divertira. Le Roi se mêle depuis peu de faire des vers; MM. de Saint-Aignan ${ }^{2}$ et Dangeau ${ }^{8}$ lui apprennent comme il s'y faut prendre. Il fit l'autre jour un petit madrigal, que lui-même ne trouva pas trop joli. Un matin il dit au maréchal de Gramont ${ }^{4}$ : "Monsieur le maréchal, je vous prie, lisez ce petit madrigal, et voyez si vous en avez jamais vu un si impertinent. Parce qu'on sait que depuis peu j'aime les vers, on m'en apporte de toutes les façons. » Le maréchal, après avoir lu, dit au Roi: "Sire, Votre Majesté juge divinement bien de toutes ro choses : il est vrai que voilà le plus sot et le plus ridicule madrigal que

1 Simon Arnauld, marquis de Pompone, minister of foreign affairs (1671), was exiled (1662) as a friend of Fouquet.

2 François de Beauvilliers, duc de Saint-Aignan (1607-1687), was a member of the Academy and author of occasional verse.

3 Author of the "Journal."

4 The duc de Gramont was made marshal of France in 1641 . 
j'aie jamais lu. » Le Roi se mit à rire, et lui dit : " N'est-il pas vrai que celui qui l'a fait est bien fat? - Sire, il n'y a pas moyen de lui donner un autre nom. - Oh bien! dit le Roi, je suis ravi que vous m'en ayez parlé si bonnement; c'est moi qui l'ai fait. — Ah! Sire, quelle 5 trahison! Que Votre Majesté me le rende; je l'ai lu brusquement. - Non, Monsieur le maréchal: les premiers sentiments sont toujours les plus naturels. " Le Roi a fort ri de cettel folie, et tout le monde trouve que voilà la plus cruelle petite chose que l'on puisse faire à un vieux courtisan. Pour moi, qui aime toujours à faire des réflexions, ro je voudrais que le Roi en fît là-dessus, et qu'il jugeât par là combien il est loin de connaître jamais la vérité.

\section{APRÈS UNE SÉPARATION}

A MADAME DE GRIGNAN

\section{A Livry, ${ }^{1}$ mardi saint $24^{\mathrm{e}}$ mars (167 I)}

Voici une terrible causerie, ma chère bonne; il y a trois heures que je suis ici. Je suis partie de Paris avec l'abbé, ${ }^{2}$ Hélène, Hébert et I 5 Marphise, dans le dessein de me retirer ici du monde et du bruit jusqu'à jeudi au soir. Je prétends être en solitude; je fais de ceci une petite Trappe ${ }^{3}$ je veux y prier Dieu, y faire mille réflexions. J'ai dessein d'y jeûner beaucoup par toutes sortes de raisons; marcher pour tout le temps que j'ai été dans ma chambre, et sur le tout m'en20 nuyer pour l'amour de Dieu. Mais, ma pauvre bonne, ce que je ferai beaucoup mieux que tout cela, c'est de penser à vous. Je n'ai pas encore cessé depuis que je suis arrivée, et ne pouvant contenir tous mes sentiments sur votre sujet, je me suis mise à vous écrire au bout de cette petite allée sombre que vous aimez, assise sur ce siège de 25 mousse où je vous ai vue quelquefois couchée. Mais, mon Dieu, où ne vous ai-je point vue ici ? et de quelle façon toutes ces pensées me traversent-elles le cœur? Il n'y a point d'endroit, point de lieu, ni dans la maison, ni dans l'église, ni dans ce pays, ni dans ce jardin, où je ne vous aie vue; il n'y en a point qui ne me fasse souvenir de 30 quelque chose; et de quelque façon que ce soit aussi, cela me perce

1 A small village near the forest of Bondy near Paris.

2 Her uncle, Christophe de Coulanges, abbé de Livry. Hélène was Madame de Sévigné's maid; Hébert's position in the household is not known; Marphise was the dog.

$3 \mathrm{~A}$ severe religious order founded in 1140 and reformed in 1662 . 
le cœur. Je vous vois, vous m'êtes présente; je pense et repense à tout; ma tête et mon esprit se creusent: mais j'ai beau tourner, j'ai beau chercher; cette chère enfant que j'aime avec tant de passion est à deux cents lieues, je ne l'ai plus. Sur cela je pleure sans pouvoir m'en empêcher; je n'en puis plus, ma chère bonne: voilà qui est bien faible, mais pour moi, je ne sais point être forte contre une tendresse si juste et si naturelle. Je ne sais en quelle disposition vous serez en lisant cette lettre. Le hasard peut faire qu'elle viendra mal à propos, et qu'elle ne sera peut-être pas lue de la manière qu'elle est écrite. A cela je ne sais point de remède; elle sert toujours à me 10 soulager présentement; c'est tout ce que je lui demande. L'état où ce lieu-ci m'a mise est une chose incroyable. Je vous prie de ne me point parler de mes faiblesses; mais vous devez les aimer et respecter mes larmes, qui viennent d'un cœur tout à vous.

Jeudi saint $26^{\mathrm{e}}$ mars 15

Si j'avais tant pleuré mes péchés que j'ai pleuré pour vous depuis que je suis ici, je serais fort bien disposée pour faire mes pâques et mon jubilé. ${ }^{1}$ J'ai passé ici le temps que j'avais résolu, de la manière dont je l'avais imaginé, à la réserve de votre souvenir, qui m'a plus tourmentée que je ne l'avais prévu. C'est une chose étrange qu'une 20 imagination vive, qui représente toutes choses comme si elles étaient encore : sur cela on songe au présent, et quand on a le cour comme je l'ai, on se meurt. Je ne sais où me sauver de vous : notre maison de Paris m'assomme encore tous les jours, et Livry m'achève. Pour vous, c'est par un effet de mémoire que vous pensez à moi : la Pro- 25 vence n'est point obligée de me rendre à vous, comme ces lieux-ci doivent vous rendre à moi. J'ai trouvé de la douceur dans la tristesse que j'ai eue ici : une grande solitude, un grand silence, un office triste, des ténèbres chantées avec dévotion (je n'avais jamais été à Livry la semaine sainte), un jeûne canonique, et une beauté dans ces jardins, 3o dont vous seriez charmée: tout cela m'a plu. Hélas! que je vous y ai souhaitée! Quelque difficile que vous soyez sur les solitudes, vous auriez été contente de celle-ci; mais je m'en retourne à Paris par nécessité; j'y trouverai de vos lettres, et je veux demain aller à la Passion du P. Bourdaloue ou du P. Mascaron $;^{2}$ j'ai toujours honoré 35

1 To do one's jubilee is to perform certain practices in order to obtain special indulgence.

2 Jules Mascaron (1634-1703), a distinguished preacher, bishop of Tulle and Agen. 
les belles passions. Adieu, ma chère Comtesse: voilà ce que vous aurez de Livry; j'achèverai cette lettre à Paris. Si j'avais eu la force de ne vous point écrire d'ici, et de faire un sacrifice à Dieu de tout ce que j'y ai senti, cela vaudrait mieux que toutes les pénitences du 5 monde ; mais, au lieu d'en faire un bon usage, j'ai cherché de la consolation à vous en parler: ah! ma bonne, que cela est faible et misérable!

\section{MORT DE TURENNE}

\section{A MADAME DE GRIGNAN}

A Paris, mercredi $28^{\mathrm{e}}$ août $\left(\mathrm{I}^{6} 75\right)$.

Si l'on pouvait écrire tous les jours, je le trouverais fort bon; et souvent je trouve le moyen de le faire, quoique mes lettres ne partent Io pas. Le plaisir d'écrire est uniquement pour vous; car à tout le reste du monde, on voudrait avoir écrit, et c'est parce qu'on le doit. Vraiment, ma fille, je m'en vais bien vous parler encore de M. de Turenne. ${ }^{1}$ $\mathrm{M}^{\mathrm{me}} \mathrm{d}^{\prime}$ Elbeuf, ${ }^{2}$ qui demeure pour quelques jours chez le cardinal de Bouillon, ${ }^{3}$ me pria hier de dîner avec eux deux, pour parler de leur

I 5 affliction. $M^{\text {me }}$ de la Fayette y était. Nous fîmes bien précisément ce que nous avions résolu : les yeux ne nous séchèrent pas. Elle avait un portrait divinement bien fait de ce héros, et tout son train était arrivé à onze heures : tous ces pauvres gens étaient fondus en larmes, et déjà tous habillés de deuil. Il vint trois gentilshommes, qui pensèrent 20 mourir de voir ce portrait: c'étaient des cris qui faisaient fendre le cœur; ils ne pouvaient prononcer une parole; ses valets de chambre, ses laquais, ses pages, ses trompettes, tout était fondu en larmes et faisait fondre les autres. Le premier qui put prononcer une parole répondit à nos tristes questions: nous nous fîmes raconter sa mort.

25 Il voulait se confesser le soir, et en se cachotant il avait donné les ordres pour le soir, et devait communier le lendemain, qui était le dimanche. Il croyait donner la bataille, et monta à cheval à deux heures le samedi, après avoir mangé. Il avait bien des gens avec lui : il les laissa tous à trente pas de la hauteur où il voulait aller. Il 30 dit au petit d'Elbeuf : ${ }^{4}$ " Mon neveu, demeurez là, vous ne faites que tourner autour de moi, vous me feriez reconnaître.) Il trouva $\mathrm{M}$.

1 Turenne (1611-1675) was marshal of France and one of her greatest military heroes.

2 A niece of Turenne, sister of the duc de Bouillon, second wife of the duc d'Elbeuf.

3 Brother of the duc de Bouillon, nephew of Turenne.

4 Son of Madame d'Elbeuf, at this time only fourteen years of age. 
d'Hamilton ${ }^{1}$ près de l'endroit où il allait, qui lui dit: "Monsieur, venez par ici ; on tirera où vous allez. - Monsieur, lui dit-il, je m'y en vais: je ne veux point du tout être tué aujourd'hui; cela scra le mieux du monde." Il tournait son cheval, il aperçut Saint-Hilaire, ${ }^{2}$ qui lui dit le chapeau à la main: "Jetez les yeux sur cette batterie que j'ai fait mettre là." Il retourne deux pas, et sans être arrêté il reçut le coup qui emporta le bras ct la main qui tenaient le chapeau de Saint-Hilaire, et perça le corps après avoir fracassé le bras de ce héros. Ce gentilhomme le regardait toujours; il ne le voit point tomber; le cheval l'emporta où il avait laissé le petit d'Elbeuf; il ıo n'était point encore tombé, mais il était penché le nez sur l'arçon: dans ce moment, le cheval s'arrête; il tomba entre les bras de ses gens ; il ouvrit deux fois de grands yeux et la bouche, et puis demeura tranquille pour jamais : songez qu'il était mort et qu'il avait une partie du cœur emportée. On crie, on pleure; M. d'Hamilton fait cesser ce i 5 bruit et ôter le petit d'Elbeuf, qui était jeté sur ce corps, qui ne le voulait pas quitter et qui se pâmait de crier. On jette un manteau; on le porte dans une haie; on le garde à petit bruit; un carrosse vient; on l'emporte dans sa tente: ce fut là où M. de Lorges, M. de Roye, ${ }^{3}$ et beaucoup d'autres pensèrent mourir de douleur; mais il fallut se faire 20 violence et songer aux grandes affaires qu'il avait sur les bras. On lui a fait un service militaire dans le camp, où les larmes et les cris faisaient le véritable deuil: tous les officiers pourtant avaient des écharpes de crêpe; tous les tambours en étaient couverts, qui ne frappaient qu'un coup; les piques traînantes et les mousquets renversés ; mais ces cris 25 de toute une armée ne se peuvent pas représenter, sans que l'on n'en soit ému. Ses deux véritables neveux ${ }^{4}$ (car pour l'aîné, ${ }^{5}$ il faut le dégrader) étaient à cette pompe, dans l'état que vous pouvez penser. M. de Roye tout blessé s'y fit porter; car cette messe ne fut dite que quand ils eurent repassé le Rhin. Je pense que le pauvre chevalier 30 était bien abîmé de douleur. Quand ce corps a quitté son armée, ç'a été encore une autre désolation; partout où il a passé, ç'a été des clameurs ; mais à Langres ils se sont surpassés: ils allèrent tous audevant de lui, tous habillés de deuil, au nombre de plus de deux cents,

1 A field marshal, killed 1676 .

2 Son of a cobbler, lieutenant general in the artillery.

3 Both were nephews of Turenne. The duc de Lorges was marshal of France and took command of the forces after the death of his uncle.

4 The comte de Lorges and the comte de Roye.

5 The duc de Bouillon, or the duc de Duras. 
suivis du peuple; tout le clergé en cérémonie; ils firent dire un service solennel dans la ville, et en un moment se cotisèrent tous pour cette dépense, qui monte à cinq mille francs, parce qu'ils reconduisirent le corps jusqu'à la première ville, et voulurent défrayer tout le train. Que

5 dites-vous de ces marques naturelles d'une affection fondée sur un mérite extraordinaire? Il arrive à Saint-Denis ce soir ou demain; tous ses gens l'allaient reprendre à deux lieues d'ici; il sera dans une chapelle en dépôt, ${ }^{1}$ en attendant qu'on prépare la chapelle. Il y aura un service, en attendant celui de Notre-Dame, qui sera solennel.

\section{UN PRINTEMPS}

\section{A MADAME DE GRIGNAN}

Aux Rochers, ${ }^{2}$ mercredi ${ }^{1} 9^{\mathrm{e}}$ avril ( $\mathrm{I} 690$ ).

Je reviens encore à vous, ma bonne, pour vous dire que si vous avez envie de savoir, en détail, ce que c'est qu'un printemps, il faut venir à moi. Je n'en connaissais moi-même que la superficie; j'en examine cette année jusqu'aux premiers petits commencements. Que pensez-

I 5 vous donc que ce soit que la couleur des arbres depuis huit jours? répondez. Vous allez dire : “Du vert. » Point du tout, c'est du rouge. Ce sont de petits boutons, tout prêts à partir, qui font un vrai rouge ; et puis ils poussent tous une petite feuille, et comme c'est inégalement, cela fait un mélange trop joli de vert et de rouge. Nous couvons tout cela des yeux; nous parions de grosses sommes, - mais c'est à ne jamais payer - que ce bout d'allée sera tout vert dans deux heures; on dit que non: on parie. Les charmes ont leur manière, les hêtres une autre. Enfin, je sais sur cela toụt ce que l'on peut savoir.

\section{A MADAME DE GRIGNAN}

Aux Rochers, ce $26^{\mathrm{e}}$ avril ( 1690 ).

25 Il fait un temps merveilleux, Dieu merci. J'ai si bien fait, que le printemps est achevé : tout est vert. Je n'ai pas eu de peine à faire pousser tous ces boutons, à faire changer le rouge en vert. Quand j'ai eu fini tous ces charmes, il a fallu aller aux hêtres, puis aux chênes; c'est ce qui m'a donné le plus de peine, et j'ai besoin encore de huit

2 Country residence of Madame de Sévigné near Vitré. 
jours pour n'avoir plus rien à me reprocher. Je commence à jouir de toutes mes fatigues, et je crois, tout de bon, que non seulement je n'ai pas nui à toutes ces beautés, mais qu'en cas de besoin je saurais fort bien faire un printemps, tant je me suis appliquée à regarder, à observer, à épiloguer celui-ci, ce que je n'avais jamais fait avec tant d'exactitude. Je dois cette capacité à mon grand loisir, et, en vérité, ma chère bonne, c'est la plus jolie occupation du monde. C'est dommage, qu'en me mettant si fort dans cette belle jeunesse, il ne m'en soit demeuré quelque chose ;

Mais, hélas! quand l'âge nous glace,

Nos beaux jours ne reviennent jamais! 1

Cela est triste; mais j'aime à me donner quelquefois de ces coups de patte, pour mortifier mon imagination, qui est encore toute pleine de bagatelles et des agréments où il faudrait renoncer, quoiqu'on les appelle innocents. J'en prends à témoin M. de la Garde, ${ }^{2}$ qui renoncera ${ }_{15}$ à Pauline ${ }^{3}$ même, au premier jour. Je suis bien loin de cette perfection, et je vous aime encore trop, ma chère bonne, pour oser me vanter de plaire à saint Augustin.

1 From Molière's "Pastorale comique," 6th entrée.

2 The marquis de la Garde was a cousin of M. de Grignan.

3 Pauline de Grignan, later marquise de Simiane, daughter of Madame de Grignan. 


\section{MARIE-MADELEINE DE LA VERGNE COMTESSE DE LA FAYETTE}

Paris, I634-I693, Paris

Madame de La Fayette was one of the most learned women of her age, particularly in the languages and literatures, which she studied under Ménage. She possessed also rare good sense and judgment. At the age of twenty-two she married the comte de La Fayette, whom she apparently did not find congenial, since they soon dropped out of each other's lives. She did not, however, lack friends, the duchess of Orleans, Madame de Sévigné, Huet, Segrais, La Fontaine, and especially La Rochefoucauld being in the number. The first of her two most important novels, "Zayde," appeared in I670 under the name of Segrais. Her masterpiece, "La Princesse de Clèves," came out eight years later anonymously. It was particularly in this last work, the first piece of French fiction which conforms to the scope of the modern novel, that Madame de La Fayette showed the keen precision of her psychological analysis and the sober dignity and clearness of her style.

\section{MORT DE HENRI II}

Enfin le jour du tournoi arriva. Les reines ${ }^{1}$ se rendirent dans les galeries et sur les échafauds qui leur avaient été destinés. Les quatre tenants parurent au bout de la lice, avec une quantité de chevaux et de livrées, qui faisaient le plus magnifique spectacle qui eût jamais 5 paru en France.

Le roi ${ }^{2}$ n'avait point d'autres couleurs que le blanc et le noir, qu'il portait toujours à cause de madame de Valentinois, ${ }^{3}$ qui était veuve. M. de Ferrare ${ }^{4}$ et toute sa suite avaient du jaune et du rouge. M. de Guise ${ }^{5}$ parut avec de l'incarnat et du blanc: on ne savait d'abord par Io quelle raison il avait ces couleurs, mais on se souvint que c'étaient celles d'une belle personne qu'il ávait aimée pendant qu'elle était fille,

1 Queen Catherine de Medici, wife of Henri II ; and Mary Stuart, the Reine Dauphine, wife of the Dauphin, later François II.

2 Henri II.

${ }^{3}$ Diana of Poitiers (1499-1566), mistress of Henri II, over whom she wielded a great influence.

4 The duc de Ferrara, cousin of Henri II, and a great favorite at court.

5 The duc de Guise (1519-1563), the Balafré, a well-known general and statesman. 
et qu'il aimait encore, quoiqu'il n'osât plus le lui faire paraitrc. M. de Nemours ${ }^{1}$ avait du jaune et du noir; on en chercha inutilement la raison. Madame de Clèves ${ }^{2}$ n'eut pas de peine à la deviner: elle se souvint d'avoir dit devant lui qu'elle aimait le jaune, et qu'elle était fâchée d'être blonde, parce qu'elle n'en pouvait mettre. Ce prince ${ }^{3}$ crut pouvoir paraitre avec cette couleur sans indiscrétion : puisque madame de Clèves n'en mettant point, on ne pouvait soupçonner que ce fût la sienne.

Jamais on n'a fait voir tant d'adresse que les quatre tenants en firent paraître. Quoique le roi fût le meilleur homme de cheval de ıo son royaume, on ne savait à qui donner l'avantage. M. de Nemours avait un agrément dans toutes ses actions qui pouvait faire pencher en sa faveur des personnes moins intéressées que madame de Clèves. Sitôt qu'elle le vit paraitre au bout de la lice, elle sentit une émotion extraordinaire; et à toutes les courses de ce prince elle avait de la 15 peine à cacher sa joie lorsqu'il avait heureusement fourni sa carrière. ${ }^{4}$

Sur le soir, comme tout était presque fini, et que l'on était près de se retirer, le malheur de l'Etat fit que le roi voulut encore rompre une lance. Il manda au comte de Montgomery, ${ }^{5}$ qui était extrêmement adroit, qu'il se mît sur la lice. Le comte supplia le roi de l'en dis- 20 penser, et allégua toutes les excuses dont il put s'aviser; mais le roi, quasi en colère, lui fit dire qu'il le voulait absolument.

La reine manda au roi qu'elle le conjurait de ne plus courir; qu'il avait si bien fait qu'il devait être content, et qu'elle le suppliait de revenir auprès d'elle.

Le roi répondit que c'était pour l'amour d'elle qu'il allait courir encore, et entra dans la barrière. Elle lui renvoya M. de Savoie, ${ }^{6}$ pour le prier une seconde fois de revenir; mais tout fut inutile. Il courut; les lances se brisèrent, et un éclat de celle du comte de Montgomery lui donna dans l'œil et y demeura. Ce prince tomba du coup. Ses 30 écuyers et M. de Montmorency, ${ }^{7}$ qui était un des maréchaux de camp, coururent à lui. Ils furent étonnés de le voir si blessé ; mais le roi ne s'étonna point. Il dit que c'était peu de chose, et qu'il pardonnait au

1 The duc de Nemours ( $153^{1-1585}$ ), an able and elegant soldier and courtier.

2 The princesse de Clèves, wife of $M$. de Clèves, but in love with, and loved by, M. de Nemours. 8 De Nemours. 4 "run over the course."

5 After the death of Henri II he retired for a time and then became a prominent Huguenot leader.

6 Husband of Madame, Marguerite de France, sister of Henri II.

7 M.de Montmorency $\left(149^{2-1567)}\right.$ was a distinguished marshal of France and constable. 
comte de Montgomery. On peut juger quel trouble et quelle affliction apporta un accident aussi funeste dans une journée destinée à la joie. Sitôt que l'on eut porté le roi dans son lit, et que les chirurgiens eurent visité sa plaie, ils la trouvèrent très considérable.

$5 \quad$ M. le connétable ${ }^{1}$ se souvint, dans ce moment, de la prédiction que l'on avait faite au roi, qu'il serait tué dans un combat singulier; et il ne douta pas que la prédiction ne fût accomplie.

Le roi d'Espagne, ${ }^{2}$ qui était alors à Bruxelles, étant averti de cet accident, envoya son médecin, qui était un homme d'une grande répuıo tation; mais il jugea le roi sans espérance. . . .

Le mal du roi se trouva si considérable, que le septième jour il fut désespéré des médecins. Il reçut la certitude de sa mort avec une fermeté extraordinaire, et d'autant plus admirable, qu'il perdait la vie par un accident si malheureux, qu'il mourait à la fleur de son âge, I 5 heureux, adoré de ses peuples....

" La Princesse de Clèves », Part third

1 de Montmorency.

2 Philip II. 


\section{JEAN RACINE}

\section{La Ferté-Milon, I639- I699, Paris}

Racine was left an orphan when a mere child and was cared for by his grandparents. When about ten years of age he began his studies at the college at Beauvais; six years later he entered Port-Royal des Champs, where, under the Jansenist masters, he acquired a knowlege of the classics, especially of Greek. He was at first intended for the law. His inclinations, however, turned him to literature, and, after trying his hand at a few odes (particularly "La nymphe de la Seine" (1660), written on the occasion of the king's marriage), a few sonnets, and other lighter forms of verse, he attempted writing for the stage. At this, Port-Royal and some of his relatives were horrified, and the young poet was sent to Uzès in the south of France, to an uncle who was vicar-general of the diocese, and who, it was hoped, might secure a benefice for him. But his sojourn at Uzès did not prevent his writing verses and dreaming of Paris, whither he went in $166_{3}$, more than ever determined to follow his literary bent. He became acquainted with La Fontaine, Boileau, and Molière, whose theatrical company played his "Thébaïde " ( 1664 ), and his "Alexandre" (1665). A complete rupture with his old masters of Port-Royal came soon after the representation of these pieces, as did also a break in the friendship of Molière, from whose theater Racine withdrew the "Alexandre "after the sixth performance, taking it and also Mlle. du Parc, Molière's best actress, to the rival theater, the Hôtel de Bourgogne.

"Andromaque," played in 1667 , the first of his great masterpieces, had a success which rivaled that of "Le Cid" in 1636 . In the working out of this play, as in most of his other plays, love assumes an importance not hitherto known in French drama. "Les plaideurs," a comedy, appeared in 1668, "Britannicus" in 1669, "Bérénice" in 1670, "Bajazet" in 1672, "Mithridate" in 1673 , "Iphigénie " in 1674 , "Phèdre " in I 677. The growing success of his plays rather aroused than quieted the opposing factions, composed mainly of friends of the aged Corneille or enemies of Boileau, and, after "Phèdre," in 1677 , Racine determined to renounce writing for the stage. In the same year he made his peace with Port-Royal, married, and was, with Boileau, appointed historiographer to the king.

He produced nothing more for the stage until r689, when, asked by Madame de Maintenon to write a play for the girls' school at Saint-Cyr, he wrote the first of his two Biblical plays, "Esther." Two years later "Athalie" was modestly, and not very successfully, given at the same school. Sensitive to the failure of "Athalie," and with his disfavor at court increasing in measure as he became more closely attached to Port-Royal and Jansenism, Racine lived in retirement from 1691 until his death in 1699 . He had been a member of the Academy since 1673 . 


\section{ANDROMAQUE}

I

Pyrrhus, Andromaque, Phonix, Céphise ${ }^{1}$

PYRRHUS, a Phonix

Où donc est la princesse?

Ne m'avais-tu pas dit qu'elle était en ces lieux?

Je le croyais.

$$
\text { PHAENIX }
$$

\section{ANDROMAQUE, à Céphise}

$\mathrm{Tu}$ vois le pouvoir de mes yeux. PYRRHUS

Que dit-elle, Phœnix ?

\section{ANDROMAQUE}

Hélas! tout m'abandonne.

\section{PHCENIX}

Allons, Seigneur, marchons sur les pas d'Hermione.

\section{CÉPHISE}

Qu'attendez-vous? rompez ce silence obstiné.

$$
\text { ANDROMAQUE }
$$

Il a promis mon fils.

$$
\begin{aligned}
& \text { CÉPHISE } \\
& \text { Il ne l'a pas donné. }
\end{aligned}
$$

\section{ANDROMAQUE}

Non, non, j'ai beau pleurer, sa mort est résolue.

\section{PYRRHUS}

Daigne-t-elle sur nous tourner au moins la vue?

\section{ANDROMAQUE}

Sortons.

$$
\text { Je ne fais que l'irriter encor. }
$$

1 Andromaque, widow of Hector, faithful to the memory of her husband, refuses the hand of Pyrrhus, king of Epirus. In order to induce her to marry him, Pyrrhus threatens to deliver her son Astyanax to the Greeks, who desire to kill him. 
PYRRHUS

Allons aux Grecs livrer le fils d'Hector.

ANDROMAQUE

Ah! Seigneur, arrêtez ! Que prétendez-vous faire?

$\mathrm{Si}$ vous livrez le fils, livrez-leur donc la mère.

Vos serments m'ont tantôt juré tant d'amitié!

Dieux! ne pourrai-je au moins toucher votre pitié ?

Sans espoir de pardon m'avez-vous condamnée?

\section{PYRRHUS}

Phœnix vous le dira, ma parole est donnée.

\section{ANDROMAQUE}

Vous qui braviez pour moi tant de périls divers!

\section{PYRRHUS}

J'étais aveugle alors : mes yeux se sont ouverts.

Sa grâce à vos désirs pouvait être accordée ;

Mais vous ne l'avez pas seulement demandée.

C'en est fait.

\section{ANDROMAQUE}

Ah! Seigneur, vous entendiez assez

Des soupirs qui craignaient de se voir repoussés.

Pardonnez à l'éclat d'une illustre fortune

Ce reste de fierté qui craint d'être importune.

Vous ne l'ignorez pas: Andromaque, sans vous,

N'aurait jamais d'un maître embrassé les genoux.

\section{PYRRHUS}

Non, vous me haïssez; et dans le fond de l'âme

Vous craignez de devoir quelque chose à ma flamme.

Ce fils même, ce fils, l'objet de tant de soins,

Si je l'avais sauvé, vous l'en aimeriez moins.

La haine, le mépris, contre moi tout s'assemble ;

Vous me haïssez plus que tous les Grecs ensemble. Jouissez à loisir d'un si noble courroux.

Allons, Phœenix.

ANDROMAQUE

Allons rejoindre mon époux.

Madame ... CÉPHISE 


\section{ANDROMAQUE}

Et que veux-tu que je lui dise encore?

Auteur de tous mes maux, crois-tu qu'il les ignore?

Seigneur, voyez l'état où vous me réduisez.

J'ai vu mon père mort, et nos murs embrasés ;

J'ai vu trancher les jours de ma famille entière,

Et mon époux sanglant traîné sur la poussière,

Son fils, seul avec moi, réservé pour les fers.

Mais que ne peut un fils? Je respire, je sers.

J'ai fait plus: je me suis quelquefois consolée

Io . Qu'ici, plutôt qu'ailleurs, le sort m'eût exilée;

Qu'heureux dans son malheur, le fils de tant de rois,

Puisqu'il devait servir, fût tombé sous vos lois.

J'ai cru que sa prison deviendrait son asile.

Jadis Priam soumis fut respecté d'Achille ${ }^{\mathbf{1}}$ :

I5 J'attendais de son fils encor plus de bonté.

Pardonne, cher Hector, à ma crédulité.

Je n'ai pu soupçonner ton ennemi d'un crime;

Malgré lui-même enfin je l'ai cru magnanime.

$\mathrm{Ah}$ ! s'il l'était assez pour nous laisser du moins

Au tombeau qu'à ta cendre ont élevé mes soins,

Et que finissant là ma haine et nos misères,

Il ne séparât point des dépouilles si chères!

Va m'attendre, Phœnix.

PYRRHUS

\section{II}

Andromaque, Céphise

CÉPHISE

Je vous l'avais prédit, qu'en dépit de la Grèce,

De votre sort encor vous seriez la maîtresse.

ANDROMAQUE

Hélas! de quel effet tes discours sont suivis !

Il ne me restait plus qu'à condamner mon fils.

\section{CÉPHISE}

Madame, à votre époux c'est être assez fidèle: Trop de vertu pourrait vous rendre criminelle. 
ANDROMAQUE

Quoi? je lui donnerais Pyrrhus pour successeur?

\section{CÉPHISE}

Ainsi le veut son fils, que les Grecs vous ravissent.

Pensez-vous qu'après tout ses mânes en rougissent;

Qu'il méprisât, Madame, un roi victorieux

Qui vous fait remonter au rang de vos aïeux,

Qui foule aux pieds pour vous vos vainqueurs en colère,

Qui ne se souvient plus qu'Achille était son père,

Qui dément ses exploits et les rend superflus?

ANDROMAQUE

Dois-je les oublier, s'il ne s'en souvient plus?

Dois-je oublier Hector privé de funérailles,

Et traîné sans honneur autour de nos murailles ?

Dois-je oublier son père à mes pieds renversé,

Ensanglantant l'autel qu'il tenait embrassé?

Songe, songe, Céphise, à cette nuit cruelle

Qui fut pour tout un peuple une nuit éternelle.

Figure-toi Pyrrhus, les yeux étincelants,

Entrant à la lueur de nos palais brûlants,

Sur tous mes frères morts se faisant un passage,

Et de sang tout couvert échauffant le carnage.

Songe aux cris des vainqueurs, songe aux cris des mourants, 20

Dans la flamme étouffés, sous le fer expirants.

Peins-toi dans ces horreurs Andromaque éperdue:

Voilà comme Pyrrhus vint s'offrir à ma vue;

Voilà par quels exploits il sut se couronner;

Enfin voilà l'époux que tu me veux donner.

Non, je ne serai point complice de ses crimes;

Qu'il nous prenne, s'il veut, pour dernières victimes.

Tous mes ressentiments ${ }^{1}$ lui seraient asservis. ${ }^{2}$

\section{CÉPHISE}

Hé bien! allons donc voir expirer votre fils :

On n'attend plus que vous. V.ous frémissez, Madame!

\section{ANDROMAQUE}

Ah! de quel souvenir viens-tu frapper mon âme!

Quoi ? Céphise, j'irai voir expirer encor

Ce fils, ma seule joie, et l'image d'Hector : 
Ce fils, que de sa flamme il me laissa pour gage! Hélas! je m'en souviens, le jour que son courage Lui fit chercher Achille, ou plutôt le trépas, Il demanda son fils, et le prit dans ses bras : "Chère épouse, dit-il en essuyant mes larmes, J'ignore quel succès le sort garde à mes armes; Je te laisse mon fils pour gage de ma foi : S'il me perd, je prétends qu'il me retrouve en toi. Si d'un heureux hymen la mémoire t'est chère, Montre au fils à quel point tu chérissais le père. » Et je puis voir répandre un sang si précieux? Et je laisse avec lui périr tous ses aïeux?

Roi barbare, faut-il que mon crime l'entraîne?

Si je te hais, est-il coupable de ma haine?

T'a-t-il de tous les siens reproché le trépas?

S'est-il plaint à tes yeux des maux qu'il ne sent pas ?

Mais cependant, mon fils, tu meurs, si je n'arrête Le fer que le cruel tient levé sur ta tête.

Je l'en puis détourner, et je t'y vais offrir? •

Non, tu ne mourras point: je ne le puis souffrir. Allons trouver Pyrrhus. Mais non, chère Céphise, $\mathrm{Va}$ le trouver pour moi.

\section{CÉPHISE}

Que faut-il que je dise?

\section{ANDROMAQUE}

Dis-lui que de mon fils l'amour est assez fort. . . . Crois-tu que dans son cœur il ait juré sa mort?

L'amour peut-il si loin pousser sa barbarie?

CÉPHISE

Madame, il va bientôt revenir en furie.

ANDROMAQUE

Hé bien! va l'assurer. . .

\section{CÉPHISE}

De quoi? de votre foi ?

\section{ANDROMAQUE}

Hélas! pour la promettre est-elle encore à moi ?

$\mathrm{O}$ cendres d'un époux! ô Troyens! ô mon père!

$\mathrm{O}$ mon fils, que tes jours coûtent cher à ta mère!

Allons. 


\section{CÉPHISE}

Où donc, Madame? et que résolvez-vous ?

ANDROMAQUE

Allons sur son tombeau consulter mon époux.

- Act III, scene 8

\section{BRITANNICUS}

I

Agrippine, Junie ${ }^{1}$

AGRIPPINE

Madame, ou je me trompe, ou durant vos adieux

Quelques pleurs répandus ont obscurci vos yeux.

Puis-je savoir quel trouble a formé ce nuage?

Doutez-vous d'une paix dont je fais mon ouvrage?

JUNIE

Après tous les ennuis que ce jour m'a coûtés, $\mathrm{Ai}$-je pu rassurer mes esprits agités ?

Hélas! à peine encor je conçois ce miracle.

Quand même à vos bontés je craindrais quelque obstacle,

Le changement, Madame, est commun à la cour ;

Et toujours quelque crainte accompagne l'amour.

\section{AGRIPPINE}

Il suffit, j'ai parlé, tout a changé de face :

Mes soins à vos soupçons ne laissent point de place.

Je réponds d'une paix jurée entre mes mains :

Néron m'en a donné des gages trop certains.

$\mathrm{Ah}$ ! si vous aviez vu par combien de caresses

Il m'a renouvelé la foi de ses promesses!

Par quels embrassements il vient de m'arrêter!

Ses bras, dans nos adieux, ne pouvaient me quitter;

Sa facile bonté, sur son front répandue, Jusqu'aux moindres secrets est d'abord descendue.

Il s'épanchait en fils, qui vient en liberté

Dans le sein de sa mère oublier sa fierté.

1 The emperor Néron, whose career of cruelty and oppression was beginning to show itself, feigned a reconciliation with his mother, Agrippine, with whom he no longer desired to share the empire. Under pretext of this reconciliation he gave a feast and invited Britannicus, his rival, who is in love with Junie. 
Mais bientôt, reprenant un visage sévère, Tel que d'un empereur qui consulte sa mère, Sa confidence auguste a mis entre mes mains Des secrets d'où dépend le destin des humains. Non, il le faut ici confesser à sa gloire, Son cœur n'enferme point une malice noire; Et nos seuls ennemis, altérant sa bonté, Abusaient contre nous de sa facilité. Mais enfin, à son tour, leur puissance décline; Rome encore une fois va connaître Agrippine: Déjà de ma faveur on adore le bruit. Cependant en ces lieux n'attendons pas la nuit. Passons chez Octavie, et donnons-lui le reste D'un jour autant heureux que je l'ai cru funeste.

I 5 Mais qu'est-ce que j'entends? Quel tumulte confus? Que peut-on faire?

\author{
JUNIE \\ O ciel, sauvez Britannicus!
}

II

Agrippine, Junie, Burrhus

AGRIPPINE

Burrhus, où courez-vous! Arrêtez. Que veut dire . . .

BURRHUS

Madame, c'en est fait, Britannicus expire.

Ah, mon prince!

JUNIE

AGRIPPINE

Il expire?

BURRHUS

Ou plutôt il est mort,

20 Madame.

$$
\text { JUNIE }
$$

Pardonnez, Madame, à ce transport.

Je vais le secourir, si je puis, ou le suivre. 
III

Agrippine, Burrhus

AGRIPPINE

Quel attentat, Burrhus!

BURRHUS

Je n'y pourrai survivre,

Madame: il faut quitter la cour et l'Empereur.

\section{AGRIPPINE}

Quoi ? du sang de son frère il n'a point eu d'horreur?

\section{BURRHUS}

Ce dessein s'est conduit avec plus de mystère.

A peine l'Empereur a vu venir son frère,

Il se bève, il l'embrasse, on se tait, et soudain

César prend le premier une coupe à la main :

" Pour achever ce jour sous de meilleurs auspices,

Ma main de cette coupe épanche les prémices,

Dit-il ; Dieux, que j'appelle à cette effusion,

Venez favoriser notre réunion.»

Par les mêmes serments Britannicus se lie;

La coupe dans ses mains par Narcisse est remplie;

Mais ses lèvres à peine en ont touché les bords,

Le fer ne produit point de si puissants efforts, ${ }^{1}$

Madame: la lumière à ses yeux est ravie;

Il tombe sur son lit sans chaleur et sans vie.

Jugez combien ce coup frappe tous les esprits :

La moitié s'épouvante et sort avec des cris ;

Mais ceux qui de la cour ont un plus long usage

Sur les yeux de César composent leur visage.

Cependant sur son lit il demeure penché;

D'aucun étonnement il ne paraît touché :

" Ce mal dont vous craignez, dit-il, la violence,

A souvent sans péril attaqué son enfance.»

Narcisse veut en vain affecter quelque ennui,

Et sa perfide joie éclate malgré lui.

Pour moi, dût l'empereur punir ma hardiesse,

D'une odieuse cour j'ai traversé la presse ;

Et j'allais, accablé de cet assassinat,

Pleurer Britannicus, César et tout l'État.

AGRIPPINE

Le voici. Vous verrez si c'est moi qui l'inspire.

1 In the sense of effets. 
IV

Agrippine, Néron, Burrhus, Narcisse

Dieux!

NÉRON, voyant Agrippine

\title{
AGRIPPINE
}

Arrêtez, Néron: j'ai deux mots à vous dire. Britannicus est mort, je reconnais les coups; Je connais l'assassin.

\author{
NÉRON \\ Et qui, Madame? \\ AGRIPPINE \\ Vous. \\ NÉRON
}

Moi! Voilà les soupçons dont vous êtes capable. Il n'est point de malheurs dont je ne sois capable; Et si l'on veut, Madame, écouter vos discours, Ma main de Claude même aura tranché les jours. Son fils vous était cher: sa mort peut vous confondre; Mais des coups du destin je ne puis pas répondre.

\section{AGRIPPINE}

Non, non, Britannicus est mort empoisonné :

Narcisse a fait le coup, vous l'avez ordonné.

$$
\text { NÉRON }
$$

Madame, mais qui peut vous tenir ce langage?

\section{NARCISSE}

Hé, Seigneur, ce soupçon vous fait-il tant d'outrage? Britannicus, Madame, eut des desseins secrets

I5 Qui vous auraient coûté de plus justes regrets. Il aspirait plus loin qu'à l'hymen de Junie :

De vos propres bontés il vous aurait punie.

Il vous trompait vous-même; et son cœur offensé Prétendait tôt ou tard rappeler le passé.

Soit donc que malgré vous le sort vous ait servie, Soit qu'instruit des complots qui menaçaient sa vie, Sur ma fidélité César s'en soit remis,

Laissez les pleurs, Madame, à vos seuls ennemis. Qu'ils mettent ce malheur au rang des plus sinistres, 


\section{AGRIPPINE}

Poursuis, Néron, avec de tels ministres.

Par des faits glorieux tu te vas signaler.

Poursuis. 'Tu n'as pas fait ce pas pour reculer.

Ta main a commencé par le sang de ton frère;

Je prévois que tes coups viendront jusqu'à ta mère.

Dans le fond de ton cœur je sais que tu me hais;

Tu voudras t'affranchir du joug de mes bienfaits.

Mais je veux que ma mort te soit même inutile.

$\mathrm{Ne}$ crois pas qu'en mourant je te laisse tranquille.

Rome, ce ciel, ce jour que tu reçus de moi,

Partout, à tout moment, m'offriront devant toi.

Tes remords te suivront comme autant de furies;

Tu croiras les calmer par d'autres barbaries;

Ta fureur, s'irritant soi-même dans son cours,

D'un sang toujours nouveau marquera tous tes jours.

Mais j'espère qu'enfin le ciel, las de tes crimes,

Ajoutera ta perte à tant d'autres victimes ;

Qu'après t'être couvert de leur sang et du mien,

Tu te verras forcé de répandre le tien;

Et ton nom paraîtra, dans la race future,

Aux plus cruels tyrans une cruelle injure.

Voilà ce que mon cœur se présage de toi.

Adieu : tu peux sortir.

NÉRON

Narcisse, suivez-moi.

- Act V, scenes 3-6

PHÈDRE

\section{Phèdre, ${ }^{1}$ Enone}

PHÈDRE

N'allons point plus avant. Demeurons, chère Enone.

Je ne me soutiens plus: ma force m'abandonne.

Mes yeux sont éblouis du jour que je revoi,

Et mes genoux tremblants se dérobent sous moi.

Hélas !

(Elle s'assit)

CENONE

Dieux tout-puissants, que nos pleurs vous apaisent.

1 Phèdre, wife of Thésée, king of Athens, feels remorseful on account of her passion for her stepson Hippolyte. She confesses her guilty love to đEnone. 


\section{PHÈDRE}

Que ces vains ornements, que ces voiles me pèsent! Quelle importune main, en formant tous ces nœuds, A pris soin sur mon front d'assembler mes cheveux? Tout m'afflige et me nuit, et conspire à me nuire.

\section{ENONE}

Comme on voit tous ses vœux l'un l'autre se détruire! Vous-même, condamnant vos injustes desseins,

Tantôt à vous parer vous excitiez nos mains ;

Vous-même, rappelant votre force première, Vous vouliez vous montrer et revoir la lumière.

Vous la voyez, Madame; et prête à vous cacher,

Vous haïssez le jour que vous veniez chercher?

\section{PHÈDRE}

Noble et brillant auteur d'une triste famille, Toi, dont ma mère osait se vanter d'être fille, Qui peut-être rougis du trouble où tu me vois, I 5 Soleil, je te viens voir pour la dernière fois.

\section{CENONE}

Quoi? vous ne perdrez point cette cruelle envie? Vous verrai-je toujours, renonçant à la vie, Faire de votre mort les funestes apprêts?

\section{PHÈDRE}

Dieux! que ne suis-je assise à l'ombre des forêts !

Quand pourrai-je, au travers d'une noble poussière, Suivre de l'œil un char fuyant dans la carrière?

Quoi, Madame?

\section{ENONE}

\section{PHÈDRE}

Insensée, où suis-je? et qu'ai-je dit? Où laissé-je égarer mes vœux et mon esprit? Je l'ai perdu: les Dieux m'en ont ravi l'usage. Enone, la rougeur me couvre le visage : Je te laisse trop voir mes honteuses douleurs; Et mes yeux, malgré moi, se remplissent de pleurs.

\section{ENONE}

Ah! s'il vous faut rougir, rougissez d'un silence Qui de vos maux encore aigrit la violence. 
Rebelle à tous nos soins, sourde à tous nos discours,

Voulez-vous sans pitié laisser finir vos jours?

Quelle fureur les borne au milieu de leur course?

Quel charme ou quel poison en a tari la source?

Les ombres par trois fois ont obscurci les cieux

Depuis que le sommeil n'est entré dans vos yeux,

Et le jour a trois fois chassé la nuit obscure

Depuis que votre corps languit sans nourriture.

A quel affreux dessein vous laissez-vous tenter?

De quel droit sur vous-même osez-vous attenter?

Vous offensez les Dieux auteurs de votre vie;

Vous trahissez l'époux à qui la foi vous lie;

Vous trahissez enfin vos enfants malheureux,

Que vous précipitez sous un joug rigoureux.

Songez qu'un même jour leur ravira leur mère,

Et rendra l'espérance au fils de l'étrangère,

A ce fier ennemi de vous, de votre sang,

Ce fils qu'une Amazone a porté dans son flanc,

Cet Hippolyte . . .

PHÈDRE

Ah, Dieux !

ENONE

Ce reproche vous touche.

PHÈDRE

Malheureuse, quel nom est sorti de ta bouche?

GENONE

Hé bien! votre colère éclate avec raison:

J'aime à vous voir frémir à ce funeste nom.

Vivez donc. Que l'amour, le devoir vous excite.

Vivez, ne souffrez pas que le fils d'une Scythe, ${ }^{1}$

Accablant vos enfants d'un empire odieux,

Commande au plus beau sang de la Grèce et des Dieux.

Mais ne différez point: chaque moment vous tue.

Réparez promptement votre force abattue,

Tandis que de vos jours, prêts à se consumer,

Le flambeau dure encore, et peut se rallumer.

PHÈDRE

J'en ai trop prolongé la coupable durée.

1 The Amazons were believed to have come originally from Scythia. 


\section{CENONE}

Quoi? de quelques remords êtes-vous déchirée?

Quel crime a pu produire un trouble si pressant?

Vos mains n'ont point trempé dans le sang innocent?

PHÈDRE

Grâces au ciel, mes mains ne sont point criminelles.

Plût aux Dieux que mon cœur fût innocent comme elles !

CENONE

Et quel affreux projet avez-vous enfanté

Dont votre cœur encor doive être épouvanté?

PHÈDRE

Je t'en ai dit assez. Epargne-moi le reste.

Je meurs, pour ne point faire un aveu si funeste.

CENONE

Mourez donc, et gardez un silence inhumain;

Mais pour fermer vos yeux cherchez une autre main.

Quoiqu'il vous reste à peine une faible lumière, Mon âme chez les morts descendra la première.

Mille chemins ouverts y conduisent toujours,

Et ma juste douleur choisira les plus courts.

Cruelle, quand ma foi vous a-t-elle déçue?

Songez-vous qu'en naissant mes bras vous ont reçue?

Mon pays, mes enfants, pour vous j'ai tout quitté.

Réserviez-vous ce prix à ma fidélité?

PHÈDRE

Quel fruit espères-tu de tant de violence?

Tu frémiras d'horreur si je romps le silence.

\section{CENONE}

Et que me direz-vous qui ne cède, grands Dieux!

A l'horreur de vous voir expirer à mes yeux?

\section{PHẼDRE}

Quand tu sauras mon crime, et le sort qui m'accable, 25 Je n'en mourrai pas moins, j'en mourrai plus coupable.

\section{ENONE}

Madame, au nom des pleurs que pour vous j'ai versés, Par vos faibles genoux que je tiens embrassés, Délivrez mon esprit de ce funeste doute. 
Tu le veux. Lève-toi.

PHÈDRE

\author{
ENONE \\ Parlez, je vous écoute. \\ PHÈDRE
}

Ciel! que lui vais-je dire, et par où commencer?

\title{
CENONE
}

Par de vaines frayeurs cessez de m'offenser.

PHÈDRE

$O$ haine de Vénus! $O$ fatale colère !

Dans quels égarements l'amour jeta ma mère!

CENONE

Oublions-les, Madame ; et qu'à tout l'avenir Un silence éternel cache ce souvenir.

PHÈDRE

Ariane, ma sœur, de quel amour blessée, Vous mourûtes aux bords où vous fûtes laissée!

CENONE

Que faites-vous, Madame? et quel mortel ennui Contre tout votre sang vous anime aujourd'hui?

PHÈDRE

Puisque Vénus le veut, de ce sang déplorable Je péris la dernière et la plus misérable.

Aimez-vous?

CENONE

PHÈDRE

De l'amour j'ai toutes les fureurs.

Pour qui?

๔ENONE

PHÈDRE

Tu vas ouïr le comble des horreurs.

J'aime ... A ce nom fatal, je tremble, je frissonne. J'aime . . 


\section{PHÈDRE}

$\mathrm{Tu}$ connais ce fils de l'Amazone, Ce prince si longtemps par moi-même opprimé ?

CENONE

Hippolyte? Grands Dieux!

PHÈDRE

C'est toi qui l'as nommé.

GENONE

Juste ciel! tout mon sang dans mes veines se glace.

O désespoir! ô crime! ô déplorable race!

Voyage infortuné! Rivage malheureux,

Fallait-il approcher de tes bords dangereux?

\section{PHÈDRE}

Mon mal vient de plus loin. A peine au fils d'Égée Sous les lois de l'hymen je m'étais engagée,

Mon repos, mon bonheur semblait être affermi ;

Athènes me montra mon superbe ennemi.

Je le vis, je rougis, je pâlis à sa vue;

Un trouble s'éleva dans mon âme éperdue;

Mes yeux ne voyaient plus, je ne pouvais parler;

I 5 Je sentis tout mon corps et transir et brûler;

Je reconnus Vénus et ses feux redoutables,

D'un sang qu'elle poursuit tourments inévitables.

Par des vœux assidus je crus les détourner:

Je lui bấtis un temple, et pris soin de l'orner;

De victimes moi-même à toute heure entourée,

Je cherchais dans leurs flancs ma raison égarée.

D'un incurable amour remèdes impuissants!

En vain sur les autels ma main brûlait l'encens :

Quand ma bouche implorait le nom de la Déesse,

J'adorais Hippolyte; et le voyant sans cesse,

Même au pied des autels que je faisais fumer,

J'offrais tout à ce dieu que je n'osais nommer.

Je l'évitais partout. $O$ comble de misère!

Mes yeux le retrouvaient dans les traits de son père.

Contre moi-même enfin j'osai me révolter :

J'excitai mon courage à le persécuter.

Pour bannir l'ennemi dont j'étais idolâtre, J'affectai les chagrins d'une injuste marâtre;

Je pressai son exil, et mes cris éternels 
L'arrachèrent du sein et des bras paternels.

Je respirais, Enone ; et depuis son absence,

Mes jours moins agités coulaient dans l'innocence.

Soumise à mon époux, et cachant mes ennuis,

De son fatal hymen je cultivais les fruits.

Vaines précautions! Cruelle destinée!

Par mon époux lui-même à Trézène amenée,

J'ai revu l'ennemi que j'avais éloigné :

Ma blessure trop vive aussitôt a saigné.

Ce n'est plus une ardeur dans mes veines cachée :

C'est Vénus toute entière à sa proie attachée.

J'ai conçu pour mon crime une juste terreur;

J'ai pris la vie en haine, et ma flamme en horreur.

Je voulais en mourant prendre soin de ma gloire,

Et dérober au jour une flamme si noire :

Je n'ai pu soutenir tes larmes, tes combats;

Je t'ai tout avoué ; je ne m'en repens pas,

Pourvu que de ma mort respectant les approches,

Tu ne m'affliges plus par d'injustes reproches,

Et que tes vains secours cessent de rappeler

Un reste de chaleur tout prêt à s'exhaler.

\section{ATHALIE}

\section{Le Chour}

TOUT LE CHCUR, chante

Tout l'univers est plein de sa magnificence.

Qu'on l'adore ce Dieu, qu'on l'invoque à jamais.

Son empire a des temps précédé la naissance.

Chantons, publions ses bienfaits.

UNE VOIX, seule

En vain l'injuste violence

$\mathrm{Au}$ peuple qui le loue imposerait silence :

Son nom ne périra jamais.

Le jour annonce au jour sa gloire et sa puissance.

Tout l'univers est plein de sa magnificence.

Chantons, publions ses bienfaits.

TOUT LE CHCUR, répète

Tout l'univers est plein de sa magnificence:

Chantons, publions ses bienfaits. 
UNE VOIX, seule

Il donne aux fleurs leur aimable peinture.

Il fait naître et mûrir les fruits.

Il leur dispense avec mesure

Et la chaleur des jours et la fraîcheur des nuits ;

Le champ qui les reçut les rend avec usure.

UNE AUTRE

Il commande au soleil d'animer la nature,

Et la lumière est un don de ses mains;

Mais sa loi sainte, sa loi pure

Est le plus riche don qu'il ait fait aux humains.

UNE AUTRE

10

O mont de Sinaï, conserve la mémoire

De ce jour à jamais auguste et renommé,

Quand, sur ton sommet enflammé,

Dans un nuage épais le Seigneur enfermé

Fit luire aux yeux mortels un rayon de sa gloire.

Dis-nous pourquoi ces feux et ces éclairs,

Ces torrents de fumée, et ce bruit dans les airs,

Ces trompettes et ce tonnerre:

Venait-il renverser l'ordre des éléments ?

Sur ses antiques fondements

Venait-il ébranler la terre?

UNE AUTRE

Il venait révéler aux enfants des Hébreux

De ses préceptes saints la lumière immortelle.

Il venait à ce peuple heureux

Ordonner de l'aimer d'une amour éternelle.

TOUT LE CHCEUR

O divine, ô charmante loi!

O justice! ô bonté suprême!

Que de raisons, quelle douceur extrême

D'engager à ce Dieu son amour et sa foi !

UNE VOIX, seule

D'un joug cruel il sauva nos aïeux, Les nourrit au désert d'un pain délicieux. Il nous donne ses lois, il se donne lui-même.

Pour tant de biens, il commande qu'on l'aime. 
LE CHOEUR

O justice! ô bonté suprême!

LA MÊME VOIX

Des mers pour eux il entr'ouvrit les eaux, D'un aride rocher fit sortir des ruisseaux.

Il nous donne ses lois, il se donne lui-même.

Pour tant de biens, il commande qu'on l'aime.

LE CHCEUR

O divine, ô charmante loi!

Que de raisons, quelle douceur extrême

D'engager à ce Dieu son amour et sa foi !

UNE AUTRE VOIX, seule

Vous qui ne connaissez qu'une crainte servile,

Ingrats, un Dieu si bon ne peut-il vous charmer?

IO

Est-il donc à vos cœurs, est-il si difficile

Et si pénible de l'aimer?

L'esclave craint le tyran qui l'outrage ;

Mais des enfants l'amour est le partage.

Vous voulez que ce Dieu vous comble de bienfaits, Et ne l'aimer jamais?

TOUT LE CHCEUR

O divine, ô charmante loi !

O justice! ô bonté suprême!

Que de raisons, quelle douceur extrême

D'engager à ce Dieu son amour et sa foi! 


\section{JACQUES-BÉNIGNE BOSSUET}

Dijon, 1627-1704, Paris

Bossuet came of a family of provincial magistrates. He began his studies at the Jesuit college of his native town, Dijon. In 1642 he went to Paris and took up theology and philosophy at the college of Navarre. He was already conspicuous for the force of his eloquence. He became doctor of theology and priest in 1652 , and then began exercising his great power as an orator, in Metz, a town in which the Reform was deeply rooted. In $6_{59}$ he returned to Paris, where he preached for the next ten years with almost unprecedented success. The bishopric of Condom was given to him in I669. The following year he was appointed tutor to the Dauphin. He thereupon resigned his bishopric, and for ten years devoted his efforts to his new charge, writing for the use of his royal pupil the "Discours sur l'histoire universelle"; the "Politique tirée de l'Écriture Sainte"; and the "Traité de la connaissance de Dieu et de soi-même."

The Dauphin's education was ended in $168 \mathrm{I}$, and Bossuet was then appointed to the bishopric of Meaux. The remaining years of his life were spent in active service in the church. Meanwhile, as the champion of orthodoxy, he was prominent in the controversies against Protestantism ("Histoire des variations des églises protestantes," I688) and Quietism.

He had been elected to the Academy in $167 \mathrm{I}$, and, even before that date, had pronounced some of the funeral orations for which he won such fame, and of which the best are on Henrietta, Queen of England (1669); on Henrietta of England, duchesse d'Orléans ( 1670 ); on Maria Theresa of Austria, queen of France (r683); on Anne de Gonzague (1685); on Michel le Tellier (I686); on the prince de Condé ( 1687 ). He died in 1704 .

\section{SUR L'AMBITION}

\section{SECOND POINT}

La fortune, trompeuse en toute autre chose, est du moins sincère en ceci, qu'elle ne nous cache pas ses tromperies; au contraire, elle les étale dans le plus grand jour, et, outre ses légèretés ordinaires, elle se plaît de temps en temps d'étonner le monde par des coups d'une 5 surprise terrible, comme pour rappeler toute sa force en la mémoire des hommes, et de peur qu'ils n'oublient jamais ses inconstances, sa malignité, ses bizarreries. C'est ce qui m'a fait souvent penser que 
toutes les complaisances de la fortune ne sont pas des faveurs, mais des trahisons; qu'elle ne nous donne que pour avoir prise sur nous, et que les biens que nous recevons de sa main ne sont pas tant des présents qu'elle nous fait que des gages que nous lui donnons pour être éternellement ses captifs, assujettis aux retours fâcheux de sa dure et malicieuse puissance.

Cette vérité, établie sur tant d'expériences convaincantes, devrait détromper les ambitieux de tous les biens de la terre; et c'est au contraire ce qui les engage. Car au lieu d'aller à un bien solide et éternel sur lequel le hasard ne domine pas, et de mépriser par cette ro vue la fortune toujours changeante, la persuasion de son inconstance fait qu'on se donne tout à fait à elle, pour trouver des appuis contre elle-même. Car écoutez parler ce politique habile et entendu : la fortune l'a élevé bien haut, et dans cette élévation, il se moque des petits esprits qui donnent tout au dehors, ${ }^{1}$ et qui se repaissent de titres et ${ }_{15}$ d'une belle montre de grandeur. Pour lui, il appuie sa famille sur des fondements plus certains, sur des charges considérables, sur des richesses immenses, qui soutiendront éternellement la fortune de sa maison. Il pense s'être affermi contre toute sorte d'attaques: aveugle et malavisé! Comme si ces soutiens magnifiques qu'il cherche contre 20 la puissance de la fortune n'étaient pas encore de sa dépendance!

C'est trop parler de la fortune dans la chaire de vérité. Écoute, homme sage, homme prévoyant, qui étends si loin aux siècles futurs - les précautions de ta prudence; c'est Dieu même qui te va parler, et qui va confondre tes vaines pensées par la bouche de son prophète 25 Ezéchiel. "Assur, dit ce saint prophète, s'est élevé comme un grand arbre, comme les cèdres du Liban; le ciel l'a nourri de sa rosée, la terre l'a engraissé de sa substance ${ }^{2}$; ) — les puissances l'ont comblé [de] leurs bienfaits et il suçait de son côté le sang du peuple. "C'est pourquoi il s'est élevé, superbe en sa hauteur, beau en sa ver- 30 dure, étendu en ses branches, fertile en ses rejetons: les oiseaux faisaient leurs nids sur ses branches; " — les familles de ses domestiques, les peuples se mettaient à couvert sous son ombre; un grand nombre de créatures, et les grands et les petits, étaient attachés à sa fortune. - " Ni les cèdres ni les pins », — c'est à dire les plus grands 35 de la cour, — ne l'égalaient pas: Abietes non adaequaverunt summitatem ejus. . . aemulata sunt eum omnia ligna voluptatis quae erant in

1 "sacrifice everything for appearances."

2 See Ezekiel xxxi for this and the following quotations. 
paradiso Dei. Autant que ce grand arbre s'était poussé en haut, autant semblait-il avoir jeté en bas de fortes et profondes racines.

Voilà une grande fortune; un siècle n'en voit pas beaucoup de semblables; mais voyez sa ruine et sa décadence : "Parce qu'il s'est 5 élevé superbement, et qu'il a porté son faîte jusqu'aux nues, et que son cœur s'est enflé dans sa hauteur: pour cela, dit le Seigneur, je le couperai par la racine, je l'abattrai d'un grand coup et le porterai par terre; - il viendra une disgrâce et il ne pourra plus se soutenir. Tous ceux qui se reposaient sous son ombre se retireront de lui, de Io peur d'être accablés sous sa ruine. Il tombera d'une grande chute; on le verra tout de son long couché sur la montagne, fardeau inutile de la terre: " Projicient eum super montes; ou, s'il se soutient durant sa vie, il mourra au milieu de ses grands desseins, et laissera à des mineurs des affaires embrouillées qui ruineront sa famille; ou Dieu 15 frappera son fils unique, et le fruit de son travail passera en des mains étrangères; ou Dieu lui fera succéder un dissipateur qui, se trouvant tout d'un coup dans de si grands biens dont l'amas ne lui a coûté aucunes peines, se jouera des sueurs d'un homme insensé qui se sera damné pour le laisser riche: et devant la troisième génération, le mauvais 20 ménage et les dettes auront consumé tous ses héritages. "Les branches de ce grand arbre se verront rompues dans toutes les vallées »: je veux dire, ces terres et ces seigneuries, qu'il avait ramassées comme une province, avec tant de soin et de travail, se partageront en plusieurs mains, et tous ceux qui verront ce grand changement 25 diront, en levant les épaules et regardant avec étonnement les restes de cette fortune ruinée : Est-ce là que devait aboutir toute cette grandeur formidable au monde? est-ce là ce grand arbre qui portait son faîte jusqu'aux nues? Il n'en reste plus qu'un tronc inutile. Est-ce là ce fleuve impétueux qui semblait devoir inonder toute la terre? Je 30 n'aperçois plus qu'un peu d'écume. O homme, que penses-tu faire, et pourquoi te travailles-tu vainement?

- Mais je saurai bien m'affermir et profiter de l'exemple des autres; j'étudierai le faible de leur conduite, et c'est là que j'apporterai le remède. - Folle précaution! car ceux-là ont-ils profité de 35 l'exemple de ceux qui les précéd[ai]ent? O homme, ne te trompe pas, l'avenir a des événements trop secrets, et les pertes et les ruines entrent par trop d'endroits dans la fortune des hommes pour pouvoir être arrêtées de toutes parts. Tu arrêtes cette eau d'un côté, elle pénètre de l'autre; elle bouillonne même par-dessous la terre. — Mais 
je jouirai de mon travail. - Eh quoi! pour dix ans de vie!... - Mais je regarde ma postérité et mon nom. - Mais peut-être que ta postérité n'en jouira pas. - Mais peut-être aussi qu'elle en jouira. - Et tant de sueurs, et tant de travaux, et tant de crimes, et tant d'injustices, sans pouvoir jamais arracher de la fortune, à laquelle tu te dévoues, qu'un misérable peut-être! Regarde qu'il n'y a rien d'assuré pour toi, non pas même un tombeau pour graver dessus tes titres superbes, seuls restes de ta grandeur abattue: l'avarice ou la négligence de tes héritiers le refuseront peut-être à ta mémoire; tant on pensera peu à toi quelques années après ta mort! Ce qu'il y a d'assuré, to c'est la peine de tes rapines, la vengeance éternelle de tes concussions et de ton ambition infinie. $\mathrm{O}$ les dignes restes de ta grandeur! ô les belles suites de ta fortune! ô folie! ô illusion! ô étrange aveuglement des enfants des hommes!

Chrétiens, méditez ces choses; chrétiens, qui que vous soyez, qui 15 croyez vous affermir sur la terre, servez-vous de cette pensée pour chercher le solide et la consistance. Oui, l'homme doit s'affermir; il ne doit pas borner ses desseins dans des limites si resserrées que celles de cette vie: qu'il pense hardiment à l'éternité. En effet, il tâche, autant qu'il peut, que le fruit de son travail n'ait point de fin; il ne 20 peut pas toujours vivre, mais il souhaite que son ouvrage subsiste toujours: son ouvrage, c'est sa fortune, qu'il tâche, autant qu'il lui est possible, de faire voir aux siècles futurs telle qu'il l'a faite. Il y a dans l'esprit de l'homme un désir avide de l'éternité; si on le sait appliquer, c'est notre salut. Mais voici l'erreur: c'est que l'homme l'attache à 25 ce qu'il aime; s'il aime les biens périssables, il y médite quelque chose d'éternel; c'est pourquoi il cherche de tous côtés des soutiens à cet édifice caduc, soutiens aussi caducs que l'édifice même qui lui paraît chancelant. O homme, désabuse-toi : si tu aimes l'éternité, cherche-la donc en elle-même, et ne crois pas pouvoir appliquer sa 30 consistance inébranlable à cette eau qui passe et à ce sable mouvant. O éternité, tu n'es qu'en Dieu; mais plutôt, ô éternité, tu es Dieu même: c'est là que je veux chercher mon appui, mon établissement, ma fortune, mon repos assuré et en cette vie et en l'autre, Amen.

- "Sermon sur l'ambition», second point 


\section{CONCLUSION DU DISCOURS SUR L'HISTOIRE UNIVERSELLE}

Mais souvenez-vous, Monseigneur, ${ }^{1}$ que ce long enchaînement des causes particulières, qui font et défont les empires, dépend des ordres secrets de la divine Providence. Dieu tient du plus haut des cieux les rênes de tous les royaumes; il a tous les cœurs en sa main: tantôt il 5 retient les passions, tantôt il leur lâche la bride, et par là il remue tout le genre humain. Veut-il faire des conquérants? Il fait marcher l'épouvante devant eux, et il inspire à eux et à leurs soldats une hardiesse invincible. Veut-il faire des législateurs? Il leur envoie son esprit de sagesse et de prévoyance; il leur fait prévenir les maux qui ro menacent les États, et poser les fondements de la tranquillité publique. Il connaît la sagesse humaine, toujours courte par quelque endroit ; il l'éclaire, il étend ses vues, et puis il l'abandonne à ses ignorances: il l'aveugle, il la précipite; il la confond par elle-même : elle s'enveloppe, elle s'embarrasse dans ses propres subtilités, et ses précautions lui

I 5 sont un piège. Dieu exerce par ce moyen ses redoutables jugements, selon les règles de sa justice toujours infaillible. C'est lui qui prépare les effets dans les causes les plus éloignées, et qui frappe ces grands coups dont le contre-coup porte si loin. Quand il veut lâcher le dernier, et renverser les empires, tout est faible et irrégulier dans les 20 conseils. L'Égypte, autrefois si sage, marche enivrée, étourdie et chancelante, parce que le Seigneur a répandu l'esprit de vertige dans ses conseils; elle ne sait plus ce qu'elle fait, elle est perdue. Mais que les hommes ne s'y trompent pas: Dieu redresse quand il lui plaît le sens égaré ; et celui qui insultait à l'aveuglement des autres tombe lui25 même dans les ténèbres plus épaisses, sans qu'il faille souvent autre chose, pour lui renverser le sens, que ses longues prospérités.

C'est ainsi que Dieu règne sur tous les peuples. Ne parlons plus de hasard ni de fortune, ou parlons-en seulement comme d'un nom dont nous couvrons notre ignorance. Ce qui est hasard à l'égard de 30 nos conseils incertains est un dessein concerté dans un conseil plus haut, c'est-à-dire, dans ce conseil éternel qui renferme toutes les causes et tous les effets dans un même ordre. De cette sorte tout concourt à la même fin; et c'est faute d'entendre le tout, que nous trouvons du hasard ou de l'irrégularité dans les rencontres particulières.

1 Louis (166i-1711), called the Grand Dauphin, son of Louis XIV, father of Louis, duc de Bourgogne (1682-1712), and grandfather of Louis XV (1710-1774). Bossuet was his tutor. 
Par là se vérifie ce que dit l'apôtre, que « Dieu est heureux et le seul puissant, roi des rois, et seigneur des seigneurs. " ${ }^{1}$ Heureux, dont le repos, est inaltérable, qui voit tout changer sans changer lui-même, ct qui fait tous les changements par un conseil immuable; qui donne et ôte la puissance, qui la transporte d'un homme à un autre, d'une maison à une autre, d'un peuple à un autre, pour montrer qu'ils ne l'ont tous que par emprunt, et qu'il est le seul en qui elle réside naturellement.

C'est pourquoi tous ceux qui gouvernent se sentent assujettis à une force majeure. Ils font plus ou moins qu'ils ne pensent, et leurs conseils n'ont jamais manqué d'avoir des effets imprévus. $\mathrm{Ni}$ ils ne sont to maitres des dispositions que les siècles passés ont mises dans les affaires, ni ils ne peuvent prévoir le cours que prendra l'avenir, loin qu'ils le puissent forcer. Celui-là seul tient tout en sa main, qui sait le nom de ce qui est et de ce qui n'est pas encore, qui préside à tous les temps, et prévient tous les conseils.

Alexandre ne croyait pas travailler pour ses capitaines, ni ruiner sa maison par ses conquêtes. Quand Brutus inspirait au peuple romain un amour immense de la liberté, il ne songeait pas qu'il jetait dans les esprits le principe de cette licence effrénée par laquelle la tyrannie qu'il voulait détruire devait être un jour rétablie plus dure que sous 20 les Tarquins. Quand les Césars flattaient les soldats, ils n'avaient pas dessein de donner des maitres à leurs successeurs et à l'empire. En un mot, il n'y a point de puissance humaine qui ne serve malgré elle à d'autres desseins que les siens: Dieu seul sait tout réduire à sa volonté. C'est pourquoi tout est surprenant, à ne regarder que les 25 causes particulières, et néanmoins tout s'avance avec une suite réglée. Ce discours vous le fait entendre; et pour ne plus parler des autres empires, vous voyez par combien de conseils imprévus, mais toutefois suivis en eux-mêmes, la fortune de Rome a été menée de Romulus jusqu'à Charlemagne.

\section{(n)}


des hommes. Chrétiens, ne murmurez pas si Madame a été choisie pour nous donner une telle instruction. Il n'y a rien ici de rude pour elle, puisque, comme vous le verrez par la suite, Dieu la sauve par le même coup qui nous instruit. Nous devrions être assez convaincus 5 de notre néant; mais s'il faut des coups de surprise à nos cœurs enchantés de l'amour du monde, celui-ci est assez grand et assez terrible. O nuit désastreuse! ô nuit effroyable, où retentit tout à coup, comme un éclat de tonnerre, cette étonnante nouvelle: Madame se meurt! Madame est morte! Qui de nous ne se sentit frappé à ce ro coup, comme si quelque tragique accident avait désolé sa famille? Au premier bruit d'un mal si étrange, on accourut à Saint-Cloud de toutes parts; on trouve tout consterné, excepté le cœur de cette princesse. Partout on entend des cris ; partout on voit la douleur et le désespoir, et l'image de la mort. Le roi, la reine, Monsieur, toute la cour, tout i 5 le peuple, tout est abattu, tout est désespéré; et il me semble que je vois l'accomplissement de cette parole du prophète: "Le roi pleurera, le prince sera désolé, et les mains tomberont au peuple de douleur et d'étonnement. " ${ }^{1}$

Mais et les princes et les peuples gémissaient en vain. En vain 20 Monsieur, en vain le roi même tenait Madame serrée par de si étroits embrassements. Alors ils pouvaient dire l'un et l'autre avec saint Ambroise $^{2}$ : Stringebam brachia, sed jam amiseram quam tenebam: " Je serrais les bras, mais j'avais déjà perdu ce que je tenais.» La princesse leur échappait parmi des embrassements si tendres, et la 25 mort plus puissante nous l'enlevait entre ces royales mains. Quoi donc, elle devait périr sitôt! Dans la plupart des hommes, les changements se font peu à peu, et la mort les prépare ordinairement à son dernier coup. Madame cependant a passé du matin au soir, ainsi que l'herbe des champs. Le matin elle fleurissait; avec quelles grâces, 30 vous le savez: le soir nous la vîmes séchée; et ces fortes expressions par lesquelles l'Écriture sainte exagère l'inconstance des choses humaines, devaient être pour cette princesse si précises et si littérales. Hélas! nous composions son histoire de tout ce qu'on peut imaginer de plus glorieux! Le passé et le présent nous garantissaient l'avenir, 35 et on pouvait tout attendre de tant d'excellentes qualités. Elle allait s'acquérir $^{3}$ deux puissants royaumes ${ }^{4}$ par des moyens agréables:

1 Ezekiel vii, 27.

2 Ambrose (340-397), a father of the Latin church.

3 "win the esteem of," through her part in the treaty of Dover.

4 France and England. 
toujours douce, toujours paisible autant que généreuse et bienfaisante, son crédit n'y aurait jamais été odieux: on ne l'eût point vue s'attirer la gloire avec une ardeur inquiète et précipitée; elle l'eût attendue sans impatience, comme sûre de la posséder. Cet attachement qu'elle a montré si fidèle pour le roi jusques à la mort lui en donnait les moyens. Et certes c'est le bonheur de nos jours, que l'estime se puisse joindre avec le devoir, et qu'on puisse autant s'attacher au mérite et à la personne du prince qu'on en révère la puissance et la majesté. Les inclinations de Madame ne l'attachaient pas moins fortement à tous ses autres devoirs. La passion qu'elle ressentait pour la gloire de ro Monsieur n'avait point de bornes. Pendant que ce grand prince, marchant sur les pas de son invincible frère, secondait avec tant de valeur et de succès ses grands et héroïques desseins dans la campagne de Flandre, ${ }^{1}$ la joie de cette princesse était incroyable. C'est ainsi que ses généreuses inclinations la menaient à la gloire par les voies que le 15 monde trouve les plus belles; et si quelque chose manquait encore à son bonheur, elle eût tout gagné par sa douceur et par sa conduite.

Telle était l'agréable histoire que nous faisions pour Madame; et pour achever ces nobles projets, il n'y avait que la durée de sa vic, dont nous ne croyions pas devoir être en peine. Car qui eût pu seu- 20 lement penser que les années eussent dû manquer à une jeunesse qui semblait si vive? Toutefois c'est par cet endroit que tout se dissipe en un moment. Au lieu de l'histoire d'une belle vie, nous sommes réduits à faire l'histoire d'une admirable, mais triste mort. A la vérité, Messieurs, rien n'a jamais égalé la fermeté de son âme, ni ce courage 25 paisible qui, sans faire effort pour s'élever, s'est trouvé par sa naturelle situation au-dessus des accidents les plus redoutables. Oui, Madame fut douce envers la mort comme elle l'était envers tout le monde. Son grand cœur ni ne s'aigrit, ni ne s'emporta contre elle. Elle ne la brave non plus avec fierté, contente de l'envisager sans 30 émotion et de la recevoir sans trouble. Triste consolation, puisque, malgré ce grand courage, nous l'avons perdue! C'est la grande vanité des choses humaines. Après que par le dernier effet de notre courage nous avons pour ainsi dire surmonté la mort, elle éteint en nous jusqu'à ce courage par lequei nous semblions la défier. La voilà, malgré 35 ce grand cœur, cette princesse si admirée et si chérie! la voilà telle que la mort nous l'a faite: encore ce reste tel quel va-t-il disparaître : cette ombre de gloire va s'évanouir, et nous l'allons voir dépouillée 
même de cette triste décoration. ${ }^{1}$ Elle va descendre à ces sombres lieux, à ces demeures souterraines, ${ }^{2}$ pour y dormir dans la poussière avec les grands de la terre, comme parle $\mathrm{Job}^{\mathbf{3}}$; avec ces rois et ces princes anéantis, parmi lesquels à peine peut-on la placer, tant les 5 rangs y sont pressés, tant la mort est prompte à remplir ces places. Mais ici notre imagination nous abuse encore. La mort ne nous laisse pas assez de corps pour occuper quelque place, et on ne voit là que les tombeaux qui fassent quelque figure. Notre chair change bientôt de nature: notre corps prend un autre nom; même celui de cadavre, Io dit Tertullien, ${ }^{4}$ parce qu'il nous montre encore quelque forme humaine, ne lui demeure pas longtemps; il devient un je ne sais quoi, qui n'a plus de nom dans aucune langue, tant il est vrai que tout meurt en lui, jusqu'à ces termes funèbres par lesquels on exprimait ses malheureux restes.

— "Oraison funèbre de Henriette-Anne d'Angleterre "

\section{BATAILLE DE ROCROI}

I5 Dieu nous a révélé que lui seul il fait les conquérants, et que seul il les fait servir à ses desseins. Quel autre a fait un Cyrus, ${ }^{5}$ si ce n'est Dieu, qui l'avait nommé, deux cents ans avant sa naissance, dans les oracles d'Isaïe ? ${ }^{\circ}$ " Tu n'es pas encore, lui disait-il, mais je te vois, et je t'ai nommé par ton nom: tu t'appelleras Cyrus: je marcherai 20 devant toi dans les combats : à ton approche je mettrai les rois en fuite: je briserai les portes d'airain. C'est moi qui étends les cieux, qui soutiens la terre, qui nomme ce qui n'est pas comme ce qui est »: c'est-à-dire c'est moi qui fais tout, et moi qui vois dès l'éternité tout ce que je fais. Quel autre a pu former un Alexandre, si ce n'est ce 25 même Dieu, qui en a fait voir de si loin et par des figures si vives l'ardeur indomptable à son prophète Daniel ? "Le voyez-vous, dit-il, ce conquérant; avec quelle rapidité il s'élève de l'occident comme par bonds, et ne touche pas à terre ?») ${ }^{7}$ Semblable dans ses sauts hardis et dans sa légère démarche à ces animaux vigoureux et bondissants, il ne .30 s'avance que par vives et impétueuses saillies, et n'est arrêté ni par montagnes ni par précipices. Déjà le roi de Perse est entre ses mains :

1 The cathedral of Saint-Denis had been elaborately draped for the occasion.

2 The tombs beneath the cathedral.

3 Job xxi, 26.

4 A church father and ecclesiastical writer of the second century.

5 Cyrus, "the Great," founder of the Persian Empire, died 529 в.c.

6 Isaiah xlv, I-7.

7 Daniel viii, 5 . 
" A sa vue il s'est animé : efferatus est in eum», dit le prophète; "il l'abat, il le foule aux pieds: nul ne le peut défendre des coups qu'il lui porte, ni lui arracher sa proie. " ${ }^{1}$ A n'entendre que ces paroles de Daniel, qui croiriez-vous voir, Messieurs, sous cette figure, Alexandre ou le prince de Condé ? ${ }^{2}$

Dieu donc lui avait donné cette indomptable valeur pour le salut de la France, durant la minorité d'un roi de quatre ans. ${ }^{8}$ Laissez-le croître, ce roi chéri du ciel ; tout cédera à ses exploits : supérieur aux siens comme aux ennemis, il saura tantôt se servir, tantôt se passer de ses plus fameux capitaines; et seul, sous la main de Dieu, qui sera ro continuellement à son secours, on le verra l'assuré rempart de ses états. Mais Dieu avait choisi le duc d'Enghien pour le défendre dans son enfance. Aussi, vers les premiers jours de son règne, à l'âge de vingt-deux ans, le duc conçut un dessein où les vieillards expérimentés ne purent atteindre; mais la victoire le justifia devant Rocroi. ${ }^{4}$ L'ar- 15 mée ennemie est plus forte, il est vrai; elle est composée de ces vieilles bandes walonnes, italiennes et espagnoles, qu'on n'avait $\mathrm{pu}$ rompre jusqu'alors. Mais pour combien fallait-il compter le courage qu'inspirait à nos troupes le besoin pressant de l'État, les avantages passés, et un jeune prince du sang qui portait la victoire dans ses 20 yeux? Don Francisco de Mellos $^{5}$ l'attend de pied ferme; et sans pouvoir reculer, les deux généraux et les deux armées semblent avoir voulu se renfermer dans des bois et dans des marais, pour décider leur querelle, comme deux braves, en champ clos. Alors que ne viton pas? Le jeune prince parut un autre homme. Touchée d'un si 25 digne objet, sa grande âme se déclara toute entière: son courage croissait avec les périls, et ses lumières avec son ardeur. A la nuit qu'il fallut passer en présence des ennemis, comme un vigilant capitaine, il reposa le dernier; mais jamais il ne reposa plus paisiblement. A la veille d'un si grand jour, et dès la première bataille, il est tran- 30 quille, tant il se trouve dans son naturel: et on sait que le lendemain, à l'heure marquée, il fallut réveiller d'un profond sommeil cet autre Alexandre. Le voyez-vous, comme il vole ou à la victoire ou à

1 Daniel viii, 6-7.

2 Louis de Bourbon (1621-1686), prince de Condé, was one of the greatest generals of the seventeenth century. During his father's life his title was duc d'Enghien.

${ }^{3}$ Louis XIV was born in 1638 ; his father, Louis XIII, died in 1643 .

4 At Rocroi, in 1643 , Condé, against the advice of his elders, attacked the Spaniards and defeated them.

5 Francisco Manoel de Mello (161 I-1666), a Portuguese historian and poet, and soldier in the Spanish service. 
la mort? Aussitôt qu'il eut porté de rang en rang l'ardeur dont il était animé, on le vit presque en même temps pousser l'aile droite des ennemis, soutenir la nôtre ébranlée, rallier le Français à demi vaincu, mettre en fuite l'Espagnol victorieux, porter partout la terreur, et 5 étonner de ses regards étincelants ceux qui échappaient à ses coups. Restait cette redoutable infanterie de l'armée d'Espagne, dont les gros , bataillons serrés, semblables à autant de tours, mais à des tours qui sauraient réparer leurs brèches, demeuraient inébranlables au milieu de tout le reste en déroute, et lançaient des feux de toutes parts. Trois Io fois le jeune vainqueur s'efforça de rompre ces intrépides combattants : trois fois il fut repoussé par le valeureux comte de Fontaines, ${ }^{1}$ qu'on voyait porté dans sa chaise, et, malgré ses infirmités, montrer qu'une âme guerrière est maîtresse du corps qu'elle anime. Mais enfin il faut céder. C'est en vain qu'à travers des bois, avec sa cavalerie toute

I 5 fraîche, Bek ${ }^{2}$ précipite sa marche pour tomber sur nos soldats épuisés : le prince l'a prévenu: les bataillons enfoncés demandent quartier: mais la victoire va devenir plus terrible pour le duc d'Enghien que le combat. Pendant qu'avec un air assuré il s'avance pour recevoir la parole de ces braves gens, ceux-ci, toujours en garde, craignent la sur20 prise de quelque nouvelle attaque: leur effroyable décharge met les nôtres en furie: on ne voit plus que carnage: le sang enivre le soldat, jusqu'à ce que le grand prince, qui ne put voir égorger ces lions comme de timides brebis, calma les courages émus, et joignit au plaisir de vaincre celui de pardonner. Quel fut alors l'étonnement de ces vieilles

25 troupes et de leurs braves officiers, lorsqu'ils virent qu'il n'y avait plus de salut pour eux qu'entre les bras du vainqueur? De quels yeux regardèrent-ils le jeune prince, dont la victoire avait relevé la haute contenance, à qui la clémence ajoutait de nouvelles grâces? Qu'il eût encore volontiers sauvé la vie au brave comte de Fontaines! Mais il 3o se trouva par terre, parmi ces milliers de morts dont l'Espagne sent encore la perte. Elle ne savait pas que le prince qui lui fit perdre tant de ses vieux régiments à la journée de Rocroi, en devait achever les restes dans les plaines de Lens. ${ }^{8}$ Ainsi la première victoire fut le gage de beaucoup d'autres. Le prince fléchit le genou, et dans le champ de 35 bataille rend au Dieu des armées la gloire qu'il lui envoyait. Là on

1 Paul Bernard, comte de Fontaines or Fuentes (1570-1643), was killed at Rocroi.

2 Governor of Luxembourg and commander in the Spanish service. He was seriously wounded at Lens in 1648 .

3 Condé won a victory at Lens, in 1648 , over the archduke Leopold. 
célébra Rocroi délivré, les menaces d'un redoutable ennemi tournées à sa honte, la régence affermie, la France en repos, et un règne, qui devait être si beau, commencé par un si heureux présage. L'armée commença l'action de grâces ; toute la France suivit: on y élevait jusqu'au ciel le coup d'essai du duc d'Enghien: c'en serait assez pour 5 illustrer une autre vie que la sienne; mais pour lui, c'est le premier pas de sa course.

— "Oraison funèbre du prince de Condé " 


\section{LOUIS BOURDALOUE}

Bourges, I632-I 704 , Paris

At the age of sixteen Bourdaloue entered the order of the Jesuits, and, after completing his studies, taught under them until 1659 . For the next ten years he preached in the provinces, then took up his work in Paris, at the moment when Bossuet became the preceptor to the Dauphin, and began the series of Advent and Lenten sermons which made him the most popular court preacher France had known. During the last years of his peculiarly uneventful and austere life he devoted himself largely to charitable enterprises.

His works consist of his sermons, which are moral rather than dogmatic, concrete rather than abstract, and developed and expressed with simplicity, clearness, and force.

\section{L'ABUS DES RICHESSES}

Il suffit d'être riche pour tirer, quoique injustement, toutes ces conséquences avantageuses : qu'on n'a plus besoin de personne ; qu'on doit tenir tout le monde dans la dépendance; qu'on peut, sans obstacle et sans contradiction, se rendre délicat, impérieux, bizarre; qu'on est 5 au-dessus de la censure, et comme en pouvoir de faire impunément toutes choses ; qu'on est sûr de l'approbation et de la louange, ou pour mieux dire, de l'adulation et de la flatterie; que, sans mérite, on a ce qui tient lieu de tout mérite. Conséquences dont se laissent infatuer, non seulement les esprits populaires et bornés, mais les sages mêmes, Io et ceux qui, du reste, auraient de la solidité ; en sorte que les uns et les autres, éblouis de l'éclat qui les environne, et enivrés de leur fortune, se disent à eux-mêmes, aussi bien que le pharisien : ... je ne suis pas comme le reste des hommes, et le reste des hommes n'est pas comme moi. . .

I 5 N'avoir besoin de personne, premier effet de l'opulence, et disposition prochaine et infaillible à mépriser tout le monde. Dans l'indépendance où se trouve le riche mondain, et dans l'état où le met sa fortune de se pouvoir passer du secours d'autrui, de l'amitié d'autrui, des grâces d'autrui, il ne considère plus que lui-même, et il ne vit plus 20 que pour lui-même. Affabilité, doucèur, patience, déférence, ce sont des noms qu'il ne connaît point, parce qu'ils expriment des vertus 
dont il ne fait aucun usage, et sans lesquelles il a de quoi se soutenir. Qu'ai-je affaire de celui-ci, et que me reviendra-t-il d'avoir des égards pour celui-là? Enflé qu'il est de ce sentiment, il ne sait ce que c'est que de céder, que de s'abaisser, que de plier, dans des occasions néanmoins où la charité et la raison le demandent. . . .

Voir tout le monde dans la dépendance, c'est-à-dire, se voir recherché de tout le monde, redouté de tout le monde, obéi de tout le monde, autre effet de la richesse; et qu'y a-t-il de plus propre à entretenir la présomption d'une âme superbe? On sait bien que l'humiliation d'un riche, s'il voulait se rendre justice, serait de penser quels sont ces io serviteurs, et ces amis prétendus dont il se glorifie: amis, serviteurs que le seul intérêt conduit, et qui, s'attachant à sa fortune, n'ont souvent qu'un fonds de mépris et qu'une secrète haine pour sa personne. Mais l'orgueil, ingénieux à se tromper, ne laisse pas de profiter de cela même, se faisant, sinon une douceur, au moins une gloire, d'avoir 15 sous ce nom d'amis beaucoup de mercenaires et beaucoup d'esclaves. S'il n'a pas de quoi se faire aimer, il a de quoi se faire craindre; et, soit qu'on l'aime ou qu'on le haïsse, c'est toujours un sujet de complaisance pour lui de voir qu'on est intéressé à le ménager. De là vient, dit le plus sage des hommes, Salomon ${ }^{1}$ (morale admirable, et dont 20 nous faisons à toute heure l'épreuve sensible), de là vient que le riche, par là même qu'il est riche, prétend avoir un titre pour devenir fâcheux, de difficile abord, d'humeur inégale, chagrin quand il lui plaît, impatient, colère; un titre pour rebuter les uns, pour choquer les autres, pour être à tous insupportable. . . .

Être en pouvoir de tout entreprendre et de tout faire avec impunité, troisième effet de l'abondance pour quiconque sait s'en prévaloir. Car où voit-on des riches, disait Salvien, ${ }^{2}$ déplorant les abus de son siècle ? et ne le puis-je pas dire comme lui, où voit-on des riches passer par la rigueur des lois? dans quel tribunal les punit-on? quelle justice 30 contre eux obtient-on, ou espère-t-on ? quelle intégrité ne corrompentils pas? quels arrêts si justes et si sévères n'éludent-ils pas? de quel mauvais pas, pour user de l'expression commune, un riche criminel et scélérat ne se tire-t-il pas hautement et tête levée; et de quel crime si noir ne trouve-t-il pas moyen de se laver? Les lois sont pour les 35 misérables, ajoutait le même Père; les châtiments, pour ceux à qui la pauvreté en pourrait déjà tenir lieu; mais, pour les riches, il n'y a

1 See Proverbs xviii.

2 Salvianus was a church father of the fifth century. 
qu'indulgence, que connivence, que tolérance ; l'équité la plus inflexible et le droit le plus rigoureux se tournent pour eux en faveur. Or voilà, reprend le prophète royal, ce qui les rend fiers et insolents. Ils ne sentent jamais la pointe de la correction, et ils ne sont point châtiés 5 comme les autres hommes. On ne les reprend point, on ne les confond point, on ne les condamne point, et c'est pour cela que l'orgueil se saisit d'eux et les remplit. ...

Enfin quiconque est riche est éminemment toutes choses, et sans mérite il a tout mérite. Il est noble sans naissance, savant sans étude, ıo brave sans valeur; il a la qualité, la probité, la prudence, l'habileté. Sans autre distinction que l'or et l'argent qu'il possède, il parvient aux honneurs. Par là il règne et il domine; par là il est chéri des grands et adoré des petits ; par là il n'y a point d'alliance où il ne prétende, point de rival sur qui il ne l'emporte; en un mot, par là il n'est exclu I 5 de rien et se fait ouverture à tout. Ne serait-ce pas une espèce de prodige, s'il savait alors se garantir de l'orgueil et se tenir dans les bornes d'une modestie chrétienne?

— «Sermon sur les richesses », part second

\section{LA MANIE DU JEU}

Vous le savez: on joue, mais sans retenue; et l'excès est tel, que ceux mêmes qui en sont coupables sont obligés de le condamner. Que. 20 j'en prenne à témoin un joueur de profession, et que devant Dieu je le prie de me répondre si son jeu ne va pas trop loin, je dis trop loin selon la raison, le christianisme et la conscience, il en conviendra. En effet, dans la plupart des jeux, surtout des jeux que l'usage du monde autorise le plus, il y a trois sortes d'excès opposés à la raison et à la 25 religion. Excès dans le temps qu'on y emploie, excès dans la dépense qu'on y fait, excès dans l'attachement et l'ardeur avec laquelle on s'y porte: tout cela contraire aux règles de la vraie piété et aux maximes éternelles de la loi de Dieu. Ne condamnons point les choses dans la spéculation. Disons ce qui se pratique et ce qui se passe devant nos 30 yeux. Un homme du monde qui fait du jeu sa plus commune et presque son unique occupation, qui n'a point d'affaire plus importante que le jeu, ou plutôt qui n'a point d'affaire si importante qu'il n'abandonne pour le jeu; qui regarde le jeu non point comme un divertissement passager propre à remettre l'esprit des fatigues d'un long travail et à 35 le distraire, mais comme un exercice réglé, comme un emploi, comme 
un état fixe et une condition; qui donne au jeu les journées entières, les semaines, les mois, toute la vie (car il y en a de ce caractère, et vous en connaissez): une femme qui se sent chargée d'elle-même jusqu'à ne pouvoir en quelque sorte se supporter, ni supporter personne, dès qu'une partie de jeu vient à lui manquer; qui n'a d'autre entretien que de son jeu, qui du. matin au soir n'a dans l'idée que son jeu; qui n'ayant pas, à l'entendre parler, assez de force pour soutenir quelques moments de réflexion sur les vérités du salut, trouve néanmoins assez de santé pour passer les nuits, dès qu'il est question de son jeu: dites-le-moi, mes chers auditeurs, cet homme, cette femme, gardent-ils ro dans le jeu la modération convenable? cela est-il chrétien?... .

Cependant d'un excès on tombe dans un autre. Excès dans le temps que l'on perd au jeu, et excès dans la dépense qu'on y fait. Jouer rarement, mais hasarder beaucoup chaque fois, ou hasarder peu, mais jouer continuellement, ce sont deux excès défendus l'un et l'autre ${ }_{15}$ par la loi de Dieu: mais au-dessus de l'un et de l'autre, un troisième excès c'est de jouer souvent et toujours de risquer beaucoup en jouant. Or ne vous y trompez pas, quand je dis un jeu où vous hasardez beaucoup, un gros jeu, je ne veux pas seulement parler des riches et des grands du siècle; je parle de tous en général et de chacun en parti- 20 culier, conformément aux facultés et à l'état. 'Tel jeu n'est rien pour celui-là, mais il est tout pour celui-ci. L'un peut aisément porter telle dépense, mais elle passe les forces de l'autre, et ce qui serait un léger dommage pour le premier doit avoir pour le second de fâcheuses suites. Ainsi, on a des dettes à payer, on a une nombreuse famille à 25 entretenir et des enfants à pourvoir, on a des domestiques à récompenser, on a des aumônes à faire et des pauvres à soulager. A peine les revenus y peuvent-ils suffire, et si l'on était fidèle à remplir ces devoirs, on ne trouverait plus rien, ou presque rien pour le jeu. Toutefois on veut jouer, et c'est un principe qu'on a tellement posé dans 30 le système de sa vie, que nulle considération n'en fera jamais revenir. On le veut à quelque prix que ce soit, et pour cela que fait-on? Voilà le désordre et l'iniquité la plus criante. Parce qu'on ne peut pas acquitter ses dettes si l'on joue, ou qu'on ne peut jouer si l'on acquitte ses dettes, on laisse languir des créanciers, on se rend insen- 35 sible aux cris de l'artisan et du marchand, on use d'industrie et de détours pour se soustraire à leurs justes poursuites et pour leur lier les mains ; on les remet de mois en mois, d'années en années, et ce sont des délais sans fin; on n'a rien, dit-on, à leur donner, et néanmoins 
on trouve de quoi jouer. Parce qu'on ne peut accorder ensemble le jeu et l'entretien d'une maison, on abandonne la maison, et l'on ménage tout pour le jeu; on voit tranquillement et de sang-froid des enfants manquer des choses les plus nécessaires; on plaint jusqu'aux 5 moindres frais, dès qu'il s'agit de subvenir à leurs besoins; on les éloigne de ses yeux, et on les confie à des étrangers, à qui l'on en donne la charge sans y ajouter les moyens de la soutenir; on ne les a pas actuellement ces moyens, à ce qu'on prétend, mais pourtant on a de quoi jouer. Parce qu'il faudrait diminuer de son jeu, si l'on voulait Io compter exactement avec des domestiques et les satisfaire, on reçoit leurs services, on les exige à la rigueur, et du reste on ne veut point entendre parler de récompense; c'est une matière sur laquelle il ne leur est pas permis de s'expliquer, et un discours dont on se tient offensé : des paroles, on leur en donnera libéralement; des promesses, I 5 on leur en fera tant qu'ils en demanderont; ils ne perdront rien dans l'avenir, mais à condition qu'ils perdront tout dans le présent, et que cet avenir, à force de le prolonger, ne viendra jamais: les affaires ne permettent pas encore de penser à eux, et cependant elles permettent de jouer. Parce que dans les nécessités publiques l'aumône coûterait, zo et que le jeu en pourrait souffrir, on ne connaît point ce commandement; on est témoin des misères du prochain, sans en être ému; ou si le cœur ne peut trahir ses sentiments naturels, l'esprit n'est que trop ingénieux à imaginer des prétextes pour en arrêter les effets : on est pauvre soi-même, ou volontiers on se dit pauvre lorsqu'il y a des 25 pauvres à soulager; mais on cesse de l'être dès que le moment et l'occasion se présentent de jouer. 'Tout cela veut dire qu'on sacrifie à son jeu les droits les plus inviolables et les intérêts les plus sacrés: que l'on fait du jeu sa première loi; que pour ne pas se détacher du jeu, on se détache de toute autre chose; et que dans la concurrence 30 de toute autre chose avec le jeu, quelque essentielle qu'elle soit par elle-même, on retient le jeu et l'on renonce à tout le reste. Or, comment appelez-vous cela ? et si ce n'est pas un excès, faites-m'en concevoir un autre plus condamnable. ...

Quel spectacle de voir un cercle de gens occupés d'un jeu qui les 35 possède, et qui seul est le sujet de toutes les réflexions de leur esprit et de tous les désirs de leur cœur! Quels regards fixes et immobiles, quelle attention! Il ne faut pas un moment les troubler, pas une fois les interrompre, surtout si l'envie du gain s'y mêle. Or elle y entre presque toujours. De quels mouvements divers l'âme est-elle agitée 
selon les divers caprices du hasard! De là les dépits secrets et les mélancolies; de là les aigreurs et les chagrins; de là les désolations et les désespoirs, les colères et les transports, les blasphèmes et les imprécations. Je n'ignore pas ce que la politesse du siècle vous a là-dessus appris, que sous un froid affecté et sous un air de dégagement et de liberté prétendue, elle vous enseigne à cacher tous ces sentiments et à les déguiser; qu'en cela consiste un des premiers mérites du jeu, et que c'est ce qui en fait la plus belle réputation. Mais si le visage est serein, l'orage en est-il moins violent dans le cœur? et n'est-ce pas alors une double peine, que de la ressentir tout entière au dedans, et ro d'être obligé, par je ne sais quel honneur, de la dissimuler au dehors? Voilà donc ce que le monde appelle divertissement ; mais ce que j'appelle, moi, passion, et une des plus tyranniques et des plus criminelles passions.

— "Sermon sur les divertissements du monde », Part second 


\section{JEAN DE LA BRUYÈRE}

Paris, $1645-1696$, Versailles

Jean de La liruyère came of a good bourgeois family. He received a careful education, and was admitted to the bar, but in 1673 he gave up law and bought a post in the revenue department at Caen, continuing, however, to live in Paris. This post he sold in 1687 . Meanwhile, in $168_{4}$, he had been appointed tutor to the grandson of the great Condé. The rest of his life was spent with the Condé family. In I 688 he brought out a translation of "The Characters" of Theophrastus, followed by "Les caractères ou les mœurs de ce siècle" from his own hand. The success of this volume led him to add considerably, in subsequent editions, to the number of his reflections. The first edition contained 418 articles; the eighth, published in 1694 , had grown to I I 19 , throughout which he pictured, with remarkable keenness of observation, wit, and satire, the life and society, the oppression and foibles, of his day.

In addition to "Les caractères," he left his "Iiscours de réception à l'Académie précédé d'une préface" (he was received into the Academy in 1693) and the "Dialogues sur le quiétisme," the latter unfinished at his death. The following selections are from "Les caractères."

Il y a dans l'art un point de perfection, comme de bonté ou de maturité dans la nature; celui qui le sent et qui l'aime a le goût parfait: celui qui le sent et qui aime en deçà ou au delà, a le goût défectueux. Il y a donc un bon et un mauvais goût, et l'on dispute des goûts 5 avec fondement.

Entre toutes les différentes expressions qui peuvent rendre une seule de nos pensées, il n'y en a qu'une qui soit la bonne: on ne la rencontre pas toujours en parlant ou en écrivant; il est vrai néanmoins qu'elle existe, que tout ce qui ne l'est point est faible et ne satisfait ro point un homme d'esprit qui veut se faire entendre.

Un bon auteur, et qui écrit avec soin, éprouve souvent que l'expression qu'il cherchait depuis longtemps sans la connaître et qu'il a enfin trouvée est celle qui était la plus simple, la plus naturelle, qui semblait devoir se présenter d'abord et sans effort.

I5 Ceux qui écrivent par humeur sont sujets à retoucher à leurs ouvrages; comme elle n'est pas toujours fixe et qu'elle varie en eux 
selon les occasions, ils se refroidissent bientôt pour les expressions et les termes qu'ils ont le plus aimés.

Quand une lecture vous élève l'esprit, et qu'elle vous inspire des sentiments nobles et courageux, ne cherchez pas une autre règle pour juger de l'ouvrage: il est bon et fait de main d'ouvrier.

J'approche d'une petite ville, et je suis déjà sur une hauteur d'où je la découvre. Elle est située à mi-côte; une rivière baigne ses murs et coule ensuite dans une belle prairic; elle a une forêt épaisse qui la couvre des vents froids et de l'aquilon. Je la vois dans un jour si favorable, que je compte ses tours et ses clochers; elle me parait peinte 10 sur le penchant de la colline. Je me récrie et je dis: Quel plaisir de vivre sous un si beau ciel et dans ce séjour si délicieux! Je descends dans la ville, où je n'ai pas couché deux nuits, que je ressemble à ceux qui l'habitent: j'en veux sortir.

Un homme fort riche peut manger des entremets, faire peindre ses 15 lambris et ses alcôves, jouir d'un palais à la campagne et d'un autre à la ville, avoir un grand équipage, mettre un duc dans sa famille et faire de son fils un grand seigneur : cela est juste et de son ressort ; mais il appartient peut-être à d'autres de vivre contents.

La vie est courte et ennuyeuse; elle se passe toute à désirer. L'on 20 remet à l'avenir son repos et ses joies, à cet âge souvent où les meilleurs biens ont déjà disparu, la santé et la jeunesse. Ce temps arrive, qui nous surprend encore dans les désirs : on en est là, quand la fièvre nous saisit et nous éteint; si l'on eût guéri, ce n'était que pour désirer plus longtemps.

Il n'y a pour l'homme que trois événements : naître, vivre et mourir: il ne se sent pas naître, il souffre à mourir, et il oublie de vivre.

\section{ROMAN D'ÉMIRE}

Il y avait à Simyrne une très belle fille qu'on appelait Émire, et qui était moins connue dans toute la ville par sa beauté que par la sévérité de ses mœurs, et surtout par l'indifférence qu'elle conservait pour tous 30 les hommes, qu'elle voyait, disait-elle, sans aucun péril, et sans d'autres dispositions que celles où elle se trouvait pour ses amis ou pour ses frères. Elle ne croyait pas la moindre partie de toutes les folies qu'on 
disait que l'amour avait fait faire dans tous les temps; et celles qu'elle avait vues elle-même, elle ne les pouvait comprendre; elle ne connaissait que l'amitié. Une jeune et charmante personne, à qui elle devait cette expérience, ${ }^{1}$ la lui avait rendue si douce qu'elle ne pensait qu'à 5 la faire durer, et n'imaginait pas par quel autre sentiment elle pourrait jamais se refroidir sur celui de l'estime et de la confiance, dont elle était si contente. Elle ne parlait que d'Euphrosine: c'était le nom de cette fidèle amie ; et tout Smyrne ne parlait que d'elle et d'Euphrosine : leur amitié passait en proverbe. Émire avait deux frères qui étaient ıo jeunes, d'une excellente beauté, et dont toutes les femmes de la ville étaient éprises; et il est vrai qu'elle les aima toujours comme une sœur aime ses frères. Il y eut un prêtre de Jupiter qui avait accès dans la maison de son père, à qui elle plut, qui osa le lui déclarer, et ne s'attira que du mépris. Un vieillard, qui, se confiant en sa naissance et I 5 en ses grands biens, avait cu la même audace, eut aussi la même aventure. Elle triomphait cependant; et c'était jusqu'alors au milieu de ses frères, d'un prêtre et d'un vieillard, qu'elle se disait insensible. Il sembla que le Ciel voulût l'exposer à de plus fortes épreuves, qui ne servirent néanmoins qu'à la rendre plus vaine, et qu'à l'affermir dans zo la réputation d'une fille que l'amour ne pouvait toucher. De trois amants que ses charmes lui acquirent successivement, et dont elle ne craignit pas de voir toute la passion, le premier, dans un transport amoureux, se perça le sein à ses pieds; le second, plein de désespoir de n'être pas écouté, alla se faire tuer à la guerre de Crète; et le troi-

25 sième mourut de langueur et d'insomnie. Celui qui les devait venger n'avait pas encore paru. Ce vieillard, qui avait été si malheureux dans ses amours, s'en était guéri par des réflexions sur son âge et sur le caractère de la personne à qui il voulait plaire: il désira de continuer de la voir, et elle le souffrit. Il lui amena un jour son fils, qui était jeune, 30 d'une physionomie agréable, et qui avait une taille fort noble. Elle le vit avec intérêt; et comme il se tut beaucoup en la présence de son père, elle trouva qu'il n'avait pas assez d'esprit, et désira qu'il en eût eu davantage. Il la vit seul, parla assez, et avec esprit ; mais comme il la regarda peu, et qu'il parla encore moins d'elle et de sa beauté, elle 35 fut surprise et comme indignée qu'un homme si bien fait et si spirituel ne fût pas galant. Elle s'entretint de lui avec son amie, qui voulut le voir. Il n'eut des yeux que pour Euphrosine; il lui dit qu'elle était belle : et Émire, si indifférente, devenue jalouse, comprit que Ctésiphon 
était persuadé de ce qu'il disait, et que non seulement il était galant, mais même qu'il était tendre. Elle se trouva depuis ce temps moins libre avec son amie. Elle désira de les voir ensemble une seconde fois, pour être plus éclaircie; et une seconde entrevue lui fit voir encore plus qu'elle ne craignait de voir, et changea ses soupçons en ccrtitude. Elle s'éloigne d'Euphrosine, ne lui connaît plus le mérite qui l'avait charmée, perd le goût de sa conversation: elle ne l'aime plus; et ce changement lui fait sentir que l'amour dans son cœur a pris la place de l'amitié. Ctésiphon et Euphrosine se voient tous les jours, s'aiment, songent à s'épouser, s'épousent. La nouvelle s'en répand par toute la so ville; et l'on publie que deux personnes enfin ont eu cette joie si rare de se marier à ce qu'ils aimaient. Emire l'apprend, et s'en désespère. Elle ressent tout son amour: elle recherche Euphrosine pour le seul plaisir de revoir Ctésiphon; mais ce jeune mari est encore l'amant de sa femme, et trouve une maîtresse dans une nouvelle épouse; il ne 15 voit dans Émire que l'amie d'une personne qui lui est chère. Cette fille infortunée perd le sommeil, et ne veut plus manger: elle s'affaiblit; son esprit s'égare; elle prend son frère pour Ctésiphon, et elle lui parle comme à un amant. Elle se détrompe, rougit de son égarement: elle retombe bientôt dans de plus grands, et n'en rougit plus ; 20 elle ne les connaît plus.' Alors elle craint les hommes, mais trop tard; c'est sa folie. Elle a des intervalles où sa raison lui revient, et où elle gémit de la retrouver. La jeunesse de Smyrne, qui l'a vue si fière et si insensible, trouve que les dieux l'ont trop punie.

\section{LE DISEUR DE NOUVELLES}

Arrias a tout lu, a tout vu, il veut le persuader ainsi; c'est un 25 homme universel, et il se donne pour tel; il aime mieux mentir que de se taire ou de paraître ignorer quelque chose. On parle à la table d'un grand d'une cour du Nord: il prend la parole et l'ôte à ceux qui allaient dire ce qu'ils en savent; il s'oriente dans cette région lointaine comme s'il en était originaire; il discourt des mœurs de cette cour, des 30 femmes du pays, de ses lois et de ses coutumes; il récite des historiettes qui y sont arrivées; il les trouve plaisantes, et il en rit le premier jusqu'à éclater. Quelqu'un se hasarde de le contredire et lui prouve nettement qu'il dit des choses qui ne sont pas vraies. Arrias ne se trouble point, prend feu au contraire contre l'interrupteur. "Je n'a- 35 vance, lui dit-il, je ne raconte rien que je ne sache d'original; je l'ai 
appris de Séthon, ambassadeur de France dans cette cour, revenu à Paris depuis quelques jours, que je connais familièrement, que j'ai fort interrogé, et qui ne m'a caché aucune circonstance.» Il reprenait le fil de sa narration avec plus de confiance qu'il ne l'avait commencée, 5 lorsque l'un des conviés lui dit: "C'est Sethon à qui vous parlez, luimême, et qui arrive de son ambassade. »

\section{LE RICHE}

Giton a le teint frais, le visage plein et les joues pendantes, l'œil fixe et assuré, les épaules larges, l'estomac haut, ${ }^{1}$ la démarche ferme et délibérée. Il parle avec confiance; il fait répéter celui qui l'entreso tient, et il ne goûte que médiocrement tout ce qu'il lui dit. Il déploie un ample mouchoir, et se mouche avec grand bruit; il crache fort loin, et il éternue fort haut. Il dort le jour, il dort la nuit, et profondément; il ronfle en compagnie. Il occupe à table et à la promenade plus de place qu'un autre; il tient le milieu en se promenant avec ses I5 égaux; il s'arrête, et l'on s'arrête; il continue de marcher, et l'on marche; tous se règlent sur lui. Il interrompt, il redresse ceux qui ont la parole; on ne l'interrompt pas, on l'écoute aussi longtemps qu'il veut parler; on est de son avis, on croit les nouvelles qu'il débite. S'il s'assied, vous le voyez s'enfoncer dans un fauteuil, croiser les jambes

2o l'une sur l'autre, froncer le sourcil, abaisser son chapeau sur ses yeux pour ne voir personne, ou le relever ensuite, et découvrir son front par fierté et par audace. Il est enjoué, grand rieur, impatient, présomptueux, colère, libertin, politique, mystérieux sur les affaires du temps; il se croit des talents et de l'esprit. Il est riche.

\section{LE PAUVRE}

25 Phédon a les yeux creux, le teint échauffé, ${ }^{2}$ le corps sec et le visage maigre : il dort peu, et d'un sommeil fort léger; il est abstrait, rêveur, et il a, avec de l'esprit, l'air d'un stupide; il oublie de dire ce qu'il sait, ou de parler d'événements qui lui sont connus; et s'il le fait quelquefois, il s'en tire mal; il croit peser à ceux à qui il parle; il conte briè30 vement, mais froidement; il ne se fait pas écouter, il ne fait point rire. Il applaudit, il sourit à ce que les autres lui disent, il est de leur avis ; il court, il vole pour leur rendre de petits services; il est complaisant, flatteur, empressé. Il est mystérieux sur ses affaires, quelquefois 
menteur; il est superstitieux, scrupuleux, timide. Il marche doucement et légèrement, il semble craindre de fouler la terre ; il marche les yeux baissés, et il n'ose les lever sur ceux qui passent. Il n'est jamais du nombre de ceux qui forment un cercle pour discourir; il se met derrière celui qui parle, recueille furtivement ce qui se dit, et il se retire si on le regarde. Il n'occupe point de lieu, il ne tient point de place; il va les épaules serrées, le chapeau abaissé sur ses yeux pour n'être point vu; il se replie et se renferme dans son manteau : il n'y a point de rues ni de galeries si embarrassées et si remplies de monde, ou il ne trouve moyen de passer sans effort, et de se couler sans être aperçu. 10 Si on le prie de s'asseoir, il se met à peine sur le bord d'un siège ; il parle bas dans la conversation, et il articule mal ; libre néanmoins sur les affaires publiques, chagrin contre le siècle, médiocrement prévenu des ${ }^{1}$ ministres et du ministère. Il n'ouvre la bouche que pour répondre ; il tousse, il se mouche sous son chapeau; il crache presque sur soi, et is il attend qu'il soit seul pour éternuer, ou, si cela lui arrive, c'est à l'insu de la compagnie; il n'en coûte à personne ni salut ni compliment. Il est pauvre.

\section{LA COUR}

L'on parle d'une région ${ }^{2}$ où les vieillards sont galants, polis et civils ; les jeunes gens, au contraire, durs, féroces, sans mœurs ni politesse; ils 20 se trouvent affranchis de la passion des femmes dans un âge où l'on commence ailleurs à la sentir; ils leur préfèrent des repas, des viandes et des amours ridicules. Celui-là, chez eux, est sobre et modéré, qui ne s'enivre que de vin; l'usage trop fréquent qu'ils en ont fait le leur a rendu insipide. Ils cherchent à réveiller leur goût déjà éteint par des 25 eaux-de-vie et par toutes les liqueurs les plus violentes; il ne manque à leur débauche que de boire de l'eau-forte. Les femmes du pays précipitent le déclin de leur beauté par des artifices qu'elles croient servir à les rendre belles: leur coutume est de peindre leurs lèvres, leurs joues, leurs sourcils et leurs épaules, qu'elles étalent avec leur gorge, leurs bras 30 et leurs oreilles, comme si elles craignaient de cacher l'endroit par où elles pourraient plaire, ou de ne pas se montrer assez. Ceux qui habitent cette contrée ont une physionomie qui n'est pas nette, mais confuse, embarrassée dans une épaisseur de cheveux étrangers qu'ils préfèrent aux naturels, et dont ils font un long tissu pour couvrir leur tête: il 35 descend à la moitié du corps, change les traits et empêche qu'on ne 
connaisse les hommes à leur visage. Ces peuples d'ailleurs ont leur dieu et leur roi. Les grands de la nation s'assemblent tous les jours, à une certaine heure, dans un temple qu'ils nomment église. Il y a au fond de ce temple un autel consacré à leur dieu, où un prêtre célèbre 5 des mystères qu'ils appellent saints, sacrés et redoutables. Les grands forment un vaste cercle au pied de cet autel, et paraissent debout, le dos tourné directement au prêtre et aux saints mystères, et les faces élevées vers leur roi, que l'on voit à genoux sur une tribune, et à qui ils semblent avoir tout l'esprit et tout le cœur appliqués. On ne laisse Io pas de voir dans cet usage une espèce de subordination, car ce peuple paraît adorer le prince, et le prince adorer Dieu. Les gens du pays le nomment ***; il est à quelque quarante-huit degrés d'élévation du pôle, et à plus de onze cents lieues de mer des Iroquois et des Hurons.

\section{L'ÉGOÏSTE}

Gnathon ne vit que pour soi, et tous les hommes ensemble sont à son I 5 égard comme s'ils n'étaient point. Non content de remplir à une table la première place, il occupe lui seul celle de deux autres; il oublie que le repas est pour lui et pour toute la compagnie. Il se rend maître du plat, et fait son propre de ${ }^{1}$ chaque service; il ne s'attache à aucun des mets qu'il n'ait achevé d'essayer de tous ; il voudrait pouvoir les savou-

20 rer tous tout à la fois. Il ne se sert à table que de ses mains; il manie les viandes, les remanie, démembre, déchire, et en use de manière qu'il faut que les conviés, s'ils veulent manger, mangent ses restes. Il ne leur épargne aucune de ces malpropretés dégoûtantes, capables d'ôter l'appétit aux plus affamés; le jus et les sauces lui dégouttent du men25 ton et de la barbe; s'il enlève un ragoût de dessus un plat, il le répand en chemin dans un autre plat et sur la nappe: on le suit à la trace ; il mange haut et avec grand bruit; il roule les yeux en mangeant ; la table est pour lui un râtelier; il écure ses dents, et il continue à manger. Il se fait, quelque part où il se trouve, une manière d'établisse30 ment, et ne souffre pas d'être plus pressé au sermon ou au théâtre que dans sa chambre. Il n'y a dans un carrosse que les places du fond qui lui conviennent: dans toute autre, si on veut l'en croire, il pâlit et tombe en faiblesse. S'il fait un voyage avec plusieurs, il les prévient dans les hôtelleries, et il sait toujours se conserver dans la meilleure 35 chambre le meilleur lit. Il tourne tout à son usage; ses valets, ceux 1 "appropriates." 
d'autrui, courent dans le même temps pour son service; tout ce qu'il trouve sous sa main lui est propre, hardes, équipages. Il embarrasse tout le monde, ne se contraint pour personne, ne plaint personne, ne connait de maux que les siens, que sa réplétion et sa bile, ne pleure point la mort des autres, n'appréhende que la sienne, qu'il rachèterait volontiers de l'extinction du genre humain.

\section{CORNEILLE ET RACINE}

Corneille ne peut être égalé dans les endroits où il excelle: il a pour lors un caractère original et inimitable; mais il est inégal. Ses premières comédies sont sèches, languissantes, et ne laissaient pas espérer qu'il dût ensuite aller si loin; comme ses dernières font qu'on s'étonne ro qu'il ait pu tomber de si haut. Dans quelques-unes de ses meilleures pièces, il y a des fautes inexcusables contre les mœurs, un style de déclamateur qui arrête l'action et la fait languir, des négligences dans les vers et dans l'expression qu'on ne peut comprendre en un si grand homme. Ce qu'il y a eu en lui de plus éminent, c'est l'esprit, qu'il avait i 5 sublime, auquel il a été redevable de certains vers, les plus heureux qu'on ait jamais lus ailleurs, de la conduite de son théâtre, qu'il a quelquefois hasardée contre les règles des anciens, et enfin de ses dénoûments, car il ne s'est pas toujours assujetti au goût des Grecs et à leur grande simplicité : il a aimé au contraire à charger la scène d'événe- 20 ments dont il est presque toujours sorti avec succès : admirable surtout par l'extrême variété et le peu de rapport qui se trouve pour le dessein entre un si grand nombre de poèmes qu'il a composés. Il semble qu'il y ait plus de ressemblance dans ceux de Racine, et [qu'ils] tendent un peu plus à une même chose; mais il est égal, soutenu, toujours le 25 même partout, soit pour le dessein et la conduite de ses pièces, qui sont justes, régulières, prises dans le bon sens et dans la nature, soit pour la versification, qui est correcte, riche dans ses rimes, élégante, nombreuse, harmonieuse : exact, riche imitateur des anciens, dont il a suivi scrupuleusement la netteté et la simplicité de l'action; à qui le 30 grand et le merveilleux n'ont pas même manqué, ainsi qu'à Corneille, ni le touchant ni le pathétique. Quelle plus grande tendresse que celle qui est répandue dans tout le Cid, dans Polyeucte et dans les Horaces? Quelle grandeur ne se remarque point en Mithridate, en Porus et en Burrhus? Ces passions encore favorites des anciens, que les tragiques 35 aimaient à exciter sur les théâtres, et qu'on nomme la terreur et la 
pitié, ont été connues de ces deux poètes. Oreste, dans l'Andromaque de Racine, et Phèdre du même auteur, comme l'CEdipe et les Horaces de Corneille, en sont la preuve. Si cependant il est permis de faire entre eux quelque comparaison et les marquer l'un et l'autre par ce 5 qu'ils ont eu de plus propre et par ce qui éclate le plus ordinairement dans leurs ouvrages, peut-être qu'on pourrait parler ainsi: Corneille nous assujettit à ses caractères et à ses idées, Racine se conforme aux nôtres ; celui-là peint les hommes comme ils devraient être, celui-ci les peint tels qu'ils sont. Il y a plus dans le premier de ce que l'on admire, ro et de ce que l'on doit même imiter; il y a plus dans le second de ce que l'on reconnait dans les autres, ou de ce que l'on éprouve dans soimême. L'un élève, étonne, maitrise, instruit; l'autre plaît, remue, touche, pénètre. Ce qu'il y a de plus beau, de plus noble et de plus impérieux dans la raison, est manié par le premier; et par l'autre, ce I 5 qu'il y a de plus flatteur et de plus délicat dans la passion. Ce sont dans celui-là des maximes, des règles, des préceptes ; et dans celui-ci du goût et des sentiments. L'on est plus occupé aux pièces de Corneille; l'on est plus ébranlé et plus attendri à celles de Racine. Corneille est plus moral, Racine plus naturel. Il semble que l'un imite 2o Sophocle, et que l'autre doit plus à Euripide.

\section{LES PAYSANS}

L'on voit certains animaux farouches, des mâles et des femelles, répandus par la campagne, noirs, livides, et tout brûlés du soleil, attachés à la terre qu'ils fouillent et qu'ils remuent avec une opiniâtreté invincible; ils ont comme une voix articulée, et, quand ils se lèvent sur 25 leurs pieds, ils montrent une face humaine; et en effet ils sont des hommes. Ils se retirent la nuit dans des tanières, où ils vivent de pain noir, d'eau et de racines; ils épargnent aux autres hommes la peine de semer, de labourer et de recueillir pour vivre, et méritent ainsi de ne pas manquer de ce pain qu'ils ont semé. 


\title{
FRANÇOIS DE SALIGNAC DE LA MOTHE-FÉNELON
}

\author{
Château de Fénelon, in Périgord, 1651 - 17 I 5 , Cambrai
}

Coming of one of France's old families, Fénelon received a very careful education, first at home, and then in Paris, and was ordained priest in 1675 , at the age of twenty-four. The eloquence of his sermons, his "Traité de l'éducation des filles" (written in $168 \mathrm{I}$, published in $\mathrm{I} 687$ ), and the aid he rendered, at the request of the king, in calming the disturbance aroused by the revocation of the Edict of Nantes, began to attract attention to him, and in I 689 he was appointed tutor to the duke of Burgundy, grandson of Louis XIV. Fénelon was a man of remarkable refinement, grace, and modesty, and his adaptability, added to gentle firmness, fitted him peculiarly to succeed with a pupil as impetuous and passionate as the duke of Burgundy. For the use of his pupil he wrote some "Fables" in prose, the "Dialogues des morts," and the "Aventures de Télémaque," in which the political principles involved were directly opposed to those of the reign of Louis XIV. He was elected to the Academy in I 693, and was made archbishop of Cambrai in I695; two years later his defense of Quietism, in the "Maximes des saints" (1697), brought upon him the ill will of Bossuet, of the Papal court, and of Louis XIV. The remaining years of his life were spent in the administration of his diocese, though he meanwhile found time to write, among other things, the "Traité de l'existence de Dieu" (I 7 I 3 ), and the "Lettre à l'Académie française" (published in 1716$)$, one of the most important critical works after the "Art poétique" of Boileau.

\section{LA BÉTIQUE ${ }^{1}$}

Le fleuve Bétis ${ }^{2}$ coule dans un pays fertile, et sous un ciel doux, qui est toujours serein. Le pays a pris le nom du fleuve, qui se jette dans le grand Océan, assez près des colonnes d'Hercule, et de cet endroit où la mer furieuse, rompant ses digues, sépara autrefois la terre de Tharsis ${ }^{3}$ d'avec la grande Afrique. Ce pays semble avoir conservé les délices de l'âge d'or. Les hivers y sont tièdes, et les rigoureux aquilons n'y soufflent jamais. L'ardeur de l'été y est toujours tempérée par des zéphirs rafraîchissants, qui viennent adoucir l'air vers le milieu du jour.

I One of the three divisions of ancient Spain, situated in the south.

2 Now the Guadalquivir.

3 Tarshish. 
Ainsi toute l'année n'est qu'un heureux hymen du printemps et de l'automne, qui semblent se donner la main. La terre, dans les vallons et dans les campagnes unies, porte chaque année une double moisson. Les chemins y sont bordés de lauriers, de grenadiers, de jasmins, et 5 d'autres arbres toujours verts et toujours fleuris. Les montagnes sont couvertes de troupeaux, qui fournissent des laines fines recherchées de toutes les nations connues. Il y a plusieurs mines d'or et d'argent dans ce beau pays; mais les habitants, simples et heureux dans leur simplicité, ne daignent pas seulement compter l'or et l'argent parmi ıo leurs richesses; ils n'estiment que ce qui sert véritablement aux besoins de l'homme.

Quand nous avons commencé à faire notre commerce chez ces peuples, nous avons trouvé l'or et l'argent parmi eux employés aux mêmes usages que le fer; par exemple, pour des socs de charrue.

I 5 Comme ils ne faisaient aucun commerce au dehors, ils n'avaient besoin d'aucune monnaie. Ils sont presque tous bergers ou laboureurs. On voit en ce pays peu d'artisans: car ils ne veulent souffrir que les arts qui servent aux véritables nécessités des hommes; encore même la plupart des hommes en ce pays, étant adonnés à l'agriculture ou à con20 duire des troupeaux, ne laissent pas d'exercer les arts nécessaires pour leur vie simple et frugale.

Les femmes filent cette belle laine, et en font des étoffes fines d'une merveilleuse blancheur: elles font le pain, apprêtent à manger ; et ce travail leur est facile; car on vit en ce pays de fruits ou de lait, 25 et rarement de viande. Elles emploient le cuir de leurs moutons à faire une légère chaussure pour elles, pour leurs maris et pour leurs enfants; elles font des tentes, dont les unes sont de peaux cirées et les autres d'écorces d'arbres ; elles font et lavent tous les habits de la famille, et tiennent les maisons dans un ordre et une propreté admirables. Leurs

30 habits sont aisés à faire; car, en ce doux climat, on ne porte qu'une pièce d'étoffe fine et légère, qui n'est point taillée, et que chacun met à longs plis autour de son corps pour la modestie, lui donnant la forme qu'il veut.

Les hommes n'ont d'autres arts à exercer, outre la culture des terres 35 et la conduite des troupeaux, que l'art de mettre le bois et le fer en œuvre; encore même ne se servent-ils guère du fer, excepté pour les instruments nécessaires au labourage. Tous les arts qui regardent l'architecture leur sont inutiles; car ils ne bâtissent jamais de maison. C'est, disent-ils, s'attacher trop à la terre, que de s'y faire une demeure 
qui dure beaucoup plus que nous; il suffit de se défendre des injures de l'air. Pour tous les autres arts estimés chez les Grecs, chez les Egyptiens, et chez tous les autres peuples bien policés, ils les détestent comme des inventions de la vanité et de la mollesse.

Quand on leur parle des peuples qui ont l'art de faire des bâtiments superbes, des meubles d'or et d'argent, des étoffes ornées de broderies et de pierres précieuses, des parfums exquis, des mets délicieux, des instruments dont l'harmonie charme, ils répondent en ces termes: Ces peuples sont bien malheureux d'avoir employé tant de travail et d'industrie à se corrompre eux-mêmes! Ce superflu amollit, enivre, ro tourmente ceux qui le possèdent: il tente ceux qui en sont privés, de vouloir l'acquérir par l'injustice et par la violence. Peut-on nommer bien un superflu qui ne sert qu'à rendre les hommes mauvais ? Les hommes de ces pays sont-ils plus sains et plus robustes que nous? vivent-ils plus longtemps? sont-ils plus unis entre eux ? mènent-ils une 15 vie plus libre, plus tranquille, plus gaie? Au contraire, ils doivent être jaloux les uns des autres, rongés par une lâche et noire envie, toujours agités par l'ambition, par la crainte, par l'avarice, incapables des plaisirs purs et simples, puisqu'ils sont esclaves de tant de fausses nécessités dont ils font dépendre tout leur bonheur.

C'est ainsi, continuait Adoam, que parlent ces hommes sages, qui n'ont appris la sagesse qu'en étudiant la simple nature. Ils ont horreur de notre politesse, et il faut avouer que la leur est grande dans leur aimable simplicité. Ils vivent tous ensemble sans partager les terres; chaque famille est gouvernée par son chef, qui en est le véritable roi. 25 Le père de famille est en droit de punir chacun de ses enfants ou petits-enfants qui fait une mauvaise action; mais, avant que de le punir, il prend les avis du reste de la famille. Ces punitions n'arrivent presque jamais ; car l'innocence des mœurs, la bonne foi, l'obéissance, et l'horreur du vice, habitent dans cette heureuse terre. Il semble 30 qu'Astrée, ${ }^{1}$ qu'on dit qui est retirée dans le ciel, est encore ici-bas cachée parmi ces hommes. Il ne faut point de juges parmi eux, car leur propre conscience les juge. Tous les biens sont communs: les fruits des arbres, les légumes de la terre, le lait des troupeaux, sont -des richesses si abondantes, que des peuples si sobres et si modérés 35 n'ont pas besoin de les partager. Chaque famille, errante dans ce beau pays, transporte ses tentes d'un lieu en un autre, quand elle a consumé

1 The heroine in the "Astrée" (1607-1627), a pastoral novel by D'Urfé, came to represent more or less ideal perfection in woman. 
les fruits et épuisé les pâturages de l'endroit où elle s'était mise. Ainsi, ils n'ont point d'intérêts à soutenir les uns contre les autres, et ils s'aiment tous d'un amour fraternel que rien ne trouble. C'est le retranchement des vaines richesses et des plaisirs trompeurs, qui leur con5 serve cette paix, cette union et cette liberté. Ils sont tous libres et tous égaux. On ne voit parmi eux aucune distinction, que celle qui vient de l'expérience des sages vieillards, ou de la sagesse extraordinaire de quelques jeunes hommes qui égalent les vieillards consommés en vertu. La fraude, la violence, le parjure, les procès, les guerres ne Io font jamais entendre leur voix cruelle et empestée, dans ce pays chéri des dieux. Jamais le sang humain n'a rougi cette terre; à peine $y$ voit-on couler celui des agneaux. Quand on parle à ces peuples des batailles sanglantes, des rapides conquêtes, des renversements d'États qu'on voit dans les autres nations, ils ne peuvent assez s'étonner.

${ }_{15}$ Quoi! disent-ils, les hommes ne sont-ils pas assez mortels, sans se donner encore les uns aux autres une mort précipitée? La vie est si courte! et il semble qu'elle leur paraisse trop longue! Sont-ils sur la terre pour se déchirer les uns les autres, et pour se rendre mutuellement malheureux?

20 Au reste, ces peuples de la Bétique ne peuvent comprendre qu'on admire tant les conquérants qui subjuguent les grands empires. Quelle folie, disent-ils, de mettre son bonheur à gouverner les autres hommes, dont le gouvernement donne tant de peine, si on veut les gouverner avec raison, et suivant la justice! Mais pourquoi prendre plaisir à les

25 gouverner malgré eux? C'est tout ce qu'un homme sage peut faire, que de vouloir s'assujettir à gouverner un peuple docile dont les dieux l'ont chargé, ou un peuple qui le prie d'être comme son père et son pasteur. Mais gouverner les peuples contre leur volonté, c'est se rendre très misérable, pour avoir le faux honneur de les tenir dans

3o l'esclavage. Un conquérant est un homme que les dieux, irrités contre le genre humain, ont donné à la terre dans leur colère, pour ravager les royaumes, pour répandre partout l'effroi, la misère, le désespoir, et pour faire autant d'esclaves qu'il y a d'hommes libres. Un homme qui cherche la gloire ne la trouve-t-il pas assez en conduisant avec sagesse

35 ce que les dieux ont mis dans ses mains? Croit-il ne pouvoir mériter des louanges, qu'en devenant violent, injuste, hautain, usurpateur, et tyrannique sur tous ses voisins? Il ne faut jamais songer à la guerre, que pour défendre sa liberté. Heureux celui qui n'étant point esclave d'autrui, n'a point la folle ambition de faire d'autrui son esclave! 
Ces grands conquérants, qu'on nous dépeint avec tant de gloire, ressemblent à ces fleuves débordés qui paraissent majestueux, mais qui ravagent toutes les fertiles campagnes qu'ils devraient seulement arroser. . . .

Télémaque était ravi d'entendre ces discours d'Adoam, et il se réjouissait qu'il y eût encore au monde un peuple, qui, suivant la droite nature, fût si sage et si heureux tout ensemble. Oh! combien ces mœurs, disait-il, sont-elles éloignées des mœurs vaines et ambitieuses des peuples qu'on croit les plus sages! nous sommes tellement gâtés, qu'à peine pouvons-nous croire que cette simplicité si naturelle puisse io être véritable. Nous regardons les mœurs de ce peuple comme une belle fable, et il doit regarder les nôtres comme un songe monstrueux.

— "T'élémaque », Book VII

TABLEAU DES FUNÉRAILLES DE PHOCION PAR POUSSIN ${ }^{1}$

\section{Parrhasius, Poussin}

Parrhasius. Qu'avez-vous mis aux deux côtés de ce tableau, pour accompagner vos figures principales?

Poussin. Au côté droit sont deux ou trois arbres dont le tronc est 15 d'une écorce âpre et noueuse. Ils ont peu de branches, dont le vert, qui est un peu faible, se perd insensiblement dans le sombre azur du ciel. Derrière ces longues tiges d'arbres, on voit la ville d'Athènes.

Parrhasius. Il faut un contraste bien marqué dans le côté gauche.

Poussin. Le voici. C'est un terrain raboteux; on y voit des creux qui 20 sont dans une ombre très forte, et des pointes de roches fort éclairées. Là se présentent aussi quelques buissons assez sauvages. Il y a un peu au-dessus un chemin qui mène à un bocage sombre et épais : un ciel extrêmement clair donne encore plus de force à cette verdure sombre.

Parrhasius. Bon; voilà qui est bien. Je vois que vous savez le 25 grand art des couleurs, qui est de fortifier l'une par son opposition avec l'autre.

Poussin. Au-delà de ce terrain rude se présente un gazon frais et tendre. On y voit un berger appuyé sur sa houlette, et occupé à regarder ses moutons blancs comme la neige, qui errent en paissant dans une 30 prairie. Le chien du berger est couché et dort derrière lui. Dans cette

1 Parrhasios was a Greek painter of the fourth century в.C. Poussin (1594-1665) was a distinguished French painter; his "Obsequies of Phocion" (in the National Gallery, London), like most of his pictures, is at the same time a landscape and a historical painting. Phocion was an Athenian general, orator, and statesman, born about 400 B.C. 
campagne, on voit un autre chemin où passe un chariot traîné par des bœufs. Vous remarquez d'abord la force et la pesanteur de ces animaux, dont le cou est penché vers la terre, et qui marchent à pas lents. Un homme d'un air rustique est devant le chariot; une femme marche 5 derrière, et elle paraît la fidèle compagne de ce simple villageois. Deux autres femmes voilées sont sur le chariot.

Parrhasius. Rien ne fait un plus sensible plaisir que ces peintures champêtres. Nous les devons aux poètes. Ils ont commencé à chanter dans leurs vers les grâces naïves de la nature simple et sans art : nous ıo les avons suivis. Les ornements d'une campagne où la nature est belle font une image plus riante que toutes les magnificences que l'art a pu inventer.

Poussin. On voit au côté droit, dans ce chemin, sur un cheval alezan, un cavalier enveloppé dans un manteau rouge. Le cavalier et le I 5 cheval sont penchés en avant; ils semblent s'élancer pour courir avec plus de vitesse. Les crins du cheval, les cheveux de l'homme, son manteau, tout est flottant, et repoussé par le vent en arrière.

Parrhasius. Ceux qui ne savent que représenter des figures gracieuses n'ont atteint que le genre médiocre. Il faut peindre l'action et 2o le mouvement, animer les figures, et exprimer les passions de l'âme. Je vois que vous êtes bien entré dans le goût de l'antique.

Poussin. Plus avant on trouve un gazon sous lequel paraît un terrain de sable. Trois figures humaines sont sur cette herbe: il y en a une debout, couverte d'une robe blanche à grands plis flottants; les 25 deux autres sont assises auprès d'elle sur le bord de l'eau, et il y en a une qui joue de la lyre. Au bout de ce terrain couvert de gazon, on voit un bâtiment carré, orné de bas-reliefs et de festons, d'un bon goût d'architecture simple et noble. C'est sans doute un tombeau de quelque citoyen qui était mort peut-être avec moins de vertu, mais 3o plus de fortune que Phocion.

Parrhasius. Je n'oublie pas que vous m'avez parlé du bord de l'eau. Est-ce la rivière d'Athènes nommée Ilissus?

Poussin. Oui ; elle paraît en deux endroits aux côtés de ce tombeau. Cette eau est pure et claire: le ciel serein, qui est peint dans cette 35 eau, sert à la rendre encore plus belle. Elle est bordée de saules naissants et d'autres arbrisseaux tendres dont la fraîcheur réjouit la vue.

Parrhasius. Jusque-là il ne me reste rien à souhaiter. Mais vous avez encore un grand et difficile objet à me représenter; c'est là que je vous attends. 
Poussin. Quoi?

Parrhasius. C'est la ville. C'est là qu'il faut montrer que vous savez l'histoire, le costume, l'architecture.

Poussin. J'ai peint cette grande ville d'Athènes sur la pente d'un long coteau, pour la mieux faire voir. Les bâtiments y sont par degrés dans un amphithéâtre naturel. Cette ville ne paraît point grande du premier coup d'œil: on n'en voit près de soi qu'un morceau assez médiocre; mais le derrière qui s'enfuit découvre une grande étendue d'édifices.

Parrhasius. Y avez-vous évité la confusion?

Poussin. J'ai évité la confusion et la symétrie. J'ai fait beaucoup de bâtiments irréguliers; mais ils ne laissent pas de faire un assemblage gracieux, où chaque chose a sa place la plus naturelle. Tout se démêle et se distingue sans peine; tout s'unit et fait corps: ainsi il y a une confusion apparente, et un ordre véritable quand on l'observe de près. 15

Parrhasius. N'avez-vous pas mis sur le devant quelque principal édifice?

Poussin. J'y ai mis deux temples. Chacun a une grande enceinte comme il la doit avoir, où l'on distingue le corps du temple des autres bâtiments qui l'accompagnent. Le temple qui est à la main droite a 20 un portail orné de quatre grandes colonnes de l'ordre corinthien, avec un fronton et des statues. Autour de ce temple on voit des festons pendants : c'est une fête que j'ai voulu représenter suivant la vérité de l'histoire. Pendant qu'on emporte Phocion hors de la ville vers le bûcher, tout le peuple en joie et en pompe fait une grande solennité 25 autour du temple dont je vous parle. Quoique ce peuple paraisse assez loin, on ne laisse pas de remarquer sans peine une action de joie pour honorer les dieux. Derrière ce temple paraît une grosse tour très haute, au sommet de laquelle est une statue de quelque divinité. Cette tour est comme une grosse colonne.

Parrhasius. Où est-ce que vous en avez pris l'idée?

Poussin. Je ne m'en souviens plus: mais elle est sûrement prise dans l'antique, car jamais je n'ai pris la liberté de rien donner à l'antiquité qui ne fût tiré de ses monuments. On voit aussi auprès de cette tour un obélisque sacré. . . .

Parrhasius. Je ne suis pas encore content. Qu'avez-vous mis derrière toute cette ville?

Poussin. C'est un lointain où l'on voit des montagnes escarpées et assez sauvages. Il y en a une, derrière ces beaux temples et cette 
pompe si riante dont je vous ai parlé, qui est un roc tout nu et affreux. Il m'a paru que je devais faire le tour de la ville cultivé et gracieux, comme celui des grandes villes l'est toujours. Mais j'ai donné une certaine beauté sauvage au lointain, pour me conformer à l'histoire, 5 qui parle de l'Attique comme d'un pays rude et stérile.

Parrhasius. J'avoue que ma curiosité est bien satisfaite, et je serais jaloux pour la gloire de l'antiquité, si on pouvait l'être d'un homme qui l'a imitée si modestement.

— « Dialogues des morts », LII, Parrhasius et Poussin

\section{L'ÉLOQUENCE}

Il ne faut pas faire à l'éloquence le tort de penser qu'elle n'est qu'un Io art frivole, dont un déclamateur se sert pour imposer à la faible imagination de la multitude, et pour trafiquer de la parole : c'est un art très sérieux, qui est destiné à instruire, à réprimer les passions, à corriger les mœurs, à soutenir les lois, á diriger les délibérations publiques, à rendre les hommes bons et heureux. Plus un déclamateur ferait

15 d'efforts pour m'éblouir par les prestiges de son discours, plus je me révolterais contre sa vanité : son empressement pour faire admirer son esprit me paraîtrait le rendre indigne de toute admiration. Je cherche un homme sérieux, qui me parle pour moi, et non pour lui; qui veuille mon salut, et non sa vaine gloire. L'homme digne d'être écouté est 20 celui qui ne se sert de la parole que pour la pensée, et de la pensée que pour la vérité et la vertu. Rien n'est plus méprisable qu'un parleur de métier, qui fait de ses paroles ce qu'un charlatan fait de ses remèdes. ...

Le véritable orateur n'orne son discours que de vérités lumineuses, 25 que de sentiments nobles, que d'expressions fortes et proportionnées à ce qu'il tâche d'inspirer. Il pense, il sent, et la parole suit. "Il ne dépend point des paroles, " dit saint Augustin, «mais les paroles dépendent de lui.» ${ }^{1}$ Un homme qui a l'âme forte et grande, avec quelque facilité naturelle de parler et un grand exercice, ne doit jamais 30 craindre que les termes lui manquent; ses moindres discours auront des traits originaux que les déclamateurs fleuris ne pourront jamais imiter. Il n'est point esclave des mots; il va droit à la vérité. Il sait que la passion est comme l'âme de la parole. Il remonte d'abord au premier principe sur la matière qu'il veut débrouiller; il met ce principe

1 "De doctrina christiana," IV, XXVIII, 6I. 
dans son vrai point de vue; il le tourne et le retourne, pour y accoutumer ses auditeurs les moins pénétrants; il descend jusqu'aux dernières conséquences par un enchaînement court et sensible. Chaque vérité est mise en sa place par rapport au tout: elle prépare, elle amène, elle appuie une autre vérité qui a besoin de son secours. Cet arrangement sert à éviter les répétitions qu'on peut épargner au lecteur; mais il ne retranche aucune des répétitions par lesquelles il est essentiel de ramener souvent l'auditeur au point qui décide lui scul de tout.

Il faut lui montrer souvent la conclusion dans le principe. I) ce ro principe, comme du centre, se répand la lumière sur toutes les parties de cet ouvrage; de même qu'un peintre place dans son tableau le jour, en sorte que d'un seul endroit il distribue à chaque objet son degré de lumière. 'Tout le discours est un; il se réduit à une seule proposition mise au plus grand jour par des tours variés. Cette unité de dessein 15 fait qu'on voit d'un seul coup d'œil l'ouvrage entier, comme on voit de la place publique d'une ville toutes les rues et toutes les portes, quand toutes les rues sont droites, égales et en symétrie. Le discours est la proposition développée; la proposition est le discours en abrégé. . . .

Quiconque ne sent pas la beauté et la force de cette unité et de cet 20 ordre n'a encore rien vu au grand jour; il n'a vu que des ombres dans la caverne de Platon. ${ }^{1}$ Que dirait-on d'un architecte qui ne sentirait aucune différence entre un grand palais dont tous les bâtiments seraient proportionnés pour former un tout dans le même dessin, et un amas confus de petits édifices qui ne feraient point un vrai tout, quoiqu'ils 25 fussent les uns auprès des autres? Quelle comparaison entre le Colisée et une multitude confuse de maisons irrégulières d'une ville! Un ouvrage n'a une véritable unité que quand on ne peut en rien ôter sans couper dans le vif.

Il n'a un véritable ordre que quand on ne peut en déplacer aucune 30 partie sans affaiblir, sans obscurcir, sans déranger le tout. . . .

Tout auteur qui ne donne point cet ordre à son discours ne possède pas assez sa matière ; il n'a qu'un goût imparfait et qu'un demi-génie. L'ordre est ce qu'il y a de plus rare dans les opérations de l'esprit. Quand l'ordre, la justesse, la force et la véhémence se trouvent réunis, 35

1 An allusion to Book VII of the "Republic," in which Plato compares men to prisoners chained against one wall and able to see in a mirror on the opposite wall only the reflections of men walking in the street above. In the same way the truth and beauty we see is only the reflection of eternal truth and beauty. 
le discours est parfait. Mais il faut avoir tout vu, tout pénétré et tout embrassé pour savoir la place précise de chaque mot: c'est ce qu'un déclamateur livré à son imagination et sans science ne peut discerner.

Isocrate ${ }^{1}$ est doux, insinuant, plein d'élégance; mais peut-on le 5 comparer à Homère? Allons plus loin: je ne crains pas de dire que Démosthène me paraît supérieur à Cicéron. Je proteste que personne n'admire Cicéron plus que je fais: il embellit tout ce qu'il touche; il fait honneur à la parole; il fait des mots ce qu'un autre n'en saurait faire; il a je ne sais combien de sortes d'esprit, il est même court et Io véhément toutes les fois qu'il veut l'être, contre Catilina, contre Verrès, contre Antoine. Mais on remarque quelque parure dans son discours : l'art y est merveilleux, mais on l'entrevoit; l'orateur, en pensant au salut de la république, ne s'oublie pas et ne se laisse pas oublier. Démosthène paraît sortir de soi et ne voir que la patrie. Il ne cherche I 5 point le beau; il le fait sans y penser. Il est au-dessus de l'admiration. Il se sert de la parole comme un homme modeste de son habit pour se couvrir. Il tonne, il foudroie. C'est un torrent qui entraine tout. On ne peut le critiquer, parce qu'on est saisi ; on pense aux choses qu'il dit, et non à ses paroles. On le perd de vue; on n'est occupé que de 2o Philippe, ${ }^{2}$ qui envahit tout. Je suis charmé de ces deux orateurs; mais j'avoue que je suis moins touché de l'art infini et de la magnifique éloquence de Cicéron que de la rapide simplicité de Démosthène.

— «Lettre à l'Académie », Projet de rhétorique

1 A great Attic orator (436-338 в.c.).

2 Philip of Macedon, against whom Demosthenes directed his "Philippics." 


\title{
BERNARD LE BOUVIER DE FONTENELLE
}

\author{
Rouen, I657-1757, Paris
}

Fontenelle, nephew of Corneille, was educated by the Jesuits and took up the study of law. He soon gave up law, however, and, like Voltaire, though not so successfully, tried his hand at most branches of literature. His first real success came with the "Entretiens sur la pluralité des mondes" (I686). He was elected to the Academy in I69I, and in 1697 to the Academy of Sciences, of which he was made secretary in $\mathrm{I} 699$. It was in this latter capacity that he wrote the "Histoire de l'Académie des sciences" and the "Eloges des académiciens de l'Académie royale des sciences morts depuis l'an I699." In these "Eloges," as well as in the "Entretiens," he showed, to a remarkable degree, the ability to express in clear terms, easily understood by all, the abstruse questions of science and philosophy.

Fontenelle was an elegant man of the world, and for many years a conspicuous and much-admired figure in the various fashionable "salons," into which, through his popularization of learning, he introduced many new interests.

His best works, in addition to the above, are the "Dialogues des morts" ( 1683 ), the "Histoire des oracles" ( 1687 ), and the "Digression sur les anciens et les modernes" ( 1688 ).

\section{LA SCIENCE POUR TOUS}

Je suis à peu près dans le même cas où se trouva Cicéron, lorsqu'il entreprit de mettre en sa langue des matières de philosophie, qui jusque-là n'avaient été traitées qu'en grec. Il nous apprend qu'on disait que ses ouvrages seraient fort inutiles, parce que ceux qui aimaient la philosophie s'étant bien donné la peine de la chercher dans les livres grecs, négligeraient après cela de la voir dans les livres latins, qui ne seraient pas originaux, et que ceux qui n'avaient pas de goût pour la philosophie ne se souciaient de la voir ni en latin ni en grec.

A cela il répond qu'il arriverait tout le contraire, que ceux qui n'étaient pas philosophes seraient tentés de le devenir par la facilité de ıo lire les livres latins, et que ceux qui l'étaient déjà par la lecture des livres grecs, seraient bien aises de voir comment ces choses-là avaient été maniées en latin. 
Cicéron avait raison de parler ainsi. L'excellence de son génie et la grande réputation qu'il avait déjà acquise, lui garantissaient le succès de cette nouvelle sorte d'ouvrages qu'il donnait au public; mais moi, je suis bien éloigné d'avoir les mêmes sujets de confiance dans une 5 entreprise presque pareille à la sienne. J'ai voulu traiter la philosophie d'une manière qui ne fût point philosophique ; j'ai tâché de l'amener à un point, où elle ne fût ni trop sèche pour les gens du monde, ni trop badine pour les savants. Mais si on me dit à peu près comme à Cicéron, qu'un pareil ouvrage n'est propre ni aux savants, qui n'y Io peuvent rien apprendre, ni aux gens du monde, qui n'auront point d'envie d'y rien apprendre, je n'ai garde de répondre ce qu'il répondit. Il se peut bien faire qu'en cherchant un milieu où la philosophie convînt à tout le monde, j'en aie trouvé un où elle ne convienne à personne; les milieux sont trop difficiles à tenir, et je ne crois pas qu'il

I 5 me prenne envie de me mettre une seconde fois dans la même peine.

Je dois avertir ceux qui liront ce livre, et qui ont quelque connaissance de la physique, que je n'ai point du tout prétendu les instruire, mais seulement les divertir, en leur présentant d'une manière un peu 2o plus agréable et plus égayée, ce qu'ils savent déjà plus solidement, et j'avertis ceux à qui ces matières sont nouvelles, que j'ai cru pouvoir les instruire et les divertir tout ensemble. Les premiers iront contre mon intention, s'ils cherchent ici de l'utilité; et les seconds, s'ils n'y cherchent que de l'agrément.

25 Je ne m'amuserai point à dire que j'ai choisi dans toute la philosophie la matière la plus capable de piquer la curiosité. Il semble que rien ne devrait nous intéresser davantage, que de savoir comment est fait ce monde que nous habitons, s'il y a d'autres mondes semblables, et qui soient habités aussi; mais après tout, s'inquiète de tout cela qui 30 veut. Ceux qui ont des pensées à perdre, les peuvent perdre sur ces sortes de sujets; mais tout le monde n'est pas en état de faire cette dépense inutile.

J'ai mis dans ces Entretiens une femme que l'on instruit, et qui n'a jamais oui parler de ces choses-là. J'ai cru que cette fiction me servi-

35 rait et à rendre l'ouvrage plus susceptible d'agrément, et à encourager les dames par l'exemple d'une femme, qui ne sortant jamais des bornes d'une personne qui n'a nulle teinture de science, ne laisse pas d'entendre ce qu'on lui dit, et de ranger dans sa tête sans confusion les tourbillons et les mondes. Pourquoi y aurait-il des femmes qui 
cédassent à cette marquise imaginaire, qui ne conçoit que ce qu'elle ne peut se dispenser de concevoir?

A la vérité elle s'applique un peu, mais qu'est-ce ici que s'appliquer? Ce n'est pas pénétrer à force de méditation une chose obscure d'ellemême, ou expliquée obscurément, c'est seulement ne point lire sans se 5 représenter nettement ce qu'on lit. Je ne demande aux dames pour tout ce système de philosophie, que la même application qu'il faut donner à la Princesse de Clèves, si on veut en suivre bien l'intrigue, et en connaître toute la beauté. Il est vrai que les idées de ce livre-ci sont moins familières à la plupart des femmes que celles de la Prin- ıo cesse de Clèves, mais elles n'en sont pas plus obscures, et je suis sûr qu'à une seconde lecture tout au plus, il ne leur en sera rien échappé.

Comme je n'ai pas prétendu faire un système en l'air, et qui n'eût aucun fondement, j'ai employé de vrais raisonnements de physique, et j'en ai employé autant qu'il a été nécessaire. Mais il se trouve heureu- 15 sement dans ce sujet que les idées de physique y sont riantes d'ellesmêmes, et que dans le même temps qu'elles contentent la raison, elles donnent à l'imagination un spectacle qui lui plaît autant que s'il était fait exprès pour elle.

— « Entretiens sur la pluralité des mondes », Préface

\section{LE SYSTÈME DE COPERNIC}

Figurez-vous un Allemand nommé Copernic, qui fait main-basse sur 20 tous ces cercles différents, et sur tous ces cieux solides qui avaient été imaginés par l'antiquité. Il détruit les uns, il met les autres en pièces. Saisi d'une noble fureur d'astronome, il prend la Terre, et l'envoie bien loin du centre de l'univers, où elle s'était placée, et dans ce centre, il $\mathrm{y}$ met le Soleil, à qui cet honneur était bien mieux dû. Les planètes 25 ne tournent plus autour de la Terre, et ne l'enferment plus au milieu du cercle qu'elles décrivent. Si elles nous éclairent, c'est en quelque sorte par hasard, et parce qu'elles nous rencontrent en leur chemin. Tout tourne présentement autour du Soleil; la Terre y tourne elle-même; et pour la punir du long repos qu'elle s'était attribué, Copernic la 30 charge le plus qu'il peut de tous les mouvements qu'elle donnait aux planètes et aux cieux. Enfin de tout cet équipage céleste dont cette petite Terre se faisait accompagner et environner, il ne lui est demeuré que la Lune qui tourne encore autour d'elle. 
Attendez un peu, dit la marquise, il vient de vous prendre un enthousiasme qui vous a fait expliquer les choses si pompeusement, que je ne crois pas les avoir entendues. Le Soleil est au centre de l'univers, et là il est immobile; après lui qu'est-ce qui suit ?

5 C'est Mercure, répondis-je, il tourne autour du Soleil, en sorte que le Soleil est à peu près le centre du cercle que Mercure décrit. Audessus de Mercure est Vénus, qui tourne de même autour du Soleil. Ensuite vient la Terre, qui étant plus élevée que Mercure et Vénus, décrit autour du Soleil un plus grand cercle que ces planètes. Enfin Io suivent Mars, Jupiter, Saturne, selon l'ordre où je vous les nomme, et vous voyez bien que Saturne doit décrire autour du Soleil le plus grand cercle de tous; aussi emploie-t-il plus de temps qu'aucune autre planète à faire sa révolution.

Et la Lune? vous l'oubliez, interrompit-elle.

I5 Je la retrouverai bien, repris-je. La Lune tourne autour de la Terre, et ne l'abandonne point; mais comme la Terre avance toujours dans le cercle qu'elle décrit autour du Soleil, la Lune la suit, en tournant toujours autour d'elle; et si elle tourne autour du Soleil, ce n'est que pour ne point quitter la Terre.

20 Je vous entends, répondit-elle, et j'aime la Lune, de nous être restée, lorsque toutes les autres planètes nous abandonnaient. Avouez que si votre Allemand eût pu nous la faire perdre, il l'aurait fait volontiers ; car je vois dans tout son procédé, qu'il était bien mal intentionné pour la Terre.

25 Je lui sais bon gré, répliquai-je, d'avoir rabattu la vanité des hommes, qui s'étaient mis à la plus belle place de l'univers, et j'ai du plaisir à voir présentement la Terre dans la foule des planètes.

Bon, répondit-elle, croyez-vous que la vanité des hommes s'étende jusqu'à l'astronomie? Croyez-vous m'avoir humiliée pour m'avoir 30 appris que la Terre tourne autour du Soleil? Je vous jure que je ne m'en estime pas moins.

Mon Dieu, Madame, repris-je, je sais bien qu'on sera moins jaloux du rang qu'on tient dans l'univers, que de celui qu'on croit devoir tenir dans une chambre, et que la préséance de deux planètes ne sera

35 jamais une si grande affaire, que celle de deux ambassadeurs. Cependant la même inclination qui fait qu'on veut avoir la place la plus honorable dans une cérémonie, fait qu'un philosophe dạns un système se met au centre du monde, s'il peut. Il est bien aise que tout soit fait pour lui; il suppose, peut-être sans s'en apercevoir, ce principe 
qui le flatte, et son cœur ne laisse pas de s'intéresser à une affaire de pure spéculation.

Franchement, répliqua-t-elle, c'est là une calomnie que vous avez inventée contre le genre humain. On n'aurait donc jamais dû recevoir le système de Copernic, puisqu'il est si humiliant.

Aussi, repris-je, Copernic lui-même se défiait-il fort du succès de son opinion. Il fut très longtemps à ne la vouloir pas publier. Enfin il s'y résolut à la prière de gens très considérables ; mais aussi le jour qu'on lui apporta le premier exemplaire imprimé de son livre, savez-vous ce qu'il fit? Il mourut. Il ne voulut point essuyer toutes les contradic- ro tions qu'il prévoyait, et se tira habilement d'affaire.

— " Entretiens sur la pluralité des mondes », Premier soir

\section{SOCRATE ET MONTAIGNE}

Montaigne. C'est donc vous, divin Socrate! Que j'ai de joie de vous voir! Je suis tout fraîchement venu en ce pays-ci, et dès mon arrivée je me suis mis à vous y chercher. Enfin, après avoir rempli mon livre ${ }^{1}$ de votre nom et de vos éloges, je puis m'entretenir avec 15 vous, et apprendre comment vous possédiez cette vertu si naïve, dont les allures étaient si naturelles, et qui n'avait point d'exemple, même dans les heureux siècles où vous viviez.

Socrate. Je suis bien aise de voir un mort qui me paraît avoir été philosophe; mais, comme vous êtes nouvellement venu de là-haut, et 20 qu'il y a longtemps que je n'ai vu ici personne (car on me laisse assez seul, et il n'y a pas beaucoup de presse à rechercher ma conversation), trouvez bon que je vous demande des nouvelles. Comment va le monde? N'est-il pas bien changé?

Montaigne. Extrêmement. Vous ne le reconnaîtriez pas.

Socrate. J'en suis ravi. Je m'étais toujours bien douté qu'il fallait qu'il devînt meilleur et plus sage qu'il n'était de mon temps.

Montaigne. Que voulez-vous dire? Il est plus fou et plus corrompu qu'il n'a jamais été. C'est le changement dont je voulais parler, et je m'attendais bien à savoir de vous l'histoire du temps que vous ave $z$ vu, 30 et où régnait tant de probité et de droiture.

Socrate. Et moi, je m'attendais au contraire à apprendre des merveilles du siècle où vous venez de vivre. Quoi ! les hommes d'à présent ne se sont point corrigés des sottises de l'antiquité ?

$$
1 \text { I.e. his "Essais." }
$$


Montaigne. Je crois que c'est parce que vous êtes ancien que vous parlez de l'antiquité si familièrement; mais sachez qu'on a grand sujet d'en regretter les mœurs, et que de jour en jour tout empire.

Socrate. Cela se peut-il? Il me semble que de mon temps les choses 5 allaient déjà bien de travers. Je croyais qu'à la fin elles prendraient un train plus raisonnable, et que les hommes profiteraient de l'expérience de tant d'années.

Montaigne. Et les hommes font-ils des expériences? Ils sont faits comme les oiseaux qui se laissent toujours prendre dans les mêmes ı filets, où l'on a déjà pris cent mille oiseaux de leur espèce. Il n'y a personne qui n'entre tout neuf dans la vie, et les sottises des pères sont perdues pour les enfants.

Socrate. Mais pourquoi ne fait-on point d'expériences? Je croirais que le monde devrait avoir une vieillesse plus sage, et plus réglée que ${ }_{15}$ n'a été sa jeunesse.

Montaigne. Les hommes de tous les siècles ont les mêmes penchants, sur lesquels la raison n'a aucun pouvoir. Ainsi, partout où il y a des hommes, il y a des sottises, et les mêmes sottises.

Socrate. Et, sur ce pied-là, comment voudriez-vous que les siècles de 20 l'antiquité eussent mieux valu que le siècle d'aujourd'hui?

Montaigne. Ah! Socrate, je savais bien que vous aviez une manière particulière de raisonner, et d'envelopper si adroitement ceux à qui vous aviez affaire dans les arguments dont ils ne prévoyaient pas la conclusion, que vous les ameniez où il vous plaisait, et c'est ce que 25 vous appeliez être la sage-femme de leurs pensées, et les faire accoucher. J'avoue que me voilà accouché d'une proposition toute contraire à celle que j'avançais ; cependant je ne saurais encore me rendre. Il est sûr qu'il ne se trouve plus de ces âmes vigoureuses et roides de l'antiquité, des Aristides, des Phocions, des Périclès, ni enfin 30 des Socrates.

Socrate. A quoi tient-il? Est-ce que la nature s'est épuisée, et qu'elle n'a plus la force de produire ces grandes âmes; et pourquoi ne se serait-elle encore épuisée en rien, hormis en hommes raisonnables? Aucun de ses ouvrages n'a encore dégénéré; pourquoi n'y aurait-il 35 que les hommes qui dégénérassent?

Montaigne. C'est un point de fait, ils dégénèrent. Il semble que la nature nous ait autrefois montré quelques échantillons de grands hommes, pour nous persuader qu'elle en aurait su faire si elle avait voulu, et qu'ensuite elle ait fait tout le reste avec assez de négligence. 
Socrate. Prenez garde à une chose. L'antiquité est un objet d'une espèce particulière, l'éloignement le grossit. Si vous eussiez connu Aristide, Phocion, Périclès et moi, puisque vous voulez me mettre de ce nombre, vous eussiez trouvé dans votre siècle des gens qui nous ressemblaient. Ce qui fait d'ordinaire qu'on est si prévenu pour l'antiquité, c'est qu'on a du chagrin contre son siècle, et l'antiquité en profite. On met les anciens bien haut, pour abaisser ses contemporains. Quand nous vivions, nous estimions nos ancêtres plus qu'ils ne méritaient; et, à présent, notre postérité nous estime plus que nous ne méritons; mais, et nos ancêtres, et nous, et notre postérité, tout cela ro est bien égal, et je crois que le spectacle du monde serait bien ennuyeux pour qui le regarderait d'un certain œil, car c'est toujours la même chose.

Montaigne. J'aurais cru que tout était en mouvement, que tout changeait, et que les siècles différents avaient leurs différents caractères I 5 comme les hommes. En effet, ne voit-on pas des siècles savants, et d'autres qui sont ignorants? N'en voit-on pas de naifs, et d'autres qui sont plus raffinés? N'en voit-on pas de sérieux et de badins, de polis et de grossiers?

Socrate. Il est vrai.

Montaigne. Et pourquoi donc n'y aura-t-il pas des siècles plus vertueux, et d'autres plus méchants?

Socrate. Ce n'est pas une conséquence. Les habits changent, mais ce n'est pas à dire que la figure des corps change aussi. La politesse, ou la grossièreté, la science, ou l'ignorance, le plus ou le moins d'une 25 certaine naïveté, le génie sérieux ou badin, ce ne sont là que les dehors de l'homme, et tout cela change; mais le cœur ne change point, et tout l'homme est dans le cœur. 


\section{LOUIS DE SAINT-SIMON}

Paris, $1675-1755$, Paris

Saint-Simon was the son of a favorite of Louis XIII, and had Louis XIV as godfather. He received a careful education, and then, at the age of sixteen, entered the army. But after one of his colleagues had been advanced over him, he resigned from active service (1702), and though he continued to attend at court, he could never forgive Louis XIV for his slight. His infatuation for his title of duke and peer gave him the deepest interest in the privileges of the nobles, and led him to see visions of a new France regenerated by the peerage, and, at the same time, explains his hostile attitude toward public and private opponents. For a time during the Regency Saint-Simon played a considerable part in political circles; but his favor was not of long duration, and again he went into retirement, this time until his death in 1755 . It was during this retirement that he put into final shape the "Mémoires" which he had begun as early as 1694. Written in a style as impetuous as the author himself, warped by strong prejudices which he did not seek to overcome, the "Mémoires" of Saint-Simon portray with the utmost vividness and clearness the principal figures and the real life of the period they cover - the last twenty years of the reign of Louis XIV, and the Regency.

An abridged edition of the "Mémoires" appeared in $1788-1789$ in seven volumes. The first complete edition came out in $1829-1830$.

\section{MORT DE MONSEIGNEUR ${ }^{1}$}

Là, dans la chambre, et par tout l'appartement, on lisait apertement sur les visages. Monseigneur. n'était plus ; on le savait, on le disait; nulle contrainte ne retenait plus à son égard, et ces premiers moments étaient ceux des premiers mouvements peints au naturel, et pour lors 5 affranchis de toute politique, quoique avec sagesse, par le trouble, l'agitation, la surprise, la foule, le spectacle confus de cette nuit si rassemblée. ${ }^{2}$

Les premières pièces offraient les mugissements contenus des valets, désespérés de la perte d'un maître si fait exprès pour eux, et pour les ro consoler d'une autre ${ }^{\mathbf{3}}$ qu'ils ne prévoyaient qu'avec transissement, et qui, par celle-ci, devenait la leur propre. Parmi eux s'en remarquaient

1 The Grand Dauphin (1661-1711), only son of Louis XIV.

2 I.e. when there was such a gathering.

3 I.e. that of the king. 
d'autres des plus éveillés de gens principaux de la cour, qui étaient accourus aux nouvelles, et qui montraient bien, à leur air, de quelle boutique ils étaient balayeurs. ${ }^{1}$

Plus avant commençait la foule des courtisans de toute espèce. Le plus grand nombre, c'est-à-dire les sots, tiraient des soupirs de leurs talons, et, avec des yeux égarés et secs, louaient Monseigneur, mais toujours de la même louange, c'est-à-dire de bonté, et plaignaient le Roi de la perte d'un si bon fils. Les plus fins d'entre eux, ou les plus considérables, s'inquiétaient déjà de la santé du Roi; ils se savaient bon gré de conserver tant de jugement parmi ce trouble, et n'en lais- ro saient pas douter par la fréquence de leurs répétitions. D'autres, vraiment affligés, et de cabale frappée, ${ }^{2}$ pleuraient amèrement, ou se contenaient avec un effort aussi aisé à remarquer que les sanglots. Les plus forts de ceux-là, ou les plus politiques, les yeux fichés à terre, et reclus en des coins, méditaient profondément aux suites d'un événe- ${ }_{1} 5$ ment si peu attendu, et bien davantage sur eux-mêmes. Parmi ces diverses sortes d'affligés, point ou peu de propos, de conversation nulle, quelque exclamation parfois échappée à la douleur, et parfois répondue par une douleur voisine, un mot en un quart d'heure, des yeux sombres ou hagards, des mouvements de mains moins rares qu'involontaires, 20 immobilité du reste presque entière; les simples curieux et peu soucieux presque nuls, ${ }^{3}$ hors les sots qui avaient le caquet en partage; les questions et le redoublement du désespoir des affligés, et l'importunité pour les autres. Ceux qui déjà regardaient cet événement comme favorable avaient beau pousser la gravité jusqu'au maintien chagrin et 25 austère; le tout n'était qu'un voile clair, qui n'empêchait pas de bons yeux de remarquer et de distinguer tous leurs traits. Ceux-ci se tenaient aussi tenaces en place que les plus touchés, en garde contre l'opinion, contre la curiosité, contre leur satisfaction, contre leurs mouvements; mais leurs yeux suppléaient au peu d'agitation de leurs 30 corps. Des changements de posture, comme des gens peu assis ou mal debout ; un certain soin de s'éviter les uns les autres, même de se rencontrer des yeux; les accidents momentanés qui arrivaient de ces rencontres; un je ne sais quoi de plus libre en toute la personne, à travers le soin de se tenir et de se composer; un vif, une sorte d'étin- 35 celant autour d'eux, les distinguait malgré qu'ils en eussent.

1 I.e. what faction they belonged to.

2 I.e. who belonged to the party afflicted by the death of Monseigneur.

3 I.e. saying nothing and expressing no feeling. 
Les deux princes; et les deux princesses ${ }^{1}$ assises à leurs côtés, prenant soin d'eux, étaient les plus exposés à la pleine vue. $\mathrm{M}^{\mathrm{gr}}$ le duc de Bourgogne pleurait d'attendrissement et de bonne foi, avec un air de douceur, des larmes de nature, de religion, de patience. M. le 5 duc de Berry, tout d'aussi bonne foi, en versait en abondance, mais des larmes pour ainsi dire sanglantes, tant l'amertume en paraissait grande, et poussait non des sanglots, mais des cris, mais des hurlements. Il se taisait parfois, mais de suffocation, puis éclatait, mais avéc un tel bruit, et un bruit si fort, la trompette forcée du désespoir, ro que la plupart éclataient aussi à ces redoublements si douloureux, ou par un aiguillon d'amertume, ou par un aiguillon de bienséance. Cela fut au point qu'il fallut le déshabiller là même, et se précautionner de remèdes et de gens de la Faculté. ${ }^{2} \mathrm{M}^{\mathrm{me}}$ la duchesse de Berry était hors d'elle; on verra bientôt pourquoi. Le désespoir le plus amer était

I 5 peint avec horreur sur son visage; on y voyait comme écrit une rage de douleur, non d'amitié, mais d'intérêt; des intervalles secs, mais profonds et farouches, puis un torrent de larmes et de gestes involontaires, et cependant retenus, qui montraient une amertume d'âme extrême, fruit de la méditation profonde qui venait de précéder. Sou2o vent réveillée par les cris de son époux, prompte à le secourir, à le soutenir, à l'embrasser, à lui présenter quelque chose à sentir, on voyait un soin vif pour lui, mais tôt après une chute profonde en ellemême, puis un torrent de larmes qui lui aidaient à suffoquer ses cris. $\mathrm{M}^{\mathrm{me}}$ la duchesse de Bourgogne consolait aussi son époux, et y avait 25 moins de peine qu'à acquérir le besoin d'être elle-même consolée, à quoi pourtant, sans rien montrer de faux, on voyait bien qu'elle faisait de son mieux pour s'acquitter d'un devoir pressant de bienséance sentie, mais qui se refuse au plus grand besoin: le fréquent moucher répondait aux cris du prince son beau-frère; quelques larmes 30 amenées du spectacle, et souvent entretenues avec soin, fournissaient à l'art du mouchoir pour rougir et grossir les yeux et barbouiller le visage, et cependant le coup d'œil fréquemment dérobé se promenait sur l'assistance et sur la contenance de chacun.

Le duc de Beauvillier, ${ }^{3}$ debout auprès d'eux, l'air tranquille et froid

1 The princes and princesses were (1) Louis, duke of Burgundy (1682-1712), the eldest son of Monseigneur, grandson of Louis XIV, father of Louis XV; (2) his wife, Marie-Adélaïde de Savoy; (3) Charles, duke of Berry (1686-1714), brother of the duke of Burgundy, third son of Monseigneur; (4) his wife, Marie-Louise-Élisabeth d'Orléans, daughter of Philip d'Orléans, who was regent after the death of Louis XIV.

2 "physicians."

${ }_{3} 6_{4} 8-1714$; tutor of the duke of Burgundy and the dukes of Anjou and of Berry. 
comme à chose non avenue, ou à spectacle ordinaire, donnait ses ordres pour le soulagement des princes, pour que peu de gens entrassent quoique les portes fussent ouvertes à chacun, en un mot pour tout ce qu'il était besoin, sans empressement, sans se méprendre en quoi que ce soit ni aux gens ni aux choses: vous l'auriez cru au lever ou au petit couvert, servant à l'ordinaire. Ce flegme dura sans la moindre altération, également éloigné d'être aise par religion et de cacher aussi le peu d'affliction qu'il ressentait, pour conserver toujours la vérité.

Madame, ${ }^{1}$ rhabillée en grand habit, arriva hurlante, ne sachant bonnement pourquoi ni l'un ni l'autre, les inonda tous de ses larmes ro en les embrassant, fit retentir le château d'un renouvellement de cris, et fournit un spectacle bizarre d'une princesse qui se remet en cérémonie en pleine nuit pour venir pleurer et crier parmi une foule de femmes en déshabillé de nuit, presque en mascarades. . . .

Il faut avouer que, pour qui est bien au fait de la carte intime d'une I 5 cour, les premiers spectacles d'événements rares de cette nature si intéressante à tant de divers égards, sont d'une satisfaction extrême: chaque visage vous rappelle les soins, les intrigues, les sueurs employées à l'avancement des fortunes, à la formation, à la force des cabales, les adresses à se maintenir et à en écarter d'autres, les moyens de toute 20 espèce mis en œuvre pour cela, les liaisons plus ou moins avancées, les éloignements, les froideurs, les haines, les mauvais offices, les manèges, les avances, les ménagements, les petitesses, les bassesses de chacun, le déconcertement des uns au milieu de leur chemin, au milieu ou au comble de leurs espérances, la stupeur de ceux qui en jouissaient en 25 plein, le poids donné du même coup à leurs contraires et à la cabale opposée, la vertu de ressort qui pousse dans cet instant leurs menées et leurs concerts à bien, la satisfaction extrême et inespérée de ceuxlà, et j'en étais des plus avant, la rage qu'en conçoivent les autres, leur embarras et leur dépit à le cacher, la promptitude des yeux à voler par- 30 tout en sondant les âmes à la faveur de ce premier trouble de surprise et de dérangement subit, la combinaison de tout ce qu'on y remarque, l'étonnement de ne pas trouver ce qu'on avait cru de quelques-uns faute de cœur ou d'assez d'esprit en eux, et plus en d'autres qu'on n'avait pensé : tout cet amas d'objets vifs et de choses si importantes 35 forme un plaisir à qui le sait prendre, qui, tout peu solide qu'il devient, est un des plus grands dont on puisse jouir dans une cour.

1 Charlotte-Élisabeth, widow of Philip d'Orléans (brother of Louis X1V) and mother of the regent. 
Ce fut donc à celui-là que je me livrai tout entier en moi-même, avec d'autant plus d'abandon que, dans une délivrance bien réelle, je me trouvais étroitement lié et embarqué avec les têtes principales qui n'avaient point de larmes à donner à leurs yeux. Je jouissais de leur 5 avantage sans contrepoids, et de leur satisfaction, qui augmentait la mienne, qui consolidait mes espérances, qui me les élevait, qui m’assurait un repos auquel, sans cet événement, je voyais si peu d'apparence que.je ne cessais point de m'inquiéter d'un triste avenir, et que, d'autre part, ennemi de liaison ${ }^{1}$ et presque personnel des principaux personIo nages que cette perte accablait, je vis, du premier coup d'œil vivement porté, tout ce qui leur échappait et tout ce qui les accablerait, avec un plaisir qui ne se peut rendre. J'avais si fort imprimé dans ma tête les différentes cabales, leurs subdivisions, leurs replis, leurs divers personnages et leurs degrés, la connaissance de leurs chemins, de leurs res-

I 5 sorts, de leurs divers intérêts, que la méditation de plusieurs jours ne m'aurait pas développé et représenté toutes ces choses plus nettement que ce premier aspect de tous ces visages, qui me rappelaient encore ceux que je ne voyais pas, et qui n'étaient pas les moins friands à s'en repaître.

— "Mémoires ", Grands Écrivains, Vol. XXI, pp. 3 I ff.

\section{JUGEMENT DE SAINT-SIMON SUR SES MÉMOIRES}

20 Me voici enfin parvenu au terme jusqu'au quel je m'étais proposé de conduire ces Mémoires. Il n'y en peut avoir de bons que de parfaitement vrais, ni de vrais qu'écrits par qui a vu et manié lui-même les choses qu'il écrit, ou qui les tient de gens dignes de la plus grande foi, qui les ont vues et maniées; et de plus, il faut que celui qui écrit 25 aime la vérité jusqu'à lui sacrifier toutes choses. De ce dernier point, j'ose m'en rendre témoignage à moi-même, et me persuader qu'aucun de tout ce qui m'a connu n'en disconviendrait. C'est même cet amour de la vérité qui a le plus nui à ma fortune; je l'ai senti souvent, mais j'ai préféré la vérité à tout, et je n'ai pu me ployer à aucun déguise30 ment; je puis dire encore que je l'ai chérie jusque contre moi-même. On s'apercevra aisément des duperies où je suis tombé, et quelquefois grossières, séduit par l'amitié ou par le bien de l'État, que j'ai sans cesse préféré à toute autre considération, sans réserve, et toujours à tout intérêt personnel, comme encore [en] bien d'autres occasions que j'ai négligé

1 Saint-Simon belonged to the party of the Duke of Burgundy and detested Monseigneur, the Grand Dauphin. 
d'écrire, parce qu'elles ne regardaient que moi, sans connexion d'éclaircissements ou de curiosité sur les affaires ou le cours du monde. ...

Reste à toucher l'impartialité, ce point si essentiel et tenu pour si difficile, je ne crains point de le dire, impossible à qui écrit ce qu'il a vu et manié. On est charmé des gens droits et vrais; on cst irrité contre les fripons dont les cours fourmillent; on l'est encore plus contre ceux dont on a reçu du mal. Le stoïque est une belle et noble chimère. Je ne me pique donc pas d'impartialité, je le ferais vaincment. On trouvera trop, dans ces Mémoires, que la louange et le blâme coulent de source à l'égard de ceux dont je suis affecté, et que ro l'un et l'autre est plus froid sur ceux qui me sont plus indifférents; mais néanmoins vif toujours pour la vertu, et contre les malhonnêtes gens, selon leur degré de vices ou de vertu. 'Toutefois, je me rendrai encore ce témoignage, et je me flatte que le tissu de ces Mémoires ne 'me le rendra pas moins, que j'ai été infiniment en garde contre mes I $_{5}$ affections et mes aversions, et encore plus contre celles-ci, pour ne parler des uns et des autres que la balance à la main, non seulement ne rien outrer, mais ne rien grossir, m'oublier, me défier de moi comme d'un ennemi, rendre une exacte justice, et faire surnager à tout la vérité la plus pure. C'est en cette manière que je puis assurer que 20 j'ai été entièrement impartial, et je crois qu'il n'y a point d'autre manière de l'être. . . .

Dirai-je enfin un mot du style, de sa négligence, de répétitions trop prochaines des mêmes mots, quelquefois de synonymes trop multipliés, surtout de l'obscurité qui naît souvent de la longueur des phrases, 25 peut-être de quelques répétitions? J'ai senti ces défauts ; je n'ai pu les éviter, emporté toujours par la matière, et peu attentif à la manière de la rendre, sinon pour la bien expliquer. Je ne fus jamais un sujet académique, je n'ai pu me défaire d'écrire rapidement. Ie rendre mon style plus correct et plus agréable en le corrigeant, ce serait 30 refondre tout l'ouvrage, et ce travail passerait mes forces, il courrait risque d'être ingrat. Pour bien corriger ce qu'on a écrit il faut savoir bien écrire ; on verra aisément ici que je n'ai pas dû m'en piquer. Je n'ai songé qu'à l'exactitude et à la vérité. J'ose dire que l'une et l'autre se trouvent étroitement dans mes Mémoires, qu'elles en sont la loi et 35 l'âme, et que le style mérite en leur faveur une bénigne indulgence. Il en a d'autant plus besoin, que je ne puis le promettre meilleur pour la suite que je me propose.

- " Mémoires », Chéruel, Vol. XX, pp. 89 ff. 


\section{ALAIN-RENÉ LE SAGE}

\section{Sarzeau, I668-i 747, Boulogne-sur-Mer}

Le Sage came of an old "famille de robe" in easy circumstances. He was left an orphan at the age of fourteen. His uncle, who became his guardian, educated him first at the college at Vannes, then at the University of Paris; but in the meantime he squandered the boy's property. The young Le Sage, thus thrown upon his own resources, soon gave up the career of law, into which he had entered, and took up literature. After training his hand by translations, particularly of the letters of Aristænetus, and by adaptations from the Spanish, he obtained his first real success in 1707 with a one-act comedy entitled "Crispin rival de son maitre," and the story, or collection of stories, entitled "Le diable boiteux." Two years later appeared "Turcaret," a bitter satire on the vices of finance, the best of his comedies and one of the best plays of the eighteenth century.

He continued writing for the stage, mostly light farces for the Théâtre de la Foire. These brought him in some much-needed money, but add nothing to his reputation. Meanwhile, however, he was preparing another masterpiece, "Gil Blas," a novel of manners, showing a wide appreciation of the foibles of men and of the abuses of society and politics. The first six books of "Gil Blas" were published in 1715 , three more came out in 1724 , and still three more in 1735 .

Le Sage wrote also several other novels which, though not equal to "Gil Blas," may still be read with considerable interest. The best are the "Histoire de Guzman d'Alfarache" (1732) and "Le bachelier de Salamanque" (1736).

\section{MONSIEUR TURCARET}

\section{Turcaret, La Baronne, Marine}

La Baronne. Je suis ravie de vous voir, monsieur Turcaret, pour vous faire des compliments sur les vers que vous m'avez envoyés.

M. Turcaret (riant). Oh! oh!

La Baronne. Savez-vous bien qu'ils sont du dernier galant? Jamais 5 les Voiture, ni les Pavillon ${ }^{1}$ n'en ont fait de pareils.

M. Turcaret. Vous plaisantez, apparemment?

La Baronne. Point du tout.

$11_{32-1705}$; member of the French Academy, author of "Lettres" and "Poésies." 
M. Turcaret. Sérieusement, madame, les trouvez-vous bien tournés?

La Baronne. Le plus spirituellement du monde.

M. Turcaret. Ce sont pourtant les premiers vers que j'ai faits de ma vie.

La Baronne. On ne le dirait pas.

M. Turcaret. Je n'ai pas voulu emprunter le secours de quelque auteur, comme cela se pratique.

La Baronne. On le voit bien. Les auteurs de profession ne pensent et ne s'expriment pas ainsi : on ne saurait les soupçonner de les avoir 10 faits.

M. Turcaret. J'ai voulu voir par curiosité si je serais capable d'en composer, et l'amour m'a ouvert l'esprit.

La Baronne. Vous êtes capable de tout, monsieur, il n'y a rien d'impossible pour vous.

Marine (à M. Turcaret). Votre prose, monsieur, mérite aussi des compliments : elle vaut bien votre poésie, au moins.

M. Turcaret. Il est vrai que ma prose a son mérite : elle est signée et approuvée par quatre fermiers-généraux.

Marine. Cette approbation vaut mieux que celle de l'Académie. 20

La Baronne (a M. Turcaret). Pour moi, je n'approuve point votre prose, monsieur, et il me prend envie de vous quereller.

M. Turcaret. D'où vient?

La Baronne. Avez-vous perdu la raison de m'envoyer un billet au porteur ?'1 Vous faites tous les jours quelque folie comme cela.

M. Turcaret. Vous vous moquez?

La Baronne. De combien est-il ce billet? Je n'ai pas pris garde à la somme, tant j'étais en colère contre vous!

M. Turcaret. Bon! il n'est que de dix mille écus.

La Baronne. Comment! de dix mille écus? Ah! si j'avais su cela, 30 je vous l'aurais renvoyé sur-le-champ.

M. Turcaret. Fi donc!

La Baronne. Mais je vous le renverrai.

M. Turcaret. Oh! vous l'avez reçu; vous ne le rendrez point.

Marine (à part). Oh! pour cela, non.

La Baronne (à M. Turcaret). Je suis plus offensée du motif que de la chose même.

M. Turcaret. Eh! pourquoi ?

1 " check payable to bearer." 
La Baronne. En m'accablant tous les jours de présents, il semble que vous vous imaginiez avoir besoin de ces liens-là pour m'attacher à vous.

M. Turcaret. Quelle pensée! Non, madame, ce n'est point dans 5 cette vue que...

La Baronne ('interrompant). Mais vous vous trompez, monsieur; je ne vous en aime point davantage pour cela.

M. Turcaret (à part). Qu'elle est franche! qu'elle est sincère!

La Baronne. Je ne suis sensible qu'à vos empressements, qu'à vos Io soins.

M. Turcaret (à part). Quel bon cœur!

La Baronne. Qu'au seul plaisir de vous voir.

M. Turcaret (à part). Elle me charme.... (A la Baronne) Adieu, charmante Philis.

15 La Baronne. Quoi! vous sortez si tôt?

$M$. Turcaret. Oui, ma reine. Je ne viens ici que pour vous saluer en passant. Je vais à une de nos assemblées, pour m'opposer à la réception d'un pied plat, d'un homme de rien, qu'on veut faire entrer dans notre compagnie. Je reviendrai dès que je pourrai m'échapper. (Il lui baise la main.)

La Baronne. Fussiez-vous déjà de retour.

Marine (à M. Turcaret, en lui faisant la récérence). Adieu, monsieur. Je suis votre très humble servante.

M. Turcaret. A propos, Marine, il me semble qu'il y a longtemps que je ne t'ai rien donné. . . . (Il lui donne une poignée d'argent.) 'Tiens; 25 je donne sans compter, moi.

Marine (prenant l'argent). Et moi, je reçois de même, monsieur. Oh! nous sommes tous deux gens de bonne foi. (MI. Turcaret sort.)

— " Turcaret », Act I, scene 6

\section{GIL BLAS CHEZ L'ARCHEVÊQUE DE GRENADE}

Le jour suivant, monseigneur me fit appeler de bon matin : c'était pour me donner une homélie à transcrire. Mais il me recommanda de 30 la copier avec toute l'exactitude possible. Je n'y manquai pas: je n'oubliai ni accent, ni point, ni virgule. Aussi la joie qu'il en témoigna fut mêlée de surprise. Père éternel! s'écria-t-il avec transport, lorsqüil eut parcouru des yeux tous les feuillets de ma copie, vit-on jamais rien de plus correct? Vous êtes trop bon copiste, pour n'être pas 
grammairien. Parlez-moi confidemment, mon ami: n'avez-vous rien trouvé, en écrivant, qui vous ait choqué ? quelque négligence dans le style, ou quelque terme impropre? Cela peut fort bien m'être échappé dans le feu de la composition. Oh! monseigneur, lui répondis-je d'un air modeste, je ne suis point assez éclairé pour faire des observations critiques; et quand je le serais, je suis persuadé que les ouvrages de Votre Grandeur échapperaient à ma censure. Le prélat sourit de ma réponse. Il ne répliqua point; mais il me laissa voir, au travers de toute sa piété, qu'il n'était pas auteur impunément.

J'achevai de gagner ses bonnes grâces par cette flatterie. Je lui ro devins plus cher de jour en jour; et j'appris enfin de don Fernand, ${ }^{1}$ qui le venait voir très souvent, que j'en étais aimé de manière que je pouvais compter ma fortune faite. Cela me fut confirmé peu de temps après par mon maítre même : et voici à quelle occasion. Un soir il répéta devant moi avec enthousiasme, dans son cabinet, une homélie 15 qu'il devait prononcer le lendemain dans la cathédrale. Il ne se contenta pas de me demander ce que j'en pensais en général, il m'obligea de lui dire les endroits qui m'avaient le plus frappé. J'eus le bonheur de lui citer ceux qu'il estimait davantage, ses morceaux favoris. Par là, je passai dans son esprit pour un homme qui avait une connais- 20 sance délicate des vraies beautés d'un ouvrage. Voilà, s'écria-t-il, ce . qu'on appelle avoir du goût et du sentiment! Va, mon ami, tu n'as pas, je t'assure, l'oreille béotienne. En un mot, il fut si content de moi, qu'il me dit avec vivacité : Sois, Gil Blas, sois désormais sans inquiétude sur ton sort; je me charge de t'en faire un des plus agréables. 25 Je t'aime; et pour te le prouver, je te fais mon confident.

Je n'eus pas sitôt entendu ces paroles, que je tombai aux pieds de Sa Grandeur, tout pénétré de reconnaissance. J'embrassai de bon cœur ses jambes cagneuses, et je me regardai comme un homme qui était en train de s'enrichir. Oui, mon enfant, reprit l'archevêque, dont $3 \circ$ mon action avait interrompu le discours, je veux te rendre dépositaire de mes plus secrètes pensées. Écoute avec attention ce que je vais te dire. Je me plais à prêcher. Le Seigneur bénit mes homélies; elles touchent les pécheurs, les font rentrer en eux-mêmes, et recourir à la pénitence. J'ai la satisfaction de voir un avare, effrayé des images 35 que je présente à sa cupidité, ouvrir ses trésors et les répandre d'une prodigue main; d'arracher un voluptueux aux plaisirs, de remplir

1 A relative of the archbishop of Grenada, who obtained for Gil Blas his position as secretary. 
d'ambitieux les ermitages, et d'affermir dans son devoir une épouse ébranlée par un amant séducteur. Ces conversions, qui sont fréquentes, devraient toutes seules m'exciter au travail. Néanmoins, je t'avouerai ma faiblesse, je me propose encore un autre prix, un prix que la déli5 catesse de ma vertu me reproche inutilement: c'est l'estime que le monde a pour les écrits fins et limés. L'honneur de passer pour un parfait orateur a des charmes pour moi. On trouve mes ouvrages également forts et délicats; mais je voudrais bien éviter le défaut des bons auteurs qui écrivent trop longtemps, et me sauver avec toute ma Io réputation.

Ainsi, mon cher Gil Blas, continua le prélat, j'exige une chose de ton zèle: quand tu t'apercevras que ma plume sentira la vieillesse, lorsque tu me verras baisser, ne manque pas de m'en avertir. Je ne me fie point à moi là-dessus ; mon amour-propre pourrait me séduire.

15 Cette remarque demande un esprit désintéressé. Je fais choix du tien que je connais bon; je m'en rapporterai à ton jugement. Grâce au ciel, lui dis-je, monseigneur, vous êtes encore fort éloigné de ce tempslà. De plus, un esprit de la trempe de celui de Votre Grandeur se conservera beaucoup mieux qu'un autre, ou, pour parler plus juste, zo vous serez toujours le même. Je vous regarde comme un autre cardinal Ximénès, ${ }^{1}$ dont le génie supérieur, au lieu de s'affaiblir par les années, semblait en recevoir de nouvelles forces. Point de flatterie, interrompit-il, mon ami! Je sais que je puis tomber tout d'un coup. A mon âge on commence à sentir les infirmités, et les infirmités du 25 corps altèrent l'esprit. Je te le répète, Gil Blas, dès que tu jugeras que ma tête s'affaiblira, donne-m'en aussitôt avis. Ne crains pas d'être franc et sincère; je recevrai cet avertissement comme une marque d'affection pour moi. D'ailleurs, il y va de ton intérêt. Si par malheur pour toi il me revenait qu'on dît dans la ville que mes discours n'ont 30 plus leur force ordinaire, et que je devrais me reposer, je te le déclare tout net, tu perdrais avec mon amitié la fortune que je t'ai promise. Tel serait le fruit de ta sotte discrétion.

Le patron cessa de parler en cet endroit pour attendre ma réponse, qui fut une promesse de faire ce qu'il souhaitait. Depuis ce temps-

35 là, il n'eut plus rien de caché pour moi; je devins son favori. . . .

Deux mois après, dans le temps de ma plus grande faveur, nous eûmes une chaude alarme au palais épiscopal : l'archevêque tomba en apoplexie. On le secourut si promptement et on lui donna de si bons

${ }_{1}^{1} 43^{6-1517}$; a Spanish cardinal and statesman. 
remèdes, que quelques jours après il n'y paraissait plus. Mais son esprit en reçut une rude atteinte. Je le remarquai bien dès la première homélie qu'il composa. Je ne trouvai pas toutefois la différence qu'il y avait de celle-là aux autres assez sensible pour conclure que l'orateur commençait à baisser. J'attendis encore une homélie, pour mieux savoir à quoi m'en tenir. Oh! pour celle-là, elle fut décisive. Tantôt le bon prélat se rebattait, tantôt il s'élevait trop haut, ou descendait trop bas. C'était un discours diffus, une rhétorique de régent usé, une capucinade.

Je ne fus pas le seul qui y prit garde. La plupart des auditeurs, ro comme s'ils eussent été aussi gagés pour l'examiner, se disaient tout bas les uns aux autres: Voilà un sermon qui sent l'apoplexie. Allons, monsieur l'arbitre des homélies, me dis-je alors à moi-même, préparezvous à faire votre office. Vous voyez que monseigneur tombe; vous devez l'en avertir, non seulement comme dépositaire de ses pensées, i 5 mais encore de peur que quelqu'un de ses amis ne soit assez franc pour vous prévenir. En ce cas-là vous savez ce qu'il en arriverait; vous seriez biffé de son testament, ò̀ il y aura sans doute pour vous un meilleur legs que la bibliothèque du licencié Sédillo. ${ }^{1}$

Après ces réflexions j'en faisais d'autres toutes contraires. L'aver- 20 tissement dont il s'agissait me paraissait délicat à donner: je jugeais qu'un auteur entêté de ses ouvrages pourrait le recevoir mal; mais, rejetant cette pensée, je me représentais qu'il était impossible qu'il le prît en mauvaise part, après l'avoir exigé de moi d'une manière si pressante. Ajoutons à cela que je comptais bien de lui parler avec 25 adresse, et de lui faire avaler la pilule tout doucement. Enfin, trouvant que je risquais davantage à garder le silence qu'à le rompre, je me déterminai à parler.

Je n'étais plus embarrassé que d'une chose; je ne savais de quelle façon entamer la parole. Heureusement l'orateur lui-même me tira de $3^{\circ}$ cet'embarras, en me demandant ce qu'on disait de lui dans le monde, et si l'on était satisfait de son dernier discours. Je répondis qu'on admirait toujours ses homélies, mais qu'il me semblait que la dernière n'avait pas si bien que les autres affecté l'auditoire. Comment donc! mon ami, répliqua-t-il avec étonnement, aurait-elle trouvé quelque 35 Aristarque ? ${ }^{2}$ Non, monseigneur, lui repartis-je, non. Ce ne sont pas

1 One of the first masters of Gil Blas, who left him his library composed of five or six volumes.

2 A noted Alexandrian grammarian and an impartial critic of the second century B.c. 
des ouvrages tels que les vôtres que l'on ose critiquer: il n'y a personne qui n'en soit charmé. Néanmoins, puisque vous m'avez recommandé d'être franc et sincère, je prendrai la liberté de vous dire que votre dernier discours ne me paraît pas tout à fait de la force des pré5 cédents. Ne pensez-vous pas cela comme moi?

Ces paroles firent pâlir mon maître, qui me dit avec un souris forcé : Monsieur Gil Blas, cette pièce n'est donc pas de votre goût? Je ne dis pas cela, monseigneur, interrompis-je tout déconcerté. Je la trouve excellente, quoique un peu au-dessous de vos autres ouvrages. Je vous Io entends, répliqua-t-il. Je vous parais baisser, n'est-ce pas? Tranchez le mot, vous croyez qu'il est temps que je songe à la retraite? Je n'aurais pas été assez hardi, lui dis-je, pour vous parler si librement, si Votre Grandeur ne me l'eût ordonné. Je ne fais donc que lui obéir, et je la supplie très humblement de ne me point savoir mauvais gré 15 de ma hardiesse. A Dieu ne plaise, interrompit-il avec précipitation, à Dieu ne plaise que je vous la reproche! Il faudrait que je fusse bien injuste. Je ne trouve point du tout mauvais que vous me disiez votre sentiment; c'est votre sentiment seul que je trouve mauvais. J'ai été furieusement la dupe de votre intelligence bornée.

2o Quoique démonté, je voulus chercher une modification pour rajuster les choses; mais le moyen d'apaiser un auteur irrité, et de plus un auteur accoutumé à s'entendre louer? N'en parlons plus, dit-il, mon enfant. Vous êtes encore trop jeune pour démêler le vrai du faux. Apprenez que je n'ai jamais composé de meilleure homélie que 25 celle qui a le malheur de n'avoir pas votre approbation. Mon esprit, grâce au ciel, n'a rien encore perdu de sa vigueur. Désormais je choisirai mieux mes confidents; j'en veux de plus capables que vous de décider. Allez, poursuivit-il en me poussant par les épaules hors de son cabinet, allez dire à mon trésorier qu'il vous compte cent ducats, 30 et que le ciel vous conduise avec cette somme! Adieu, monsieur Gil Blas; je vous souhaite toutes sortes de prospérités, avec un peu plus de goût.

— " Gil Blas », Book VII, chaps. 3 and 4 


\title{
CHARLES DE SECONDAT, BARON DE MONTESQUIEU
}

\author{
Château de la Brède, I689-1755, Paris
}

Montesquieu came of a family of " noblesse de robe," and received a careful education at the hands of the Oratoriens of Juilly. He studied law, being destined for the magistrature, and in 1714 entered the Parliament of Bordeaux as councilor. In 1716 he succeeded one of his uncles as president. His leisure moments, in the meantime, were spent in reading, pen in hand. The "Lettres persanes," a satire on the social and political institutions of the period, "le plus profond des livres frivoles," appeared in 1721 . The following year he spent in Paris. He sold his presidency of the Parliament of Bordeaux in 1726. Two years later he was received into the Academy, and the same year he left France for an extensive trip through various countries, acquainting himself particularly with England. In $173^{1}$ he returned to the Château de la Brède, where, rich with the experience of past travel and study, he wrote the "Considérations sur les causes de la grandeur et de la décadence des Romains" (1734), which served somewhat as an introduction to his great masterpiece, "L'esprit des lois" (1748), a study of the fundamental interrelations of men. He died in 1755 .

\section{LA CURIOSITÉ PARISIENNE}

\section{RICCA A IBBEN, A SMYRNE}

Les habitants de Paris sont d'une curiosité qui va jusqu'à l'extravagance. Lorsque j'arrivai, je fus regardé comme si j'avais été envoyé du ciel : vieillards, hommes, femmes, enfants, tous voulaient me voir. Si je sortais, tout le monde se mettait aux fenêtres; si j'étais aux Tuileries, je voyais aussitôt un cercle se former autour de moi; les femmes même faisaient un arc-en-ciel nuancé de mille couleurs, qui m'entourait. Si j'étais aux spectacles, je trouvais d'abord cent lorgnettes dressées contre ma figure: enfin jamais homme n'a tant été vu que moi. Je souriais quelquefois d'entendre des gens qui n'étaient presque jamais sortis de leur chambre, qui disaient entre eux : "Il Io faut avouer qu'il a l'air bien persan." Chose admirable! je trouvais de mes portraits partout; je me voyais multiplié dans toutes les boutiques, sur toutes les cheminées, tant on craignait de ne m'avoir pas assez vu. 
Tant d'honneurs ne laissent pas d'être à charge: je ne me croyais pas un homme si curieux et si rare; et quoique j'aie très bonne opinion de moi, je ne me serais jamais imaginé que je dusse troubler le repos d'une grande ville où je n'étais point connu. Cela me fit résoudre 5 à quitter l'habit persan, et à en endosser un à l'européenne, pour voir s'il resterait encore dans ma physionomie quelque chose d'admirable. Cet essai me fit connaître ce que je valais réellement. Libre de tous les ornements étrangers, je me vis apprécié au plus juste. J'eus sujet de me plaindre de mon tailleur, qui m'avait fait perdre en un instant Io l'attention et l'estime publique: car j'entrai tout à coup dans un néant affreux. Je demeurais quelquefois une heure dans une compagnie sans qu'on m'eût regardé, et qu'on m'eût mis en occasion d'ouvrir la bouche. Mais si quelqu'un, par hasard, apprenait à la compagnie que j'étais Persan, j'entendais aussitôt autour de moi un bourdonnement : I5 " $\mathrm{Ah}$ ! Ah! monsieur est Persan? C'est une chose bien extraordinaire ! Comment peut-on être Persan?»

A Paris, le 6 de la lune de chalval, i 7 i 2.

— «Lettres persanes », Letter XXX

\section{LE DÉSIR DE LA GLOIRE}

\section{USBEC A IBBEN, A SMYRNE}

Le désir de la gloire n'est point différent de cet instinct que toutes les créatures ont pour leur conservation. Il semble que nous augmen20 tons notre être lorsque nous pouvons le porter dans la mémoire des autres : c'est une nouvelle vie que nous acquérons, et qui nous devient aussi précieuse que celle que nous avons reçue du ciel.

Mais comme tous les hommes ne sont pas également attachés à la vie, ils ne sont pas aussi également sensibles à la gloire. Cette noble 25 passion est bien toujours gravée dans leur cœur: mais l'imagination et l'éducation la modifient de mille manières.

Cette différence, qui se trouve d'homme à homme, se fait encore plus sentir de peuple à peuple.

On peut poser pour maxime que, dans chaque État, le désir de la 30 gloire croît avec la liberté des sujets, et diminue avec elle: la gloire n'est jamais compagne de la servitude.

Un homme de bon sens me disait l'autre jour : "On est en France, à bien des égards, plus libre qu'en Perse; aussi y aime-t-on plus la gloire. Cette heureuse fantaisie fait faire à un Français, avec plaisir 
et avec goût, ce que votre sultan n'obtient de ses sujets qu'en leur mettant sans cesse devant les yeux les supplices et les récompenses. " Aussi, parmi nous, le prince est-il jaloux de l'honneur du dernier de ses sujets. Il y a pour le maintenir des tribunaux respectables: c'est le trésor sacré de la nation, et le seul dont le souverain n'est pas le maitre, parce qu'il ne peut l'être sans choquer ses intérêts. Ainsi, si un sujet se trouve blessé dans son honneur par son prince, soit par quelque préférence, soit par la moindre marque de mépris, il quitte sur-le-champ sa cour, son emploi, son service, et se retire chez lui.

"La différence qu'il y a des troupes françaises aux vôtres, c'est que ro les unes, composées d'esclaves naturellement lâches, ne surmontent la crainte de la mort que par celle du châtiment, ce qui produit dans l'âme un nouveau genre de terreur qui la rend comme stupide: au lieu que les autres se présentent aux coups avec délice, et bannissent la crainte par une satisfaction qui lui est supérieure.

"Mais le sanctuaire de l'honneur, de la réputation et de la vertu, semble être établi dans les républiques et dans les pays où l'on peut prononcer le mot de patrie. A Rome, à Athènes, à Lacédémone, l'honneur payait seul les services les plus signalés. Une couronne de chêne ou de laurier, une statue, un éloge, était une récompense 20 immense pour une bataille gagnée ou une ville prise.

"Là, un homme qui avait fait une belle action se trouvait suffisamment récompensé par cette action même. Il ne pouvait voir un de ses compatriotes qu'il ne ressentît le plaisir d'être son bienfaiteur; il comptait le nombre de ses services par celui de ses concitoyens. Tout 25 homme est capable de faire du bien à un homme; mais c'est ressembler aux dieux que de contribuer au bonheur d'une société entière.

" Or cette noble émulation ne doit-elle point être entièrement éteinte dans le cœur de vos Persans, chez qui les emplois et les dignités ne sont que des attributs de la fantaisie du souverain? La réputation et 30 la vertu y sont regardées comme imaginaires, si elles ne sont accompagnées de la faveur du prince, avec laquelle elles naissent et meurent de même. Un homme qui a pour lui l'estime publique n'est jamais sûr de ne pas être déshonoré demain. Le voilà aujourd'hui général d'armée: peut-être que le prince le va faire son cuisinier, et qu'il ne 35 lui laissera plus à espérer d'autre éloge que celui d'avoir fait un bon ragoût. »

A Paris, le $5_{5}$ de la lune de gemmadi, 2, I 7 I 5 .

— " Lettres persanes », Letter LXXXIX 


\section{L'ANGLETERRE}

Si cette nation ${ }^{1}$ habitait une île, elle ne serait point conquérante, parce que des conquêtes séparées l'affaibliraient. Si le terrain de cette île était bon, elle le serait encore moins, parce qu'elle n'aurait pas besoin de la guerre pour s'enrichir. Et comme aucun citoyen ne dépen5 drait d'un autre citoyen, chacun ferait plus de cas de sa liberté que de la gloire de quelques citoyens ou d'un seul.

Là on regarderait les hommes de guerre comme des gens d'un métier qui peut être utile et souvent dangereux, comme des gens dont les services sont laborieux pour la nation même; et les qualités civiles ı y seraient plus considérées.

Cette nation, que la paix et la liberté rendraient aisée, affranchie des préjugés destructeurs, serait portée à devenir commerçante. Si elle avait quelqu'une de ces marchandises primitives qui servent à faire de ces choses auxquelles la main de l'ouvrier donne un grand prix, elle I 5 pourrait faire des établissements propres à se procurer la jouissance de ce don du ciel dans toute son étendue. ${ }^{2}$

Si cette nation était située vers le nord, et qu'elle eût un grand nombre de denrées superflues, comme elle manquerait aussi d'un grand nombre de marchandises que son climat lui refuserait, elle ferait un 20 commerce nécessaire, mais grand, avec les peuples du midi; et choisissant les Etats qu'elle favoriserait d'un commerce avantageux, elle ferait des traités réciproquement utiles avec la nation qu'elle aurait choisie. $^{3}$

Dans un État où d'un côté l'opulence serait extrême, et de l'autre 25 les impôts excessifs, on ne pourrait guère vivre sans industrie avec une fortune bornée. Bien des gens, sous prétexte de voyages ou de santé, s'exileraient de chez eux, et iraient chercher l'abondance dans les pays de la servitude même.

Une nation commerçante a un nombre prodigieux de petits intérêts 30 particuliers; elle peut donc choquer et être choquée d'une infinité de manières. Celle-ci deviendrait souverainement jalouse; et elle s'affligerait plus de la prospérité des autres qu'elle ne jouirait de la sienne.

Et ses lois, d'ailleurs douces ct faciles, pourraient être si rigides à l'égard du commerce et de la navigation qu'on ferait chez elle qu'elle 35 semblerait ne négocier qu'avec des ennemis.

1 England.

$2 \mathrm{He}$ is referring to woolen goods.

$3 \mathrm{~A}$ reference to the treaty of Methuen, between England and Portugal, concerning mutual customs regulations. 
Si cette nation envoyait au loin des colonies, elle le ferait plus pour étendre son commerce que sa domination.

Comme on aime à établir ailleurs ce qu'on trouve établi chez soi, elle donnerait aux peuples de ses colonies la forme de son gouvernement propre; et ce gouvernement portant avec lui la prospérité, on verrait se former de grands peuples dans les forêts même qu'clle enverrait habiter. ${ }^{1}$

Il pourrait être qu'elle aurait autrefois subjugué une nation voisine, qui, par sa situation, la bonté de ses ports, la nature de ses richesses, lui donnerait de la jalousie: ainsi, quoiqu'elle lui eût donné ses propres to lois, elle la tiendrait dans une grande dépendance; de façon que les citoyens y seraient libres, et que l'État lui-même serait esclave. ${ }^{2}$

L'État conquis aurait un très bon gouvernement civil, mais il serait accablé par le droit des gens ; et on lui imposerait des lois de nation à nation, qui seraient telles, que sa prospérité ne serait que précaire, ${ }_{15}$ et seulement en dépôt pour un maître.

La nation dominante habitant une grande île, et étant en possession d'un grand commerce, aurait toutes sortes de facilités pour avoir des forces de mer; et comme la conservation de sa liberté demanderait qu'elle n'eût ni places, ni forteresses, ni armées de terre, elle aurait 20 besoin d'une armée de mer qui la garantît des invasions; et sa marine serait supérieure à celle de toutes les autres puissances, qui, ayant besoin d'employer leurs finances pour la guerre de terre, n'en auraient plus assez pour la guerre de mer.

L'empire de la mer a toujours donné aux peuples qui l'ont possédé 25 une fierté naturelle, parce que, sc sentant capables d'insulter partout, ils croient que leur pouvoir n'a pas plus de bornes que l'Océan.

Cette nation pourrait avoir une grande influence dans les affaires de ses voisins. Car, comme elle n'emploierait pas sa puissance à conquérir, on rechercherait plus son amitié, et l'on craindrait plus sa haine $3^{\circ}$ que l'inconstance de son gouvernement et son agitation intérieure ne sembleraient le permettre.

Ainsi, ce serait le destin de la puissance exécutrice d'être presque toujours inquiétée au dedans, et respectée au dehors.

S'il arrivait que cette nation devînt en quelques occasions le centre 35 des négociations de l'Europe, elle y porterait un peu plus de probité et de bonne foi que les autres, parce que ses ministres étant souvent obligés de justifier leur conduite devant un conseil populaire, leurs

1 The English colonies in America.

2 Ireland. 
négociations ne pourraient être secrètes, et ils seraient forcés d'être, à cet égard, un peu plus honnêtes gens.

De plus, comme ils seraient en quelque façon garants des événements qu'une conduite détournée pourrait faire naítre, le plus sûr pour 5 eux serait de prendre le plus droit chemin.

Si les nobles avaient eu dans de certains temps un pouvoir immodéré dans la nation, et que le monarque eût trouvé le moyen de les abaisser en élevant le peuple, ${ }^{1}$ le point de l'extrême servitude aurait été entre le moment de l'abaissement des grands, et celui où le peuple Io aurait commencé à sentir son pouvoir. ${ }^{2}$

Il pourrait être que cette nation ayant été autrefois soumise à un pouvoir arbitraire, en aurait en plusieurs occasions conservé le style: de manière que, sur le fond d'un gouvernement libre, on verrait souvent la forme d'un gouvernement absolu. . . .

I 5 Les dignités, faisant partie de la constitution fondamentale, seraient plus fixes qu'ailleurs; mais d'un autre côté, les grands, dans ce pays de liberté, s'approcheraient plus du peuple; les rangs seraient donc plus séparés, et les personnes plus confondues.

Ceux qui gouvernent ayant une puissance qui se remonte, pour 20 ainsi dire, et se refait tous les jours, auraient plus d'égard pour ceux qui leur sont utiles que pour ceux qui les divertissent: ainsi on y verrait peu de courtisans, de flatteurs, de complaisants, enfin de toutes ces sortes de gens qui font payer aux grands le vide même de leur esprit.

On n'y estimerait guère les hommes par des talents ou des attributs 25 frivoles, mais par des qualités réelles; et de ce genre il n'y en a que deux : les richesses et le mérite personnel.

Il y aurait un luxe solide, fondé, non pas sur le raffinement de la vanité, mais sur celui des besoins réels; et l'on ne chercherait guère dans les choses que les plaisirs que la nature y a mis.

30 On y jouirait d'un grand superflu, et cependant les choses frivoles y seraient proscrites : ainsi, plusieurs ayant plus de biens que d'occasions de dépense, l'emploieraient d'une manière bizarre; et dans cette nation il y aurait plus d'esprit que de goût. . . .

Les lois n'y étant pas faites pour un particulier plus que pour un 35 autre, chacun se regarderait comme monarque; et les hommes, dans cette nation, seraient plutôt des confédérés que des concitoyens. . . .

Aucun citoyen ne craignant aucun citoyen, cette nation serait fière ; car la fierté des rois n'est fondée que sur leur indépendance.

1 Under Henry VII.

2 Under Henry VII and Henry VIII. 
Les nations libres sont superbes, les autres peuvent plus aisément être vaines.

Mais ces hommes si fiers, vivant beaucoup avec eux-mêmes, se trouveraient souvent au milieu de gens inconnus; ils seraient timides, et l'on verrait en eux, la plupart du temps, un mélange bizarre de mauvaise honte et de fierté.

Le caractère de la nation paraítrait surtout dans leurs ouvrages d'esprit, dans lesquels on verrait des gens recueillis, et qui auraient pensé tout seuls.

La société nous apprend à sentir les ridicules; la retraite nous rend ro plus propres à sentir les vices. Leurs écrits satiriques seraient sanglants ; et l'on verrait bien des Juvénals chez eux, avant d'avoir trouvé un Horace.

Dans les monarchies extrêmement absolues, les historiens trahissent la vérité, parce qu'ils n'ont pas la liberté de la dire; dans les États ${ }_{5}$ extrêmement libres, ils trahissent la vérité, à cause de leur liberté même, qui, produisant toujours des divisions, chacun devient aussi esclave des préjugés de sa faction qu'il le serait d'un despote.

Leurs poètes auraient plus souvent cette rudesse originale de l'invention, qu'une certaine délicatesse que donne le goût, on y trouverait 20 quelque chose qui approcherait plus de la force de Michel-Ange que de la grâce de Raphaël.

— "L'esprit des lois», Book XIX, chap. 27

\section{PORTRAIT DE MONTESQUIEU PAR LUI-MÊME}

Ma machine est si heureusement construite, que je suis frappé par tous les objets assez pour qu'ils puissent me donner du plaisir, pas assez pour qu'ils puissent me causer de la peine.

J'ai l'ambition qu'il faut pour me faire prendre part aux choses de cette vie; je n'ai point celle qui pourrait me faire trouver du dégoût dans le poste où la nature m'a mis. ...

L'étude a été pour moi le souverain remède contre les dégoûts de la vie, n'ayant jamais eu de chagrin qu'une heure de lecture n'ait 30 dissipé.

Je m'éveille le matin avec une joie secrète de voir la lumière; je vois la lumière avec une espèce de ravissement; et tout le reste du jour je suis content. Je passe la nuit sans m'éveiller, et le soir, quand 
je vais au lit, une espèce d'engourdissement m'empêche de faire des réflexions. ... .

J'ai eu naturellement de l'amour pour le bien et l'honneur de ma patrie, et peu pour ce qu'on appelle la gloire; j'ai toujours senti une 5 joie secrète lorsqu'on a fait quelque règlement qui allait au bien commun....

J'aime les maisons où je puis me tirer d'affaire avec mon esprit de tous les jours. ...

Quand je me fie à quelqu'un, je le fais sans réserve; mais je me fie ıo à très peu de personnes.

Ce qui m'a toujours donné une assez mauvaise opinion de moi, c'est qu'il y a fort peu d'états dans la république auxquels j'eusse été véritablement propre. Quant à mon métier de président, j'ai le cœur très droit; je comprenais assez les questions en elles-mêmes; mais I 5 quant à la procédure, je n'y entendais rien. Je m'y suis pourtant appliqué, mais ce qui m'en dégoûtait le plus, c'est que je voyais à des bêtes le même talent qui me fuyait, pour ainsi dire. . . .

Je n'ai jamais vu couler de larmes sans en être attendri.

Je suis amoureux de l'amitié.

20 Je pardonne aisément par la raison que je ne suis pas haineux. Il me semble que la haine est douloureuse. Lorsque quelqu'un a voulu se réconcilier avec moi, j'ai senti ma vanité flattée, et j'ai cessé de regarder comme ennemi un homme qui me rendait le service de me donner une bonne opinion de moi. . . .

25 Il m'est aussi impossible d'aller chez quelqu'un dans des vues d'intérêt, qu'il m'est impossible de rester dans les airs.

Quand j'ai été dans le monde, je l'ai aimé comme si je ne pouvais souffrir la retraite ; quand j'ai été dans mes terres, je n'ai plus songé au monde. ... .

30 Je suis, je crois, le seul homme qui ait mis des livres au jour sans être touché de la réputation de bel esprit. Ceux qui m'ont connu savent que, dans mes conversations, je ne cherchais pas trop à le paraître, et que j'avais assez le talent de prendre la langue de ceux avec qui je vivais. ...

35 J'ai eu pour principe de ne jamais faire par autrui ce que je pouvais par moi-même: c'est ce qui m'a porté à faire ma fortune par les moyens que j'avais dans mes mains, la modération et la frugalité, et non par des moyens étrangers, toujours bas ou injustes. . . .

Je n'ai pas laissé, je crois, d'augmenter mon bien ; j'ai fait de grandes 
améliorations à mes terres : mais je sentais que c'était plutôt pour une certaine idée d'habileté que cela me donnait, que pour l'idée de devenir plus riche. ...

Je ne sache pas encore avoir dépensé quatre louis par air, ni fait une visite par intérêt. Dans ce que j'entreprenais, je n'employais que la prudence commune, et j'agissais moins pour ne pas manquer les affaires que pour ne pas manquer aux affaires. . . .

J'ai la maladie de faire des livres et d'en être honteux quand je les ai faits.

Je n'ai pas aimé à faire ma fortune par le moyen de la cour; j'ai ro songé à la faire en faisant valoir mes terres, et à tenir toute ma fortune immédiatement de la main des I)ieux. $\mathrm{N}-$, qui avait de certaines fins, - me fit entendre qu'on me donnerait une pension; je dis que, n'ayant point fait de bassesses, je n'avais pas besoin d'être consolé par des grâces.

Je suis un bon citoyen, mais dans quelque pays que je fusse né, je l'aurais été tout de même. Je suis un bon citoyen parce que j'ai toujours été content de l'état où je suis, que j'ai toujours approuvé ma fortune, que je n'ai jamais rougi d'elle, ni envié celle des autres. Je suis un bon citoyen, parce que j'aime le gouvernement où je suis né, 20 sans le craindre, et que je n'en attends d'autre faveur que ce bien inestimable que je partage avec tous mes compatriotes; et je rends grâces au ciel de ce qu'ayant mis en moi de la médiocrité en tout, il a bien voulu mettre un peu de modération dans mon âme. . . .

$\mathrm{Si}$ je savais quelque chose qui me fût utile et qui fût préjudiciable 25 à ma famille, je le rejetterais de mon esprit. Si je savais quelque chose qui fût utile à ma famille, et qui ne le fût pas à ma patrie, je chercherais à l'oublier. Si je savais quelque chose utile à ma patrie, et qui fût préjudiciable à l'Europe et au genre humain, je le regarderais comme un crime. 


\section{PIERRE CARLET DE CHAMBLAIN DE MARIVAUX}

Paris, $1688-1763$, Paris

Marivaux's life was uneventful. His chief interests were in his literary work through which he won a more or less scanty livelihood. His training for his career was in the "salons," rather than in textbooks, and so, in what he wrote, he sought to reproduce "the language of conversation and the tone of familiar and varied ideas which enter into it." $\mathrm{He}$ attained to one of the first places in French literary circles of his day through his light, elegant, and graceful comedies, - of which the best are "La surprise de l'amour" (1722); "Le jeu de l'amour et du hasard" (1730); "Le legs" (1736); "Les fausses confidences" (I737); and "L'épreuve" (1740), - and through his novels, in which he shows a remarkably acute and subtle psychological analysis of the very beginnings and most delicate shades of love. His best novels are "Le paysan parvenu" (1735-1736) and "La vie de Marianne" (1731-1741).

\section{LE JEU DE L'AMOUR ET DU HASARD ${ }^{1}$ \\ Pasquin, ${ }^{2}$ Lisette}

Pasquin. Enfin, ma reine, je vous vois, et je ne vous quitte plus; car j'ai trop pâti d'avoir manqué de votre présence, et j'ai cru que vous esquiviez la mienne.

Lisette. Il faut vous avouer, monsieur, qu'il en était quelque chose.

5 Pasquin. Comment donc, ma chère âme, élixir de mon cœur, avezvous entrepris la fin de ma vie?

Lisette. Non, mon cher, la durée m'en est trop précieuse.

Pasquin. Ah! que ces paroles me fortifient!

Lisette. Et vous ne devez point douter de ma tendresse.

Pasquin. Je voudrais bien pouvoir baiser ces petits mots-là, et les cueillir sur votre bouche avec la mienne.

1 Silvia has temporarily changed places with her maid Lisette in order to discover the real character of her expected suitor Dorante, who, on his side, has effected the same exchange with his valet Pasquin. Thus Lisette has taken Pasquin, who loves her, for Dorante, and Pasquin has taken Lisette for Silvia. The truth is brought to light in this scene.

2 Arlequin, the original name of this character, was changed to Pasquin when the play was taken up by the Comédie française. 
Lisette. Mais vous me pressiez sur notre mariage, et mon père ne m'avait pas encore permis de vous répondre. Je viens de lui parler, et j'ai son aveu pour vous dire que vous pouvez lui demander ma main quand vous voudrez.

Pasquin. Avant que je la demande à lui, souffrez que je la demande à vous: je veux lui rendre mes grâces de la charité qu'elle aura de vouloir bien entrer dans la mienne, qui en est véritablement indigne.

Lisette. Je ne vous refuse pas de vous la prêter un moment à condition que vous la prendrez pour toujours.

Pasquin. Chère petite main rondelette et potelée, je vous prends 10 sans marchander: je ne suis pas en peine de l'honneur que vous me ferez, il n'y a que celui que je vous rendrai qui m'inquiète.

Lisette. Vous m'en rendrez plus qu'il ne m'en faut.

Pasquin. Ah! que nenni: vous ne savez pas cette arithmétique-là aussi bien que moi.

Lisette. Je regarde pourtant votre amour comme un présent du ciel.

Pasquin. Le présent qu'il vous a fait ne le ruinera pas, il est bien mesquin.

Lisette. Je ne le trouve que trop magnifique.

Pasquin. C'est que vous ne le voyez pas au grand jour.

Lisette. Vous ne sauriez croire combien votre modestie m'embarrasse.

Pasquin. Ne faites point dépense d'embarras: je serais bien effronté si je n'étais modeste.

Lisette. Enfin, monsieur, faut-il vous dire que c'est moi que votre 25 tendresse honore?

Pasquin. Ahi, ahi! je ne sais plus où me mettre.

Lisette. Encore une fois, monsieur, je me connais.

Pasquin. Eh! je me connais bien aussi, et je n'ai pas là une fameuse connaissance, ni vous non plus quand vous l'aurez faite; 30 mais c'est là le diable que de me connaître: vous ne vous attendez pas au fond du sac!

Lisette (à part). Tant d'abaissement n'est pas naturel. (Haut.) D'où vient me dites-vous cela?

Pasquin. Et voilà où gît le lièvre.

Lisette. Mais encore? Vous m'inquiétez. Est-ce que vous n'êtes pas...

Pasquin. Ahi, ahi! vous m'ôtez ma couverture.

Lisette. Sachons de quoi il s'agit. 
Pasquin (à part). Préparons un peu cette affaire-là. (Haut.) Madame, votre amour est-il d'une constitution bien robuste? Soutiendra-t-il bien la fatigue que je vais lui donner? Un mauvais gite lui fait-il peur? Je vais le loger petitement.

5 Lisette. Ah! tirez-moi d'inquiétude. En un mot, qui êtes-vous?

Pasquin. Je suis ... N'avez-vous jamais vu de fausse monnaie? Savez-vous ce que c'est qu'un louis d'or faux? Eh bien! je ressemble assez à cela.

Lisette. Achevez donc. Quel est votre nom?

ı Pasquin. Mon nom! (A part.) Lui dirai-je que je m'appelle Pasquin? Non; cela rime trop avec coquin.

Lisette. Eh bien?

Pasquin. Ah! dame! il y a un peu à tirer ici. ${ }^{1}$ Haïssez-vous la qualité de soldat?

I 5 Lisette. Qu'appelez-vous un soldat?

Pasquin. Oui, par exemple, un soldat d'antichambre.

Lisette. Un soldat d'antichambre! Ce n'est donc point Dorante à qui je parle enfin?

Pasquin. C'est lui qui est mon capitaine.

20 Lisette. Faquin!

Pasquin (à part). Je n'ai pu éviter la rime.

Lisette. Mais voyez ce magot, tenez!

Pasquin (à part). La jolie culbute que je fais là!

Lisette. Il y a une heure que je lui demande grâce, et que je 25 m'épuise en humilités pour cet animal-là.

Pasquin. Hélas! madame, si vous préfériez l'amour à la gloire, je vous ferais bien autant de profit qu'un monsieur.

Lisette (riant). Ah! ah! ah! je ne saurais pourtant m'empêcher d'en rire, avec sa gloire ! et il n'y a plus que ce parti-là à prendre. . . Va, $30 \mathrm{va}$, ma gloire te pardonne; elle est de bonne composition.

Pasquin. Tout de bon, charitable dame? Ah! que mon amour vous promet de reconnaissance!

Lisette. 'Touche là, Pasquin, je suis prise pour dupe. Le soldat d'antichambre de monsieur vaut bien la coiffeuse de madame.

35 Pasquin. La coiffeuse de madame!

Lisette. C'est mon capitaine, ou l'équivalent.

Pasquin. Masque!

Lisette. Prends ta revanche. 
Pasquin. Mais voyez cette magotte, avec qui, depuis une heure, j'entre en confusion de ma misère.

lisette. Venons au fait. M'aimes-tu?

Pasquin. Pardi, oui. En changeant de nom, tu n'as pas changé de visage ; et tu sais bien que nous nous sommes promis fidélité, en dépit 5 de toutes les fautes d'orthographe.

Lisette. Va, le mal n'est pas grand; consolons-nous: ne faisons semblant de rien, et n'apprêtons point à rire. Il y a apparence que ton maître est encore dans l'erreur à l'égard de ma maîtresse, ne l'avertis de rien; laissons les choses comme elles sont. Je crois que le ro voici qui entre. Monsieur, je suis votre servante.

Pasquin. Et moi votre valet, madame. (Riant.) Ah! Ah! Ah!

- Act III, scene 6

\section{LES EMBARRAS DE PARIS}

Ah! Ah! Marianne, eh ! c'est vous, s'écria-t-elle. Eh! pourquoi donc en fiacre? Est-ce que vous venez de si loin? Non, madame, lui disje ; mais je me suis blessée en tombant, et il m'était impossible de 15 marcher; je vous conterai mon accident, quand je serai rentrée. Ayez à présent la bonté de m'aider avec le cocher à descendre.

Le cocher ouvrait la portière pendant que je parlais. Allez, allez, me dit-il, arrivez; ne vous embarrassez pas, mademoiselle; pardi! je vous descendrai bien tout seul. Une belle enfant comme vous, qu'est- 20 ce que cela pèse? C'est le plaisir. Venez, venez; jetez-vous hardiment : je vous porterais encore plus loin que vous n'iriez sur vos jambes.

En effet, il me prit entre ses bras, et me transporta comme une plume jusqu'à la boutique, où je m'assis tout d'un coup. . . .

A peine fus-je assise, que je tirai de l'argent pour payer le cocher ; 25 mais madame Dutour, ${ }^{1}$ en femme d'expérience, crut devoir me conduire là-dessus, et me trouva trop jeune pour m'abandonner ce petit détail. Laissez-moi faire, me dit-elle, je vais le payer; où vous a-t-il prise? Auprès de la paroisse, lui dis-je. Eh! c'est tout près d'ici, répliqua-t-elle en comptant quelque monnaie. Tenez, voilà ce qu'il 30 vous faut.

Ce qu'il me faut! cela! dit le cocher, qui lui rendit sa monnaie avec un dédain brutal; oh! que nenni: cela ne se mesure pas à l'aune. Mais que veut-il dire avec son aune, cet homme? répliqua gravement

1 Madame Dutour kept a little dry-goods store. Marianne was in her employ. 
madame Dutour: vous devez être content; on sait peut-être bien ce que c'est qu'un carrosse, ce n'est pas d'aujourd'hui qu'on en paie.

Eh! quand ce serait de demain, dit le cocher, qu'est-ce que cela avance? Donnez-moi mon affaire, et ne crions pas tant; voyez de 5 quoi elle se mêle! Est-ce vous que j'ai menée? Est-ce qu'on vous demande quelque chose? Quelle diable de femme avec ses douze sous! Elle marchande cela comme une botte d'herbes.

Madame Dutour était fière, parée, et qui plus est assez jolie; ce qui lui donnait encore une autre espèce de gloire.

ro Les femmes d'un certain état s'imaginent en avoir plus de dignité, quand elles ont un joli visage; elles regardent cet avantage-là comme un rang. La vanité s'aide de tout, et remplace ce qui lui manque avec ce qu'elle peut. Madame Dutour se sentit donc offensée de l'apostrophe ignoble du cocher (je vous raconte cela pour vous divertir): la

$I_{5}$ botte d'herbes sonna mal à ses oreilles. Comment ce jargon-là pouvaitil venir à la bouche de quelqu'un qui la voyait? $Y$ avait-il rien dans son air qui fît penser à pareille chose? En vérité, mon ami, il faut avouer que vous êtes bien impertinent, et il me convient bien d'écouter vos sottises! dit-elle. Allons, retirez-vous. Voilà votre argent; 20 prenez ou laissez: qu'est-ce que cela signifie? Si j'appelle un voisin, on vous apprendra à parler aux bourgeois plus honnêtement que vous ne faites.

Eh bien! qu'est-ce que me vient conter cette chiffonnière ? répliqua l'autre en vrai fiacre. ${ }^{1}$ Gare! prenez garde à elle; elle a son fichu des 25 dimanches. Ne semble-t-il pas qu'il faille tant de cérémonies pour parler à madame? On parle bien à Perrette. ${ }^{2}$ Eh! palsambleu! payez-moi. Quand vous seriez encore quatre fois plus bourgeoise que vous êtes, qu'est-ce que cela me fait? Faut-il pas que mes chevaux vivent? Avec quoi dîneriez-vous, vous qui parlez, si on ne vous payait pas votre 30 toile? Auriez-vous la face si large? Fi! que cela est vilain d'être crasseuse !

Le mauvais exemple débauche. Madame Dutour, qui s'était maintenue jusque-là dans les bornes d'une assez digne fierté, ne put résister à cette dernière brutalité du cocher: elle laissa là le rôle de femme 35 respectable qu'elle jouait, et qui ne lui rapportait rien, se mit à sa commodité, en revint à la manière de quereller qui était à son usage,

1 No longer generally used in the sense of "coachman."

2 One of the names most commonly applied, in Marivaux's time, to a girl of the lower classes. 
c'est-à-dire, aux discours d'une commère de comptoir subalterne : elle ne s'y épargna pas. . . .

Attends, attends, ivrogne, avec ton fichu des dimanches: tu vas voir la Perrette qu'il te faut; je vais te la montrer, moi, s'écria-t-elle en courant se saisir de son aune qui était à côté du comptoir.

Et quand elle fut armée: Allons, sors d'ici! s'écria-t-elle, ou je te mesure avec cela, ni plus ni moins qu'une pièce de toile, puisque toile il y a. Jarnibleu! ne me frappez pas, lui dit le cocher qui lui tenait le bras; ne soyez pas si osée! je me donne au diable, ne badinons pas! Voyez-vous! Je suis un gaillard qui n'aime pas les coups, ou la peste to m'étouffe! Je ne vous demande que mon dû, entendez-vous? Il n'y a pas de mal à ça.

Le bruit qu'ils faisaient attirait du monde; on s'arrêtait devant la boutique. Me laisseras-tu! lui disait madame Dutour, qui disputait toujours son aune contre le cocher: levez-vous donc, Marianne; appelez is monsieur Richard! Monsieur Richard! criait-elle tout de suite ellemême; et c'était notre hôte qui logeait au second et qui n'y était pas. Elle s'en douta. Messieurs, dit-elle en apostrophant la foule qui s'était arrêtée devant la porte, je vous prends tous à témoins; vous voyez ce qui en est, il m'a battue (cela n'était pas vrai); je suis maltraitée. Une 20 femme d'honneur comme moi! Eh vite, eh vite; allez chez le commissaire: il me connait bien, c'est moi qui le fournis; on n'a qu'à lui dire que c'est chez madame Dutour. Courez-y, madame Catau; courez-y, ma mie, criait-elle à une servante du voisinage ; le tout avec une cornette ${ }^{1}$ que les secousses que le cocher donnait à ses bras, 25 avaient rangée de travers.

Elle avait beau crier, personne ne bougeait, ni messieurs, ni Catau. ... .

Le seul intérêt des bonnes mœurs devait engager madame Dutour à composer avec ce misérable : il n'était pas honnête à elle de soutenir $3^{\circ}$ l'énergie de ses expressions; mais elle en dévorait le scandale en faveur de la rage qu'elle avait d'y répondre; elle était trop fâchée pour avoir les oreilles délicates.

Oui, malotru! oui, douze sous, tu n'en auras pas davantage, disaitelle. Et moi je ne les prendrai pas, douze diablesses, répondait le 35 cocher. Encore ne les vaux-tu pas, continuait-elle; n'es-tu pas honteux, fripon? quoi! pour venir d'auprès de la paroisse ici? quand ce serait pour un carrosse d'ambassadeur. Tiens, jarni de ma vie! un denier

1 A sort of headdress of the period. 
avec, tu ne l'aurais pas: j'aimerais mieux te voir mort, il n'y aurait pas grande perte; et souviens-toi seulement que c'est aujourd'hui la Saint-Mathieu: bon jour, bonne œuvre; ne l'oublie pas. Et laisse venir demain; tu verras comme il sera fait. C'est moi qui te le dis, 5 qui ne suis pas une chiffonnière, mais bel et bien madame Dutour, madame pour toi, madame pour les autres, et madame tant que je serai au monde, entends-tu?

— "La vie de Marianne ", Part second 


\title{
LUC DE CLAPIERS, MARQUIS DE VAUVENARGUES
}

\author{
Aix in Provence, $1715-1747$, Paris
}

Vauvenargues came of a poor but noble family. His education was much neglected. At the age of eighteen he entered military service, resigning his post through ill health and disappointment ten years later. He next made some attempt to enter the diplomatic service, but without success, and then took up literature, and published, in 1746 , the "Introduction à la connaissance de l'esprit humain." Joined to this were some "Réflexions sur divers sujets," "Conseils à un jeune homme," "Réflexions critiques sur quelques poètes," and some "Caractères." He is best known for his "Réflexions" or "Maximes," whose general tone is optimistic. He died in 1747 .

\section{RÉFLEXIONS ET MAXIMES}

III

Lorsqu'une pensée est trop faible pour porter une expression simple, c'est la marque pour la rejeter.

IV

La clarté orne les pensées profondes.

$\mathrm{V}$

L'obscurité est le royaume de l'erreur.

VI

Il n'y aurait point d'erreurs qui ne périssent d'elles-mêmes, rendues clairement.

IX

Lorsqu'une pensée s'offre à nous comme une profonde découverte, et que nous prenons la peine de la développer, nous trouvons souvent que c'est une vérité qui court les rues.

XII

C'est un grand signe de médiocrité de louer toujours modérément. Io 
La prospérité fait peu d'amis.

\section{XVIII}

Les longues prospérités s'écoulent quelquefois en un moment: comme les chaleurs de l'été sont emportées par un jour d'orage.

\section{XLIII}

C'est une preuve de petitesse d'esprit, lorsqu'on distingue toujours 5 ce qui est estimable de ce qui est aimable. Les grandes âmes aiment naturellement ce qui est digne de leur estime.

$$
\text { LV }
$$

Il n'y a guère de gens plus aigres que ceux qui sont doux par intérêt.

\section{LVII}

Il est faux qu'on ait fait fortune, lorsqu'on ne sait pas en jouir.

\section{LXIII}

Io Les gens d'esprit seraient presque seuls, sans les sots qui s'en piquent.

\section{LXVII}

Il est difficile d'estimer quelqu'un comme il veut l'être.

\section{LXXV}

Le sentiment de nos forces les augmente.

$$
\text { CVII }
$$

Les maximes des hommes décèlent leur cœur.

CCXV

I5 Savoir bien rapprocher les choses, voilà l'esprit juste. Le don de rapprocher beaucoup de choses et de grandes choses fait les esprits vastes. Ainsi la justesse paraît être le premier degré, et une condition très nécessaire de la vraie étendue d'esprit.

\section{CCXVII}

Je n'approuve point la maxime qui veut qu'un honnête homme sache 20 un peu de tout. C'est savoir presque toujours inutilement, et quelquefois pernicieusement, que de savoir superficiellement et sans principes. 
Il est vrai que la plupart des hommes ne sont guère capables de connaître profondément; mais il est vrai aussi que cette science superficielle qu'ils recherchent ne sert qu'à contenter leur vanité. Elle nuit à ceux qui possèdent un vrai génie: car elle les détourne nécessairement de leur objet principal, consume leur application dans les détails, et sur des objets étrangers à leurs besoins et à leurs talents naturels ; et enfin elle ne sert point, comme ils s'en flattent, à prouver l'étendue de leur esprit. De tout temps on a vu des hommes qui savaient beaucoup avec un esprit très médiocre; et au contraire, des esprits très vastes qui savaient fort peu. Ni l'ignorance n'est défaut d'esprit, ni le ro savoir n'est preuve de génie.

\section{CCLXXX}

Ceux qui sont nés éloquents parlent quelquefois avec tant de clarté et de brièveté des grandes choses, que la plupart des hommes n'imaginent pas qu'ils en parlent avec profondeur. Les esprits pesants, les sophistes, ne reconnaissent pas la philosophie, lorsque l'éloquence la 15 rend populaire, et qu'elle ose peindre le vrai avec des traits fiers et hardis. Ils traitent de superficielle et de frivole cette splendeur d'expression qui emporte avec elle la preuve des grandes pensées. Ils veulent des définitions, des discussions, des détails et des arguments. Si Locke ${ }^{1}$ eût rendu vivement en peu de pages les sages vérités de 20 ses écrits, ils n'auraient pas osé le compter parmi les philosophes de son siècle.

\section{CCLXXXI}

C'est un malheur que les hommes ne puissent d'ordinaire posséder aucun talent sans avoir quelque envie d'abaisser les autres. S'ils ont la finesse, ils décrient la force; s'ils sont géomètres ou physiciens, ils 25 écrivent contre la poésie et l'éloquence : et les gens du monde, qui ne pensent pas que ceux qui ont excellé dans quelque genre jugent mal d'un autre talent, se laissent prévenir par leurs décisions. Ainsi, quand la métaphysique ou l'algèbre sont à la mode, ce sont des métaphysiciens ou des algébristes qui font la réputation des poètes et des musi- 30 ciens, ou tout au contraire: l'esprit dominant assujettit les autres à son tribunal, et la plupart du temps à ses erreurs.

1 John Locke $\left(163^{2-1704)}\right.$, one of the most celebrated philosophers and influential thinkers of modern times, author of the "Essay concerning Humane Understanding" (1690). 
CCCXXXv

On ne peut avoir l'âme grande ou l'esprit un peu pénétrant sans quelque passion pour les lettres. Les arts sont consacrés à peindre les traits de la belle nature; les sciences, à la vérité. Les arts ou les sciences embrassent tout ce qu'il y a, dans les objets de la pensée, de 5 noble ou d'utile: de sorte qu'il ne reste à ceux qui les rejettent que ce qui est indigne d'être peint ou enseigné.

\section{CCCXXXVII}

Deux études sont importantes : l'éloquence et la vérité; la vérité, pour donner un fondement solide à l'éloquence, et bien disposer notre vie; l'éloquence, pour diriger la conduite des autres hommes et ro défendre la vérité.

\section{CCCXXXVIII}

La plupart des grandes affaires se traitent par écrit; il ne suffit donc pas de savoir parler: tous les intérêts subalternes, les engagements, les plaisirs, les devoirs de la vie civile, demandent qu'on sache parler; c'est donc peu de savoir écrire. Nous aurions besoin tous les ${ }_{1} 5$ jours d'unir l'une et l'autre éloquence : mais nulle ne peut s'acquérir, si d'abord on ne sait penser; et on ne sait guère penser, si l'on n'a des principes fixes et puisés dans la vérité. Tout confirme notre maxime : l'étude du vrai la première, l'éloquence après.

\section{CCCLXV}

La clarté est la bonne foi des philosophes.

\section{CCCLXVI}

20 La netteté est le vernis des maîtres.

CCCLXXI

Pour savoir si une pensée est nouvelle, il n'y a qu'à l'exprimer bien simplement. 


\section{VOLTAIRE \\ (FRANÇOIS-MARIE AROUET)

$$
\text { Paris, } 1694-1778 \text {, Paris }
$$

François-Marie Arouet, son of a well-to-do notary, was born at Paris in I694. He received his education in the Jesuit college, Louis-le-Grand, showing in his studies marks of unusual brilliancy and a particular aptitude for writing verse. His reputation for versifying, in fact, soon got him into trouble, for, accused of writing satirical and malicious verses against the Regent and others, he was first exiled from Paris ( $17 \times 6$ ), and then imprisoned in the Bastile for nearly a year (1717-1718). During this imprisonment he wrote part of the "Henriade," an epic poem, which did not, however, appear until ${ }_{1723}$. In 1718 he won his first literary success, with a tragedy entitled "EDdipe." At this time he assumed the name of Voltaire. Fortune seemed now for a time to smile upon him, but his sharp wit again got him into trouble, and, as a result of a quarrel with the chevalier de Rohan-Chabot (December, 1725), he was again imprisoned, and was released five months later, only to go to England in exile (1 126$)$. The next three years he spent in England, making, in the meantime, the acquaintance of many of the greatest English thinkers, and becoming an admirer of England's literature and of her social and political institutions. He returned to France in 1729 , and then appeared in quick succession "Brutus" (1730), a tragedy; the "Histoire de Charles XII" (173I); "Zaïre" (1732), a tragedy inspired by "Othello"; the "Lettres philosophiques" or "Lettres anglaises" (1734).

After the publication of the "Lettres anglaises," in which Voltaire expresses his sympathy for England, he found it necessary to leave Paris. He took refuge with Madame du Châtelet at Cirey, and spent most of the next fifteen years with her, working now at the sciences or philosophy, now at literature, and bringing out, among other things, "Alzire" (I 736), a tragedy; "Mérope" (1743), a tragedy; "Zadig" (1747), a story. He was received into the Academy in 1746 .

For some years Voltaire had been in correspondence with Frederick the Great of Prussia, and finally, in 1750 , he yielded to the repeated solicitations of the king and went to Berlin. He was received with the greatest enthusiasm, but, in less than three years, annoyances of one kind or another made his residence in the Prussian capital impossible. Meanwhile, in 1751 , he had published the "Siècle de Louis XIV," one of his most important works.

Two years after leaving Prussia Voltaire settled at "Les Délices," on the outskirts of Geneva (1755). However, he found Protestant Geneva no more tolerant than Catholic Paris, and in $175^{8}$ he again crossed the border and bought an estate at Ferney on the French frontier. There he passed the last twenty years of his life, keeping up a correspondence with the most distinguished men of Europe, in the full possession and enjoyment of the glory, 
influence, and fortune which his success had brought him. Early in 1778 he decided to visit Paris, and it was there, idolized by a people on whom his writings had had so great an influence, that he died, May 30,1778 , at the age of eighty-four.

In addition to the volumes of lyric, epic, and dramatic poetry, of history, philosophy, criticism, and fiction (particularly "Candide"), Voltaire left a very extensive and most remarkable correspondence, which, with his historical works, forms perhaps the most interesting part of his productions.

\section{CHARLES XII A BENDER ${ }^{1}$}

L'ordre est donné dans le moment : les Turcs marchent aux retranchements: les Tartares les attendaient déjà, et les canons commençaient à tirer. Les janissaires d'un côté, et les Tartares de l'autre, forcent en un instant ce petit camp. A peine vingt Suédois tirèrent 5 l'épée; les trois cents soldats furent enveloppés et faits prisonniers sans résistance.

Le roi était alors à cheval entre sa maison et son camp, avec les généraux Hord, Dardoff, et Sparre; voyant que tous les soldats s'étaient laissé prendre en sa présence, il dit de sang-froid à ces trois ıo officiers: "Allons défendre la maison; nous combattrons, ajouta-t-il en souriant, pro aris et focis. ${ }^{2}$ ")

Aussitôt il galope avec eux vers cette maison, où il avait mis environ quarante domestiques en sentinelle, et qu'on avait fortifiée du mieux qu'on avait pu.

I5 Ces généraux, tout accoutumés qu'ils étaient à l'opiniâtre intrépidité de leur maître, ne pouvaient se lasser d'admirer qu'il voulût de sangfroid et en plaisantant se défendre contre dix canons et toute une armée: ils le suivirent avec quelques gardes et quelques domestiques, qui faisaient en tout vingt personnes.

20 Mais quand ils furent à la porte, ils la trouvèrent assiégée de janissaires; déjà près de deux cents Turcs ou Tartares étaient entrés par une fenêtre et s'étaient rendus maîtres de tous les appartements, à la réserve d'une grande salle où les domestiques du roi s'étaient retirés. Cette salle était heureusement près de la porte par où le roi voulait

1 After being defeated by the Russians at Pultava (1709), Charles XII (I682-1718), king of Sweden, with a few followers, among them his faithful lieutenants, Hord, Dardoff, and Axel Sparre, took refuge at Bender in Turkey. The Sultan, however, having signed a treaty with Russia, was forced to ask Charles to leave his states, and, on his refusal to do so, to send against him a small army of janizaries commanded by a pasha, and Tartars commanded by a khan.

2 "for our altars and our hearths." 
entrer avec sa petite troupe de vingt personnes: il s'était jeté en bas de son cheval, le pistolet et l'épée à la main, et sa suite en avait fait autant.

Les janissaires tombent sur lui de tous côtés; ils étaient animés par la promesse qu'avait faite le bacha de huit ducats d'or à chacun de ceux qui auraient seulement touché son habit, en cas qu'on pût le prendre. Il blessait et il tuait tous ceux qui s'approchaient de sa personne. Un janissaire qu'il avait blessé lui appuya son mousqueton sur le visage; si le bras du 'Turc n'avait fait un mouvement, causé par la foule qui allait et qui venait comme des vagues, le roi était ro mort; la balle glissa sur son nez, lui emporta un bout de l'oreille et alla casser le bras au général Hord, dont la destinée était d'être toujours blessé à côté de son maître. ${ }^{1}$

Le roi enfonça son épée dans l'estomac du janissaire; en même temps, ses domestiques, qui étaient enfermés dans la grande salle, en 15 ouvrent la porte; le roi entre comme un trait, suivi de sa petite troupe; on referme la porte dans l'instant, et on la barricade avec tout ce qu'on peut trouver. Voilà Charles XII dans cette salle, enfermé avec toute sa suite, qui consistait en près de soixante hommes, officiers, gardes, secrétaires, valets de chambre, domestiques de toute espèce.

Les janissaires et les Tartares pillaient le reste de la maison, et remplissaient les appartements. "Allons un peu chasser de chez moi ces barbares ", dit-il ; et, se mettant à la tête de son monde, il ouvrit lui-même la porte de la salle qui donnait dans son appartement à coucher; il entre, et fait feu sur ceux qui pillaient.

Les Turcs, chargés de butin, épouvantés de la subite apparition de ce roi qu'ils étaient accoutumés à respecter, jettent leurs armes, sautent par la fenêtre, ou se retirent jusque dans les caves; le roi, profitant de leur désordre, et les siens animés par le succès, poursuivent les Turcs de chambre en chambre, tuent ou blessent ceux qui ne fuient 30 point, et en un quart d'heure nettoient la maison d'ennemis:

Le roi aperçut, dans la chaleur du combat, deux janissaires qui se cachaient sous son lit; il en tua un d'un coup d'épée; l'autre lui demanda pardon en criant amman. ${ }^{2}$ " Je te donne la vie, dit le roi au Turc, à condition que tu iras faire au bacha un fidèle récit de ce que 35 tu as vu. » Le Turc promit aisément ce qu'on voulut, et on lui permit de sauter par la fenêtre comme les autres.

${ }^{1} \mathrm{He}$ had been wounded at Pultava.

2 "pardon." 
Les Suédois étant enfin maîtres de la maison, refermèrent et barricadèrent encore les fenêtres. Ils ne manquaient point d'armes; une chambre basse, pleine de mousquets et de poudre, avait échappé à la recherche tumultueuse des janissaires; on s'en servit à propos: les 5 Suédois tiraient à travers les fenêtres, presque à bout portant, sur cette multitude de 'Turcs, dont ils tuèrent deux cents en moins d'un demi-quart d'heure.

Le canon tirait contre la maison, mais, les pierres étant fort molles, il ne faisait que des trous et ne renversait rien.

Io Le $\mathrm{kan}^{1}$ des Tartares et le bacha, qui voulaient prendre le roi en vie, honteux de perdre du monde et d'occuper une armée entière contre soixante personnes, jugèrent à propos de mettre le feu à la maison pour obliger le roi de se rendre. Ils firent lancer sur le toit, contre les portes et contre les fenêtres, des flèches entortillées de 15 mèches allumées: la maison fut en flammes en un moment; le toit tout embrasé était près de fondre sur les Suédois. Le roi donna tranquillement ses ordres pour éteindre le feu. Trouvant un petit baril plein de liqueur, il prend le baril lui-même, et, aidé de deux Suédois, il le jette à l'endroit où le feu était le plus violent. Il se trouva que ce baril 20 était rempli d'eau-de-vie; mais la précipitation, inséparable d'un tel embarras, empêcha d'y penser. L'embrasement redoubla avec plus de rage: l'appartement du roi était consumé ; la grande salle où les Suédois se tenaient était remplie d'une fumée affreuse, mêlée de tourbillons de feu qui entraient par les portes des appartements voisins; 25 la moitié du toit était abîmée dans la maison même; l'autre tombait en dehors en éclatant dans les flammes.

Un garde, nommé Walberg, osa, dans cette extrémité, crier qu'il fallait se rendre. "Voilà un étrange homme, dit le roi, qui s'imagine qu'il n'est pas plus beau d'être brûlé que d'être prisonnier ! » Un autre 30 garde, nommé Rosen, s'avisa de dire que la maison de la chancellerie, qui n'était qu'à cinquante pas, avait un toit de pierre et était à l'épreuve du feu; qu'il fallait faire une sortie, gagner cette maison et s'y défendre : "Voilà un vrai Suédois! ", s'écria le roi. Il embrassa ce garde et le créa colonel sur-le-champ. « Allons, mes amis, dit-il, prenez 35 avec vous le plus de poudre et de plomb que vous pourrez, et gagnons la chancellerie l'épée à la main. »

Les Turcs, qui cependant entouraient cette maison tout embrasée, voyaient avec une admiration mêlée d'épouvante que les Suédois n'en

1 The title of sovereign princes in Tartar countries. 
sortaient point, mais leur étonnement fut encore plus grand lorsqu'ils virent ouvrir les portes et le roi et les siens fondre sur eux en désespérés. Charles et ses principaux officiers étaient armés d'épées et de pistolets: chacun tira deux coups à la fois à l'instant que la porte s'ouvrit, et, dans le même clin d'œil, jetant leurs pistolets et s'armant de leurs épées, ils firent reculer les 'Turcs plus de cinquante pas; mais le moment d'après, cette petite troupe fut entourée: le roi, qui était en bottes, selon sa coutume, s'embarrassa dans ses éperons et tomba. Vingt et un janissaires se jettent aussitôt sur lui ; il jette en l'air son épée pour s'épargner la douleur de la rendre. Les Turcs l'emmènent io au quartier du bacha, les uns le tenant sous les jambes, les autres sous les bras, comme on porte un malade que l'on craint d'incommoder.

$\mathrm{Au}$ moment que le roi se vit saisi, la violence de son tempérament et la fureur où un combat si long et si terrible avait dû le mettre firent place tout à coup à la douceur et à la tranquillité : il ne lui échappa 15 pas un mot d'impatience, pas un coup d'œil de colère. Il regardait les janissaires en souriant, et ceux-ci le portaient en criant: Allah! avec une indignation mêlée de respect. Ses officiers furent pris au même temps, et dépouillés par les Turcs et par les Tartares. Ce fut le r 2 février de l'an I 7 I 3 qu'arriva cet étrange événement, qui eut encore 20 des suites singulières.

— « Histoire de Charles XII », Book VI

\section{L'HOMME DE LA NATURE}

A M. J.-J. ROUSSEAU, A PARIS

30 août ( 1755 )

J'ai reçu, monsieur, votre nouveau livre contre le genre humain ${ }^{1}$ je vous en remercie. Vous plairez aux hommes, à qui vous dites leurs vérités, mais vous ne les corrigerez pas. On ne peut peindre avec des couleurs plus fortes les horreurs de la société humaine, dont notre 25 ignorance et notre faiblesse se promettent tant de consolations. On n'a jamais employé tant d'esprit à vouloir nous rendre bêtes : il prend envie de marcher à quatre pattes, quand on lit votre ouvrage. Cependant, comme il y a plus de soixante ans que j'en ai perdu l'habitude, je sens malheureusement qu'il m'est impossible de la reprendre, et je 30 laisse cette allure naturelle à ceux qui en sont plus dignes que vous et moi. Je ne peux non plus m'embarquer pour aller trouver les 
sauvages du Canada; premièrement, parce que les maladies dont je suis accablé me retiennent auprès du plus grand médecin ${ }^{1}$ de l'Europe, et que je ne trouverais pas les mêmes secours chez les Missouris ; secondement, parce que la guerre ${ }^{2}$ est portée dans ces pays-là, et que 5 les exemples de nos nations ont rendu les sauvages presque aussi méchants que nous. Je me borne à être un sauvage paisible dans la solitude que j'ai choisie auprès de votre patrie, ${ }^{3}$ où vous devriez être. ...

M. Chappuis m'apprend que votre santé est bien mauvaise; il faudrait la venir rétablir dans l'air natal, jouir de la liberté, boire avec Io moi du lait de nos vaches, et brouter nos herbes.

Je suis très philosophiquement et avec la plus tendre estime, etc.

\section{LE CARNAVAL DE VENISE}

Un soir que Candide, suivi de Martin, allait se mettre à table avec les étrangers qui logeaient dans la même hôtellerie, un homme à visage couleur de suie l'aborda par derrière, et, le prenant par le bras, lui dit :

15 Soyez prêt à partir avec nous, n'y manquez pas. Il se retourne, et voit Cacambo. Il n'y avait que la vue de Cunégonde qui pût l'étonner et lui plaire davantage. Il fut sur le point de devenir fou de joie. Il embrasse son cher ami. Cunégonde est ici, sans doute? où est-elle? Mène-moi vers elle, que je meure de joie avec elle. Cunégonde n'est 20 point ici, dit Cacambo : elle est à Constantinople. Ah ciel! à Constantinople! mais fût-elle à la Chine, j'y vole, partons. Nous partirons après souper, reprit Cacambo; je ne peux vous en dire davantage; je suis esclave, mon maitre m'attend; il faut que j'aille le servir à table : ne dites mot, soupez, et tenez-vous prêt.

25 Candide, partagé entre la joie et la douleur, charmé d'avoir revu son agent fidèle, étonné de le voir esclave, plein de l'idée de retrouver sa maîtresse, le cœur agité, l'esprit bouleversé, se mit à table avec Martin, qui voyait de sang-froid toutes ces aventures, et avec six étrangers, qui étaient venus passer le carnaval à Venise.

30 Cacambo, qui versait à boire à l'un des six étrangers, s'approcha de l'oreille de son maître, sur la fin du repas, et lui dit: Sire, Votre Majesté partira quand elle voudra, le vaisseau est prêt. Ayant dit ces mots, il sortit. Les convives étonnés se regardaient sans proférer une seule parole, lorsqu'un autre domestique s'approchant de son maître,

1 Théodore Tronchin (1709-178I). 2 The French and Indian War began in 1754 .

3 Voltaire was at this time at the Délices on the outskirts of Geneva. 
lui dit: Sire, la chaise de Votre Majesté est à Padoue, et la barque est prête. Le maître fit un signe, et le domestique partit. 'Tous les convives se regardèrent encore, et la surprise commune redoubla. Un troisième valet s'approchant aussi d'un troisième étranger, lui dit: Sire, croyez-moi, Votre Majesté ne doit pas rester ici plus longtemps, 5 je vais tout préparer; et aussitôt il disparut.

Candide et Martin ne doutèrent pas alors que ce ne fût une mascarade du carnaval. Un quatrième domestique dit au quatrième maître: Votre Majesté partira quand elle voudra, et sortit comme les autres. Le cinquième valet en dit autant au cinquième maître. Mais le sixième ro valet parla différemment au sixième étranger, qui était auprès de Candide; il lui dit: Ma foi, Sire, on ne veut plus faire crédit à Votre Majesté, ni à moi non plus, et nous pourrions bien être coffrés cette nuit vous et moi; je vais pourvoir à mes affaires : adieu.

Tous les domestiques ayant disparu, les six étrangers, Candide, et I $_{5}$ Martin, demeurèrent dans un profond silence. Enfin Candide le rompit: Messieurs, dit-il, voilà une singulière plaisanterie. Pourquoi êtesvous tous rois? Pour moi, je vous avoue que ni moi ni Martin, nous ne le sommes.

Le maître de Cacambo prit alors gravement la parole, et dit en 20 italien: Je ne suis point plaisant, je m'appelle Achmet III $^{1}$ j'ai été grand sultan plusieurs années ; je détrônai mon frère ; mon neveu m'a détrôné; on a coupé le cou à mes vizirs; j'achève ma vie dans le vieux sérail; mon neveu le grand sultan Mahmoud me permet de voyager quelquefois pour ma santé, et je suis venu passer le carnaval 25 à Venise.

Un jeune homme qui était auprès d'Achmet parla après lui, et dit : Je m'appelle Ivan ; ${ }^{2}$ j'ai été empereur de toutes les Russies; j'ai été détrôné au berceau ; mon père et ma mère ont été enfermés ; on m'a élevé en prison; j'ai quelquefois la permission de voyager, accompagné zo de ceux qui me gardent; et je suis venu passer le carnaval à Venise.

Le troisième dit: Je suis Charles-Edouard, ${ }^{3}$ roi d'Angleterre; mon père m'a cédé ses droits au royaume; j'ai combattu pour les soutenir ;

1 Achmet III (1673-1736), dethroned his brother Mustapha II, and was forced to abdicate in favor of his nephew Mahmud I. He was poisoned in prison in 1736 .

2 Ivan VI (1740-1764), enthroned soon after birth, but dethroned and exiled a few weeks later. He was murdered in prison in 1764 .

3 Charles Edward, "The Young Pretender" (1720-1788). In 1745 he made a futile attempt to recover the throne for his father, "The Old Pretender" (1688-1766), son of James II of England, dethroned in 1688. 
on a arraché le cœur à huit cents de mes partisans, et on leur en a battu les joues; j'ai été mis en prison; je vais à Rome faire une visite au roi mon père, détrôné ainsi que moi et mon grand-père; et je suis venu passer le carnaval à Venise.

5 Le quatrième prit alors la parole et dit: Je suis roi des Polaques $;^{1}$ le sort de la guerre m'a privé de mes états héréditaires; mon père a éprouvé les mêmes revers; je me résigne à la Providence comme le sultan Achmet, l'empereur Ivan, et le roi Charles-Édouard, à qui Dieu donne une longue vie; et je suis venu passer le carnaval à Venise.

Io Le cinquième dit: Je suis aussi roi des Polaques $;^{2}$ j'ai perdu mon royaume deux fois; mais la Providence m'a donné un autre état dans lequel j'ai fait plus de bien que tous les rois des Sarmates ${ }^{3}$ ensemble n'en ont jamais pu faire sur les bords de la Vistule. Je me résigne aussi à la Providence; et je suis venu passer le carnaval à Venise.

I 5 Il restait au sixième monarque à parler. Messieurs, dit-il, je ne suis pas si grand seigneur que vous; mais enfin j'ai été roi tout comme un autre ; je suis Théodore ; ${ }^{4}$ on m'a élu roi en Corse ; on m'a appelé Votre Majesté, et à présent à peine m'appelle-t-on monsieur; j'ai fait frapper de la monnaie, et je ne possède pas un denier; j'ai eu deux 20 secrétaires-d'état, et j'ai à peine un valet; je me suis vu sur un trône, et j'ai longtemps été à Londres en prison sur la paille; j'ai bien peur d'être traité de même ici, quoique je sois venu, comme Vos Majestés, passer le carnaval à Venise.

Les cinq autres rois écoutèrent ce discours avec une noble compas25 sion. Chacun d'eux donna vingt sequins au roi Théodore pour avoir des habits et des chemises; Candide lui fit présent d'un diamant de deux mille sequins. Quel est donc, disaient les cinq rois, cet homme qui est en état de donner cent fois autant que chacun de nous, et qui le donne? Etes-vous roi aussi, monsieur? - Non, messieurs, et n'en 30 ai nulle envie.

1 Augustus 1 II ( $1696-176_{3}$ ), elector of Saxony ( $1733^{-1763)}$ ), king of Poland ( $1735^{-}$ 1763), succeeding Stanislas Leszczynski. Both Saxony and Poland suffered severely from the wars in which he was entangled. His father, Augustus the Strong (1670-1733), elector of Saxony (1694-1733), was elected king of Poland in 1697, dethroned in 1704, and reinstated in 1709 .

2 Stanislas Leszczynski (1677-1766), elected king of Poland in 1704, deposed in 1709 , chosen king again in 1733 , but forced to abdicate in 1735 . In 1737 he received from his son-in-law, Louis XV, the duchies of Lorraine and Bar.

3 In ancient geography Sarmatia extended from the Vistula to the Volga, comprising a large part of Poland and Russia.

4 Baron Theodor von Neuhof (1686-1756), a German adventurer, crowned king of Corsica in 1736 , and deposed in 1738 . 
Dans l'instant qu'on sortait de table, il arriva dans la même hôtellerie quatre altesses sérénissimes qui avaient aussi perdu leurs états par le sort de la guerre, et qui venaient passer le reste du carnaval à Venise; mais Candide ne prit pas seulement garde à ces nouveaux venus. Il n'était occupé que d'aller trouver sa chère Cunégonde à 5 Constantinople.

- "Candide ", Chap. XXVI

\section{LA VANITÉ 1}

Qu'as-tu, petit bourgeois d'une petite ville; Quel accident étrange, en allumant ta bile, A sur ton large front répandu la rougeur?

D'où vient que tes gros yeux pétillent de fureur?

Réponds donc. - L'univers doit venger mes injures ;

L'univers me contemple, et les races futures

Contre mes ennemis déposeront pour moi.

- L'univers, mon ami, ne pense point à toi,

L'avenir encor moins : conduis bien ton ménage,

Divertis-toi, bois, dors, sois tranquille, sois sage.

De quel nuage épais ton crâne est offusqué!

- Ah! j'ai fait un discours, ${ }^{2}$ et l'on s'en est moqué !

Des plaisants de Paris j'ai senti la malice;

Je vais me plaindre au roi, qui me rendra justice;

Sans doute il punira ces ris audacieux.

- Va, le roi n'a point lu ton discours ennuyeux ;

Il a trop peu de temps, et trop de soins à prendre,

Son peuple à soulager, ses amis à défendre,

La guerre à soutenir; en un mot les bourgeois

Doivent très rarement importuner les rois.

La cour te croira fou : reste chez toi, bonhomme.

- Non, je n'y puis tenir; de brocards on m'assomme.

Les quand, les qui, les quoi, ${ }^{3}$ pleuvant de tous côtés,

Sifflent à mon oreille, en cent lieux répétés.

On méprise à Paris mes chansons judaïques, ${ }^{4}$

1 Le Franc de Pompignan ( $1709-1784$ ), against whom "La vanité" was written, had said: Il faut que tout l'univers sache que Leurs Majestés se sont occupées de mon discours d l'Académie. He wrote, among other things, a translation of the Psalms and various religious poems.

2 The discours in question is the one he delivered before the "forty immortals" of the Academy at his reception to that body in 1759 , in which he violently attacked the literature and philosophy of the period.

3 Titles of leaflets current in Paris at that time.

4 I.e. the religious poems of Pompignan. 
Et mon Pater anglais, ${ }^{1}$ et mes rimes tragiques,

Et ma prose aux Quarante! un tel renversement

D'un état policé détruit le fondement;

L'intérêt du public se joint à ma vengeance ;

Je prétends des plaisants réprimer la licence.

Pour trouver bons mes vers il faut faire une loi;

Et de ce même pas je vais parler au roi.

Ainsi, nouveau venu, sur les rives de Seine, Tout rempli de lui-même, un pauvre énergumène

De son plaisant délire amusait les passants.

Souvent notre amour-propre éteint notre bon sens ;

Souvent nous ressemblons aux grenouilles d'Homère, ${ }^{2}$

Implorant à grands cris le fier Dieu de la guerre,

Et les Dieux des enfers, et Bellone ${ }^{3}$ et Pallas, ${ }^{4}$

Et les foudres des cieux, pour se venger des rats. . . .

Je suis loin de blâmer le soin très légitime

De plaire à ses égaux, et d'être en leur estime.

Un conseiller du roi sur la terre inconnu,

Doit dans son cercle étroit, chez les siens bien venu,

Etre approuvé du moins de ses graves confrères;

Mais on ne peut souffrir ces bruyants téméraires,

Sur la scène du monde ardents à s'étaler.

Veux-tu te faire acteur? on voudra te siffler.

Gardons-nous d'imiter ce fou de Diogène,

25 Qui, pouvant chez les siens, en bon bourgeois d'Athène,

A l'étude, au plaisir doucement se livrer,

Vécut dans un tonneau pour se faire admirer.

Malheur à tout mortel, et surtout dans notre âge,

Qui se fait singulier pour être un personnage!

Piron ${ }^{5}$ seul eut raison, quand dans un goût nouveau,

Il fit ce vers heureux, digne de son tombeau:

Ci-git qui ne fut rien. - Quoi que l'orgueil en dise,

Humains, faibles humains, voilà votre devise.

Combien de rois, grands Dieux! jadis si révérés,

Dans l'éternel oubli sont en foule enterrés!

1 A translation of the "Universal Prayer" of Pope.

2 An allusion to the "battle of the frogs and mice."

3 Goddess of war among the Romans, wife or sister of Mars.

4 Goddess of wisdom and war among the Greeks.

5 Alexis Piron (1689-1773), an author whose best known work is the comedy,

"La métromanie" (1738). The first lines of his epitaph, written by himself, run:

Ci-git Piron, qui ne fut rien,

Pas même académicien. 
La terre a vu passer leur empire et leur trône.

On ne sait en quel lieu florissait Babylone.

Le tombeau d'Alexandre, aujourd'hui renversé,

Avec sa ville altière a péri dispersé.

César n'a point d'asile où son ombre repose ;

Et l'ami Pompignan pense être quelque chose!

\section{LA TOLÉRANCE}

Ce n'est plus aux hommes que je m'adresse; c'est à toi, Dieu de tous les êtres, de tous les mondes et de tous les temps: s'il est permis à de faibles créatures perdues dans l'immensité, et imperceptibles au reste de l'univers, d'oser te demander quelque chose, à toi qui as tout ro donné, à toi dont les décrets sont immuables comme éternels, daigne regarder en pitié les erreurs attachées à notre nature; que ces erreurs ne fassent point nos calamités. 'Tu ne nous as point donné un cœur pour nous haïr, et des mains pour nous égorger; fais que nous nous aidions mutuellement à supporter le fardeau d'une vie pénible et pas- 15 sagère; que les petites différences entre les vêtements qui couvrent nos débiles corps, entre tous nos langages insuffisants, entre tous nos usages ridicules, entre toutes nos lois imparfaites, entre toutes nos opinions insensées, entre toutes nos conditions si disproportionnées à nos yeux et si égales devant toi; que toutes ces petites nuances qui 20 distinguent les atomes appelés hommes ne soient pas des signaux de haine et de persécution; que ceux qui allument des cierges en plein midi pour te célébrer supportent ceux qui se contentent de la lumière de ton soleil ; que ceux qui couvrent leur robe d'une toile blanche pour dire qu'il faut t'aimer ne détestent pas ceux qui disent la même chose 25 sous un manteau de laine noire; qu'il soit égal de t'adorer dans un jargon formé d'une ancienne langue, ou dans un jargon plus nouveau ; que ceux dont l'habit est teint en rouge ou en violet, qui dominent sur une petite parcelle d'un petit tas de la boue de ce monde et qui possèdent quelques fragments arrondis d'un certain métal, jouissent sans 30 orgueil de ce qu'ils appellent grandeur et richesse, et que les autres les voient sans envie; car tu sais qu'il n'y a dans ces vanités ni de quoi envier, ni de quoi s'enorgueillir.

Puissent tous les hommes se souvenir qu'ils sont frères! qu'ils aient en horreur la tyrannie exercée sur les âmes, comme ils ont en exé- 35 cration le brigandage qui ravit par la force le fruit du travail et de 
l'industrie paisible! Si les fléaux de la guerre sont inévitables, ne nous haïssons pas, ne nous déchirons pas les uns les autres dans le sein de la paix, et employons l'instant de notre existence à bénir également en mille langages divers, depuis Siam jusqu'à la Californie, la bonté qui 5 nous a donné cet instant!

— "Traité de la tolérance », Chap. XXIII 


\section{JEAN-JACQUES ROUSSEAU}

\section{Geneva, I 7 I 2-I 778 , Ermenonville}

Jean-Jacques Rousseau was born at Geneva in I712. His mother died at his birth, and he was left in the hands of his father, a watchmaker by trade and a dancing master, an intelligent but more or less irresponsible man, who early instilled into his son a love for books, good and bad alike. In 1722 the father had to leave Geneva. He left the young Jean-Jacques behind, in the care of an uncle, who, after sending him to school for two years, apprenticed him first with a notary and then with an engraver. But a spirit of restlessness had already got hold of the boy, and in 1728 , when he was sixteen years of age, tired of restraint and of the bad treatment of his master, he turned his back upon Geneva. He was directed by a priest he chanced to meet to Madame de Warens, a Catholic proselytizer, who in turn sent him to a seminary in Turin to be taught the doctrines of Catholicism. He then became successively a valet, a wandering showman, a student and teacher of music, and a private tutor. In the meantime he had made the home of Madame de Warens his headquarters, and spent most of his time with her, studying, at odd moments, philosophy and Latin, and always finding time to spend hours in the haunts he loved so well in field and forest.

Finally, in $174 \mathrm{I}$, his wandering spirit took him to Paris, where he spent most of the next fifteen years. There, living from hand to mouth, mostly as secretary, but trying his hand also at the composition of operas, at writing comedies, and at copying music, he became acquainted with Diderot and Grimm and several of the other "philosophes."

The first success which brought him clearly before the public came when, in 1749 , he was awarded the prize offered by the Academy of Dijon for the best dissertation on the subject: "Le rétablissement des sciences et des arts a-t-il contribué à épurer les mœurs?" He contended that man was naturally good and that civilization had tended to corrupt him. This theme thus accepted, runs through Rousseau's work and becomes somewhat of a fixed idea in his life. We see its constant development in the "Discours sur l'origine de l'inégalité" (1755), the "Lettre à D'Alembert sur les spectacles" (1758), the "Nouvelle Héloïse" (176r), the "Contrat social" ( 1762 ), the "Emile ou de l'éducation" ( 1762 ). From 1756 to 1762 , while writing these masterpieces, Rousseau had been passing at Montmorency perhaps the happiest years of his life, first in one of the estates of Madame d'Epinay, then in one of the Maréchal de Luxembourg. But after the publication of the "Emile," which was condemned by the Parliament to be burned, he had to flee from France. He sought refuge in Switzerland, but his eccentricities and extremely sensitive nature made trouble for him wherever he found himself, and in 1766 he fled 
to England. A conviction that persecution was hounding his steps gave him no peace, however, and in less than two years he returned to France, wandering from place to place, until finally, in 1770 , he came to Paris. There he spent the last years of his life, copying music as a profession, but meanwhile writing the "Dialogues de Rousseau, juge de Jean-Jacques" (1772-1776), and the "Rêveries d'un promeneur solitaire" (1777). In the spring of 1778 he retired to a cottage at Ermenonville, and died there on July 2 of the same year.

One of his greatest works, in fact the most remarkable production of the kind in literature, the "Confessions," he left in manuscript. Though completed before 1770 , their extremely personal character did not permit their publication until after the author's death. The first complete edition appeared in 1788 .

\section{ORIGINES DE LA SOCIÉTÉ HUMAINE}

Le premier qui ayant enclos un terrain s'avisa de dire Ceci est à moi, et trouva des gens assez simples pour le croire, fut le vrai fondateur de la société civile. Que de crimes, de guerres, de meurtres, que de misères et d'horreurs n'eût point ćpargnés au genre humain celui qui, 5 arrachant les pieux ou comblant le fossé, eût crié à ses semblables : "Gardez-vous d'écouter cet imposteur; vous êtes perdus si vous oubliez que les fruits sont à tous, et que la terre n'est à personne! » Mais il y a grande apparence qu'alors les choses en étaient déjà venues au point de ne pouvoir plus durer comme elles étaient : car cette idée ı de propriété, dépendant de beaucoup d'idées antérieures qui n'ont pu naître que successivement, ne se forma pas tout d'un coup dans l'esprit humain: il fallut faire bien des progrès, acquérir bien de l'industrie et des lumières, les transmettre et les augmenter d'âge en âge, avant que d'arriver à ce dernier terme de l'état de nature. Reprenons donc les

I 5 choses de plus haut, et tâchons de rassembler sous un seul point de vue cette lente succession d'événements et de connaissances dans leur ordre le plus naturel.

Le premier sentiment de l'homme fut celui de son existence; son premier soin celui de sa conservation. Les productions de la terre lui 20 fournissaient tous les secours nécessaires ; l'instinct le porta à en faire usage. ...

Telle fut la condition de l'homme naissant; telle fut la vie d'un animal borné d'abord aux pures sensations, et profitant à peine des dons que lui offrait la nature, loin de songer à lui rien arracher. Mais 25 il se présenta bientôt des difficultés; il fallut apprendre à les vaincre : la hauteur des arbres qui l'empêchait d'atteindre à leurs fruits, la 
concurrence des animaux qui cherchaient à s'en nourrir, la férocité de ceux qui en voulaient à sa propre vie, tout l'obligea de s'appliquer aux exercices du corps; il fallut se rendre agile, vite à la course, vigoureux au combat. Les armes naturelles, qui sont les branches d'arbres et les pierres, se trouvèrent bientôt sous sa main. Il apprit à surmonter les obstacles de la nature, à combattre au besoin les autres animaux, à disputer sa subsistance aux hommes mêmes, ou à se dédommager de ce qu'il fallait céder au plus fort.

A mesure que le genre humain s'étendit, les peines se multiplièrent avec les hommes. La différence des terrains, des climats, des saisons, ı put les forcer à en mettre dans leurs manières de vivre. Des années stériles, des hivers longs et rudes, des étés brûlants, qui consument tout, exigèrent d'eux une nouvelle industrie. Le long de la mer et des rivières ils inventèrent la ligne et l'hameçon, et devinrent pêcheurs et ichthyophages. Dans les forêts ils se firent des arcs et des flèches, et 15 devinrent chasseurs et guerriers. Dans les pays froids ils se couvrirent des peaux des bêtes qu'ils avaient tuées. Le tonnerre, un volcan, ou quelque heureux hasard, leur fit connaître le feu, nouvelle ressource contre la rigueur de l'hiver : ils apprirent à conserver cet élément, puis à le reproduire, et enfin à en préparer les viandes qu'auparavant ils 20 dévoraient crues.

Cette application réitérée des êtres divers à lui-même, et des uns aux autres, dut naturellement engendrer dans l'esprit de l'homme les perceptions de certains rapports. Ces relations que nous exprimons par les mots de grand, de petit, de fort, de faible, de vite, de lent, de 25 peureux, de hardi, et d'autres idées pareilles, comparées au besoin, et presque sans y songer, produisirent enfin chez lui quelque sorte de réflexion, ou plutôt une prudence machinale qui lui indiquait les précautions les plus nécessaires à sa sûreté.

Les nouvelles lumières qui résultèrent de ce développement aug- 30 mentèrent sa supériorité sur les autres animaux en la lui faisant connaître. Il s'exerça à leur dresser des pièges, il leur donna le change en mille manières; et quoique plusieurs le surpassassent en force au combat, ou en vitesse à la course, de ceux qui pouvaient lui servir ou lui nuire, il devint avec le temps le maître des uns et le fléau 35 des autres. C'est ainsi que le premier regard qu'il porta sur lui-même y produisit le premier mouvement d'orgueil ; c'est ainsi que sachant encore à peine distinguer les rangs, et se contemplant au premier par son espèce, il se préparait de loin à y prétendre par son individu. . . . . 
A mesure que les idées et les sentiments se succèdent, que l'esprit et le cœur s'exercent, le genre humain continue à s'apprivoiser, les liaisons s'étendent et les liens se resserrent. On s'accoutuma à s'assembler devant les cabanes ou autour d'un grand arbre: le chant et la 5 danse, vrais enfants de l'amour et du loisir, devinrent l'amusement ou plutôt l'occupation des hommes et des femmes oisifs et attroupés. - Chacun commença à regarder les autres et à vouloir être regardé soimême, et l'estime publique eut un prix. Celui qui chantait ou dansait le mieux, le plus beau, le plus fort, le plus adroit, ou le plus éloquent, ıo devint le plus considéré ; et ce fut là le premier pas vers l'inégalité, et vers le vice en même temps : de ces premières préférences naquirent d'un côté la vanité et le mépris, de l'autre la honte et l'envie, et la fermentation causée par ces nouveaux levains produisit enfin des composés funestes au bonheur et à l'innocence. . . .

I5 Tant que les hommes se contentèrent de leurs cabanes rustiques, tant qu'ils se bornèrent à coudre leurs habits de peaux avec des épines ou des arêtes, à se parer de plumes et de coquillages, à se peindre le corps de diverses couleurs, à perfectionner ou embellir leurs arcs et leurs flèches, à tailler avec des pierres tranchantes quelques canots de pêcheurs ou quelques grossiers instruments de musique; en un mot, tant qu'ils ne s'appliquèrent qu'à des ouvrages qu'un seul pouvait faire, et qu'à des arts qui n'avaient pas besoin du concours de plusieurs mains, ils vécurent libres, sains, bons et heureux autant qu'ils pouvaient l'être par leur nature et continuèrent à jouir entre eux des douceurs 25 d'un commerce indépendant: mais dès l'instant qu'un homme eut besoin du secours d'un autre, dès qu'on s'aperçut qu'il était utile à un seul d'avoir des provisions pour deux, l'égalité disparut, la propriété s'introduisit, le travail devint nécessaire, et les vastes forêts se changèrent en des campagnes riantes qu'il fallut arroser de la sueur des 3o hommes, et dans lesquelles on vit bientôt l'esclavage et la misère germer et croître avec les moissons.

La métallurgie et l'agriculture furent les deux arts dont l'invention produisit cette grande révolution. Pour le poète, c'est l'or et l'argent; mais pour le philosophe, ce sont le fer et le blé qui ont civilisé les 35 hommes et perdu le genre humain.

- (Discours sur l'origine de l'inégalité parmi les hommes », Part II 


\section{LES MONTAGNES DU VALAIS}

Je gravissais lentement et à pied des sentiers assez rudes, conduit par un homme que j'avais pris pour être mon guide, et dans lequel, durant toute la route, j'ai trouvé plutôt un ami qu'un mercenaire. Je voulais rêver, et j'en étais toujours détourné par quelque spectacle inattendu. Tantôt d'immenses roches pendaient en ruines au-dessus de ma tête. Tantôt de hautes et bruyantes cascades m'inondaient de leur épais brouillard. Tantôt un torrent éternel ouvrait à mes côtés un abîme dont les yeux n'osaient sonder la profondeur. Quelquefois je me perdais dans l'obscurité d'un bois touffu. Quelquefois, en sortant d'un gouffre, une agréable prairie réjouissait tout à coup mes regards. Io Un mélange étonnant de la nature sauvage et de la nature cultivée montrait partout la main des hommes, où l'on eût cru qu'ils n'avaient jamais pénétré: à côté d'une caverne on trouvait des maisons; on voyait des pampres secśs où l'on n'eût cherché que des ronces, des vignes dans des terres éboulées, d'excellents fruits sur des rochers, et 15 des champs dans des précipices.

Ce n'était pas seulement le travail des hommes qui rendait ces pays étranges si bizarrement contrastés; la nature semblait encore prendre plaisir à s'y mettre en opposition avec elle-même, tant on la trouvait différente en un même lieu sous divers aspects. Au levant les fleurs 20 du printemps, au midi les fruits de l'automne, au nord les glaces de l'hiver: elle réunissait toutes les saisons dans le même instant, tous les climats dans le même lieu, des terrains contraires sur le même sol, et formait l'accord inconnu partout ailleurs des productions des plaines et de celles des Alpes. Ajoutez à tout cela les illusions de l'optique, les 25 pointes des monts différemment éclairées, le clair-obscur du soleil et des ombres, et tous les accidents de lumière qui en résultaient le matin et le soir; vous aurez quelque idée des scènes continuelles qui ne cessèrent d'attirer mon admiration, et qui semblaient m'être offertes en un vrai théâtre; car la perspective des monts étant verticale frappe 30 les yeux tout à la fois et bien plus puissamment que celle des plaines, qui ne se voit qu'obliquement, en fuyant, et dont chaque objet vous en cache un autre.

J'attribuai, durant la première journée, aux agréments de cette variété le calme que je sentais renaitre en moi. J'admirais l'empire 35 qu'ont sur nos passions les plus vives les êtres les plus insensibles, et je méprisais la philosophie de ne pouvoir pas même autant sur lâme 
qu'une suite d'objets inanimés. Mais cet état paisible ayant duré la nuit et augmenté le lendemain, je ne tardai pas de juger qu'il avait encore quelque cause autre qui ne m'était pas connue. J'arrivai ce jour-là sur des montagnes les moins élevées, et, parcourant ensuite 5 leurs inégalités, sur celles des plus hautes qui étaient à ma portée. Après m'être promené dans les nuages, j'atteignais un séjour plus serein, d'où l'on voit dans la saison le tonnerre et l'orage se former au-dessous de soi; image trop vaine de l'âme du sage, dont l'exemple n'exista jamais, ou n'existe qu'aux mêmes lieux d'où ${ }^{1}$ l'on en a tiré Io l'emblème.

Ce fut là que je démêlai sensiblement dans la pureté de l'air où je me trouvais la véritable cause du changement de mon humeur, et du retour de cette paix intérieure que j'avais perdue depuis si longtemps. En effet, c'est une impression générale qu'éprouvent tous les hommes, I 5 quoiqu'ils ne l'observent pas tous, que sur les hautes montagnes, où l'air est pur et subtil, on se sent plus de facilité dans la respiration, plus de légèreté dans le corps, plus de sérénité dans l'esprit; les plaisirs y sont moins ardents, les passions plus modérées. Les méditations y prennent je ne sais quel caractère grand et sublime, proportionné aux 20 objets qui nous frappent, je ne sais quelle volupté tranquille qui n'a rien d'âcre et de sensuel. Il semble qu'en s'élevant au-dessus du séjour des hommes on y laisse tous les sentiments bas et terrestres, et qu'à mesure qu'on approche des régions éthérées, l'âme contracte quelque chose de leur inaltérable pureté. On y est grave sans mélancolie, pai25 sible sans indolence, content d'être et de penser: tous les désirs trop vifs s'émoussent; ils perdent cette pointe aiguë qui les rend douloureux; ils ne laissent au fond du cœur qu'une émotion légère et douce ; et c'est ainsi qu'un heureux climat fait servir à la félicité de l'homme les passions qui font ailleurs son tourment. Je doute qu'aucune agita30 tion violente, aucune maladie de vapeurs pût tenir contre un pareil séjour prolongé, et je suis surpris que des bains de l'air salutaire et bienfaisant des montagnes ne soient pas un des grands remèdes de la médecine et de la morale. . . .

Supposez les impressions réunies de ce que je viens de vous décrire, 35 et vous aurez quelque idée de la situation délicieuse où je me trouvais. Imaginez la variété, la grandeur, la beauté, de mille étonnants spectacles ; le plaisir de ne voir autour de soi que des objets tout nouveaux, des oiseaux étrangers, des plantes bizarres et inconnues, d'observer en

1 I.e. from the mountain heights. 
quelque sorte une autre nature, et de se trouver dans un nouveau monde. Tout cela fait aux yeux un mélange inexprimable, dont le charme augmente encore par la subtilité de l'air qui rend les couleurs plus vives, les traits plus marqués, rapproche tous les points de vue; les distances paraissant moindres que dans les plaines, où l'épaisseur de l'air couvre la terre d'un voile, l'horizon présente aux yeux plus d'objets qu'il semble n'en pouvoir contenir: enfin, ce spectacle a je ne sais quoi de magique, de surnaturel, qui ravit l'esprit et les sens; on oublie tout, on s'oublie soi-même, on ne sait plus où l'on est.

— «La Nouvelle Héloïse », Part I, letter 23, Saint-Preux to Julie

\section{LES VENDANGES A CLARENS}

J'avoue que la misère qui couvre les champs en certains pays où le ro publicain dévore les fruits de la terre, l'âpre avidité d'un fermier avare, l'inflexible rigueur d'un maître inhumain, ôtent beaucoup d'attrait à ces tableaux. Des chevaux étiques près d'expirer sous les coups, de malheureux paysans exténués de jeûnes, excédés de fatigue et couverts de haillons, des hameaux de masures, offrent un triste spectacle 15 à la vue : on a presque regret d'être homme quand on songe aux malheureux dont il faut manger le sang. Mais quel charme de voir de bons et sages régisseurs faire de la culture de leurs terres l'instrument de leurs bienfaits, leurs amusements, leurs plaisirs; verser à pleines mains les dons de la Providence, engraisser tout ce qui les entoure, 20 hommes et bestiaux, des biens dont regorgent leurs granges, leurs caves, leurs greniers; accumuler l'abondance et la joie autour d'eux, et faire du travail qui les enrichit une fête continuelle! Comment se dérober à la douce illusion que ces objets font naître? On oublie son siècle et ses contemporains, on se transporte au temps des patriarches ; 25 on veut mettre soi-même la main à l'œuvre, partager les travaux rustiques et le bonheur qu'on y voit attaché. O temps de l'amour et de l'innocence, où les femmes étaient tendres et modestes, où les hommes étaient simples et vivaient contents! O Rachel! fille charmante et si constamment aimée, heureux celui qui, pour t'obtenir, ne regretta pas 30 quatorze ans d'esclavage! O douce élève de Noëmi! heureux le bon vieillard dont tu réchauffais les pieds et le cœur! Non, jamais la beauté ne règne avec plus d'empire qu'au milieu des soins champêtres. C'est là que les grâces sont sur leur trône, que la simplicité les pare, 
que la gaieté les anime, et qu'il faut les adorer malgré soi. Pardon, milord, ${ }^{1}$ je reviens à nous.

Depuis un mois les chaleurs de l'automne apprêtaient d'heureuses vendanges; les premières gelées en ont amené l'ouverture; le pampre 5 grillé, laissant la grappe à découvert, étale aux yeux les dons du père Lyée, ${ }^{2}$ et semble inviter les mortels à s'en emparer. Toutes les vignes chargées de ce fruit bienfaisant que le ciel offre aux infortunés pour leur faire oublier leur misère; le bruit des tonneaux, des cuves, des légréfass ${ }^{3}$ qu'on relie de toutes parts ; le chant des vendangeuses dont Io ces coteaux retentissent; la marche continuelle de ceux qui portent la vendange au pressoir; le rauque son des instruments rustiques qui les anime au travail ; l'aimable et touchant tableau d'une allégresse générale qui semble en ce moment étendue sur la face de la terre; enfin le voile de brouillard que le soleil élève au matin comme une toile de 15 théâtre pour découvrir à l'œil un si charmant spectacle : tout conspire à lui donner un air de fête; et cette fête n'en devient que plus belle à la réflexion, quand on songe qu'elle est la seule où les hommes aient su joindre l'agréable à l'utile.

M. de Wolmar, dont ici le meilleur terrain consiste en vignobles, a 20 fait d'avance tous les préparatifs nécessaires. Les cuves, le pressoir, le cellier, les futailles, n'attendaient que la douce liqueur pour laquelle ils sont destinés. $M^{\text {me }}$ de Wolmar s'est chargée de la récolte; le choix des ouvriers, l'ordre et la distribution du travail, la regardent. $\mathrm{M}^{\text {me }} \mathrm{d}^{\prime}$ Orbe préside aux festins de vendange et au salaire des journa25 liers selon la police établie, dont les lois ne s'enfreignent jamais ici. Mon inspection à moi est de faire observer au pressoir les directions de Julie, dont la tête ne supporte pas la vapeur des cuves; et Claire ${ }^{4}$ n'a pas manqué d'applaudir à cet emploi, comme étant tout à fait du ressort d'un buveur.

3o Les tâches ainsi partagées, le métier commun pour remplir les vides est celui de vendangeur. 'Tout le monde est sur pied de grand matin : on se rassemble pour aller à la vigne. $M^{\text {me }}$ d'Orbe, qui n'est jamais assez occupée au gré de son activité, se charge, pour surcroît, de faire avertir et tancer les paresseux, et je puis me vanter qu'elle s'acquitte 35 envers moi de ce soin avec une maligne vigilance. . . .

1 Edward Bomston, a friend of Saint-Preux and of the Wolmars.

2 Lyaeus pater, one of the names of Bacchus.

3 Sorte de foudre ou de grand tonneau du pays (Rousseau).

${ }^{4}$ Claire ( $M^{\text {me }} d^{\prime}$ 'Orbe), cousin of Julie ( $M^{m e}$ de Wolmar), is here teasing Saint-Preux, thinking of an occasion when he had drunk too much. 
Depuis huit jours que cet agréable travail nous occupe, on est à peine à la moitié de l'ouvrage. Outre les vins destinés pour la vente et pour les provisions ordinaires, lesquels n'ont d'autre façon que d'être recueillis avec soin, la bienfaisante fée en prépare d'autres plus fins pour nos buveurs ; et j'aide aux opérations magiques dont je vous ai parlé, ${ }^{1}$ pour tirer d'un même vignoble des vins de tous les pays. Pour l'un, elle fait tordre la grappe ${ }^{2}$ quand elle est mûre et la laisse flétrir au soleil sur la souche; pour l'autre, elle fait égrapper le raisin et trier les grains avant de les jeter dans la cuve; pour un autre, elle fait cueillir avant le lever du soleil du raisin rouge, et le porter douce- ro ment sur le pressoir couvert encore de sa fleur et de sa rosée, pour en exprimer du vin blanc. Elle prépare un vin de liqueur en mêlant dans les tonneaux du moût réduit en sirop sur le feu; un vin sec, en l'empêchant de cuver; un vin d'absinthe pour l'estomac; un vin muscat avec des simples. Tous ces vins différents ont leur apprêt particulier ; 15 toutes ces préparations sont saines et naturelles: c'est ainsi qu'une économe industrie supplée à la diversité des terrains, et rassemble vingt climats en un seul.

Vous ne sauriez concevoir avec quel zèle, avec quelle gaieté tout cela se fait. On chante, on rit toute la journée, et le travail n'en va 20 que mieux. 'Tout vit dans la plus grande familiarité ; tout le monde est égal, et personne ne s'oublie. Les dames sont sans airs, les paysannes sont décentes, les hommes badins et non grossiers. C'est à qui trouvera les meilleures chansons, à qui fera les meilleurs contes, à qui dira les meilleurs traits. L'union même engendre les folâtres querelles ; 25 et l'on ne s'agace mutuellement que pour montrer combien on est sûr les uns des autres. On ne revient point ensuite faire chez soi les messieurs; on passe aux vignes toute la journée: Julie y a fait faire une loge où l'on va se chauffer quand on a froid, et dans laquelle on se réfugie en cas de pluie. On dîne avec les paysans et à leur heure, $3^{\circ}$ aussi bien qu'on travaille avec eux. On mange avec appétit leur soupe un peu grossière, mais bonne, saine, et chargée d'excellents légumes. On ne ricane point orgueilleusement de leur air gauche et de leurs compliments rustauds; pour les mettre à leur aise, on s'y prête sans affectation. Ces complaisances ne leur échappent pas, ils y sont sen- 35 sibles; et voyant qu'on veut bien sortir pour eux de sa place, ils s'en tiennent d'autant plus volontiers dans la leur. . . .

\footnotetext{
1 Cf. Part V, letter 2, in which Saint-Preux describes the domestic arrangements at Clarens. 2 I.e. twisting the stem of the bunch.
} 
Le soir, on revient gaiement tous ensemble. On nourrit et loge les ouvriers tout le temps de la vendange: et même le dimanche, après le prêche du soir, on se rassemble avec eux et l'on danse jusqu'au souper. ...

5 Le lieu d'assemblée est une salle à l'antique avec une grande cheminée où l'on fait bon feu. La pièce est éclairée de trois lampes, auxquelles M. de Wolmar a seulement fait ajouter des capuchons de fer-blanc pour intercepter la fumée et réfléchir la lumière. Pour prévenir l'envie et les regrets, on tâche de ne rien étaler aux yeux de ces

Io bons gens qu'ils ne puissent retrouver chez eux, de ne leur montrer d'autre opulence que le choix du bon dans les choses communes, et un peu plus de largesse dans la distribution. Le souper est servi sur deux longues tables. Le luxe et l'appareil des festins n'y sont pas, mais l'abondance et la joie y sont. Tout le monde se met à table, I 5 maîtres, journaliers, domestiques ; chacun se lève indifféremment pour servir, sans exclusion, sans préférence, et lè service se fait toujours avec grâce et avec plaisir. On boit à discrétion; la liberté n'a point d'autres bornes que l'honnêteté. La présence de maîtres si respectés contient tout le monde, et n'empêche pas qu'on ne soit à son aise et 20 gai. Que s'il arrive à quelqu'un de s'oublier, on ne trouble point la fête par des réprimandes, mais il est congédié sans rémission dès le lendemain. ...

Après le souper on veille encore une heure ou deux en teillant du chanvre: chacun dit sa chanson tour à tour. Quelquefois les vendan25 geuses chantent en chœur toutes ensemble, ou bien alternativement à voix seule et en refrain. La plupart de ces chansons sont de vieilles romances dont les airs ne sont pas piquants, mais ils ont je ne sais quoi d'antique et de doux qui touche à la longue. Les paroles sont simples, naïves, souvent tristes; elles plaisent pourtant. . . .

Voilà comment se passe la soirée. Quand l'heure de la retraite approche, $\mathbf{M}^{\mathrm{me}}$ de Wolmar dit: "Allons tirer le feu d'artifice." A l'instant chacun prend son paquet de chènevottes, signe honorable de son travail; on les porte en triomphe au milieu de la cour; on les rassemble en un tas, on en fait un trophée; on y met le feu : mais n'a 35 pas cet honneur qui veut: Julie l'adjuge en présentant le flambeau à celui ou celle qui a fait ce soir-là le plus d'ouvrage ; fût-ce elle-même, elle se l'attribue sans façon. L'auguste cérémonie est accompagnée d'acclamations et de battements de mains. Les chènevottes font un feu clair et brillant qui s'élève jusqu'aux nues, un vrai feu de joie, 
autour duquel on saute, on rit. Ensuite on offre à boire à toute l'assemblée: chacun boit à la santé du vainqueur, et va se coucher content d'une journée passée dans le travail, la gaieté, l'innocence, et qu'on ne serait pas fâché de recommencer le lendemain, le surlendemain, et toute sa vie.

- " La Nouvelle Héloïse », Part V, letter 7,

Saint-Preux to Milord Edouard

\section{SI J'ÉTAIS RICHE}

Comme je serais peuple avec le peuple, je serais campagnard aux champs ; et quand je parlerais d'agriculture, le paysan ne se moquerait pas de moi. Je n'irais pas me bâtir une ville en campagne, et mettre au fond d'une province les Tuileries devant mon appartement. Sur le penchant de quelque agréable colline bien ombragée, j'aurais une ro petite maison rustique: une maison blanche avec des contrevents verts; et quoique une couverture de chaume soit en toute saison la meilleure, je préférerais magnifiquement, non la triste ardoise, mais la tuile, parce qu'elle a l'air plus propre et plus gai que le chaume, qu'on ne couvre pas autrement les maisons dans mon pays, et que cela me 15 rappellerait un peu l'heureux temps de ma jeunesse. J'aurais pour cour une basse-cour, et pour écurie une étable avec des vaches, pour avoir du laitage que j'aime beaucoup. J'aurais un potager pour jardin, et pour parc un joli verger. . . . Les fruits, à la discrétion des promeneurs, ne seraient ni comptés ni cueillis par mon jardinier; et mon 20 avare magnificence n'étalerait point aux yeux des espaliers superbes auxquels à peine on osât toucher. Or, cette petite prodigalité serait peu coûteuse, parce que j'aurais choisi mon asile dans quelque province éloignée où l'on voit peu d'argent et beaucoup de denrées, et où règnent l'abondance et la pauvreté.

Là je rassemblerais une société, plus choisie que nombreuse, d'amis aimant le plaisir et s'y connaissant, de femmes qui pussent sortir de leur fauteuil et se prêter aux jeux champêtres, prendre quelquefois, au lieu de la navette et des cartes, la ligne, les gluaux, le râteau des faneuses, et le panier des vendangeuses. Là, tous les airs de la ville 30 seraient oubliés, et, devenus villageois au village, nous nous trouverions livrés à des foules d'amusements divers qui ne nous donneraient chaque soir que l'embarras du choix pour le lendemain. L'exercice et la vie active nous feraient un nouvel estomac et de nouveaux goûts. Tous nos repas seraient des festins, où l'abondance plairait plus que la 35 
délicatesse. La gaieté, les travaux rustiques, les folâtres jeux, sont les premiers cuisiniers du monde, et les ragoûts fins sont bien ridicules à des gens en haleine depuis le lever du soleil. Le service n'aurait pas plus d'ordre que d'élégance; la salle à manger serait partout, dans le 5 jardin, dans un bateau, sous un arbre; quelquefois au loin, près d'une source vive, sur l'herbe verdoyante et fraîche, sous des touffes d'aunes et de coudriers, une longue procession de gais convives porterait en chantant l'apprêt du festin; on aurait le gazon pour table et pour chaises, les bords de la fontaine serviraient de buffet, et le dessert Io pendrait aux arbres. Les mets seraient servis sans ordre, l'appétit dispenserait des façons; chacun, se préférant ouvertement à tout autre, trouverait bon que tout autre se préférât de même à lui : de cette familiarité cordiale et modérée naîtrait, sans générosité, sans fausseté, sans contrainte, un conflit badin plus charmant cent fois que

I 5 la politesse, et plus fait pour lier les cœurs. Point d'importun laquais épiant nos discours, critiquant tout bas nos maintiens, comptant nos morceaux d'un œil avide, s'amusant à nous faire attendre à boire, et murmurant d'un trop long dîner. Nous serions nos valets pour être nos maîtres; chacun serait servi par tous; le temps passerait sans le zo compter; le repas serait le repos, et durerait autant que l'ardeur du jour. S'il passait près de nous quelque paysan retournant au travail, ses outils sur l'épaule, je lui réjouirais le cœur par quelques bons propos, par quelques coups de bon vin qui lui feraient porter plus gaiement sa misère ; et moi j'aurais aussi le plaisir de me sentir émou25 voir un peu les entrailles, et de me dire en secret: "Je suis encore homme. » 


\title{
DENIS DIDEROT
}

\author{
Langres, $1713-1784$, Paris
}

Denis Diderot, an unusually fertile thinker, was born at Langres in 1713 , of plebeian stock. He received an excellent education, first under the Jesuits at Langres, then at the college of Harcourt at Paris. He next took up the study of law, but, not attracted by the profession, he gave it up, and for some years worked out a scanty subsistence by tutoring, translating, or doing what other literary hack work happened to fall into his hands. He first attracted attention by his "Lettre sur les aveugles" (1749), a work for which he was thrown into prison. On his release three months later he entered upon his great life work. A publisher by the name of Lebreton had conceived the idea of publishing a translation of Chambers's Encyclopedia. At Diderot's instigation, however, a new and more comprehensive work was planned. Diderot and D'Alembert assumed the editorship of it, and brought out the first volume of the "Encyclopédie" in $175 \mathrm{I}$. But the opposition of church and state made the progress of the work difficult, and it was only after more than twenty years of incredible labor, for which he was but poorly paid, that Diderot brought out, in 1772 , the last of the twenty-eight volumes. Meanwhile one after another of his collaborators, D'Alembert among them, had become discouraged, and the main burden of the work fell back upon Diderot.

In addition to the numerous articles on the most varied subjects throughout the "Encyclopédie," and other productions of lesser importance, Diderot wrote the "Salons," critical estimates of the art exhibits for various years ; "Le fils naturel" (1757); "Le neveu de Rameau," not published until I823; and a correspondence in which we find a vivid description of the circle in which he moved.

\section{CONDITIONS DE LA GRANDE POÉSIE}

En général, plus un peuple est civilisé, poli, moins ses mœurs sont poétiques ; tout s'affaiblit en s'adoucissant. Quand est-ce que la nature prépare des modèles à l'art ? C'est au temps où les enfants s'arrachent les cheveux autour du lit d'un père moribond; où une mère découvre son sein, et conjure son fils par les mamelles qui l'ont allaité ; où un ami se coupe la chevelure, et la répand sur le cadavre de son ami; où c'est lui qui le soutient par la tête et qui le porte sur un bûcher, qui recueille sa cendre et qui la renferme dans une urne qu'il va, en certains jours, arroser de ses pleurs ; où les veuves échevelées se déchirent 
le visage de leurs ongles, si la mort leur a ravi un époux; où les chefs du peuple, dans les calamités publiques, posent leur front humilié dans la poussière, ouvrent leurs vêtements dans la douleur, et se frappent la poitrine; où un père prend entre ses bras son fils nouveau-né, 5 l'élève vers le ciel, et fait sur lui sa prière aux dieux; où le premier mouvement d'un enfant, s'il a quitté ses parents, et qu'il les revoie après une longue absence, c'est d'embrasser leurs genoux, et d'en attendre, prosterné, la bénédiction; où ses repas sont des sacrifices qui commencent et finissent par des coupes remplies de vin, et versées Io sur la terre; où le peuple parle à ses maîtres, et où ses maîtres l'entendent et lui répondent; où l'on voit un homme le front ceint de bandelettes devant un autel, et une prêtresse qui étend les mains sur lui en invoquant le ciel et en exécutant les cérémonies expiatoires et lustratives ${ }^{1}$; où des pythies, écumantes par la présence d'un démon I 5 qui les tourmente, sont assises sur des trépieds, ont les yeux égarés, et font mugir de leurs cris prophétiques le fond obscur des antres; où les dieux, altérés de sang humain, ne sont apaisés que par son effusion; où des bacchantes, armées de thyrses, s'égarent dans les forêts et inspirent l'effroi au profane qui se rencontre sur leur passage. . . .

20 Je ne dis pas que ces mœurs soient bonnes, mais qu'elles sont poétiques.

Qu'est-ce qu'il faut au poète? Est-ce une nature brute ou cultivée, paisible ou troublée? Préférera-t-il la beauté d'un jour pur et serein à l'horreur d'une nuit obscure, où le sifflement interrompu des vents se 25 mêle par intervalles au murmure sourd et continu d'un tonnerre éloigné, et où il voit l'éclair allumer le ciel sur sa tête? Préférera-t-il le spectacle d'une mer tranquille à celui des flots agités? le muet et froid aspect d'un palais, à la promenade parmi des ruines? un édifice construit, un espace planté de la main des hommes, au touffu d'une 30 antique forêt, au creux ignoré d'une roche déserte? Des nappes d'eau, des bassins, des cascades, à la vue d'une cataracte qui se brise en tombant à travers des rochers, et dont le bruit se fait entendre au loin du berger qui a conduit son troupeau dans la montagne et qui l'écoute avec effroi ?

35 La poésie veut quelque chose d'énorme, de barbare et de sauvage.

C'est lorsque la fureur de la guerre civile ou du fanatisme arme les hommes de poignards, et que le sang coule à grands flots sur la terre, que le laurier d'Apollon s'agite et verdit. Il en veut être arrosé. Il se 
flétrit dans les temps de la paix et du loisir. Le siècle d'or eût produit une chanson peut-être ou une élégie. La poésie épique et la poésie dramatique demandent d'autres mœurs.

Quand verra-t-on naître des poètes? Ce sera après les temps de désastres et de grands malheurs, lorsque les peuples harassés commenceront à respirer. Alors les imaginations, ébranlées par des spectacles terribles, peindront des choses inconnues à ceux qui n'en ont pas été les témoins. N'avons-nous pas éprouvé, dans quelques circonstances, une sorte de terreur qui nous était étrangère? Pourquoi n'a-t-elle rien produit? N'avons-nous plus de génie?

Le génie est de tous les temps; mais les hommes qui le portent en eux demeurent engourdis, à moins que des événements extraordinaires n'échauffent la masse, et ne les fassent paraître. Alors les sentiments s'accumulent dans la poitrine, la travaillent; et ceux qui ont un organe, pressés de parler, le déploient et se soulagent.

Quelle sera donc la ressource d'un poète, chez un peuple dont les mœurs sont faibles, petites et maniérées ; où l'imitation rigoureuse des conversations ne formerait qu'un tissu d'expressions fausses, insensées et basses; où il n'y a plus ni franchise ni bonhomie; où un père appelle son fils monsieur et où une mère appelle sa fille mademoiselle ; 20 où les cérémonies publiques n'ont rien d'auguste, la conduite domestique rien de touchant et d'honnête, les actes solennels rien de vrai ? Il tâchera de les embellir; il choisira les circonstances qui prêtent le plus à son art ; il négligera les autres, et il osera en supposer quelquesunes.

Mais quelle finesse de goût ne lui faudra-t-il pas, pour sentir jusqu'où les mœurs publiques et particulières peuvent être embellies? S'il passe la mesure, il sera faux et romanesque.

Si les mœurs qu'il supposera ont été autrefois, et que ce temps ne soit pas éloigné ; si un usage est passé, mais qu'il en soit resté une 30 expression métaphorique dans la langue; si cette expression porte un caractère d'honnêteté ; si elle marque une piété antique, une simplicité qu'on regrette; si l'on y voit les pères plus respectés, les mères plus honorées, les rois populaires; qu'il ose. Loin de lui reprocher d'avoir failli contre la vérité, on supposera que ces vieilles et bonnes mœurs 35 se sont apparemment conservées dans cette famille.

- «De la poésie dramatique », XVIII, Des mœurs 


\section{LE ROSSIGNOL ET LE COUCOU ${ }^{1}$}

- Sur les sept heures, ils se sont mis à des tables de jeu; et MM. le Roy, ${ }^{2}$ Grimm, ${ }^{3}$ l'abbé Galiani ${ }^{4}$ et moi, nous avons causé. Oh! pour cette fois, je vous apprendrai à connaître l'abbé, que peutêtre vous n'avez regardé jusqu'à présent que comme un agréable. 5 Il est mieux que cela.

Il s'agissait entre Grimm et $M$. le Roy du génie qui crée; et de la méthode qui ordonne. Grimm déteste la méthode; c'est, selon lui, la pédanterie des lettres. Ceux qui ne savent qu'arranger feraient aussi bien de rester en repos; ceux qui ne peuvent être instruits que par Io des choses arrangées feraient tout aussi bien de rester ignorants. "Mais c'est la méthode qui fait valoir. - Et qui gâte. — Sans elle, on ne profiterait de rien. - Qu'en se fatiguant, et cela n'en serait que mieux. Où est la nécessité que tant de gens sachent autre chose que leur métier? »Ils dirent beaucoup de choses que je ne vous rapporte I 5 pas; et ils en diraient encore, si l'abbé Galiani ne les eût interrompus comme ceci :

" Mes amis, je me rappelle une fable; écoutez-là. Elle sera peutêtre un peu longue, mais elle ne vous ennuiera pas.

« Un jour, au fond d'une forêt, il s'éleva une contestation sur le 20 chant entre le rossignol et le coucou. Chacun prise son talent.

"- Quel oiseau, disait le coucou, a le chant aussi facile, aussi simple, " aussi naturel et aussi mesuré que moi ?"

"-Quel oiseau, disait le rossignol, l'a plus doux, plus varié, plus "éclatant, plus léger, plus touchant que moi ? )

25 "Le coucou: " Je dis peu de choses; mais elles ont du poids, de ( l'ordre, et on les retient. )

" Le rossignol : « J'aime à parler; mais je suis toujours nouveau, et ( je ne fatigue jamais. J'enchante les forêts ; le coucou les attriste. Il " est tellement attaché à la leçon de sa mère, qu'il n'oserait hasarder un 30 " ton qu'il n'a point pris d'elle. Moi, je ne reconnais point de maître; “ je me joue des règles. C'est surtout lorsque je les enfreins qu'on " m'admire. Quelle comparaison de sa fastidieuse méthode avec mes " heureux écarts? )

1 This selection is from a letter dated October 20,1760 , and addressed to Mademoiselle Voland.

${ }^{2}$ Le Roy (1723-1789) was one of the collaborators for the "Encyclopédie."

3 Frédéric Melchior Grimm (1723-1807) was author of "Correspondance littéraire."

4 Galiani (1728-1787) was a distinguished Italian litterateur and diplomat, appointed secretary to the embassy at Paris in 1759 . 
« Le coucou essaya plusieurs fois d'interrompre le rossignol. Mais les rossignols chantent toujours, et n'écoutent point ; c'est un peu leur défaut. Le nôtre, entraîné par ses idées, les suivait avec rapidité, sans se soucier des réponses de son rival.

" Cependant, après quelques dits et contredits, ils convinrent de 5 s'en rapporter au jugement d'un tiers animal.

" Mais où trouver ce tiers également instruit et impartial qui les jugera? Ce n'est pas sans peine qu'on trouve un bon juge. Ils vont en cherchant un partout.

"Ils traversaient une prairie, lorsqu'ils y aperçurent un âne des ro plus graves et des plus solennels. Depuis la création de l'espèce, aucun n'avait porté d'aussi longues oreilles. "Ah! dit le coucou en " les voyant, nous sommes trop heureux : notre querelle est une affaire " d'oreilles; voilà notre juge: Dieu le fit pour nous tout exprès."

" L'âne. broutait. Il n'imaginait guère qu'un jour il jugerait de 15 musique. Mais la Providence s'amuse à beaucoup d'autres choses. Nos deux oiseaux s'abattent devant lui, le complimentent sur sa gravité et sur son jugement, lui exposent le sujet de leur dispute, et le supplient très humblement de les entendre et de décider.

" Mais l'âne, détournant à peine sa lourde tête et n'en perdant pas 20 un coup de dent, leur fait signe de ses oreilles qu'il a faim, et qu'il ne tient pas aujourd'hui son lit de justice. Les oiseaux insistent; l'âne continue à brouter. En broutant, son appétit s'apaise. Il y avait quelques arbres plantés sur la lisière du pré. " Eh bien! leur dit-il, « allez là: je m’y rendrai; vous chanterez, je digérerai, je vous écou- 25 " terai, et puis je vous dirai mon avis.»

"Les oiseaux vont à tire-d'aile, et se perchent; l'âne les suit, de l'air et du pas d'un président à mortier qui traverse les salles du palais. Il arrive, il s'étend à terre, et dit: "Commencez, la cour vous écoute. » C'est lui qui était toute la cour.

« Le coucou dit: "Monseigneur, il n'y a pas un mot à perdre de " mes raisons; saisissez bien le caractère de mon chant, et surtout " daignez en observer l'artifice et la méthode." Puis, se rengorgeant et battant à chaque fois des ailes, il chanta : "Coucou, coucou, coucou" cou, coucoucou, coucou, coucoucou.» Et, après avoir combiné cela 35 de toutes les manières possibles, il se tut.

" Le rossignol, sans préambule, déploie sa voix, s'élance dans les modulations les plus hardies, suit les chants les plus neufs et les plus recherchés: ce sont des cadences ou des tenues à perte d'haleine; 
tantôt on entendait les sons descendre et murmurer au fond de sa gorge comme l'onde du ruisseau qui se perd sourdement entre des cailloux, tantôt on les entendait s'élever, se renfler peu à peu, remplir l'étendue des airs, et y demeurer comme suspendus. Il était successi5 vement doux, léger, brillant, pathétique, et, quelque caractère qu'il prît, il peignait; mais son chant n'était pas fait pour tout le monde.

“ Emporté par son enthousiasme, il chanterait encore; mais l'âne, qui avait déjà bâillé plusieurs fois, l'arrêta, et lui dit: " Je me doute " que tout ce que vous avez chanté là est fort beau, mais je n'y entends ıo " rien; cela me paraît bizarre, brouillé, décousu. Vous êtes peut-être " plus savant que votre rival, mais il est plus méthodique que vous, et " je suis, moi, pour la méthode. »

Et l'abbé s'adressant à M. le Roy, et montrant Grimm du doigt : "Voilà, dit-il, le rossignol, et vous êtes le coucou, et moi je suis l'âne I5 qui vous donne gain de cause. Bonsoir. "

Les contes de l'abbé sont bons, mais il les joue supérieurement: on n'y tient pas. Vous auriez trop ri de lui voir tendre son cou en l'air, et faire la petite voix pour le rossignol ; se rengorger et prendre le ton rauque pour le coucou; redresser ses oreilles, et imiter la gra20 vité bête et lourde de l'âne; et tout cela naturellement, et sans y tâcher. C'est qu'il est pantomime depuis la tête jusqu'aux pieds.

\section{DÉLIRE MUSICAL}

$\mathrm{Le}^{1}$ voilà qui se met à se promener en murmurant dans son gosier quelques-uns des airs de l'Ile des fous, du Peintre amoureux de son modèle, du Maréchal ferrant, de la Plaideuse, ${ }^{2}$ et de temps en temps il 25 s'écriait, en levant les mains et les yeux au ciel: " Si cela est beau, mordieu! si cela est beau! comment peut-on porter à sa tête une paire d'oreilles, et faire une pareille question? " Il commençait à entrer en passion et à chanter tout bas, il élevait le ton à mesure qu'il se passionnait davantage; vinrent ensuite les gestes, les grimaces du 30 visage et les contorsions du corps; et je dis: "Bon, voilà la tête qui se perd et quelque scène nouvelle qui se prépare."

En effet, il part d'un éclat de voix : Je suis un pauvre misérable... Monseigneur, monseigneur, laissez-moi partir. . . . O terre, reçois mon

1 I.e. le neveu de Rameau.

2 Operas by Duni and Philidor. The words below are from the "Ile des fous" and the "Servante maîtresse." 
or, conserve bien mon trísor. . . Mon âme, mon âme, ma vie! O terre!... Le voilì, le petit ami! - Aspettare e non venire. . . A Zerbina penserete. . . . Sempre in contrasti con te si stà. . . . Il entassait et brouillait ensemble trente airs italiens, français, tragiques, comiques, de toutes sortes de caractères. 'Tantôt avec une voix de basse-taille il descendait jusqu'aux enfers ; tantôt s'égosillant et contrefaisant le fausset, il déchirait le haut des airs, imitant de la démarche, du maintien, du geste, les différents personnages chantants ; successivement furieux, radouci, impérieux, ricaneur. Ici, c'est une jeune fille qui pleure, et il en rend toute la minauderie : là il est prêtre, il est roi, ıo il est tyran, il menace, il commande, il s'emporte; il est esclave, il obéit; il s'apaise, il se désole, il se plaint, il rit; jamais hors de ton, de mesure, du sens des paroles et du caractère de l'air.

Tous les pousse-bois ${ }^{1}$ avaient quitté leurs échiquiers et s'étaient rassemblés autour de lui; les fenêtres du café étaient occupées en 15 dehors par les passants qui s'étaient arrêtés au bruit. On faisait des éclats de rire à entr'ouvrir le plafond. Lui n'apercevait rien, il continuait, saisi d'une aliénation d'esprit, d'un enthousiasme si voisin de la folie qu'il est incertain qu'il en revienne, s'il ne faudra pas le jeter dans un fiacre et le mener droit aux Petites-Maisons, ${ }^{2}$ en chantant un lam- 20 beau des Lamentations d'Ioumelli. ${ }^{3}$ Il répétait avec une précision, une vérité et une chaleur incroyables les plus beaux endroits de chaque morceau; ce beau récitatif obligé ${ }^{4}$ où le prophète peint la désolation de Jérusalem, il l'arrosa d'un torrent de larmes qui en arrachèrent de tous les yeux. Tout y était, et la délicatesse du chant, et la force de 25 l'expression, et la douleur. Il insistait sur les endroits où le musicien s'était particulièrement montré un grand maître. S'il quittait la partie du chant, c'était pour prendre celle des instruments, qu'il laissait subitement pour revenir à la voix, entrelaçant l'une à l'autre de manière à conserver les liaisons et l'unité du tout; s'emparant de nos âmes, et les 30 tenant suspendues dans la situation la plus singulière que j'aie jamais éprouvée. . . . Admirais-je ? oui, j'admirais. Etais-je touché de pitié ? j'étais touché de pitié ; mais une teinte ridicule était fondue dans ces sentiments, et les dénaturait.

Mais vous vous seriez échappé en éclats de rire à la manière dont il 35 contrefaisait les différents instruments. Avec des joues renflées et

1 " chess players."

2 An insane asylum.

3 Nicola Jomelli (1714-1774), an Italian composer.

4 Declamation or song accompanied or interrupted by instrumental music. 
bouffies, et un son rauque et sombre, il rendait les cors et les bassons ; il prenait un son éclatant et nasillard pour les hautbois; précipitant sa voix avec une rapidité incroyable pour les instruments à cordes dont il cherchait les sons les plus approchés; il sifflait les petites flûtes, il 5 roucoulait les traversières, ${ }^{1}$ criant, chantant, se démenant comme un forcené, faisant lui seul les danseurs, les danseuses, les chanteurs, les chanteuses, tout un orchestre, tout un théâtre lyrique, et se divisant en vingt rôles divers ; courant, s'arrêtant, avec l'air d'un énergumène, étincelant des yeux, écumant de la bouche.

ro Il faisait une chaleur à périr, et la sueur qui suivait les plis de son front et la longueur de ses joues se mêlait à la poudre de ses cheveux, ruisselait et sillonnait le haut de son habit. Que ne lui vis-je pas faire? Il pleurait, il riait, il soupirait, il regardait, ou attendri, ou tranquille, ou furieux ; c'était une femme qui se pâme de douleur, c'était un malI 5 heureux livré à tout son désespoir; un temple qui s'élève; des oiseaux qui se taisent au soleil couchant; des eaux ou qui murmurent dans un lieu solitaire et frais, ou qui descendent en torrent du haut des montagnes; un orage, une tempête, la plainte de ceux qui vont périr, mêlée au sifflement des vents, au fracas du tonnerre; c'était la nuit 20 avec ses ténèbres; c'était l'ombre et le silence; car le silence même se peint par des sons. Sa tête était tout à fait perdue.

— " Le neveu de Rameau » 1 "German flutes." 


\title{
GEORGE-LOUIS LECLERC DE BUFFON
}

\author{
Montbard, I 707- 1788 , Paris
}

Buffon was born of a prominent family in Burgundy, and was educated by the Jesuits at Dijon. His interests were at first mainly in mathematics, but they turned to the natural sciences, and in 1739 he was appointed director of the "Jardin du Roi," to-day the "Jardin des plantes." This position he filled with the utmost care and attention, displaying unusual ability in making the garden beautiful and, at the same time, of great scientific value. Meanwhile he was devoting his leisure to study, and in 1749 brought out the first of the long series of volumes which, including the "Epoques de la nature," go to form his "Histoire naturelle." The dignity and color of his style, and the breadth of view displayed, give Buffon a place among the greatest prose writers of France.

He was made a member of the Academy of Sciences in 1739 , and was elected to the French Academy in 1753 . At his reception to the latter he pronounced his famous "Discours sur le style." He died in 1788.

\section{LES PREMIERS HOMMES}

Les premiers hommes, témoins des mouvements convulsifs de la terre encore récents et très fréquents, n'ayant que les montagnes pour asiles contre les inondations, chassés souvent de ces mêmes asiles par le feu des volcans, tremblants sur une terre qui tremblait sous leurs pieds, nus d'esprit et de corps, exposés aux injures de tous les éléments, victimes de la fureur des animaux féroces, dont ils ne pouvaient éviter de devenir la proie; tous également pénétrés du sentiment commun d'une terreur funeste, tous également pressés par la nécessité, n'ont-ils pas très promptement cherché à se réunir, d'abord pour se défendre par le nombre, ensuite pour s'aider et travailler de concert à ıo se faire un domicile et des armes? Ils ont commencé par aiguiser, en forme de haches, ces cailloux durs, ces jades, ces pierres de foudre, ${ }^{1}$ que l'on a crues tombées des nues et formées par le tonnerre, et qui néanmoins ne sont que les premiers monuments de l'art de l'homme dans l'état de pure nature: il aura bientôt tiré du feu de ces mêmes 15 cailloux en les frappant les uns contre les autres: il aura saisi la flamme des volcans, ou profité du feu de leurs laves brûlantes pour le communiquer, pour se faire jour dans les forêts, les broussailles ; car, 
avec le secours de ce puissant élément, il a nettoyé, assaini, purifié les terrains qu'il voulait habiter; avec la hache de pierre, il a tranché, coupé les arbres; menuisé le bois, façonné ses armes et les instruments de première nécessité. Et, après s'être munis de massues et d'autres 5 armes pesantes et défensives, ces premiers hommes n'ont-ils pas trouvé le moyen d'en faire d'offensives plus légères, pour atteindre de loin ? Un nerf, un tendon d'animal, des fils d'aloès, ou l'écorce souple d'une plante ligneuse, leur ont servi de corde pour réunir les deux extrémités d'une branche élastique dont ils ont fait leur arc; ils ont aiguisé Io d'autres petits cailloux pour en armer la flèche. Bientôt ils auront eu des filets, des radeaux, des canots, et s'en sont tenus là tant qu'ils n'ont formé que de petites nations composées de quelques familles, ou plutôt de parents issus d'une même famille, comme nous le voyons encore aujourd'hui chez les sauvages qui veulent demeurer sauvages,

I 5 et qui le peuvent, dans les lieux où l'espace libre ne leur manque pas plus que le gibier, le poisson et les fruits. Mais dans tous ceux où l'espace s'est trouvé confiné par les eaux, ou resserré par les hautes montagnes, ces petites nations, devenues trop nombreuses, ont été forcées de partager leur terrain entre elles, et c'est de ce moment que zo la terre est devenue le domaine de l'homme: il en a pris possession par ses travaux de culture, et l'attachement à la patrie a suivi de très près les premiers actes de sa propriété. L'intérêt particulier faisant partie de l'intérêt national, l'ordre, la police et les lois ont dû succéder, et la société prendre de la consistance et des forces. . . .

25 Le premier trait de l'homme qui commence à se civiliser, est l'empire qu'il sait prendre sur les animaux; et ce premier trait de son intelligence devient ensuite le plus grand caractère de sa puissance sur la nature: car ce n'est qu'après sè les être soumis qu'il a, par leur secours, changé la face de la terre, converti les déserts en guérets et 30 les bruyères en épis. En multipliant les espèces utiles d'animaux, l'homme augmente sur la terre la quantité de mouvement et de vie; il ennoblit en même temps la suite entière des êtres, et s'ennoblit lujmême en transformant le végétal en animal, et tous deux en sa propre substance, qui se répand ensuite par une nombreuse multiplication:

35 partout il produit l'abondance, toujours suivie de la grande population; des millions d'hommes existent dans le même espace qu'occupaient autrefois deux ou trois cents sauvages; des milliers d'animaux, où il $\mathrm{y}$ avait à peine quelques individus ; par lui et pour lui les germes précieux sont les seuls développés, les productions de la chasse la plus 
noble les seules cultivées; sur l'arbre immense de la fécondité, les branches à fruit seules subsistantes et toutes perfectionnées.

Le grain dont l'homme fait son pain n'est point un don de la nature, mais le grand, l'utile fruit de ses recherches et de son intelligence dans le premier des arts ; nulle part sur la terre on n'a trouvé du blé sauvage, et c'est évidemment une herbe perfectionnée par ses soins : il a donc fallu reconnaître et choisir entre mille et mille autres cette herbe précieuse ; il a fallu la semer, la recueillir nombre de fois pour s'apercevoir de sa multiplication, toujours proportionnée à la culture et à l'engrais des terres. Et cette propriété, pour ainsi dire unique, qu'a le ro froment de résister, dans son premier âge, au froid de nos hivers, quoique soumis, comme toutes les plantes annuelles, à périr après avoir donné sa graine; et la qualité merveilleuse de cette graine qui convient à tous les hommes, à tous les animaux, à presque tous les climats, qui d'ailleurs se conserve longtemps sans altération, sans perdre la puis- I 5 sance de se reproduire; tout nous démontre que c'est la plus heureuse découverte que l'homme ait jamais faite, et que, quelque ancienne qu'on veuille la supposer, elle a néanmoins été précédée de l'art de l'agriculture, fondé sur la science et perfectionné par l'observation.

Si l'on veut des exemples plus modernes ęt même récents de la 20 puissance de l'homme sur la nature des végétaux, il n'y a qu'à comparer nos légumes, nos fleurs et nos fruits avec les mêmes espèces telles qu'elles étaient il y a cent cinquante ans. ...

Combien de fois n'a-t-il pas fallu que l'homme ait tenté la nature pour en obtenir ces espèces excellentes! combien de milliers de germes 25 n'a-t-il pas été obligé de confier à la terre pour qu'elle les ait enfin produits ! Ce n'est qu'en semant, élevant, cultivant et mettant à fruit un nombre presque infini de végétaux de la même espèce, qu'il a pu reconnaitre quelques individus portant des fruits plus doux et meilleurs que les autres: et cette première découverte, qui suppose déjà tant 30 de soins, serait encore demeurée stérile à jamais s'il n'en eût fait une seconde, qui suppose autant de génie que la première exigeait de patience; c'est d'avoir trouvé le moyen de multiplier par la greffe ces individus précieux, qui malheureusement ne peuvent faire une lignée aussi noble qu'eux, ni propager par eux-mêmes leurs excellentes qua- 35 lités. . . .

Tous ces exemples modernes et récents prouvent que l'homme n'a connu que tard l'étendue de sa puissance, et que même il ne la connaît pas encore assez; elle dépend en entier de l'exercice de son 
intelligence: ainsi, plus il observera, plus il cultivera la nature, plus il aura de moyens pour se la soumettre, et plus de facilités pour tirer de son sein des richesses nouvelles, sans diminuer les trésors de son inépuisable fécondité.

5 Et que ne pourrait-il pas sur lui-même, je veux dire sur sa propre espèce, si la volonté était toujours dirigée par l'intelligence! Qui sait jusqu'à quel point l'homme pourrait perfectionner sa nature, soit au moral, soit au physique? Y a-t-il une seule nation qui puisse se vanter d'être arrivée au meilleur gouvernement possible, qui serait de rendre

ıo tous les hommes, non pas également heureux, mais moins inégalement malheureux, en veillant à leur conservation, à l'épargne de leurs sueurs et de leur sang par la paix, par l'abondance des subsistances, par les aisances de la vie et les facilités pour leur propagation? Voilà le but moral de toute société qui chercherait à s'améliorer. Et pour le phyI 5 sique, la médecine et les autres arts dont l'objet est de nous conserver, sont-ils aussi avancés, aussi connus que les arts destructeurs enfantés par la guerre? Il semble que de tout temps l'homme ait fait moins de réflexions sur le bien que de recherches pour le mal: toute société est mêlée de l'un et de l'autre; et comme de tous les sentiments qui affectent la multitude, la crainte est le plus puissant, les grands talents dans l'art de faire du mal ont été les premiers qui aient frappé l'esprit de l'homme; ensuite ceux qui l'ont amusé ont occupé son cœur; et ce n'est qu'après un trop long usage de ces deux moyens de faux honneur et de plaisir stérile, qu'enfin il a reconnu que sa vraie gloire 25 est la science, et la paix son vrai bonheur.

— "Septième époque de la nature »

\section{SUR LE STYLE}

Pour bien écrire, il faut posséder pleinement son sujet; il faut y réfléchir assez pour voir clairement l'ordre de ses pensées, et en former une suite, une chaîne continue, dont chaque point représente une idée ; et, lorsqu'on aura pris la plume, il faudra la conduire successivement 30 sur ce premier trait, sans lui permettre de s'en écarter, sans l'appuyer trop inégalement, sans lui donner d'autre mouvement que celui qui sera déterminé par l'espace qu'elle doit parcourir. C'est en cela que consiste la sévérité du style ; c'est aussi ce qui en fera l'unité et ce qui en réglera la rapidité ; et cela seul aussi suffira pour le rendre précis 35 et simple, égal et clair, vif et suivi. A cette première règle, dictée par 
le génie, si l'on joint de la délicatesse et du goût, du scrupule sur le choix des expressions, de l'attention à ne nommer les choses que par les termes les plus généraux, le style aura de la noblesse. Si l'on y joint encore de la défiance pour son premier mouvement, du mépris pour tout ce qui n'est que brillant, et une répugnance constante pour l'équivoque et la plaisanterie, le style aura de la gravité, il aura même de la majesté. Enfin, si l'on écrit comme l'on pense, si l'on est convaincu de ce que l'on veut persuader, cette bonne foi avec soi-même, qui fait la bienséance pour les autres et la vérité du style, lui fera produire tout son effet, pourvu que cette persuasion intérieure ne se ro marque pas par un enthousiasme trop fort, et qu'il y ait partout plus de candeur que de confiance, plus de raison que de chaleur.

C'est ainsi, messieurs, qu'il me semblait, en vous lisant, que vous me parliez, que vous m'instruisiez. Mon âme, qui recueillait avec avidité ces oracles de la sagesse, voulait prendre l'essor et s'élever jusqu'à 15 vous: vains efforts! Les règles, disiez-vous encore, ne peuvent suppléer au génie; s'il manque, elles seront inutiles. Bien écrire, c'est tout à la fois bien penser, bien sentir et bien rendre; c'est avoir en même temps de l'esprit, de l'âme et du goût. Le style suppose la réunion et l'exercice de toutes les facultés intellectuelles: les idées 20 seules forment le fond du style, l'harmonie des paroles n'en est que l'accessoire, et ne dépend que de la sensibilité des organes. Il suffit d'avoir un peu d'oreille pour éviter les dissonances, et de l'avoir exercée, perfectionnée par la lecture des poètes et des orateurs, pour que mécaniquement on soit porté à l'imitation de la cadence poétique et 25 des tours oratoires. Or, jamais l'imitation n'a rien créé : aussi cette harmonie des mots ne fait ni le fond, ni le ton du style, et se trouve souvent dans des écrits vides d'idées.

Le ton n'est que la convenance du style à la nature du sujet; il ne doit jamais être forcé; il naîtra naturellement du fond même de la 30 chose, et dépendra beaucoup du point de généralité auquel on aura porté ses pensées. Si l'on s'est élevé aux idées les plus générales, et si l'objet en lui-même est grand, le ton paraitra s'élever à la même hauteur; et si, en le soutenant à cette élévation, le génie fournit assez pour donner à chaque objet une forte lumière, si l'on peut ajouter la 35 beauté du coloris à l'énergie du dessin, si l'on peut, en un mot, représenter chaque idée par une image vive et bien terminée, et former de chaque suite d'idées un tableau harmonieux et mouvant, le ton sera non seulement élevé, mais sublime. 
Ici, messieurs, l'application ferait plus que la règle; les exemples instruiraient mieux que les préceptes: mais, comme il ne m'est pas permis de citer les morceaux sublimes qui m'ont si souvent transporté en lisant vos ouvrages, je suis contraint de me borner à des réflexions.

5 Les ouvrages bien écrits seront les seuls qui passeront à la postérité. La quantité des connaissances, la singularité des faits, la nouveauté même des découvertes, ne sont pas de sûrs garants de l'immortalité ; si les ouvrages qui les contiennent ne roulent que sur de petits objets, s'ils sont écrits sans goût, sans noblesse et sans génie, ils périront, Io parce que les connaissances, les faits et les découvertes s'enlèvent aisément, se transportent, et gagnent même à être mis en œuvre par des mains plus habiles. Ces choses sont hors de l'homme, le style est l'homme même. Le style ne peut donc ni s'enlever, ni se transporter, ni s'altérer: s'il est élevé, noble, sublime, l'auteur sera également I 5 admiré dans tous les temps ; car il n'y a que la vérité qui soit durable, et mème éternelle. Or, un beau style n'est tel en effet que par le nombre infini des vérités qu'il présente. Toutes les beautés intellectuelles qui s'y trouvent, tous les rapports dont il est composé, sont autant de vérités aussi utiles, et peut-être plus précieuses pour l'esprit zo humain, que celles qui peuvent faire le fond du sujet.

Le sublime ne peut se trouver que dans les grands sujets. La poésie, l'histoire et la philosophie ont toutes le même objet, et un très grand objet, l'homme et la nature. La philosophie décrit et dépeint la nature; la poésie la peint et l'embellit; elle peint aussi les hommes, 25 elle les agrandit, les exagère ; elle crée les héros et les dieux : l'histoire ne peint que l'homme, et le peint tel qu'il est; ainsi le ton de l'historien ne deviendra sublime que quand il fera le portrait des plus grands hommes, quand il exposera les plus grandes actions, les plus grands mouvements, les plus grandes révolutions, et, partout ailleurs, il suffira 30 qu'il soit majestueux et grave. Le ton du philosophe pourra devenir sublime toutes les fois qu'il parlera des lois de la nature, des êtres en général, de l'espace, de la matière, du mouvement et du temps, de l'âme, de l'esprit humain, des sentiments, des passions; dans le reste, il suffira qu'il soit noble et élevé. Mais le ton de l'orateur et du poète, 35 dès que le sujet est grand, doit toujours être sublime, parce qu'ils sont les maîtres de joindre. à la grandeur de leur sujet autant de couleur, autant de mouvement, autant d'illusion qu'il leur plait ; et que, devant toujours peindre et toujours grandir les objets, ils doivent aussi partout employer toute la force et déployer toute l'étendue de leur génie. 


\title{
BEAUMARCHAIS
}

(PIERRE-AUGUSTIN CARON)

\author{
Paris, 1732-1 799, Paris
}

Pierre-Augustin Caron was born at Paris in 1732 . He first applied himself to his father's profession, watchmaking, and at the age of twenty-one invented a new escapement. Being ambitious and remarkably versatile, he soon signed himself watchmaker to the king, became music master to the king's daughters, comptroller in the household of Louis XV, a successful man of affairs, and, as a side issue, an author of two comedies which have won him lasting fame. The name by which he is known, Beaumarchais, was assumed after his first marriage, when he purchased letters of nobility ( 1761 ). In 1764 he visited Spain on business and to look after the interests of one of his sisters, an incident which inspired his first play, "Eugénie" (1 767 ). Neither "Eugénie" nor "Les deux amis," which appeared in 1770, had any success. Soon after the appearance of this latter play began a series of lawsuits, resulting from a claim of Beaumarchais against the estate of Paris-Duverney, with whom he had had business relations. These suits, before they were finally closed, were to call forth the "Mémoires" against Goëzman, - masterpieces of audacity, irony, and wit, which more than offset the accusations brought against him in his suits, and made him the idol of the people, who saw in his attack against Goëzman a reflection of their own case against the government. In 1775 he brought out "Le barbier de Séville," and soon after wrote "Le mariage de Figaro," which, however, for political reasons, was not played until ${ }_{1} 784$, when it had a brilliant success, as much perhaps on account of its political satire, as for its literary excellence. In the meantime he furnished arms to the American colonists for large amounts which were not paid until years after his death, and undertook secret missions in regard to the suppression of certain pamphlets about Louis XV and Marie Antoinette. IIe also took charge of the famous Kehl edition of Voltaire's works. During the French revolution he became very much entangled in questionable enterprises and lost his property. He died in 1799 .

His greatest creation is Figaro, an energetic, ambitious, somewhat unscrupulous character of unusual ability, who felt that society was not giving him a fair deal. Figaro represents the restless revolutionary malcontents of the Tiers-Etat. "Un grand," he says, " nous fait assez de bien quand il ne nous fait pas de mal."

In "Le mariage de Figaro" the political and social satire becomes more bitter than in "Le barbier." One feels that the crisis of the Revolution is near at hand. Beaumarchais's two plays mark epochs not only in literature but in history as well. "La mère coupable" (1792) adds nothing to his reputation. 


\section{UNE QUERELLE}

\section{Bartholo, Rosine ${ }^{1}$}

Bartholo. Il est enfin parti! (A part.) Dissimulons.

Rosine. Convenez pourtant, monsieur, qu'il est bien gai, ce jeune soldat! A travers son ivresse, on voit qu'il ne manque ni d'esprit, ni d'une certaine éducation.

5 Bartholo. Heureux, m'amour, d'avoir pu nous en délivrer! Mais n'es-tu pas un peu curieuse de lire avec moi le papier qu'il t'a remis ?

Rosine. Quel papier?

Bartholo. Celui qu'il a feint de ramasser pour te le faire accepter.

Rosine. Bon! c'est la lettre de mon cousin l'officier, qui était tomıo bée de ma poche.

Bartholo. J'ai idée, moi, qu'il l'a tirée de la sienne.

Rosine. Je l'ai très bien reconnue.

Bartholo. Qu'est-ce qu'il coûte d'y regarder?

Rosine. Je ne sais pas seulement ce que j'en ai fait.

I 5 Bartholo (montrant la pochette). Tu l'as mise là.

Rosine. Ah! ah! par distraction.

Bartholo. Ah! sûrement. Tu vas voir que ce sera quelque folie.

Rosine (a part). Si je ne le mets pas en colère, il n'y aura pas moyen de refuser.

20 Bartholo. Donne donc, mon cœur.

Rosine. Mais quelle idée avez-vous en insistant, monsieur? est-ce encore quelque méfiance ? ${ }^{2}$

Bartholo. Mais vous, quelle raison avez-vous de ne pas la montrer?

Rosine. Je vous répète, monsieur, que ce papier n'est autre que la

25 lettre de mon cousin, que vous m'avez rendue hier toute décachetée; et puisqu'il en est question, je vous dirai tout net que cette liberté me déplaît excessivement.

Bartholo. Je ne vous entends pas!

Rosine. Vais-je examiner les papiers qui vous arrivent? Pourquoi 30 vous donnez-vous les airs de toucher à ceux qui me sont adressés? Si c'est jalousie, elle m'insulte; s'il s'agit de l'abus d'une autorité usurpée, j'en suis plus révoltée encore.

1 Bartholo desires to marry his ward Rosine, who dislikes him. Rosine is interested in the count Almaviva, who has just left the house, having, in order to gain admission, disguised himself as a soldier and pretended that he was intoxicated. Before leaving, Almaviva had given Rosine a note.

2 He had previously accused her of having written a note. 
Bartholo. Comment, révoltée! Vous ne m’avez jamais parlé ainsi.

Rosine. Si je me suis modérée jusqu'à ce jour, ce n'était pas pour vous donner le droit de m'offenser impunément.

Bartholo. De quelle offense me parlez-vous?

Rosine. C'est qu'il est inouï qu'on se permette d'ouvrir les lettres 5 de quelqu'un.

Bartholo. De sa femme?

Rosine. Je ne la suis pas encore. Mais pourquoi lui donnerait-on la préférence d'une indignité qu'on ne fait à personne?

Bartholo. Vous voulez me faire prendre le change, et détourner ro mon attention du billet, qui sans doute est une missive de quelque amant; mais je le verrai, je vous assure.

Rosine. Vous ne le verrez pas. Si vous m'approchez, je m'enfuis de cette maison, et je demande retraite au premier venu.

Bartholo. Qui ne vous recevra point.

Rosine. C'est ce qu'il faudra voir.

Bartholo. Nous ne sommes pas ici en France, où l'on donne toujours raison aux femmes. Mais pour vous en ôter la fantaisie, je vais fermer la porte.

Rosine (pendant qu'il y va). Ah! ciel! que faire?... Mettons vite 20 à la place la lettre de mon cousin, et donnons-lui beau jeu à la prendre. (Elle fait l'échange, et met la lettre du cousin dans sa pochette, de façon qu'elle sort un peu.)

Bartholo (revenant). Ah! j'espère maintenant la voir.

Rosine. De quel droit, s'il vous plaît?

Bartholo. Du droit le plus universellement reconnu, celui du plus fort.

Rosine. On me tuera plutôt que de l'obtenir de moi.

Bartholo (frappant du pied). Madame! madame!

Rosine (tombe sur un fauteuil, et feint de se trouver mal). Ah, quelle indi- 30 gnité ! . .

Bartholo. Donnez cette lettre, ou craignez ma colère !

Rosine (renversée). Malheureuse Rosine!

Bartholo. Qu'avez-vous donc?

Rosine. Quel avenir affreux!

Bartholo. Rosine!

Rosine. J'étouffe de fureur.

Bartholo. Elle se trouve mal.

Rosine. Je m'affaiblis, je meurs! 
Bartholo (hui tâte le pouls, et dit à part). Dieu! la lettre! Lisons-la sans qu'elle en soit instruite. (Il continue à lui tâter le pouls, et prend la lettre, qu'il tâche de lire en se tournant un peu.)

Rosine (toujours renversée). Infortunée, ah! . . .

5 Bartholo (lui quitte le bras, et dit à part). Quelle rage a-t-on d'apprendre ce qu'on craint toujours de savoir!

Rosine. Ah! pauvre Rosine!

Bartholo. L'usage des odeurs ... produit ces affections spasmodiques. (Il lit par derrière le fautenil en lui tâtant le pouls. Rosine se relève Io un peu, le regarde finement, fait un geste de tête, et se remet sans parler.)

Bartholo (à part). O ciel! c'est la lettre de son cousin. Maudite inquiétude! Comment l'apaiser maintenant? Qu'elle ignore au moins que je l'ai lue! (Il fait semblant de la soutenir, et remet la lettre dans la pochette.)

I5 Rosine (soupire). Ah!...

Bartholo. Hé bien! ce n'est rien, mon enfant; un petit mouvement de vapeurs, voilà tout; car ton pouls n'a seulement pas varié. (Il va prendre un facon sur la console.)

Rosine (à part). Il a remis la lettre! fort bien.

20 Bartholo. Ma chère Rosine, un peu de cette eau spiritueuse.

Rosine. Je ne veux rien de vous: laissez-moi.

Bartholo. Je conviens que j'ai montré trop de vivacité sur ce billet.

Rosine. Il s'agit bien du billet! C'est votre façon de demander les 25 choses qui est révoltante.

Bartholo (à genoux). Pardon: j'ai bientôt senti tous mes torts; et tu me vois à tes pieds, prêt à les réparer.

Rosine. Oui, pardon! lorsque vous croyez que cette lettre ne vient pas de mon cousin.

30 Bartholo. Qu'elle soit d'un autre ou de lui, je ne veux aucun éclaircissement.

Rosine (lui présentant la lettre). Vous voyez qu'avec de bonnes façons on obtient tout de moi. Lisez-la.

Bartholo. Cet honnête procédé dissiperait mes soupçons, si j'étais 35 assez malheureux pour en conserver.

Rosine. Lisez-la donc, monsieur.

Bartholo (se retire). A Dieu ne plaise que je te fasse une pareille injure!

Rosine. Vous me contrariez de la refuser. 
Bartholo. Reçois en réparation cette marque de ma parfaite confiance. Je vais voir la pauvre Marceline, ${ }^{1}$ que ce Figaro a, je ne sais pourquoi, saignée du pied ; n'y viens-tu pas aussi ?

Rosine. J'y monterai dans un moment.

Bartholo. Puisque la paix est faite, mignonne, donne-moi ta main. Si tu pouvais m'aimer, comme tu serais heureuse!

Rosine (baissant les yeux). Si vous pouviez me plaire, ah! comme je vous aimerais!

Bartholo. Je te plairai, je te plairai; quand je dis que je te plairai!

— "Le barbier de Séville ", Act II, scene 15

\section{MONOLOGUE DE FIGARO}

Parce que vous êtes un grand seigneur, ${ }^{2}$ vous vous croyez un grand io génie 1 ... noblesse, fortune, un rang, des places; tout cela rend si fier! Qu'avez-vous fait pour tant de bien? vous vous êtes donné la peine de naitre, et rien de plus: du reste, homme assez ordinaire! tandis que moi, morbleu! perdu dans la foule obscure, il m'a fallu déployer plus de science et de calculs pour subsister seulement, qu'on i 5 n'en a mis depuis cent ans à gouverner toutes les Espagnes; et vous voulez jouter.... (Il s'assied sur un banc.) Est-il rien de plus bizarre que ma destinée! Fils de je ne sais pas qui, volé par des bandits, élevé dans leurs mœurs, je m'en dégoûte, et veux courir une carrière honnête; et partout je suis repoussé! J'apprends la chimie, la 20 pharmacie, la chirurgie; et tout le crédit d'un grand seigneur peut à peine me mettre à la main une lancette vétérinaire. - Las d'attrister des bêtes malades, et pour faire un métier contraire, je me jette à corps perdu dans le théâtre; me fussé-je mis une pierre au cou! Je broche une comédie dans les mœurs du sérail; auteur espagnol, je 25 croyais pouvoir y fronder Mahomet sans scrupule: à l'instant un envoyé ... de je ne sais où, se plaint que j'offense dans mes vers la Sublime Porte, la Perse, une partie de la presqu'île de l'Inde, toute l'Égypte, les royaumes de Barca, de Tripoli, de Tunis, d'Alger et de Maroc - et voilà ma comédie flambée, pour plaire aux princes maho- 30 métans, dont pas un, je crois, ne sait lire, et qui nous meurtrissent l'omoplate, en nous disant: Chiens de chrétiens! - Ne pouvant avilir

1 Figaro had incapacitated Bartholo's servants in order to facilitate an interview between Rosine and Almaviva.

2 I.e. the count Almaviva (the same in line 21), who had been making love to Suzanne, Figaro's fiancée. 
l'esprit, on se venge en le maltraitant. - Mes joues se creusaient; mon terme était échu : je voyais de loin arriver l'affreux recors, la plume fichée dans sa perruque: en frémissant je m'évertue. Il s'élève une question sur la nature des richesses; et comme il n'est pas nécessaire 5 de tenir les choses pour en raisonner, n'ayant pas un sou, j'écris sur la valeur de l'argent et sur son produit net. Sitôt je vois, du fond d'un fiacre, baisser pour moi le pont d'un château-fort, à l'entrée duquel je laissai l'espérance et la liberté. (Il se lève.) Que je voudrais bien tenir un de ces puissants de quatre jours, si légers sur le mal qu'ils ordonnent, ı quand une bonne disgrâce a cuvé son orgueil! Je lui dirais .. . que les sottises imprimées n'ont d'importance qu'aux lieux où l'on en gêne le cours ; que, sans la liberté de blâmer, il n'est point d'éloge flatteur, et qu'il n'y a que les petits hommes qui redoutent les petits écrits. (Il se rassied.) Las de nourrir un obscur pensionnaire, on me met un I 5 jour dans la rue; et comme il faut dîner, quoiqu'on ne soit plus en prison, je taille encore ma plume, et demande à chacun de quoi il est question. On me dit que pendant ma retraite économique il s'est établi dans Madrid un système de liberté sur la vente des productions, qui s'étend même à celles de la presse; et que, pourvu que je ne parle en 20 mes écrits ni de l'autorité, ni du culte, ni de la politique, ni de la morale, ni des gens en place, ni des corps en crédit, ni de l'Opéra, ni des autres spectacles, ni de personne qui tienne à quelque chose, je puis tout imprimer librement, sous l'inspection de deux ou trois censeurs. Pour profiter de cette douce liberté, j'annonce un écrit périodique, et, 25 croyant n'aller sur les brisées d'aucun autre, je le nomme Journal inutile. Pou-ou! je vois s'élever contre moi mille pauvres diables à la feuille ${ }^{1}$; on me supprime; et me voilà derechef sans emploi! - Le désespoir m'allait saisir; on pense à moi pour une place, mais par malheur j'y étais propre: il fallait un calculateur, ce fut un danseur qui

30 l'obtint. Il ne me restait plus qu'à voler; je me fais banquier de pharaon: alors, bonnes gens! je soupe en ville, et les personnes dites comme il faut m'ouvrent poliment leur maison, en retenant pour elles les trois quarts du profit. J'aurais bien pu me remonter; je commençais même à comprendre que, pour gagner du bien, le savoir-faire vaut 35 mieux que le savoir. Mais comme chacun pillait autour de moi, en exigeant que je fusse honnête, il fallut bien périr encore. Pour le coup je quittais le monde, et vingt brasses d'eau m'en allaient séparer, lorsqu'un Dieu bienfaisant m'appelle à mon premier état. Je reprends 
ma trousse et mon cuir anglais ${ }^{1}$; puis, laissant la fumée aux sots qui s'en nourrissent, et la honte au milieu du chemin, comme trop lourde à un piéton, je vais rasant de ville en ville, et je vis enfin sans souci. Un grand scigneur passe à Séville; il me reconnaît, je le marie; et, pour prix d'avoir eu par mes soins son épouse, il veut intercepter la mienne! Intrigue, orage à ce sujet. ... O O bizarre suite d'événements ! Comment cela m'est-il arrivé? Pourquoi ces choses et non pas d'autres? Qui les a fixées sur ma tête? Forcé de parcourir la route où je suis entré sans le savoir, comme j'en sortirai sans le vouloir, je l'ai jonchée d'autant de fleurs que ma gaieté me l'a permis: encore je ro dis ma gaieté, sans savoir si elle est à moi plus que le reste, ni même quel est ce moi dont je m'occupe: un assemblage informe de parties inconnues, puis un chétif être imbécile, un petit animal folâtre, un jeune homme ardent au plaisir, ayant tous les goûts pour jouir, faisant tous les métiers pour vivre, maître ici, valet là, selon qu'il plaît ${ }_{1} 5$ à la fortune! ambitieux par vanité, laborieux par nécessité, mais paresseux . . . avec délices! orateur selon le danger, poète par délassement, musicien par occasion, amoureux par folles bouffées ; j'ai tout vu, tout fait, tout usé.

- "Le mariage de Figaro », Act V, scene 3 1 "strop." 


\title{
JACQUES-HENRI BERNARDIN DE SAINT-PIERRE
}

\author{
Le Havre, I 737-I 8 I 4, Éragny
}

Bernardin de Saint-Pierre, by profession an engineer, did a considerable amount of wandering about, professionally and otherwise, through Holland, Germany, Poland, Russia, and the Ile de France, vainly attempting, meanwhile, to find an occasion for the materialization of his fanciful Utopian ideas, and in reality finding nothing but disappointment. Soon after his return to France, in $\mathrm{I} 77 \mathrm{I}$, he made the acquaintance of J.-J. Rousseau, and became one of his most ardent admirers and disciples. In 1773 he published the "Voyage à l'Ile de France," which attracted but little attention. In I 784 appeared the "Etudes de la nature," which brought him fame and led to his appointment, in 1792, as intendant of the Jardin des Plantes, a post which Buffon had held. He became professor at the Ecole Normale in I794, and died in I 8 I 4 .

By far his most popular if not his most significant work is "Paul et Virginie" ( I 788), a charmingly simple love tale whose hero and heroine experience perfect happiness until civilization, the church, and the state disturb their peace. He thus continues in Rousseau's footsteps, believing in the natural goodness of man, and excelled Rousseau in the warmth and variety of coloring, the tropical luxuriance, which he gave his landscapes. Rousseau gives us the sentiment of nature, Bernardin de Saint-Pierre the sensation.

Mention should also be made of the "Chaumière indienne" (I79I) and the "Harmonies de la nature" (1796).

\section{LES NUAGES}

Dans une belle nuit d'été, quand le ciel est serein, et chargé seulement de quelques vapeurs légères propres à arrêter et à réfrảnger ${ }^{1}$ les rayons du soleil lorsqu'ils traversent les extrémités de notre atmosphère, transportez-vous dans une campagne d'où l'on puisse aperce5 voir les premiers feux de l'aurore. Vous verrez d'abord blanchir, à l'horizon, le lieu où elle doit paraitre; et cette espèce d'auréole lui a fait donner, à cause de sa couleur, le nom d'aube, du mot latin alba, qui veut dire blanche. Cette blancheur monte insensiblement au ciel, et se teint en jaune à quelques degrés au-dessus de l'horizon; le jaune, Io en s'élevant à quelques degrés plus haut, passe à l'orangé; et cette

1 "refract." 
nuance d'orangé s'élève au-dessus en vermillon vif qui s'étend jusqu'au zénith. De ce point, vous apercevez au ciel, derrière vous, le violet à la suite du vermillon, puis l'azur, ensuite le gros bleu ou indigo, et enfin le noir tout à fait à l'occident.

Quoique ce développement de couleurs présente une multitude infinie de nuances intermédiaires qui se succèdent assez rapidement, cependant il y a un moment, et, si je me le rappelle bien, c'est celui où le soleil est près de montrer son disque, où le blanc éblouissant se fait voir à l'horizon; le jaune pur, à quarante-cinq degrés d'élévation; la couleur de feu, au zénith; à quarante-cinq degrés au-dessous, vers ro l'occident, le bleu pur; et à l'occident même, le voile sombre de la nuit qui touche encore l'horizon. Du moins j'ai cru remarquer cette progression entre les tropiques, où il n'y a presque pas de réfraction horizontale qui fasse anticiper la lumière sur les ténèbres, comme dans nos climats.

J.-J. Rousseau me disait un jour que, quoique le champ de ces couleurs célestes soit le bleu, les teintes du jaune qui se fondent avec lui n'y produisent point la couleur verte, comme il arrive dans nos couleurs matérielles, lorsqu'on mêle ces deux nuances ensemble. Mais je lui répondis que j'avais aperçu plusieurs fois du vert au ciel, non seu- 20 lement entre les tropiques, mais sur l'horizon de Paris. A la vérité cette couleur ne se voit guère ici que dans quelque belle soirée d'été. J'ai aperçu aussi dans les nuages des tropiques, principalement sur la mer et dans les tempêtes, toutes les couleurs qu'on peut voir sur la terre. Il y en a alors de cuivrées, de couleur de fumée de pipe, de 25 brunes, de rousses, de noires, de grises, de livides, de couleur marron, et de celle de gueule de four enflammé. Quant à celles qui y paraissent dans les jours sereins, il y en a de si vives et de si éclatantes, qu'on n'en verra jamais de semblables dans aucun palais, quand on y rassemblerait toutes les pierreries du Mogol. Quelquefois les vents alizés du 30 nord-est ou du sud-est, qui y soufflent constamment, cardent les nuages comme si c'étaient des flocons de soie; puis ils les chassent à l'occident, en les croisant les uns sur les autres comme les mailles d'un panier à jour. Ils jettent, sur les côtés de ce réseau, les nuages qu'ils n'ont pas employés, et qui ne sont pas en petit nombre ; ils les roulent 35 en énormes masses blanches comme la neige, les contournent sur leurs bords en forme de croupes, et les entassent les uns sur les autres comme les Cordillères du Pérou, en leur donnant des formes de montagnes, de cavernes et de rochers ; ensuite, vers le soir, ils calmissent 
un peu, comme s'ils craignaient de déranger leur ouvrage. Quand le soleil vient à descendre derrière ce magnifique réseau, on voit passer par tous ses losanges une multitude de rayons lumineux qui y font un tel effet que les deux côtés de chaque losange qui en sont éclairés 5 paraissent relevés d'un filet d'or, et les deux autres, qui devraient être dans l'ombre, sont teints d'un superbe nacarat. Quatre ou cinq gerbes de lumière, qui s'élèvent du soleil couchant jusqu'au zénith, bordent de franges d'or les sommets indécis de cette barrière céleste, et vont frapper des reflets de leurs feux les pyramides des montagnes aériennes ıo collatérales, qui semblent alors être d'argent et de vermillon. C'est dans ce moment qu'on aperçoit, au milieu de leurs croupes redoublées, une multitude de vallons qui s'étendent à l'infini, en se distinguant à leur ouverture par quelque nuance de couleur de chair ou de rose. Ces vallons célestes présentent, dans leurs divers contours, des teintes iniI 5 mitables de blanc, qui fuient à perte de vue dans le blanc, ou des ombres qui se prolongent, sans se confondre, sur d'autres ombres. Vous voyez çà et là sortir des flancs caverneux de ces montagnes, des fleuves de lumière qui se précipitent en lingots d'or et d'argent sur des rochers de corail. Ici, ce sont de sombres rochers, percés à jour, qui 2o laissent apercevoir par leurs ouvertures le bleu pur du firmament; là, ce sont de longues grèves sablées d'or, qui s'étendent sur de riches fonds du ciel, ponceaux, écarlates, et verts comme l'émeraude. La réverbération de ces couleurs occidentales se répand sur la mer, dont elle glace les flots azurés de safran et de pourpre. Les matelots,

25 appuyés sur les passavants du navire, admirent en silence ces paysages aériens. Quelquefois ce spectacle sublime se présente à eux à l'heure de la prière, et semble les inviter à élever leurs cœurs comme leurs vœux vers les cieux. Il change à chaque instant: bientôt ce qui était lumineux est simplement coloré; et ce qui était coloré est dans 30 l'ombre. Les formes en sont aussi variables que les nuances; ce sont tour à tour des îles, des hameaux, des collines plantées de palmiers, de grands ponts qui traversent des fleuves, des campagnes d'or, d'améthystes, de rubis, ou plutôt ce n'est rien de tout cela; ce sont des couleurs et des formes célestes qu'aucun pinceau ne peut rendre, ni 35 aucune langue exprimer. . . .

Ces concerts admirables de lumières et de formes, qui ne se manifestent que dans la partie inférieure des nuages, la moins éclairée du soleil, sont produits par des lois qui me sont tout à fait inconnues. Mais quelle que soit leur variété, elles s'y réduisent à cinq couleurs ; 
le jaune y paraît une génération du blanc, le rouge une nuance plus foncée du jaune, le bleu une teinte de rouge plus renforcée, et le noir la dernière teinte du bleu. On ne peut douter de cette progression, lorsqu'on observe, le matin, comme je l'ai dit, le développement de la lumière dans les cieux; vous y voyez ces cinq couleurs, avec leurs nuances intermédiaires, s'engendrer les unes des autres à peu près dans cet ordre: le blanc, le jaune soufre, le jaune citron, le jaune d'œuf, l'orangé, la couleur aurore, le ponceau, le rouge plein, le rouge carminé, le pourpre, le violet, l'azur, l'indigo et le noir. Chacune de ces couleurs ne semble être qu'une teinte forte de celle qui la précède, ro et une teinte légère de celle qui la suit; en sorte que toutẹs ensemble ne paraissent que des modulations d'une progression dont le blanc est le premier terme, et le noir le dernier.

— "Etudes de la nature », $\mathrm{X}^{\mathrm{e}}$ Etude

\section{LE NAUFRAGE DU SAINT-GERAN}

Depuis le moment où le Saint-Géran ${ }^{1}$ aperçut que nous étions à portée de le secourir il ne cessa de tirer du canon de trois minutes en ${ }_{1} 5$ trois minutes. M. de La Bourdonnaye fit allumer de grands feux de distance en distance sur la grève, et envoya chez tous les habitants du voisinage chercher des vivres, des planches, des câbles et des tonneaux vides. On en vit arriver bientôt une foule, accompagnés de leurs noirs, chargés de provisions et d'agrès, qui venaient des habitations de la 20 Poudre-d'Or, du quartier de Flacque et de la rivière du Rempart. Un des plus anciens de ces habitants s'approcha du gouverneur, et lui dit : "Monsieur, on a entendu, toute la nuit, des bruits sourds dans la montagne; dans les bois les feuilles des arbres remuent sans qu'il fasse du vent; les oiseaux de marine se réfugient à terre: certaine- 25 ment tous ces signes annoncent un ouragan. - Eh bien! mes amis, répondit le gouverneur, nous y sommes préparés, et sûrement le vaisseau l'est aussi. »

En effet, tout présageait l'arrivée prochaine d'un ouragan. Les nuages qu'on distinguait au zénith étaient, à leur centre, d'un noir 30 affreux, et cuivrés sur leurs bords. L'air retentissait des cris des pailleen-cul, ${ }^{2}$ des frégates, des coupeurs-d'eau et d'une multitude d'oiseaux

1 Paul has received news that Virginia is on the Saint-Géran just arriving from France. He goes to welcome her, but a hurricane comes on, and the ship, close in to shore, is in great danger. M. de La Bourdonnaye, governor of the island, has come to render all possible assistance. 
de marine, qui, malgré l'obscurité de l'atmosphère, venaient de tous les points de l'horizon chercher des retraites dans l'île.

Vers les neuf heures du matin, on entendit du côté de la mer des bruits épouvantables, comme si des torrents d'eau, mêlés à des ton5 nerres, eussent roulé du haut des montagnes. Tout le monde s'écria: "Voilà l'ouragan!), et dans l'instant un tourbillon affreux de vent enleva la brume qui couvrait l'île d'Ambre et son canal. Le SaintGéran parut alors à découvert, avec son pont chargé de monde, ses vergues et ses mâts de hune amenés sur le tillac, son pavillon en Io berne, quatre câbles sur son avant, et un de retenu sur son arrière. Il était mouillé. entre l'île d'Ambre et la terre, en deçà de la ceinture de récifs qui entoure l'île de France, et qu'il avait franchie par un endroit où jamais vaisseau n'avait passé avant lui. Il présentait son avant aux flots qui venaient de la pleine mer, et à chaque lame d'eau qui s'engaI 5 geait dans le canal, sa proue se soulevait tout entière, de sorte qu'on en voyait la carène en l'air ; mais, dans ce mouvement, sa poupe venant à plonger, disparaissait à la vue jusqu'au couronnement, comme si elle eût été submergée. Dans cette position, où le vent et la mer le jetaient à terre, il lui était également impossible de s'en aller par où

20 il était venu, ou, en coupant ses câbles, d'échouer sur le rivage, dont il était séparé par de hauts fonds semés de récifs. Chaque lame qui venait briser sur la côte s'avançait en mugissant jusqu'au fond des anses, et y jetait des galets à plus de cinquante pieds dans les terres ; puis, venant à se retirer, elle découvrait une grande partie du lit du 25 rivage, dont elle roulait les cailloux avec un bruit rauque et affreux. La mer, soulevée par le vent, grossissait à chaque instant, et tout le canal compris entre cette île et l'île d'Ambre n'était qu'une vaste nappe d'écumes blanches, creusée de vagues profondes. Ces écumes s'amassaient dans le fond des anses à plus de six pieds de hauteur, et le vent, 30 qui en balayait la surface, les portait par-dessus l'escarpement du rivage à plus d'une demi-lieue dans les terres. A leurs flocons blancs et innombrables qui étaient chassés horizontalement jusqu'au pied des montagnes, on eût dit d'une neige qui sortait de la mer. L'horizon offrait tous les signes d'une longue tempête; la mer y paraissait con35 fondue avec le ciel. Il s'en détachait sans cesse des nuages d'une forme horrible, qui traversaient le zénith avec la vitesse des oiseaux, tandis que d'autres y paraissaient immobiles comme de grands rochers. On n'apercevait aucune partie azurée du firmament; une lueur olivâtre et blafarde éclairait seule tous les objets de la terre, de la mer et des cieux. 
Dans les balancements du vaisseau, ce qu'on craignait arriva. Les câbles de son avant rompirent, et, comme il n'était plus retenu que par une seule ansière, il fut jeté sur les rochers à une demi-encâblure du rivage. Ce ne fut qu'un cri de douleur parmi nous. Paul allait s'élancer à la mer, lorsque je le saisis par le bras: "Mon fils, lui dis-je, 5 voulez-vous périr? —Que j'aille à son secours, s'écria-t-il, ou que je meure ! » Comme le désespoir lui ôtait la raison, pour prévenir sa perte, Domingue et moi lui attachâmes à la ceinture une longue corde dont nous saisîmes l'une des extrémités. Paul alors s'avança vers le Saint-Géran, tantôt nageant, tantôt marchant sur les récifs. Quelque- so fois il avait l'espoir de l'aborder, car la mer, dans ses mouvements irréguliers, laissait le vaisseau presque à sec, de manière qu'on eût pu en faire le tour à pied; mais bientôt après, revenant sur ses pas avec une nouvelle furie, elle le couvrait d'énormes voûtes d'eau qui soulevaient tout l'avant de sa carène, et rejetaient bien loin sur le rivage le ${ }_{5} 5$ malheureux Paul, les jambes en sang, la poitrine meurtrie, et à demi noyé. A peine ce jeune homme avait-il repris l'usage de ses sens, qu'il se relevait et retournait avec une nouvelle ardeur vers le vaisseau, que la mer cependant entr'ouvrait par d'horribles secousses. Tout l'équipage, désespérant alors de son salut, se précipitait en foule à la mer, 20 sur des vergues, des planches, des cages à poules, des tables et des tonneaux. On vit alors un objet digne d'une éternelle pitié : une jeune demoiselle parut dans la galerie de la poupe du Sizint-Géran, tendant les bras vers celui qui faisait tant d'efforts pour la joindre. C'était Virginie. Elle avait reconnu son amant à son intrépidité. La vue de 25 cette aimable personne, exposée à un si terrible danger, nous remplit de douleur et de désespoir. Pour Virginie, d'un port noble et assuré, elle nous faisait signe de la main, comme nous disant un éternel adieu. Tous les matelots s'étaient jetés à la mer. Il n'en restait plus qu'un sur le pont, qui était nerveux comme Hercule. .. . On entendit aussitôt 30 ces cris redoublés des spectateurs : " Sauvez-la, sauvez-la, ne la quittez pas!» Mais, dans ce moment, une montagne d'eau d'une effroyable grandeur s'engouffra entre l'île d'Ambre et la côte, et s'avança en rugissant vers le vaisseau, qu'elle menaçait de ses flancs noirs et de ses sommets écumants.

A cette terrible vue, le matelot s'élança seul à la mer; et Virginie, voyant la mort inévitable, posa une main sur son cœur, et, levant en haut des yeux sereins, parut un ange qui prend son vol vers les cieux. 
O jour affreux! hélas! tout fut englouti. La lame jeta bien avant dans les terres une partie des spectateurs qu'un mouvement d'humanité avait portés à s'avancer vers Virginie, ainsi que le matelot qui l'avait voulu sauver à la nage. Cet homme, échappé à une mort cer5 taine, s'agenouilla sur le sable, en disant: " $O$ mon Dieu! vous m'avez sauvé la vie; mais je l'aurais donnée de bon cœur pour cette digne demoiselle.» Domingue et moi nous retirâmes des flots le malheureux Paul, sans connaissance, rendant le sang par la bouche et par les oreilles. Le gouverneur le fit mettre entre les mains des chirurgiens; 1o et nous cherchâmes de notre côté, le long du rivage, si la mer n'y apportait point le corps de Virginie: mais le vent ayant tourné subitement, comme il arrive dans les ouragans, nous eûmes le chagrin de penser que nous ne pourrions pas même rendre à cette fille infortunée les devoirs de la sépulture.

— "Paul et Virginie » 


\title{
ANDRÉ CHÉNIER
}

\author{
Constantinople, I $762-1794$, Paris
}

André Chénier was born in Constantinople in 1762 , his father being French consul there at that time. When he was four years of age the family moved to France. After completing his studies at the Collège de Navarre, Paris, André served in the army for a few months $(1782-1783)$, and then somewhat later $(1784)$ traveled in Switzerland and Italy. In 1787 he went to England as secretary to the French ambassador, Monsieur de la Luzerne. Soon after the Revolution broke out he returned to Paris, his sympathies being with the revolutionists; but believing in a constitutional monarchy, he shortly became horrified by the spirit of the extremists among the radical party, wrote articles and pamphlets in defense of his position, was arrested as a suspect on March 7, 1794 , and executed on July 25 , two days before the fall of Robespierre would have saved him.

Very little of his poetry appeared during his lifetime (the first edition came out in 1819), though some of it was written before his residence in Switzerland, and enjoyed by a small circle of friends. In addition to the short poems (eclogues, idyls, elegies, etc.) of classical style, on which his fame largely rests, and the political poems (odes and iambics), written during the last four years of his life and containing some of his best verses, he planned and in part wrote some long didactic and philosophical poems ("Amérique," "Hermès") after the spirit of the encyclopedists.

His poetry is simple, graceful, and elegant, showing a very decided influence of the Greek masters, whom he learned to love through his mother, who belonged to a cultured Greek family. With him lyric poetry ceased to be the mere plaything, the game, it had been in the eighteenth century, and became the sincere and serious expression of profound personal sentiment, with a slight touch of melancholia and sentimentality, though he was rather Hellenic than Romantic. He made free use of enjambment. "Sur des pensers nouveaux," he said, "faisons des vers antiques." Although cut off almost at the beginning of his career, he stands out as one of the greatest poets of France, certainly as the greatest French poet of the eighteenth century.

\section{LE JEUNE MALADE}

"Apollon, dieu sauveur, dieu des savants mystères, Dieu de la vie, et dieu des plantes salutaires, Dieu vainqueur de Python, ${ }^{1}$ dieu jeune et triomphant,

1 The monstrous hundred-headed serpent killed by Apollo near Delphi. 
Prends pitié de mon fils, de mon unique enfant! Prends pitié de sa mère aux larmes condamnée, Qui ne vit que pour lui, qui meurt abandonnée, Qui n'a pas dû rester pour voir mourir son fils ; Dieu jeune, viens aider sa jeunesse. Assoupis, Assoupis dans son sein cette fièvre brûlante Qui dévore la fleur de sa vie innocente. Apollon, si jamais, échappé du tombeau, Il retourne au Ménale ${ }^{1}$ avoir soin du troupeau, Ces mains, ces vieilles mains orneront ta statue De ma coupe d'onyx à tes pieds suspendue; Et, chaque été nouveau, d'un taureau mugissant La hache à ton autel fera couler le sang.

Eh bien! mon fils, es-tu toujours impitoyable?

I5 Ton funeste silence est-il inexorable?

Mon fils, tu veux mourir? Tu veux, dans ses vieux ans,

Laisser ta mère seule avec ses cheveux blancs?

Tu veux que ce soit moi qui ferme ta paupière? Que j'unisse ta cendre à celle de ton père?

C'est toi qui me devais ces soins religieux, Et ma tombe attendait tes pleurs et tes adieux. Parle, parle, mon fils, quel chagrin te consume? Les maux qu'on dissimule en ont plus d'amertume. Ne lèveras-tu point ces yeux appesantis?

- Ma mère, adieu; je meurs, et tu n'as plus de fils. Non, tu n'as plus de fils, ma mère bien-aimée. Je te perds. Une plaie ardente, envenimée, Me ronge; avec effort je respire, et je crois Chaque fois respirer pour la dernière fois.

30 Je ne parlerai pas. Adieu; ce lit me blesse, Ce tapis qui me couvre accable ma faiblesse; Tout me pèse et me lasse. Aide-moi, je me meurs. Tourne-moi sur le flanc. Ah! j'expire! ô douleurs!

- Tiens, mon unique enfant, mon fils, prends ce breuvage, Sa chaleur te rendra ta force et ton courage. La mauve, le dictame ont, avec les pavots, Mêlé leurs sucs puissants qui donnent le repos: Sur le vase bouillant, attendrie à mes larmes, Une Thessalienne a composé des charmes.

1 Mænalus is a mountain in southeastern Arcadia. 
Ton corps débile a vu trois retours du soleil

Sans connaître Cérès, ${ }^{1}$ ni tes yeux le sommeil.

Prends, mon fils, laisse-toi fléchir à ma prière;

C'est ta mère, ta vieille inconsolable mère

Qui pleure; qui jadis te guidait pas à pas,

T'asseyait sur son sein, te portait dans ses bras;

Que tu disais aimer, qui t'apprit à le dire ;

Qui chantait, et souvent te forçait à sourire

Lorsque tes jeunes dents, par de vives douleurs,

De tes yeux enfantins faisaient couler des pleurs.

Tiens, presse de ta lèvre, hélas! pâle et glacée,

Par qui eette mamelle était jadis pressée,

Un suc qui te nourrisse et vienne à ton secours,

Comme autrefois mon lait nourrit tes premiers jours.

- O coteaux d'Erymanthe ! ${ }^{2}$ ô vallons! ô bocage!

$\mathrm{O}$ vent sonore et frais qui troublais le feuillage,

Et faisais frémir l'onde, et sur leur jeune sein

Agitais les replis de leur robe de lin!

De légères beautés troupe agile et dansante. . .

Tu sais, tu sais, ma mère? aux bords de l'Érymanthe.

Là, ni loups ravisseurs, ni serpents, ni poisons . . .

$O$ visage divin! ô fêtes! ô chansons!

Des pas entrelacés, des fleurs, une onde pure,

Aucun lieu n'est si beau dans toute la nature.

Dieux! ces bras et ces fleurs, ces cheveux, ces pieds nus

Si blancs, si délicats! je ne les verrai plus!

Oh! portez, portez-moi sur les bords d'Érymanthe;

Que je la voie encor, cette vierge charmante!

Oh! que je voie au loin la fumée à longs flots

S'élever de ce toit au bord de cet enclos. ...

Assise à tes côtés, ses discours, sa tendresse,

Sa voix, trop heureux père! enchante ta vieillesse.

Dieux! par-dessus la haie élevée en remparts,

Je la vois, à pas lents, en longs cheveux épars,

Seule, sur un tombeau, pensive, inanimée,

S'arrêter et pleurer sa mère bien-aimée.

Oh! que tes yeux sont doux! que ton visage est beau!

Viendras-tu point aussi pleurer sur mon tombeau ?

Viendras-tu point aussi, la plus belle des belles,

Dire sur mon tombeau: Les Parques sont cruelles!

1 Goddess of the harvests, used here in the sense of "bread."

2 Erymanthus is a mountain between Arcadia and Achaia. 
- Ah! mon fils, c'est l'amour! c'est l'amour insensé

Qui t'a jusqu'à ce point cruellement blessé ?

Ah! mon malheureux fils! Oui, faibles que nous sommes,

C'est toujours cet amour qui tourmente les hommes.

S'ils pleurent en secret, qui lira dans leur cœur

Verra que cet amour est toujours leur vainqueur.

Mais, mon fils, mais dis-moi, quelle nymphe charmante,

Quelle vierge as-tu vue au bord de l'Érymanthe ?

N'es-tu pas riche et beau? du moins quand la douleur

N'avait point de ta joue éteint la jeune fleur?

Parle. Est-ce cette Églé, fille du roi des ondes,

Ou cette jeune Irène aux longues tresses blondes?

Ou ne serait-ce point cette fière beauté

Dont j'entends le beau nom chaque jour répété,

Dont j'apprends que partout les belles sont jalouses?

Qu'aux temples, aux festins, les mères, les épouses,

Ne sauraient voir, dit-on, sans peine et sans effroi?

Cette belle Daphné ? . . . - Dieux! ma mère, tais-toi,

Tais-toi. Dieux! qu'as-tu dit ? Elle est fière, inflexible;

Comme les immortels, elle est belle et terrible!

Mille amants l'ont aimée; ils l'ont aimée en vain.

Comme eux j'aurais trouvé quelque refus hautain.

Non, garde que jamais elle soit informée. . . .

Mais, ô mort! ô tourment! ô mère bien-aimée!

$\mathrm{Tu}$ vois dans quels ennuis dépérissent mes jours.

Écoute ma prière et viens à mon secours :

Je meurs; va la trouver: que tes traits, que ton âge,

De sa mère à ses yeux offrent la sainte image.

Tiens, prends cette corbeille et nos fruits les plus beaux;

30 Prends notre Amour d'ivoire, honneur de ces hameaux;

Prends la coupe d'onyx à Corinthe ravie;

Prends mes jeunes chevreaux, prends mon cœur, prends ma vie;

Jette tout à ses pieds; apprends-lui qui je suis ;

Dis-lui que je me meurs, que tu n'as plus de fils.

35 Tombe aux pieds du vieillard, gémis, implore, presse ;

Adjure cieux et mers, dieu, temple, autel, déesse ;

Pars; et si tu reviens sans les avoir fléchis,

Adieu, ma mère, adieu, tu n'auras plus de fils.

- J'aurai toujours un fils; va, la belle espérance

Me dit. . . . » Elle s'incline, et, dans un doux silence,

Elle couvre ce front, terni par les douleurs, 
De baisers maternels entremêlés de pleurs.

Puis elle sort en hâte, inquiète et tremblante, Sa démarche de crainte et d'âge chancelante. Elle arrive; et bientôt revenant sur ses pas, Haletante, de loin: "Mon cher fils, tu vivras, Tu vivras.» Elle vient s'asseoir près de la couche:

Le vieillard la suivait, le sourire à la bouche.

La jeune belle aussi, rouge et le front baissé,

Vient, jette sur le lit un coup d'œil. L'insensé

Tremble; sous ses tapis il veut cacher sa tête.

" Ami, depuis trois jours tu n'es d'aucune fête,

Dit-elle ; que fais-tu? pourquoi veux-tu mourir?

Tu souffres. On me dit que je peux te guérir;

$\mathrm{Vis}$, et formons ensemble une seule famille:

Que mon père ait un fils, et ta mère une fille.»

LES DERNIERS VERS D'ANDRÉ CHÉNIER

Saint-Lazare, ${ }^{1}$

Quelle Thémis ${ }^{2}$ terrible aux têtes criminelles,

Quels pleurs d'une noble pitié,

Des antiques bienfaits quels souvenirs fidèles,

Quels beaux échanges d'amitié

Font digne de regrets l'habitacle des hommes?

La peur blême et louche est leur dieu.

Le désespoir! . . . le fer. Ah! lâches que nous sommes,

Tous, oui, tous. Adieu, terre, adieu.

Vienne, vienne la mort! Que la mort me délivre!

Ainsi donc, mon cœur abattu

Cède au poids de ses maux? Non, non, puissé-je vivre!

Ma vie importe à la vertu;

Car l'honnête homme enfin, victime de l'outrage,

Dans les cachots, près du cercueil,

Relève plus altiers son front et son langage

Brillants d'un généreux orgueil.

S'il est écrit aux cieux que jamais une épée

N'étincellera dans mes mains,

Dans l'encre et l'amertume une autre arme trempée

Peut encor servir les humains.

1 One of the establishments used as a state prison during the Reign of Terror.

2 Goddess of justice. 
Justice, vérité, si ma bouche sincère,

Si mes pensers les plus secrets

Ne froncèrent jamais votre sourcil sévère,

Et si les infâmes progrès,

$\mathrm{Si}$ la risée atroce ou (plus atroce injure !)

L'encens de hideux scélérats

Ont pénétré vos cœurs d'une longue blessure,

Sauvez-moi ; conservez un bras

Qui lance votre foudre, un amant qui vous venge.

Mourir sans vider mon carquois !

Sans percer, sans fouler, sans pétrir dans leur fange

Ces bourreaux barbouilleurs de lois,

Ces tyrans effrontés de la France asservie,

Égorgée!... O mon cher trésor,

O ma plume! Fiel, bile, horreur, dieux de ma vie!

Par vous seuls je respire encor.

Quoi! nul ne restera pour attendrir l'histoire

Sur tant de justes massacrés ; . . .

Pour consoler leurs fils, leurs veuves et leurs mères ;

Pour que des brigands abhorrés

Frémissent aux portraits noirs de leur ressemblance;

Pour descendre jusqu'aux enfers

Chercher le triple fouet, le fouet de la vengeance,

Déjà levé sur ces pervers ;

Pour cracher sur leurs noms, pour chanter leur supplice!

Allons, étouffe tes clameurs ;

Souffre, ô cœur gros de haine, affamé de justice.

Toi, Vertu, pleure si je meurs.

Composé le 7 thermidor 1794 , au matin, peu d'instants avant d'aller au supplice.

Comme un dernier rayon, comme un dernier zéphyre

Animent la fin d'un beau jour,

$\mathrm{Au}$ pied de l'échafaud j'essaye encor ma lyre.

Peut-être est-ce bientôt mon tour;

Peut-être avant que l'heure en cercle promenée

Ait posé sur l'émail brillant,

Dans les soixante pas où sa route est bornée,

Son pied sonore et vigilant, 
Le sommeil du tombeau pressera ma paupière!

Avant que de ses deux moitiés

Ce vers que je commence ait atteint la dernière,

Peut-être en ces murs effrayés

Le messager de mort, noir recruteur des ombres, Escorté d'infâmes soldats,

Remplira de mon nom ces longs corridors sombres ...

— "Iambes" 


\section{MADAME DE STAËL \\ (ANNE-LOUISE-GERMAINE NECKER, BARONNE DE STAËL-HOLSTEIN)}

Paris, I 766-I 8 I 7 , Paris

Anne-Louise-Germaine Necker, only child of an eminent banker, was born in $\mathbf{1} 766$. When a mere child her natural precocity was encouraged by meeting, in her mother's "salon," some of the most distinguished men of her time. Her interests soon led her to literature, one of her first literary attempts being her "Lettres sur les écrits et le caractère de Jean-Jacques Rousseau" (1788), with whom she was infatuated and whose influence went with her through life. At the age of twenty she married the baron de Staël-IIolstein, Swedish ambassador at the French court, the marriage being purely one of convenience. Like Chénier she at first welcomed the Revolution, but later abhorred its horrors. During the Consulate her "salon" became the center of the faction which stood for constitutional monarchy, and Napoleon exiled her from Paris. In the meantime, in 1800 , she had brought out a work in two volumes, entitled "De la littérature considérée dans ses rapports avec les institutions sociales." She next turned to fiction and published her first novel, "Delphine" (1802), which, like the second, "Corinne" ( 1807 ), owes much of its interest to the insight it gives us into the nature of the authoress herself and her views regarding the relation of the individual to society.

After her exile from Paris she visited Germany twice, became acquainted with the Weimar circle, and acquired that intelligent appreciation of German life and literature and history, which enabled her to produce her masterpiece, "De l'Allemagne." The first edition, which appeared in 18 ro, was destroyed by order of Napoleon; the second was published in London in 1813 . Her home meanwhile had been her château at Coppet on Lake Geneva, where, though she was in political disfavor with Napoleon, some of her greatest contemporaries sought her out. In 1812 she left Coppet to visit St. Petersburg, Sweden, and England, but returned to France after the fa!l of Napoleon. She died in 1817 .

Compared to Chateaubriand, Madame de Staël was a thinker, not an artist; and, though of a sentimental disposition, she had great faith in reason. She was cosmopolitan in her interests; in her "De l'Allemagne" she introduced into France new ideas and ideals, a picture of a new literature, - the irregular, subjective literature of the North. She broadened the horizon of France and led the people away from the absolute ideal which Boileau had set up, and which had held good through the eighteenth century; thus she helped to break down dogmatic authority and rule and made way for the free individualism of the Romantic School. 


\section{LES RUINES IDE POMPÉI}

Les ruines de Pompéi sont proches du Vésuve, et c'est par ces ruines que Corinne et lord Nelvil commencèrent leur voyage. IIs étaient silencieux l'un et l'autre; car le moment de la décision de leur sort approchait, et cette vague espérance dont ils avaient joui si longtemps, et qui s'accorde si bien avec l'indolence et la rêverie qu'inspire le climat d'Italie, devait enfin être remplacée par une destinée positive. Ils virent ensemble Pompéi, la ruine la plus curieuse de l'antiquité. A Rome, l'on ne trouve guère que les débris des monuments publics, et ces monuments ne retracent que l'histoire politique des siècles écoulés ; mais à Pompéi, c'est la vie privée des anciens qui s'offre à vous telle ro qu'elle était. Le volcan qui a couvert cette ville de cendres l'a préservée des outrages du temps. Jamais des édifices exposés à l'air ne se seraient ainsi maintenus, et ce souvenir enfoui s'est retrouvé tout entier. Les peintures, les bronzes étaient encore dans leur beauté première, et tout ce qui peut servir aux usages domestiques est conservé d'une 15 manière effrayante. Les amphores sont encore préparées pour le festin du jour suivant; la farine qui allait être pétrie est encore là; les restes d'une femme sont encore ornés des parures qu'elle portait dans le jour de fête que le volcan a troublé, et ses bras desséchés ne remplissent plus le bracelet de pierreries qui les entoure encore. On ne peut voir 20 nulle part une image aussi frappante de l'interruption subite de la vie. Le sillon des roues est visiblement marqué sur les pavés dans les rues, et les pierres qui bordent les puits portent la trace des cordes qui les ont creusées peu à peu. On voit encore sur les murs d'un corps de garde les caractères mal formés, les figures grossièrement esquissées 25 que les soldats traçaient pour passer le temps, tandis que ce temps avançait pour les engloutir.

Quand on se place au milieu du carrefour des rues, d'où l'on voit de tous les côtés la ville qui subsiste encore presque en entier, il semble qu'on attende quelqu'un, que le maître soit prêt à venir; et l'appa- 30 rence même de vie qu'offre ce séjour fait sentir plus tristement son éternel silence. C'est avec des morceaux de lave pétrifiée que sont bâties la plupart de ces maisons qui ont été ensevelies par d'autres laves. Ainsi, ruines sur ruines, et tombeaux sur tombeaux! Cette histoire du monde, où les époques se comptent de débris en débris, 35 cette vie humaine, dont la trace se suit à la lueur des volcans qui l'ont consumée, remplissent le cœur d'une profonde mélancolie. Qu'il y a 
longtemps que l'homme existe! qu'il y a longtemps qu'il vit, qu'il souffre et qu'il périt! Où peut-on retrouver ses sentiments et ses pensées? L'air qu'on respire dans ces ruines en est-il encore empreint, ou sont-elles pour jamais déposées dans le ciel, où règne l'immortalité ?

5 Quelques feuilles brûlées des manuscrits qui ont été trouvés à Herculanum et à Pompéi, et que l'on essaye de dérouler à Portici, sont tout ce qui nous reste pour interpréter les malheureuses victimes que le volcan, la foudre de la terre, a dévorées. Mais, en passant près de ces cendres que l'art parvient à ranimer, on tremble de respirer, de peur qu'un souffle n'enlève cette poussière, où de nobles idées sont peutêtre encore empreintes.

Les édifices publics, dans cette ville même de Pompéi, qui était une des moins grandes d'Italie, sont encore assez beaux. Le luxe des anciens avait presque toujours pour but un objet d'intérêt public.

${ }_{15}$ Leurs maisons particulières sont très petites, et l'on n'y voit point la recherche de la magnificence, mais un goût vif pour les beaux-arts s'y fait remarquer. Presque tout l'intérieur était orné de peintures les plus agréables, et de pavés de mosaïque artistement travaillés. Il y a beaucoup de ces pavés sur lesquels on trouve écrit: Salve (salut). Ce 20 mot est placé sur le seuil de la porte. Ce n'était pas sûrement une simple politesse que ce salut, mais une invocation à l'hospitalité. Les chambres sont singulièrement étroites, peu éclairées, n'ayant jamais de fenêtres sur la rue, et donnant présque toutes sur un portique qui est dans l'intérieur de la maison, ainsi que la cour de marbre qu'il 25 entoure. Au milieu de cette cour est une citerne simplement décorée. Il est évident, par ce genre d'habitation, que les anciens vivaient presque toujours en plein air, et que c'était ainsi qu'ils recevaient leurs amis. Rien ne donne une idée plus douce et plus voluptueuse de l'existence, que ce climat, qui unit intimement l'homme avec la nature. Il

30 semble que le caractère des entretiens et de la société doit être tout autre avec de telles habitudes, que dans les pays où la rigueur du froid force à se renfermer dans les maisons. On comprend mieux les dialogues de Platon, en voyant ces portiques sous lesquels les anciens se promenaient la moitié du jour. Ils étaient sans cesse animés par le 35 spectacle d'un beau ciel : l'ordre social, tel qu'ils le concevaient, n'était point l'aride combinaison du calcul et de la force, mais un heureux ensemble d'institutions qui excitaient les facultés, développaient l'âme, et donnaient à l'homme pour but le perfectionnement de lui-même et de ses semblables. 
L'antiquité inspire une curiosité insatiable. Les érudits qui s'occupent seulement à recueillir une collection de noms qu'ils appellent l'histoire, sont sûrement dépourvus de toute imagination. Mais pénétrer dans le passé, interroger le cœur humain à travers les siècles, saisir un fait par un mot, et le caractère et les mœurs d'une nation par un fait; enfin remonter jusqu'aux temps les plus reculés, pour tâcher de se figurer comment la terre, dans sa première jeunesse, apparaissait aux regards des hommes, et de quelle manière ils supportaient alors ce don de la vie, que la civilisation a tant compliqué maintenant; c'est un effort continuel de l'imagination, qui devine et découvre les so plus beaux secrets que la réflexion et l'étude puissent nous révéler. Ce genre d'intérêt et d'occupation attirait singulièrement Oswald, et il répétait souvent à Corinne que, s'il n'avait pas eu dans son pays de nobles intérêts à servir, il n'aurait trouvé la vie supportable que dans les contrées où les monuments de l'histoire tiennent lieu de l'existence 15 présente. Il faut au moins regretter la gloire, quand il n'est plus possible de l'obtenir. C'est l'oubli seul qui dégrade l'âme; mais elle peut trouver un asile dans le passé, quand d'arides circonstances privent les actions de leur but.

En sortant de Pompéi et repassant à Portici, Corinne et lord Nelvil 20 furent bientôt entourés par les habitants, qui les engageaient à grands cris à venir voir la montagne; c'est ainsi qu'ils appellent le Vésuve. A-t-il besoin d'être nommé? Il est pour les Napolitains la gloire et la patrie; leur pays est signalé par cette merveille. Oswald voulut que Corinne fût portée sur une espèce de palanquin jusqu'à l'ermitage de 25 Saint-Salvador, qui est à moitié chemin de la montagne, et où les voyageurs se reposent avant d'entreprendre de gravir sur le sommet. Il allait à cheval à côté d'elle, pour surveiller ceux qui la portaient; et plus son cœur était rempli par les généreuses pensées qu'inspirent la nature et l'histoire, plus il adorait Corinne.

Au pied du Vésuve, la campagne est la plus fertile et la mieux cultivée que l'on puisse trouver dans le royaume de Naples, c'est-à-dire dans la contrée de l'Europe la plus favorisée du ciel. La vigne célèbre dont le vin est appelé lacryma Christi, se trouve dans cet endroit, et tout à côté des terres dévastées par la lave. On dirait que la nature a 35 fait un dernier effort en ce lieu voisin du volcan, et s'est parée de ses plus beaux dons avant de périr. A mesure que l'on s'élève on découvre, en se retournant, Naples et l'admirable pays qui l'environne. Les rayons du soleil font scintiller la mer comme des pierres précieuses; 
mais toute la splendeur de la création s'éteint par degrés, jusqu'à la terre de cendre et de fumée qui annonce l'approche du volcan. Les laves ferrugineuses des années précédentes tracent sur le sol leur large et noir sillon, et tout est aride autour d'elles. A une certaine hauteur 5 les oiseaux ne volent plus, à telle autre les plantes deviennent très rares, puis les insectes même ne trouvent plus rien pour subsister dans cette nature consumée. Enfin tout ce qui a vie disparaît; vous entrez dans l'empire de la mort, et la cendre de cette terre pulvérisée roule seule sous vos pieds mal affermis.

Nè greggi nè armenti

Guida bifolco mai, guida pastore.

Jamais le berger ni le pasteur ne conduisent en ce lieu ni leurs brebis ni leurs troupeaux.

Un ermite habite là, sur les confins de la vie et de la mort. Un I 5 arbre, le dernier adieu de la végétation, est devant sa porte; et c'est à l'ombre de son pâle feuillage que les voyageurs ont coutume d'attendre que la nuit vienne, pour continuer leur route; car pendant le jour les feux du Vésuve ne s'aperçoivent que comme un nuage de fumée, et la lave, si ardente de nuit, paraît sombre à la clarté du 20 soleil. Cette métamorphose elle-même est un beau spectacle, qui renouvelle chaque soir l'étonnement que la continuité du même aspect pourrait affaiblir. L'impression de ce lieu, sa solitude profonde, donnèrent à lord Nelvil plus de force pour révéler ses secrets sentiments ; et, désirant encourager la confiance de Corinne, il consentit à lui par25 ler, et lui dit avec une vive émotion : - Vous voulez lire jusqu'au fond de l'âme de votre malheureux ami: eh bien! je vous avouerai tout: mes blessures vont se rouvrir, je le sens ; mais, en présence de cette nature immuable, faut-il donc avoir tant de peur des souffrances que le temps entraîne avec lui ?

- "Corinne ", Book XI, chap. 4

\section{DE L'ESPRIT DE CONVERSATION}

30 En Orient, quand on n'a rien à se dire, on fume du tabac de rose ensemble, et de temps en temps on se salue les bras croisés sur la poitrine, pour se donner un témoignage d'amitié; mais dans l'Occident on a voulu se parler tout le jour, et le foyer de l'âme s'est souvent dissipé dans ces entretiens où l'amour-propre est sans cesse en mouve35 ment pour faire effet tout de suite, et selon le goût du moment et du cercle où l'on se trouve. 
Il me semble reconnu que Paris est la ville du monde où l'esprit et le goût de la conversation sont le plus généralement répandus; et ce qu'on appelle le mal du pays, ce regret indéfinissable de la patrie, qui est indépendant des amis même qu'on y a laissés, s'applique particulièrement à ce plaisir de causer, que les Français ne retrouvent nulle part au même degré que chez eux. Volney raconte ${ }^{1}$ que des Français émigrés voulaient, pendant la révolution, établir une colonie et défricher des terres en Amérique; mais de temps en temps ils quittaient toutes leurs occupations pour aller, disaient-ils, causer à la ville; et cette ville, la Nouvelle-Orléans, était à six cents lieues de leur demeure. 1o Dans toutes les classes, en France, on sent le besoin de causer : la parole n'y est pas seulement, comme ailleurs, un moyen de se communiquer ses idées, ses sentiments et ses affaires, mais c'est un instrument dont on aime à jouer, et qui ranime les esprits, comme la musique chez quelques peuples, et les liqueurs fortes chez quelques autres.

Le genre de bien-être que fait éprouver une conversation animée, ne consiste pas précisément dans le sujet de cette conversation; les idées ni les connaissances qu'on peut y développer n'en sont pas le principal intérêt; c'est une certaine manière d'agir les uns sur les autres, de se faire plaisir réciproquement et avec rapidité, de parler 20 aussitôt qu'on pense, de jouir à l'instant de soi-même, d'être applaudi sans travail, de manifester son esprit dans toutes les nuances par l'accent, le geste, le regard, enfin de produire à volonté comme une sorte d'électricité qui fait jaillir des étincelles, soulage les uns de l'excès même de leur vivacité, et réveille les autres d'une apathie pénible. . . 25

Le cours des idées, depuis un siècle, a été tout à fait dirigé par la conversation. On pensait pour parler, on parlait pour être applaudi, et tout ce qui ne pouvait pas se dire semblait être de trop dans l'âme. C'est une disposition très agréable que le désir de plaire; mais elle diffère pourtant beaucoup du besoin d'être aimé : le désir de plaire 30 rend dépendant de l'opinion, le besoin d'être aimé en affranchit: on pourrait désirer de plaire à ceux même à qui l'on ferait beaucoup de mal, et c'est précisément ce qu'on appelle de la coquetterie; cette coquetterie n'appartient pas exclusivement aux femmes; il y en a dans toutes les manières qui servent à témoigner plus d'affection 35 qu'on n'en éprouve réellement. La loyauté des Allemands ne leur permet rien de semblable; ils prennent la grâce au pied de la lettre,

1 " De la colonie du Poste-Vincennes sur la Wabash," Article IV. Volney (1757-1820) visited America in 1795 . 
ils considèrent le charme de l'expression comme un engagement pour la conduite, et de là vient leur susceptibilité ; car ils n'entendent pas un mot sans en tirer une conséquence, et ne conçoivent pas qu'on puisse traiter la parole en art libéral, qui n'a ni but ni résultat si ce 5 n'est le plaisir qu'on y trouve. L'esprit de conversation a quelquefois l'inconvénient d'altérer la sincérité du caractère; ce n'est pas une tromperie combinée, mais improvisée, si l'on peut s'exprimer ainsi. Les Français ont mis dans ce genre une gaieté qui les rend aimables, mais il n'en est pas moins certain que ce qu'il y a de plus sacré dans Io ce monde a été ébranlé par la grâce, du moins par celle qui n'attache de l'importance à rien, et tourne tout en ridicule.

Les bons mots des Français ont été cités d'un bout de l'Europe à l'autre; de tout temps ils ont montré leur brillante valeur, et soulagé leurs chagrins d'une façon vive et piquante; de tout temps ils ont eu I 5 besoin les uns des autres, comme d'auditeurs alternatifs qui s'encourageaient mutuellement; de tout temps ils ont excellé dans l'art de ce qu'il faut dire, et même de ce qu'il faut taire, quand un grand intérêt l'emporte sur leur vivacité naturelle; de tout temps ils ont eu le talent de vivre vite, d'abréger les longs discours, de faire place aux succes20 seurs avides de parler à leur tour; de tout temps, enfin, ils ont su ne prendre du sentiment et de la pensée que ce qu'il en faut pour animer l'entretien, sans lasser le frivole intérêt qu'on a d'ordinaire les uns pour les autres.

Les Français parlent toujours légèrement de leurs malheurs, dans 25 la crainte d'ennuyer leurs amis ; ils devinent la fatigue qu'ils pourraient causer, par celle dont ils seraient susceptibles: ils se hâtent de montrer élégamment de l'insouciance pour leur propre sort, afin d'en avoir l'honneur au lieu d'en recevoir l'exemple. Le désir de paraitre aimable conseille de prendre une expression de gaieté, quelle que soit la dispo30 sition intérieure de l'âme; la physionomie influe par degrés sur ce qu'on éprouve, et ce qu'on fait pour plaire aux autres émousse bientôt en soi-même ce qu'on ressent.

Une femme d'esprit a dit que Paris était le lieu du monde où l'on pouvait le mieux se passer de bonheur: c'est sous ce rapport qu'il con35 vient si bien à la pauvre espèce humaine; mais rien ne saurait faire qu'une ville d'Allemagne devînt Paris, ni que les Allemands pussent, sans se gâter entièrement, recevoir comme nous le bienfait de la distraction. A force de s'échapper à eux-mêmes ils finiraient par ne plus se retrouver. 
Le talent et l'habitude de la société servent beaucoup à faire connaitre les hommes: pour réussir en parlant, il faut observer avec perspicacité l'impression qu'on produit à chaque instant sur cux, celle qu'ils veulent nous cacher, celle qu'ils cherchent à nous exagérer, la satisfaction contenue des uns, le sourire forcé des autres; on voit passer sur le front de ceux qui nous écoutent des blâmes à demi formés, qu'on peut éviter en se hâtant de les dissiper avant que l'amourpropre y soit engagé. L'on y voit naitre aussi l'approbation qu'il faut fortifier, sans cependant exiger d'elle plus qu'elle ne veut donner. Il n'est point d'arène où la vanité se montre sous des formes plus variées io que dans la conversation.

J'ai connu un homme que les louanges agitaient au point que, quand on lui en donnait, il exagérait ce qu'il venait de dire, et s'efforçait tellement d'ajouter à son succès, qu'il finissait toujours par le perdre. Je n'osais pas l'applaudir, de peur de le porter à l'affectation, et qu'il ne $\mathrm{I}_{5}$ se rendît ridicule par le bon cœur de son amour-propre. Un autre craignait tellement d'avoir l'air de désirer de faire effet, qu'il laissait tomber ses paroles négligemment et dédaigneusement. Sa feinte indolence trahissait seulement une prétention de plus, celle de n'en point avoir. Quand la vanité se montre, elle est bienveillante; quand elle 20 se cache, la crainte d'être découverte la rend amère, et elle affecte l'indifférence, la satiété, enfin tout ce qui peut persuader aux autres qu'elle n'a pas besoin d'eux. Ces différentes combinaisons sont amusantes pour l'observateur, et l'on s'étonne toujours que l'amour-propre ne prenne pas la route si simple d'avouer naturellement le désir de 25 plaire, et d'employer autant qu'il est possible la grâce et la vérité pour y parvenir.

Le tact qu'exige la société, le besoin qu'elle donne de se mettre à la portée des différents esprits, tout ce travail de la pensée, dans ses rapports avec les hommes, serait certainement utile, à beaucoup 30 d'égards, aux Allemands, en leur donnant plus de mesure, de finesse et d'habileté ; mais dans ce talent de causer, il y a une sorte d'adresse qui fait perdre toujours quelque chose à l'inflexibilité de la morale: si l'on pouvait se passer de tout ce qui tient à l'art de ménager les hommes, le caractère en aurait sûrement plus de grandeur et d'énergie. 35

— "De l'Allemagne », Book I, chap. I I 


\section{FRANÇOIS-RENÉ DE CHATEAUBRIAND \\ Saint-Malo, 1768 - 1848 , Paris}

François-René de Chateaubriand, of an ancient but poverty-stricken family of Brittany, the youngest of a family of ten children, was born at Saint-Malo in 1768 . His education was not thorough, his youth being more or less idly spent among the fisherfolk of his birthplace. It was first planned that he should enter the navy, but not receiving an appointment, he served for a time in the army, and then, in the spring of 1791 , sailed for America. Being always a fanciful dreamer, he apparently had some thought of seeking the Northwest Passage, but he soon gave up what little idea he may ever have had of such a quest and was back in France before the expiration of nine months. After his return he married, joined the "émigrés," was wounded at Thionville, escaped to England, and there, for part of his seven years' stay, suffered extreme poverty. During his residence in England he wrote the "Essai sur les révolutions" ( 1797 ), in which he showed a skepticism which he refuted, later on, in the "Génie du christianisme" (1802). Before this date he had returned to France (1800), and had published "Atala" (180r), an Indian love tale drawn from the rich fund of impressions received in America. In the "Génie" Chateaubriand champions the Christian religion as the most poetical of all religions, the most favorable to the arts and letters, and the one to which the modern world owes most. Appearing at a time when Napoleon was seeking to reëstablish Catholic worship, the "Génie" was well received in spite of the weakness of its proofs.

Napoleon appointed Chateaubriand secretary to the embassy at Rome, then ambassador to the Valais, a post which Chateaubriand indignantly resigned after the assassination of the duc d'Enghien (1804). In 1806 Chateaubriand started for a year's trip through the Orient and back to France through Spain, gaining impressions for the "Martyrs" (1809), a prose epic treating of the persecutions of the Christians in the time of Diocletian, and exemplifying the doctrines advocated in the "Génie." The account of his travels appeared in the "Itinéraire de Paris à Jérusalem" in I $8 \mathrm{Ir}$. In this same year he was elected to the Academy, though, for political reasons, Napoleon did not allow him to read his inaugural address.

Under the Restoration he became a prominent political figure, but retired from politics after the July Revolution, and wrote the "Mémoires d'outretombe," in which, among pages of remarkable excellence, his extreme egotism appears.

The "Génie du christianisme" exposed the ideas which mark the beginning of a new era. Christian, national, and medieval subjects were to take the place of pagan, mythological, and ancient subjects. With Chateaubriand art became personal, imaginative, emotional. A disciple of Rousseau 
and Bernardin de Saint-Pierre, he depicts idyllic love in the wilds of the New World ("Atala"), and reveals the innermost melancholy emotions of his own heart ("René "), and thus leads up to the lyric outburst of the Romantic School.

\section{LE MÉSCHACEBÉ}

Ce dernier fleuve (le Méschacebé), dans un cours de plus de mille lieues, arrose une délicieuse contrée que les habitants des Etats-Unis appellent le Nouvel Éden, et à laquelle les Français ont laissé le doux nom de Louisiane. Mille autres fleuves, tributaires du Méschacebé, le Missouri, l'Illinois, l'Akanza, l'Ohio, le Wabache, le Tenase, l'engraissent de leur limon et la fertilisent de leurs eaux. Quand tous ces fleuves se sont gonflés des déluges de l'hiver, quand les tempêtes ont abattu des pans entiers de forêts, les arbres déracinés s'assemblent sur les sources. Bientôt la vase les cimente, les lianes les enchaînent, et les plantes, y prenant racine de toutes parts, achèvent de consolider io ces débris. Charriés par les vagues écumantes, ils descendent au Méschacebé; le fleuve s'en empare, les pousse au golfe Mexicain, les échoue sur des bancs de sable, et accroît ainsi le nombre de ses embouchures. Par intervalle, il élève sa voix en passant sur les monts, et répand ses eaux débordées autour des colonnades des forêts et des 15 pyramides des tombeaux indiens; c'est le Nil des déserts. Mais la grâce est toujours unie à la magnificence dans les scènes de la nature ; tandis que le courant du milieu entraine vers la mer les cadavres des pins et des chênes, on voit sur les deux courants latéraux remonter, le long des rivages, des îles flottantes de pistia ${ }^{1}$ et de nénuphar, dont 20 les roses jaunes s'élèvent comme de petits pavillons. Des serpents verts, des hérons bleus, des flamants roses, de jeunes crocodiles, s'embarquent passagers sur ces vaisseaux de fleurs ; et la colonie, déployant aux vents ses voiles d'or, va aborder endormie dans quelque anse retirée du fleuve.

Les deux rives du Méschacebé présentent le tableau le plus extraordinaire. Sur le bord occidental, des savanes se déroulent à perte de vue; leurs flots de verdure, en s'éloignant, semblent monter dans l'azur du ciel, où ils s'évanouissent. On voit dans ces prairies sans bornes errer à l'aventure des troupeaux de trois ou quatre mille buffles 30 sauvages. Quelquefois un bison chargé d'années, fendant les flots à la nage, se vient coucher, parmi de hautes herbes, dans une île du

1 "tropical duckweed" or "floating lettuce." 
Méschacebé. A son front orné de deux croissants, ${ }^{1}$ à sa barbe antique et limoneuse, vous le prendriez pour le dieu du fleuve, qui jette un œil satisfait sur la grandeur de ses ondes et la sauvage abondance de ses rives.

5 Telle est la scène sur le bord occidental; mais elle change sur le bord opposé, et forme avec la première un admirable contraste. Suspendus sur le cours des eaux, groupés sur les rochers et sur les montagnes, dispersés dans les vallées, des arbres de toutes les formes, de toutes les couleurs, de tous les parfums, se mêlent, croissent ensemble, Io montent dans les airs à des hauteurs qui fatiguent les regards. Les vignes sauvages, les bignonias, les coloquintes, s'entrelacent au pied de ces arbres, escaladent leurs rameaux, grimpent à l'extrémité des branches, s'élancent de l'érable au tulipier, du tulipier à l'alcée, en formant mille grottes, mille voûtes, mille portiques. Souvent, égarées

I 5 d'arbre en arbre, ces lianes traversent des bras de rivière, sur lesquels elles jettent des ponts de fleurs. Du sein de ces massifs, le magnolia élève son cône immobile; surmonté de ses larges roses blanches, il domine toute la forêt, et n'a d'autre rival que le palmier, qui balance légèrement auprès de lui ses éventails de verdure.

20 Une multitude d'animaux placés dans ces retraites par la main du Créateur y répandent l'enchantement et la vie. De l'extrémité des avenues on aperçoit des ours enivrés de raisin qui chancellent sur les branches des ormeaux; des cariboux se baignent dans un lac; des écureuils noirs se jouent dans l'épaisseur des feuillages, des oiseaux-

25 moqueurs, des colombes de Virginie, de la grosseur d'un passereau, descendent sur les gazons rougis par les fraises; des perroquets verts à la tête jaune, des piverts empourprés, des cardinaux de feu, grimpent en circulant au haut des cyprès; des colibris étincellent sur le jasmin des Florides, et des serpents oiseleurs sifflent suspendus aux dômes 30 des bois, en s'y balançant comme des lianes.

Si tout est silence et repos dans les savanes de l'autre côté du fleuve, tout ici, au contraire, est mouvement et murmure : des coups de bec contre le tronc des chênes, des froissements d'animaux qui marchent, broutent ou broient entre leurs dents les noyaux des fruits; des bruis35 sements d'ondes, de faibles gémissements, de sourds meuglements, de doux roucoulements, remplissent ces déserts d'une tendre et sauvage harmonie. Mais quand une brise vient à animer ces solitudes, à balancer ces corps flottants, à confondre ces masses de blanc, d'azur, de 
vert, de rose, à mêler toutes les couleurs, à réunir tous les murmures : alors il sort de tels bruits du fond des forêts, il se passe de telles choses aux yeux, que j'essayerais en vain de les décrire à ceux qui n'ont point parcouru ces champs primitifs de la nature.

— "Atala », Prologue

\section{BATAILLE IES FRANCS ET DES ROMAINS}

A l'aile opposée de l'armée se tenait immobile la troupe superbe des chevaliers romains : leur casque était d'argent, surmonté d'une louve de vermeil ; leur cuirasse étincelait d'or, et un large baudrier d'azur suspendait à leur flanc une lourde épée ibérienne. ${ }^{1}$ Sous leurs selles ornées d'ivoire s'étendait une housse de pourpre, et leurs mains, couvertes de gantelets, tenaient les rênes de soie qui leur servaient à ro guider de hautes cavales plus noires que la nuit.

Les archers crétois, ${ }^{2}$ les vélites ${ }^{3}$ romains et les différents corps des Gaulois étaient répandus sur le front de l'armée. L'instinct de la guerre est si naturel chez ces derniers, que souvent, dans la mêlée, les soldats deviennent des généraux, rallient leurs compagnons dispersés, ouvrent 15 un avis salutaire et indiquent le poste qu'il faut prendre. Rien n'égale l'impétuosité de leurs attaques : tandis que le Germain délibère, ils ont franchi les torrents et les monts; vous les voyez au pied de la citadelle, et ils sont au haut du retranchement emporté. En vain les cavaliers les plus légers voudraient les devancer à la charge, les Gaulois 20 rient de leurs efforts, voltigent à la tête des chevaux et semblent leur dire: "Vous saisiriez plutôt les vents sur la plaine, ou les oiseaux dans les airs. ")

Tous ces barbares avaient la tête élevée, les couleurs vives, les yeux bleus, le regard farouche et menaçant; ils portaient de larges braies, 25 et leur tunique était chamarrée de morceaux de pourpre; un ceinturon de crin pressait à leur côté leur fidèle épée. L'épée du Gaulois ne le quitte jamais : mariée, pour ainsi dire, avec son maître, elle l'accompagne pendant la vie, elle le suit sur le bûcher funèbre, et descend avec lui au tombeau. Tel était le sort qu'avaient jadis les épouses dans les 30 Gaules, tel est aussi celui qu'elles ont encore au rivage de l'Indus. . . .

Cependant l'œil était frappé d'un mouvement universel: on voyait les signaux du porte-étendard qui plantait le jalon des lignes, la course impétueuse du cavalier, les ondulations des soldats qui se nivelaient

1 "Iberian."

2 "Cretan."

3 "light infantry." 
sous le cep ${ }^{1}$ du centurion. On entendait de toutes parts les grêles hennissements des coursiers, le cliquetis des chaînes, les sourds roulements des balistes et des catapultes, les pas réguliers de l'infanterie, la voix des chefs qui répétaient l'ordre, le bruit des piques qui s'élevaient et 5 s'abaissaient au commandement des tribuns. Les Romains se formaient en bataille aux éclats de la trompette, de la corne et du lituus; et nous Crétois, fidèles à la Grèce au milieu de ces peuples barbares, nous prenions nos rangs au son de la lyre.

Mais tout l'appareil de l'armée romaine ne servait qu'à rendre ro l'armée des ennemis plus formidable, par le contraste d'une sauvage simplicité.

Parés de la dépouille des ours, des veaux marins, ${ }^{2}$ des urochs $^{3}$ et des sangliers, les Francs se montraient de loin comme un troupeau de bêtes féroces. Une tunique courte et serrée laissait voir toute la hauI 5 teur de leur taille et ne leur cachait pas le genou. Les yeux de ces Barbares ont la couleur d'une mer orageuse; leur chevelure blonde, ramenée en avant sur leur poitrine, et teinte d'une liqueur rouge, est semblable à du sang et à du feu. La plupart ne laissent croître leur barbe qu'au-dessus de la bouche, afin de donner à leurs lèvres plus de 20 ressemblance avec le mufle des dogues et des loups. Les uns chargent leur main droite d'une longue framée et leur main gauche d'un bouclier qu'ils tournent comme une roue rapide; d'autres, au lieu de ce bouclier, tiennent une espèce de javelot, nommé angon, où s'enfoncent deux fers recourbés; mais tous ont à la ceinture la redoutable fran25 cisque, espèce de hache à deux tranchants, dont le manche est recouvert d'un dur acier; arme funeste que le Franc jette en poussant un cri de mort et qui manque rarement de frapper le but qu'un œil intrépide a marqué.

Ces Barbares, fidèles aux usages des anciens Germains, s'étaient 30 formés en coin, ${ }^{4}$ leur ordre accoutumé de bataille. Le formidable triangle, où l'on ne distinguait qu'une forêt de framées, des peaux de bêtes et des corps demi-nus, s'avançait avec impétuosité, mais d'un mouvement égal, pour percer la ligne romaine. A la pointe de ce triangle étaient placés des braves qui conservaient une barbe longue 35 et hérissée, et qui portaient au bras un anneau de fer. Ils avaient juré de ne quitter ces marques de servitude qu'après avoir sacrifié un Romain. Chaque chef, dans ce vaste corps, était environné des

1 A vine stock was the insignia of the centurion.

2 "sea calves." 3 "aurochs."

4 "in a wedge." 
guerriers de sa famille, afin que, plus ferme dans le choc, il remportât la victoire ou mourût avec ses amis. Chaque tribu se ralliait sous un symbole; la plus noble d'entre elles se distinguait par des abeilles ou trois fers de lance. ${ }^{1}$ Le vieux roi des Sicambres, Pharamond, ${ }^{2}$ conduisait l'armée entière et laissait une partie du commandement à son petit-fils Mérovée. Les cavaliers francs, en face de la cavalerie romaine, couvraient les deux côtés de leur infanterie; à leurs casques en forme de gueules ouvertes, ombragées de deux ailes de vautour, à leurs corselets de fer, à leurs boucliers blancs, on les eût pris pour des fantômes ou pour ces figures bizarres que l'on aperçoit au milicu des ro nuages pendant une tempête. Clodion, fils de Pharamond et père de Mérovée, brillait à la tête de ces cavaliers menaçants.

Sur une grève, derrière cet essaim d'ennemis, on apercevait leur camp, semblable à un marché de laboureurs et de pêcheurs; il était rempli de femmes et d'enfants, et retranché avec des bateaux de cuir 15 et des chariots attelés de grands bœufs. Non loin de ce camp champêtre, trois sorcières en lambeaux faisaient sortir de jeunes poulains d'un bois sacré, afin de découvrir par leur course à quel parti Tuiston ${ }^{3}$ promettait la victoire. La mer d'un côté, des forêts de l'autre, formaient le cadre de ce grand tableau.

Le soleil du matin, s'échappant des replis d'un nuage d'or, verse tout à coup sa lumière sur les bois, l'océan et les deux armées. La terre paraît embrasée du feu des casques et des lances, les instruments guerriers sonnent l'air antique de Jules César partant pour les Gaules. La rage s'empare de tous les cœurs, les yeux roulent du sang, la main 25 frémit sur l'épée. Les chevaux se cabrent, creusent l'arène, secouent leur crinière, frappent de leur bouche écumante leur poitrine enflammée, ou lèvent vers le ciel leurs naseaux brûlants, pour respirer les sons belliqueux. Les Romains commencent le chant de Probus : ${ }^{4}$

"Quand nous aurons vaincu mille guerriers francs, combien ne vain- 30 crons-nous pas de millions de Perses!»

Les Grecs répètent en chœur le pæan, et les Gaulois l'hymne des Druides. Les Francs répondent à ces cantiques de mort: ils serrent leurs boucliers contre leur bouche, et font entendre un mugissement

1 Chateaubriand seems here to be trying to connect the three lance heads with the fleur-de-lis.

2 Nothing definite is known of the Pharamond, the Mérovée, and the Clodion mentioned here.

${ }^{3}$ In Germanic mythology Tuiston is one of the divinities of the lower world.

4 Roman emperor, born in 232 A.D. 
semblable au bruit de la mer que le vent brise contre un rocher; puis tout à coup, poussant un cri aigu, ils entonnent le bardit à la louange de leurs héros :

"Pharamond! Pharamond! nous avons combattu avec l'épée.

5 "Nous avons lancé la francisque à deux tranchants; la sueur tombait du front des guerriers et ruisselait le long de leurs bras. Les aigles et les oiseaux aux pieds jaunes poussaient des cris de joie; le corbeau nageait dans le sang des morts; tout l'océan n'était qu'une plaie : les vierges ont pleuré longtemps!

"Pharamond! Pharamond! nous avons combattu avec l'épée.

"Nos pères sont morts dans les batailles, tous les vautours en ont gémi; nos pères les rassasiaient de carnage! Choisissons des épouses dont le lait soit du sang et qui remplissent de valeur le cour de nos fils. Pharamond, le bardit est achevé, les heures de la

15 vie s'écoulent, nous sourirons quand il faudra mourir!»

Ainsi chantaient quarante mille barbares. Leurs cavaliers haussaient et baissaient leurs boucliers blancs en cadence, et à chaque refrain ils frappaient du fer d'un javelot leur poitrine couverte de fer. - "Les Martyrs ", Book VI

\section{SOUVENIRS DE JEUNESSE}

Ces récits occupaient tout le temps du coucher de ma mère et de 20 ma sœur: elles se mettaient au lit mourantes de peur; je me retirais au haut de ma tourelle; la cuisinière rentrait dans la grosse tour, et les domestiques descendaient dans leur souterrain.

La fenêtre de mon donjon s'ouvrait sur la cour intérieure; le jour, j'avais en perspective les créneaux de la courtine opposée, où végétaient 25 des scolopendres et croissait un prunier sauvage. Quelques martinets, qui, durant l'été, s'enfonçaient en criant dans les trous des murs, étaient mes seuls compagnons. La nuit, je n'apercevais qu'un petit morceau du ciel et quelques étoiles. Lorsque la lune brillait et qu'elle s'abaissait à l'occident, j'en étais averti par ses rayons, qui venaient à 3o mon lit au travers des carreaux losangés de la fenêtre. Des chouettes, voletant d'une tour à l'autre, passant et repassant entre la lune et moi, dessinaient sur mes rideaux l'ombre mobile de leurs ailes. Relégué dans l'endroit le plus désert, à l'ouverture des galeries, je ne perdais pas un murmure des ténèbres. Quelquefois le vent semblait courir à 35 pas légers; quelquefois il laissait échapper des plaintes ; tout à coup 
ma porte était ébranlée avec violence, les souterrains poussaient des mugissements, puis ces bruits expiraient pour recommencer encore. A quatre heures du matin, la voix du maître du château, appelant le valet de chambre à l'entrée des voûtes séculaires, se faisait entendre comme la voix du dernier fantôme de la nuit. Cette voix remplaçait pour moi la douce harmonie au son de laquelle le père de Montaigne éveillait son fils. ${ }^{1}$

L'entêtement du comte de Chateaubriand à faire coucher un enfant seul au haut d'une tour pouvait avoir quelque inconvénient; mais il tourna à mon avantage. Cette manière violente de me traiter me laissa io le courage d'un homme, sans m'ôter cette sensibilité d'imagination dont on voudrait aujourd'hui priver la jeunesse. Au lieu de chercher à me convaincre qu'il n'y avait point de revenants, on me força de les braver. Lorsque mon père me disait avec un sourire ironique : "Monsieur le chevalier aurait-il peur? ", il m'eût fait coucher avec un mort. I 5 Lorsque mon excellente mère me disait: "Mon enfant, tout n'arrive que par la permission de Dieu; vous n'avez rien à craindre des mauvais esprits, tant que vous serez bon chrétien »; j'étais mieux rassuré que par tous les arguments de la philosophie. Mon succès fut si complet que les vents de la nuit, dans ma tour déshabitée, ne servaient 20 que de jouets à mes caprices et d'ailes à mes songes. Mon imagination allumée, se propageant sur tous les objets, ne trouvait nulle part assez de nourriture et aurait dévoré la terre et le ciel. C'est cet état moral qu'il faut maintenant décrire. Replongé dans ma jeunesse, je vais essayer de me saisir dans le passé, de me montrer tel que j'étais, 25 tel peut-être que je regrette de n'être plus, malgré les tourments que j'ai endurés. . . .

Mes jours s'écoulaient d'une manière sauvage, bizarre, insensée, et pourtant pleine de délices.

Au nord du château s'étendait une lande semée de pierres drui- 30 diques; j'allais m'asseoir sur une de ces pierres au soleil couchant. La cime dorée des bois, la splendeur de la terre, l'étoile du soir scintillant à travers les nuages de rose, me ramenaient à mes songes : j'aurais voulu jouir de ce spectacle avec l'idéal objet de mes désirs. Je suivais en pensée l'astre du jour; je lui donnais ma beauté à 35 conduire afin qu'il la présentât radieuse avec lui aux hommages de l'univers. Le vent du soir qui brisait les réseaux tendus par l'insecte

1 In order not to shock his son's nerves, Montaigne's father had him awakened by music. 
sur la pointe des herbes, l'alouette de bruyère qui se posait sur un caillou, me rappelaient à la réalité ; je reprenais le chemin du manoir, le cœur serré, le visage abattu.

Les jours d'orage en été, je montais au haut de la grosse tour de 5 l'ouest. Le roulement du tonnerre sous les combles du château, les torrents de pluie qui tombaient en grondant sur le toit pyramidal des tours, l'éclair qui sillonnait la nue et marquait d'une flamme électrique les girouettes d'airain, excitaient mon enthousiasme: comme Ismen sur les remparts de Jérusalem, ${ }^{1}$ j'appelais la foudre; j'espérais qu'elle Io m'apporterait Armide.

Le ciel était-il serein, je traversais le grand Mail, autour duquel étaient des prairies divisées par des haies plantées de saules. J'avais établi un siège, comme un nid, dans un de ces saules: là, isolé entre le ciel et la terre, je passais des heures avec les fauvettes; ma nymphe ${ }^{2}$

I 5 était à mes côtés. J'associais également son image à la beauté de ces nuits de printemps toutes remplies de la fraîcheur de la rosée, des soupirs du rossignol et du murmure des brises.

D'autres fois je suivais un chemin abandonné, une onde ornée de ses plantes rivulaires ; j'écoutais les bruits qui sortent des lieux infré20 quentés; je prêtais l'oreille à chaque arbre; je croyais entendre la clarté de la lune chanter dans les bois ; je voulais redire ces plaisirs, et les paroles expiraient sur mes lèvres. ...

Plus la saison était triste, plus elle était en rapport avec moi : le temps des frimas, en rendant les communications moins faciles, isole 25 les habitants des campagnes; on se sent mieux à l'abri des hommes.

Un caractère moral s'attache aux scènes de l'automne : ces feuilles qui tombent comme nos ans, ces fleurs qui se fanent comme nos heures, ces nuages qui fuient comme nos illusions, cette lumière qui s'affaiblit comme notre intelligence, ce soleil qui se refroidit comme 30 nos amours, ces fleuves qui se glacent comme notre vie, ont des rapports secrets avec nos destinées.

Je voyais avec un plaisir indicible le retour de la saison des tempêtes, le passage des cygnes et des ramiers, le rassemblement des corneilles dans la prairie de l'étang, et leur perchée à l'entrée de la nuit sur les 35 plus hauts chênes du grand Mail. Lorsque le soir élevait une vapeur bleuâtre au carrefour des forêts, que les complaintes ou les lais du vent gémissaient dans les mousses flétries, j'entrais en pleine possession

1 See Canto XII of the "Gerusalemme liberata" of Tasso. Armide is the heroine.

2 I.e. the lady of his dreams. 
des sympathies de mą nature. Rencontrais-je quelque laboureur au bout d'un guéret, je m'arrêtais pour regarder cet homme germé à l'ombre des épis parmi lesquels il devait être moissonné, et qui, retournant la terre de sa tombe avec le soc de la charrue, mêlait ses sueurs brûlantes aux pluies glacées de l'automne: le sillon qu'il creusait était 5 le monument destiné à lui survivre. . . .

Le soir je m'embarquais sur l'étang, conduisant seul mon bateau au milieu des joncs et des larges feuilles flơttantes du nénuphar. Là se réunissaient les hirondelles prêtes à quitter nos climats. Je ne perdais pas un seul de leurs gazouillis.... Elles se jouaient sur l'eau au ro tomber du soleil, poursuivaient les insectes, s'élançaient ensemble dans les airs, comme pour éprouver leurs ailes, se rabattaient à la surface du lac, puis se venaient suspendre aux roseaux que leur poids courbait, et qu'elles remplissaient de leur ramage confus.

La nuit descendait; les roseaux agitaient leurs champs de que- 15 nouilles et de glaives, parmi lesquels la caravane emplumée, poules d'eau, sarcelles, martins-pêcheurs, bécassines, se taisait; le lac battait ses bords; les grandes voix de l'automne sortaient des marais et des bois ; j'échouais mon bateau au rivage et retournais au château. Dix heures sonnaient. A peine retiré dans ma chambre, ouvrant mes 20 fenêtres, fixant mes regards au ciel, je commençais une incantation. Je montais avec ma magicienne sur les nuages: roulé dans ses cheveux et dans ses voiles, j'allais, au gré des tempêtes, agiter la cime des forêts, ébranler le sommet des montagnes, ou tourbillonner sur les mers. ... 


\section{ALPHONSE DE PRAT DE LAMARTINE \\ Mâcon, I790-I 869, Paris}

After a youth in which the influence of his mother and sisters was more felt than that of harsher schoolmasters, Lamartine had his deepest emotions aroused by the death $(1818)$ of a young lady whom he loved. These emotions of love and sorrow he expressed in the "Méditations" (1820) with that depth and spontaneity, that truth and sincerity, which French poetry had scarcely known since the sixteenth century. With the "Méditations" starts a new era in lyric poetry, not yet in the form, for Lamartine did not invent new forms, but in the subject matter, which was the spontaneous outburst of a man's innermost self.

The "Nouvelles méditations" (1823) and the "Harmonies poétiques et religieuses" ( 1830 ) continued to increase his fame, but did not strike a deeper or truer note than the first "Méditations." He was received into the Academy in 1830 . But poetry seemed to him an "accident," an "aventure heureuse" in his life; his ambitions were political rather than literary. After the publication of the "Méditations" he served in the diplomatic corps for some years, retired when Louis-Philippe came to the throne, but was elected deputy in 1833 , before his return from the Orient. In the Chamber of Deputies he had an opportunity to display the remarkable powers of his oratory. His "Histoire des Girondins" (I847) had much to do with the fall of the July monarchy, and for a time after its downfall Lamartine found himself at the head of the provisional government. But with the establishment of Napoleon III, Lamartine retired to private life. During the remaining years of his life financial distress forced him to turn out volume after volume of fiction, history, and literary criticism, which added nothing to his fame. He died in 1869 .

\section{L'ISOLEMENT}

Souvent sur la montagne, à l'ombre du vieux chêne, $\mathrm{Au}$ coucher du soleil, tristement je m'assieds ;

Je promène au hasard mes regards sur la plaine, Dont le tableau changeant se déroule à mes pieds.

Ici gronde le fleuve aux vagues écumantes;

Il serpente, et s'enfonce en un lointain obscur;

Là le lac immobile étend ses eaux dormantes

Où l'étoile du soir se lève dans l'azur. 
Au sommet de ces monts couronnés de bois sombres, Le crépuscule encor jette un dernier rayon; Et le char vaporeux de la reine des ombres Monte, et blanchit déjà les bords de l'horizon.

Cependant, s'élançant de la flèche gothique, Un son religieux se répand dans les airs:

Le voyageur s'arrête, et la cloche rustique Aux derniers bruits du jour mêle de saints concerts.

Mais à ces doux tableaux mon âme indifférente N'éprouve devant eux ni charme ni transports;

Je contemple la terre ainsi qu'une ombre errante:

Le soleil des vivants n'échauffe plus les morts.

De colline en colline en vain portant ma vue, Du sud à l'aquilon, de l'aurore au couchant, Je parcours tous les points de l'immense étendue,

Et je dis : "Nulle part le bonheur ne m'attend."

Que me font ces vallons, ces palais, ces chaumières, Vains objets dont pour moi le charme est envolé ?

Fleuves, rochers, forêts, solitudes si chères, Un seul être vous manque, et tout est dépeuplé !

Que le tour du soleil ou commence ou s'achève, D'un œil indifférent je le suis dans son cours ;

En un ciel sombre ou pur qu'il se couche ou se lève, Qu'importe le soleil ? je n'attends rien des jours.

Quand je pourrais le suivre en sa vaste carrière, Mes yeux verraient partout le vide et les déserts :

Je ne désire rien de tout ce qu'il éclaire ;

Je ne demande rien à l'immense univers.

Mais peut-être au delà des bornes de sa sphère,

Lieux où le vrai soleil éclaire d'autres cieux,

$\mathrm{Si}$ je pouvais laisser ma dépouille à la terre,

Ce que j'ai tant rêvé paraîtrait à mes yeux!

Là, je m'enivrerais à la source où j'aspire ;

Là, je retrouverais et l'espoir et l'amour,

Et ce bien idéal que toute âme désire,

Et qui n'a pas de nom au terrestre séjour ! 
Que ne puis-je, porté sur le char de l'Aurore, Vague objet de mes vœux, m'élancer jusqu'à toi ! Sur la terre d'exil pourquoi resté-je encore? Il n'est rien de commun entre la terre et moi.

5 Quand la feuille des bois tombe dans la prairie, Le vent du soir s'élève et l'arrache aux vallons;

Et moi, je suis semblable à la feuille flétrie : Emportez-moi comme elle, orageux aquilons!

— "Méditations poétiques »

\section{LE LAC ${ }^{1}$}

Ainsi, toujours poussés vers de nouveaux rivages,

Io Dans la nuit éternelle emportés sans retour, Ne pourrons-nous jamais sur l'océan des âges Jeter l'ancre un seul jour?

O lac! l'année à peine a fini sa carrière, Et près des flots chéris qu'elle devait revoir,

15 Regarde! je viens seul m'asseoir sur cette pierre Où tu la vis s'asseoir !

Tu mugissais ainsi sous ces roches profondes;

Ainsi tu te brisais sur leurs flancs déchirés; Ainsi le vent jetait l'écume de tes ondes Sur ses pieds adorés.

Un soir, t'en souvient-il ? nous voguions en silence ; On n'entendait au loin, sur l'onde et sous les cieux, Que le bruit des rameurs qui frappaient en cadence Tes flots harmonieux.

Tout à coup des accents inconnus à la terre

Du rivage charmé frappèrent les échos;

Le flot fut attentif, et la voix qui m'est chère Laissa tomber ces mots :

" $\mathrm{O}$ temps, suspends ton vol! et vous, heures propices, Suspendez votre cours!

1 Lamartine met "Julie," Madame Charles, in 1816 , and with her had often loitered around and on Lake Bourget. His deep bereavement at her death in 1818 appears in some of the "Méditations." The "Lac" was written in 1817 , before her death. 
Laissez-nous savourer les rapides délices

Des plus beaux de nos jours!

« Assez de malheureux ici-bas vous implorent:

Coulez, coulez pour eux ;

Prenez avec leurs jours les soins qui les dévorent ;

Oubliez les heureux.

" Mais je demande en vain quelques moments encore,

Le temps m'échappe et fuit;

Je dis à cette nuit: "Sois plus lente "; et l'aurore

Va dissiper la nuit.

" Aimons donc, aimons donc! de l'heure fugitive,

Hâtons-nous, jouissons !

L'homme n'a point de port, le temps n'a point de rive;

Il coule, et nous passons !»

Temps jaloux, se peut-il que ces moments d'ivresse,

Où l'amour à longs flots nous verse le bonheur,

S'envolent loin de nous de la même vitesse

Que les jours de malheur?

Hé quoi! n'en pourrons-nous fixer au moins la trace?

Quoi! passés pour jamais? quoi! tout entiers perdus?

Ce temps qui les donna, ce temps qui les efface,

$\mathrm{Ne}$ nous les rendra plus?

Eternité, néant, passé, sombres abîmes,

Que faites-vous des jours que vous engloutissez?

Parlez: nous rendrez-vous ces extases sublimes

Que vous nous ravissez?

O lac! rochers muets! grottes! forêt obscure!

Vous que le temps épargne ou qu'il peut rajeunir,

Gardez de cette nuit, gardez, belle nature,

$\mathrm{Au}$ moins le souvenir!

Qu'il soit dans ton repos, qu'il soit dans tes orages,

Beau lac, et dans l'aspect de tes riants coteaux,

Et dans ces noirs sapins, et dans ces rocs sauvages

Qui pendent sur tes eaux! 
Qu'il soit dans le zéphyr qui frémit et qui passe, Dans les bruits de tes bords par tes bords répétés, Dans l'astre au front d'argent qui blançhit ta surface De ses molles clartés!

Que le vent qui gémit, le roseau qui soupire, Que les parfums légers de ton air embaumé, Que tout ce qu'on entend, l'on voit ou l'on respire, Tout dise : " Ils ont aimé !»

— " Méditations poétiques »

\section{LE CRUCIFIX}

Toi que j'ai recueilli sur sa bouche expirante Avec son dernier souffle et son dernier adieu, Symbole deux fois saint, don d'une main mourante, Image de mon Dieu;

Que de pleurs ont coulé sur tes pieds que j'adore, Depuis l'heure sacrée où, du sein d'un martyr,

Dans mes tremblantes mains tu passas, tiède encore De son dernier soupir!

Les saints flambeaux jetaient une dernière flamme;

Le prêtre murmurait ces doux chants de la mort, Pareils aux chants plaintifs que murmure une femme A l'enfant qui s'endort.

De son pieux espoir son front gardait la trace, Et sur ses traits, frappés d'une auguste beauté, La douleur fugitive avait empreint sa grâce, La mort sa majesté.

Le vent qui caressait sa tête échevelée

Me montrait tour à tour ou me voilait ses traits, Comme l'on voit flotter sur un blanc mausolée L'ombre des noirs cyprès.

Un de ses bras pendait de la funèbre couche;

L'autre, languissamment replié sur son cœur, Semblait chercher encore et presser sur sa bouche L'image du Sauveur. 
Ses lèvres s'entr'ouvraient pour l'embrasser encore,

Mais son âme avait fui dans ce divin baiser,

Comme un léger parfum que la flamme dévore

Avant de l'embraser.

Maintenant tout dormait sur sa bouche glacée,

Le souffle se taisait dans son sein endormi,

Et sur l'œil sans regard la paupière affaissée

Retombait à demi.

Et moi, debout, saisi d'une terreur secrète,

Je n'osais m'approcher de ce reste adoré,

Comme si du trépas la majesté muette

L'eût déjà consacré.

Je n'osais!... Mais le prêtre entendit mon silence,

Et, de ses doigts glacés prenant le crucifix:

"Voilà le souvenir, et voilà l'espérance :

Emportez-les, mon fils!»

Oui, tu me resteras, ô funèbre héritage!

Sept fois, depuis ce jour, l'arbre que j'ai planté

Sur sa tombe sans nom a changé de feuillage;

Tu ne m'as pas quitté.

Placé près de ce cœur, hélas! où tout s'efface,

Tu l'as contre le temps défendu de l'oubli,

Et mes yeux goutte à goutte ont imprimé leur trace Sur l'ivoire amolli.

O dernier confident de l'âme qui s'envole,

Viens, reste sur mon cœur! parle encore, et dis-moi

Ce qu'elle te disait quand sa faible parole

N'arrivait plus qu'à toi ;

A cette heure douteuse où l'âme recueillie, Se cachant sous le voile, épaissi sur nos yeux, Hors de nos sens glacés pas à pas se replie,

Sourde aux derniers adieux;

Alors qu'entre la vie et la mort incertaine, Comme un fruit par son poids détaché du rameau, Notre âme est suspendue et tremble à chaque haleine

Sur la nuit du tombeau; 
Quand des chants, des sanglots la confuse harmonie N'éveille déjà plus notre esprit endormi, Aux lèvres du mourant collé dans l'agonie,

Comme un dernier ami :

Pour éclairer l'horreur de cet étroit passage, Pour relever vers Dieu son regard abattu, Divin consolateur dont nous baisons l'image, Réponds, que lui dis-tu?

Tu sais, tu sais mourir! et tes larmes divines,

Dans cette nuit terrible où tu prias en vain, De l'olivier sacré baignèrent les racines

Du soir jusqu'au matin.

De la croix, où ton œil sonda ce grand mystère, $\mathrm{Tu}$ vis ta mère en pleurs et la nature en deuil ;

$\mathrm{Tu}$ laissas comme nous tes amis sur la terre,

Et ton corps au cercueil!

Au nom de cette mort, que ma faiblesse obtienne

De rendre sur ton sein ce douloureux soupir:

Quand mon heure viendra, souviens-toi de la tienne,

Je chercherai la place où sa bouche expirante Exhala sur tes pieds l'irrévocable adieu, Et son âme viendra guider mon âme errante Au sein du même Dieu.

Ah! puisse, puisse alors sur ma funèbre couche, Triste et calme à la fois, comme un ange éploré, Une figure en deuil recueillir sur ma bouche L'héritage sacré!

Soutiens ses derniers pas, charme sa dernière heure; Et, gage consacré d'espérance et d'amour, De celui qui s'éloigne à celui qui demeure

Passe ainsi tour à tour,

Jusqu'au jour où, des morts perçant la voûte sombre, Une voix dans le ciel, les appelant sept fois, Ensemble éveillera ceux qui dorment à l'ombre De l'éternelle croix! 


\section{UN VILLAGE DANS LES ALPES}

Sur un des verts plateaux des Alpes de Savoie,

Oasis dont la roche a fermé toute voie,

Où l'homme n'aperçoit, sous ses yeux effrayés,

Qu'abîme sur sa tête et qu'abîme à ses pieds,

La nature étendit quelques étroites pentes

Où le granit retient la terre entre ses fentes,

Et ne permet qu'à peine à l'arbre d'y germer,

A l'homme de gratter la terre et d'y semer.

D'immenses châtaigniers aux branches étendues

Y cramponnent leurs pieds dans les roches fendues,

Et pendent en dehors sur des gouffres obscurs,

Comme la giroflée aux parois des vieux murs;

On voit à mille pieds, au-dessous de leurs branches,

La grande plaine bleue avec ses routes blanches,

Les moissons jaune d'or, les bois comme un point noir,

Et les lacs renvoyant le ciel comme un miroir;

La toise de pelouse, à leur ombre abritée,

Par la dent des chevreaux et des ânes broutée,

Epaissit sous leurs troncs ses duvets fins et courts,

Dont mille filets d'onde humectent le velours,

Et pendant le printemps, qui n'est qu'un court sourire,

Enivre de ses fleurs le vent qui les respire.

Des monts tout blancs de neige encadrent l'horizon,

Comme un mur de cristal, de ma haute prison,

Et, quand leurs pics sereins sont sortis des tempêtes,

Laissent voir un pan bleu de ciel pur sur nos têtes.

On n'entend d'autre bruit, dans cet isolement,

Que quelques voix d'enfants, ou quelque bêlement

De génisse ou de chèvre au ravin descendues,

Dont le pas fait tinter les cloches suspendues;

Les sons entrecoupés du nocturne Angélus,

Que le père et l'enfant écoutent les fronts nus,

Et le sourd ronflement des cascades d'écume,

Auquel, en l'oubliant, l'oreille s'accoutume,

Et qui semble, fondu dans ces bruits du désert,

La basse sans repos d'un éternel concert.

Les maisons, au hasard sous les arbres perchées,

En groupes de hameaux sont partout épanchées, Semblent avoir poussé, sans plans et sans dessein, Sur la terre, avec l'arbre et le roc, de son sein. 
Les pauvres habitants, dispersés dans l'espace, Ne s'y disputent pas le soleil et la place,

Et chacun sous son chêne, au plus près de son champ, A sa porte au matin et son mur au couchant.

Des sentiers où des bœufs le lourd sabot s'aiguise

Mènent de l'un à l'autre, et de là vers l'église

Dont depuis deux cents ans à tous ces pieds humains

Le baptême et la mort ont frayé les chemins.

Elle s'élève seule au bout du cimetière

Avec ses murs épais et bas, verdis de lierre, Et ses ronces grimpant en échelle, en feston, Jusqu'au chaume moussu qui lui sert de fronton.

On ne peut distinguer cette chaumière sainte Qu'au plus grand abandon du petit champ d'enceinte,

I 5 Où le sol des tombeaux, par la mort cultivé, N'offre qu'un tertre ou deux tous les ans élevé, Que recouvrent bientôt la mauve et les orties, Premières fleurs toujours de nos cendres sorties, Et qu'à l'humble clocher qui surmonte les toits Et s'ouvre aux quatre vents pour répandre sa voix.

Ma demeure est auprès; ma maison isolée Par l'ombre de l'église est au midi voilée, Et les troncs des noyers qui la couvrent du nord Aux regards des passants en dérobent l'abord.

25 Des quartiers de granit que nul ciseau ne taille, Tels que l'onde les roule, en forment la muraille: Ces blocs irréguliers, noircis par les hivers, De leur mousse natale y sont encor couverts ; La joubarbe, la menthe, et ces fleurs parasites Que la pluie enracine aux parois décrépites, Y suspendent partout leurs panaches flottants, Et les font comme un pré reverdir au printemps. Trois fenêtres d'en haut, par le toit recouvertes, Deux au jour du matin, l'autre au couchant, ouvertes, 35 Se creusant dans le mur comme des nids pareils, Reçoivent les premiers et les derniers soleils ; Le toit, qui sur les murs déborde d'une toise, A pour tuiles des blocs et des pavés d'ardoise, Que d'un rebord vivant le pigeon bleu garnit, Et sous les soliveaux l'hirondelle a son nid. 
Pour défendre ce toit des coups de la tempête,

Des quartiers de granit sont posés sur le faîte, Et, faisant ondoyer les tuiles et les bois,

$\mathrm{Au}$ vol de l'ouragan ils opposent leur poids.

Bien que si haut assise au sommet d'une chaîne,

Son horizon borné n'a ni grand ciel, ni plaine:

Adossé au penchant d'un étroit mamelon,

Elle n'a pour aspect qu'un oblique vallon

Qui se creuse un moment comme un lac de verdure,

Pour donner au verger espace et nourriture;

Puis, reprenant sa pente et s'y rétrécissant,

De ravins en ravins avec les monts descend.

Les troncs noirs des noyers, un pan de roche grise,

L'herbe de mon verger, les murs nus de l'église,

Le cimetière avec ses sillons et ses croix,

Et puis un peu de ciel, c'est tout ce que je vois.

Mais combien au regard du peintre et du poète,

En vie, en mouvement, la nature rachète

Ce qu'elle a refusé d'espace à l'horizon!

Une cascade tombe au pied de la maison,

Et le long d'une roche, en nappe blanche et fine,

$\mathrm{Y}$ joue avec le vent dont un souffle l'incline,

$\mathrm{Y}$ joue avec le jour dont le rayon changeant

Semble s'y dérouler dans ses réseaux d'argent,

Et, par des rocs aigus dans sa chute brisée,

Aux feuilles du jardin se suspend en rosée.

Légère, elle n'a pas ce bruit tonnant et sourd

Qu'en se précipitant roule un torrent plus lourd;

Elle n'a qu'une plainte intermittente et douce,

Selon qu'elle rencontre ou la pierre ou la mousse,

Que le vent faible ou fort la fouette à ses parois,

Lui prête ou lui retire ou lui rend plus de voix;

Dans les sons inégaux que son onde module

Chaque soupir de l'âme en note s'articule:

Harpe toujours tendue, où le vent et les eaux

Rendent dans leurs accords des chants toujours nouveaux,

Et qui semble la nuit, en ces notes étranges,

L'air sonore des cieux froissé du vol des anges. 


\section{INVOCATION D'HAROLD MOURANT}

" Triomphe, disait-il, immortelle Nature, Tandis que devant toi ta frêle créature Elevant ses regards de ta beauté ravis, Va passer et mourir! Triomphe, tu survis!

Qu'importe? Dans ton sein, que tant de vie inonde,

L'être succède à l'être, et la mort est féconde!

Le temps s'épuise en vain à te compter des jours ;

Le siècle meurt et meurt, et tu renais toujours!

Un astre dans le ciel s'éteint? tu le rallumes!

Un volcan dans ton sein frémit? tu le consumes!

L'océan de ses flots t'inonde? tu les bois!

Un peuple entier périt dans les luttes des rois?

La terre, de leurs os engraissant ses entrailles, Sème l'or des moissons sur le champ des batailles !

15 Le brin d'herbe foulé se flétrit sous mes pas, Le gland meurt, l'homme tombe, et tu ne les vois pas!

Plus riante et plus jeune au moment qu'il expire, Hélas! comme à présent tu sembles lui sourire, Et, t'épanouissant dans toute ta beauté, Opposer à sa mort ton immortalité !

"Quoi donc! N'aimes-tu pas au moins celui qui t'aime?

N'as-tu point de pitié pour notre heure suprême?

Ne peux-tu, dans l'instant de nos derniers adieux, D'un nuage de deuil te voiler à nos yeux?

Mes yeux moins tristement verraient ma dernière heure $\mathrm{Si}$ je pensais qu'en toi quelque chose me pleure, Que demain la clarté du célestè rayon

Viendra d'un jour plus pâle éclairer mon gazon, Et que les flots, les vents et la feuille qui tombe, Diront : " Il n'est plus là ; taisons-nous sur sa tombe.» Mais non: tu brilleras demain comme aujourd'hui! Ah! si tu peux pleurer, Nature, c'est pour lui! Jamais être formé de poussière et de flamme A tes purs éléments ne mêla mieux son âme; Jamais esprit mortel ne comprit mieux ta voix, Soit qu'allant respirer la sainte horreur des bois, Mon pas mélancolique, ébranlant leurs ténèbres, Troublât seul les échos de leurs dômes funèbres; Soit qu'au sommet des monts, écueils brillants de l'air, J'entendisse rouler la foudre, et que l'éclair, 
S'échappant coup sur coup dans le choc des nuages, Brillât d'un feu sanglant comme l'œil des orages; Soit que, livrant ma voile aux haleines des vents, Sillonnant de la mer les abîmes mouvants, J'aimasse à contempler une vague écumante Crouler sur mon esquif en ruine fumante, Et m'emporter au loin sur son dos triomphant, Comme un lion qui joue avec un faible enfant. Plus je fus malheureux, plus tu me fus sacrée!

Plus l'homme s'éloigna de mon âme ulcérée,

Plus dans la solitude, asile du malheur,

Ta voix consolatrice enchanta ma douleur.

Et maintenant encore . . . à cette heure dernière . . .

Tout ce que je regrette en fermant ma paupière,

C'est le rayon brillant du soleil du midi

Qui se réfléchira sur mon marbre attiédi!»

- " Le dernier chant du pélerinage d'Harold » 


\title{
ALFRED DE VIGNY
}

\author{
Loches, I $797-1863$, Paris
}

Alfred de Vigny was born at Loches in 1797. At the age of sixteen he enlisted, and retained his connection with the army for about fourteen years. Meanwhile, in I822, he published a little collection of "Poèmes," worked over and supplemented, under the title of "Poèmes antiques et modernes," in 1826, I829, and I837. His "Cinq-Mars," a historical romance after the manner of Scott, appeared in 1826 . His other romances were "Stello" (I832), and the "Servitude et grandeur militaires," a collection of sketches (1835). "Chatterton" (I835), De Vigny's best drama, was preceded by "Othello" (I829), a free translation of Shakespeare's "Othello," and "La maréchale d'Ancre" (I831).

Essentially a serious, melancholy, and solitary genius, De Vigny was, for a time, somewhat attached to the Romantic movement. During the latter half of his life he lived in retirement, publishing from time to time, in the "Revue des deux mondes," poems which were collected in a small volume in 1863 under the title of "Destinées." On his poems, some thirty in number, his reputation mainly rests. They show considerable depth of thought, a fine sense of proportion, and are expressed in language of noble and dignified simplicity.

\section{LE COR}

I

J'aime le son du Cor, le soir, au fond des bois, Soit qu'il chante les pleurs de la biche aux abois, Ou l'adieu du chasseur que l'écho faible accueille, Et que le vent du nord porte de feuille en feuille.

Que de fois, seul, dans l'ombre à minuit demeuré, J'ai souri de l'entendre, et plus souvent pleuré!

Car je croyais ouïr de ces bruits prophétiques Qui précédaient la mort des Paladins antiques.

O montagne d'azur! ô pays adoré !

Cascades qui tombez des neiges entraînées, Sources, gaves, ruisseaux, torrents des Pyrénées;

1 Both Frazona and Marboré are in the central Pyrenees. 
Monts gelés et fleuris, trône des deux saisons, Dont le front est de glace et le pied de gazons! C'est là qu'il faut s'asseoir, c'est là qu'il faut entendre Les airs lointains du Cor mélancolique et tendre.

Souvent un voyageur, lorsque l'air est sans bruit,

De cette voix d'airain fait retentir la nuit;

A ses chants cadencés autour de lui se mêle

L'harmonieux grelot du jeune agneau qui bêle.

Une biche attentive, au lieu de se cacher,

Se suspend immobile au sommet du rocher,

Et la cascade unit, dans une chute immense, Son éternelle plainte aux chants de la romance.

Ames des Chevaliers, revenez-vous encor?

Est-ce vous qui parlez avec la voix du Cor?

Roncevaux! Roncevaux ! ${ }^{1}$ dans ta sombre vallée

L'ombre du grand Roland n'est donc pas consolée!

Tous les preux étaient morts, mais aucun n'avait fui. Il reste seul debout, Olivier près de lui;

L'Afrique ${ }^{2}$ sur le mont l'entoure et tremble encore.

( Roland, tu vas mourir, rends-toi, criait le More ;

" Tous tes pairs sont couchés dans les eaux des torrents. ) Il rugit comme un tigre, et dit: " $\mathrm{Si}$ je me rends, Africain, ce sera lorsque les Pyrénées Sur l'onde avec leurs corps rouleront entraînées. »

" Rends-toi donc, répond-il, ou meurs, car les voilà. »

Et du plus haut des monts un grand rocher roula.

Il bondit, il roula jusqu'au fond de l'abîme,

Et de ses pins dans l'onde, il vint briser la cime.

" Merci, cria Roland; tu m'as fait un chemin.»

Et jusqu'au pied des monts le roulant d'une main,

1 According to the "Chanson de Roland," Roland, nephew of Charlemagne, was attacked by the Saracens at Roncevaux in the Pyrenees while he was protecting Charlemagne's retreat from Spain. His friend Olivier had remained with him.

2 I.e. the Saracens. 
Sur le roc affermi comme un géant s'élance, Et, prête à fuir, l'armée à ce seul pas balance.

\section{III}

Tranquilles cependant, Charlemagne et ses preux

Descendaient la montagne et se parlaient entre eux.

A l'horizon déjà, par leurs eaux signalées, De Luz et d'Argelès ${ }^{1}$ se montraient les vallées.

L'armée applaudissait. Le luth du troubadour S'accordait pour chanter les saules de l'Adour ${ }^{2}$; Le vin français coulait dans la coupe étrangère; Le soldat, en riant, parlait à la bergère.

Roland gardait les monts; tous passaient sans effroi. Assis nonchalamment sur un noir palefroi Qui marchait revêtu de housses violettes, Turpin disait, tenant les saintes amulettes:

( Sire, on voit dans le ciel des nuages de feu; Suspendez votre marche; il ne faut tenter Dieu. Par monsieur saint Denis, ${ }^{3}$ certes ce sont des âmes Qui passent dans les airs sur ces vapeurs de flammes.

"Deux éclairs ont relui, puis deux autres encor.»

Ici l'on entendit le son lointain du Cor.

L'Empereur étonné, se jetant en arrière, Suspend du destrier la marche aventurière.

" Entendez-vous? dit-il. _ Oui, ce sont des pasteurs Rappelant les troupeaux épars sur les hauteurs,

25 Répondit l'archevêque, ou la voix étouffée Du nain vert Obéron, ${ }^{4}$ qui parle avec sa Fée.»

Et l'Empereur poursuit; mais son front soucieux Est plus sombre et plus noir que l'orage des cieux. Il craint la trahison, et, tandis qu'il y songe, Le Cor éclate et meurt, renaît et se prolonge.

1 Luz and Argelès are in the Hautes-Pyrénées.

2'The Adour rises in the Hautes-Pyrénées and flows down to Bayonne.

3 Patron saint of France, said to have been beheaded at Paris, 272 A.D.

4 The king of the fairies. 
" Malheur! c'est mon neveu! malheur! car, si Roland Appelle à son secours, ce doit être en mourant. Arrière, chevaliers, repassons la montagne! Tremble encor sous nos pieds, sol trompeur de l'Espagne!»

\section{IV}

Sur le plus haut des monts s'arrêtent les chevaux;

L'écume les blanchit; sous leurs pieds, Roncevaux

Des feux mourants du jour à peine se colore.

A l'horizon lointain fuit l'étendard du More.

"Turpin, n'as-tu rien vu dans le fond du torrent?"

" J'y vois deux chevaliers : l'un mort, l'autre expirant.

Tous deux sont écrasés sous une roche noire;

Le plus fort, dans sa main, élève un Cor d'ivoire,

Son âme en s'exhalant nous appela deux fois.»

Dieu ! que le son du Cor est triste au fond des bois!

- "Livre moderne"

\section{LA MORT DU LOUP}

I

Les nuages couraient sur la lune enflammée

Comme sur l'incendie on voit fuir la fumée,

Et les bois étaient noirs jusques à l'horizon.

Nous marchions, sans parler, dans l'humide gazon,

Dans la bruyère épaisse et dans les hautes brandes,

Lorsque, sous des sapins pareils à ceux des Landes, ${ }^{1}$

Nous avons aperçu les grands ongles marqués ${ }^{2}$

Par les loups voyageurs que nous avions traqués.

Nous avons écouté, retenant notre haleine

Et le pas suspendu. - Ni le bois ni la plaine

Ne poussaient un soupir dans les airs; seulement

La girouette en deuil criait au firmament;

Car le vent, élevé bien au-dessus des terres,

N'effleurait de ses pieds que les tours solitaires,

Et les chênes d'en bas, contre les rocs penchés,

Sur leurs coudes semblaient endormis et couchés. 
Rien ne bruissait donc, lorsque, baissant la tête, Le plus vieux des chasseurs qui s'étaient mis en quête, A regardé le sable en s'y couchant; bientôt Lui que jamais, ici l'on ne vit en défaut,

A déclaré tout bas que ces marques récentes Annonçaient la démarche et les griffes puissantes De deux grands loups-cerviers et de deux louveteaux. Nous avons tous alors préparé nos couteaux, Et, cachant nos fusils et leurs lueurs trop blanches, Nous allions pas à pas en écartant les branches. Trois s'arrêtent, et moi, cherchant ce qu'ils voyaient, J'aperçois tout à coup deux yeux qui flamboyaient, Et je vois au delà quatre formes légères

Qui dansaient sous la lune au milieu des bruyères, Comme font chaque jour, à grand bruit sous nos yeux Quand le maître revient, les lévriers joyeux. Leur forme était semblable et semblable la danse ; Mais les enfants du Loup se jouaient en silence, Sachant bien qu'à deux pas, ne dormant qu'à demi, Se couche dans ses murs l'homme, leur ennemi. Le père était debout, et plus loin, contre un arbre, Sa louve reposait comme celle de marbre ${ }^{1}$ Qu'adoraient les Romains, et dont les flancs velus Couvaient les demi-dieux Rémus et Romulus. Le Loup vient et s'assied, les deux jambes dressées, Par leurs ongles crochus dans le sable enfoncées. Il s'est jugé perdu, puisqu'il était surpris, Sa retraite coupée et tous ses chemins pris ; Alors il a saisi, dans sa gueule brûlante, Du chien le plus hardi la gorge pantelante, Et n'a pas desserré ses mâchoires de fer, Malgré nos coups de feu qui traversaient sa chair, Et nos couteaux aigus qui, comme des tenailles, Se croisaient en plongeant dans ses larges entrailles, Jusqu'au dernier moment où le chien étranglé, Mort longtemps avant lui, sous ses pieds a roulé. Le Loup le quitte alors et puis il nous regarde. Les couteaux lui restaient au flanc jusqu'à la garde, Le clouaient au gazon tout baigné dans son sang;

Il nous regarde encore, ensuite il se recouche, 
Tout en léchant le sang répandu sur sa bouche, Et, sans daigner savoir comment il a péri, Refermant ses grands yeux, meurt sans jeter un cri.

J'ai reposé mon front sur mon fusil sans poudre, Me prenant à penser, et n'ai pu me résoudre A poursuivre sa louve et ses fils, qui, tous trois, Avaient voulu l'attendre, et, comme je le crois, Sans ses deux louveteaux, la belle et sombre veuve Ne l'eût pas laissé seul subir la grande épreuve; Mais son devoir était de les sauver, afin

De pouvoir leur apprendre à bien souffrir la faim, A ne jamais entrer dans le pacte des villes Que l'homme a fait avec les animaux serviles Qui chassent devant lui, pour avoir le coucher, Les premiers possesseurs du bois et du rocher.

Hélas ! ai-je pensé, malgré ce grand nom d'Hommes, Que j'ai honte de nous, débiles que nous sommes! Comment on doit quitter la vie et tous ses maux, C'est vous qui le savez, sublimes animaux!

A voir ce que l'on fut sur terre et ce qu'on laisse, Seul le silence est grand; tout le reste est faiblesse.

- Ah! je t'ai bien compris, sauvage voyageur,

Et ton dernier regard m'est allé jusqu'au cœur! Il disait : "Si tu peux, fais que ton âme arrive, A force de rester studieuse et pensive, Jusqu'à ce haut degré de stoïque fierté Où, naissant dans les bois, j'ai tout d'abord monté.

Gémir, pleurer, prier, est également lâche.

Fais énergiquement ta longue et lourde tâche

Dans la voie où le sort a voulu t'appeler,

Puis, après, comme moi, souffre et meurs sans parler. » 


\title{
VICTOR-MARIE HUGO
}

\author{
Besançon, I 802-I 885 , Paris
}

Son of an officer under Napoleon I, Victor Hugo passed part of his childhood in Italy and Spain where his father was stationed. He early showed great aptitude for poetry, and, at the age of twenty, published his first volume of verse ("Odes," 1822), followed in I824 and I 826 by a second and third volume, entitled "Odes et ballades." Without giving evidence of the entire independence Hugo later developed, the "Odes et ballades" were clearly in line with the new literary ideals. Hugo's success put him forward as the natural leader of the younger generation of poets, who formed themselves into a "Cénacle." Chateaubriand, Madame de Staël, and Lamartine had made it possible for this new literary school, called the Romantic School, to take definite form, and now its theories were expounded by Hugo in the Preface to "Cromwell" (1827), a long drama not written to be played. Three years later Hugo produced "Hernani" (I830), a drama in verse in which the new ideas were exemplified and in which the Romanticists won a victory over the violent opposition of the exponents of conservatism. "Hernani" was followed by "Marion Delorme" (1831); "Le roi s'amuse" (1832); "Ruy Blas" (1838); and the "Burgraves" (1843), by the failure of which Hugo was led to give up writing for the stage.

In the meantime he had published "Notre-Dame de Paris" (183r), an archæological novel filled with brilliant pictures and affording striking glimpses of the Paris of the fifteenth century. Of his other novels "Les misérables" (1862), a powerful prose epic, is the most remarkable; though mention should also be made of "Les travailleurs de la mer" (1866) and "Quatrevingt-treize" (1874).

But it was as a lyric poet that Hugo stands out above his contemporaries, if not as the greatest of all French poets. "Les orientales" (I829), "Les feuilles d'automne" (183r), "Les chants du crépuscule" (I 835 ), "Les voix intérieures" (1837), "Les rayons et les ombres" (I840), "Les contemplations" (1856), all displayed a wealth of imagination, an infinite variety of form, an entire mastery of versification, a wonderful command of language, and a striking richness of color. These same qualities, often carried to the extreme, are found in the "Légende des siècles" (1859, 1877, 1883).

Hugo was elected to the Academy in 1841. During the latter part of the reign of Louis Philippe he entered somewhat into politics. He became an ardent republican after the downfall of the July monarchy, strongly opposed the Napoleonic restoration, and thus, after the "coup d'état" of $185 \mathrm{I}$, had to leave France. He spent the next eighteen years in Jersey and Guernsey, and while in exile launched forth against Napoleon III "Les châtiments" (1853), 
"Napoléon le petit" (1853), and the "Histoire d'un crime" (written in 1852). He did not return to Paris until the fall of the empire, when again he played a considerable part in politics. At his death in 1885 the republican government of France gave him a national funeral, and he is generally recognized as the greatest literary figure of the nineteenth century.

\section{TRISTESSE D'OLYMPIO}

Les champs n'étaient point noirs, les cieux n'étaient pas mornes ;

Non, le jour rayonnait dans un azur sans bornes

Sur la terre étendu,

L'air était plein d'encens et les prés de verdures

Quand il revit ces lieux où par tant de blessures

Son cœur s'est répandu.

L'automne souriait; les coteaux vers la plaine

Penchaient leurs bois charmants qui jaunissaient à peine ;

Le ciel était doré ;

Et les oiseaux, tournés vers celui que tout nomme,

Disant peut-être à Dieu quelque chose de l'homme,

Chantaient leur chant sacré.

Il voulut tout revoir, l'étang près de la source,

La masure où l'aumône avait vidé leur bourse,

Le vieux frêne plié,

Les retraites d'amour au fond des bois perdues,

L'arbre où dans les baisers leurs âmes confondues

Avaient tout oublié.

Il chercha le jardin, la maison isolée,

La grille d'où l'œil plonge en une oblique allée,

Les vergers en talus.

Pâle, il marchait. - Au bruit de son pas grave et sombre

Il voyait à chaque arbre, hélas! se dresser l'ombre

Des jours qui ne sont plus.

Il entendait frémir dans la forêt qu'il aime

Ce doux vent qui, faisant tout vibrer en nous-même,

$Y$ réveille l'amour,

Et, remuant le chêne ou balançant la rose,

Semble l'âme de tout qui va sur chaque chose

Se poser tour à tour. 
Les feuilles qui gisaient dans le bois solitaire, S'efforçant sous ses pas de s'élever de terre, Couraient dans le jardin;

Ainsi, parfois, quand l'âme est triste, nos pensées

S'envolent un moment sur leurs ailes blessées, Puis retombent soudain.

Il contempla longtemps les formes magnifiques

Que la nature prend dans les champs pacifiques;

Il rêva jusqu'au soir ;

Tout le jour il erra le long de la ravine,

Admirant tour à tour le ciel, face divine,

Le lac, divin miroir.

Hélas! se rappelant ses douces aventures, Regardant, sans entrer, par-dessus les clôtures,

Ainsi qu'un paria,

Il erra tout le jour. Vers l'heure où la nuit tombe,

Il se sentit le cœur triste comme une tombe,

Alors il s'écria :

- « $\mathrm{O}$ douleur! j'ai voulu, moi dont l'âme est troublée,

Savoir si l'urne encor conservait la liqueur,

Et voir ce qu'avait fait cette heureuse vallée

De tout ce que j'avais laissé là de mon cœur !

"Que peu de temps suffit pour changer toutes choses!

Nature au front serein, comme vous oubliez!

25 Et comme vous brisez dans vos métamorphoses

Les fils mystérieux où nos cœurs sont liés!

"Nos chambres de feuillage en halliers sont changées;

L'arbre où fut notre chiffre est mort ou renversé ;

Nos roses dans l'enclos ont été ravagées

Par les petits enfants qui sautent le fossé.

"Un mur clôt la fontaine où, par l'heure échauffée,

Folâtre, elle buvait en descendant des bois ;

Elle prenait de l'eau dans sa main, douce fée,

Et laissait retomber des perles de ses doigts!

" On a pavé la route âpre et mal aplanie, Où, dans le sable pur se dessinant si bien, 
Et de sa petitesse étalant l'ironie,

Son pied charmant semblait rire à côté du mien.

" La borne du chemin, qui vit des jours sans nombre,

Où jadis pour m'entendre elle aimait à s'asseoir,

S'est usée en heurtant, lorsque la route est sombre,

Les grands chars gémissants qui reviennent le soir.

« La forêt ici manque et là s'est agrandie.

De tout ce qui fut nous presque rien n'est vivant;

Et, comme un tas de cendre éteinte et refroidie,

L'amas des souvenirs se disperse à tout vent!

( N'existons-nous donc plus? Avons-nous eu notre heure?

Rien ne la rendra-t-il à nos cris superflus?

L'air joue avec la branche au moment où je pleure ;

Ma maison me regarde et ne me connaît plus.

( D'autres vont maintenant passer où nous passâmes.

Nous y sommes venus, d'autres vont y venir;

Et le songe qu'avaient ébauché nos deux âmes,

Ils le continueront sans pouvoir le finir!

"Car personne ici-bas ne termine et n'achève;

Les pires des humains sont comme les meilleurs;

Nous nous réveillons tous au même endroit du rêve.

Tout commence en ce monde et tout finit ailleurs. . . .

“ Dieu nous prête un moment les prés et les fontaines, Les grands bois frissonnants, les rocs profonds et sourds, Et les cieux azurés et les lacs et les plaines,

Pour y mettre nos cœurs, nos rêves, nos amours ;

“ Puis il nous les retire. Il souffle notre flamme.

Il plonge dans la nuit l'astre où nous rayonnons;

Et dit à la vallée, où s'imprima notre âme,

D'effacer notre trace et d'oublier nos noms.

" Eh bien! oubliez-nous, maison, jardin, ombrages !

Herbe, use notre seuil! ronce, cache nos pas!

Chantez, oiseaux ! ruisseaux, coulez! croissez, feuillages!

Ceux que vous oubliez ne vous oublieront pas. . . . 
( Dans ces jours où la tête au poids des ans s'incline, Où l'homme, sans projets, sans but, sans visions, Sent qu'il n'est déjà plus qu'une tombe en ruine Où gisent ses vertus et ses illusions ;

"Quand notre âme en rêvant descend dans nos entrailles, Comptant dans notre cœur, qu'enfin la glace atteint, Comme on compte les morts sur un champ de batailles, Chaque douleur tombée et chaque songe éteint,

" Comme quelqu'un qui cherche en tenant une lampe,

Loin des objets réels, loin du monde rieur, Elle arrive à pas lents par une obscure rampe Jusqu'au fond désolé du gouffre intérieur;

( Et là, dans cette nuit qu'aucun rayon n'étoile, L'âme en un repli sombre où tout semble finir, Sent quelque chose encor palpiter sous un voileC'est toi qui dors dans l'ombre, ô sacré souvenir! ”

— «Les rayons et les ombres »

\section{L'EXPIATION $^{1}$}

Il neigeait. On était vaincu par sa conquête. Pour la première fois l'aigle baissait la tête. Sombres jours! l'empereur revenait lentement, Laissant derrière lui brûler Moscou ${ }^{2}$ fumant. Il neigeait. L'âpre hiver fondait en avalanche. Après la plaine blanche une autre plaine blanche. On ne connaissait plus les chefs ni le drapeau. Hier la grande armée, et maintenant troupeau. On ne distinguait plus les ailes ni le centre. Il neigeait. Les blessés s'abritaient dans le ventre Des chevaux morts; au seuil des bivouacs désolés On voyait des clairons à leur poste gelés, Restés debout, en selle et muets, blancs de givre, Collant leur bouche en pierre aux trompettes de cuivre. Boulets, mitraille, obus, mêlés aux flocons blancs,

1 The "expiation" is for the overthrowing of the Directory by Napoleon on the eighteenth Brumaire (November 9, 1799), an expiation found not so much in subsequent defeats as in his successor, Napoleon III.

2 The retreat from Russia took place in the beginning of the winter of 1812 . 
Pleuvaient; les grenadiers, surpris d'être tremblants,

Marchaient pensifs, la glace à leur moustache grise.

Il neigeait, il neigeait toujours! La froide bise

Sifflait; sur le verglas, dans des lieux inconnus,

On n'avait pas de pain et l'on allait pieds nus.

Ce n'étaient plus des cœurs vivants, des gens de guerre,

C'était un rêve errant dans la brume, un mystère,

Une procession d'ombres sur le ciel noir.

La solitude, vaste, épouvantable à voir,

Partout apparaissait, muette vengeresse.

Le ciel faisait sans bruit avec la neige épaisse

Pour cette immense armée un immense linceul;

Et, chacun se sentant mourir, on était seul.

Sortira-t-on jamais de ce funeste empire?

Deux ennemis! le czar, le nord. Le nord est pire.

On jetait les canons pour brûler les affûts.

Qui se couchait, mourait. Groupe morne et confus,

Ils fuyaient; le désert dévorait le cortège.

On pouvait, à des plis qui soulevaient la neige,

Voir que des régiments s'étaient endormis là.

$\mathrm{O}$ chutes d'Annibal! lendemains d'Attila !

Fuyards, blessés, mourants, caissons, brancards, civières,

On s'écrasait aux ponts pour passer les rivières,

On s'endormait dix mille, on se réveillait cent.

$\mathrm{Ney},{ }^{1}$ que suivait naguère une armée, à présent

S'évadait, disputant sa montre à trois cosaques.

Toutes les nuits, qui-vive! alerte! assauts! attaques!

Ces fantômes prenaient leur fusil, et sur eux

Ils voyaient se ruer, effrayants, ténébreux,

Avec des cris pareils aux voix des vautours chauves,

D'horribles escadrons, tourbillons d'hommes fauves,

Toute une armée ainsi dans la nuit se perdait.

L'empereur était là, debout, qui regardait.

Il était comme un arbre en proie à la cognée.

Sur ce géant, grandeur jusqu'alors épargnée,

Le malheur, bûcheron sinistre, était monté ;

Et lui, chêne vivant, par la hache insulté,

Tressaillant sous le spectre aux lugubres revanches,

Il regardait tomber autour de lui ses branches.

Chefs, soldats, tous mouraient. Chacun avait son tour.

1 Ney (1769-1815), a distinguished general under the Empire, was put to death, by order of Louis XVIII, for having gone over to Napoleon during the Hundred Days. 
Tandis qu'environnant sa tente avec amour,

Voyant son ombre aller et venir sur la toile,

Ceux qui restaient, croyant toujours à son étoile,

Accusaient le destin de lèse-majesté,

$5 \quad$ Lui se sentit soudain dans l'âme épouvanté.

Stupéfait du désastre et ne sachant que croire,

L'empereur se tourna vers Dieu; l'homme de gloire

Trembla; Napoléon comprit qu'il expiait

Quelque chose peut-être, et, livide, inquiet,

Devant ses légions sur la neige semées :

Est-ce le châtiment, dit-il, Dieu des armées?-

Alors il s'entendit appeler par son nom

Et quelqu'un qui parlait dans l'ombre lui dit: Non.

\section{Waterloo! ${ }^{1}$ Waterloo! Waterloo! morne plaine!}

I 5 Comme une onde qui bout dans une urne trop pleine,

Dans ton cirque de bois, de coteaux, de vallons,

La pâle mort mêlait les sombres bataillons.

D'un côté c'est l'Europe et de l'autre la France.

Choc sanglant! des héros Dieu trompait l'espérance;

Tu désertais, victoire, et le sort était las.

O Waterloo! je pleure et je m'arrête, hélas !

Car ces derniers soldats de la dernière guerre

Furent grands; ils avaient vaincu toute la terre,

Chassé vingt rois, passé les Alpes et le Rhin,

Et leur âme chantait dans les clairons d'airain!

Le soir tombait; la lutte était ardente et noire.

Il avait l'offensive et presque la victoire;

Il tenait Wellington acculé sur un bois.

Sa lunette à la main il observait parfois

Le centre du combat, point obscur où tressaille

La mêlée, effroyable et vivante broussaille,

Et parfois l'horizon, sombre comme la mer.

Soudain, joyeux, il dit: Grouchy ! ${ }^{2}$ - C'était Blücher !

L'espoir changea de camp, le combat changea d'âme,

La mêlée en hurlant grandit comme une flamme.

La batterie anglaise écrasa nos carrés.

La plaine où frissonnaient nos drapeaux déchirés

1 The battle of Waterloo was fought on June 18,1815 .

2 Napoleon expected Grouchy with reënforcements; instead came Bliicher to reënforce the enemy. 
Ne fut plus, dans les cris des mourants qu'on égorge,

Qu'un gouffre flamboyant, rouge comme une forge;

Gouffre où les régiments, comme des pans de murs,

Tombaient, où se couchaient comme des épis mûrs

Les hauts tambours-majors aux panaches énormes,

Où l'on entrevoyait des blessures difformes!

Carnage affreux! moment fatal! L'homme inquiet

Sentit que la bataille entre ses mains pliait.

Derrière un mamelon la garde était massée,

La garde, espoir suprême et suprême pensée!

Allons! faites donner la garde ${ }^{1}$ cria-t-il, -

Et lanciers, grenadiers aux guêtres de coutil,

Dragons que Rome eût pris pour des légionnaires,

Cuirassiers, canonniers qui traînaient des tonnerres,

Portant le noir colback ou le casque poli,

Tous, ceux de Friedland ${ }^{2}$ et ceux de Rivoli, ${ }^{3}$

Comprenant qu'ils allaient mourir à cette fête,

Saluèrent leur dicu, debout dans la tempête.

Leur bouche, d'un seul cri, dit: Vive l'empereur I

Puis, à pas lents, musique en tête, sans fureur,

Tranquille, souriant à la mitraille anglaise,

La garde impériale entra dans la fournaise.

Hélas! Napoléon, sur sa garde penché,

Regardait ; et, sitôt qu'ils avaient débouché

Sous les sombres canons crachant des jets de soufre,

Voyait, l'un après l'autre, ẹn cet horrible gouffre,

Fondre ces régiments de granit et d'acier,

Comme fond une cire au souffle d'un brasier.

Ils allaient, l'arme au bras, front haut, graves, stoïques.

Pas un ne recula. Dormez, morts héroïques!

Le reste de l'armée hésitait sur leurs corps

Et regardait mourir la garde. - C'est alors

Qu'élevant tout à coup sa voix désespérée,

La Déroute, géante à la face effarée,

Qui, pâle, épouvantant les plus fiers bataillons

Changeant subitement les drapeaux en haillons,

A de certains moments, spectre fait de fumées,

Se lève grandissante au milieu des armées,

La Déroute apparut au soldat qui s'émeut,

Et, se tordant les bras, cria: Sauve qui peut !

1 "send out the guard."

2 Friedland was the scene of a victory of Napoleon over the Russians, June 14, 1807.

8 Bonaparte defeated the Austrians at Rivoli, January 14, 1797. 
Sauve qui peut! affront! horreur! toutes les bouches

Criaient ; à travers champs, fous, éperdus, farouches,

Comme si quelque souffle avait passé sur eux,

Parmi les lourds caissons et les fourgons poudreux,

Roulant dans les fossés, se cachant dans les seigles,

Jetant shakos, manteaux, fusils, jetant les aigles,

Sous les sabres prussiens, ces vétérans, ô deuil!

Tremblaient, hurlaient, pleuraient, couraient.-En un clin d'œil,

Commé s'envole au vent une paille enflammée,

S'évanouit ce bruit qui fut la grande armée,

Et cette plaine, hélas! où l'on rêve aujourd'hui,

Vit fuir ceux devant qui l'univers avait fui!

Quarante ans sont passés, et ce coin de la terre,

Waterloo, ce plateau funèbre et solitaire,

I 5 Ce champ sinistre où Dieu mêla tant de néants,

Tremble encor d'avoir vu la fuite des géants!

Napoléon les vit s'écouler comme un fleuve;

Hommes, chevaux, tambours, drapeaux ; et dans l'épreuve

Sentant confusément revenir son remords,

Levant les mains au ciel, il dit: Mes soldats morts,

Moi vaincu! mon empire est brisé comme verre.

Est-ce le châtiment cette fois, Dieu sévère?-

Alors parmi les cris, les rumeurs, le canon,

Il entendit la voix qui lui répondait : Non!

Il croula. Dieu changea la chaîne de l'Europe.

Il est, au fond des mers que la brume enveloppe,

Un roc hideux, ${ }^{1}$ débris des antiques volcans.

Le Destin prit des clous, un marteau, des carcans,

Saisit, pâle et vivant, ce voleur du tonnerre,

Et, joyeux, s'en alla sur le pic centenaire

Le clouer, excitant par son rire moqueur

Le vautour Angleterre à lui ronger le cœur.

Evanouissement d'une splendeur immense!

Du soleil qui se lève à la nuit qui commence,

Toujours l'isolement, l'abandon, la prison ;

Un soldat rouge au seuil, la mer à l'horizon,

Des rochers nus, des bois affreux, l'ennui, l'espace,

Des voiles s'enfuyant comme l'espoir qui passe,

Toujours le bruit des flots, toujours le bruit des vents!

1 The island of St. Helena, to which Napoleon was sent after Waterloo. 
Adieu, tente de pourpre aux panaches mouvants, Adieu, le cheval blanc que César éperonne!

Plus de tambours battant aux champs, plus de couronne,

Plus de rois prosternés dans l'ombre avec terreur,

Plus de manteau traînant sur eux, plus d'empereur!

Napoléon était retombé Bonaparte.

Comme un Romain blessé par la flèche du Parthe, ${ }^{1}$

Saignant, morne, il songeait à Moscou qui brûla.

Un caporal anglais lui disait: Halte-là!-

Son fils ${ }^{2}$ aux mains des rois, sa femme ${ }^{3}$ aux bras d'un autre! ro

Plus vil que le pourceau qui dans l'égout se vautre,

Son sénat, qui l'avait adoré, l'insultait.

$\mathrm{Au}$ bord des mers, à l'heure où la bise se tait,

Sur les escarpements croulant en noirs décombres,

Il marchait, seul, rêveur, captif des vagues sombres.

Sur les monts, sur les flots, sur les cieux, triste et fier,

L'œil encore ébloui des batailles d'hier,

Il laissait sa pensée errer à l'aventure.

Grandeur, gloire, ô néant! calme de la nature!

Les aigles qui passaient ne le connaissaient pas.

Les rois, ses guichetiers, avaient pris un compas

Et l'avaient enfermé dans un cercle inflexible.

Il expirait. La mort de plus en plus visible

Se levait dans sa nuit et croissait à ses yeux,

Comme le froid matin d'un jour mystérieux.

Son âme palpitait, déjà presque échappée.

Un jour enfin il mit sur son lit son épée,

Et se coucha près d'elle, et dit: C'est aujourd'hui ! -

On jeta le manteau de Marengo ${ }^{4}$ sur lui.

Ses batailles du Nil, du Danube, du Tibre,

Se penchaient sur son front; il dit: Me voici libre!

Je suis vainqueur! je vois mes aigles accourir ! -

Et, comme il retournait sa tête pour mourir,

Il aperçut, un pied dans la maison déserte,

Hudson Lowe ${ }^{5}$ guettant par la porte entr'ouverte.

1 The Parthians were dangerous even when retreating, as they would skillfully shoot darts over their shoulders.

2 After Napoleon's exile to St. Helena the king of Rome ( $S_{I I-1} \delta_{32}$ ) was intrusted by the allied powers to his grandfather, the emperor of Austria.

3 Soon after Napoleon's death his wife, Marie Louise, married Count Neipperg, who had been courting her for some time.

4 The scene of a victory of Bonaparte over the Austrians in 1800 .

5 Hudson Lowe $\left(1769^{-1} 8_{44}\right)$ was an English officer and governor of St. Helena during Napoleon's captivity there. 
Alors, géant broyé sous le talon des rois, Il cria : La mesure est comble cette fois !

Seigneur! c'est maintenant fini! Dieu que j'implore, Vous m'avez châtié ! - La voix dit: Pas encore!

— " Les châtiments »

\section{LA FILLE DU POÈTE}

Quand nous habitions tous ensemble Sur nos collines d'autrefois, Où l'eau court, où le buisson tremble Dans la maison qui touche aux bois,

Elle avait dix ans, et moi trente $;^{1}$

I0 J'étais pour elle l'univers.

$\mathrm{Oh}$ ! comme l'herbe est odorante Sous les arbres profonds et verts !

Elle faisait mon sort prospère, Mon travail léger, mon ciel bleu. Lorsqu'elle me disait: Mon père, Tout mon cœur s'écriait: Mon Dieu!

A travers mes songes sans nombre, J'écoutais son parler joyeux, Et mon cœur s'éclairait dans l'ombre

20 A la lumière de ses yeux.

Elle avait l'air d'une princesse Quand je la tenais par la main. Elle cherchait des fleurs sans cesse Et des pauvres dans le chemin.

Elle donnait comme on dérobe, En se cachant aux yeux de tous. Oh! la belle petite robe Qu'elle avait, vous rappelez-vous?

Le soir, auprès de ma bougie, Elle jasait à petit bruit,

1 Hugo was twenty-two when his oldest daughter, Léopoldine, was born. She, with her husband, was drowned in 1843 , soon after their marriage. 
Tandis qu'à la vitre rougie

Heurtaient les papillons de nuit.

Les anges se miraient en elle.

Que son bonjour était charmant!

Le ciel mettait dans sa prunelle

Ce regard qui jamais ne ment.

Oh! je l'avais, si jeune encore, Vue apparaître en mon destin!

C'était l'enfant de mon aurore,

Et mon étoile du matin!

Quand la lune claire et sereine

Brillait aux cieux, dans ces beaux mois,

Comme nous allions dans la plaine!

Comme nous courions dans les bois!

Puis, vers la lumière isolée

Etoilant le logis obscur,

Nous revenions par la vallée

En tournant le coin du vieux mur;

Nous revenions, cœurs pleins de flamme,

En parlant des splendeurs du ciel.

Je composais cette jeune âme

Comme l'abeille fait son miel.

Doux ange aux candides pensées,

Elle était gaie en arrivant. . . .

Toutes ces choses sont passées

Comme l'ombre et comme le vent!

Villequier, 4 septembre 1844

— "Les contemplations"

SAISON DES SEMAILLES

LE SOIR

C'est le moment crépusculaire.

J'admire, assis sous un portail,

Ce reste de jour dont s'éclaire

La dernière heure du travail. 
Dans les terres, de nuit baignées, Je contemple, ému, les haillons

D'un vieillard qui jette à poignées

La moisson future aux sillons.

Sa haute silhouette noire

Domine les profonds labours.

On sent à quel point il doit croire A la fuite utile des jours.

Il marche dans la plaine immense,

$\mathrm{Va}$, vient, lance la graine au loin, Rouvre sa main, et recommence, Et je médite, obscur témoin,

Pendant que, déployant ses voiles, L'ombre, où se mêle une rumeur, Semble élargir jusqu'aux étoiles

Le geste auguste du semeur.

- "Les chansons des rues et des bois »

\section{QUASIMODO}

Quasimodo était carillonneur de Notre-Dame. . . . Sa cathédrale lui suffisait. Elle était peuplée de figures de marbre, rois, saints, évêques, qui du moins ne lui éclataient pas de rire au nez et n'avaient pour lui 20 qu'un regard tranquille et bienveillant. Les autres statues, celles des monstres et des démons, n'avaient pas de haine pour lui Quasimodo. Il leur ressemblait trop pour cela. Elles raillaient bien plutôt les autres hommes. Les saints étaient ses amis, et le bénissaient; les monstres étaient ses amis et le gardaient. Aussi avait-il de longs épanchements 25 avec eux. Aussi passait-il quelquefois des heures entières, accroupi devant une de ces statues, à causer solitairement avec elle. Si quelqu'un survenait, il s'enfuyait comme un amant surpris dans sa sérénade. . . .

Ce qu'il aimait avant tout dans l'édifice maternel, ce qui réveillait son âme et lui faisait ouvrir ses pauvres ailes qu'elle tenait si miséra30 blement reployées dans sa caverne, ce qui le rendait parfois heureux, c'était les cloches. Il les aimait, les caressait, leur parlait, les comprenait. Depuis le carillon de l'aiguille de la croisée $^{1}$ jusqu'à la grosse 
cloche du portail, il les avait toutes en tendresse. Le clocher de la croisée, les deux tours, étaient pour lui comme trois grandes cages dont les oiseaux, élevés par lui, ne chantaient que pour lui. C'était pourtant ces mêmes cloches qui l'avaient rendu sourd, mais les mères aiment souvent le mieux l'enfant qui les a fait le plus souffrir.

Il est vrai que leur voix était la seule qu'il pût entendre encore. A ce titre, la grosse cloche était sa bien-aimée. C'était elle qu'il préférait dans cette famille de filles bruyantes qui se trémoussait autour de lui, les jours de fête. Cette grande cloche s'appelait Marie. Elle était seule dans la tour méridionale avec sa sœur Jacqueline, cloche de moindre ıo taille, enfermée dans une cage moins grande à côté de la sienne. Cette Jacqueline était ainsi nommée du nom de la femme de Jean Montagu, ${ }^{1}$ lequel l'avait donnée à l'église, ce qui ne l'avait pas empêché d'aller figurer sans tête à Montfaucon. Dans la deuxième tour il y avait six autres cloches, et enfin les six plus petites habitaient le clocher sur la 15 croisée avec la cloche de bois, qu'on ne sonnait que depuis l'aprèsdîner du jeudi absolut ${ }^{2}$ jusqu'au matin de la fête de Pâques. Quasimodo avait donc quinze cloches dans son sérail, mais la grosse Marie était la favorite.

On ne saurait se faire une idée de sa joie les jours de grande volée. 20 $\mathrm{Au}$ moment où l'archidiacre ${ }^{\mathbf{8}}$ l'avait lâché et lui avait dit: Allez, il montait la vis ${ }^{4}$ du clocher plus vite qu'un autre ne l'eût descendue. Il entrait tout essoufflé dans la chambre aérienne de la grosse cloche ; il la considérait un moment avec recueillement et amour; puis il lui adressait doucement la parole, il la flattait de la main, comme un bon 25 cheval qui va faire une longue course. Il la plaignait de la peine qu'elle allait avoir. Après ces premières caresses, il criait à ses aides, placés à l'étage inférieur de la tour, de commencer. Ceux-ci se pendaient aux câbles, le cabestan criait, et l'énorme capsule de métal s'ébranlait lentement. Quasimodo, palpitant, la suivait du regard. Le premier 30 choc du battant et de la paroi d'airain faisait frissonner la charpente sur laquelle il était monté. Quasimodo vibrait avec la cloche. Va! criait-il avec un éclat de rire insensé. Cependant le mouvement du bourdon s'accélérait, et, à mesure qu'il parcourait un angle plus ouvert, l'œil de Quasimodo s'ouvrait aussi de plus en plus phosphorique et flam- 35 boyant. Enfin la grande volée commençait, toute la tour tremblait,

1 Jean de Montagu, minister of Charles VI, born about 1349 , was decapitated in 1409 . 2 "Thursday of Holy Week."

8 Claude Frollo, who had adopted Quasimodo.

4 "winding staircase." 
charpentes, plombs, pierres de taille, tout grondait à la fois, depuis les pilotis de la fondation jusqu'aux trèfles du couronnement. Quasimodo allait bouillant à grosse écume; il allait, venait; il tremblait avec la tour de la tête aux pieds. La cloche, déchaînée et furieuse, présentait 5 alternativement aux deux parois de la tour sa gueule de bronze d'oú s'échappait ce souffle de tempête qu'on entend à quatre lieues. Quasimodo se plaçait devant cette gueule ouverte; il s'accroupissait, se relevait avec les retours de la cloche, aspirait ce souffle renversant, regardait tour à tour la place profonde qui fourmillait à deux cents ro pieds au-dessous de lui et l'énorme langue de cuivre qui venait de seconde en seconde lui hurler dans l'oreille. C'était la seule parole qu'il entendît, le seul son qui troublât pour lui le silence universel. Il s'y dilatait comme un oiseau au soleil. Tout à coup la frénésie de la cloche le gagnait; son regard devenait extraordinaire; il attendait le

I 5 bourdon au passage, comme l'araignée attend la mouche, et se jetait brusquement sur lui à corps perdu. Alors, suspendu sur l'abîme, lancé dans le balancement formidable de la cloche, il saisissait le monstre d'airain aux oreillettes, ${ }^{1}$ l'étreignait de ses deux genoux, l'éperonnait de ses deux talons, et redoublait de tout le choc et de tout le

20 poids de son corps la furie de la volée. Cependant la tour vacillait; lui, criait et grinçait des dents, ses cheveux roux se hérissaient, sa poitrine faisait le bruit d'un soufflet de forge, son œil jetait des flammes, la cloche monstrueuse hennissait toute haletante sous lui, et alors ce n'était plus ni le bourdon de Notre-Dame ni Quasimodo, c'était un 25 rêve, un tourbillon, une tempête; le vertige à cheval sur le bruit; un esprit cramponné à une croupe volante; un étrange centaure moitié homme, moitié cloche; une espèce d'Astolphe ${ }^{2}$ horrible emporté sur un prodigieux hippogriphe de bronze vivant.

La présence de cet être extraordinaire faisait circuler dans toute la 30 cathédrale je ne sais quel souffle de vie. . . . Elle était possédée et remplie de Quasimodo comme d'un génie familier. On eût dit qu'il faisait respirer l'immense édifice.

- "Notre-Dame de Paris»

1 Earlike projections on the top of the bell.

2 Astolfo, a character in the Charlemagne romances, whose horn inspired universal terror. 


\title{
CHARLES-AUGUSTIN SAINTE-BEUVE
}

\author{
Boulogne-sur-Mer, $1804-1869$, Paris
}

Sainte-Beuve renounced the study of medicine which he had at first taken up, entered with enthusiasm into the Romantic Movement, and, in the "Tableau de la poésie française au seizième siècle" (1828), a work crowned by the Academy, took occasion to favor the new literary ideas as opposed to the old. The following year he published a volume of poetry, "Poésies de Joseph Delorme" (1829), followed by the "Consolations" (1830) and the "Pensées d'août" (1837).

But in the meantime he had drifted away from Romanticism and had begun writing, for the "Revue de Paris" and the "Revue des deux mondes," essays which appeared in book form under the titles "Portraits littéraires" (3 vols., 1832-1839) and "Portraits contemporains" (5 vols., 1846). Later, from 1850 on, he published each Monday, first in "Le constitutionnel," then in "Le moniteur" and "Le temps," a series of articles on the most varied literary and historical subjects of ancient and modern times. These articles were collected under the titles "Causeries du lundi" (1 5 vols., I85I-1862), "Nouveaux lundis" (13 vols., 1863-1869), "Premiers lundis" (3 vols., published after his death), and comprise the most remarkable collection of literary essays in any language.

Meanwhile he had found time to write a history of Port-Royal ( 5 vols., I $840-$ 1859), developing in it a sketch of the literature of the seventeenth century in its relations with Jansenism, and a work on "Chateaubriand et son groupe littéraire" (186r). He was made a member of the Academy in 1845 , professor in the Collège de France in 1857 , and senator in 1865 .

\section{RACINE}

Ce qu'il ne faut jamais perdre de vue quand on juge Racine aujourd'hui, c'est la perfection, l'unité et l'harmonie de l'ensemble, ce qui en fait la principale beauté. A prendre les choses isolément et par parties, on se tromperait bientôt; le caractère essentiel échapperait, et l'on prononcerait à côté. Au contraire, à bien sentir cette perfection de l'ensemble, cela devient une lumière générale qui réfléchit sur chaque détail et qui l'éclaire. . . .

L'unité, la beauté de l'ensemble chez Racine se subordonne tout. Dans les moments même de la plus grande passion, la volonté du poète, sans se laisser apercevoir, dirige, domine, gouverne, modère. Il ro 
y a le calme de l'âme supérieure et divine, même au travers et au-dessus de tous les pleurs et de toutes les tendresses.

C'est là un genre de beauté invisible et spirituelle, ignorée des talents qui mettent tout en dehors: même quand ce qu'on met en 5 dehors serait le plus beau et le plus riche du monde, il y a toujours entre cette dernière manière et l'autre la même différence à peu près qu'entre le monde de l'idolâtrie, du paganisme ou, si l'on aime mieux, du panthéisme le plus efflorescent, et le monde accompli tel qu'il existe pour qui le voit avec les yeux d'un Platon ou d'un Fénelon, pour ceux Io qui croient à la création distincte, qui maintiennent l'homme souverain, et roi avant tout, en tête de son ordre, et (s'y mêlât-il même de l'illusion humaine) au centre de la sphère et de la coupole rayonnante.

Racine est un grand dramatique, et il l'a été naturellement, par vocation. Il a pris la tragédie dans les conditions où elle était alors, I 5 et il s'y est développé avec aisance et grandeur, en l'appropriant singulièrement à son propre génie. Mais il y a un tel équilibre dans les facultés de Racine, et il a de si complètes facultés rangées sans tumulte sous sa volonté lumineuse, qu'on se figure aisément qu'une autre quelconque de ses facultés eût donné avec avantage également 20 et gloire, et sans que l'équilibre eût été rompu.

Le cardinal de Retz, en ses Mémoires, a dit de Turenne, ${ }^{1}$ le plus parfait de nos héros comme Racine est le plus parfait de nos poètes, et qui a fini par ses plus belles campagnes comme Racine par sa plus belle tragédie: “ $\mathrm{M}$. de Turenne a eu, dès sa jeunesse, toutes les

25 bonnes qualités, et il a acquis les grandes d'assez bonne heure. Il ne lui en a manqué aucune, que celles dont il ne s'est pas avisé. Il avait presque toutes les vertus comme naturelles; il n'a jamais eu le brillant d'aucune. On l'a cru plus capable d'être à la tête d'une armée que d'un parti, et je le crois aussi, parce qu'il n'était pas naturellement 30 entreprenant: mais toutefois, qui le sait? Il a toujours eu en tout, comme en son parler, de certaines obscurités qui ne se sont développées que dans les occasions, mais qui ne se sont jamais développées qu'à sa gloire. »

On ne peut dire de Racine comme de Turenne qu'il n'a pas eu le 35 brillant de ses qualités, mais il n'en a pas eu l'étalage ni l'appareil; il n'en a pas eu l'impétueux et le soudain, comme Corneille par exemple l'avait, avec un peu trop de jactance aussi; et il a toujours eu en tout,

1 Turenne ( $1611-1675)$, a marshal of France, distinguished himself in the Thirty Years' War and under Louis XIV. 
comme en son parler, non pas de certaines obscurités, mais de certaines retenues, qui ne se sont développées que dans les occasions et selon les sujets, mais qui ne s'y sont jamais développées qu'à sa gloire.

Racine est tendre, dit-on, c'est un élégiaque dramatique. Prenez garde! celui qui a fait la scène du troisième acte de Mithridate et Britannicus, le peintre de Burrhus, est-il gêné à manier la tragédie d'État et à tirer le drame sévère du cœur de l'histoire?

Ainsi de tout pour Racine : il serait téméraire de lui nier ce qu'il n'a pas fait, tant il a été accompli sans effort dans tout ce qu'il a fait! Pour moi, je me le figure à merveille dans d'autres genres que la tra- 10 gédie; par exemple, donnant un poème épique, dans le goût de celui du Tasse ; des élégies, comme les belles et sobres méditations premières, comme les élégies closes de Lamartine; des satires comme la Dunciade de Pope; des épigrammes comme celles de Le Brun ${ }^{1}$. . .; des romans historiques plus aisés que celui de Manzoni ${ }^{2}$; des comé- 15 dies comme les Plaideurs en pouvaient promettre. Des odes, il en a fait; des Petites Lettres $^{3}$ comme Pascal, il en a trop bien commencé. Orateur académique, il l'a été, et avec éclat. Et toujours et partout (remarquez!) on aurait le même Racine, avec ses traits nobles, élégants et choisis, recouvrant sa force et sa passion; toujours quel- 20 que chose de naturel et de soigné à la fois, et d'accompli, toujours l'auteur sans tourment, au niveau et au centre de son genre et de son sujet.

Mais la forme dramatique était celle que son temps lui offrait la plus ouverte et la plus digne de lui; il y entra tout entier, et au troisième 25 pas il y était maître. Il y versa tous ses dons, et il en reçut des ressorts nouveaux dont il s'aida toujours, dont il ne souffrit jamais. En ne sortant pas, un seul instant, de l'originalité distincte qu'il portait et cachait en ses œuvres harmonieuses, en ne cessant jamais de faire ce que lui seul eût pu faire, il marcha toujours, variant ses progrès, 3o diversifiant ses tons, poussant sur tous les points ses qualités même les plus tendres et les plus enchanteresses à une sorte de grandeur, jusqu'à ce qu'il arrivât, après cette adorable suite des Bérénice, des Monime et des Iphigénie, à ce caractère de Phèdre, aussi tendre qu'aucun et le plus passionné, le plus antique et déjà chrétien, le plus 35 attachant à la fois et le plus terrible sous son éclair sacré. . . .

1 Le Brun (1729-1807), a French poet whose epigrams are particularly clever.

2 Manzoni ( $1784-1873)$, an Italian poet and novelist, author of "I promessi sposi."

3 The "Lettres provinciales." 
L'œuvre de Racine, comme toutes les belles œuvres, essuya sans doute en naissant bien des mauvais vouloirs et des critiques. Pourtant cette contradiction chétive disparaît de loin dans l'applaudissement universel et dans l'admiration très vite unanime. Le propre de l'œuvre 5 de Racine, en effet, est d'être parfaite, d'une perfection à la fois profonde et évidente. A quelque degré qu'on s'arrête dans l'intelligence de son œuvre, on a l'idée d'une certaine perfection; on ne tombe jamais sur une impression incomplète ou qui offense. Shakespeare a besoin d'être compris tout à fait pour ne jamais choquer et rebuter ; ıo Molière lui-même est un peu ainsi. Il y a chez eux des choses qui ne s'expliquent et ne se légitiment qu'au dernier point de vue. Avec Racine, bien qu'il soit vrai que plus on avance et plus on admire, on admire encore quand on ne va pas très avant. Son élévation est tellement graduée et accessible, qu'il y en a pour chacun; à chaque gradin

15 du temple, on peut faire station; même quand on n'a pas toute la vue, on a une vue complète en soi, symétrique et harmonieuse. Son œuvre parfaite se trouve avec ses hauteurs et ses profondeurs, placée au milieu de tout le monde, proportionnément comprise de tous, éclairée par tous les aspects.

20 Surtout, j'insiste là-dessus, jamais rien qui offense ni même qui étonne ; rien d'étrange; sa manière comme sa physionomie est d'une beauté heureuse, ouverte sans être banale, d'une de ces beautés incontestables et qui existent pour tous. Racine et Louis XIV sont, régulièrement parlant, les deux plus beaux visages de cette Cour.

25 Isa poésie de Racine est au centre de la poésie française; elle en est le centre incontesté : en est-elle le centre unique? Ceci devient une autre question.

— "Port-Royal », Book VI

\section{QU'EST-CE QU'UN CLASSIQUE?}

Un vrai classique, comme j'aimerais à l'entendre définir, c'est un auteur qui a enrichi l'esprit humain, qui en a réellement augmenté le 30 trésor, qui lui a fait faire un pas de plus, qui a découvert quelque vérité morale non équivoque, ou ressaisi quelque passion éternelle dans ce cœur où tout semblait connu et exploré ; qui a rendu sa pensée, son observation ou son invention, sous une forme n'importe laquelle, mais large et grande, fine et sensée, saine et belle en soi ; qui a parlé 
à tous dans un style à lui et qui se trouve aussi celui de tout le monde, dans un style nouveau sans néologisme, nouveau et antique, aisément contemporain de tous les âges. ... .

Au reste, il ne s'agit véritablement de rien sacrifier, de rien déprécier. Le Temple du goût, je le crois, est à refaire; mais, en le rebâtissant, il s'agit simplement de l'agrandir, et qu'il devienne le Panthéon de tous les nobles humains, de tous ceux qui ont accru pour une part notable et durable la somme des jouissances et des titres de l'esprit. Pour moi, qui ne saurais à aucun degré prétendre (c'est trop évident) à être architecte ou ordonnateur d'un tel Temple, je me bornerai à ıo exprimer quelques vœux, à concourir en quelque sorte pour le devis. Avant tout je voudrais n'exclure personne entre les dignes, et que chacun y fût à sa place, depuis le plus libre des génies créateurs et le plus grand des classiques sans le savoir, Shakespeare, jusqu'au tout dernier des classiques en diminutif, Andrieux. ${ }^{1}$ "Il y a plus d'une 15 demeure dans la maison de mon père »; que cela soit vrai du royaume du beau ici-bas non moins que du royaume des cieux. Homère, comme toujours et partout, y serait le premier, le plus semblable à un dieu; mais derrière lui, et tel que le cortège des trois rois mages d'Orient, se verraient ces trois poètes magnifiques, ces trois 20 Homères longtemps ignorés de nous, et qui ont fait, eux aussi, à l'usage des vieux peuples d'Asie, des épopées immenses et vénérées, les poètes Valmiki ${ }^{2}$ et $\mathrm{Vyasa}^{\mathbf{3}}$ des Indous, et le Firdousi ${ }^{4}$ des Persans: il est bon, dans le domaine du goût, de savoir du moins que de tels hommes existent et de ne pas scinder le genre humain. 25 Cet hommage rendu à ce qu'il suffit d'apercevoir et de reconnaître, nous ne sortirions plus de nos horizons, et l'œil s'y complairait en mille spectacles agréables ou augustes, s'y réjouirait en mille rencontres variées et pleines de surprise, mais dont la confusion apparente ne serait jamais sans accord et sans harmonie. Les plus antiques des 30 sages et des poètes, ceux qui ont mis la morale humaine en maximes et qui l'ont chantée sur un mode simple converseraient entre eux avec des paroles rares et suaves, ${ }^{5}$ et ne seraient pas étonnés, dès le premier

1 Andrieux (1759-1833), French poet and dramatist, author of "Le meunier SansSouci," etc.

2 Valmiki, ancient Hindu author to whom the Sanskrit epic "Ramayana" is attributed.

3 Vyasa, theologian, philosopher, and poet, compiler of the "Vedas."

4 Firdusi (about 940-1020), a great epic poet of Persia, author of the "Shahnamah," which celebrates the deeds of Iranian and Persian sovereigns.

5 Dante's "Inferno," IV, II. 
mot, de s'entendre. Les Solon, ${ }^{1}$ les Hésiode, ${ }^{2}$ les Théognis, ${ }^{8}$ les Job, les Salomon, et pourquoi pas Confucius lui-même? accueilleraient les plus ingénieux modernes, les La Rochefoucauld et les La Bruyère, lesquels se diraient en les écoutant: "Ils savaient tout ce que nous 5 savons, et, en rajeunissant l'expérience, nous n'avons rien trouvé. » Sur la colline la plus en vue et de la pente la plus accessible, Virgile entouré de Ménandre, ${ }^{4}$ de Tibulle, ${ }^{5}$ de Térence,${ }^{6}$ de Fénelon, se livrerait avec eux à des entretiens d'un grand charme et d'un enchantement sacré: son doux visage serait éclairé du rayon et coloré de pudeur, ıo comme ce jour où, entrant au théâtre de Rome dans le moment qu'on venait d'y réciter ses vers, il vit le peuple sc lever tout entier devant lui par un mouvement unanime, et lui rendre les mêmes hommages qu'à Auguste lui-même. Non loin de lui, et avec le regret d'être séparé d'un ami si cher, Horace présiderait à son tour (autant qu'un

I 5 poète et qu'un sage si fin peut présider) le groupe des poètes de la vie civile et de ceux qui ont su causer quoiqu'ils aient chanté, - Pope, Despréaux, l'un devenu moins irritable, l'autre moins grondeur; Montaigne, ce vrai poète, en serait, et il achèverait d'ôter à ce coin charmant tout air d'école littéraire. La Fontaine s'y oublierait, et, 2o désormais moins volage, n'en sortirait plus. Voltaire y passerait, mais, tout en s'y plaisant, il n'aurait pas la patience de s'y tenir. Sur la même colline que Virgile, et un peu plus bas, on verrait Xénophon, d'un air simple qui ne sent en rien le capitaine, et qui le fait ressembler plutôt à un prêtre des Muses, réunir autour de lui les attiques de 25 toute langue et de tout pays, les Addison, les Pellisson, ${ }^{7}$ les Vauvenargues, tous ceux qui sentent le prix d'une persuasion aisée, d'une simplicité exquise et d'une douce négligence mêlée d'ornement. Au centre du lieu, trois grands hommes aimeraient souvent à se rencontrer devant le portique du principal temple (car il y en aurait plusieurs dans

30 l'enceinte), et, quand ils seraient ensemble, pas un quatrième, si grand qu'il fût, n'aurait l'idée de venir se mêler à leur entretien ou à leur silence, tant il paraîtrait en eux de beauté, de mesure dans la grandeur, et de cette perfection d'harmonie qui ne se présente 'qu'un jour dans

\footnotetext{
1 Solon (about $63_{3} 8$ в.c.-about 559 B.c.), the Athenian lawgiver.

2 Hesiod, a Greek poet, born about 735 B.c.

3 Theognis, a Greek elegiac poet of the sixth century в.C.

4 Menander ( $34^{2}$ B.C. -291 B.C.), an Athenian comic poet.

5 Tibullus, a Roman elegiac poet of the first century B.C.

6 Terence, a Latin comic poet of the second century B.C.

7 Pellisson (1624-1693), author of the "Histoire de l'Académie française."
} 
la pleine jeunesse du monde. Leurs trois noms sont devenus l'idéal de l'art: Platon, Sophocle et Démosthène. Et, malgré tout, ces demidieux une fois honorés, ne voyez-vous point là-bas une foule nombreuse et familière d'esprits excellents qui va suivre de préférence les Cervantes, les Molière toujours, les peintres pratiques de la vie, ces amis indulgents et qui sont encore les premiers des bienfaiteurs, qui prennent l'homme entier avec le rire, lui versent l'expérience dans la gaieté, et savent les moyens puissants d'une joie sensée, cordiale et légitime? Je ne veux pas continuer ici plus longtemps cette description qui, si elle était complète, tiendrait tout un livre. Le moyen âge, 10 croyez-le bien, et Dante occuperaient des hauteurs consacrées : aux pieds du chantre du Paradis, l'Italie se déroulerait presque tout entière comme un jardin; Boccace et l'Arioste s'y joueraient, et le Tasse ${ }^{1}$ retrouverait la plaine d'orangers de Sorrente. En général, les nations diverses y auraient chacune un coin réservé, mais les auteurs se plai- 15 raient à en sortir, et ils iraient en se promenant reconnaître, là où l'on s'y attendrait le moins, des frères ou des maîtres. Lucrèce, ${ }^{2}$ par exemple, aimerait à discuter l'origine du monde et le débrouillement du chaos avec Milton; mais, en raisonnant tous deux dans leur sens, ils ne seraient d'accord que sur les tableaux divins de la poésie et de 20 la nature.

Voilà nos classiques ; l'imagination de chacun peut achever le dessin et même choisir son groupe préféré. Car il faut choisir, et la première condition du goût, après avoir tout compris, est de ne pas voyager sans cesse, mais de s'asseoir une fois et de se fixer. Rien ne blase et 25 n'éteint plus le goût que les voyages sans fin; l'esprit poétique n'est pas le Juif errant. ${ }^{3}$ Ma conclusion pourtant, quand je parle de se fixer et de choisir, ce n'est pas d'imiter ceux même qui nous agréent le plus entre nos maîtres dans le passé. Contentons-nous de les sentir, de les pénétrer, de les admirer, et nous, venus si tard, tâchons du 30 moins d'être nous-mêmes. Faisons notre choix dans nos propres instincts. Ayons la sincérité et le naturel de nos propres pensées, de nos sentiments, cela se peut toujours; joignons-y, ce qui est plus difficile, l'élévation, la direction, s'il se peut, vers quelque but haut placé ; et tout en parlant notre langue, en subissant les conditions des 35

1 Tasso was born at Sorrento in 1544 .

2 Lucretius, a Roman philosopher and poet of the first century B.C.

3 The Juif errant is a legendary character with whom have been connected the words of Christ: "Thou shalt wander on the earth till I return"; also the title of a famous novel by Eugène Sue (1804-1857). 
âges où nous sommes jetés et où nous puisons notre force comme nos défauts, demandons-nous de temps en temps, le front levé vers les collines et les yeux attachés aux groupes des mortels révérés: Que diraient-ils de nous?

5 Mais pourquoi parler toujours d'être auteur et d'écrire? Il vient un âge, peut-être, où l'on n'écrit plus. Heureux ceux qui lisent, qui relisent, ceux qui peuvent obéir à leur libre inclination dans leurs lectures! Il vient une saison dans la vie, où, tous les voyages étant faits, toutes les expériences achevées, on n'a pas de plus vives jouissances ıo que d'étudier et d'approfondir les choses qu'on sait, de savourer ce qu'on sent, comme de voir et de revoir les gens qu'on aime: pures délices du cœur et du goût dans la maturité. C'est alors que ce mot de classique prend son vrai sens, et qu'il se définit pour tout homme de goût par un choix de prédilection et irrésistible. Le goût est fait I 5 alors, il est formé et définitif; le bon sens chez nous, s'il doit venir, est consommé. On n'a plus le temps d'essayer ni l'envie de sortir à la découverte. On s'en tient à ses amis, à ceux qu'un long commerce a éprouvés. Vieux vin, vieux livres, vieux amis. On se dit comme Voltaire dans ces vers délicieux :

Jouissons, écrivons, vivons, mon cher Horace ! . .

J'ai vécu plus que toi: mes vers dureront moins;

Mais, au bord du tombeau, je mettrai tous mes soins

A suivre les leçons de ta philosophie,

A mépriser la mort en savourant la vie,

Enfin, que ce soit Horace ou tout autre, quel que soit l'auteur qu'on préfère et qui nous rende nos propres pensées en toute richesse et maturité, on va demander alors à quelqu'un de ces bons et antiques 30 esprits un entretien de tous les instants, une amitié qui ne trompe pas, qui ne saurait nous manquer, et cette impression habituelle de sérénité et d'aménité qui nous réconcilie, nous en avons souvent besoin, avec les hommes et avec nous-même. 


\title{
ALFRED DE MUSSET
}

\author{
Paris, I $810-1857$, Paris
}

Alfred de Musset first studied law, then medicine, but soon gave up each, and, under the encouragement of Victor Hugo and the "Cénacle," turned to poetry. His first volume of verse, "Contes d'Espagne et d'Italie," appeared in 1830. It was in line with the ideals of the Romanticists, and was well received by the younger generation. It was followed in 1832 by the "Spectacle dans un fauteuil," in which Musset showed a greater independence toward the Romantic School. His memorable liaison with George Sand, which began the following year ( 1833 ), was of short duration, but it aroused the deepest emotions of Musset's sensitive nature, and led to the passionate outbursts of disappointment and grief, and oftentimes melancholy discontent and disenchantment with life, in the "Nuits," the "Lettre à Lamartine," the "Espoir en Dieu," which, with the "Ode à la Malibran," give him a place by the side of the greatest poets of France.

After I 840 Musset's work was chiefly in prose : the "Contes et nouvelles," and those charming, graceful, and delicate comedies, "Fantasio," "On ne badine pas avec l'amour," "Un caprice," "Il ne faut jurer de rien," "Il faut qu'une porte soit ouverte ou fermée," some of which still form a part of the repertoire of the French stage.

He was elected to the Academy in 1852 . He was already broken in spirit and health, and died in 1857 , his last years being spent in a vain attempt to drown his misery.

\section{LA NUIT DE IDÉCEMBRE}

\section{Le Poìte}

Du temps que j'étais écolier, Je restais un soir à veiller

Dans notre salle solitaire.

Devant ma table vint s'asseoir

Un pauvre enfant vêtu de noir,

Qui me ressemblait comme un frère.

Son visage était triste et beau.

A la lueur de mon flambeau,

Dans mon livre ouvert il vint lire.

Il pencha son front sur ma main, 
Et resta jusqu'au lendemain, Pensif, avec un doux sourire.

Comme j'allais avoir quinze ans, Je marchais un jour, à pas lents, Dans un bois, sur une bruyère. Au pied d'un arbre vint s'asseoir Un jeune homme vêtu de noir, Qui me ressemblait comme un frère.

IO

Je lui demandai mon chemin;

Il tenait un luth d'une main, De l'autre un bouquet d'églantine. Il me fit un salut d'ami, Et, se détournant à demi, Me montra du doigt la colline.

A l'âge où l'on croit à l'amour, J'étais seul dans ma chambre un jour, Pleurant ma première misère. Au coin de mon feu vint s'asseoir Un étranger vêtu de noir, Qui me ressemblait comme un frère.

Il était morne et soucieux; D'une main il montrait les cieux, Et de l'autre il tenait un glaive. De ma peine il semblait souffrir, Mais il ne poussa qu'un soupir, Et s'évanouit comme un rêve.

A l'âge où l'on est libertin, Pour boire un toast en un festin, Un jour je soulevai mon verre. En face de moi vint s'asseoir Un convive vêtu de noir, Qui me ressemblait comme un frère.

Il secouait sous son manteau Un haillon de pourpre en lambeau, Sur sa tête un myrte stérile. Son bras maigre cherchait le mien, Et mon verre, en touchant le sien, Se brisa dans ma main débile. 
Un an après, il était nuit, J'étais à genoux près du lit Où venait de mourir mon père. $\mathrm{Au}$ chevet du lit vint s'asseoir Un orphelin vêtu de noir,

Qui me ressemblait comme un frère.

Ses yeux étaient noyés de pleurs;

Comme les anges de douleurs, Il était couronné d'épine ;

Son luth à terre était gisant,

Sa pourpre de couleur de sang,

Et son glaive dans sa poitrine.

Je m'en suis si bien souvenu,

Que je l'ai toujours reconnu

A tous les instants de ma vie.

C'est une étrange vision;

Et cependant, ange ou démon, J'ai vu partout cette ombre amie.

Lorsque plus tard, las de souffrir, Pour renaitre ou pour en finir, J'ai voulu m'exiler de France ${ }^{1}$ Lorsqu' impatient de marcher, J'ai voulu partir, et chercher Les vestiges d'une espérance;

A Pise, au pied de l'Apennin;

A Cologne, en face du Rhin;

A Nice, au penchant des vallées;

A Florence, au fond des palais ;

A Brigues, dans les vieux chalets; Au sein des Alpes désolées;

A Gênes, sous les citronniers, A Vevay, sous les verts pommiers; Au Havre, devant l'Atlantique; A Venise, à l'affreux Lido, Où vient sur l'herbe d'un tombeau Mourir la pâle Adriatique;

1 An allusion to his trip to Italy with George Sand. 
Partout où, sous ces vastes cieux, J'ai lassé mon cœur et mes yeux Saignant d'une éternelle plaie ; Partout où le boîteux Ennui, Traînant ma fatigue après lui, M'a promené sur une claie;

Partout où, sans cesse altéré De la soif d'un monde ignoré, J'ai suivi l'ombre de mes songes; Partout où, sans avoir vécu, J'ai revu ce que j'avais vu, La face humaine et ses mensonges;

Partout où, le long des chemins, J'ai posé mon front dans mes mains, Et sangloté comme une femme; Partout où j'ai, comme un mouton Qui laisse sa laine au buisson, Senti se dénuer mon âme ;

Partout où j'ai voulu dormir, Partout où j'ai voulu mourir, Partout où j'ai touché la terre, Sur ma route est venu s'asseoir Un malheureux vêtu de noir, Qui me ressemblait comme un frère.

Qui donc es-tu, toi que dans cette vie Je vois toujours sur mon chemin? Je ne puis croire, à ta mélancolie,

Que tu sois mon mauvais Destin. Ton doux sourire a trop de patience, Tes larmes ont trop de pitié.

En te voyant, j'aime la Providence.

Ta douleur même est sœur de ma souffrance; Elle ressemble à l'Amitié. . . .

Qui donc es-tu, spectre de ma jeunesse,

Pélerin que rien n'a lassé ?

Dis-moi pourquoi je te trouve sans cesse

Assis dans l'ombre où j'ai passé.

Qui donc es-tu, visiteur solitaire, 
Hôte assidu de mes douleurs?

Qu'as-tu donc fait pour me suivre sur terre?

Qui donc es-tu, qui donc es-tu, mon frère,

Qui n'apparais qu'au jour des pleurs?

— "Poésies nouvelles \#

\section{La Vision}

- Ami, notre père est le tien.

Je ne suis ni l'ange gardien,

Ni le mauvais destin des hommes.

Ceux que j'aime, je ne sais pas

De quel côté s'en vont leurs pas

Sur ce peu de fange où nous sommes.

Je ne suis ni dieu ni démon,

Et tu m'as nommé par mon nom

Quand tu m'as appelé ton frère;

Où tu vas, j'y serai toujours,

Jusques au dernier de tes jours,

Où j'irai m'asseoir sur ta pierre.

Le ciel m'a confié ton cœur.

Quand tu seras dans la douleur,

Viens à moi sans inquiétude;

Je te suivrai sur le chemin,

Mais je ne puis toucher ta main,

Ami, je suis la Solitude.

— « Poésies nouvelles »

\section{CHANSON}

Quand on perd, par triste occurrence,

Son espérance

Et sa gaîté,

Le remède au mélancolique,

C'est la musique

Et la beauté !

Plus oblige et peut davantage

Un beau visage

Qu'un homme armé,

Et rien n'est meilleur que d'entendre

Air doux et tendre

Jadis aimé ! 


\section{TRISTESSE}

J'ai perdu ma force et ma vie, Et mes amis et ma gaîté;

J'ai perdu jusqu'à la fierté

Qui faisait croire à mon génie.

Quand j'ai connu la Vérité, J'ai cru que c'était une amie; Quand je l'ai comprise et sentie, J'en étais déjà dégoûté.

Et pourtant elle est éternelle, IO Et ceux qui se sont passés d'elle Ici-bas ont tout ignoré.

Dieu parle, il faut qu'on lui réponde; Le seul bien qui me reste au monde Est d'avoir quelquefois pleuré.

— "Poésies nouvelles "

\section{SOUVENIR}

I5 - Oui, sans doute, tout meurt; ce monde est un grand rêve;

Et le peu de bonheur qui nous vient en chemin, Nous n'avons pas plus tôt ce roseau dans la main, Que le vent nous l'enlève.

Oui, les premiers baisers, oui, les premiers serments

20 Que deux êtres mortels échangèrent sur terre, Ce fut au pied d'un arbre effeuillé par les vents, Sur un roc en poussière.

Ils prirent à témoin de leur joie éphémère Un ciel toujours voilé qui change à tout moment, 25 Et des astres sans nom que leur propre lumière Dévore incessamment.

Tout mourait autour d'eux, l'oiseau dans le feuillage, La fleur entre leurs mains, l'insecte sous leurs piés, La source desséchée où vacillait l'image

De leurs traits oubliés; 
Et sur tous ces débris joignant leurs mains d'argile, Etourdis des éclairs d'un instant de plaisir, Ils croyaient échapper à cet Etre immobile Qui regarde mourir!

— Insensés! dit le sage. - Heureux! dit le poète.

Et quels tristes amours as-tu donc dans le cœur,

Si le bruit du torrent te trouble et t'inquiète,

Si le vent te fait peur?

J'ai vu sous le soleil tomber bien d'autres choses

Que les feuilles des bois et l'écume des eaux,

Bien d'autres s'en aller que le parfum des roses

Et le chant des oiseaux.

Mes yeux ont contemplé des objets plus funèbres

Que Juliette morte au fond de son tombeau, ${ }^{1}$

Plus affreux que le toast à l'ange des ténèbres

Porté par Roméo.

J'ai vu ma seule amie, à jamais la plus chère,

Devenue elle-même un sépulcre blanchi,

Une tombe vivante où flottait la poussière

De notre mort chéri,

De notre pauvre amour, que, dans la nuit profonde,

Nous avions sur nos cœurs si doucement bercé!

C'était plus qu'une vie, hélas ! c'était un monde Qui s'était effacé!

Oui, jeune et belle encor, plus belle, osait-on dire,

Je l'ai vue, et ses yeux brillaient comme autrefois.

Ses lèvres s'entr'ouvraient, et c'était un sourire,

Et c'était une voix;

Mais non plus cette voix, non plus ce doux langage,

Ces regards adorés dans les miens confondus;

Mon cœur, encor plein d'elle, errait sur son visage,

Et ne la trouvait plus.

Et pourtant j'aurais pu marcher alors vers elle, Entourer de mes bras ce sein vide et glacé,

1 "Romeo and Juliet," Act V, scene 3. 
Et j'aurais pu crier: "Qu'as-tu fait, infidèle, Qu'as-tu fait du passé ? ”

Mais non: il me semblait qu'une femme inconnue Avait pris par hasard cette voix et ces yeux; Et je laissai passer cette froide statue En regardant les cieux.

Eh bien! ce fut sans doute une horrible misère Que ce riant adieu d'un être inanimé. Eh bien! qu'importe encore? O nature ! ô ma mère ! En ai-je moins aimé ?

La foudre maintenant peut tomber sur ma tête; Jamais ce souvenir ne peut m'être arraché! Comme le matelot brisé par la tempête, Je m'y tiens attaché.

Je ne veux rien savoir, ni si les champs fleurissent, $\mathrm{Ni}$ ce qu'il adviendra du simulacre humain, $\mathrm{Ni}$ si ces vastes cieux éclaireront demain Ce qu'ils ensevelissent.

Je me dis seulement: "A cette heure, en ce lieu, Un jour, je fus aimé, j'aimais, elle était belle. J'enfouis ce trésor dans mon âme immortelle, Et je l'emporte à Dieu!»

\section{FANTASIO ${ }^{1}$}

Elsbeth (seule). Il me semble qu'il y a quelqu'un derrière ces bosquets. Est-ce le fantôme de mon pauvre bouffon que j'aperçois dans

25 ces bluets, assis sur la prairie? Répondez-moi; qui êtes-vous? que faites-vous là à cueillir ces fleurs? (Elle s'avance vers un tertre.)

Fantasio (assis, viêtu en bouffon, avec une bosse et une perruque). Je suis un brave cueilleur de fleurs, qui souhaite le bonjour à vos beaux yeux.

Elsbeth. Que signifie cet accoutrement? qui êtes-vous pour venir 3o parodier sous cette large perruque un homme que j'ai aimé ? Êtesvous écolier en bouffonneries?

1 For his amusement Fantasio has become the king's fool, rigging himself out as nearly as possible like his predecessor, Saint-Jean, who has just died. Fantasio aids the Princess Elsbeth to escape the marriage which the king, her father, is planning for her. 
Fantasio. Plaise à Votre Altesse sérénissime, je suis le nouveau bouffon du roi; le majordome m'a reçu favorablement; je suis présenté au valet de chambre; les marmitons me protègent depuis hier au soir, et je cueille modestement des fleurs en attendant qu'il me vienne de l'esprit.

Elsbeth. Cela me paraît douteux, que vous cueilliez jamais cette fleur-là.

Fantasio. Pourquoi? l'esprit peut venir à un homme vieux, tout comme à une jeune fille. Cela est si difficile quelquefois de distinguer un trait spirituel d'une grosse sottise! Beaucoup parler, voilà l'impor- Io tant; le plus mauvais tireur de pistolet peut attraper la mouche, ${ }^{1}{ }^{\prime}$ 'il tire sept cent quatre-vingts coups à la minute, tout aussi bien que le plus habile homme qui n'en tire qu'un ou deux bien ajustés. Je ne demande qu'à être nourri convenablement pour la grosseur de mon ventre, et je regarderai mon ombre au soleil pour voir si ma perruque is pousse.

Elsbeth. En sorte que vous voilà revêtu des dépouilles de SaintJean? Vous avez raison de parler de votre ombre; tant que vous aurez ce costume, elle lui ressemblera toujours, je crois, plus que vous.

Fantasio. Je fais en ce moment une élégie qui décidera de mon sort. 20 Elsbeth. En quelle façon?

Fantasio. Elle prouvera clairement que je suis le premier homme du monde, ou bien elle ne vaudra rien du tout. Je suis en train de bouleverser l'univers pour le mettre en acrostiche; la lune, le soleil et les étoiles se battent pour entrer dans mes rimes, comme des écoliers 25 à la porte d'un théâtre de mélodrames.

Elsbeth. Pauvre homme! quel métier tu entreprends! faire de l'esprit à tant par heure! N'as-tu ni bras ni jambes, et ne ferais-tu pas mieux de labourer la terre que ta propre cervelle?

Fantasio. Pauvre petite! quel métier vous entreprenez! épouser 30 un sot que vous n'avez jamais vu! — N'avez-vous ni cœur ni tête, et ne feriez-vous pas mieux de vendre vos robes que votre corps?

Elsbeth. Voilà qui est hardi, monsieur le nouveau venu!

Fantasio. Comment appelez-vous cette fleur-là, s'il vous plaît?

Elsbeth. Une tulipe. Que veux-tu prouver?

Fantasio. Une tulipe rouge, ou une tulipe bleue?

Elsbeth. Bleue, à ce qu'il me semble.

Fantasio. Point du tout, c'est une tulipe rouge. 
Elsbeth. Veux-tu mettre un habit neuf à une vieille sentence? tu n'en as pas besoin pour dire que des goûts et des couleurs il ne faut pas disputer.

Fantasio. Je ne dispute pas; je vous dis que cette tulipe est une 5 tulipe rouge, et cependant je conviens qu'elle est bleue.

Elsbeth. Comment arranges-tu cela?

Fantasio. Comme votre contrat de mariage. Qui peut savoir sous le soleil s'il est né bleu ou rouge? Les tulipes elles-mêmes n'en savent rien. Les jardiniers et les notaires font des greffes si extraordinaires, ro que les pommes deviennent des citrouilles, et que les chardons sortent de la mâchoire de l'âne pour s'inonder de sauce dans le plat d'argent d'un évêque. Cette tulipe que voilà s'attendait bien à être rouge; mais on l'a mariée; elle est tout étonnée d'être bleue : c'est ainsi que le monde entier se métamorphose sous les mains de l'homme; et la

I 5 pauvre dame nature doit se rire parfois au nez de bon cœur, quand elle mire dans ses lacs et dans ses mers son éternelle mascarade. Croyez-vous que ça sentît la rose dans le paradis de Moïse ? ça ne sentait que le foin vert. La rose est fille de la civilisation; c'est une marquise comme vous et moi.

2o Elsbeth. La pâle fleur de l'aubépine peut devenir une rose, et un chardon peut devenir un artichaut; mais une fleur ne peut en devenir une autre: ainsi qu'importe à la nature? on ne la change pas, on l'embellit ou on la tue. La plus chétive violette mourrait plutôt que de céder si l'on voulait, par des moyens artificiels, altérer sa forme 25 d'une étamine.

Fantasio. C'est pourquoi je fais plus de cas d'une violette que d'une fille de roi.

Elsbeth. Il y a de certaines choses que les bouffons eux-mêmes n'ont pas le droit de railler; fais-y attention. Si tu as écouté ma 30 conversation avec ma gouvernante, prends garde à tes oreilles.

Fantasio. Non pas à mes oreilles, mais à ma langue. Vous vous trompez de sens; il y a une erreur de sens dans vos paroles.

Elsbeth. Ne me fais pas de calembour, si tu veux gagner ton argent, et ne me compare pas à des tulipes, si tu ne veux gagner autre chose.

35 Fantasio. Qui sait? un calembour console de bien des chagrins, et jouer avec les mots est un moyen comme un autre de jouer avec les pensées, les actions et les êtres. Tout est calembour ici-bas, et il est aussi difficile de comprendre le regard d'un enfant de quatre ans que le galimatias de trois drames modernes. 
Elsbeth. Tu me fais l'effet de regarder le monde à travers un prisme tant soit peu changeant.

Fantasio. Chacun a ses lunettes; mais personne ne sait au juste de quelle couleur en sont les verres. Qui est-ce qui pourra me dire au juste si je suis heureux ou malheureux, bon ou mauvais, triste ou gai, 5 bête ou spirituel?

Elsbeth. Tu es laid, du moins; cela est certain.

Fantasio. Pas plus certain que votre beauté. Voilà votre père qui vient avec votre futur mari. Qui est-ce qui peut savoir si vous l'épouserez? (Il sort.)

- " Fantasio », Act II, scene I 


\section{LAMENNAIS \\ (HUGUES-FÉLICITÉ-ROBER'T DE LAMENNAIS) \\ Saint-Malo, $1782-1854$, Paris}

Lamennais's mother died when he was young, his father went into bankruptcy, and the boy in consequence obtained a large part of his education through the somewhat desultory reading he did in his uncle's library. He did, however, with slight aid, acquaint himself with several foreign languages, ancient and modern. When a youth he became deeply interested in Rousseau, and showed a decided bent toward philosophical and theological discussion. His "Réflexions sur l'état de l'église en France" (1 808) was suppressed by the police because of his ultramontane tendencies. In it, too, he took a decided stand against the materialism of the eighteenth century.

He was ordained priest in 1816 , more or less against his will. The next year appeared the first of the four volumes of the "Essai sur l'indifférence en matière de religion," causing a great sensation. He favored the renunciation of personal opinion and judgment and the vesting of ecclesiastical authority in the Holy See. His ideal became pure theocracy. In 1830 he founded a paper, "L'avenir," in which he expressed decidedly liberal views and a desire to connect them with the church. His paper was suppressed the following year and his views were condemned by the Pope. In the "Paroles d'un croyant" (1834), a book also condemned by the Pope, but very widely read and translated, he renounced all authority, and two years later, in "Les affaires de Rome," he attacked the papacy.

During the remaining years of his life he published various works, the most important being the "Esquisse d'une philosophie" (1841-I 846). He was elected to the Assemblée nationale in 1848 , and died in 1854 , without becoming reconciled to the church.

\section{LA PROVIDENCE}

Deux hommes étaient voisins, et chacun d'eux avait une femme et plusieurs petits enfants, et son seul travail pour les faire vivre.

Et l'un de ces deux hommes s'inquiétait en lui-même, disant: $\mathrm{Si}$ je meurs ou que je tombe malade, que deviendront ma femme et mes 5 enfants?

Et cette pensée ne le quittait point, et elle rongeait son cœur comme un ver ronge le fruit où il est caché.

Or, bien que la même pensée fût venue également à l'autre père, il ne s'y était point arrêté; car, disait-il, Dieu qui connaît toutes ses Io créatures et qui veille sur elles, veillera aussi sur moi, et sur ma femme, et sur mes enfants. 
Et celui-ci vivait tranquille, tandis que le premier ne goûtait pas un instant de repos ni de joie intérieurement.

Un jour qu'il travaillait aux champs, triste et abattu à cause de sa crainte, il vit quelques oiseaux entrer dans un buisson, en sortir, et puis bientôt y revenir encore.

Et, s'étant approché, il vit deux nids posés côte à côte, et dans chacun plusieurs petits nouvellement éclos et encore sans plumes.

Et quand il fut retourné à son travail, de temps en temps il levait les yeux, et regardait ces oiseaux qui allaient et venaient portant la nourriture à leurs petits.

Or, voilà qu'au moment où l'une des mères rentrait avec sa becquée, un vautour la saisit, l'enlève, et la pauvre mère, se débattant vainement sous sa serre, jetait des cris perçants.

A cette vue, l'homme qui travaillait sentit son âme plus troublée qu'auparavant ; car, pensait-il, la mort de la mère, c'est la mort des 15 enfants. Les miens n'ont que moi non plus. Que deviendront-ils si je leur manque!

Et tout le jour il fut sombre et triste, et la nuit il ne dormit point.

Le lendemain, de retour aux champs, il se dit: Je veux voir les petits de cette pauvre mère: plusieurs sans doute ont déjà péri. Et 20 il s'achemina vers le buisson.

Et, regardant, il vit les petits bien portants; pas un ne semblait avoir pâti.

Et, ceci l'ayant étonné, il se cacha pour observer ce qui se passerait.

Et, après un peu de temps, il entendit un léger cri, et il aperçut la 25 seconde mère rapportant en hâte la nourriture qu'elle avait recueillie et elle la distribua à tous les petits indistinctement, et il y en eut pour tous, et les orphelins ne furent point délaissés dans leur misère.

Et le père qui s'était défié de la Providence raconta le soir à l'autre père ce qu'il avait vu.

Et celui-ci lui dit : "Pourquoi s'inquiéter? Jamais Dieu n'abandonne les siens. Son amour a des secrets que nous ne connaissons point. Croyons, espérons, aimons et poursuivons notre route en paix.

" Si je meurs avant vous, vous serez le père de mes enfants; si vous mourez avant moi, je serai le père des vôtres.

" Et, si l'un et l'autre nous mourons avant qu'ils soient en âge de pourvoir eux-mêmes à leurs nécessités, ils auront pour père le Père qui est dans les cieux.») 


\section{LA MUSIQUE DANS LA NATURE ET DANS LE TEMPLE CHRÉTIEN}

Reportez-vous par la pensée au fond des vastes solitudes d'un monde nouveau, de ses forêts, de ses savanes traversées par des fleuves sans nom, de ses montagnes d'où se précipitent d'impétueux torrents, du pied desquelles s'échappent d'innombrables ruisseaux, qui 5 lentement coulent sur un lit de mousse, ou s'épanchent en nappes sur lès prairies de la vallée, et prêtez l'oreille. De tout cela il s'élève une voix formée de mille voix, de la voix des grandes eaux et de celle des sources qui tombent goutte à goutte des rochers; de la voix des vents qui bruissent dans la cime des arbres et murmurent dans l'herbe; de Io la foudre qui déchire les nuées; de la voix des myriades d'êtres vivants qui pullulent au sein de ce monde primitif. Cette voix est la voix de la Nature, indistincte, confuse, mais majestueuse, solennelle, immense, pleine de mystères et de vagues émotions.

Des profondeurs du Temple sort pareillement une voix qui monte I 5 dans les airs et se propage au loin. Solennelle aussi, mystérieuse, et comme l'écho d'un monde invisible, elle remue les secrètes puissances de l'homme, elle éveille en lui toute une vie interne, assoupie jusqu'alors. Qui, dans la campagne, vers le soir, à l'heure où s'éteignent les feux du couchant, où la nuit étend ses ailes sombres sur les bois, les

20 prés, les buissons, les eaux, pour abriter le sommeil des pauvres créatures fatiguées; qui, à cette heure de calme et de silence, quand vient à soupirer la cloche du hameau, ne se sent pas comme emporté en des régions inconnues, aériennes, peuplées de formes indécises, de pensées rêveuses et de pressentiments infinis?

25 Cette voix correspondante à la voix de la Nature, se spécifie comme elle, s'individualise en chacun des éléments divers qu'elle contient virtuellement, se développe pour manifester la variété dans l'unité. 'Tous les arts dérivés du son se produisent, s'engendrent l'un l'autre, à mesure qu'achève de se réaliser la Création humaine. Pénétrez au30 dedans du Temple: un mystère de vie va s'y accomplir. La sculpture, la peinture y ont semé avec profusion les êtres de tout ordre. Déjà vous les voyez tressaillir, en quelque façon, par le jeu des ombres mobiles et de la mystique lumière que projettent entre les hautes arches, les lampes et les torches enflammées. Sous l'influence de cette

35 lumière, les fleurs qu'elle colore ouvrent leur calice, exhalent leurs parfums. Puis, soudain, l'air frémit; une voix retentit sous les longues 
voûtes, d'autres voix lui répondent; elles se mêlent sans se confondre ; les ondes harmonieuses se plient, se replient, s'entrelacent, s'affaiblissent, s'enflent, s'affaiblissent encore, pressent leur mouvement, le ralentissent. On entend le tonnerre gronder, les vents murmurer, et, au milieu de ces bruits formidables de la nature inanimée, les accents doux, joyeux, plaintifs, tendres, passionnés, de ce qui vit et sent. . . .

Figurez-vous être, au déclin du jour, dans l'immense cathédrale chrétienne. Une frayeur religieuse, quelque chose de semblable à ce vague sentiment de l'infini qu'on éprouve au sein des grandes solitudes de la nature, vous saisit à l'aspect de ces vastes nefs, de ces gigan- ı tesques piliers dont les sommets se perdent dans les ombres croissantes. Avec les dernières lueurs, la nuit éteint les derniers bruits; un silence mystérieux vous enveloppe de toute part. Au dehors de vous des ténèbres muettes; au dedans l'invisible souffle d'une puissance inconnue qui vous pénètre et vous domine irrésistiblement. I5 Séparé de ce qui frappe les sens, il se fait en vous comme un travail étrange; des esprits passent devant l'œil interne, l'imagination se peuple de fantômes sans corps; le temps qui n'a plus de mesure, semble lui-même s'être évanoui. Tout à coup, dans le lointain, apparaît un point lumineux, puis un autre, puis un autre encore; vous 20 commencez à discerner les masses de l'édifice, les murs pareils aux flancs d'une montagne escarpée, les fortes arêtes des angles, les courbures des arcs, les énormes pendentifs. La lumière augmente: sur ces masses, qu'unissent des lignes harmonieuses, se montrent les plantes, les animaux, les formes innombrables des êtres sortis de leurs 25 entrailles inépuisablement fécondes. Eclatants de mille couleurs dont les reflets se croisent et se mélangent, ils portent à vos sens comme une révélation de la vie, et les suaves vapeurs qui parfument l'atmosphère en accroissent encore l'impression. Lorsqu'au milieu de ce monde naissant, vibre soudain la voix tour à tour majestucuse, douce, 30 sévère de l'orgue, qu'elle remplit de ses accords indéfiniment variés les voûtes frémissantes, ne dirait-on pas la voix de tous ces êtres dont la création vient de s'opérer sous vos yeux? Mais leur langage indéterminé ne parle qu'à ce qui sent, et non pas à ce qui pense. 'Tel est le caractère de l'art musical. 


\section{GEORGE SAND \\ (AMANTINE-LUCILE-AURORE DUPIN, BARONNE DUDEVANT) \\ Paris, $1804-1876$, Nohant}

Aurore Dupin herself gives a sincere account of her own youth in her "Histoire de ma vie" (1854-1855). In 1822 she married M. Dudevant, but her marriage was not a happy one, and she separated from her husband and settled in Paris (1831), looking to literature as a profession. Her first novel, "Rose et Blanche" (1831), was written in collaboration with Jules Sandeau. At this time she assumed the nom de plume of George Sand, under which appeared the long list of her romances.

Her first novels, "Indiana" (I831), "Valentine" (1832), "Lélia" (1833), "Jacques" (1834), "Mauprat" (1837), were purely romantic, reflecting more or less her own life and experiences. Then, her interests broadening, she turned to the study of socialistic and vaguely humanitarian problems of her time, and wrote "Consuelo" (1842-1843), "La comtesse de Rudolstadt" ( 1844 ), and "Le meunier d'Angibault" (1845). But she appeared at her best, perhaps, in the charming idyllic masterpieces which portray the life about her own home in Berry, "La mare au diable" ( 1846$)$, "La petite Fadette" (1849), "François le Champi" (1850), and "Les maîtres sonneurs" (1853).

Her work all shows a style as easy as Balzac's was labored, and an inexhaustible imagination, which, even through old age, gave life, grace, and a sympathetic charm to everything she touched.

\section{SCENE RUSTIQUE}

Je marchais sur la lisière d'un champ que des paysans étaient en train de préparer pour la semaille prochaine. L'arène était vaste comme celle du tableau d'Holbein. ${ }^{1}$ Le paysage était vaste aussi et encadrait de grandes lignes de verdure, un peu rougie aux approches 5 de l'automne, ce large terrain d'un brun vigoureux, où des pluies

1 An engraving of Holbein's (1497-1543) pictures an old man plowing while Death is urging on his team. Below it is the quatrain :

A la sueur de ton visaige

Tu gagnerois ta pauvre vie;

Après long travail et usaige

Voici la Mort qui te convie. 
récentes avaient laissé, dans quelques sillons, des lignes d'eau que le soleil faisait briller comme de minces filets d'argent. La journée était claire et tiède, et la terre, fraîchement ouverte par le tranchant des charrues, exhalait une vapeur légère. Dans le haut du champ un vieillard, dont le dos large et la figure sévère rappelaient celui d'Holbein, mais dont les vêtements n'annonçaient pas la misère, poussait gravement son area $^{1}{ }^{1}$ de forme antique, traîné par deux bœufs tranquilles, à la robe d'un jaune pâle, véritables patriarches de la prairie, hauts de taille, un peu maigres, les cornes longues et rabattues, de ces vieux travailleurs qu'une longue habitude a rendus frères, comme on ro les appelle dans nos campagnes, et qui, privés l'un de l'autre, se refusent au travail avec un nouveau compagnon et se laissent mourir de chagrin. Les gens qui ne connaissent pas la campagne taxent de fable l'amitić du bœuf pour son camarade d'attelage. Qu'ils viennent voir au fond de l'étable un pauvre animal maigre, exténué, battant de 15 sa queue inquiète ses flancs décharnés, soufflant avec effroi et dédain sur la nourriture qu'on lui présente, les yeux tournés vers la porte, en grattant du pied la place vide à ses côtés, flairant les jougs et les chaînes que son compagnon a portés, et l'appelant sans cesse avec de déplorables mugissements. Le bouvier dira:

- C'est une paire de bœufs perdue; son frère est mort, et celui-là ne travaillera plus. Il faudrait pouvoir l'engraisser pour l'abattre; mais il ne veut pas manger, et bientôt il sera mort de faim.

Le vieux laboureur travaillait lentement, en silence, sans efforts inutiles. Son docile attelage ne se pressait pas plus que lui; mais 25 grâce à la continuité d'un labeur sans distraction et d'une dépense de forces éprouvées et soutenues, son sillon était aussi vite creusé que celui de son fils, qui menait, à quelque distance, quatre bœufs moins robustes, dans une veine de terres plus fortes et plus pierreuses.

Mais ce qui attira ensuite mon attention était véritablement un beau 30 spectacle, un noble sujet pour un peintre. A l'autre extrémité de la plaine labourable, un jeune homme de bonne mine conduisait un attelage magnifique: quatre paires de jeunes animaux à robe sombre mêlée de noir fauve à reflets de feu, avec ces têtes courtes et frisées qui sentent encore le taureau sauvage, ces gros yeux farouches, ces 35 mouvements brusques, ce travail nerveux et saccadé qui s'irrite encore du joug et de l'aiguillon et n'obéit qu'en frémissant de colère à la domination nouvellement imposée. C'est ce qu'on appelle des bœufs 
fraîchement liés. ${ }^{1}$ L'homme qui les gouvernait avait à défricher un coin naguère abandonné au pâturage et rempli de souches séculaires, travail d'athlète auquel suffisaient à peine son énergie, sa jeunesse et ses huit animaux quasi indomptés.

5 Un enfant de six à sept ans, beau comme un ange, et les épaules couvertes, sur sa blouse, d'une peau d'agneau qui le faisait ressembler au petit saint Jean-Baptiste des peintres de la Renaissance, marchait dans le sillon parallèle à la charrue et piquait le flanc des bœufs avec une gaule longue et légère, armée d'un aiguillon peu acéré. Les fiers

ıo animaux frémissaient sous la petite main de l'enfant, et faisaient grincer les jougs et les courroies liés à leur front, en imprimant au timon de violentes secousses. Lorsqu'une racine arrêtait le soc, le laboureur criait d'une voix puissante, appelant chaque bête par son nom, mais plutôt pour calmer que pour exciter ; car les bœufs, irrités par cette I 5 brusque résistance, bondissaient, creusaient la terre de leurs larges pieds fourchus, et se seraient jetés de côté emportant l'areau à travers champs, si, de la voix et de l'aiguillon, le jeune homme n'eût maintenu les quatre premiers, tandis que l'enfant gouvernait les quatre autres. Il criait aussi, le pauvret, d'une voix qu'il voulait rendre terrible et qui 2o restait douce comme sa figure angélique. Tout cela était beau de force ou de grâce: le paysage, l'homme, l'enfant, les taureaux sous le joug ; et, malgré cette lutte puissante, où la terre était vaincue, il y avait un sentiment de douceur et de calme profond qui planait sur toutes choses. Quand l'obstacle était surmonté et que l'attelage reprenait sa 25 marche égale et solennelle, le laboureur, dont la feinte violence n'était qu'un exercice de vigueur et une dépense d'activité, reprenait tout à coup la sérénité des âmes simples et jetait un regard de contentement paternel sur son enfant, qui se retournait pour lui sourire. Puis la voix mâle de ce jeune père de famille entonnait le chant solennel et mélan30 colique que l'antique tradition du pays transmet, non à tous les laboureurs indistinctement, mais aux plus consommés dans l'art d'exciter et de soutenir l'ardeur des bœufs de travail. Ce chant, dont l'origine fut peut-être considérée comme sacrée, et auquel de mystérieuses influences ont dû être attribuées jadis, est réputé encore aujourd'hui 35 posséder la vertu d'entretenir le courage de ces animaux, d'apaiser leurs mécontentements et de charmer l'ennui de leur longue besogne. Il ne suffit pas de savoir bien les conduire en traçant un sillon parfaitement rectiligne, de leur alléger la peine en soulevant ou enfonçant à 
point le fer dans la terre: on n'est point un parfait laboureur si on ne sait chanter aux bœufs, et c'est là une science à part qui exige un goût et des moyens particuliers.

Ce chant n'est, à vrai dire, qu'une sorte de récitatif interrompu et repris à volonté. Sa forme irrégulière et ses intonations fausses selon les règles de l'art musical le rendent intraduisible. Mais ce n'en est pas moins un beau chant, et tellement approprié à la nature du travail qu'il accompagne, à l'allure du bœuf, au calme des lieux agrestes, à la simplicité des hommes qui le disent, qu'aucun génie étranger au travail de la terre ne l'eût inventé, et qu'aucun chanteur autre qu'un fin ıo laboureur de cette contrée ne saurait le redire. Aux époques de l'année où il n'y a pas d'autre travail et d'autre mouvement dans la campagne que celui du labourage, ce chant si doux et si puissant monte comme une voix de la brise, à laquelle sa tonalité particulière donne une certaine ressemblance. La note finale de chaque phrase, tenue et I $_{5}$ tremblée avec une longueur et une puissance d'haleine incroyable, monte d'un quart de ton en faussant systématiquement. Cela est sauvage, mais le charme en est indicible, et quand on s'est habitué à l'entendre, on ne conçoit pas qu'un autre chant pût s'élever à ces heures et dans ces lieux-là, sans en déranger l'harmonie.

Il se trouvait donc que j'avais sous les yeux un tableau qui contrastait avec celui d'Holbein, quoique ce fût une scène pareille. Au lieu d'un triste vieillard, un homme jeune et dispos; au lieu d'un attelage de chevaux efflanqués et harassés, un double quadrige de bœufs robustes et ardents; au lieu de la mort, un bel enfant; au lieu d'une 25 image de désespoir et d'une idée de destruction, un spectacle d'énergie et une pensée de bonheur.

C'est alors que le quatrain français

A la sueur de ton visaige, etc.,

et le $O$ fortunatos agricolas ${ }^{1}$ de Virgile me revinrent ensemble à 30 l'esprit, et qu'en voyant ce couple si beau, l'homme et l'enfant, accomplir dans des conditions si poétiques, et avec tant de grâce unie à la force, un travail plein de grandeur et de solennité, je sentis une pitié profonde mêlée à un respect involontaire. Heureux le laboureur ! oui, sans doute, je le serais à sa place, si mon bras, devenu tout d'un coup 35 robuste, et ma poitrine devenue puissante, pouvaient ainsi féconder et chanter la nature, sans que mes yeux cessassent de voir et mon 
cerveau de comprendre l'harmonie des couleurs et des sons, la finesse des tons et la grâce des contours, en un mot la beauté mystérieuse des choses! et surtout sans que mon cœur cessât d'être en relation avec le sentiment divin qui a présidé à la création immortelle et sublime.

- "La mare au diable »

\section{LE CORNEMUSEUX INSPIRÉ}

5 Un mois environ après ce jour-là, Joseph vint me trouver à la maison. - Le temps est arrivé, me dit-il avec un regard net et une parole sûre, où je veux que les deux seules personnes en qui j'ai confiance connaissent mon fluter. Je veux donc que Brulette vienne ici demain soir, parce que nous y serons tranquilles tous les trois. Je sais que tes

so parents partent le matin pour aller en pèlerinage, rapport à la fièvre de ton frère cadet; tu seras donc seul dans ta maison, qui est si bien éloignée dans la campagne que nous ne risquons pas d'être entendus. J'ai averti Brulette, elle est consentante à sortir du bourg à la nuit; je l'attendrai dans le petit chemin, et nous viendrons ici te trouver

I 5 sans que personne s'en avise. Brulette compte sur toi pour ne jamais parler de ça, et son grand-père, qui veut tout ce qu'elle souhaite, y est consentant aussi, moyennant ta parole, que j'ai donnée d'avance.

A l'heure dite, j'étais devant ma porte, ayant poussé toutes les huisseries pour que les passants (s'il en passait) me crussent couché ou 20 absent, et j'attendais l'arrivée de Brulette et de Joseph. On était alors au printemps, et, comme il avait tonné dans le jour, le ciel était encore chargé de nuages très épais. Il faisait de bons coups de vent tiède qui apportaient toutes les jolies senteurs du mois de mai. J'écoutais les rossignols qui se répondaient dans la campagne aussi loin que l'ouïe 25 pouvait s'étendre, et je me disais que Joseph aurait grand'peine à flûter aussi finement. Je regardais au loin toutes les petites clartés des maisons s'éteindre une à une dans le bourg; et environ dix minutes après que la dernière fut souffée je vis arriver devant moi le jeune couple que j'attendais. Ils avaient marché si doucement sur les herbes 30 nouvelles, et si bien cotoyé les grands buissons du chemin, que je ne les avais ni vus ni entendus approcher. Je les fis entrer chez nous, où j'avais allumé la lampe, et quand je les vis tous deux, elle toujours si coquettement coiffée et si quiètement fière, lui toujours si froid et si pensif, je me représentai mal mes deux amoureux enflammés de tendresse. 35 Pendant que je causais un peu avec Brulette pour lui faire les 
honneurs de ma demeurance, qui était assez gentille et dont j'aurais souhaité qu'elle prît envie, Joseph, sans me rien dire, s'était mis en devoir d'accommoder sa flûte. Il trouva que le temps humide l'avait enrhumée, et jeta une poignée de chènevottes dans l'âtre pour l'y réchauffer. Quand les chènevottes s'enflammèrent, elles envoyèrent une grande clarté à son visage penché vers le foyer, et je lui trouvai un air si étrange que j'en fis tout bas l'observation à Brulette.

- Vous aurez beau penser, lui dis-je, qu'il ne se cache le jour et ne court la nuit que pour flûter tout son soûl, je sais, moi, qu'il a en lui et autour de lui quelque secret qu'il ne nous dit pas.

- Bah! fit-elle en riant, parce que Véret le sabotier s'imagine de l'avoir vu avec un grand homme noir à l'orme Râteau?

— Possible qu'il ait rêvé ça, répondis-je; mais moi je sais bien ce que j'ai vu et entendu à la forêt.

- Qu'est-ce que tu as vu, Tiennet? dit tout d'un coup Joset, qui 15 ne perdait rien de notre discours, encore que nous eussions parlé bien bas. Qu'est-ce que tu as entendu? Tu as vu celui qui est mon ami, et que je ne peux te montrer: mais ce que tu as entendu, tu vas l'entendre encore, si la chose te plaît.

Là-dessus il souffla dans sa flûte, l'œil tout en feu, et la figure 20 embrasée par une fièvre.

Ce qu'il flûta, ne me le demandez point. Je ne sais si le diable y eût connu quelque chose; tant qu'à ${ }^{1}$ moi, je n'y connus rien, sinon qu'il me parut bien que c'était le même air que j'avais ouï cornemuser dans la fougeraie. Mais j'avais eu si belle peur dans ce moment-là, 25 que je ne m'étais point embarrassé d'écouter le tout; et, soit que la musique en fût longue, soit que Joseph y mît du sien, il ne décota ${ }^{2}$ de flûter d'un gros quart d'heure, mettant ses doigts bien finement, ne désoufflant mie, et tirant si grande sonnerie de son méchant roseau, que dans des moments on eût dit trois cornemuses jouant ensemble. 30 Par d'autres fois, il faisait si doux qu'on entendait le grelet au dedans de la maison et le rossignol au dehors; et quand Joset faisait doux, je confesse que j'y prenais plaisir, bien que le tout ensemble fût si mal ressemblant à ce que nous avons coutume d'entendre que ça me représentait un sabbat de fous.

- Oh! oh! que je lui dis quand il eut fini, voilà bien une musique enragée! Où diantre prends-tu tout ça? à quoi que ça peut servir, et qu'est-ce que tu veux signifier par là?

$$
1 \text { "as for." }
$$

2 " did not cease." 
Il ne me fit point réponse, ct scmbla même qu'il ne m'entendait point. Il regardait Brulette qui s'était appuyée contre une chaise et qui avait la figure tournée du côté du mur.

Comme elle ne disait mot, Joset fut pris d'une flambée de colère, 5 soit contre elle, soit contre lui-même, et je le vis faire comme s'il voulait briser sa flûte entre ses mains; mais au moment même, la belle fille regarda de son côté, et je fus bien étonné de voir qu'elle avait des grosses larmes au long des joues.

Alors Joseph courut auprès d'elle, et, lui prenant vivement les mains : ıо - Explique-toi, ma mignonne, dit-il, et fais-moi connaître si c'est de compassion pour moi que tu pleures, ou si c'est de contentement?

- Je ne sache point, répondit-elle, que le contentement d'une chose comme ça puisse faire pleurer. Ne me demande donc point si c'est que j'ai de l'aise ou du mal; ce que je sais, c'est que je ne m'en puis I 5 empêcher, voilà tout.

- Mais à quoi est-ce que tu as pensé, pendant ma flûterie? dit Joseph en la fixant beaucoup.

- A tant de choses, que je ne saurais point t'en rendre compte, répliqua Brulette.

20 - Mais enfin, dis-en une, reprit-il sur un ton qui signifiait de l'impatience et du commandement.

- Je n'ai pensé à rien, dit Brulette ; mais j'ai eu mille ressouvenances du temps passé. Il ne me semblait point te voir flûter, encore que je t'ouïsse bien clairement; mais tu me paraissais comme dans

25 l'âge où nous demeurions ensemble, et je me sentais comme portée avec toi par un grand vent qui nous promenait tantôt sur les blés mûrs, tantôt sur des herbes folles, tantôt sur des eaux courantes; et je voyais des prés, des bois, des fontaines, des pleins champs de fleurs et des pleins ciels d'oiseaux qui passaient dans les nuées. J'ai vu aussi, dans 30 ma songerie, ta mère et mon grand-père assis devant le feu, et causant de choses que je n'entendais point, tandis que je te voyais à genoux dans un coin, disant ta prière, et que je me sentais comme endormie dans mon petit lit. J'ai vu encore la terre couverte de neige, et des saulnées remplies d'alouettes, et puis des nuits remplies d'étoiles filantes,

35 et nous les regardions, assis tous deux sur un tertre, pendant que nos bêtes faisaient le petit bruit de tondre l'herbe ; enfin, j'ai vu tant de rêves que c'est déjà embrouillé dans ma tête; et si ça m'a donné l'envie de pleurer, ce n'est point par chagrin, mais par une secousse de mes esprits que je ne veux point t'expliquer du tout. 
- C'est bien! dit Joset. Ce que j'ai songé, ce que j'ai vu en flûtant, tu l'as vu aussi! Merci, Brulette! Par toi, je sais que je ne suis point fou et qu'il y a une vérité dans ce qu'on entend comme dans ce qu'on voit. Oui, oui! fit-il encore en se promenant dans la chambre à grandes enjambées et en élevant sa flûte au-dessus dc sa tête; ça parle, ce méchant bout de roseau ; ça dit ce qu'on pense; ça montre comme avec les yeux; ça raconte comme avec les mots; ça aime comme avec le cœur; ça vit, ça existe! Et à présent, Joset le fou, Joset l'innocent, Joset l'ébervigé, ${ }^{1}$ tu peux bien retomber dans ton imbécillité ; tu es aussi fort, aussi savant, aussi heureux qu'un autre!

Disant cela. il s'assit, sans plus faire attention à aucune chose autour de lui.

— «Les maîtres sonneurs »

\section{LE PUY EN VELAY ${ }^{2}$}

Rien, mon ami, ne peut te donner l'idée de la beauté pittoresque de ce bassin du Puy, et je ne connais point de site dont le caractère soit plus difficile à décrire. Ce n'est pas la Suisse, c'est moins terrible; ce I 5 n'est pas l'Italie, c'est plus beau; c'est la France centrale avec tous ses vésuves éteints et revêtus d'une splendide végétation; ce n'est pourtant ni l'Auvergne ni le Limousin que tu connais. Ici point de riche Limagne, arène vaste et tranquille de moissons et de prairies abritées au loin par un horizon de montagnes soudées ensemble; 20 point de plateaux fertiles fermés de fossés naturels. Non, tout est cime et ravin, et la culture ne peut s'emparer que de profondeurs resserrées et de versants rapides. Elle s'en empare, elle se glisse partout, jetant ses frais tapis de verdure, de céréales, de légumineuses avides de la cendre fertilisée des volcans, jusque dans les interstices des 25 coulées de lave qui la rayent dans tous les sens. A chaque détour anguleux de ces coulées, on entre dans un désordre nouveau qui semble aussi infranchissable que celui que l'on quitte; mais quand des bords élevés de cette enceinte tourmentée on peut l'embrasser d'un coup d'œil, on y retrouve les vastes proportions et les suaves harmo- 30 nies qui font qu'un tableau est admirable, et que l'imagination n'y peut rien ajouter.

1 "light-headed."

2 Le Puy is a picturesque town of twenty thousand inhabitants in the Haute-Loire. 
L'horizon est grandiose. Ce sont d'abord les Cévennes. Dans un lointain brumeux, on distingue le Mézenc avec ses longues pentes et ses brusques coupures, derrière lesquelles se dresse le Gerbier des Joncs, cône volcanique qui rappelle le Soracte, mais qui, partant d'une 5 base plus imposante, fait un plus grand effet. D'autres montagnes de formes variées, les unes imitant dans leurs formes hémisphériques les ballons vosgiens, ${ }^{1}$ les autres plantées en murailles droites, çà et là vigoureusement ébréchées, circonscrivent un espace de ciel aussi vaste que celui de la campagne de Rome, mais profondément creusé en Io coupe, comme si tous les volcans qui ont labouré cette région eussent été contenus dans un cratère commun d'une dimension fabuleuse.

Au-dessous de cette magnifique ceinture, les détails du tableau se dessinent parfois avec une prodigieuse netteté. On distingue une seconde, une troisième, et par endroits une quatrième enceinte de I 5 montagnes également variées de formes, s'abaissant par degrés vers le niveau central des trois rivières qui sillonnent ce que l'on peut appeler la plaine; mais cette plaine n'est qu'une apparence relative; il n'est pas un point du sol qui n'ait été soulevé, tordu ou crevassé par les convulsions géologiques. Des accidents énormes ont jailli du sein de 2o cette vallée, et, dénudés par l'action des eaux, ils forment aujourd'hui ces dykes monstrueux qu'on trouve déjà en Auvergne, mais qui se présentent ici avec d'autres formes et dans de plus vastes proportions. Ce sont des blocs d'un noir rougeâtre qu'on dirait encore brûlants, et qui, au coucher du soleil, prennent l'aspect de la braise à demi éteinte. ${ }_{25}$ Sur leurs vastes plates-formes, taillées à pic et dont les flancs se renflent parfois en forme de tours et de bastions, les habitants bâtirent des temples, puis des forteresses et des églises, enfin des villages. Le Puy est en parti dressé sur la base d'un de ces dykes, le rocher Corneille, une des masses homogènes les plus compactes et les plus 30 monumentales qui existent, et dont le sommet, jadis consacré aux dieux de la Gaule, puis à ceux de Rome, porte encore les débris d'une citadelle du moyen âge, et domine les coupoles romanes d'une admirablè basilique tirée de son flanc.

Cette basilique est elle-même un accident grandiose dans ce gran35 diose décor naturel. Elle se découpe, noire et puissante, sur les fonds vaporeux des lointains de la campagne, car dans ce tableau, vu d'ensemble, l'horizon des Cévennes se détache seul sur le ciel, et là, je crois, est le secret de son magique aspect. Les détails vus ainsi comme 
repoussoirs à des perspectives profondes prennent toute l'importance qu'ils ont effectivement et se trouvent en proportion avec l'importance des masses lointaines. C'est l'isolement de Rome sur son ciel sans bornes qui fait que la grandeur réelle de ses monuments est difficilement appréciable à celui qui en approche. Rome, c'est ici qu'clle devrait être située! C'est ce gigantesque piédestal d'une seule roche qu'il eût fallu à la pensée de Michel-Ange pour lancer dans les airs le dôme magistral de Saint-Pierre.

— "Le marquis de Villemer» 


\title{
JULES MICHELET
}

\author{
Paris, I 798-I 874, Hyères
}

Michelet, one of the most brilliant historians of France, was the son of a printer who was ruined under the Consulate and Empire. He nevertheless attended the Lycée Charlemagne, finishing his course there with distinction in 1816. He then took up teaching before coming up for the "agrégation" in 1821 . Immediately after the termination of his university career he was appointed to a professorship in the Collège Rollin. He then, in succession, became lecturer at the Ecole Normale, assistant under Guizot at the Sorbonne, and professor at the Collège de France (I838). Though he did not enter into active political life, he always took part freely in political discussion, and, on refusing to take the oath of allegiance to the Empire, he had to resign his professorship, and also a post in the record office, after the "coup d'état" which put Napoleon III in power. He thenceforth gave himself up to literary work, with which he had for years been occupied.

His great work is the "Histoire de France." The first and most remarkable part, down to the Renaissance, in which, in a succession of brilliant tableaux, he gives a living picture of the Middle Ages, appeared from 1833 to 1844 . The history of the Revolution (1847 to 1853), and of the Renaissance to the Revolution (1855 to 1867 ), followed. Meanwhile he brought out many minor works dealing with various subjects, many of them connected with his masterpiece: "Des Jésuits" (1843); "Du prêtre, de la femme, et de la famille" (1845); "L'oiseau" (1856); "L'amour" (1859); "La femme" (1860); "La bible de l'humanité" (1864); "La montagne" (I868). During the last years before his death in 1874 he was working on the history of the nineteenth century.

\section{SUPPLICE DE JEANNE D'ARC ${ }^{1}$}

Il était neuf heures : Jeanne fut revêtue d'habits de femme et mise sur un chariot. A son côté se tenait le confesseur frère Martin l'Advenu, l'huissier Massieu était de l'autre. Le moine augustin frère Isambart, qui avait déjà montré tant de charité et de courage, ne 5 voulut pas la quitter. On assure que le misérable Loyseleur ${ }^{2}$ vint aussi sur la charrette et lui demanda pardon; les Anglais l'auraient tué sans le comte de Warwick. ${ }^{3}$. . .

1 Joan of Arc, born 1412, was burned on May 30, I43I.

2 Joan of Arc's confessor, who, under pretext of advising her, betrayed her before the judges.

8 The count of Warwick, favorite of Henry V, tutor of Henry VI, directed the trial of Joan of Arc. He was named regent of France in 1437 and died at Rouen in 1439. 
Le terme du triste voyage était le Vieux-Marché, le marché au poisson. Trois échafauds avaient été dressés. Sur l'un était la chaire épiscopale et royale, le trône du cardinal d'Angleterre, parmi les sièges de ses prélats. Sur l'autre devaient figurer les personnages du lugubre drame, le prédicateur, les juges et le bailli, enfin la condamnée. On voyait à part un grand échafaud de plâtre, chargé et surchargé de bois ; on n'avait rien plaint au bûcher, il effrayait par sa hauteur. Ce n'était pas seulement pour rendre l'exécution plus solennelle; il y avait une intention : c'était afin que, le bûcher étant si haut échafaudé, le bourreau n'y atteignît que par le bas, pour allumer seulement, ro qu'ainsi il ne pût abréger le supplice, ni expédier la patiente, comme il faisait des autres, leur faisant grâce de la flamme. Ici, il ne s'agissait pas de frauder la justice, de donner au feu un corps mort; on voulait qu'elle fût bien réellement brûlée vive, que, placée au sommet de cette montagne de bois et dominant le cercle des lances et des épées, I 5 elle pût être observée de toute la place. Lentement, longuement brûlée sous les yeux d'une foule curieuse, il y avait lieu de croire qu'à la fin elle laisserait surprendre quelque faiblesse, qu'il lui échapperait quelque chose qu'on pût donner pour un désaveu, tout au moins des mots confus qu'on pourrait interpréter, peut-être de basses prières, 20 d'humiliants cris de grâce, comme d'une femme éperdue. . . .

Alors le juge d'Église, l'évêque de Beauvais, ${ }^{1}$ l'exhorta bénignement à s'occuper de son âme et à se rappeler tous ses méfaits pour s'exciter à la contrition. Les assesseurs avaient jugé qu'il était de droit de lui relire son abjuration ${ }^{2}$; l'évêque n'en fit rien. Il craignait des démen- 25 tis, des réclamations. Mais la pauvre fille ne songeait guère à chicaner ainsi sa vie; elle avait bien d'autres pensées. Avant même qu'on l'eût exhortée à la contrition, elle s'était mise à genoux, invoquant Dieu, la Vierge, saint Michel et sainte Catherine, pardonnant à tous et demandant pardon, disant aux assistants : "Priez pour moi!...) Elle 30 requérait surtout les prêtres de dire chacun une messe pour son âme. .. . Tout cela de façon si dévote, si humble et si touchante, que l'émotion gagnant, personne ne put plus se contenir: l'évêque de Beauvais se mit à pleurer, celui de Boulogne sanglotait, et voilà que les Anglais eux-mêmes pleuraient et larmoyaient aussi. . . .

1 Cauchon, bishop of Beauvais, had done all in his power to have Joan of Arc condemned.

2 In a moment of weakness and under threat of death Joan of Arc had abjured her "mission," i.e. had confessed that she had been mistaken in believing that she had a mission from God to crown Charles VII king, and to drive out the English from France. 
Cependant, les juges, un moment décontenancés, s'étaient remis et raffermis. L'évêque de Beauvais, s'essuyant les yeux, se mit à lire la condamnation. Il remémora à la coupable tous ses crimes, schisme, idolâtrie, invocation de démons, comment elle avait été admise à péni5 tence, et comment, " séduite par le prince du mensonge, elle était retombée, ô douleur! comme le chien qui retourne à son vomissement. . . . Donc, nous prononçons que vous êtes un membre pourri, et, comme tel, retranché de l'Église. Nous vous livrons à la puissance séculière, la priant toutefois de modérer son jugement, en vous évitant ı la mort et la mutilation des membres. »)

Délaissée ainsi de l'Église, elle se remit en toute confiance à Dieu. Elle demanda la croix. Un Anglais lui passa une croix de bois, qu'il fit d'un bâton; elle ne la reçut pas moins dévotement, elle la baisa et la mit, cette rude croix, sous ses vêtements et sur sa chair. . . Mais elle I 5 aurait voulu la croix de l'église, pour la tenir devant ses yeux jusqu'à la mort. Le bon huissier Massieu et frère Isambart firent tant, qu'on la lui apporta de la paroisse Saint-Sauveur. Comme elle embrassait cette croix, et qu'Isambart l'encourageait, les Anglais commencèrent à trouver tout cela bien long; il devait être au moins midi ; 2o les soldats grondaient, les capitaines disaient: "Comment! prêtre, nous ferez-vous dîner ici ? . . . ) Alors, perdant patience et n'attendant pas l'ordre du bailli, qui seul pourtant avait autorité pour l'envoyer à la mort, ils firent monter deux sergents pour la tirer des mains des prêtres. Au pied du tribunal, elle fut saisie par les hommes d'armes, 25 qui la traînèrent au bourreau, lui disant: " Fais ton office. . . . " Cette furie des soldats fit horreur; plusieurs des assistants, des juges même, s'enfuirent, pour n'en pas voir davantage.

Quand elle se trouva en bas dans la place, entre ces Anglais qui portaient les mains sur elle, la nature pâtit et la chair se troubla ; elle cria 30 de nouveau: " $O$ Rouen, tu seras donc ma dernière demeure!.... Elle n'en dit pas plus, et ne pécha pas par ses lèvres, dans ce moment même d'effroi et de trouble. ...

Elle n'accusa ni son roi ni ses saintes. Mais parvenue au haut du bûcher, voyant cette grande ville, cette foule immobile et silencieuse, 35 elle ne put s'empêcher de dire: "Ah! Rouen, Rouen, j'ai grand'peur que tu n'aies à souffrir de ma mort! ” Celle qui avait sauvé le peuple et que le peuple abandonnait n'exprima en mourant (admirable douceur d'âme !) que de la compassion pour lui. . . .

Elle fut liée sous l'écriteau infâme, mitrée d'une mitre où on lisait : 
" Hérétique, relapse, apostate, ydolastre. " . . . Et alors le bourreau mit le feu. ... Elle le vit d'en haut et poussa un cri... Puis, comme le frère qui l'exhortait ne faisait pas attention à la flamme, elle eut peur pour lui, s'oubliant elle-même, et elle le fit descendre. . . .

La flamme montait. Au moment où elle la toucha, la malheureuse frémit et demanda de l'eau bénite; de l'eau, c'était apparemment le cri de la frayeur. ... Mais, se relevant aussitôt, elle ne nomma plus que Dieu, que ses anges et ses saintes. Elle leur rendit témoignage : "Oui, mes voix étaient de Dieu, mes voix ne m'ont pas trompée! . . . Que toute incertitude ait cessé dans les flammes, cela doit nous faire ro croire qu'elle accepta la mort pour la délivrance promise, qu'elle n'entendit plus le salut au sens judaïque et matériel, comme elle avait fait jusque-là, qu'elle vit clair enfin, et que, sortant des ombres, elle obtint ce qui lui manquait encore de lumière et de sainteté.

Cette grande parole est attestée par le témoin obligé et juré de la I mort, par le dominicain qui monta avec elle sur le bûcher, qu'elle en fit descendre, mais qui d'en bas lui parlait, l'écoutait et lui tenait la croix.

Nous avons encore un autre témoin de cette mort sainte, un témoin bien grave, qui lui-même fut sans doute un saint. Cet homme, dont 20 l'histoire doit conserver le nom, était le moine augustin déjà mentionné, frère Isambart de la Pierre; dans le procès, il avait failli périr pour avoir conseillé la Pucelle, et néanmoins, quoique si bien désigné à la haine des Anglais, il voulut monter avec elle dans la charrette, lui fit venir la croix de la paroisse, l'assista parmi cette foule furieuse, et sur 25 l'échafaud et au bûcher.

Vingt ans après, les deux vénérables religieux, simples moines, voués à la pauvreté et n'ayant rien à gagner ni à craindre en ce monde, déposent ce qu'on vient de lire: “ Nous l'entendions, disentils, dans le feu, invoquer ses saintes, son $\operatorname{archange~}^{1}$; elle répétait le 30 nom du Sauveur. ... Enfin laissant tomber sa tête, elle poussa un grand cri : " Jésus! »

"Dix mille hommes pleuraient. ...) Quelques Anglais seuls riaient ou tâchaient de rire. Un d'eux, des plus furieux, avait juré de mettre un fagot au bûcher; elle expirait au moment oủ il le mit, il se 35 trouva mal; ses camarades le menèrent à une taverne pour le faire boire et reprendre ses esprits; mais il ne pouvait se remettre : " J'ai vu, disait-il, hors de lui-même, j'ai vu de sa bouche, avec le dernier 
soupir, s'envoler une colombe. " D'autres avaient lu dans les flammes le mot qu'elle répétait: "Jésus!) Le bourreau alla le soir trouver frère Isambart; il était tout épouvanté; il se confessa, mais il ne pouvait croire que Dieu lui pardonnât jamais. ... Un secrétaire du 5 roi d'Angleterre disait tout haut en revenant: "Nous sommes perdus ; nous avons brûlé une sainte!»

— " Histoire de France », Book X, chap. 4

\section{LA BRETAGNE}

Asseyons-nous à cette formidable pointe du $\mathrm{Raz},{ }^{1}$ sur ce rocher miné, à cette hauteur de trois cents pieds, d'où nous voyons sept lieues de côtes. C'est ici, en quelque sorte, le sanctuaire du monde ro celtique. Ce que vous apercevez par delà la baie des Trépassés, est l'île de Sein, triste banc de sable sans arbres et presque sans abri; quelques familles y vivent, pauvres et compatissantes, qui, tous les ans, sauvent des naufragés. Cette île était la demeure des vierges sacrées qui donnaient aux Celtes beau temps ou naufrage. Là, elles céléI 5 braient leur triste et meurtrière orgie; et les navigateurs entendaient avec effroi de la pleine mer le bruit des cymbales barbares. Cette île, dans la tradition, est le berceau de Myrdhyn, ${ }^{2}$ le Merlin du moyen âge. Son tombeau est de l'autre côté de la Bretagne, dans la forêt de Brocéliande, sous la fatale pierre où sa Vyvyan l'a enchanté. Tous ces 20 rochers que vous voyez, ce sont des villes englouties; c'est Douarnenez ${ }^{3}$ c'est Is, ${ }^{4}$ la Sodome bretonne ; ces deux corbeaux, qui vont toujours volant lourdement au rivage, ne sont rien autre que les âmes du roi Grallon ${ }^{5}$ et de sa fille ; et ces sifflements, qu'on croirait ceux de la tempête, sont les crierien, ombres des naufragés qui demandent la 25 sépulture.

A Lanvau, près Brest, s'élève, comme la borne du continent, une grande pierre brute. De là, jusqu'à Lorient, et de Lorient à Quiberon et Carnac, sur toute la côte méridionale de la Bretagne, vous - ne pouvez marcher un quart d'heure sans rencontrer quelques-uns de

1 The extreme western point of the Finistère (finis terrae). Beyond it lies the Ile de Sein.

2 The Merlin of the Arthurian cycle was enchanted by Vivian.

3 The modern Douarnenez is a town of 12,000 inhabitants in the Finistère. It has been believed that an older town near by had been engulfed.

4 A legendary town believed to have been engulfed because of the sins of its inhabitants.

${ }^{5}$ Legendary king of Cornouaille. 
ces monuments informes qu'on appelle druidiques. Vous les voyez souvent de la route dans des landes couvertes de houx et de chardons. Ce sont de grosses pierres basses, dressées et souvent un peu arrondies par le haut; ou bien, une table de pierre portant sur trois ou quatre pierres droites. Qu'on veuille y voir des autels, des tombeaux, ou de simples souvenirs de quelque événement, ces monuments ne sont rien moins qu'imposants, quoi qu'on ait dit. Mais l'impression en est triste, ils ont quelque chose de singulièrement rude et rebutant. On croit sentir dans ce premier essai de l'art une main déjà intelligente, mais aussi dure, aussi pcu humaine que le roc qu'elle a façonné. ro Nulle inscription, nul signe, si ce n'est peut-être sous les pierres renversées de Loc-Maria-Ker, encore si peu distincts qu'on est tenté de les prendre pour des accidents naturels. Si vous interrogez les gens du pays, ils répondront brièvement que ce sont les maisons des Korrigans, des Courils, petits hommes lascifs qui, le soir, barrent le chemin, I 5 et vous forcent de danser avec eux jusqu'à ce que vous en mouriez de fatigue. Ailleurs, ce sont les fées qui, descendant des montagnes en filant, ont apporté ces rocs dans leur tablier. Ces pierres éparses sont toute une noce pétrifiée. Une pierre isolée, vers Morlaix, témoigne du malheur d'un paysan qui, pour avoir blasphémé, a été avalé par la lune. 20

Je n'oublierai jamais le jour où je partis de grand matin d'Auray, la ville sainte des chouans, ${ }^{1}$ pour visiter, à quelques lieues, les grands monuments druidiques de Loc-Maria-Ker et de Carnac. Le premier de ces villages, à l'embouchure de la sale et fétide rivière d'Auray, avec ses îles du Morbihan, ${ }^{2}$ plus nombreuses qu'il n'y a de jours dans 25 l'an, regarde par-dessus une petite baie la plage de Quiberon, de sinistre mémoire. Il tombait du brouillard, comme il y en a sur ces côtes la moitié de l'année. De mauvais ponts sur des marais, puis le bas et sombre manoir avec la longue avenue de chênes qui s'est religieusement conservée en Bretagne; des bois fourrés et bas, où les 30 vieux arbres même ne s'élèvent jamais bien haut; de temps en temps un paysan qui passe sans regarder; mais il vous a bien vu avec son œil oblique d'oiseau de nuit. Cette figure explique leur fameux cri de guerre, et le nom de chouans, que leur donnaient les bleus. Point de maisons sur les chemins; ils reviennent chaque soir au village. Par- 35 tout de grandes landes, tristement parées de bruyères roses et de

1 The name of the Bretons who, in 1793 , revolted against the Republic. The republicans were called the bleus.

2 The Morbihan is southeast of the Finistère. 
diverses plantes jaunes; ailleurs, ce sont des campagnes blanches de sarrasin. Cette neige d'été, ces couleurs sans éclat et comme flétries d'avance, affligent l'œil plus qu'elles ne le récréent, comme cette couronne de paille et de fleurs dont se pare la folle d'Hamlet. En avan5 çant vers Carnac, c'est encore pis. Véritables plaines de roc où quelques moutons noirs paissent le caillou. $\mathrm{Au}$ milieu de tant de pierres, dont plusieurs sont dressées d'elles-mêmes, les alignements de Carnac n'inspirent aucun étonnement. Il en reste quelques centaines debout; la plus haute a quatorze pieds.

Io Le Morbihan est sombre d'aspect et de souvenirs; pays de vieilles haines, de pèlerinages et de guerre civile, terre de caillou et race de granit.

— "Histoire de France », Book III, Tableau de la France

\section{LES VOLONTAIRES DE 1792 - LA MARSEILLAISE}

Détournez les yeux de Paris, et contemplez, je vous prie, si votre regard peut l'embrasser, l'immense, l'inconcevable grandeur du mouve-

15 ment. Six cent mille volontaires inscrits veulent marcher à la frontière. Il ne manque que des fusils, des souliers, du pain. Les cadres sont tout préparés ; les fédérations ${ }^{1}$ pacifiques de $\mathrm{I} 790$ sont les bataillons frémissants de r 792. Les mêmes chefs souvent y commandent; ceux qui menèrent le peuple aux fêtes vont le guider aux combats. . . .

Ces innombrables volontaires ont gardé tous un caractère de l'époque vraiment unique qui les enfanta à la gloire. Et maintenant, où qu'ils soient, dans la mort ou dans la vie, morts immortels, savants illustres, vieux et glorieux soldats, ils restent tous marqués d'un signe qui les met à part dans l'histoire. Ce signe, cette formule, ce mot qui

25 fit trembler toute la terre, n'est autre que leur simple nom : Volontaires de 1792 .

Leurs maîtres, qui les instruisirent et disciplinèrent leur enthousiasme, qui marchèrent devant eux comme une colonne de feu, c'étaient les sous-officiers ou soldats de l'ancienne armée, que la Révo30 lution venait de jeter en avant, ses fils qui n'étaient rien sans elle, qui par elle avaient déjà gagné leur plus grande bataille, la victoire de la liberté. Génération admirable, qui vit en un même rayon la liberté et la gloire, et vola le feu du ciel.

1 Associations formed throughout France to defend the principles of liberty. They united in one grand national federation on July 14, 1790, at Paris. This same popular patriotic spirit inspired numberless citizens to enlist when danger threatened the country. 
C'était le jeune, l'héroïque, le sublime Hoche, ${ }^{1}$ qui devait vivre si peu, celui que personne ne put voir sans l'adorer. - C'était la pureté même, cette noble figure virginale et guerrière, Marceau ${ }^{2}$ pleuré de l'ennemi. - C'était l'ouragan des batailles, le colérique Kléber, ${ }^{8}$ qui, sous cet aspect terrible, eut le cœur humain et bon, qui, dans ses notes secrètes, plaint la nuit les campagnes vendéennes qu'il lui faut ravager le jour. - C'était l'homme de sacrifice, qui voulut toujours le devoir, et la gloire pour lui jamais, qui la donna souvent aux autres, et même aux dépens de sa vie, un juste, un héros, un saint, l'irréprochable Desaix. ${ }^{4}$

Et puis après ces héros, arrivent les ambitieux, les avides, les poli- ıо tiques, les redoutés capitaines, qui plus tard ont cherché fortune avec ou contre César. ${ }^{5}$ L'épée la plus acérée, l'âpre Piémontais, Masséna, ${ }^{6}$ avec son profil de loup. Des rois, ou gens propres à l'être, des Bernadotte $^{7}$ et des Soult. ${ }^{8}$ Le grand sabre de Murat ${ }^{9}$. . . . Tels furent les officiers, les maîtres et les instructeurs des légions de $179^{2}$.

Grands maitres, qui enseignaient d'exemple. Il ne faudrait pas croire néanmoins que ces rudes et vaillants soldats, comme beaucoup de ceux-ci, les Augereau, ${ }^{10}$ les Lefebvre, ${ }^{11}$ représentassent l'esprit, le grand souffle du moment sacré. Ah! ce qui le rendait sublime, c'est qu'à proprement parler ce moment n'était pas militaire. Il fut 20 héroiqque. Par-dessus l'élan de la guerre, sa fureur et sa violence, planait toujours la grande pensée, vraiment sainte, de la Révolution, l'affranchissement du monde.

En récompense, il fut donné à la grande âme de la France, en ce moment désintéressé et sacré, de trouver un chant, ${ }^{12}$ - un chant qui, 25

1 Hoche (1768-1797), a French general who served with distinction in Alsace in 1793 , and in the Vendée in $1795^{-17} 796$.

2 Marceau ( $1769-1796)$ served in the Vendée in 1793 and captured Coblenz in 1794. He was conspicuous for his humane treatment of the conquered.

3 Kléber (1753-1800) distinguished himself in the Vendée (1793) and in Egypt, where he was assassinated.

4 Desaix ( $1768-1800$ ), a French general who served with distinction in Egypt and at Marengo, where he was killed.

6 Masséna ( $\left.1756-1 S_{17}\right)$, a distinguished marshal of France.

7 Bernadotte $(1764-1844)$, marshal of France. He became king of Sweden in 1818 , under the name of Charles XIV.

8 Soult $(1769-185 \mathrm{I})$, marshal of France. He distinguished himself at Austerlitz and in Spain.

9 Murat ( $1771-1815$ ), brother-in-law of Napoleon; king of Naples from 1808 to 1814 .

10 Augereau ( $1756-1816)$, a marshal of France.

11 Lefebvre (1755-1820), a marshal of France.

12 The "Marseillaise," the national hymn of France, composed in 1792 by Rouget de Lisle $(1760-1836)$. 
répété de proche en proche, a gagné toute la terre. Cela est divin et rare d'ajouter un chant éternel à la voix des nations.

Il fut trouvé à Strasbourg, à deux pas de l'ennemi. Le nom que lui donna l'auteur est le Chant de l'armée du Rhin. Trouvé en mars 5 ou avril, au premier moment de la guerre, il ne lui fallut pas deux mois pour pénétrer toute la France. Il alla frapper au fond du Midi, comme un violent écho, et Marseille répondit au Rhin. Sublime destinée de ce chant! Il est chanté des Marseillais à l'assaut des Tuileries, ${ }^{1}$ il brise le trône au ro août. On l'appelle La Marseillaise. Il est Io chanté à Valmy, ${ }^{2}$ affermit nos lignes flottantes, effraye l'aigle noir de Prusse. Et c'est encore avec ce chant que nos jeunes soldats novices gravirent le coteau de Jemmapes, ${ }^{3}$ franchirent les redoutes autrichiennes, frappèrent les vieilles bandes hongroises, endurcies aux guerres des 'Turcs. Le fer ni le feu n'y pouvaient; il fallut, pour I 5 briser leur courage, le chant de la liberté.

De toutes nos provinces, nous l'avons dit, celle qui ressentit peutêtre le plus vivement le bonheur de la délivrance, en r 789 , ce fut celle où étaient les derniers serfs, la triste Franche-Comté. Un jeune noble franc-comtois, né à Lons-le-Saulnier, Rouget de l'Isle, trouva le chant zo de la France. Rouget de l'Isle était officier de génie à vingt ans. Il était alors à Strasbourg, plongé dans l'atmosphère brûlante des bataillons de volontaires qui s'y rendaient de tous côtés. Il faut voir cette ville, en ces moments, son bouillonnant foyer de guerre, de jeunesse, de joie, de plaisir, de banquets, de bals, de revues, au pied de 25 la flèche sublime qui se mire au noble Rhin; les instruments militaires, les chants d'amour ou d'adieux, les amis qui se retrouvent, se quittent, s'embrassent aux places publiques. Les femmes prient aux églises, les cloches pleurent, et le canon tonne, comme une voix solennelle de la France à l'Allemagne.

30 Ce ne fut pas, comme on l'a dit, dans un repas de famille, que fut trouvé le chant sacré. Ce fut dans une foule émue. Les volontaires partaient le lendemain. Le maire de Strasbourg, Dietrich, ${ }^{4}$ les invita à un banquet où les officiers de la garnison vinrent fraterniser avec

1 The Tuileries, the residence of Louis XVI, defended by the Swiss guards, was stormed by the people on August 10, 1792. After this date the king's executive power was suspended.

2 Dumouriez and Kellermann defeated the Prussians at Valmy, September 20, 1792.

3 The French under Dumouriez won a victory here over the Austrians, November 6, 1792 .

4 A mineralogist, born at Strassburg 1748 , elected mayor 1790 , decapitated 1793. 
eux et leur serrer la main. Les demoiselles Dietrich, nombre de jeunes demoiselles, nobles et douces filles d'Alsace, ornaient ce repas d'adieu de leurs grâces et de leurs larmes. Tout le monde était ému; on voyait devant soi commencer la longue carrière de la guerre de la liberté, qui, trente ans durant, a noyé de sang l'Europe. Ccux qui siégeaient aux repas n'en voyaient pas tant sans doute. Ils ignoraient que, dans peu, ils auraient tous disparu, l'aimable Dictrich entre autres qui les recevait si bien, et que toutes ces filles charmantes dans un an seraient en deuil. Plus d'un, dans la joie du banquet, rêvait, sous l'impression de vagues pressentiments, comme quand on est assis, Io au moment de s'embarquer, au bord de la grande mer. Mais les coeurs étaient bien haut, pleins d'élan et de sacrifice, et tous acceptaient lorage. Cet élan commun qui soulevait toute poitrine d'un égal mouvement aurait eu besoin d'un rythme, d'un chant qui soulageât les cceurs. Le chant de la Révolution, colérique en 1792 , le $C$ Ca $i r a^{1}$ n'al- 15 lait plus à la douce et fraternelle émotion qui animait les convives. L'un d'eux la traduisit: Allons!

Et ce mot dit, tout fut trouvé. Rouget de l'Isle, c'était lui, se précipita de la salle, et il écrivit tout, musique et paroles. Il rentra en chantant la strophe: Allons, enfants de la patrie! Ce fut comme 20 un éclair du ciel. Tout le monde fut saisi, ravi, tous reconnurent ce chant, entendu pour la première fois. Tous le savaient, tous le chantèrent, tout Strasbourg, toute la France. Le monde, tant qu'il y aura un monde, le chantera à jamais.

Si ce n'était qu'un chant de guerre, il n'aurait pas été adopté des 25 nations. C'est un chant de fraternité ; ce sont des bataillons de frères qui, pour la sainte défense du foyer, de la patrie, vont ensemble d'un même cœur. C'est un chant, qui, dans la guerre, conserve un esprit de paix. Qui ne connaît la strophe sainte: Épargnez ces tristes victimes!

Telle était bien alors l'âme de la France, émue de l'imminent combat, violente contre l'obstacle, mais toute magnanime encore, d'une jeune et naïve grandeur; dans l'accès de la colère même, au-dessus de la colère.

— "Histoire de la révolution française ", Book VI, chap. 9

1 "Ça ira," like the "Carmagnole," was a popular song of the Revolution, particularly during the "Terror," when the following Terrorist lines were added:

"Ah! ça ira, ça ira, ça ira,

Les aristocrates à la lanterne."

I.e. they would hang the aristocrats to the street-lamp brackets. 


\title{
PROSPER MÉRIMÉE
}

\author{
Paris, $1803-1870$, Cannes
}

Mérimée first took up the study of law. After the revolution of 1830 he held various official posts, - under secretary, inspector of historical monuments, and, under the second empire, senator. He was received into the Academy in 1844 . In the meantime, at first under the inspiration of the Romantic School, he published in 1825 the "Théâtre de Clara Gazul," and two years later "La Guzla," pretended translations. In I829 appeared the "Chronique du règne de Charles IX," and in this same year and the years following came out the stories which show at the same time the foreign interests, the local color, the fantastic imagination of the Romanticists, and the dispassionate objective point of view, in a word the perfect artistic finish and form, of a classic. His best stories are "Tamango," "Matteo Falcone," "L'enlèvement de la redoute," "Carmen," and "Colomba" (1 840 ), his masterpiece. His historical writings belong to the latter half of his life: "Don Pedro de Castille" (I848); "Les faux Démétrius" (1852); "Les mélanges historiques et littéraires" (1855). After his death came out "Lettres à une inconnue" (1873); "Lettres à une autre inconnue" (1875); "Lettres à Panizzi" (I881); "Correspondance . inédite" (1896).

\section{L'ENLÈVEMENT DE LA REDOUTE'}

Un militaire de mes amis, qui est mort de la fièvre en Grèce il y a quelques années, me conta un jour la première affaire à laquelle il avait assisté. Son récit me frappa tellement, que je l'écrivis de mémoire aussitôt que j'en eus le loisir. Le voici :

5 - Je rejoignis le régiment le 4 septembre au soir. Je trouvai le colonel au bivac. Il me reçut d'abord assez brusquement; mais, après avoir lu la lettre de recommandation du général $\mathrm{B} \_$, il changea de manières, et m'adressa quelques paroles obligeantes.

Je fus présenté par lui à mon capitaine, qui revenait à l'instant ıo même d'une reconnaissance. Ce capitaine, que je n'eus guère le temps de connaître, était un grand homme brun, d'une physionomie dure et repoussante. Il avait été simple soldat, et avait gagné ses épaulettes

1 In this tale Mérimée apparently has in mind the redoubt of Schwardino, Russia, which was carried on September 7, 1812, by the cavalry under Murat, and the infantry under General Compans. 
et sa croix sur les champs de bataille. Sa voix, qui était enrouée ct faible, contrastait singulièrement avec sa stature presque gigantesque. On me dit qu'il devait cette voix étrange à une balle qui l'avait percé de part en part à la bataille d'Iéna. ${ }^{1}$

En apprenant que je sortais de l'école de Fontainebleau, ${ }^{2}$ il fit la 5 grimace et dit :

- Mon lieutenant est mort hier. . . .

Je compris qu'il voulait dire: "C'est vous qui devez le remplacer, et vous n'en êtes pas capable. » Un mot piquant me vint sur les lèvres, mais je me contins.

La lune se leva derrière la redoute de Cheverino, située à deux portées de canon de notre bivac. Elle était large et rouge comme cela est ordinaire à son lever. Mais, ce soir-là, elle me parut d'une grandeur extraordinaire. Pendant un instant, la redoute se détacha en noir sur le disque éclatant de la lune. Elle ressemblait au cône d'un volcan 15 au moment de l'éruption.

Un vieux soldat, auprès duquel je me trouvais, remarqua la couleur de la lune.

- Elle est bien rouge, dit-il ; c'est signe qu'il en coûtera bon pour l'avoir, cette fameuse redoute!

J'ai toujours été superstitieux, et cet augure, dans ce moment surtout, m'affecta. Je me couchai, mais je ne pus dormir. Je me levai, et je marchai quelque temps, regardant l'immense ligne de feux qui couvrait les hauteurs au delà du village de Cheverino.

Lorsque je crus que l'air frais et piquant de la nuit avait assez 25 rafraîchi mon sang, je revins auprès du feu ; je m'enveloppai soigneusement dans mon manteau, et je fermai les yeux, espérant ne pas les ouvrir avant le jour. Mais le sommeil me tint rigueur. Insensiblement mes pensées prenaient une teinte lugubre. Je me disais que je n'avais pas un ami parmi les cent mille hommes qui couvraient cette plaine. 30 Si j'étais blessé, je serais dans un hôpital, traité sans égards par des chirurgiens ignorants. Ce que j'avais entendu dire des opérations chirurgicales me revint à la mémoire. Mon cœur battait avec violence, et machinalement je disposais, comme une espèce de cuirasse, le mouchoir et le portefeuille que j'avais sur la poitrine. La fatigue m'accablait, je 35 m'assoupissais à chaque instant, et à chaque instant quelque pensée sinistre se reproduisait avec plus de force et me réveillait en sursaut.

1 Scene of a famous victory by Napoleon, October 14, 1806 .

$2 \mathrm{~A}$ military school, transferred to St. Cyr in 1808 . 
Cependant la fatigue l'avait emporté, et, quand on battit la diane, j'étais tout à fait endormi. Nous nous mîmes en bataille, on fit l'appel, puis on remit les armes en faisceaux, et tout annonçait que nous allions passer une journée tranquille.

5 Vers trois heures, un aide de camp arriva, apportant un ordre. On nous fit reprendre les armes; nos tirailleurs se répandirent dans la plaine; nous les suivîmes lentement, et, au bout de vingt minutes, nous vîmes tous les avant-postes des Russes se replier et rentrer dans la redoute.

Io Une batterie d'artillerie vint s'établir à notre droite, une autre à notre gauche, mais toutes les deux bien en avant de nous. Elles commencèrent un feu très vif sur l'ennemi, qui riposta énergiquement, et bientôt la redoute de Cheverino disparut sous des nuages épais de fumée.

Notre régiment était presque à couvert du feu des Russes par un I 5 pli de terrain. Leurs boulets, rares d'ailleurs pour nous (car ils tiraient de préférence sur nos canonniers), passaient au-dessus de nos têtes, ou tout au plus nous envoyaient de la terre et de petites pierres.

Aussitôt que l'ordre de marcher en avant nous eut été donné, mon capitaine me regarda avec une attention qui m'obligea à passer deux .20 ou trois fois la main sur ma jeune moustache d'un air aussi dégagé qu'il me fut possible. Au reste, je n'avais pas peur, et la seule crainte que j'éprouvasse, c'était que l'on ne s'imaginât que j'avais peur. Ces boulets inoffensifs contribuèrent encore à me maintenir dans mon calme héroïque. Mon amour-propre me disait que je courais un 25 danger réel, puisque enfin j'étais sous le feu d'une batterie. J'étais enchanté d'être si à mon aise, et je songeai au plaisir de raconter la prise de la redoute de Cheverino, dans le salon de madame de B_-, rue de Provence.

Le colonel passa devant notre compagnie; il m'adressa la parole: 30 " Eh bien, vous allez en voir de grises pour votre début. »

Je souris d'un air tout à fait martial en brossant la manche de mon habit, sur laquelle un boulet, tombé à trente pas de moi, avait envoyé un peu de poussière.

Il paraît que les Russes s'aperçurent du mauvais succès de leurs 35 boulets; car ils les remplacèrent par des obus qui pouvaient plus facilement nous atteindre dans le creux où nous étions postés. Un assez gros éclat m'enleva mon shako et tua un homme auprès de moi.

- Je vous fais mon compliment, me dit le capitaine, comme je venais de ramasser mon shako, vous en voilà quitte pour la journée. 
Je connaissais cette superstition militaire qui croit que l'axiome non bis in idem trouve son application aussi bien sur un champ de bataille que dans une cour de justice. Je remis fièrement mon shako.

- C'est faire saluer les gens sans cérémonie, dis-je aussi gaiement que je pus.

Cette mauvaise plaisanterie, vu la circonstance, parut excellente.

- Je vous félicite, reprit le capitaine, vous n'aurez rien de plus, et vous commanderez une compagnie ce soir; car je sens bien que le four chauffe pour moi. 'Toutes les fois que j'ai été blessé, l'officier auprès de moi a reçu quelque balle morte, et, ajouta-t-il d'un ton plus ıo bas et presque honteux, leurs noms commençaient toujours par un P.

Je fis l'esprit fort ; bien des gens auraient fait comme moi; bien des gens auraient été aussi bien que moi frappés de ces paroles prophétiques. Conscrit comme je l'étais, je sentais que je ne pouvais confier mes sentiments à personne, et que je devais toujours paraitre froide- 15 ment intrépide.

Au bout d'une demi-heure, le feu des Russes diminua sensiblement ; alors nous sortîmes de notre couvert pour marcher sur la redoute.

Notre régiment était composé de trois bataillons. Le deuxième fut chargé de tourner la redoute du côté de la gorge; les deux autres 20 devaient donner l'assaut. J'étais dans le troisième bataillon.

En sortant de derrière l'espèce d'épaulement qui nous avait protégés, nous fûmes reçus par plusieurs décharges de mousqueterie qui ne firent que peu de mal dans nos rangs. Le sifflement des balles me surprit: souvent je tournais la tête, et je m'attirai ainsi quelques 25 plaisanteries de la part de mes camarades plus familiarisés avec ce bruit.

- A tout prendre, me dis-je, une bataille n'est pas une chose si terrible.

Nous avancions au pas de course, précédés de tirailleurs: tout à 30 coup les Russes poussèrent trois hourras, trois hourras distincts, puis demeurèrent silencieux et sans tirer.

- Je n'aime pas ce silence, dit mon capitaine; cela ne nous présage rien de bon.

Je trouvai que nos gens étaient un peu trop bruyants, et je ne pus 35 m'empêcher de faire intérieurement la comparaison de leurs clameurs tumultueuses avec le silence imposant de l'ennemi.

Nous parvînmes rapidement au pied de la redoute, les palissades avaient été brisées et la terre bouleversée par nos boulets. Les soldats 
s'élancèrent sur ces ruines nouvelles avec des cris de Vive l'empereur! plus forts qu'on ne l'aurait attendu de gens qui avaient déjà tant crié. Je levai les yeux, et jamais je n'oublierai le spectacle que je vis. La plus grande partie de la fumée s'était élevée et restait suspendue 5 comme un dais à vingt pieds au-dessus de la redoute. Au travers d'une vapeur bleuâtre, on apercevait derrière leur parapet à demi détruit les grenadiers russes, l'arme haute, immobiles comme des statues. Je crois voir encore chaque soldat, l'œil gauche attaché sur nous, le droit caché par son fusil élevé. Dans une embrasure, à ro quelques pieds de nous, un homme tenant une lance à feu était auprès d'un canon.

Je frissonnai et je crus que ma dernière heure était venue.

- Voilà la danse qui va commencer, s'écria mon capitaine. Bonsoir!

I5 Ce furent les dernières paroles que je l'entendis prononcer.

Un roulement de tambours retentit dans la redoute. Je vis se baisser tous les fusils. Je fermai les yeux, et j'entendis un fracas épouvantable, suivi de cris et de gémissements. J'ouvris les yeux, surpris de me trouver encore au monde. La redoute était de nouveau enve20 loppée de fumée. J'étais entouré de blessés et de morts. Mon capitaine était étendu à mes pieds : sa tête avait été broyée par un boulet, et j'étais couvert de sa cervelle et de son sang. De toute ma compagnie, il ne restait debout que six hommes et moi.

A ce carnage succéda un moment de stupeur. Le colonel, mettant 25 son chapeau au bout de son épée, gravit le premier le parapet en criant: Vive l'empereur! il fut suivi aussitôt de tous les survivants. Je n'ai presque plus de souvenir net de ce qui suivit. Nous entrâmes dans la redoute, je ne sais comment. On se battit corps à corps au milieu d'une fumée si épaisse que l'on ne pouvait se voir. Je crois que je

30 frappai, car mon sabre se trouva tout sanglant. Enfin j'entendis crier: Victoire! et la fumée diminuant, j'aperçus du sang et des morts sous lesquels disparaissait la terre de la redoute. Les canons surtout étaient enterrés sous des tas de cadavres. Environ deux cents hommes debout, en uniforme français, étaient groupés sans ordre, les uns char-

35 geant leurs fusils, les autres essuyant leurs baïonnettes. Onze prisonniers russes étaient avec eux.

Le colonel était renversé tout sanglant sur un caisson brisé, près de la gorge. Quelques soldats s'empressaient autour de lui; je m'approchai. 
— Où est le plus ancien capitaine ? demandait-il à un sergent.

Le sergent haussa les épaules d'une manière très expressive.

- Et le plus ancien lieutenant?

- Voici monsieur qui est arrivé d'hier, dit le sergent d'un ton tout à fait calme.

Le colonel sourit amèrement.

- Allons, monsieur, me dit-il, vous commandez en chef; faites promptement fortifier la gorge de la redoute avec ces chariots, car l'ennemi est en force; mais le général $\mathrm{C} \_$_ va vous faire soutenir.

- Colonel, lui dis-je, vous êtes grièvement blessé ?

_ $\mathrm{F} \_,{ }^{1}$ mon cher, mais la redoute est prise!

1 "the deuce," 


\section{HONORÉ DE BALZAC}

Tours, I 799-I 850 , Paris

Honoré de Balzac gave up the study of law for literature, in which, however, for some years he met with little success. But the "Chouans" in I 829, the "Peau de chagrin" in I83I, "Louis Lambert" in 1832 , and "Eugénie Grandet" in 1833 , established his reputation, and from then until his death there appeared under his name a constant succession of uneven but remarkable novels, which have given him the first place among French novelists. In I 842 the idea came to him to classify the various stories which he had written, and was to write, into eight divisions according to the phase of life treated, namely, "Scènes de la vie privée," "Scènes de la vie de province," "Scènes de la vie parisienne," "Scènes de la vie politique," "Scènes de la vie militaire," "Scènes de la vie de campagne," "Etudes philosophiques," "Etudes analytiques." The general collection he called the "Comédie humaine."

Balzac was an indefatigable writer, occasionally working his stories over several times before they finally appeared. Into plots which oftentimes show traces of Romanticism he wove numberless details, making his characters part of their surroundings and laying the foundation for the development of realism. His life was a constant struggle to pay off by his writings the immense losses he incurred by repeated wild business ventures. He died in $185^{\circ}$, only a few months after his marriage to Mme. de Hanska, a wealthy Polish lady. Among his best novels are "Eugénie Grandet" (1833); "Le père Goriot" (1835); "César Birotteau" (1837); "Le cousin Pons" (1846); "La cousine Bette" (1847); etc.

\section{LA MAISON DU CHAT QUI PELOTE}

Au milieu de la rue Saint-Denis, presque au coin de la rue du PetitLion, existait naguère une de ces maisons précieuses qui donnent aux historiens la facilité de reconstruire par analogie l'ancien Paris. Les murs menaçants de cette bicoque semblaient avoir été bariolés d'hié5 roglyphes. Quel autre nom le flâneur pouvait-il donner aux X et aux $\mathrm{V}$ que traçaient sur la façade les pièces de bois transversales ou diagonales dessinés dans le badigeon par de petites lézardes parallèles? Évidemment, au passage de la plus légère voiture, chacune de ces solives s'agitait dans sa mortaise. Ce vénérable édifice était surmonté Io d'un toit triangulaire dont aucun modèle ne se verra bientôt plus à Paris. Cette couverture, tordue par les intempéries du climat parisien, 
s'avançait de trois pieds sur la rue, autant pour garantir des eaux pluviales le seuil de la porte que pour abriter le mur d'un grenier et sa lucarne sans appui. Ce dernier étage fut construit en planches clouées l'une sur l'autre comme des ardoises, afin sans doute de ne pas charger cette frêle maison.

Par une matinéc pluvieuse, au mois de mars, un jeune homme, soigneusement enveloppé dans son manteau, se tenait sous l'auvent d'une boutique en face de ce vieux logis, qu'il examinait avec un enthousiasme d'archéologue. A la vérité, ce débris de la bourgeoisic du XVI $\mathrm{X}^{\mathrm{e}}$ siècle offrait à l'observateur plus d'un problème à résoudre. Io A chaque étage une singularité : au premier, quatre fenêtres longues, étroites, rapprochées l'une de l'autre, avaient des carreaux de bois dans leur partie inférieure, afin de produire ce jour douteux à la faveur duquel un habile marchand prête aux étoffes la couleur souhaitée par ses chalands. Le jeune homme semblait plein de dédain pour 15 cette partie essentielle de la maison, ses yeux ne s'y étaient pas encore arrêtés. Les fenêtres du second étage, dont les jalousies relevées laissaient voir, au travers de grands carreaux en verre de Bohême, de petits rideaux de mousseline rousse, ne l'intéressaient pas davantage. Son attention se portait particulièrement au troisième, sur d'humbles 20 croisées dont le bois travaillé grossièrement aurait mérité d'être placé au Conservatoire des arts et métiers ${ }^{1}$ pour y indiquer les premiers efforts de la menuiserie française. Ces croisées avaient de petites vitres d'une couleur si verte, que, sans son excellente vue, le jeune homme n'aurait pu apercevoir les rideaux de toile à carreaux bleus qui 25 cachaient les mystères de cet appartement aux yeux des profanes. Parfois, cet observateur, ennuyé de sa contemplation sans résultat, ou du silence dans lequel la maison était ensevelie, ainsi que tout le quartier, abaissait ses regards vers les régions inférieures. Un sourire involontaire se dessinait alors sur ses lèvres, quand il revoyait la bou- 30 tique, où se rencontraient en effet des choses assez risibles. Une formidable pièce de bois, horizontalement appuyée sur quatre piliers qui paraissaient courbés par le poids de cette maison décrépite, avait été réchampie d'autant de couches de diverses peintures que la joue d'une vieille duchesse en a reçu de rouge. Au milieu de cette large poutre 35 mignardement sculptée se trouvait un antique tableau représentant un chat qui pelotait. Cette toile causait la gaieté du jeune homme. Mais

1 An institution at Paris, founded in 1794 , in which are preserved the models and plans of various instruments used in the arts. 
il faut dire que le plus spirituel des peintres modernes n'inventerait pas de charge si comique. L'animal tenait dans une de ses pattes de devant une raquette aussi grande que lui, et se dressait sur ses pattes de derrière pour mirer une énorme balle que lui renvoyait un gentil5 homme en habit brodé. Dessin, couleur, accessoires, tout était traité de manière à faire croire que l'artiste avait voulu se moquer du marchand et des passants. En altérant cette peinture naïve, le temps l'avait rendue encore plus grotesque par quelques incertitudes qui devaient inquiéter de consciencieux flâneurs. Ainsi la queue moucheIo tée du chat était découpée de telle sorte qu'on pouvait la prendre pour un spectateur, tant la queue des chats de nos ancêtres était grosse, haute et fournie. A droite du tableau, sur un champ d'azur qui déguisait imparfaitement la pourriture du bois, les passants lisaient : GUILLAUME, et à gauche: SUCCESSEUR DU SIEUR CHE-

15 VREL. Le soleil et la pluie avaient rongé la plus grande partie de l'or moulu parcimonieusement appliqué sur les lettres de cette inscription, dans laquelle les $U$ remplaçaient les $V$ et réciproquement, selon les lois de notre ancienne orthographe. Afin de rabattre l'orgueil de ceux qui croient ${ }^{\circ}$ que le monde devient de jour en jour plus spirituel, 20 et que le moderne charlatanisme surpasse tout, il convient de faire observer ici que ces enseignes, dont l'étymologie semble bizarre à plus d'un négociant parisien, sont les tableaux morts de vivants tableaux à l'aide desquels nos espiègles ancêtres avaient réussi à amener les chalands dans leurs maisons. Ainsi la Truie qui file, le Singe vert, etc.,

25 furent des animaux en cage dont l'adresse émerveillait les passants, et dont l'éducation prouvait la patience de l'industriel au XVe siècle. De semblables curiosités enrichissaient plus vite leurs heureux possesseurs que les Providence, les Bonne Foi, les Grâce de Dieu, et les Décollation de saint Jean-Baptiste, qui se voient encore rue Saint-Denis. . . . Mal-

30 gré le bruit que faisaient quelques maraîchers attardés passant au galop pour se rendre à la grande halle, cette rue si agitée avait alors un calme dont la magie n'est connue que de ceux qui ont erré dans Paris désert, à ces heures où son tapage, un moment apaisé, renaît et s'entend dans le lointain, comme la grande voix de la mer. . . . Cet

35 inconnu $^{1}$ se dépitait si bien au moment où l'on ouvrit précipitamment la lucarne du grenier, qu'il n'y vit pas apparaître trois joyeuses figures rondelettes, blanches, roses, mais aussi communes que le sont les figures du Commerce sculptées sur certains monuments. Ces trois

1 I.e. the young man in front of the house. 
faces, encadrées par la lucarne, rappelaient les têtes d'anges bouffis semés dans les nuages qui accompagnent le Père éternel. Les apprentis respirèrent les émanations de la rue avec une avidité qui démontrait combien l'atmosphère de leur grenier était chaude et méphitique. Après avoir indiqué ce singulier factionnaire, le commis qui paraissait être le plus jovial disparut et revint en tenant à la main un instrument ${ }^{1}$ dont le métal inflexible a été récemment remplacé par un cuir souple; puis tous prirent une expression malicieuse en regardant le badaud, qu'ils aspergèrent d'une pluie fine et blanchâtre dont le parfum prouvait que les trois mentons venaient d'être rasés. Élevés sur la pointe ı de leurs pieds et réfugiés au fond de leur grenier pour jouir de la colère de leur victime, les commis cessèrent de rire en voyant l'insouciant dédain avec lequel le jeune homme secoua son manteau et le profond mépris que peignit sa figure quand il leva les yeux sur la lucarne vide. En ce moment, une main blanche et délicate fit remon- 15 ter vers l'imposte la partie inférieure d'une des grossières croisées du troisième étage, au moyen de ces coulisses dont le tourniquet ${ }^{2}$ laisse souvent tomber à l'improviste le lourd vitrage qu'il doit retenir. Le passant fut alors récompensé de sa longue attente. La figure d'une jeune fille, fraîche comme un de ces blancs calices qui fleurissent au 20 sein des eaux, se montra couronnée d'une ruche en mousseline froissée qui donnait à sa tête un air d'innocence admirable. Quoique couverts d'une étoffe brune, son cou, ses épaules s'apercevaient, grâce à de légers interstices ménagés par les mouvements du sommeil. Aucune expression de contrainte n'altérait ni l'ingénuité de ce visage, ni le 25 calme de ces yeux immortalisés par avance dans les sublimes compositions de Raphaël : c'était la même grâce, la même tranquillité de ces Vierges devenues proverbiales. Il existait un charmant contraste produit par la jeunesse des joues de cette figure, sur laquelle le sommeil avait comme mis en relief une surabondance de vie, et par la vieillesse 30 de cette fenêtre massive aux contours grossiers, dont l'appui était noir. Semblable à ces fleurs de jour qui n'ont pas encore au matin déplié leur tunique roulée par le froid des nuits, la jeune fille, à peine éveillée, laissa errer ses yeux bleus sur les toits voisins et regarda le ciel; puis, par une sorte d'habitude, elle les baissa sur les sombres régions de la 35 rue, où ils rencontrèrent aussitôt ceux de son adorateur: la coquetterie la fit sans doute souffrir d'être vue en déshabillé, elle se retira vivement en arrière, le tourniquet tout usé tourna, la croisée redescendit

$$
1 \text { A syringe. }
$$$$
2 \text { "catch." }
$$ 
avec cette rapidité qui, de nos jours, a valu un nom odieux à cette naïve invention ${ }^{1}$ de nos ancêtres, et la vision disparut.

-- " La maison du chat qui pelote»

\section{MONSIEUR GRANDET}

M. Grandet inspirait l'estime respectueuse à laquelle avait droit un homme qui ne devait jamais rien à personne, qui, vieux tonnelier, 5 vieux vigneron, devinait avec la précision d'un astronome quand il fallait fabriquer pour sa récolte mille poinçons ${ }^{2}$ ou seulement cinq cents; qui ne manquait pas une seule spéculation, avait toujours des tonneaux à vendre alors que le tonneau valait plus cher que la denrée à recueillir, pouvait mettre sa vendange dans ses celliers et attendre le

ro moment de livrer son poinçon à deux cents francs quand les petits propriétaires donnaient le leur à cinq louis. Sa fameuse récolte de I8I I, sagement serrée, lentement vendue, lui avait rapporté plus de deux cent quarante mille livres. Financièrement parlant, M. Grandet tenait du tigre et du boa: il savait se coucher, se blottir, envisager ${ }_{5}$ longtemps sa proie, sauter dessus; puis il ouvrait la gueule de sa bourse, y engloutissait une charge d'écus, et se couchait tranquillement, comme le serpent qui digère, impassible, froid, méthodique.

Personne ne le voyait passer sans éprouver un sentiment d'admiration mélangé de respect et de terreur. Chacun dans Saumur n'avait20 il pas senti le déchirement poli de ses griffes d'acier? A celui-ci, maître Cruchot $^{3}$ avait procuré l'argent nécessaire à l'achat d'un domaine, mais à onze pour cent; à celui-là, M. des Grassins avait escompté des traites, mais avec un effroyable prélèvement d'intérêts. Il s'écoulait peu de jours sans que le nom de M. Grandet fût pro25 noncé, soit au marché, soit pendant les soirées dans les conversations de la ville. Pour quelques personnes, la fortune du vieux vigneron était l'objet d'un orgueil patriotique. Aussi plus d'un négociant, plus d'un aubergiste disait-il aux étrangers, avec un certain contentement:

- Monsieur, nous avons ici deux ou trois maisons millionnaires; 30 mais, quant à $M$. Grandet, il ne connaît pas lui-même sa fortune !

En I 8 I6, les plus habiles calculateurs de Saumur estimaient les biens territoriaux du bonhomme à près de quatre millions; mais comme, terme moyen, il avait dû tirer par an, depuis I 793 jusqu'en I 8 I 7, cent mille francs de ses propriétés, il était présumable qu'il possédait en

1 The guillotine.

2 "casks."

${ }^{3}$ Cruchot was Grandet's notary, des Grassins his banker. 
argent une somme presque égale à celle de ses biens-fonds. Aussi, lorsque, après une partie de boston ou quelque entretien sur les vignes, on venait à parler de M. Grandet, les gens capables disaient-ils :

- Le père Grandet?... le père Grandet doit avoir cinq à six millions.

— Vous êtes plus habile que je ne le suis, je n'ai jamais pu savoir le total, répondaient M. Cruchot ou M. des Grassins, s'ils entendaient le propos.

Quelque Parisien parlait-il des Rothschild ${ }^{1}$ ou de M. Laffitte, ${ }^{2}$ les gens de Saumur demandaient s'ils étaient aussi riches que M. Grandet. ı Si le Parisien leur jetait en souriant une dédaigneuse affirmation, ils se regardaient en hochant la tête d'un air d'incrédulité.

Une si grande fortune couvrait d'un manteau d'or toutes les actions de cet homme. Si d'abord quelques particularités de sa vie donnèrent prise au ridicule et à la moquerie, la moquerie et le ridicule s'étaient 15 usés. En ses moindres actes, M. Grandet avait pour lui l'autorité de la chose jugée. Sa parole, son vêtement, ses gestes, le clignement de ses yeux, faisaient loi dans le pays, où chacun, après l'avoir étudié comme un naturaliste étudie les effets de l'instinct chez les animaux, avait pu reconnaître la profonde et muette sagesse de ses plus légers 20 mouvements.

- L'hiver sera rude, disait-on, le père Grandet a mis ses gants fourrés : il faut vendanger. — Le père Grandet prend beaucoup de merrain, il y aura du vin cette année.

M. Grandet n'achetait jamais ni viande ni pain. Ses fermiers lui 25 apportaient par semaine une provision suffisante de chapons, de poulets, d'œufs, de beurre et de blé de rente. Il possédait un moulin dont le locataire devait, en sus du bail, venir chercher une certaine quantité de grains et lui en rapporter le son et la farine. La grande Nanon, son unique servante, quoiqu'elle ne fût plus jeune, boulangeait elle- 30 même tous les samedis le pain de la maison. M. Grandet s'était arrangé avec les maraîchers, ses locataires, pour qu'ils le fournissent de légumes. Quant aux fruits, il en récoltait une telle quantité, qu'il en faisait vendre une grande partie au marché. Son bois de chauffage était coupé dans ses haies ou pris dans les vieilles truisses ${ }^{8}$ à moitié 35 pourries qu'il enlevait au bord de ses champs, et ses fermiers le lui charroyaient dans son bûcher et recevaient ses remerciments.

1 The Rothschilds are a well-known Jewish family of bankers.

2 A celebrated financier and banker $(1767-1844)$.

3 Trees that have been subjected to destructive periodic trimming. 
Ses seules dépenses connues étaient le pain bénit, la toilette de sa femme, celle de sa fille et le paiement de leurs chaises à l'église; la lumière, les gages de la grande Nanon, ${ }^{1}$ l'étamage de ses casseroles; l'acquittement des impositions, les réparations de ses bâtiments et les 5 frais de ses exploitations. Il avait six cents arpents de bois, récemment achetés, qu'il faisait surveiller par le garde d'un voisin, auquel il promettait une indemnité. Depuis cette acquisition seulement, il mangeait du gibier. Les manières de cet homme étaient fort simples. Il parlait peu. Généralement, il exprimait ses idées par de petites phrases 10 sentencieuses et dites d'une voix douce. Depuis la Révolution, époque à laquelle il attira les regards, le bonhomme bégayait d'une manière fatigante aussitôt qu'il avait à discourir longuement ou à soutenir une discussion. Ce bredouillement, l'incohérence de ses paroles, le flux de mots où il noyait sa pensée, son manque apparent de logique, attribués à I 5 un défaut d'éducation, étaient affectés, et seront suffisamment expliqués par quelques événements de cette histoire. D'ailleurs, quatre phrases, exactes autant que des formules algébriques, lui servaient habituellement à embrasser, à résoudre toutes les difficultés de la vie et du commerce: Je ne sais pas. Je ne puis pas. Je ne veux pas. Nous verrons cela.

$20 \quad$ Il ne disait jamais ni oui ni non, et n'écrivait point.

Lui parlait-on, il écoutait froidement, se tenait le menton dans la main droite en appuyant son coude droit sur le revers de la main gauche, et se formait en toute affaire des opinions desquelles il ne revenait point. Il méditait longuement les moindres marchés. Quand, 25 après une savante conversation, son adversaire lui avait livré le secret de ses prétentions en croyant le tenir, il lui répondait:

- Je ne puis rien conclure sans avoir consulté ma femme.

Sa femme qu'il avait réduite à un ilotisme complet, était en affaires son paravent le plus commode. Il n'allait jamais chez personne, ne 30 voulait ni recevoir, ni donner à dîner; il ne faisait jamais de bruit, et semblait économiser tout, même le mouvement. Il ne dérangeait rien chez les autres par un respect constant de la propriété.

Néanmoins, malgré la douceur de sa voix, malgré sa tenue circonspecte, le langage et les habitudes du tonnelier perçaient, surtout quand 35 il était au logis, où il se contraignait moins que partout ailleurs.

Au physique, Grandet était un homme de cinq pieds, trapu, carré, ayant des mollets de douze pouces de circonférence, des rotules noueuses, et de larges épaules; son visage était rond, tanné, marqué de

1 Grandet's domestic. 
petite vérole; son menton était droit, ses lèvres n'offraient aucune sinuosité, et ses dents étaient blanches; ses yeux avaient l'expression calme et dévoratrice que le peuple accorde au basilic; son front, plein de lignes transversales, ne manquait pas de protubérances significatives; ses cheveux, jaunâtres et grisonnants, étaient blanc et noir, 5 disaient quelques jeunes gens qui ne connaissaient pas la gravité d'une plaisanterie faite sur M. Grandet. Son nez, gros par le bout, supportait une loupe veinée que le vulgaire disait, non sans raison, pleine de malice. Cette figure annonçait une finesse dangereuse, une probité sans chaleur, l'égoïsme d'un homme habitué à concentrer ses senti- ıo ments dans la jouissance de l'avarice et sur le seul être qui lui fût réellement quelque chose, sa fille Eugénie, sa seule héritière. Attitude, manières, démarche, tout en lui, d'ailleurs, attestait cette croyance en soi que donne l'habitude d'avoir toujours réussi dans ses entreprises. Aussi, quoique de mœurs faciles et molles en apparence, M. 15 Grandet avait-il un caractère de bronze.

Toujours vêtu de la même manière, qui le voyait aujourd'hui le voyait tel qu'il était en r 79I. Ses forts souliers se nouaient avec des cordons de cuir; il portait en tout temps des bas de laine drapés, une culotte courte de gros drap marron à boucles d'argent, un gilet de 20 velours à raies alternativement jaune et puce, boutonné carrément, un large habit marron à grands pans, une cravate noire et un chapeau de quaker. Ses gants, aussi solides que ceux des gendarmes, lui duraient vingt mois, et, pour les conserver propres, il les posait sur le bord de son chapeau à la même place, par un geste méthodique.

Saumur ne savait rien de plus sur ce personnage.

— " Eugénie Grandet »

\section{LA MORT DU PÈRE GORIOT ${ }^{1}$}

— Pas une de ses filles ne viendrait! s'écria Rastignac. Je vais écrire à toutes deux.

- Pas une, répondit le vieillard en se dressant sur son séant. Elles ont des affaires, elles dorment, elles ne viendront pas. Je le savais. Il 30 faut mourir pour savoir ce que c'est que des enfants. ... Ah! mon ami, ne vous mariez pas, n'ayez pas d'enfants! Vous leur donnez la vie, ils vous donnent la mort. Vous les faites entrer dans le monde, ils vous

1 Le père Goriot, abandoned by his daughters after he had given them all his fortune, has taken refuge in a poor boarding house, where he is dying, attended only by one of his friends, Eugène Rastignac, and a medical student, Bianchon. 
en chassent. Non, elles ne viendront pas! Je sais cela depuis dix ans. Je me le disais quelquefois, mais je n'osais pas y croire.

Une larme roula dans chacun de ses yeux, sur la bordure rouge, sans en tomber.

5 - Ah! si j'étais riche, si j'avais gardé ma fortune, si je ne la leur avais pas donnée, elles seraient là, elles me lècheraient les joues de leurs baisers! je demeurerais dans un hôtel, j'aurais de belles chambres, des domestiques, du feu à moi ; et elles seraient tout en larmes, avec leurs maris, leurs enfants. J'aurais tout cela. Mais rien. L'argent Io donne tout, même des filles. Oh! mon argent, où est-il ? Si j'avais des trésors à laisser, elles me panseraient, elles me soigneraient, je les entendrais, je les verrais. Ah! mon cher enfant, mon seul enfant, j'aime mieux mon abandon et ma misère! Au moins quand un malheureux est aimé, il est bien sûr qu'on l'aime. Non, je voudrais être I 5 riche, je les verrais. Ma foi, qui sait ? Elles ont toutes les deux des cœurs de roche. J'avais trop d'amour pour elles pour qu'elles en eussent pour moi. Un père doit être toujours riche, il doit tenir ses enfants en bride comme des chevaux sournois. Et j'étais à genoux devant elles! Les misérables! elles couronnent dignement leur con2o duite envers moi depuis dix ans. Si vous saviez comme elles étaient - aux petits soins pour moi dans les premiers temps de leur mariage! (Oh! je souffre un cruel martyre!) Je venais de leur donner à chacune près de huit cent mille francs, elles ne pouvaient pas, ni leurs maris non plus, être rudes avec moi. L'on me recevait : "Mon bon père

25 par-ci, mon cher père par-là. " Mon couvert était toujours mis chez elles. Enfin je dînais avec leurs maris, qui me traitaient avec considération. J'avais l'air d'avoir encore quelque chose. Pourquoi ça ? Je n'avais rien dit de mes affaires. Un père qui donne huit cent mille francs à ses filles était un homme à soigner. Et l'on était aux petits soins, 30 mais c'était pour mon argent. Le monde n'est pas beau. J'ai vu cela, moi! L'on me menait en voiture au spectacle, et je restais comme je voulais aux soirées. Enfin elles se disaient mes filles, et elles m'avouaient pour leur père. J'ai encore ma finesse, allez, et rien ne m'est échappé. Tout a été à son adresse et m'a percé le cœur. Je voyais 35 bien que c'étaient des frimes; mais le mal était sans remède. Je n'étais pas chez elles aussi à l'aise qu'à la table d'en bas. Je ne savais rien dire. Aussi, quand quelques-uns de ces gens du monde demandaient à l'oreille de mes gendres : "Qui est-ce que ce monsieur-là ? — C'est le père aux écus, il est riche. - Ah diable ! ») disait-on, et l'on me regardait 
avec le respect dû aux écus. Mais si je les gênais quelquefois un peu, je rachetais bien mes défauts! D'ailleurs qui donc est parfait? (Ma tête est une plaie!) Je souffre en ce moment ce qu'il faut souffrir pour mourir, mon cher monsieur Eugène, eh bien! ce n'est rien en comparaison de la douleur que m'a causée le premier regard par lequel Anastasie m'a fait comprendre que je venais de dire une bêtise qui l'humiliait: son regard m'a ouvert toutes les veines. J'aurais voulu tout savoir, mais ce que j'ai bien su, c'est que j'étais de trop sur terre. Le lendemain je suis allé chez Delphine pour me consoler, et voilà que j'y fais une bêtise qui me l'a mise en colère. J'en suis devenu comme ro fou. J'ai été huit jours ne sachant plus ce que je devais faire. Je n'ai pas osé les aller voir de peur de leurs reproches. Et me voilà à la porte de chez mes filles. O mon Dieu! puisque tu connais les misères, les souffrances que j'ai endurées; puisque tu as compté les coups de poignard que j'ai reçus, dans ce temps qui m'a vieilli, changé, tué, 15 blanchi, pourquoi me fais-tu donc souffrir aujourd'hui ? J'ai bien expié le péché de les trop aimer. Elles se sont bien vengées de mon affection, elles m'ont tenaillé comme des bourreaux! Eh bien! les pères șont si bêtes! je les aimais tant que j'y suis retourné comme un joueur au jeu. Mes filles, c'était mon vice à moi! . . Elles avaient toutes 20 les deux besoin de quelque chose, de parures; les femmes de chambre me le disaient, et je les donnais pour être bien reçu! Mais elles m'ont fait tout de même quelques petites leçons sur ma manière d'être dans le monde. Oh! elles n'ont pas attendu le lendemain. Elles commençaient à rougir de moi. Voilà ce que c'est que de bien élever ses 25 enfants. A mon âge je ne pouvais pourtant pas aller à l'école. (Je souffre horriblement, mon Dieu! Les médecins, les médecins! Si l'on m'ouvrait la tête, je souffrirais moins.) Mes filles, mes filles, Anastasie, Delphine, je veux les voir. Envoyez les chercher par la gendarmerie, de force! la justice est pour moi, tout est pour moi, la nature, le code $3 \circ$ civil. Je proteste. La patrie périra, si les pères sont foulés aux pieds. Cela est clair. La société, le monde roulent sur la paternité, tout croule si les enfants n'aiment pas leurs pères. Oh! les voir, les entendre, n'importe ce qu'elles me diront, pourvu que j'entende leur voix, ça calmera mes douleurs, Delphine surtout. Mais dites-leur, 35 quand elles seront là, de ne pas me regarder froidement comme elles font. Ah! mon bon ami, monsieur Eugène, vous ne savez pas ce que c'est que de trouver l'or du regard changé tout à coup en plomb gris. Depuis le jour où leurs yeux n'ont plus rayonné sur moi, j'ai 
toujours été en hiver ici ; je n'ai plus eu que des chagrins à dévorer, et je les ai dévorés! J'ai vécu pour être humilié, insulté. Je les aime tant que j'avalais tous les affronts par lesquels elles me vendaient une pauvre petite jouissance honteuse. Un père se cacher pour voir ses 5 filles! Je leur ai donné ma vie, elles ne me donneront pas une heure aujourd'hui! J'ai soif, j'ai faim, le cœur me brûle, elles ne viendront pas rafraîchir mon agonie, car je meurs, je le sens. Mais elles ne savent donc pas ce que c'est que de marcher sur le cadavre de son père! Ily a un Dieu dans les cieux, il nous venge malgré nous, nous Io autres pères. Oh! elles viendront! Venez, mes chéries, venez encore me baiser, un dernier baiser, le viatique de votre père, qui priera Dieu pour vous, qui lui dira que vous avez été de bonnes filles, qui plaidera pour vous! Après tout vous êtes innocentes. Elles sont innocentes, mon ami! Dites-le bien à tout le monde, qu'on ne les inquiète pas à

I 5 mon sujet. Tout est de ma faute, je les ai habituées à me fouler aux pieds. J'aimais cela, moi. Ça ne regarde personne, ni la justice humaine, ni la justice divine. Dieu serait injuste s'il les condamnait à cause de moi. Je n'ai pas su me conduire, j'ai fait la bêtise d'abdiquer mes droits. Je me serais avili pour elles! Que voulez-vous! le plus 20 beau naturel, les meilleures âmes auraient succombé à la corruption de cette facilité paternelle. Je suis un misérable, je suis justement puni. Moi seul ai causé les désordres de mes filles, je les ai gâtées. . . . A quinze ans elles avaient voiture! Rien ne leur a résisté. Moi seul suis coupable, mais coupable par amour. Leur voix m'ouvrait le cœur. Je 25 les entends, elles viennent. Oh! oui, elles viendront. La loi veut qu'on vienne voir mourir son père, la loi est pour moi. Puis ça ne coûtera qu'une course. Je la payerai. Ecrivez-leur que j'ai des millions à leur laisser! Parole d'honneur. J'irai faire des pâtes d'Italie à Odessa. Je connais la manière. Il y a, dans mon projet, des millions à gagner.

30 Personne n'y a pensé. Ça ne se gâtera point dans le transport comme le blé, ou comme la farine. Eh! eh ! l'amidon! il y aura là des millions ! Vous ne mentirez pas, dites-leur des millions, et quand même elles viendraient par avarice, j'aime mieux être trompé, je les verrai. Je veux mes filles! je les ai faites! elles sont à moi! dit-il en se dressant sur son 35 séant, en montrant à Eugène une tête dont les cheveux blancs étaient épars et qui menaçait par tout ce qui pouvait exprimer la menace.

- Allons, lui dit Eugène, recouchez-vous, mon bon père Goriot, je vais leur écrire. Aussitôt que Bianchon sera de retour, j'irai, si elles ne viennent pas. 
— Si elles ne viennent pas ? répéta le vieillard en sanglotant. Mais je serai mort, mort dans un accès de rage, de rage! La rage me gagne! En ce moment, je vois ma vie entière. Je suis dupe! elles ne m'aiment pas, elles ne m'ont jamais aimé ! cela est clair. Si elles ne sont pas venues, elles ne viendront pas. Plus elles auront tardé, moins elles se décideront à me faire cette joie. Je les connais. Elles n'ont jamais su rien deviner de mes chagrins, de mes douleurs, de mes besoins, elles ne devineront pas plus ma mort; elles ne sont seulement pas dans le secret de ma tendresse. Oui, je le vois, pour elles, l'habitude de m'ouvrir les entrailles a ôté du prix à tout ce que je faisais. ro Elles auraient demandé à me crever les yeux, je leur aurais dit: "Crevez-les!» Je suis trop bête. Elles croient que tous les pères sont comme le leur. Il faut toujours se faire valoir. Leurs enfants me vengeront. Mais c'est dans leur intérêt de venir ici. Prévenez-les donc qu'elles compromettent leur agonie. Elles commettent tous les crimes 15 en un seul. ... Mais allez donc, dites-leur donc que, ne pas venir, c'est un parricide! Elles en ont assez commis sans ajouter celui-là. Criez donc comme moi: "Hé! Nasie! hé! Delphine! venez à votre père qui a été si bon pour vous et qui souffre!» Rien, personne. Mourrai-je donc comme un chien? Voilà ma récompense, l'abandon. 20 Ce sont des infâmes, des scélérates ; je les abomine, je les maudis ; je me relèverai la nuit de mon cercueil pour les remaudire, car, enfin, mes amis, ai-je tort? elles se conduisent bien mal! hein? Qu'est-ce que je dis? Ne m'avez-vous pas averti que Delphine est là ? C'est la meilleure des deux. . . . Vous êtes mon fils, Eugène, vous! aimez-la, 25 soyez un père pour elle. L'autre est bien malheureuse. Et leurs fortunes! Ah! mon Dieu! j'expire, je souffre un peu trop. Coupez-moi la tête, laissez-moi seulement le cœur.

- Christophe, allez chercher Bianchon! s'écria Eugène, épouvanté du caractère que prenaient les plaintes et les cris du vieillard, et rame- 30 nez-moi un cabriolet.

- Je vais aller chercher vos filles, mon bon père Goriot, je vous les ramènerai.

- De force! de force! Demandez la garde, la ligne, ${ }^{1}$ tout, tout, dit-il, en jetant à Eugène un dernier regard où brilla la raison. Dites 35 au gouvernement, au procureur du roi qu'on me les amène, je le veux!

- Mais vous les avez maudites.

1 I.e. the troops. 
— Qui est-ce qui a dit cela? répondit le vieillard stupéfait. Vous savez bien que je les aime, je les adore! Je suis guéri si je les vois. . . . Allez, mon bon voisin, mon cher enfant, allez, vous êtes bon, vous ; je voudrais vous remercier, mais je n'ai rien à vous donner que les béné5 dictions d'un mourant. . . . A boire! les entrailles me brûlent! Mettezmoi quelque chose sur la tête. La main de mes filles, ça me sauverait, je le sens. . . . Mon Dieu! qui refera leur fortune, si je m'en vais? Je veux aller à Odessa pour elles, à Odessa y faire des pâtes.

- Buvez ceci, dit Eugène, en soulevant le moribond et le prenant Io dans son bras gauche, tandis que de la main droite il tenait une tasse pleine de tisane.

— Vous devez aimer votre père et votre mère, vous! dit le vieillard en serrant de ses mains défaillantes la main d'Eugène. Comprenez-vous que je vais mourir sans les voir, mes filles? Avoir soif toujours, et ne I 5 jamais boire, voilà comment j'ai vécu depuis dix ans. ... Mes deux gendres ont tué mes filles. Oui, je n'ai plus eu de filles après qu'elles ont été mariées. Pères, dites aux Chambres de faire une loi sur le mariage! Enfin ne mariez pas vos filles si vous les aimez. Le gendre est un scélérat qui gâte tout chez une fille, il souille tout. Plus de mariages ! 20 C'est ce qui nous enlève nos filles, et nous ne les avons plus quand nous mourons. Faites une loi sur la mort des pères. C'est épouvantable, ceci! Vengeance! Ce sont mes deux gendres qui les empêchent de venir. Tuez-les! A mort le Restaud, à mort l'Alsacien. Ils sont mes assassins ! La mort ou mes filles! Ah! c'est fini, je meurs sans elles !

25 Elles! Nasie! Fifine! allons, venez donc! votre papa sort. . . .

- Mon bon père Goriot, calmez-vous, voyons, restez tranquille, ne vous agitez pas, ne pensez pas.

— Ne pas les voir, voilà l'agonie!

- Vous allez les voir.

3o - Vrai? cria le vieillard égaré. Oh! les voir! je vais les voir, entendre leurs voix. Je mourrai heureux. Eh bien! oui, je nedemande plus à vivre, je n'y tenais plus, mes peines allaient croissant. Mais les voir, toucher leurs robes, ah! rien que leurs robes, c'est bien peu; mais que je sente quelque chose d'elles! Faites-moi prendre les cheveux-veux. . . .

35 Il tomba, la tête sur l'oreiller, comme s'il recevait un coup de massue. Ses mains s'agitèrent sur la couverture comme pour prendre les cheveux de ses filles.

- Je les bénis, dit-il, en faisant un effort . . . bénis. 


\title{
THÉOPHILE GAUTIER
}

\author{
Tarbes, 181 I-I 872 , Neuilly
}

After trying his hand at painting, Théophile Gautier became one of the most enthusiastic followers of the Romantic School, and published his first volume of verse in 1830 . Later, however, he turned from the subjective sentimentality of the Romanticists to the description of objective beauty, and advocated "art for art's sake," which became the motto of the Parnassian School. Whether as novelist, poet, or critic, or as a narrator of travels through Spain, Italy, Russia, or the Orient, the artist's fine sense of color and style always appears.

His best works, in addition to his short stories and travels ("Tra los montes" (1843); "Constantinople" (1853)), are a volume of poetry, entitled "Emaux et camées" (1852), and several novels, among which are "Mademoiselle de Maupin" (1835); "Le roman de la momie" (1858); and "Le capitaine Fracasse" (1863), a novel after the style of Scarron's "Roman comique."

\section{L'ART}

Oui, l'œuvre sort plus belle

D'une forme au travail

Rebelle,

Vers, marbre, onyx, émail.

Point de contraintes fausses!

Mais que, pour marcher droit,

Tu chausses,

Muse, un cothurne étroit.

Fi du rhythme commode,

Comme un soulier trop grand,

Du mode

Que tout pied quitte et prend !

Statuaire, repousse

L'argile que pétrit

Le pouce

Quand flotte ailleurs l'esprit. 
Lutte avec le carrare,

Avec le paros dur

Et rare,

Gardiens du contour pur,

5

Emprunte à Syracuse

Son bronze où fermement S'accuse

Le trait fier et charmant ;

D'une main délicate

Io

Poursuis dans un filon

D'agate

Le profil d'Apollon.

Peintre, fuis l'aquarelle, Et fixe la couleur Trop frêle

Au four de l'émailleur.

Fais les sirènes bleues, Tordant de cent façons

Leurs queues,

Les monstres des blasons;

Dans son nimbe trilobe La Vierge et son Jésus, Le globe

Avec la croix dessus.

Tout passe. - L'art robuste Seul a l'éternité, Le buste

Survit à la cité,

Et la médaille austère

Que trouve un laboureur

Sous terre

Révèle un empereur.

Les dieux eux-mêmes meurent, Mais les vers souverains

Plus fort que les airains. 
Sculpte, lime, cisèle ;

Que ton rêve flottant

Se scelle

Dans le bloc résistant!

\section{CE QUE DISENT LES HIRONDELLES}

Déjà plus d'une feuille sèche

Parsème les gazons jaunis ;

Soir et matin, la brise est fraîche,

Hélas! les beaux jours sont finis!

On voit s'ouvrir les fleurs que garde

Le jardin, pour dernier trésor;

Le dahlia met sa cocarde

Et le souci sa toque d'or.

La pluie au bassin fait des bulles,

Les hirondelles sur le toit

Tiennent des conciliabules :

Voici l'hiver, voici le froid!

Elles s'assemblent par centaines,

Se concertant pour le départ.

L'une dit: "Oh! que dans Athènes

Il fait bon sur le vieux rempart!

“Tous les ans j'y vais et je niche

Aux métopes du Parthénon.

Mon nid bouche dans la corniche

Le trou d'un boulet de canon. »

L'autre: " J'ai ma petite chambre

A Smyrne, au plafond d'un café.

Les Hadjis ${ }^{1}$ comptent leurs grains d'ambre

Sur le seuil d'un rayon chauffé.

" J'entre et je sors, accoutumée

Aux blondes vapeurs des chibouchs, ${ }^{2}$

Et parmi des flots de fumée

Je rase turbans et tarbouchs. ${ }^{8}$ ")

1 The Mussulmans who have made the pilgrimmage to Mecca.

2 Long Turkish pipes.

3 "tarboosh" a cap worn by Greeks and Turks. 
Celle-ci : " J'habite un triglyphe $\mathrm{Au}$ fronton d'un temple, à Balbeck. ${ }^{1}$

Je m'y suspens avec ma griffe

Sur mes petits au large bec. »

Celle-là : "Voici mon adresse :

Rhodes, palais ${ }^{2}$ des Chevaliers ;

Chaque hiver, ma tente s'y dresse

Au chapiteau des noirs piliers. »

Io

15

20
La cinquième : " Je ferai halte, Car l'âge m'alourdit un peu, Aux blanches terrasses de Malte Entre l'eau bleue et le ciel bleu. »

La sixième: "Qu'on est à l'aise Au Caire, en haut des minarets! J'empâte un ornement de glaise, Et mes quartiers d'hiver sont prêts. *

" A la seconde cataracte, ${ }^{3}$

Fait ${ }^{4}$ la dernière, j'ai mon nid ;

J'en ai noté la place exacte, Dans le pschent ${ }^{5}$ d'un roi de granit. »

Toutes: « Demain combien de lieues

Auront filé sous notre essaim, Plaines brunes, pics blancs, mers bleues Brodant d'écume leur bassin!»

Avec cris et battements d'ailes, Sur la moulure aux bords étroits, Ainsi jasent les hirondelles, Voyant venir la rouille aux bois.

Je comprends tout ce qu'elles disent, Car le poète est un oiseau ; Mais, captif, ses élans se brisent Contre un invisible réseau!

1 Baalbek is a town in Asiatic Turkey.

2 A palace constructed by the Knights of St. John, who were in possession of Rhodes from about 1309 to 1522 .

4 " says." 3 Of the Nile.

5 High headdress worn by the kings of Egypt. 
Des ailes! des ailes! des ailes!

Comme dans le chant de Rückert, ${ }^{1}$

Pour voler là-bas avec elles

Au soleil d'or, au printemps vert!

— "Emaux et camées "

\section{GRENADE}

Grenade est gaie, riante, animée, quoique bien déchue de son ancienne splendeur. Les habitants se multiplient et jouent à merveille une nombreuse population; les voitures y sont plus belles et en plus grande quantité qu'à Madrid. La pétulance andalouse répand dans les rues un mouvement et une vie inconnus aux graves promeneurs castillans, qui ne font pas plus de bruit que leur ombre: ce que so nous disons là s'applique surtout à la Carrera del Darro, au Zacatin, à la place Neuve, à la calle ${ }^{2}$ de los Gomeles qui mène à l'Alhambra, ${ }^{8}$ à la place du Théâtre, aux abords de la promenade et aux principales rues artérielles. Le reste de la ville est sillonné en tous sens d'inextricables ruelles de trois à quatre pieds de large qui ne peuvent admettre ${ }_{15}$ de voitures, et rappellent tout à fait les rues moresques d'Alger. Le seul bruit qu'on y entende, c'est le sabot d'un âne ou d'un mulet qui arrache une étincelle aux cailloux luisants du pavé ou le fron-fron monotone d'une guitare qui bourdonne au fond d'une cour intérieure.

Les balcons ornés de stores, de pots de fleurs et d'arbustes, les brin- 20 dilles de vigne qui se hasardent d'une fenêtre à l'autre, les lauriersroses qui lancent leurs bouquets étincelants par-dessus les murs des jardins, les jeux bizarres du soleil et de l'ombre qui rappellent les tableaux de Decamps ${ }^{4}$ représentant des villages tures, les femmes assises sur le pas de la porte, les enfants à demi nus qui jouent et se 25 culbutent, les ânes qui vont et viennent chargés de plumets et de houppes de laine, donnent à ces ruelles, presque toujours montantes et quelquefois coupées de quelques marches, une physionomie particulière qui n'est pas sans charme et dont l'imprévu compense, et au delà, ce qui leur manque comme régularité.

Victor Hugo, dans sa charmante orientale, dit de Grenade:

Elle peint ses maisons de plus riches couleurs. ${ }^{5}$

1 German poet, 1788-1866. See "Liebesfriihling," Book III, 63.

3 This great citadel and palace of the Moors, founded in the thirteenth century, is situated on a hill above the city.

4 A French painter (1803-1860).

5 A line in the poem entitled "Grenade." 
Ce détail est d'une grande justesse. Les maisons un peu riches sont peintes extérieurement de la façon la plus bizarre, d'architectures simulées, d'ornements en grisaille et de faux bas-reliefs. Ce sont des panneaux, des cartouches, des trumeaux, des pots-à-feu, des volutes, des 5 médaillons fleuris de roses pompons, des oves, des chicorées, des amours ventrus soutenant toutes sortes d'ustensiles allégoriques sur des fonds vert-pomme, cuisse de nymphe, ventre de biche: le genre rococo poussé à sa dernière expression. L'on a d'abord de la peine à prendre ces enluminures pour des habitations sérieuses. Il vous semble ro que vous marchez toujours entre des coulisses de théâtre. Nous avions déjà vu à Tolède des façades enluminées dans ce genre, mais elles sont bien loin de celles de Grenade pour la folie des ornements et l'étrangeté des couleurs. Pour ma part, je ne hais pas cette mode, qui égaye les yeux et fait un heureux contraste avec la teinte crayeuse des I 5 murailles passées au lait de chaux. . . .

Pour aller à la promenade, l'on suit la Carrera del Darro, l'on traverse la place du Théâtre, où se dresse une colonne funèbre élevée à la mémoire de Joaquin Maïquez par Julian Romea, ${ }^{1}$ Matilde Diez et autres artistes dramatiques, et sur laquelle donne la façade de l'Arse-

20 nal, bâtiment rococo, barbouillé en jaune et garni de statues de grenadiers peints en gris de souris.

L'Alameda de Grenade est assurément l'un des endroits les plus agréables du monde: elle se nomme le Salon; singulier nom pour une promenade: figurez-vous une longue allée de plusieurs rangs d'arbres 25 d'une verdure unique en Espagne, terminée à chaque bout par une fontaine monumentale, dont les vasques portent sur les épaules de dieux aquatiques d'une difformité curieuse et d'une barbarie réjouissante. Ces fontaines, contre l'ordinaire de ces sortes de constructions, versent l'eau à larges nappes qui s'évaporent en pluie fine et en

30 brouillard humide, et répandent une fraîcheur délicieuse. Dans les allées latérales courent, encaissés par des lits de cailloux de couleur, des ruisseaux d'une transparence cristalline. Un grand parterre, orné de jets d'eau, rempli d'arbustes et de fleurs, myrtes, rosiers, jasmins, toute la corbeille de la Flore grenadine, occupe l'espace entre le Salon 35 et le Genil, et s'étend jusqu'au pont élevé par le général Sébastiani ${ }^{2}$

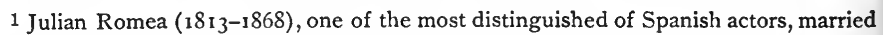
the celebrated actress Matilde Diez $\left(1818-188_{3}\right)$. He erected at Granada a monument in which rest the remains of Isidoro (not Joaquin) Maïquez (1768-1820), likewise a wellknown actor.

2 Sébastiani (1772-1851), a marshal of France and statesman, distinguished himself in many campaigns. 
du temps de l'invasion des Français. Le Genil arrive de la SierraNevada dans son lit de marbre à travers des bois de lauriers d'une beauté incomparable. Le verre, le cristal, sont des comparaisons trop opaques, trop épaisses, pour donner une idée de la pureté de cette eau qui était encore la veille étendue en nappes d'argent sur les épaules blanches de la Sierra-Nevada. C'est un torrent de diamants en fusion. ... .

Un spectacle dont les peuples du Nord ne peuvent se faire une idée, c'est l'Alameda de Grenade au coucher du soleil : la Sierra-Nevada, dont la dentelure enveloppe la ville de ce côté, prend des nuances ini- to maginables. Tous les escarpements, toutes les cimes frappées par la lumière, deviennent roses, mais d'un rose éblouissant, idéal, fabuleux, glacé d'argent, traversé d'iris et de reflets d'opale, qui ferait paraître boueuses les teintes les plus fraîches de la palette; des tons de nacre de perle, des transparences de rubis, des veines d'agate et d'aventurine 15 à défier toute la joaillerie féerique des Mille et une Nuits. Les vallons, les crevasses, les anfractuosités, tous les endroits que n'atteignent pas les rayons du soleil couchant, sont d'un bleu qui peut lutter avec l'azur du ciel et de la mer, du lapis-lazuli et du saphir; ce contraste de ton entre la lumière et l'ombre est d'un effet prodigieux : la montagne 20 semble avoir revêtu une immense robe de soie changeante, pailletée et cotelée ${ }^{1}$ d'argent; peu à peu les couleurs splendides s'effacent et se fondent en demi-teintes violettes, l'ombre envahit les croupes inférieures, la lumière se retire vers les hautes cimes, et toute la plaine est depuis longtemps dans l'obscurité que le diadème d'argent de la Sierra 25 étincelle encore dans la sérénité du ciel sous le baiser d'adieu du soleil.

Les promeneurs font encore quelques tours et se dispersent, les uns pour aller prendre des sorbets ou de l'agraz ${ }^{2}$ au café de don Pedro Hurtado, le meilleur glacier de Grenade; les autres pour se rendre à la tertulia ${ }^{8}$ chez leurs amis et leurs connaissances.

Cette heure est la plus gaie et la plus vivante de Grenade. Les boutiques des aguadores ${ }^{4}$ et des glaciers en plein vent sont éclairées par une multitude de lampes et de lanternes; les réverbères et les fanaux allumés devant les images des madones luttent d'éclat et de nombre avec les étoiles, ce qui n'est pas peu dire; et, s'il fait clair de 35 lune, l'on peut lire parfaitement les éditions les plus microscopiques. Le jour est bleu au lieu d'être jaune, voilà tout.

— "Voyage en Espagne ", XI

1 " ribbed."

8 "club."
2 "verjuice," juice of the green grape.

4 "water venders." 


\title{
GUILLAUME-VICTOR-ÉMILE AUGIER
}

\author{
Valence, I 820-1 889, Croissy
}

Augier and Dumas fils stand out as the leading playwrights of the Naturalistic School. When Augier was eight years of age his family moved to Paris, and it was there that he got his education in the Collège Henri IV. He at first studied law, but, before he was twenty-five, began writing for the stage. After a few attempts in poetical comedy he found his true vein in the problems of contemporary social life, in the treatment of which he shows great good sense. He excelled particularly in dealing with bourgeois types. By his realistic presentation of characters, Augier shows himself to be the precursor of the best dramatists of the modern French stage.

His best plays are "La pierre de touche" (1853); "Le gendre de monsieur Poirier" (I854), both in collaboration with Jules Sandeau ; "Le fils de Giboyer" (I862); "Maître Guérin" (I864); "Les effrontés" (I86I). He was elected to the Academy in 1857 .

\section{LES AMBITIONS DE MONSIEUR POIRIER ${ }^{1}$}

\section{Gaston, Poirier}

Gaston. Eh bien, cher beau-père, comment gouvernez-vous ce petit désespoir? Êtes-vous toujours furieux contre votre panier percé de gendre? Avez-vous pris votre parti?

Poirier. Non, monsieur; mais j'ai pris un parti.

Gaston. Violent?

Poirier. Nécessaire.

Gaston. Y a-t-il de l'indiscrétion à vous demander . . . ?

Poirier. Au contraire, monsieur, c'est une explication que je vous dois. ... (Il lui montre un siège; ils s'asseyent tous deux, l'un à droite et Io l'autre à gauche de la table du milieu.) En vous donnant ma fille et un million, je m'imaginais que vous consentiriez à prendre une position.

Gaston. Ne revenons pas là-dessus, je vous prie.

Poirier. Je n'y reviens que pour mémoire. ... Je reconnais que j'ai eu tort d'imaginer qu'un gentilhomme consentirait à s'occuper I 5 comme un homme, et je passe condamnation. Mais, dans mon erreur,

1 M. Poirier, a rich bourgeois ambitious to enter into aristocratic circles, has married his daughter to Gaston, marquis de Presles. He does not, however, find the satisfaction he anticipated. 
je vous ai laissé mettre ma maison sur un ton que je ne peux pas soutenir à moi seul ; et, puisqu'il est bien convenu que nous n'avons à nous deux que ma fortune, il me paraît juste, raisonnable et nécessaire de supprimer de mon train ce qu'il me faut rabattre de mes espérances. J'ai donc songé à quelques réformes que vous approuverez sans doute.

Gaston. Allez, Sully! ${ }^{1}$ allez, Turgot! . . . coupez, taillez, j’y consens! Vous me trouvez en belle humeur, profitez-en!

Poirier. Je suis ravi de votre condescendance. J'ai donc décidé, arrêté, ordonné ....

Gaston. Permettez, beau-père: si vous avez décidé, arrêté, ordonné, il me paraît superflu que vous me consultiez.

Poirier. Aussi ne vous consulté-je pas; je vous mets au courant, voilà tout.

Gaston. Ah! vous ne me consultez pas?

Poirier. Cela vous étonne?

Gaston. Un peu ; mais, je vous l'ai dit, je suis en belle humeur.

Poirier. Ma première réforme, mon cher garçon . . .

Gaston. Vous voulez dire mon cher Gaston, je pense? La langue vous a fourché.

Poirier. Cher Gaston, cher garçon . . . c'est tout un. . . . De beaupère à gendre, la familiarité est permise.

Gaston. Et, de votre part, monsieur Poirier, elle me flatte et m'honore. ... Vous disiez donc que votre première réforme ... ?

Poirier (se levant). C'est, monsieur, que vous me fassiez le plaisir 25 de ne plus me gouailler. Je suis las de vous servir de plastron.

Gaston. Là, là, monsieur Poirier, ne vous fâchez pas!

Poirier. Je sais très bien que vous me tenez pour un très petit personnage et pour un très petit esprit; mais . . .

-Gaston. Où prenez-vous cela?

Poirier. Mais vous saurez qu'il y a plus de cervelle dans ma pantoufle que sous votre chapeau.

Gaston. Ah! fi! voilà qui est trivial. ... Vous parlez comme un homme du commun.

Poirier. Je ne suis pas un marquis, moi!

Gaston. Ne le dites pas si haut, on finirait par le croire.

1 Sully (1560-1641), minister of finance under Henry IV, and Turgot (1727-1781), minister of finance under Louis XVI, were both noted for the reforms they instituted and the economy they exercised. 
Poirier. Qu'on le croie ou non, c'est le cadet de mes soucis. Je n'ai aucune prétention à la gentilhommerie, Dieu merci! je n'en fais pas assez de cas pour cela.

Gaston. Vous n'en faites pas de cas?

5 Poirier. Non, monsieur, non! Je suis un vieux libéral, tel que vous me voyez; je juge les hommes sur leur mérite, et non sur leurs titres ; je me ris des hasards de la naissance; la noblesse ne m'éblouit pas, et je m'en moque comme de l'an quarante ${ }^{1}$ je suis bien aise de vous l'apprendre.

Io Gaston. Me trouveriez-vous du mérite, par hasard?

Poirier. Non, monsieur, je ne vous en trouve pas.

Gaston. Non? Alors, pourquoi m'avez-vous donné votre fille?

Poirier (interdit). Pourquoi je vous ai donné . . . ?

Gaston. Vous aviez donc une arrière-pensée?

15 Poirier. Une arrière-pensée?

Gaston. Permettez! Votre fille ne m'aimait pas quand vous m'avez attiré chez vous ; ce n'étaient pas mes dettes qui m'avaient valu l'honneur de votre choix; puisque ce n'est pas non plus mon titre, je suis bien obligé de croire que vous aviez une arrière-pensée.

Poirier (se rasseyant). Quand même, monsieur!... quand j'aurais tâché de concilier mes intérêts avec le bonheur de mon enfant, quel mal y verriez-vous? qui me reprochera, à moi qui donne un million de ma poche, qui me reprochera de choisir un gendre en état de me dédommager de mon sacrifice, quand d'ailleurs il est aimé de ma fille?

25 J'ai pensé à elle d'abord, c'était mon devoir; à moi, ensuite, c'était mon droit.

Gaston. Je ne conteste pas, monsieur Poirier. Vous n'avez eu qu'un tort, c'est de manquer de confiance en moi.

Poirier. C'est que vous n'êtes pas encourageant.

3o Gaston. Me gardez-vous rancune de quelques plaisanteries? Je ne suis peut-être pas le plus respectueux des gendres, et je m'en accuse ; mais, dans les choses sérieuses, je suis sérieux. Il est très juste que vous cherchiez en moi l'appui que j'ai trouvé en vous.

Poirier (à part). Comprendrait-il la situation?

35 Gaston. Voyons, cher beau-père, à quoi puis-je vous être bon? si tant est que je puisse être bon à quelque chose.

1 This expression is variously explained. It is said that, when the revolutionists initiated a republican era in 1792 , the royalists ridiculed the new calendar, saying that it would not see the year 40. 
Poirier. Eh bien, j'avais rêvé que vous iriez aux 'Tuileries. ${ }^{1}$

Gaston. Encore! c'est donc votre marottc de danser à la cour?

Poirier. Il ne s'agit pas de danser. Faites-moi l'honneur de me prêter des idées moins frivoles. Je ne suis ni vain, ni futile.

Gaston. Qu'êtes-vous donc, ventre-saint-gris! cxpliquez-vous.

Poirier (piteusement). Je suis ambitieux!

Gaston. On dirait que vous en rougissez; pourquoi donc? Avec l'expérience que vous avez acquise dans les affaires, vous pouvez prétendre à tout. Le commerce est la véritable école des hommes d'État.

Poirier. C'est ce que Verdelet ${ }^{2}$ me disait ce matin.

Gaston. C'est là qu'on puise cette hauteur de vues, cette élévation de sentiments, ce détachement des petits intérêts qui font les Richelieu et les Colbert. ${ }^{3}$

Poirier. Oh! je ne prétends pas...

Gaston. Mais qu'est-ce qui pourrait donc bien lui convenir, à ce bon 15 monsieur Poirier? Une préfecture? fi donc! Le conseil d'État? non! Un poste diplomatique? justement l'ambassade de Constantinople est vacante...

Poirier. J'ai des goûts sédentaires : je n'entends pas le turc.

Gaston. Attendez! (Lui frappant sur l'épaule.) Je crois que la pairie 20 vous irait comme un gant.

Poirier. Oh! croyez-vous?

Gaston. Mais, voilà le diable! vous ne faites partie d'aucune catégorie ... vous n'êtes pas encore de l'Institut. ${ }^{4}$. .

Poirier. Soyez donc tranquille! je payerai, quand il le faudra, trois 25 mille francs de contributions directes. J'ai à la banque trois millions qui n'attendent qu'un mot de vous pour s'abattre sur de bonnes terres.

Gaston. Ah! Machiavel! ${ }^{5}$ Sixte-Quint! ${ }^{6}$ vous les roulerez tous!

Poirier. Je crois que oui.

Gaston. Mais j'aime à penser que votre ambition ne s'arrête pas en 30 si bon chemin? Il vous faut un titre.

1 After the Empire the Tuileries became the seat of the executive power and the residence of the French sovereigns.

2 Poirier's friend and former partner, whom he is constantly quoting.

3 Colbert (1619-1683) was a minister under Louis XIV.

4 The Institute is composed of five academies of which the French Academy is one.

5 Machiavelli (1469-1527) was an able Italian politician and historian of unscrupulous shrewdness.

6 Sixtus V (1521-1590) is said to have feigned that he was decrepit and would soon die, in order that the Conclave, at a loss for a choice, might elect him to the papal chair. After his election he showed remarkable vigor. 
Poirier. Oh! je ne tiens pas à ces hochets de la vanité; je suis, comme je vous le disais, un vieux libéral.

Gaston. Raison de plus. Un libéral n'est tenu de mépriser que l'ancienne noblesse; mais la nouvelle, celle qui n'a pas d'aieux ... .

5 Poirier. Celle qu'on ne doit qu'à soi-même!

Gaston. Vous serez comte.

Poirier. Non. Il faut être raisonnable. Baron, seulement.

Gaston. Le baron Poirier! . . . cela sonne bien à l'oreille.

Poirier. Oui, le baron Poirier!

Io Gaston (le regardant et partant d'un éclat de rire). Je vous demande pardon; mais là, vrai! c'est trop drôle! Baron! monsieur Poirier ! . . baron de Catillard ! ${ }^{1}$

Poirier (à part). Je suis joué !. . .

— "Le gendre de monsieur Poirier», Act III, scene 2

1 The name of a coarse winter pear, good only when cooked. 


\title{
CHARLES-MARIE-RENÉ I.ECONTE DE LISLE
}

\author{
Saint Paul, île de Réunion, I 8 I 8 - I 894, Louveciennes
}

After completing his education, the first part of which had been carried on somewhat according to the theories of Rousseau, Leconte de Lisle traveled in the East in order to fit himself for the commercial career his father had planned for him. He soon felt that his interests were not in business, and, on his return to France, he settled at Rennes, looking to journalism as a profession. In 1846 he went to Paris. Being an ardent republican, he entered with enthusiasm into the revolution of 1848 . But he was soon disillusioned in regard to politics, and after the "coup d'état" of ${ }_{1} 8_{5} \mathrm{I}$ he gave himself up to literature. His first volume of verse appeared in 1852 , "Poèmes antiques," followed by "Poèmes et poésies" (I854); "Poèmes barbares" (I862); "Poèmes tragiques" (I884); and the "Derniers poèmes" (I895), published after the death of the author. In addition to the above he made a number of translations, principally from the Greek, and in 1873 had a tragedy, "Les Erinnyes," staged at the Odéon. During the early part of his career he lived in poverty. In I870, however, the Empire granted him a pension of three hundred francs a month, and two years later the Republic made him assistant librarian to the Senate. In 1886 he was elected to the Academy to replace Victor Hugo.

Leconte de Lisle believed in art for art's sake. He condemned the subjective, personal point of view of the Romanticists, although he himself retains something of Romanticism and often in his poems expresses his own pessimism. He had an unusual love for perfection, and in his descriptions, principally of animals or exotic landscapes, he combines with the greatest art an almost scientific precision. The school of younger poets, known as the "Parnassiens," grouped themselves around him and recognized him as their leader.

\section{HÉRAKLÈS AU TAUREAU}

Le soleil déclinait vers l'écume des flots, Et les grasses brebis revenaient aux enclos;

Et les vaches suivaient, semblables aux nuées

Qui roulent sans relâche, à la file entraînées,

Lorsque le vent d'automne, au travers du ciel noir,

Les chasse à grands coups d'ailes, et qu'elles vont pleuvoir.

Derrière les brebis, toutes lourdes de laine, 
Telles s'amoncelaient les vaches dans la plaine.

La campagne n'était qu'un seul mugissement,

Et les grands chiens d'Elis ${ }^{1}$ aboyaient bruyamment.

Puis succédaient trois cents taureaux aux larges cuisses,

5 Puis deux cents au poil rouge, inquiets des génisses,

Puis douze, les plus beaux et parfaitement blancs,

Qui de leurs fouets velus rafraîchissaient leurs flancs,

Hauts de taille, vêtus de force et de courage,

Et paissant d'habitude au meilleur pâturage.

Io Plus noble encor, plus fier, plus brave, plus grand qu'eux,

En avant, isolé comme un chef belliqueux,

Phaétôn les guidait, lui, l'orgueil de l'étable,

Que les anciens bouviers disaient à Zeus semblable,

Quand le Dieu triomphant, ceint d'écume et de fleurs,

15 Nageait dans la mer glauque avec Europe en pleurs. ${ }^{2}$

Or, dardant ses yeux prompts sur la peau léonine

Dont Héraklès couvrait son épaule divine, ${ }^{3}$

Irritable, il voulut heurter d'un brusque choc

Contre cet étranger son front dur comme un roc.

20

Mais, ferme sur ses pieds, tel qu'une antique borne,

Le héros d'une main le saisit par la corne,

Et, sans rompre d'un pas, il lui ploya le col,

Meurtrissant ses naseaux furieux dans le sol.

Et les bergers en foule, autour du fils d'Alkmène, ${ }^{4}$

Stupéfaits, admiraient sa vigueur surhumaine,

Tandis que, blancs dompteurs de ce soudain péril,

De grands muscles roidis gonflaient son bras viril.

— "Poèmes antiques »

\section{KLÉARISTA}

Kléarista s'en vient par les blés onduleux

Avec ses noirs sourcils arqués sur ses yeux bleus,

Son front étroit coupé de fines bandelettes,

Et, sur son cou flexible et blanc comme le lait,

Ses tresses où, parmi les roses de Milet, ${ }^{5}$

On voit fleurir les violettes.

1 A town in ancient Greece, capital of a province of the same name.

2 Zeus, charmed by the beauty of Europa, assumed the form of a bull, and when she mounted on his back, swam with her to Crete.

3 The first of Hercules's labors was to kill the Nemean lion. He is often pictured with the lion's skin.

4 Alcmena, mother of Hercules.

5 Miletus was a city in Asia Minor, for a time rich and powerful. 
L'Aube divine baigne au loin l'horizon clair;

L'alouette sonore et joyeuse, dans l'air,

D'un coup d'aile s'envole au sifflement des merles;

Les lièvres, dans le creux des verts sillons tapis,

D'un bond inattendu remuant les épis,

Font pleuvoir la rosée en perles.

Sous le ciel jeune et frais, qui rayonne le mieux,

De la Sicilienne ${ }^{1}$ au doux rire, aux longs yeux,

Ou de l'Aube qui sort de l'écume marine?

Qui le dira? Qui sait, ô lumière, ô beauté,

Si vous ne tombez pas du même astre enchanté

Par qui tout aime et s'illumine?

Du faîte où ses béliers touffus sont assemblés,

Le berger de l'Hybla ${ }^{2}$ voit venir par les blés

Dans le rose brouillard la forme de son rêve.

Il dit: - C'était la nuit, et voici le matin ! -

Et plus brillant que l'Aube à l'horizon lointain

Dans son cœur le soleil se lève!

\section{LES ÉLÉPHANTS}

Le sable rouge est comme une mer sans limite,

Et qui flambe, muette, affaissée en son lit.

Une ondulation immobile remplit

L'horizon aux vapeurs de cuivre où l'homme habite.

Nulle vie et nul bruit. Tous les lions repus

Dorment au fond de l'antre éloigné de cent lieues,

Et la girafe boit dans les fontaines bleues,

Là-bas, sous les dattiers des panthères connus.

Pas un oiseau ne passe en fouettant de son aile

L'air épais, où circule un immense soleil.

Parfois quelque boa, chauffé dans son sommeil,

Fait onduler son dos dont l'écaille étincelle. 
Tel l'espace enflammé brûle sous les cieux clairs. Mais, tandis que tout dort aux mornes solitudes, Les éléphants rugueux, voyageurs lents et rudes, Vont au pays natal à travers les déserts.

D'un point de l'horizon, comme des masses brunes Ils viennent, soulevant la poussière, et l'on voit, Pour ne point dévier du chemin le plus droit, Sous leur pied large et sûr crouler au loin les dunes.

Celui qui tient la tête est un vieux chef. Son corps Est gercé comme un tronc que le temps ronge et mine! Sa tête est comme un roc, et l'arc de son échine Se voûte puissamment à ses moindres efforts.

Sans ralentir jamais et sans hâter sa marche, Il guide au but certain ses compagnons poudreux ; Et, creusant par derrière un sillon sablonneux, Les pèlerins massifs suivent leur patriarche.

L'oreille en évantail, la trompe entre les dents, Ils cheminent, l'œil clos. Leur ventre bat et fume, Et leur sueur dans l'air embrasé monte en brume; Et bourdonnent autour mille insectes ardents.

Mais qu'importent la soif et la mouche vorace, Et le soleil cuisant leur dos noir et plissé ?

Ils rêvent en marchant du pays délaissé, Des forêts de figuiers où s'abrita leur race.

Ils reverront le fleuve échappé des grands monts, Où nage en mugissant l'hippopotame énorme, Où, blanchis par la lune et projetant leur forme, Ils descendaient pour boire en écrasant les joncs.

Aussi, pleins de courage et de lenteur, ils passent, Comme une ligne noire, au sable illimité ;

Et le désert reprend son immobilité Quand les lourds voyageurs à l'horizon s'effacent. 


\section{LA CHUTE DES ÉTOILES}

Tombez, ô perles dénouées,

Pâles étoiles, dans la mer.

Un brouillard de roses nuées

Emerge de l'horizon clair ;

A l'Orient plein d'étincelles

Le vent joyeux bat de ses ailes

L'onde que brode un vif éclair.

Tombez, ô perles immortelles,

Pâles étoiles, dans la mer.

Plongez sous les écumes fraîches

De l'Océan mystérieux.

La lumière crible de flèches

Le faîte des monts radieux ;

Mille et mille cris, par fusées,

Sortent des bois lourds de rosées;

- Une musique vole aux cieux.

Plongez, de larmes arrosées,

Dans l'Océan mystérieux.

Fuyez, astres mélancoliques,

O Paradis lointains encor!

L'aurore aux lèvres métalliques

Rit dans le ciel et prend l'essor;

Elle se vêt de molles flammes,

Et sur l'émeraude des lames

Fait pétiller des gouttes d'or.

Fuyez, mondes où vont les âmes,

O Paradis lointains encor!

Allez, étoiles, aux nuits douces, Aux cieux muets de l'Occident.

Sur les feuillages et les mousses

Le soleil darde un œil ardent;

Les cerfs, par bonds, dans les vallées,

Se baignent aux sources troublées;

Le bruit des hommes va grondant.

Allez, ô blanches exilées,

Aux cieux muets de l'Occident.

Heureux qui vous suit, clartés mornes,

O lampes qui versez l'oubli! 
Comme vous, dans l'ombre sans bornes, Heureux qui roule enseveli !

Celui-là vers la paix s'élance :

Haine, amour, larmes, violence,

5 ,

Ce qui fut l'homme est aboli.

Donnez-nous l'éternel silence,

O lampes qui versez l'oubli!

— " Poèmes barbares »

\section{LES ELFES}

Couronnés de thym et de marjolaine, Les Elfes joyeux dansent sur la plaine.

Du sentier des bois aux daims familier, Sur un noir cheval, sort un chevalier.

Son éperon d'or brille en la nuit brune; Et, quand il traverse un rayon de lune, On voit resplendir, d'un reflet changêant Sur sa chevelure un casque d'argent.

Couronnés de thym et de marjolaine, Les Elfes joyeux dansent sur la plaine.

Ils l'entourent tous d'un essaim léger Qui dans l'air muet semble voltiger.

- Hardi chevalier, par la nuit sereine, Où vas-tu si tard? dit la jeune Reine. De mauvais esprits hantent les forêts ; Viens danser plutôt sur les gazons frais. -

Couronnés de thym et de marjolaine, Les Elfes joyeux dansent sur la plaine.

- Non! ma fiancée aux yeux clairs et doux M'attend, et demain nous serons époux. Laissez-moi passer, Elfes des prairies, Qui foulez en rond les mousses fleuries;

Ne m'attardez pas loin de mon amour, Car voici déjà les lueurs du jour. -

Couronnés de thym et de marjolaine, Les Elfes joyeux dansent sur la plaine. 
- Reste, chevalier. Je te donnerai

L'opale magique et l'anneau doré,

Et, ce qui vaut mieux que gloire et fortune,

Ma robe filée au clair de la lune.

- Non! dit-il. — Va donc! - Et de son doigt blanc 5 Elle touche au cœur le guerrier tremblant.

Couronnés de thym et de marjolaine,

Les Elfes joyeux dansent sur la plaine.

Et sous l'éperon le noir cheval part.

Il court, il bondit et va sans retard;

Mais le chevalier frissonne et se penche;

Il voit sur la route une forme blanche

Qui marche sans bruit et lui tend les bras:

- Elfe, esprit, démon, ne m'arrête pas! -

Couronnés de thym et de marjolaine, Les Elfes joyeux dansent sur la plaine.

- Ne m'arrête pas, fantôme odieux!

Je vais épouser ma belle aux doux yeux.

- $\mathrm{O}$ mon cher époux, la tombe éternelle

Sera notre lit de noce, dit-elle.

Je suis morte ! - Et lui, la voyant ainsi, D'angoisse et d'amour tombe mort aussi.

Couronnés de thym et de marjolaine, Les Elfes joyeux dansent sur la plaine. 


\section{GUSTAVE FLAUBERT \\ Rouen, I $82 \mathrm{I}-1880$, Croisset}

To please his father Flaubert went to Paris in 1840 and took up the study of law. He felt no liking for the profession, however, and soon after his father's death (I845) had left him free to follow his own inclinations he retired (I846) to a family estate at Croisset, near Rouen, and there spent the remaining thirtyfour years of his life in literary pursuits.

Though by temperament Flaubert showed tendencies toward Romanticism, he, however, became the acknowledged leader of the realists. He sought in his art to be objective and impersonal. His works throughout give evidence of a decided cult of form and color for their own sake. He wrote only a few volumes, but all with the greatest care. His first novel, "Madame Bovary" ( 1857 ), is his best, and one of the best novels of the century. In addition he wrote "Salammbô" (1862); "L'éducation sentimentale" (I870); "La tentation de saint Antoine" (1848, I874); "Trois contes" ("La légende de saint Julien l'Hospitalier," "Hérodias," "Un cœur simple") (1877). Among the manuscripts left unpublished at his death was the unfinished novel, "Bouvard et Pécuchet" (1881). He left also a very interesting correspondence.

\section{LA NOCE DE CAMPAGNE}

Les conviés arrivèrent de bonne heure dans des voitures, carrioles à un cheval, chars à bancs à deux roues, vieux cabriolets sans capote, tapissières à rideaux de cuir, et les jeunes gens des villages les plus voisins dans des charrettes où ils se tenaient debout, en rang, les mains 5 appuyées sur les ridelles pour ne pas tomber, allant au trot et secoués dur. Il en vint de dix lieues loin, de Goderville, de Normanville et de Cany. On avait invité tous les parents des deux familles, on s'était raccommodé avec les amis brouillés, on avait écrit à des connaissances perdues de vue depuis longtemps.

Io De temps à autre, on entendait des coups de fouet derrière la haie ; bientôt la barrière s'ouvrait : c'était une carriole qui entrait. Galopant jusqu'à la première marche du perron, elle s'y arrêtait court, et vidait son monde, qui sortait par tous les côtés en se frottant les genoux et en s'étirant les bras. Les dames, en bonnet, avaient des robes à la

I 5 façon de la ville, des chaînes de montre en or, des pèlerines à bouts croisés dans la ceinture, ou de petits fichus de couleur attachés dans 
le dos avec une épingle, et qui leur découvraient le cou par derrière. Les gamins, vêtus pareillement à leurs papas, semblaient incommodés par leurs habits neufs (beaucoup même étrennèrent ce jour-là la première paire de bottes de leur existence), et l'on voyait à côté d'eux, ne soufflant mot dans la robe blanche de sa première communion rallongée pour la circonstance, quelque grande fillette de quatorze ou seize ans, leur cousine ou leur sœur aînée sans doute, rougeaude, ahurie, les cheveux gras de pommade à la rose, et ayant bien peur de salir ses gants. Comme il n'y avait point assez de valets d'écurie pour dételer toutes les voitures, les messieurs retroussaient leurs manches et s'y ro mettaient eux-mêmes. Suivant leur position sociale différente, ils avaient des habits, des redingotes, des vestes, des habits-vestes ${ }^{1}$; bons habits, entourés de toute la considération d'une famille, et qui ne sortaient de l'armoire que pour les solennités; redingotes à grandes basques flottant au vent, à collet cylindrique, à poches larges comme i 5 des sacs; vestes de gros drap, qui accompagnaient ordinairement quelque casquette cerclée de cuivre à sa visière; habits-vestes très courts, ayant dans le dos deux boutons rapprochés comme une paire d'yeux, et dont les pans semblaient avoir été coupés à même un seul bloc, par la hache du charpentier. Quelques-uns encore (mais ceux-là, 20 bien sûr, devaient dîner au bas bout de la table) portaient des blouses de cérémonie, c'est-à-dire dont le col était rabattu sur les épaules, le dos froncé à petits plis et la taille attachée très bas par une ceinture cousue.

Et les chemises sur les poitrines bombaient comme des cuirasses ! 25 Tout le monde était tondu à neuf, les oreilles s'écartaient des têtes, on était rasé de près; quelques-uns même qui s'étaient levés dès avant l'aube, n'ayant pas vu clair à se faire la barbe, avaient des balafres en diagonale sous le nez, ou, le long des mâchoires, des pelures d'épiderme larges comme des écus de trois francs, et qu'avait enflammées 30 le grand air pendant la route, ce qui marbrait un peu de plaques roses toutes ces grosses faces blanches épanouies.

La mairie se trouvant à une demi-lieue de la ferme, on s'y rendit à pied, et l'on revint de même, une fois la cérémonie faite à l'église. Le cortège, d'abord uni comme une seule écharpe de couleur, qui ondu- 35 lait dans la campagne, le long de l'étroit sentier serpentant entre les blés verts, s'allongea bientôt et se coupa en groupes différents, qui s'attardaient à causer. Le ménétrier allait en avant avec son violon 
empanaché de rubans à la coquille ${ }^{1}$ les mariés venaient ensuite, les parents, les amis tout au hasard, et les enfants restaient derrière, s'amusant à arracher les clochettes des brins d'avoine, ou à se jouer entre eux, sans qu'on les vît. La robe d'Emma, ${ }^{2}$ trop longue, traînait 5 un peu par le bas; de temps à autre, elle s'arrêtait pour la tirer, et alors délicatement, de ses doigts gantés, elle enlevait les herbes rudes avec les petits dards des chardons, pendant que Charles, les mains vides, attendait qu'elle eût fini. Le père Rouault, un chapeau de soie neuf sur la tête et les parements de son habit noir lui couvrant les Io mains jusqu'aux ongles, donnait le bras à madame Bovary mère. . . . Les autres gens de la noce causaient de leurs affaires ou se faisaient des niches dans le dos, s'excitant d'avance à la gaieté; et, en y prêtant l'oreille, on entendait toujours le crincrin du ménétrier qui continuait à jouer dans la campagne. Quand il s'apercevait qu'on était loin derI 5 rière lui, il s'arrêtait à reprendre haleine, cirait longuement de colophane son archet, afin que les cordes grinçassent mieux, et puis il se remettait à marcher, abaissant et levant tour à tour le manche de son violon, pour se bien marquer la mesure à lui-même. Le bruit de l'instrument faisait partir de loin les petits oiseaux.

20 C'était sous le hangar de la charreterie ${ }^{3}$ que la table était dressée. Il y avait dessus quatre aloyaux, six fricassées de poulets, du veau à la casserole, trois gigots et, au milieu, un joli cochon de lait rôti, flanqué de quatre andouilles à l'oseille. Aux angles, se dressait l'eau-devie, dans des carafes. Le cidre doux en bouteilles poussait sa mousse 25 épaisse autour des bouchons, et tous les verres, d'avance, avaient été remplis de vin jusqu'au bord. De grands plats de crème jaune, qui flottaient d'eux-mêmes au moindre choc de la table, présentaient, dessinés sur leur surface unie, les chiffres des nouveaux époux en arabesques de nonpareille. On avait été chercher un pâtissier à Yvetot, pour les tourtes et les nougats. Comme il débutait dans le pays, il avait soigné les choses ; et il apporta, lui-même, au dessert, une pièce montée ${ }^{4}$ qui fit pousser des cris. A la base, d'abord, c'était un carré de carton bleu figurant un temple avec portiques, colonnades et statuettes de stuc tout autour, dans des niches constellées d'étoiles en 35 papier doré ; puis se tenait au second étage un donjon en gâteau de Savoie, ${ }^{5}$ entouré de menues fortifications en angélique, amandes, raisins

1 " bridge."

3 " wheelwrights' shop."

5 A kind of sponge cake.
2 Daughter of père Rouault, heroine of the novel.

4 A tall pyramidal wedding cake. 
secs, quartiers d'oranges; et enfin, sur la plate-forme supérieure, qui était une prairie verte où il $\mathrm{y}$ avait des rochers avec des lacs de confitures et des bateaux en écales de noisettes, on voyait un petit Amour, se balançant à une escarpolette de chocolat, dont les deux poteaux étaient terminés par deux boutons de rose naturelle, en guise de boules, au sommet.

Jusqu'au soir, on mangea. Quand on était trop fatigué d'être assis, on allait se promener dans les cours ou jouer une partie de bouchon dans la grange, puis on revenait à table. Quelques-uns, vers la fin, s'y endormirent et ronflèrent. Mais au café, tout se ranima; alors on ro entama des chansons, on fit des tours de force, on portait des poids, on passait sous son pouce, on essayait à soulever les charrettes sur ses épaules. ... . Le soir, pour partir, les chevaux gorgés d'avoine jusqu'aux naseaux eurent du mal à entrer dans les brancards; ils ruaient, se cabraient, les harnais se cassaient, leurs maîtres juraient ou riaient ; 15 et toute la nuit, au clair de la lune, par les routes du pays, il y eut des carrioles emportées qui couraient au grand galop, bondissant dans les saignées, sautant par-dessus les mètres de cailloux, s'accrochant aux talus, avec des femmes qui se penchaient en dehors de la portière pour saisir les guides.

Ceux qui restèrent aux Bertaux passèrent la nuit à boire dans la cuisine. Les enfants s'étaient endormis sous les bancs.

— " Madame Bovary », Part I, 4

\section{SALAMMBÔ}

La lune se levait au ras des flots; et, sur la ville ${ }^{1}$ encore couverte de ténèbres, des points lumineux, des blancheurs brillaient: le timon d'un char dans une cour, quelque haillon de toile suspendu, l'angle 25 d'un mur, un collier d'or à la poitrine d'un dieu. Les boules de verre sur les toits des temples rayonnaient çà et là comme de gros diamants. Mais de vagues ruines, des tas de terre noire, des jardins faisaient des masses plus sombres dans l'obscurité ; et au bas de Malqua, des filets de pêcheurs s'étendaient d'une maison à l'autre, comme de 30 gigantesques chauves-souris déployant leurs ailes. On n'entendait plus le grincement des roues hydrauliques qui apportaient l'eau au dernier étage des palais; et au milieu des terrasses les chameaux reposaient tranquillement couchés sur le ventre, à la manière des 
autruches. Les portiers dormaient dans les rues contre le seuil des maisons; l'ombre des colosses s'allongeait sur les places désertes; au loin quelquefois la fumée d'un sacrifice brûlant encore s'échappait par les tuiles de bronze, et la brise lourde apportait avec des parfums 5 d'aromates les senteurs de la marine et l'exhalaison des murailles, chauffées par le soleil. Autour de Carthage les ondes immobiles resplendissaient, car la lune étalait sa lueur tout à la fois sur le golfe environné de montagnes et sur le lac de 'Tunis, où des phénicoptères parmi les bancs de sable formaient de longues lignes roses, tandis qu'au Io delà, sous les catacombes, la grande lagune salée miroitait comme un morceau d'argent. La voûte du ciel bleu s'enfonçait à l'horizon, d'un côté dans le poudroiement des plaines, de l'autre dans les brumes de la mer, et sur le sommet de l'Acropole les cyprès pyramidaux bordant le temple d'Eschmoûn se balançaient, et faisaient un mur-

I5 mure, comme les flots réguliers qui battaient lentement le long du môle, au bas des remparts. . . .

Salammbô s'avança jusqu'au bord de la terrasse. Ses yeux, un instant, parcoururent l'horizon ; puis ils s'abaissèrent sur la ville endormie, et le soupir qu'elle poussa, en lui soulevant les seins, fit onduler 20 d'un bout à l'autre la longue simarre blanche qui pendait autour d'elle, sans agrafe ni ceinture. Ses sandales à pointes recourbées disparaissaient sous un amas d'émeraudes, et ses cheveux à l'abandon emplissaient un réseau en fils de pourpre.

Mais elle releva la tête pour contempler la lune, et mêlant à ses 25 paroles des fragments d'hymne, elle murmura:

"Que tu tournes légèrement, soutenue par l'éther impalpable! Il se polit autour de toi, et c'est le mouvement de ton agitation qui distribue les vents et les rosées fécondes. Selon que tu crôis et décroîs, s'allongent ou se rapetissent les yeux des chats et les taches

30 des panthères. Tu gonfles les coquillages! Tu fais bouillonner les vins! $\mathrm{Tu}$ putréfies les cadavres! Tu formes les perles au fond de la mer!

“ Et tous les germes, ô Déesse! fermentent dans les obscures profondeurs de ton humidité.

35 "Quand tu parais, il s'épand une quiétude sur la terre; les fleurs se ferment, les flots s'apaisent, les hommes fatigués s'étendent la poitrine vers toi, et le monde, avec ses océans et ses montagnes, comme en un miroir, se regarde dans ta figure. Tu es blanche, douce, lumineuse, immaculée, auxiliatrice, purifiante, sereine!» 
Le croissant de la lune était alors sur la montagne des EauxChaudes, dans l'échancrure de ses deux sommets, de l'autre côté du golfe. Il y avait en dessous une petite étoile et tout autour un cercle pâle. Salammbô reprit :

" Mais tu es terrible, maitresse ! . . C'est par toi que se produisent les monstres, les fantômes effrayants, les songes menteurs; tes yeux dévorent les pierres des édifices, et les singes sont malades toutes les fois que tu rajeunis.

"Où donc vas-tu? Pourquoi changer tes formes perpétuellement? Tantôt mince et recourbée, tu glisses dans les espaces comme une ro galère sans mâture, ou bien au milieu des étoiles tu ressembles à un pasteur qui garde son troupeau. Luisante et ronde, tu frôles la cîme des monts comme la roue d'un char.

"O Tanit! tu m'aimes, n'est-ce pas? Je t’ai tant regardée! Mais non! tu cours dans ton azur, et moi je reste sur la terre immobile.

"Taanach, ${ }^{1}$ prends ton nebal et joue tout bas sur la corde d'argent, car mon cœur est triste! ”

L'esclave souleva une sorte de harpe en bois d'ébène, plus haute qu'elle et triangulaire comme un delta; elle en fixa la pointe dans un globe de cristal, et des deux bras se mit à jouer.

Les sons se succédaient, sourds et précipités comme un bourdonnement d'abeilles, et de plus en plus sonores ils s'envolaient dans la nuit avec la plainte des flots et le frémissement des grands arbres au sommet de l'Acropole.

«Tais-toi! s'écria Salammbô.

- Qu'as-tu donc, maitresse? La brise qui souffle, un nuage qui passe, tout à présent t'inquiète et t'agite!

- Je ne sais, dit-elle.

- Tu te fatigues à des prières trop longues!

- Oh! Taanach, je voudrais m'y dissoudre comme une fleur dans 30 du vin!

- C'est peut-être la fumée de tes parfums?

- Non! dit Salammbô; l'esprit des Dieux habite dans les bonnes odeurs. ")

Alors l'esclave lui parla de son père. On le croyait parti vers la 35 contrée de l'ambre, derrière les colonnes de Mel-Karth. ${ }^{2}$ " Mais s'il ne revient pas, disait-elle, il te faudra pourtant, puisque c'était sa volonté, choisir un époux parmi les fils des Anciens. ... 
- Pourquoi ?" demanda la jeune fille. Tous ceux qu'elle avait aperçus lui faisaient horreur avec leurs rires de bête fauve et leurs membres grossiers.

"Quelquefois, Taanach, il s'exhale du fond de mon être comme de 5 chaudes bouffées, plus lourdes que les vapeurs d'un volcan. Des voix m'appellent, un globe de feu roule et monte dans ma poitrine, il m'étouffe, je vais mourir.... Oh! Je voudrais me perdre dans la brume des nuits, dans le flot des fontaines, dans la sève des arbres, sortir de mon corps, n'être qu'un souffle, qu'un rayon, et glisser, monIo ter jusqu'à toi, ô Mère! »

Elle leva ses bras le plus haut possible, en se cambrant la taille, pâle et légère comme la lune avec son blanc vêtement. Puis elle retomba sur la couche d'ivoire, haletante. 


\title{
HIPPOLYTE-ADOLPHE TAINE
}

\author{
Vouziers, $1828-1893$, Paris
}

The career of Taine, philosopher, historian, and critic, was wrapped up in his work. After graduating with highest honors from the Collège Bourbon, he entered the Ecole Normale (1848). In 1853 he took the doctor's degree, the subject of his dissertation being La Fontaine. In this work, revised and republished later under the title "La Fontaine et ses fables," and still more in the "Histoire de la littérature anglaise" (I864), Taine applied to literary criticism the determinism of scientific method, making literature a direct result of the race, the milieu, and the moment. After the events of 1870 his interests turned more particularly to history, and from 1875 to 1893 appeared the various parts, of "Les origines de la France contemporaine," namely, "L'ancien régime," "La révolution," "Le régime moderne."

Mention should be made also of his "Essais de critique et d'histoire" (1858); "Nouveaux essais de critique et d'histoire" (1865); "Derniers essais de critique et d'histoire" (1894); "Philosophie de l'art" (I865, I869). In these works whatever may be the weakness of his system, Taine shows himself to. be one of the best descriptive writers of France. No one, with the possible exception of Renan, exerted a greater influence than Taine on the generation of French authors after 1860. He was elected to the Academy in 1878 and died in 1893 .

\section{LA CHAMPAGNE ET LA FONTAINE ${ }^{1}$}

Me voici à l'aise, libre de rechercher toutes les causes qui ont pu former mon personnage ${ }^{2}$ et sa poésie; libre de voyager et de conter mon voyage. J'en ai fait un l'an dernier par la mer et le Rhin, pour revenir par la Champagne. Partout, dans ce circuit, éclate la grandeur ou la force. Au nord, l'Océan bat les falaises blanchâtres ou noie les terres plates; les coups de ce bélier monotone qui heurte obstinément la grève, l'entassement de ces eaux stériles qui assiègent l'embouchure des fleuves, la joie des vagues indomptées qui s'entrechoquent follement sur la plaine sans limites, font descendre au fond du cœur des émotions tragiques; la mer est un hôte disproportionné ıo

1 Applying the evolutionary principle that man is the result of race, milieu, and moment, Taine is here describing la Champagne in order to explain La Fontaine.

2 I.e. La Fontaine. 
et sauvage dont le voisinage laisse toujours dans l'homme un fond d'inquiétude et d'accablement. En avançant vers l'est, vous rencontrez la grasse Flandre, antique nourrice de la vie corporelle, ses plaines immenses toutes regorgeantes d'une abondance grossière, ses prai5 ries peuplées de troupeaux couchés qui ruminent, ses larges fleuves qui tournoient paisiblement à pleins bords sous les bateaux chargés, ses nuages noirâtres tachés de blancheurs éclatantes qui abattent incessamment leurs averses sur la verdure, son ciel changeant, plein de violents contrastes, et qui répand une beauté poétique sur sa lourde Io fécondité. - Au sortir de ce grand potager, le Rhin apparait, et l'on remonte vers la France. Le magnifique fleuve déploie le cortège de ses eaux bleues entre deux rangées de montagnes aussi nobles que lui; leurs cimes s'allongent par étages jusqu'au bout de l'horizon dont la ceinture lumineuse les accueille et les relie; le soleil pose une splenI 5 deur sereine sur leurs vieux flancs tailladés, sur leur dôme de forêts toujours vivantes; le soir, ces grandes images flottent dans des ondulations d'or et de pourpre, et le fleuve couché dans la brume ressemble à un roi heureux et pacifique qui, avant de s'endormir, rassemble autour de lui les plis dorés de son manteau. Des deux côtés les 20 versants qui le nourrissent se redressent avec un aspect énergique ou austère ; les pins couvrent les sommets de leurs draperies silencieuses, et descendent par bandes jusqu'au fond des gorges ; le puissant élan qui les dresse, leur roide attitude donne l'idée d'une phalange de jeunes héros barbares, immobiles et debout dans leur solitude que la culture 25 n'a jamais violée. Ils disparaissent avec les roches rouges des Vosges. Vous quittez le pays à demi allemand qui n'est à nous que depuis un siècle. Un air nouveau moins froid vous souffle aux joues; le ciel change et le sol aussi. Vous êtes entré dans la véritable France, celle qui a conquis et façonné le reste. Il semble que de tous côtés les 30 sensations et les idées affluent pour vous expliquer ce que c'est que le Français.

Je revenais par ce chemin au commencement de l'automne, et je me rappelle combien le changement de paysage me frappa. Plus de grandeur ni de puissance; l'air sauvage ou triste s'efface; la monotonie 35 et la poésie s'en vont; la variété et la gaieté commencent. Point trop de plaines ni de montagnes; point trop de soleil ni d'humidité. Nul excès et nulle énergie. Tout y semblait maniable et civilisé ; tout y était sur un petit modèle, en proportions commodes, avec un air de finesse et d'agrément. Les montagnes étaient devenues collines, les 
bois n'étaient plus guère que des bosquets, les ondulations du terrain recevaient, sans discontinuer, les cultures. De minces rivières serpentaient entre des bouquets d'aunes avec de gracieux sourires. Une raie de peupliers solitaires au bout d'un champ grisâtre, un bouleau frêle qui tremble dans une clairière de genêts, l'éclair passager d'un ruisseau à travers les lentilles d'eau qui l'obstruent, la teinte délicate dont l'éloignement revêt quelque bois écarté, voilà les beautés de notre paysage; il paraît plat aux yeux qui se sont reposés sur la noble architecture des montagnes méridionales, ou qui se sont nourris de la verdure surabondante et de la végétation héroïque du nord; les 10 grandes lignes, les fortes couleurs y manquent; mais les contours sinueux, les nuances légères, toutes les grâces fuyantes y viennent amuser l'agile esprit qui les contemple, le toucher parfois, sans l'exalter ni l'accabler. - Si vous entrez plus avant dans la vraie Champagne, ces sources de poésie s'appauvrissent et s'affinent en- 15 core. La vigne, triste plante bossue, tord ses pieds entre les cailloux. Les plaines crayeuses sous leurs moissons maigres s'étalent bariolées et ternes comme un manteau de roulier. Ça et là une ligne d'arbres marque sur la campagne la traînée d'un ruisseau blanchâtre. On aime pourtant le joli soleil qui luit doucement entre les ormes, le thym qui 20 parfume les côtes sèches, les abeilles qui bourdonnent au-dessus du sarrasin en fleur: beautés légères qu'une race sobre et fine peut seule goûter. Ajoutez que le climat n'est point propre à la durcir ni à la passionner. Il n'a ni excès ni contrastes; le soleil n'est pas terrible comme au midi, ni la neige durable comme au nord. Au plus fort de 25 juin, les nuages passent en troupes, et souvent dès février, la brume enveloppe les arbres de sa gaze bleuâtre sans se coller en givre autour de leurs rameaux. On peut sortir en toute saison, vivre dehors sans trop pâtir; les impressions extrêmes ne viennent point émousser les sens ou concentrer la sensibilité; l'homme n'est point alourdi ni exalté ; 30 pour sentir, il n'a pas besoin de violentes secousses et il n'est pas propre aux grandes émotions. Tout est moyen ici, tempéré, plutôt tourné vers la délicatesse que vers la force. La nature qui est clémente n'est point prodigue; elle n'empâte pas ses nourrissons d'une abondance brutale; ils mangent sobrement, et leurs aliments ne sont 35 point pesants. La terre, un peu sèche et pierreuse, ne leur donne guère que du pain et du vin; encore ce vin est-il léger, si léger que les gens du nord, pour y prendre plaisir, le chargent d'eau-de-vie. Ceux-ci n'iront pas, à leur exemple, s'emplir de viandes et de boissons 
brûlantes pour inonder leurs veines par un afflux soudain de sang grossier, pour porter dans leur cerveau la stupeur ou la violence; on les voit à la porte de leur chaumière, qui mangent debout un peu de pain et leur soupe; leur vin ne met dans leur tête que la vivacité et la belle 5 humeur.

— «La Fontaine et ses fables », Part I, chap. I

\section{VALEUR DES LITTÉRATURES}

La question posée est celle-ci: Etant donné une littérature, une philosophie, une société, un art, telle classe d'arts, quel est l'état moral qui la produit? Et quelles sont les conditions de race, de moment et de milieu les plus propres à produire cet état moral ? Il y a un état ro moral distinct pour chacune de ces formations et pour chacune de leurs branches; il y en a un, pour l'art en général, et pour chaque sorte d'art, pour l'architecture, pour la peinture, pour la sculpture, pour la musique, pour la poésie; chacune a son germe spécial dans le large champ de la psychologie humaine; chacune a sa loi, et c'est en vertu I 5 de cette loi qu'on la voit se lever au hasard, à ce qu'il semble, et toute seule parmi les avortements de ses voisines, comme la peinture en Flandre et en Hollande au dix-septième siècle, comme la poésie en Angleterre au seizième siècle, comme la musique en Allemagne au dix-huitième siècle. A ce moment et dans ces pays, les conditions se 20 sont trouvées remplies pour un art, et non pour les autres, et une branche seule a bourgeonné dans la stérilité générale. Ce sont ces règles de la végétation humaine que l'histoire à présent doit chercher ; c'est cette psychologie spéciale de chaque formation spéciale qu'il faut faire ; c'est le tableau complet de ces conditions propres qu'il faut au25 jourd'hui travailler à composer. Rien de plus délicat et rien de plus difficile; Montesquieu l'a entrepris, mais de son temps l'histoire était trop nouvelle pour qu'il pût réussir; on ne soupçonnait même point encore la voie qu'il fallait prendre, et c'est à peine si aujourd'hui nous commençons à l'entrevoir. De même qu'au fond l'astronomie est un

30 problème de mécanique et la physiologie un problème de chimie, de même l'histoire au fond est un problème de psychologie. Il y a un système particulier d'impressions et d'opérations intérieures qui fait l'artiste, le croyant, le musicien, le peintre, le nomade, l'homme en société ; pour chacun d'eux, la filiation, l'intensité, les dépendances des 35 idées et des émotions sont différentes; chacun d'eux a son histoire 
morale et sa structure propre, avec quelque disposition maitresse et quelque trait dominateur. Pour expliquer chacun d'eux, il faudrait écrire un chapitre d'analyse intime, et c'est à peine si aujourd'hui ce travail est ébauché. Un seul homme, Stendhal, ${ }^{1}$ par une tournure d'esprit et d'éducation singulière, l'a entrepris. ... C'est dans ses écrits, chez Sainte-Beuve, chez les critiques allemands que le lecteur verra tout le parti qu'on peut tirer d'un document littéraire; quand ce document est riche et qu'on sait l'interpréter, on y trouve la psychologie d'une âme, souvent celle d'un siècle, et parfois celle d'une race. A cet égard un grand poème, un beau roman, les confessions io d'un homme supérieur sont plus instructifs qu'un monceau d'historiens et d'histoires; je donnerais cinquante volumes de chartes et cent volumes de pièces diplomatiques pour les mémoires de Cellini, ${ }^{2}$ pour les lettres de saint Paul, pour les propos de table de Luther ${ }^{3}$ ou les comédies d'Aristophane. En cela consiste l'importance des œuvres i 5 littéraires, elles sont instructives, parce qu'elles sont belles; leur utilité croît avec leur perfection; et, si elles fournissent des documents, c'est qu'elles sont des monuments. Plus un livre rend les sentiments visibles, plus il est littéraire; car l'office propre de la littérature est de noter les sentiments. Plus un livre note des sentiments importants, 20 plus il est placé haut dans la littérature ; car c'est en représentant la façon d'être de toute une nation et de tout un siècle qu'un écrivain rallie autour de lui les sympathies de tout un siècle et de toute une nation. C'est pourquoi, parmi les documents qui nous remettent devant les yeux les sentiments des générations précédentes, une littéra- 25 ture, et notamment une grande littérature, est incomparablement le meilleur. Elle ressemble à ces appareils admirables, d'une sensibilité extraordinaire, au moyen desquels les physiciens démêlent et mesurent les changements les plus intimes et les plus délicats d'un corps. Les constitutions, les religions n'en approchent pas; des articles de code 30 et de catéchisme ne peignent jamais l'esprit qu'en gros, et sans finesse; s'il y a des documents dans lesquels la politique et le dogme soient vivants, ce sont les discours éloquents de chaire et de tribune, les mémoires, les confessions intimes, et tout cela appartient à la

1 Stendhal (Henri Beyle), (178 $\left.188_{42}\right)$, author of the psychological novels, "La chartreuse de Parme" and "Le rouge et le noir."

2 Benvenuto Cellini (1500-1571), an Italian sculptor, engraver, and goldsmith, whose autobiography is a well-known classic.

8 Luther's "Tischreden" contains his opinions on various subjects. 
littérature; en sorte qu'outre elle-même, elle a tout le bon d'autrui. C'est donc principalement par l'étude des littératures que l'on pourra faire l'histoire morale et marcher vers la connaissance des lois psychologiques, d'où dépendent les événements.

— " Histoire de la littérature anglaise », Introduction, 8

\section{SHAKESPEARE}

5 Quelle âme! quelle étendue d'action et quelle souveraineté d'une faculté unique! que de créatures diverses et quelle persistance de la même empreinte! Les voilà toutes réunies et toutes marquées du même signe, dépourvues de volonté et de raison, gouvernées par le tempérament, l'imagination ou la passion pure, privées des facultés qui sont Io contraires à celles du poète, maîtrisées par le corps que se figurent ses yeux de peintre, douées des habitudes d'esprit et de la sensibilité morale violente qu'il trouve en lui-même. Parcourez ces groupes, et vous n'y trouverez que des formes diverses et des états divers d'une puissance unique. Ici, le troupeau des brutes, des radoteurs et des I 5 commères, composés d'imagination machinale; plus loin, la compagnie des gens d'esprit agités par l'imagination gaie et folle; là-bas, le charmant essaim de jeunes femmes que soulève si haut l'imagination délicate et qu'emporte si loin l'amour abandonné ; ailleurs, la bande des scélérats endurcis par des passions sans frein, animés par

2o une verve d'artiste; au centre, le lamentable cortège des grands personnages dont le cerveau exalté s'emplit de visions douloureuses ou criminelles, et qu'un destin intérieur pousse vers le meurtre, vers la folie ou vers la mort. Montez d'un étage et contemplez la scène tout entière: l'ensemble porte la même marque que les détails. Le drame

25 reproduit sans choix les laideurs, les bassesses, les horreurs, les détails crus, les mœurs déréglées et féroces, la vie réelle tout entière telle qu'elle est, quand elle se trouve affranchie des bienséances, du bon sens, de la raison et du devoir. La comédie, promenée dans une fantasmagorie de peintures, s'égare à travers le vraisemblable et l'in-

30 vraisemblable, sans autre lien que le caprice d'une imagination qui s'amuse, décousue et romanesque à plaisir, opéra sans musique, concert de sentiments mélancoliques et tendres qui emporte l'esprit dans le monde surnaturel et figure aux yeux, par ses sylphes ailés, le génie qui l'a formée. Regardez maintenant. Ne voyez-vous pas le poète 35 debout derrière la foule de ses créatures? Elles l'ont annoncé; elles 
ont toutes montré quelque chose de lui. Agile, impétueux, passionné, délicat, son génie est l'imagination pure, touchée plus fortement et par de plus petits objets que le nôtre. De là ce style tout florissant d'images exubérantes, chargé de métaphores excessives, dont la bizarrerie semble de l'incohérence, dont la richesse est de la surabondance, 5 œuvre d'un esprit qui, au moindre choc, produit trop et bondit trop loin. De là cette psychologie involontaire et cette pénétration terrible qui, apercevant en un instant tous les effets d'une situation et tous les détails d'un caractère, les concentre dans chaque réplique du personnage, et donne à sa figure un relief et une couleur qui font illusion. Io De là notre émotion et notre tendresse. Nous lui disons comme Desdémone à Othello: " Je vous aime parce que vous avez beaucoup senti et beaucoup souffert. $)^{1}$

— "Histoire de la littérature anglaise », Book II, chap. 4

1 Apparently Act I, scene 3, where Othello says :

She loved me for the dangers I had pass'd, And I loved her that she did pity them. 


\section{JOSEPH-ERNEST RENAN}

Tréguier, $1823-1892$, Paris

Renan was five years of age when his father died. Cared for and trained by his mother and particularly by his sister Henriette, he pursued his studies with the aim of entering the priesthood. The simplicity of his faith, however, was soon shaken, and after he lost the idea that the Bible was an inspired book he renounced all thought of taking orders, but nevertheless continued the critical study of Christianity. In $185^{2}$ he took his doctor's degree, the subject of his dissertation being "Averroès et l'averroïsme." Five years later appeared the "Histoire générale des langues sémitiques" (1857) and the "Études d'histoire religieuse" ( 1857 ), followed by an "Essai sur l'origine du langage" (I859).

In 1860 he traveled to the East on an archæological mission. After his return (1861) he was called (1862) to a chair of Hebrew in the Collège de France. When, however, it became known that he did not believe in the divinity of Christ, his course was first suspended, then suppressed, until 1870 . Meanwhile he was writing his great work on the "Histoire des origines du christianisme," which comprised the "Vie de Jésus" (1863); "Les apôtres" (1866); "Saint Paul et sa mission" (1869); "L'Antéchrist" (1873); "Les évangiles" (1877); "L'église chrétienne" (1879); "Marc-Aurèle et la fin du monde antique" (I88I). Later (1887-1893) he brought out the "Histoire du peuple d'Israël."

Renan applied to his work a scientific method of treatment, which did not, however, prevent his being a great literary artist with an unusual gift of making the past live, a result which he accomplished in a spirit entirely modern and yet permeated with the mysticism of his youth. His influence on his own and the present generation has been very great. He was elected to the Academy in 1878 .

\section{LE SINA $\ddot{I}$}

Le massif du Sinaï, formé d'un granit sombre que le soleil, qui dore toute chose, baigne depuis des siècles sans le pénétrer, est un des phénomènes les plus singuliers de la surface du globe. C'est l'image parfaite des paysages d'un monde sans eau, tel qu'on se figure la

5 lune ou tout autre corps céleste privé d'atmosphère. Ce n'est pas qu'il ne s'amoncelle fréquemment sur les sommets d'effroyables orages. Mais l'orage, ailleurs bienfaisant, n'est ici que terrible; on dirait un phénomène inorganique, métallique en quelque sorte, un concert où 
n'entrerait que le son du canon, du tambour, de la trompette et de la cloche. Des dieux sévères doivent habiter ces sommets; c'est l'Olympe, moins ses eaux et ses forêts; l'Islande ou Jean-Mayen, ${ }^{1}$ moins les neiges. De tout ce qui constitue la nature, — le soleil, les nuages, l'eau, l'arbre, la verdure, l'homme, l'animal, - il n'y a ici que la pierre, striée par des filons de métal, parfois condensée en gemmes resplendissantes, toujours rebelle à la vie et l'étouffant autour d'elle. I u cuivre, des turquoises, tous les résidus d'une sorte de vitrification naturelle, voilà les produits du Sinaï. La Thora ${ }^{2}$ aussi, dit-on, en est venue, mais jamais la vie. Si l'on excepte la petite oasis du couvent de ro Sainte-Catherine, ${ }^{3}$ placée en dehors des partics vues par les Hébreux, la sècheresse est absolue; dans ce monde antihumain, pas un fruit, pas un grain de blé, pas une goutte d'eau. En revanche, nulle part ailleurs, la lumière n'est aussi intense, l'air aussi transparent, la neige aussi éblouissante. Le silence de ces solitudes terrifie; un mot pro- 15 noncé à voix basse suscite des échos étranges; le voyageur est troublé du bruit de ses pas. C'est bien la montagne des Elohim, ${ }^{4}$ avec leurs contours invisibles, leurs décevantes transparences, leurs bizarres miroitements.

— « Histoire du peuple d'Israël», Book I, chap. I 4

\section{PHILOSOPHIE DE L'HISTOIRE}

Le dessin général des formes de l'humanité ressemble à ces colos- 20 sales figures destinées à être vues de loin, et où chaque ligne n'est point accusée avec la netteté que présente unc statue ou un tableau. Les formes y sont largement plâtrées, il y a du trop, et si l'on voulait réduire le dessin au strict nécessaire, il y aurait beaucoup à retrancher. En histoire, le trait est grossier; chaque linéament, au lieu d'être 25 représenté par un individu ou par un petit nombre d'hommes, l'est par de grandes masses, par une nation, par une philosophie, par une forme religieuse. Sur les monuments de Persépolis, ${ }^{5}$ on voit les différentes nations tributaires du roi de Perse représentées par un individu portant le costume et tenant entre ses mains les productions 30

1 Jan Mayen Land is an island in the Arctic Ocean, northeast of Iceland.

2 The name given by the Jews to the Pentateuch.

3 Convent of Sinai or St. Catherine, built under the reign of Justinian.

4 Plural of the Hebrew Eloah, meaning "God."

5 Ancient capital of Persia, now in ruins. 
de son pays, pour en faire hommage au suzerain. Voici l'humanité : chaque nation, chaque forme, intellectuelle, religieuse, morale, laisse après elle un court résumé, qui en est comme l'extrait et la quintessence et qui se réduit souvent à un seul mot. Ce type abrégé et expressif 5 demeure pour représenter les millions d'hommes à jamais obscurs qui ont vécu et sont morts pour se grouper sous ce signe. Grèce, Perse, Inde, judaïsme, islamisme, stoïcisme, mysticisme, toutes ces formes étaient nécessaires pour que la grande figure fût complète; or, pour qu'elles fussent dignement représentées, il ne suffisait pas de quelques Io individus, il fallait d'énormes masses. La peinture par masses est le grand procédé de la Providence. Il y a une merveilleuse grandeur et une profonde philosophie dans la manière dont les anciens Hébreux concevaient le gouvernement de Dieu, traitant les nations comme des individus, établissant entre tous les membres d'une communauté une

I 5 parfaite solidarité, et appliquant avec un majestueux à-peu-près sa justice distributive. Dieu ne se propose que le grand dessin général. Chaque être trouve ensuite en lui des instincts qui lui rendent son rôle aussi doux que possible. C'est une pensée d'une effroyable tristesse que le peu de traces que laissent après eux les hommes, ceux-là même 20 qui semblent jouer un rôle principal. Et quand on pense que des millions de millions d'êtres sont nés et sont morts de la sorte, sans qu'il en reste de souvenir, on éprouve le même effroi qu'en présence du néant ou de l'infini. Songez donc à ces misérables existences à peine caractérisées qui, chez les sauvages, apparaissent et disparaissent 25 comme les vagues images d'un rêve. Songez aux innombrables générations qui se sont entassées dans les cimetières de nos campagnes. Mortes, mortes à jamais ?... . Non, elles vivent dans l'humanité; elles ont servi à bâtir la grande Babel qui monte vers le ciel, et où chaque assise est un peuple.

$3^{\circ}$ Je vais dire le plus ravissant souvenir qui me reste de ma première jeunesse ; je verse presque des larmes en y songeant. Un jour, ma mère et moi, en faisant un petit voyage à travers ces sentiers pierreux des côtes de Bretagne, qui laissent à tous ceux qui les ont foulés de si doux souvenirs, nous arrivâmes à une église de hameau, 35 entourée, selon l'usage, du cimetière, et nous nous y reposâmes. Les murs de l'église en granit à peine équarri et couvert de mousses, les maisons d'alentour construites de blocs primitifs, les tombes serrées, les croix renversées et effacées, les têtes nombreuses rangées sur les étages de la maisonnette qui sert d'ossuaire, attestaient que depuis les 
plus anciens jours où les saints de Bretagne avaient paru sur ces flots, on avait enterré en ce lieu. Ce jour-là, j'éprouvai le sentiment de l'immensité de l'oubli et du vaste silence où s'engloutit la vie humaine avec un effroi que je ressens encore, et qui est resté un des éléments de ma vie morale. Parmi tous ces'simples qui sont là, à l'ombre de ces vieux arbres, pas un, pas un seul ne vivra dans l'avenir. Pas un seul n'a inséré son action dans le grand mouvement des choses; pas un seul ne comptera dans la statistique définitive de ceux qui ont poussé à l'éternelle roue. Je servais alors le Dieu de mon enfance, et un regard élevé vers la croix de pierre, sur les marches de laquelle io nous étions assis, et sur le tabernacle, qu'on voyait à travers les vitraux de l'église, m'expliquait tout cela. Et puis, on voyait à peu de distance la mer, les rochers, les vagues blanchissantes, on respirait ce vent céleste qui, pénétrant jusqu'au fond du cerveau, y éveille je ne sais quelle vague sensation de largeur et de liberté. Et puis ma mère 15 était à mes côtés; il me semblait que la plus humble vie pouvait refléter le ciel grâce au pur amour et aux affections individuelles. J'estimais heureux ceux qui reposaient en ce lieu. Depuis j'ai transporté ma tente, et je m'explique autrement cette grande nuit. Ils ne sont pas morts ces obscurs enfants du hameau; car la Bretagne vit encore, et ils ont 20 contribué à faire la Bretagne ; - ils n'ont pas eu de rôle dans le grand drame, mais ils ont fait partie de ce vaste chœur, sans lequel le drame serait froid et dépourvu d'acteurs sympathiques. Et quand la Bretagne ne sera plus, la France sera, et quand la France ne sera plus, l'humanité sera encore, et éternellement l'on dira: Autrefois, il y eut un 25 noble pays, sympathique à toutes les belles choses, dont la destinée fut de souffrir pour l'humanité et de combattre pour elle. Ce jour-là le plus humble paysan qui n'a eu que deux pas à faire de sa cabane au tombeau, vivra comme nous dans ce grand nom immortel; il aura fourni sa petite part à cette grande résultante. Et quand l'humanité ne 30 sera plus, Dieu sera, et l'humanité aura contribué à le faire, et dans son vaste sein se retrouvera toute vie, et alors il sera vrai à la lettre que pas un verre d'eau, pas une parole qui aura servi l'œuvre divine du progrès ne sera perdue.

Voilà la loi de l'humanité: vaste prodigalité de l'individu, dédai- 35 gneuses agglomérations d'hommes (je me figure le mouleur gâchant largement sa matière et s'inquiétant peu que les trois quarts en tombent à terre); l'immense majorité destinée à faire tapisserie au grand bal mené par la destinée, ou plutôt à figurer dans un de ces 
personnages multiples que le drame ancien appelait le chœur. Sontils inutiles? Non; car ils ont fait figure; sans eux les lignes auraient été maigres et mesquines; ils ont servi à ce que la chose se fît d'une façon luxuriante; ce qui est plus original et plus grand. . . .

5 Personne n'est donc inutile dans l'humanité. Le sauvage, qui vit à peine la vie humaine, sert du moins comme force perdue. Or, je l'ai déjà dit, il était convenable qu'il y eût surabondance dans le dessin des formes de l'humanité. La croyance à l'immortalité n'implique pas autre chose que cette invincible confiance de l'humanité dans l'avenir. AuIo cune action ne meurt. Tel insecte qui n'a eu d'autre vocation que de grouper sous une forme vivante un certain nombre de molécules et de manger une feuille a fait une œuvre qui aura des conséquences dans la série éternelle des causes. 


\section{ÉMILE ZOLA}

Paris, $1840-1902$, Paris

Zola's father was Italian by birth, an engineer by profession, stationed in the south of France, and it was there that Emile passed his youth. $\Lambda$ t the age of eighteen he went to Paris and finished his studies at the Lycée SaintLouis. He then took a position with the Ilachette publishing house, spending his leisure hours writing stories, which gave little promise of future greatness. In 187 I came out the first of the series which won him fame and made him the acknowledged leader of the Naturalistic School. In the score of volumes comprised under the general title, "Les Rougon-Macquart, histoire naturelle et sociale d'une famille sous le second empire," Zola has attempted, with claims of scientific accuracy, to expose various hereditary tendencies, the effects of surroundings, and the development of nervous disorders. The best novels of this series are "L'assommoir" (I877); "Nana" (1880); "Germinal" (1885); "L'œuvre" (I886); "La débâcle" (I892). In addition Zola wrote "Lourdes" (I894); "Rome" (1896); "Paris" (I898); "Fécondité" (I899); "Travail" (I9OI); "Vérité" (1902), and various important critical articles. He also wrote some plays, which were not successful.

Notwithstanding his scientific claims and his extreme realism, there is present in his novels a romantic imagination which magnifies and even idealizes the most prosaic aspects of modern life.

\section{LA GRÈVE DE GERMINAL}

Et la bande, par la plaine rase, toute blanche de gelée, sous le pâle soleil d'hiver, s'en allait, débordait de la route, au travers des champs de betteraves.

Dès la Fourche-aux-Bœufs, Etienne en avait pris le commandement. Sans qu'on s'arrêtât, il criait les ordres, il organisait la marche. Jeanlin, en tête, galopait en sonnant dans sa corne une musique barbare. Puis, aux premiers rangs, les femmes s'avançaient, quelques-unes armées de bâtons, la Maheude avec des yeux ensauvagés qui semblaient chercher au loin la cité de justice promise; la Brûlé, la Levaque, la Mouquette, allongeant toutes leurs jambes sous leurs guenilles, comme des soldats io partis pour la guerre. En cas de mauvaise rencontre, on verrait bien si les gendarmes oseraient taper sur des femmes. Et les hommes suivaient, dans une confusion de troupeau, en une queue qui s'élargissait, 
hérissée de barres de fer, dominée par l'unique hache de Levaque, dont le tranchant miroitait au soleil. ... Des têtes nues s'échevelaient au grand air, on n'entendait que le claquement des sabots, pareil à un galop de bétail lâché, emporté dans la sonnerie sauvage de Jeanlin. 5 Mais, tout de suite, un nouveau cri s'éleva.

— Du pain! du pain! du pain!

Il était midi, la faim des six semaines de grève s'éveillait dans les ventres vides, fouettée par cette course en pleins champs. Les croûtes rares du matin, les quelques châtaignes de la Mouquette, étaient loin ıo déjà ; et les estomacs criaient, et cette souffrance s'ajoutait à la rage contre les traîtres.

- Aux fosses $!^{1}$ plus de travail ! du pain $! \ldots$.

La bande traversa la route de Joiselle, suivit un instant celle de Cron, remonta ensuite vers Cougny. De ce côté, des cheminées I5 d'usine rayaient l'horizon plat, des hangars de bois, des ateliers de briques, aux larges baies poussiéreuses, défilaient le long du pavé. On passa coup sur coup près des maisons basses de deux corons, ${ }^{2}$ celui des Cent-Quatre-Vingts, puis celui des Soixante-Seize; et, de chacun, à l'appel de la corne, à la clameur jetée par toutes les bouches, des 20 familles sortirent, des hommes, des femmes, des enfants, galopant eux aussi, se joignant à la queue des camarades. Quand on arriva devant Madeleine, on était bien quinze cents. La route dévalait en pente douce, le flot grondant des grévistes dut tourner le terri, ${ }^{3}$ avant de se répandre sur le carreau ${ }^{4}$ de la mine.

25 A ce moment, il n'était guère plus de deux heures. Mais les porions, ${ }^{5}$ avertis, venaient de hâter la remonte ${ }^{6}$; et, comme la bande arrivait, la sortie s'achevait, il restait au fond une vingtaine d'hommes, qui débarquèrent de la cage. ${ }^{7}$ Ils s'enfuirent, on les poursuivit à coups de pierre. Deux furent battus, un autre y laissa une manche de sa 30 veste. Cette chasse à l'homme sauva le matériel, on ne toucha ni aux câbles, ni aux chaudières. Déjà le flot s'éloignait, roulait sur la fosse voisine. ...

Sans qu'on sût d'où il partait, un nouveau mot d'ordre les lança sur une autre fosse.

35 - A la Victoire! à la Victoire!

Il n'y avait donc ni dragons ni gendarmes à la Victoire? On

1 "mines."

3 "pile of débris."

6 "getting the men up."
2 Groups of houses built by the factory owners for the workmen. 4 " yard."

7 I.e. of the elevator. 
l'ignorait. Tous semblaient rassurés. Et, faisant voltc-face, ils descendirent du côté de Beaumont, ils coupèrent à travers champs, pour rattraper la route de Joiselle. La voie du chemin de fer leur barrait le passage, ils la traversèrent en renversant les clôtures. Maintenant, ils se rapprochaient de Montsou, l'ondulation lente des terrains s'abaissait, élargissait la mer des pièces de betteraves, très loin, jusqu'aux maisons noires de Marchiennes.

C'était, cette fois, une course de cinq grands kilomètres. Un élan tel les charriait, qu'ils ne sentaient pas la fatigue atroce, leurs pieds brisés et meurtris. Toujours la queue s'allongeait, s'augmentait des ro camarades racolés en chemin, dans les corons. Quand ils eurent passé le canal au pont Magache, et qu'ils se présentèrent devant la Victoire, ils étaient deux mille. Mais trois heures avaient sonné, la sortie était faite, plus un homme ne restait au fond. Leur déception s'exhala en menaces vaines, ils ne purent que recevoir à coups de briques cassées 15 les ouvriers de la coupe à terre, ${ }^{1}$ qui arrivaient prendre leur service. Il y eut une débandade, la fosse déserte leur appartint. Et, dans leur rage de n'avoir pas une face de traitre à gifler, ils s'attaquèrent aux choses. Une poche de rancune crevait en eux, une poche empoisonnée, grossie lentement. Des années et des années de faim les 20 torturaient d'une fringale de massacre et de destruction.

Derrière un hangar, Étienne aperçut des chargeurs qui remplissaient un tombereau de charbon. ...

Sous ses ordres, une centaine de grévistes accouraient; et les chargeurs n'eurent que le temps de s'éloigner. Des hommes dételèrent 25 les chevaux qui s'effarèrent et partirent, piqués aux cuisses; tandis que d'autres, en renversant le tombereau, cassaient les brancards.

Levaque, à violents coup de hache, s'était jeté sur les tréteaux, pour abattre les passerelles. Ils résistaient, et il eut l'idée d'arracher les rails, de couper la voie, d'un bout à l'autre du carreau. Bientôt, 30 la bande entière se mit à cette besogne. Maheu fit sauter des coussinets de fonte, ${ }^{2}$ armé de sa barre de fer, dont il se servait comme d'un levier. Pendant ce temps, la Brûlé entraînant les femmes, envahissait la lampisterie, où les bâtons, à la volée, couvrirent le sol d'un carnage de lampes....

Mais ces vengeances ne donnaient pas à manger. Les ventres criaient plus haut. Et la grande lamentation domina encore :

1 I.e. those who, instead of digging the coal, prepared the galleries.

2 "Rail chairs." 
— Du pain! du pain! du pain!...

La bande, de nouveau, sillonna la plaine rase. Elle revenait sur ses pas, par les longues routes droites, par les terres sans cesse élargies. Il était quatre heures, le soleil, qui baissait à l'horizon, allongeait sur 5 le sol glacé les ombres de cette horde, aux grands gestes furieux.

On évita Montsou, on retomba plus haut dans la route de Joiselle; et, pour s'épargner le détour de la Fourche-au-Bœufs, on passa sous les murs de la Piolaine. Les Grégoire, ${ }^{1}$ précisément, venaient d'en sortir. . . L La propriété semblait dormir, avec son avenue de tilleuls Io déserte, son potager et son verger dénudés par l'hiver. Rien ne bougeait dans la maison, dont les fenêtres closes se ternissaient de la chaude buée intérieure; et, du profond silence, sortait une impression de bonhomie et de bien-être, la sensation patriarcale des bons lits et de la bonne table, du bonheur sage, où coulait l'existence des I 5 propriétaires.

Sans s'arrêter, la bande jetait des regards sombres à travers les grilles, le long des murs protecteurs, hérissés de culs de bouteille. Le cri recommença :

- Du pain! du pain! du pain!

20. Seuls, les chiens répondirent par des abois féroces, une paire de grands danois au poil fauve, qui se dressaient debout, la gueule ouverte. Et, derrière une persienne fermée, il n'y avait que les deux bonnes, Mélanie, la cuisinière, et Honorine, la femme de chambre, attirées par ce cri, suant la peur, toutes pâles de voir défiler ces sauvages.

25 Elles tombèrent à genoux, elles se crurent mortes, en entendant une pierre, une seule, qui cassait un carreau d'une fenêtre voisine. C'était une farce de Jeanlin: il avait fabriqué une fronde avec un bout de corde, il laissait en passant un petit bonjour aux Grégoire. Déjà, il s'était remis à souffler dans sa corne, la bande se perdait au loin, avec 30 le cri affaibli :

- Du pain! du pain! du pain!

On arriva à Gaston Marie, en une masse grossie encore, plus de deux mille cinq cents forcenés, brisant tout, balayant tout, avec la force accrue du torrent qui roule. Des gendarmes y avaient passé une heure 35 plus tôt, et s'en étaient allés du côté de Saint-Thomas, égarés par des paysans, sans même avoir la précaution, dans leur hâte, de laisser un poste de quelques hommes, pour garder la fosse. En moins d'un quart d'heure, les feux furent renversés, les chaudières vidées, les

1 The Grégoire were stockholders in the mine. 
bâtiments envahis et dévastés. Mais c'était surtout la pompe qu'on menaçait. Il ne suffisait pas qu'elle s'arrêtât au dernier souffle expirant de la vapeur, on se jetait sur elle comme sur une personne vivante, dont on voulait la vie.

- A toi le premier coup! répétait Étienne, en mettant un marteau au poing de Chaval. Allons! tu as juré avec les autres!

Chaval tremblait, se reculait; et, dans la bousculade, le marteau tomba, pendant que les camarades, sans attendre, massacraient la pompe à coups de barres de fer, à coups de brique, à coups de tout ce qu'ils rencontraient sous leurs mains. Quelques-uns même brisaient io sur elle des bâtons. Les écrous sautaient, les pièces d'acier et de cuivre se disloquaient, ainsi que des membres arrachés. Un coup de pioche à toute volée fracassa le corps de fonte, et l'eau s'échappa, se vida, et il y eut un gargouillement suprême pareil à un hoquet d'agonie. C'était la fin. ... .

La bande s'était remise en marche. Cinq heures allaient sonner, le soleil d'une rougeur de braise, au bord de l'horizon, incendiait la plaine immense. Un colporteur qui passait, leur apprit que les dragons descendaient du côté de Crèvecœur. Alors, ils se replièrent, un ordre courut.

- A Montsou! à la Direction !... Du pain! du pain! du pain! - (Germinal », Part V, 4

\section{PARIS VU DES HAUTEURS DE PASSY}

Paris, lentement, apparut. Pas un souffle de vent n'avait passé, ce fut comme une évocation. La dernière gaze se détacha, monta, s'évanouit dans l'air. Et la ville s'étendit sans une ombre, sous le soleil vainqueur. ... Toute une vallée sans fin de constructions entassées. 25 Sur la ligne perdue des coteaux, des amas de toitures se détachaient, tandis que l'on sentait le flot des maisons rouler au loin, derrière les plis de terrain, dans des campagnes qu'on ne voyait plus. C'était la pleine mer, avec l'infini et l'inconnu de ses vagues. Paris se déployait aussi grand que le ciel. Sous cette radieuse matinée, la ville, jaune de 30 soleil, semblait un champ d'épis mûrs ; et l'immense tableau avait une simplicité, deux tons seulement, le bleu pâle de l'air et le reflet doré des toits. L'ondée de ces rayons printaniers donnait aux choses une grâce d'enfance. On distinguait nettement les plus petits détails, tant la lumière était pure. Paris, avec le chaos inextricable de ses pierres, 35 
luisait comme sous un cristal. De temps à autre pourtant, dans cette sérénité éclatante et immobile, un souffle passait; et alors on voyait des quartiers dont les lignes mollissaient et tremblaient, comme si on les eût regardés à travers quelque flamme invisible.

5 Hélène, ${ }^{1}$ d'abord, s'intéressa aux larges étendues déroulées sous ses fenêtres, à la pente du Trocadéro et au développement des quais. Il fallait qu'elle se penchât, pour apercevoir le carré nu du Champ-deMars, fermé au fond par la barre sombre de l'École militaire. En bas, sur la vaste place et sur les trottoirs, aux deux côtés de la Seine, elle Io distinguait les passants, une foule active de points noirs emportés dans un mouvement de fourmilière; la caisse jaune d'un omnibus jetait une étincelle; des camions et des fiacres traversaient le pont, gros comme des jouets d'enfant, avec des chevaux délicats qui ressemblaient à des pièces mécaniques; et, le long des talus gazonnés, parmi d'autres I 5 promeneurs, une bonne en tablier blanc tachait l'herbe d'une clarté. Puis, Hélène leva les yeux; mais la foule s'émiettait et se perdait, les voitures elles-mêmes devenaient des grains de sable; il n'y avait plus que la carcasse gigantesque de la ville, comme vide et déserte, vivant seulement par la sourde trépidation qui l'agitait. Là, au premier plan, 20 à gauche, des toits rouges luisaient, les hautes cheminées de la Manutention ${ }^{2}$ fumaient avec lenteur; tandis que, de l'autre côté du fleuve, entre l'Esplanade ${ }^{3}$ et le Champ-de-Mars, un bouquet de grands ormes faisait un coin de parc, dont on voyait nettement les branches nues, les cimes arrondies, teintées déjà de pointes vertes. Au milieu, la

25 Seine s'élargissait et régnait, encaissée dans ses berges grises, où des tonneaux déchargés, des profils de grues à vapeur, des tombereaux alignés, mettaient le décor d'un port de mer. Hélène revenait toujours à cette nappe resplendissante sur laquelle des barques passaient, pareilles à des oiseaux couleur d'encre. Invinciblement, d'un long re30 gard, elle en remontait la coulée superbe. C'était comme un galon d'argent qui coupait Paris en deux. Ce matin-là, l'eau roulait du soleil, l'horizon n'avait pas de lumière plus éclatante. Et le regard de la jeune femme rencontrait d'abord le pont des Invalides, puis le pont de la Concorde, puis le pont Royal; les ponts continuaient, semblaient 35 se rapprocher, se superposaient, bâtissant d'étranges viaducs à plusieurs

1 Hélène Granjean, the heroine of the novel, lives at Passy, and has an outlook over a large part of Paris.

2 Where the bread for the troops was baked.

3 The square in front of the Hôtel des Invalides. 
étages, troués d'arches de toutes formes; pendant que le fleuve, entre ces constructions légères, montrait des bouts de sa robe bleue, de plus en plus perdus et étroits. Elle levait encore les ycux: là-bas, la coulée se séparait dans la débandade confuse des maisons; les ponts, des deux côtés de la Cité, devenaient des fils tendus d'une rive à l'autre; et les tours de Notre-Dame, toutes dorées, se dressaient comme les bornes de l'horizon, au delà desquelles la rivière, les constructions, les massifs d'arbres n'étaient plus que de la poussière de soleil. ...

Hélène, d'un coup d'œil paresseusement promené, embrassait Paris to entier. Des vallées s'y creusaient, que l'on devinait au mouvement des toitures; la butte des Moulins montait avec un flot bouillonnant de vieilles ardoises, tandis que la ligne des grands boulevards dévalait comme un ruisseau, où s'engloutissait une bousculade de maisons dont on ne voyait même plus les tuiles. A cette heure matinale, le soleil 15 oblique n'éclairait point les façades tournées vers le Trocadéro. Aucune fenêtre ne s'allumait. Seuls, des vitrages, sur les toits, jetaient des lueurs, de vives étincelles de mica, dans le rouge cuit des poteries environnantes. Les maisons restaient grises, d'un gris chauffé de reflets; mais des coups de lumière trouaient les quartiers, de longues rues qui 20 s'enfonçaient, droites devant Hélène, coupaient l'ombre de leurs raies de soleil. A gauche seulement, les buttes Montmartre et les hauteurs du Père-Lachaise bossuaient l'immense horizon plat, arrondi sans une cassure. Les détails si nets aux premiers plans, les dentelures innombrables des cheminées, les petites hachures noires des milliers de fe- 25 nêtres, s'effaçaient, se chinaient de jaune et de bleu, se confondaient dans un pêle-mêle de ville sans fin, dont les faubourgs hors de la vue semblaient allonger des plages de galets, noyées d'une brume violâtre, sous la grande clarté épandue et vibrante du ciel.

- "Une page d'amour », Part V

1 The Ile de la Cité on which stands Notre Dame de Paris. 


\title{
RENÉ-FRANÇOIS-ARMAND SULLY-PRUDHOMME
}

\author{
Paris, I 839-1907, Paris
}

Sully-Prudhomme, the philosopher of the Parnassian School, took up law as a profession. His first volume of verse, in which, as in his other work, an unusual delicacy of sentiment and fineness of perception are expressed with the greatest precision and finish, appeared in I865. This was followed by "Les épreuves" (1866); "Les solitudes" (1869); "Les destins" (I872); "Les vaines tendresses" (1875). He later turned more to philosophical speculations on the fundamental principles of justice (" La justice," 1878 ), and to the search for happiness, found only in altruism ("Le bonheur," 1888). He was elected to the Academy in 1881 and died at Paris in 1907.

\section{LES YEUX}

Bleus ou noirs, tous aimés, tous beaux, Des yeux sans nombre ont vu l'aurore; Ils dorment au fond des tombeaux, Et le soleil se lève encore.

Les nuits, plus douces que les jours, Ont enchanté des yeux sans nombre; Les étoiles brillent toujours, Et les yeux se sont remplis d'ombre.

Oh! qu'ils aient perdu le regard, Non, non, cela n'est pas possible! Ils se sont tournés quelque part Vers ce qu'on nomme l'invisible;

Et comme les astres penchants Nous quittent, mais au ciel demeurent,

Les prunelles ont leurs couchants, Mais il n'est pas vrai qu'elles meurent. 
Bleus ou noirs, tous aimés, tous beaux,

Ouverts à quelque immense aurore,

De l'autre côté des tombeaux

Les yeux qu'on ferme voient encore.

— "La vie intérieure »

\section{LE VASE BRISÉ}

Le vase où meurt cette verveine

D'un coup d'éventail fut fêlé;

Le coup dut effleurer à peine:

Aucun bruit ne l'a révélé.

Mais la légère meurtrissure,

Mordant le cristal chaque jour,

D'une marche invisible et sûre

En a fait lentement le tour.

Son eau fraîche a fui goutte à goutte,

Le suc des fleurs s'est épuisé ;

Personne encore ne s'en doute;

N'y touchez pas, il est brisé.

Souvent aussi la main qu'on aime,

Effleurant le cœur, le meurtrit ;

Puis le cœur se fend de lui-même,

La fleur de son amour périt;

Toujours intact aux yeux du monde,

Il sent croître et pleurer tout bas

Sa blessure fine et profonde;

Il est brisé, n'y touchez pas.

— «La vie intérieure »

\section{LE MISSEL}

Dans un missel datant du roi François premier, ${ }^{1}$

Dont la rouille des ans a jauni le papier

Et dont les doigts dévots ont usé l'armoirie,

Livre mignon, vêtu d'argent sur parchemin,

1 Francis I (1494-1547) disputed with Charles V the crown of the Holy Roman Empire, and was defeated and made prisoner by Charles at Pavia in 1525 . 
L'un de ces fins travaux d'ancienne orfèvrerie Où se sentent l'audace et la peur de la main, J'ai trouvé cette fleur flétrie.

On voit qu'elle est très vieille au vélin traversé Par sa profonde empreinte où la sève a percé : Il se pourrait qu'elle eût trois cents ans ; mais n'importe, Elle n'a rien perdu qu'un peu de vermillon, Fard qu'elle eût vu tomber même avant d'être morte, Qui ne brille qu'un jour, et que le papillon, En passant, d'un coup d'aile emporte ;

Elle n'a pas perdu de son cœur un pistil, $\mathrm{Ni}$ du frêle tissu de sa corolle un fil;

La page ondule encore où sécha la rosée

De son dernier matin, mêlée à d'autres pleurs ;

15 La Mort en la cueillant l'a seulement baisée, Et, soigneuse, n'a fait qu'éteindre ses couleurs,

Mais ne l'a pas décomposée.

Une mélancolique et subtile senteur, Pareille au souvenir qui monte avec lenteur,

L'arome du secret dans les cassettes closes, Révèle l'âge ancien de ce mystique herbier; Il semble que les jours se parfument des choses, Et qu'un passé d'amour ait l'odeur d'un sentier Où le vent balaya des roses.

Et peut-être, dans l'air sombre et léger du soir,

Un cœur, comme une flamme, autour du vieux fermoir, S'efforce, en palpitant, de se frayer passage;

Et chaque soir peut-être il attend l'Angelus, Dans l'espoir qu'une main viendra tourner la page Et qu'il pourra savoir si rien ne reste plus De la fleur qui fut son hommage.

Eh bien! rassure-toi, chevalier qui partais Pour combattre à Pavie et ne revins jamais; Ou page qui, tout bas, aimant comme on adore,

Fis un aveu d'amour d'un Ave Maria :

Cette fleur qui mourut sous des yeux que j'ignore, Depuis les trois cents ans qu'elle repose là, Où tu l'as mise elle est encore. 


\section{LES DANAÏDES ${ }^{1}$}

Toutes, portant l'amphore, une main sur la hanche, Théano, Callidie, Amymone, Agavé, Esclaves d'un labeur sans cesse inachevé, Courent du puits à l'urne oủ l'eau vaine s'épanche.

Hélas! le grès rugueux meurtrit l'épaule blanche, Et le bras faible est las du fardeau soulevé :

« Monstre, que nous avons nuit et jour abreuvé,

$\mathrm{O}$ gouffre, que nous veut ta soif que rien n'étanche?»

Elles tombent, le vide épouvante leurs cœurs ;

Mais la plus jeune alors, moins triste que ses sœurs,

Chante, et leur rend la force et la persévérance.

Tels sont l'œuvre et le sort de nos illusions :

Elles tombent toujours, et la jeune Espérance

Leur dit toujours : "Mes sœurs, si nous recommencions !"

— "Les épreuves », Amour

\section{UN SONGE}

Le laboureur m'a dit en songe: "Fais ton pain,

Je ne te nourris plus, gratte la terre et sème. »

Le tisserand m'a dit: "Fais tes habits toi-même."

Et le maçon m'a dit: "Prends la truelle en main.»

Et seul, abandonné de tout le genre humain

Dont je traînais partout l'implacable anathème,

Quand j'implorais du ciel une pitié suprême,

Je trouvais des lions debout sur mon chemin.

J'ouvris les yeux, doutant si l'aube était réelle :

De hardis compagnons sifflaient sur leur échelle,

Les métiers bourdonnaient, les champs étaient semés.

Je connus mon bonheur et qu'au monde où nous sommes Nul ne peut se vanter de se passer des hommes;

Et depuis ce jour-là je les ai tous aimés.

- "Les épreuves ", Action

1 The fifty Danaïdes, daughters of Danains, who, at the command of their father, slew their husbands on their wedding day, were condemned in Hades to pour water into sieves. 


\section{PIERRE LOTI \\ (LOUIS-MARIE-JULIEN VIAUD) \\ Rochefort, $1850-$}

After finishing his studies in his native town Loti entered the marine at the age of seventeen. In 1873 he was made ensign and in 1881 lieutenant. Meanwhile he had cruised over many seas, and it is the impressions of various points in these voyages that he gives in his books. His novels often have but little plot. There is, however, the sensation of things seen, the touch of a poet, and the wonderful coloring of an artist. He became a member of the Academy in 1891 .

The best of his works are "Mon frère Yves" (I883); "Le pêcheur d'Islande" (1886); "Madame Chrysanthème" (1887); "Ramuntcho " (1897); "Vers Ispahan" (I904); "Les désenchantées" (I906).

\section{PÊCHEURS D'ISLANDE}

... En juin.

Autour de l'Islande, il fait cette sorte de temps rare que les matelots appellent le calme blanc; c'est-à-dire que rien ne bougeait dans l'air, comme si toutes les brises étaient épuisées, finies.

Le ciel s'était couvert d'un grand voile blanchâtre, qui s'assombris5 sait par le bas, vers l'horizon, passait aux gris plombés, aux nuances ternes de l'étain. Et là-dessous, les eaux inertes jetaient un éclat pâle, qui fatiguait les yeux et qui donnait froid.

Cette fois-là, c'étaient des moires, rien que des moires changeantes qui jouaient sur la mer; des cernes très légers, comme on en ferait en Io soufflant contre un miroir. Toute l'étendue luisante semblait couverte d'un réseau de dessins vagues qui s'enlaçaient et se déformaient; très vite effacés, très fugitifs.

Éternel soir ou éternel matin, il était impossible de dire: un soleil qui n'indiquait plus aucune heure, restait là toujours, pour présider à

I5 ce resplendissement de choses mortes, il n'était lui-même qu'un autre cerne, presque sans contours, agrandi jusqu'à l'immense par un halo trouble. 
Yann et Sylvestre, en pêchant à côté l'un de l'autre, chantaient: Jean-François de Nantes, la chanson qui ne finit plus, — s'amusant de sa monotonie même et se regardant du coin de l'œil pour rire de l'espèce de drôlerie enfantine avec laquelle ils reprenaient perpétuellement les couplets, en tâchant d'y mettre un entrain nouveau à chaque fois. Leurs joues étaient roses sous la grande fraîcheur salée ; cet air qu'ils respiraient était vivifiant et vierge ; ils en prenaient plein leur poitrine, à la source même de toute vigueur et de toute existence.

Et pourtant, autour d'eux, c'étaient des aspects de non-vie, de monde fini ou pas encore créé; la lumière n'avait aucune chaleur; 10 les choses se tenaient immobiles et comme refroidies à jamais, sous le regard de cette espèce de grand œil spectral qui était le soleil.

La Marie projetait sur l'étendue une ombre qui était très longue comme le soir, et qui paraissait verte, au milieu de ces surfaces polies reflétant les blancheurs du ciel; alors, dans toute cette partie ombrée I5 qui ne miroitait pas, on pouvait distinguer par transparence ce qui se passait sous l'eau: des poissons innombrables, des myriades et des myriades, tous pareils, glissant doucement dans la même direction, comme ayant un but dans leur perpétuel voyage. C'étaient les morues qui exécutaient leurs évolutions d'ensemble, toutes en long dans le 20 même sens, bien parallèles, faisant un effet de hachures grises, et sans cesse agitées d'un tremblement rapide, qui donnait un air de fluidité à cet amas de vies silencieuses. Quelquefois, avec un coup de queue brusque, toutes se retournaient en même temps, montrant le brillant de leur ventre argenté; et puis le même coup de queue, le même 25 retournement, se propageait dans le banc tout entier par ondulations lentes, comme si des milliers de lames de métal eussent jeté, entre deux eaux, chacune un petit éclair.

Le soleil, déjà très bas, s'abaissait encore; donc c'était le soir décidément. A mesure qu'il descendait dans les zones couleur de plomb $3^{\circ}$ qui avoisinaient la mer, il devenait jaune, et son cercle se dessinait plus net, plus réel. On pouvait le fixer avec les yeux, comme on fait pour la lune.

Il éclairait pourtant; mais on eût dit qu'il n'était pas du tout loin dans l'espace ; il semblait qu'en allant, avec un navire, seulement jus- 35 qu'au bout de l'horizon, on eût rencontré là ce gros ballon triste, flottant dans l'air à quelques mètres au-dessus des eaux.

La pêche allait assez vite: en regardant dans l'eau reposée, on voyait très bien la chose se faire: les morues venir mordre, d'un 
mouvement glouton; ensuite se secouer un peu, se sentant piquées, comme pour mieux se faire accrocher le museau. Et, de minute en minute, vite, à deux mains, les pêcheurs rentraient leur ligne, — rejetant la bête à qui devait l'éventrer et l'aplatir.

5 La flotille des Paimpolais ${ }^{1}$ était éparse sur ce miroir tranquille, animant ce désert. Çà et là, paraissaient les petites voiles lointaines, déployées pour la forme puisque rien ne soufflait, et très blanches, se découpant en clair sur les grisailles des horizons.

Ce jour-là, ç'avait l'air d'un métier si calme, si facile, celui de ı pêcheur d'Islande; — un métier de demoiselle. . . .

\section{Jean-François de Nantes ; \\ Jean-François, \\ Jean-François!}

Ils chantaient, les deux grands enfants.

I5 Et Yann s'occupait bien peu d'être si beau et d'avoir la mine si noble. D'ailleurs, enfant seulement avec Sylvestre, ne chantant et ne jouant jamais qu'avec celui-là; renfermé au contraire avec les autres, et plutôt fier et sombre ; - très doux pourtant quand on avait besoin de lui ; toujours bon et serviable quand on ne l'irritait pas.

20 Eux chantaient cette chanson-là ; les deux autres, à quelques pas plus loin, chantaient autre chose, une autre mélopée faite aussi de somnolence et de vague mélancolie.

On ne s'ennuyait pas et le temps passait.

Jean-François de Nantes;

5

$$
\begin{aligned}
& \text { Jean-François, } \\
& \text { Jean-François! }
\end{aligned}
$$

. . . Ils regardaient à présent, au fond de leur horizon gris, quelque chose d'imperceptible. Une petite fumée, montant des eaux comme une queue microscopique, d'un autre gris, un tout petit peu plus foncé

30 que celui du ciel. Avec leurs yeux exercés à sonder les profondeurs, ils l'avaient vite aperçue :

- Un vapeur là-bas!

- J'ai idée, dit le capitaine en regardant bien, j'ai idée que c'est un vapeur de l'État, — le croiseur qui vient faire sa ronde. . . .

35 Cette vague fumée apportait aux pêcheurs des nouvelles de France. ...

1 Paimpol is a port in Brittany, one of the centers for fitting out the fishing boats. 
Il se rapprocha lentement; bientôt on vit sa coque noire, - c'était bien le croiseur, qui venait faire un tour dans ces fiords de l'ouest.

En même temps, une légère brise qui s'était levée, piquante à respirer, commençait à marbrer par endroits la surface des eaux mortes; elle traçait sur le luisant miroir des dessins d'un bleu vert, qui s'allongeaient en trainées, s'étendaient comme des éventails, ou se ramifiaient en forme de madrépores; cela se faisait très vite avec un bruissement, c'était comme un signe de réveil présageant la fin de cette torpeur immense. Et le ciel, débarrassé de son voilé, devenait clair ; les vapeurs, retombées sur l'horizon, s'y tassaient en amoncelle- 10 ments de ouates grises, formant comme des murailles molles autour de la mer. Les deux glaces sans fin entre lesquelles les pêcheurs étaient - celle d'en haut et celle d'en bas - reprenaient leur transparence profonde, comme si on eût essuyé les buées qui les avaient ternies. Le temps changeait, mais d'une façon rapide qui n'était pas 15 bonne.

Et, de différents points de la mer, de différents côtés de l'étendue, arrivaient des navires pêcheurs: tous ceux de France qui rôdaient dans ces parages, des Bretons, des Normands, des Boulonnais ou des Dunkerquois. Comme des oiseaux qui rallient à un rappel, ils se ras- 20 semblaient à la suite de ce croiseur; il en sortait même des coins vides de l'horizon, et leurs petites ailes grisâtres apparaissaient partout. Ils peuplaient tout à fait le pâle désert.

Plus de lente dérive, ils avaient tendu leurs voiles à la fraîche brise nouvelle et se donnaient de la vitesse pour s'approcher.

L'Islande, assez lointaine, était apparue aussi, avec un air de vouloir s'approcher comme eux; elle montrait de plus en plus nettement ses grandes montagnes de pierres nues, - - qui n'ont jamais été éclairées que par côté, par en dessous et comme à regret. Elle se continuait même par une autre Islande de couleur semblable qui s'accentuait peu à peu ; 30 - mais qui était chimérique, celle-ci, et dont les montagnes plus gigantesques n'étaient qu'une condensation de vapeurs. Et le soleil, toujours bas et traînant, incapable de monter au-dessus des choses, se voyait à travers cette illusion d'île, tellement qu'il paraissait posé devant et que c'était pour les yeux un aspect incompréhensible. Il 35 n'avait plus de halo, et son disque rond ayant repris des contours très accusés, il semblait plutôt quelque pauvre planète jaune, mourante, qui se serait arrêtée là indécise, au milieu d'un chaos. . . . 


\section{AU JAPON}

Au petit jour naissant, nous aperçûmes le Japon.

Juste à l'heure prévue, il apparut, encore lointain, en un point précis de cette mer qui, pendant tant de jours, avait été l'étendue vide.

Ce ne fut d'abord qu'une série de petits sommets roses. ... Mais 5 derrière, tout le long de l'horizon, on vit bientôt comme une lourdeur en l'air, comme un voile pesant sur les eaux: c'était cela, le vrai Japon, et peu à peu, dans cette sorte de grande nuée confuse, se découpèrent des silhouettes tout à fait opaques qui étaient les montagnes de Nagasaki.

Io Nous avions vent debout, une brise fraîche qui augmentait toujours, comme si ce pays eût soufflé de toutes ses forces contre nous pour nous éloigner de lui. - La mer, les cordages, le navire, étaient agités et bruissants.

Vers trois heures du soir, toutes ces choses lointaines s'étaient rapI 5 prochées, rapprochées jusqu'à nous surplomber de leurs masses rocheuses ou de leurs fouillis de verdure.

Et nous entrions maintenant dans une espèce de couloir ombreux, entre deux rangées de très hautes montagnes, qui se succédaient avec une bizarrerie symétrique - comme les "portants " ${ }^{1}$ d'un décor tout 20 en profondeur, extrêmement beau, mais pas assez naturel. - On eût dit que ce Japon s'ouvrait devant nous, en une déchirure enchantée, pour nous laisser pénétrer dans son cœur même.

$\mathrm{Au}$ bout de cette baie longue et étrange, il devait y avoir Nagasaki qu'on ne voyait pas encore. Tout était admirablement vert. La grande 25 brise du large, brusquement tombée, avait fait place au calme; l'air, devenu très chaud, se remplissait de parfums de fleurs. Et, dans cette vallée, il se faisait une étonnante musique de cigales; elles se répondaient d'une rive à l'autre ; toutes ces montagnes résonnaient de leurs bruissements innombrables; tout ce pays rendait comme une inces-

3o sante vibration de cristal. Nous frôlions au passage des peuplades de grandes jonques, qui glissaient tout doucement, poussées par des brises imperceptibles; sur l'eau à peine froissée, on ne les entendait pas marcher; leurs voiles blanches, tendues sur des vergues horizontales, retombaient mollement, drapées à mille plis comme des stores ;

35 leurs poupes compliquées se relevaient en château, comme celles des nefs du moyen âge. Au milieu du vert intense de ces murailles de montagnes, elles avaient une blancheur neigeuse. 
Quel pays de verdure et d'ombre, ce Japon, quel Fden inattendu! ...

Dehors, en pleine mer, il devait faire encore grand jour ; mais, ici, dans l'encaissement de cette vallée, on avait déjà une impression de soir ; au-dessous des sommets très éclairés, les bases, toutes les parties plus touffues avoisinant les eaux, étaient dans une pénombre de crépuscule. Ces jonques qui passaient, si blanches sur le fond sombre des feuillages, étaient manœuvrées sans bruit, merveilleusement, par de petits hommes jaunes, tout nus avec de longs cheveux peignés en bandeaux de femme. - A mesure qu'on s'enfonçait dans le couloir vert, ı les senteurs devenaient plus pénétrantes et le tintement monotone des cigales s'enflait comme un crescendo d'orchestre. En haut, dans la découpure lumineuse du ciel entre les montagnes, planaient des espèces de gerfauts qui faisaient: "Han! Han! Han!" avec un son profond de voix humaine; leurs cris détonnaient là tristement, 15 prolongés par l'écho.

Toute cette nature exubérante et fraîche portait en elle-même une étrangeté japonaise; cela résidait dans je ne sais quoi de bizarre qu'avaient les cimes des montagnes et, si l'on peut dire, dans l'invraisemblance de certaines choses trop jolies. Des arbres s'arrangeaient en 20 bouquets, avec la même grâce précieuse que sur les plateaux de laque. De grands rochers surgissaient tout debout, dans des poses exagérées, à côté de mamelons aux formes douces, couverts de pelouses tendres: des éléments disparates de paysage se trouvaient rapprochés, comme dans les sites artificiels.

... Et, en regardant bien, on apercevait çà et là, le plus souvent bâtie en porte-à-faux ${ }^{1}$ au-dessus d'un abîme, quelque vieille petite pagode mystérieuse, à demi cachée dans le fouillis des arbres suspendus : cela surtout jetait dès l'abord, aux nouveaux arrivants comme nous, la note lointaine et donnait le sentiment que, dans cette contrée, 30 les Esprits, les Dieux des bois, les symboles antiques chargés de veiller sur les campagnes, étaient inconnus et incompréhensibles.

— "Madame Chrysanthème »

1 "out of plumb." 


\title{
PAUL-MARIE VERLAINE
}

\author{
Metz, I 844-I 896, Paris
}

At the age of seven Paul Verlaine went to Paris, where he was educated at the Lycée Bonaparte. He first came under the influence of the Parnassian School, and in I 866 published the "Poèmes saturniens," a volume which did not meet with much success. Three years later appeared the "Fêtes galantes," and in 1870 the "Bonne chanson," in which tendencies away from the Parnassians were clearly evident. While in prison for attempting to shoot a friend he published the "Romances sans paroles" (1874). After his liberation he became in turn teacher of French in England, and professor at the college at Rethel (1877). Then came the publication of "Sagesse," in 1881 , in which he showed a new fervor for Catholicism. He became a leader in the new Decadent, or Symbolistic, School, and published the "Poètes maudits" in 1884 , and "Jadis et naguère" the same year. But his health, undermined by his irregular Bohemian life, gave way, and from 1889 on, he went from hospital to hospital until the end came in 1896 .

His literary theories are touched upon in the "Art poétique" given below. His poetry suggests more than it expresses, and, unlike the verse of the Parnassians, it resembles music more than painting, and appeals rather to the emotions than to the intellect. He was one of the most original poets of the century.

\section{MON RÊVE FAMILIER}

Je fais souvent ce rêve étrange et pénétrant

D'une femme inconnue, et que j'aime, et qui m'aime,

Et qui n'est, chaque fois, ni tout à fait la même

$\mathrm{Ni}$ tout à fait une autre, et m'aime et me comprend.

Car elle me comprend, et mon cœur, transparent

Pour elle seule, hélas ! cesse d'être un problème

Pour elle seule, et les moiteurs de mon front blême,

Elle seule les sait rafraîchir, en pleurant.

Est-elle brune, blonde ou rousse? - Je l'ignore. 
Son regard est pareil au regard des statues,

Et pour sa voix, lointaine, et calme, et grave, elle a

L'inflexion des voix chères qui se sont tues.

— "Poèmes saturniens "

\section{CHANSON D'AUTOMNE}

Les sanglots longs

Des violons

De l'automne

Blessent mon cœur

D'une langueur

Monotone.

Tout suffocant

Et blême, quand

Sonne l'heure,

Je me souviens

Des jours anciens

Et je pleure ;

Et je m'en vais

Au vent mauvais

Qui m'emporte

Deçà, delà,

Pareil à la

Feuille morte.

— «Poèmes saturniens "

Il pleure dans mon cœur Comme il pleut sur la ville, Quelle est cette langueur Qui pénètre mon cœur?

O bruit doux de la pluie Par terre et sur les toits! Pour un cœur qui s'ennuie O le chant de la pluie! 
Il pleure sans raison

Dans ce cœur qui s'écœure.

Quoi! nulle trahison?

Ce deuil est sans raison.

C'est bien la pire peine

De ne savoir pourquoi,

Sans amour et sans haine,

Mon cœur a tant de peine!

— "Romances sans paroles », III

10

Écoutez la chanson bien douce

Qui ne pleure que pour vous plaire,

Elle est discrète, elle est légère:

Un frisson d'eau sur de la mousse!

La voix vous fut connue (et chère!),

Mais à présent elle est voilée

15 Comme une veuve désolée,

Pourtant comme elle encore fière,

Et dans les longs plis de son voile

Qui palpite aux brises d'automne,

Cache et montre au cœur qui s'étonne

20

La vérité comme une étoile.

Elle dit, la voix reconnue,

Que la bonté c'est notre vie,

Que de la haine et de l'envie

Rien ne reste, la mort venue.

Elle parle aussi de la gloire

D'être simple sans plus attendre,

Et de noces d'or et du tendre

Bonheur d'une paix sans victoire.

Accueillez la voix qui persiste

Dans son naïf épithalame.

Allez, rien n'est meilleur à l'âme

Que de faire une âme moins triste! 
Elle est en peine et de passage

L'âme qui souffre sans colère.

Et comme sa morale est claire! . . .

Écoutez la chanson bien sage.

\section{ART POÉTIQUE}

De la musique avant toute chose,

Et pour cela préfère l'Impair

Plus vague et plus soluble dans l'air,

Sans rien en lui qui pèse ou qui pose.

Il faut aussi que tu n'ailles point

Choisir tes mots sans quelque méprise:

Rien de plus cher que la chanson grise

Où l'Indécis au Précis se joint.

C'est des beaux yeux derrière les voiles,

C'est le grand jour tremblant de midi,

C'est, par un ciel d'automne attiédi,

Le bleu fouillis des claires étoiles !

Car nous voulons la Nuance encor, Pas la Couleur, rien que la nuance!

$\mathrm{Oh}$ ! la nuance seule fiance

Le rêve au rêve et la flute au cor!

Fuis du plus loin la Pointe assassine,

L'Esprit cruel et le Rire impur,

Qui font pleurer les yeux de l'Azur,

Et tout cet ail de basse cuisine!

Prends l'Eloquence et tords-lui son cou!

'Tu feras bien, en train d'énergie,

De rendre un peu la Rime assagie.

Si l'on n'y veille, elle ira jusqu'où?

O qui dira les torts de la Rime!

Quel enfant sourd ou quel nègre fou

Nous a forgé ce bijou d'un sou

Qui sonne creux et faux sous la lime? 
De la musique encore et toujours !

Que ton vers soit la chose envolée

Qu'on sent qui fuit d'une âme en allée

Vers d'autres cieux à d'autres amours.

Que ton vers soit la bonne aventure

Eparse au vent crispé du matin

Qui va fleurant la menthe et le thym....

Et tout le reste est litérature.

— "Jadis et naguère " 


\section{ANATOLE FRANCE (ANATOLE-FRANÇOIS THIBAULT)}

Paris, $1844-$

Anatole France was born at Paris in 1844 . He early acquired a deep affection for books in his father's bookshop and in the boxes of old tomes on the quays. This phase of his character is evident in "Le crime de Sylvestre Bonnard" (IS8I). Endowed with a remarkable versatility of mind, with ideas and an erudition which are entirely modern, Anatole France loves to let his fancy wander over the most diverse civilizations, ages, and countries. He revives Christian antiquity in "Thaïs" ( 1890$)$. With fond and delicate touch he goes from the Middle Ages to the Renaissance, and from the Renaissance to modern times, in his charming tales, "Balthazar" (I889) ; "L'étui de nacre" (1892); "Le puits de Sainte-Claire" (I895). In "La rôtisserie de la reine Pédauque" (I893) and "Les opinions de M. Jérôme Coignard" (1893) he adopts, but with a certain geniality, the style and manner of the eighteenthcentury "conteurs." More recently, in the "Histoire contemporaine" ("L'orme du mail" (1897); "Le mannequin d'osier" (I897); "L'anneau d'améthyste" (1899); "M. Bergeret à Paris" (I901)), Anatole France has given free course to his wit and his irony in connection with contemporary questions. To this group may be attached the "Île des pingouins" (1908). He revealed himself a clever if not an impartial historian in the "Vie de Jeanne d'Arc" (1908). Mention should also be made of the two volumes of poems, "Les poèmes dorés" (1873) and "Les noces corinthiennes" (1876); and of his literary criticism, "La vie littéraire" (1889-1890).

The style of Anatole France is marvelous in its simplicity and naturalness, even when it is most subtle. It is the style of Voltaire enriched by a hundred years of literature.

\section{LA FÉE ET LE SAVANT}

Je ne saurais dire depuis combien de temps mes regards étaient attachés sans cause sur ce vieil in-folio, ${ }^{1}$ quand ils furent captivés par un spectacle tellement extraordinaire qu'un homme totalement dépourvu d'imagination, comme je suis, devait lui-même en être vivement frappé.

1 The "Chronicle of Nuremberg" (1493), by Hartmann Schedel, a humanist and doctor of Nuremberg. The edition of 1493 is remarkable for the beauty of its printing and its cuts. 
Je vis tout à coup, sans m'être aperçu de sa venue, une petite personne assise sur le dos du livre, un genou replié et une jambe pendante, à peu près dans l'attitude que prennent sur leur cheval les amazones d'Hyde Park ou du bois de Boulogne. Elle était si petite que son 5 pied ballant ne descendait pas jusqu'à la table sur laquelle s'étalait en serpentant la queue de sa robe. Mais son visage et ses formes étaient d'une femme adulte. L'ampleur de son corsage et la rondeur de sa taille ne laissaient aucun doute à cet égard, même à un vieux savant comme moi. J'ajouterai, sans crainte de me tromper, qu'elle était fort ıo belle et de mine fière, car mes études iconographiques m'ont habitué de longue date à reconnaître la pureté d'un type et le caractère d'une physionomie. La figure de cette dame, assise si inopinément sur le dos d'une Chronique de Nuremberg, respirait une noblesse mélangée de mutinerie. Elle avait l'air d'une reine, mais d'une reine capricieuse ;

I 5 et je jugeai, à la seule expression de son regard, qu'elle exerçait quelque part une grande autorité avec beaucoup de fantaisie. Sa bouche était impérieuse et ironique et ses yeux bleus riaient d'une façon inquiétante sous des sourcils noirs, dont l'arc était très pur. J'ai toujours entendu dire que les sourcils noirs sont très séants aux blondes, et 20 cette dame était blonde. En somme, l'impression qu'elle donnait était celle de la grandeur. . . .

Son costume, approprié à sa physionomie, était d'une extrême magnificence ; il consistait en une robe de brocart d'or et d'argent et en un manteau de velours nacarat, doublé de menu vair. ${ }^{1}$ La coiffure

25 était une sorte de hennin ${ }^{2}$ à deux cornes, que des perles d'un bel orient rendaient clair et lumineux comme le croissant de la lune. Sa petite main blanche tenait une baguette qui attira mon attention d'une manière d'autant plus efficace que mes études archéologiques m'ont disposé à reconnaître avec quelque certitude les insignes par lesquels 3o se distinguent les notables personnes de la légende et de l'histoire. Cette connaissance me fut utile en cette occasion. J'examinai la baguette, et je reconnus qu'elle avait été taillée dans une menue branche de coudrier. C'est, me dis-je, une baguette de féé, conséquemment, la dame qui la tient est une fée.

35 Heureux de connaître la personne à qui j'avais affaire, j'essayai de rassembler mes idées pour lui adresser un compliment respectueux. . . . Mais cette entreprise, qui coûtait beaucoup à ma timidité, me devint

1 "miniver," or Siberian squirrel.

2 "hennin," a high conical headdress worn by French women from 1430 to 1465 . 
vraiment impossible, quand je vis la dame de la Chronique tirer vivement d'une aumônière, qu'elle portait au côté, des noisettes plus petites que je n'en vis jamais, en briser les coquilles entre ses dents et me les jeter au nez, tandis qu'elle croquait l'amande avec la gravité d'un enfant qui tettc.

En une telle conjoncture, je fis ce qu'exigeait la dignité de la science, je me tus. Mais les coquilles m'ayant causé un chatouillement pénible, je portai la main à mon nez et je constatai alors, à ma grande surprise, que mes lunettes en chevauchaient l'extrémité et que je voyais la dame non à travers, mais par-dessus les verres, chose incompréhensible, ro puisque mes yeux, usés sur les vieux textes, ne distinguent pas sans besicles un melon d'une carafe, placés tous deux au bout de mon nez.

Ce nez, remarquable par sa masse, sa forme et sa coloration, attira légitimement l'attention de la fée, car elle saisit ma plume d'oie, qui s'élevait comme un panache au-dessus de l'encrier, et elle promena sur 15 mon nez les barbes de cette plume. J'eus parfois, en compagnie, l'occasion de me prêter aux espiègleries innocentes des jeunes demoiselles qui, m'associant à leurs jeux, m'offraient leur joue à baiser à travers un dossier de chaise ou m'invitaient à éteindre une bougie qu'elles élevaient tout à coup hors de la portée de mon souffle. Mais 20 jusque-là aucune personne du sexe ne m'avait soumis à des caprices aussi familiers que de m'agacer les narines avec les barbes de ma propre plume. Je me rappelai heureusement une maxime de feu mon grand-père, qui avait coutume de dire que tout est permis aux dames, et que tout ce qui vient d'elles est grâce et faveur. Je reçus donc 25 comme faveur et grâce les coquilles des noisettes et les barbes de la plume, et j'essayai de sourire. Bien plus! je pris la parole:

— Madame, dis-je, avec politesse et dignité, vous accordez l'honneur de votre visite, non à un morveux ni à un rustre, mais bien à un bibliothécaire assez heureux pour vous connaitre et qui sait que jadis vous $3^{\circ}$ emmêliez dans les crèches les crins de la jument, buviez le lait dans les jattes écumeuses, couliez des graines à gratter ${ }^{1}$ dans le dos des aïeules, faisiez pétiller l'âtre au nez des bonnes gens et, pour tout dire, mettiez le désordre et la gaieté dans la maison. Vous pouvez vous vanter, de plus, d'avoir, le soir, dans les bois, fait les plus jolies peurs du monde 35 aux couples attardés. Mais je vous croyais évanouie à jamais depuis trois siècles au moins. Se peut-il, madame, qu'on vous voie en ce temps de chemins de fer et de télégraphes? Ma concierge, qui fut 
nourrice en son temps, ne sait pas votre histoire, et mon petit voisin, que sa bonne mouche encore, affirme que vous n'existez point.

- Qu'en dites-vous? s'écria-t-elle d'une voix argentine, en se campant dans sa petite taille royale d'une façon cavalière et en fouettant 5 comme un hippogriffe le dos de la Chronique de Nuremberg.

- Je ne sais, lui répondis-je, en me frottant les yeux.

Cette réponse, empreinte d'un scepticisme profondément scientifique, fit sur mon interlocutrice le plus déplorable effet.

- Monsieur Sylvestre Bonnard, me dit-elle, vous n'êtes qu'un Io cuistre. Je m'en étais toujours doutée. Le plus petit des marmots qui vont par les chemins avec un pan de chemise à la fente de leur culotte me connaît mieux que tous les gens à lunettes de vos Instituts et de vos Académies. Savoir n'est rien, imaginer est tout. Rien n'existe que ce qu'on imagine. Je suis imaginaire. C'est exister cela, je pense !

${ }_{15}$ On me rêve et je parais! Tout n'est que rêve, et, puisque personne ne rêve de vous, Sylvestre Bonnard, c'est vous qui n'existez pas. Je charme le monde; je suis partout, sur un rayon de lune, dans le frisson d'une source cachée, dans le feuillage mouvant qui chante, dans les blanches vapeurs qui montent, chaque matin, du creux des prairies, 20 au milieu des bruyères roses, partout!... On me voit, on m'aime. On soupire, on frissonne sur la trace légère de mes pas qui font chanter les feuilles mortes. Je fais sourire les petits enfants, je donne de l'esprit aux plus épaisses nourrices. Penchée sur les berceaux, je lutine, je console et j'endors, et vous doutez que j'existe! Sylvestre 25 Bonnard, votre chaude douillette recouvre le cuir d'un âne.

Elle se tut; l'indignation gonflait ses fines narines et, tandis que j'admirais, malgré mon dépit, la colère héroïque de cette petite personne, elle promena ma plume dans l'encrier, comme un aviron dans un lac, et me la jeta au nez le bec en avant.

3o Je me frottai le visage que je sentis tout mouillé d'encre. Elle avait disparu. Ma lampe s'était éteinte: un rayon de lune traversait la vitre et descendait sur la Chronique de Nuremberg. Un vent frais, qui s'était élevé sans que je m'en aperçusse, faisait voler plumes, papiers, et pains à cacheter. Ma table était toute tachée d'encre. J'avais laissé 35 ma fenêtre entr'ouverte pendant l'orage. Quelle imprudence!

— « Le crime de Sylvestre Bonnard » 


\section{INDEX OF AUTHORS}

Augier, 378

Balzac (Guez de), 7

Balzac (Honoré de), $35^{8}$

Beaumarchais, 237

Bernardin de Saint-Pierre, 244

Boileau, 82

Bossuet, 122

Bourdaloue, 134

Buffon, 23I

Chateaubriand, 266

Chénier, $25 \mathrm{I}$

Corneille, I 5

Descartes, Io

Diderot, 223

Fénelon, 149

Flaubert, 390

Fontenelle, I 59

France, 43 I

Gautier, 37 I

Hugo, 294

La Bruyère, 140

La Fayette (Madame de), Ioo

La Fontaine, 68

Lamartine, 276

Lamennais, 328

La Rochefoucauld, 46

Leçonte de Lisle, $3^{83}$
Le Sage, 172

Loti, 420

Malherbe, 3

Marivaux, 188

Mérimée, $35^{2}$

Michelet, 342

Molière, 5 I

Montesquieu, 179

Musset (Alfred de), 3 I 7

Pascal, $3^{8}$

Racine, I03

Renan, 404

Retz (Cardinal de), 35

Rousseau, 2 I I

Saint-Simon, 166

Sainte-Beuve, 309

Sand, 332

Sévigné (Madame de), 93

Staël (Madame de), $25^{8}$

Sully-Prudhomme, 416 "

Taine, 397

Vauvenargues, 195

Verlaine, 426

Vigny (Alfred de), 288

Voltaire, 199

Zola, 409 



\section{PLEASE DO NOT REMOVE CARDS OR SLIPS FROM THIS POCKET}

\section{UNIVERSITY OF TORONTO LIBRARY}

$P Q$

1109

V7

$$
\begin{aligned}
& \text { Vreelend, Williamson Upłike } \\
& \text { Anthology of French } \\
& \text { prose and poetry }
\end{aligned}
$$


